RODOLFO MOREDA MENDES

\title{
ESTUDO DAS PROPRIEDADES GEOTÉCNICAS DE SOLOS RESIDUAIS NÃO SATURADOS DE UBATUBA (SP)
}

Tese apresentada à Escola Politécnica da Universidade de São Paulo para obtenção do título de Doutor em Engenharia.

-SÃO PAULO-

2008 
RODOLFO MOREDA MENDES

\section{ESTUDO DAS PROPRIEDADES GEOTÉCNICAS DE SOLOS RESIDUAIS TROPICAIS NÃO SATURADOS DE UBATUBA (SP)}

Tese apresentada à Escola Politécnica da Universidade de São Paulo para obtenção do título de Doutor em Engenharia.

Área de concentração:

Engenharia Geotécnica

Orientador: Prof. Livre-Docente

Fernando Antônio Medeiros Marinho

-SÃO PAULO-

2008 
Este exemplar foi revisado e alterado em relação à versão original, sob responsabilidade única do autor e com a anuência de seu orientador.

São Paulo, de outubro de 2008.

Assinatura do autor

Assinatura do orientador

FICHA CATALOGRÁFICA

Mendes, Rodolfo Moreda

Estudo das propriedades geotécnicas de solos residuais não saturados de Ubatuba (SP) / R.M. Mendes. -- ed.rev. -- São Paulo, 2008.

236 p.

Tese (Doutorado) - Escola Politécnica da Universidade de São Paulo. Departamento de Engenharia de Estruturas e Geotécnica.

1.Solo residual 2.Solo não saturado 3 .Radar de penetração no solo 4.Escorregamento dos solos I.Universidade de São Paulo. Escola Politécnica. Departamento de Engenharia de Estruturas e Geotécnica II.t. 


\section{DEDICATÓRIA}

Aos meus pais Geraldo e Lila pelo constante incentivo e ensinamentos. Á minha esposa Fabiana pelo companheirismo e amor. 


\section{AGRADECIMENTOS}

Agradeço primeiramente a Deus, que sempre me deu muita saúde, paz espiritual, motivação, sabedoria e iluminou meu caminho, sem os quais eu certamente não teria superado os diversos obstáculos encontrados nessa jornada.

Ao professor Fernando Marinho pelo grandioso e constante apoio, incentivo e orientação no decorrer do desenvolvimento dessa pesquisa, e pela confiança na minha capacitação, num momento muito importante da minha vida e carreira profissional.

À professora Maria Cristina Motta de Toledo do Instituto de Geociências da USP, pelo precioso auxílio nos trabalhos de campo e nas análises de micromorfologia.

Ao professor Renato Luiz Prado do Departamento de Geofísica do IAG-USP, pela realização e interpretação dos ensaios geofísicos.

Aos professores Marcos Massao Futai e Carlos de Sousa Pinto, pelas valiosas sugestões quando foram solicitados no decorrer dessa pesquisa.

Aos professores do programa de pós-graduação cujos ensinamentos transmitidos foram imprescindíveis para a ampliação do meu conhecimento na área de engenharia geotécnica.

Ao Instituto Geológico (Processo SMA 30.120/05) e à FAPESP (Processo nº 05/55736-5) pelo apoio financeiro concedido para a realização dessa pesquisa.

Aos amigos e pesquisadores da Seção de Geologia Aplicada e Ambiental do Instituto Geológico: Cláudio José Ferreira, Maria José Brollo, Ricardo Vedovello, Paulo César Fernandes da Silva, Daniela Girio M. Faria, Jair Santoro, Márcia Maria Nogueira Pressinotti, Lídia Keiko Tominaga e Célia Regina de Gouveia Souza, pelo convívio, discussões técnicas e amizade.

Agradeço especialmente ao amigo e pesquisador Cláudio José Ferreira pela enorme contribuição numa fase decisiva dessa pesquisa e pelo apoio concedido para a realização dos trabalhos de campo.

Aos amigos e funcionários do laboratório de mecânica dos solos, Joaquim e Antônio, pela paciência e disposição durante a realização dos ensaios experimentais dessa pesquisa.

Aos amigos da pós-graduação pela convivência durante todos esses anos.

Á todos aqueles que, direta ou indiretamente, contribuíram em algum momento para a realização e conclusão dessa pesquisa.

Á todos vocês, meu muitíssimo obrigado! 


\section{RESUMO}

A presente tese de doutoramento versa sobre o estudo das propriedades geotécnicas de solos residuais não saturados ocorrentes no município de Ubatuba, litoral norte do Estado de São Paulo. O estudo das propriedades geotécnicas foi realizado a partir de uma abordagem macro e micromorfológica, buscando estabelecer a relação existente entre a água presente no solo e sua variação sazonal. Os procedimentos e técnicas utilizadas permitiram diferenciar os horizontes de intemperismo quanto à microestrutura e porosidade, bem como caracterizar seus comportamentos físico e hídrico. Os ensaios geotécnicos, in situ e em laboratório, forneceram informações importantes sobre as propriedades dos materiais, tais como: índices físicos, distribuição granulométrica, limites de Atterberg, curvas de retenção de água e condutividade hidráulica saturada. Os dados registrados pelos equipamentos instalados no campo (pluviômetros, sensores GMS e FDR) permitiram avaliar a relação existente entre os eventos pluviométricos com a distribuição de umidade e sucção matricial ao longo dos perfis de alteração. Além disso, utilizouse metodologia geofísica de forma inédita na geotecnia brasileira para a determinação de perfis de umidade em solos residuais tropicais. Em termos gerais, os resultados obtidos permitiram estabelecer algumas relações entre as propriedades mecânicas e hidráulicas e as peculiaridades micromorfológicas dos horizontes de solos. Os resultados desse trabalho poderão ainda indicar áreas prioritárias para o monitoramento das variáveis climatológicas e geotécnicas, podendo fornecer apreciáveis subsídios para um futuro aperfeiçoamento dos parâmetros técnicos utilizados em Planos Preventivos de Defesa Civil (PPDC).

Palavras-Chave: Solo residual. Solo não saturado. Radar de penetração no solo (GPR). Escorregamentos em solos. 


\begin{abstract}
This doctoral thesis focusing on the study of the geotechnical properties of unsaturated residual soils occurring in the municipal district of Ubatuba, north coast of the State of Sao Paulo. The study of geotechnical properties was conducted from a macro and micromorfology approach, seeking to establish the relationship between the water present in the residual soil and its seasonal variations. The procedures and techniques enabled differentiate the horizons of weathering in relation to the microstructure and porosity, and characterize its physical-hydraulic behaviours. The laboratory and in situ geotechnical tests, provided important information about the properties of materials, such as: physical index, grain-size distribution, Atterberg limits, water retention curve and saturated hydraulic conductivity. The data registered by equipments installed in the field (pluviometers, FDR and GMS sensors) enabled to evaluate the relationship between the rainfall events with the distribution of moisture and suction matrix along the soil profiles. In addition, was used geophysical methodology in order unprecedented in brazilian geotechnical for the determination of moisture profiles in residual tropical soils. Overall, the results allowed establish some relationship between the hydraulic and mechanical properties and the micromorphological peculiarities of the horizons of soils. The results of this study may also indicate priority areas for monitoring the climatological and geotechnical variables, and may provide appreciable subsidies for a future improvement of the technical parameters used in Civil Defense Prevention Plans (PPDC).
\end{abstract}

Keywords: Residual soil. Unsaturated soil. Ground penetrating radar (GPR). Landslides in soils. 


\section{SUMÁRIO}

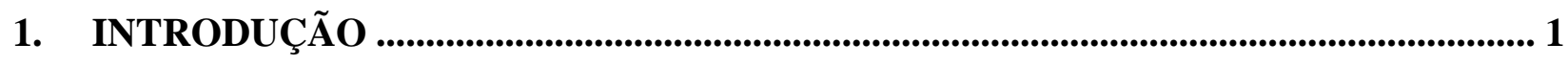

1.1. ESTUdOS EM SOLOS NÃO SATURADOS ................................................................ 1

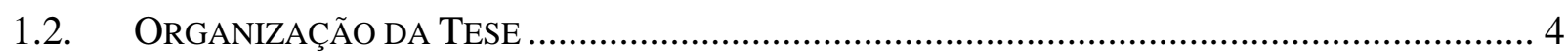

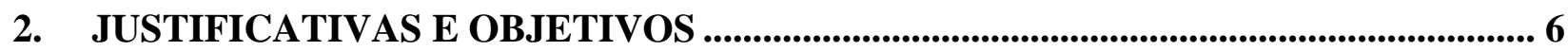

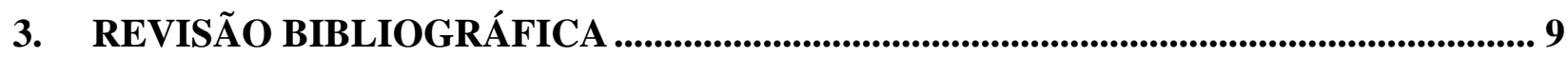

3.1. Propriedades de Solos NÃo SATURAdoS ......................................................... 9

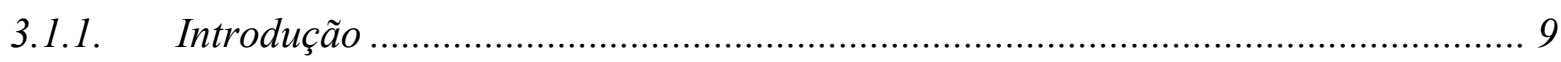

3.1.2. Curva de retenção de água (CRA) ....................................................................... 9

3.1.3. Condutividade hidráulica ......................................................................... 16

3.1.4. Variáveis de estado de tensão ...................................................................... 18

3.1.5. Resistência ao cisalhamento dos solos não saturados ...................................... 20

3.1.6. Modelos de previsão da resistência em função da curva de retenção .................. 25

3.2. CARACTERÍSTICAS DOS SOLOS RESIDUAis TROPICAIS .............................................. 29

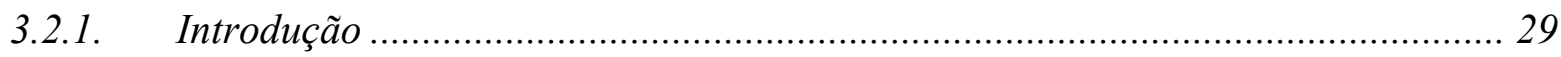

3.2.2. Aspectos mineralógicos e microestruturais.................................................... 31

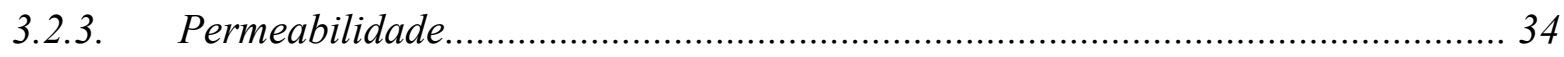

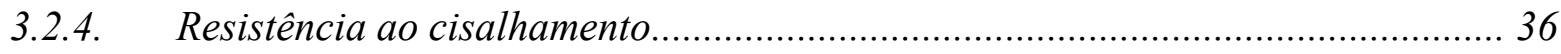

3.3. Principais Processos de InstabilizaÇÃo em TAludes E EnCOSTAS NATURAis ........ 39

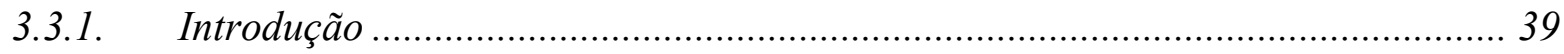

3.3.2. Escorregamentos planares rasos ................................................................. 40

3.3.3. Escorregamentos rotacionais ...................................................................... 42

3.3.4. Escorregamentos em taludes de corte ....................................................... 43

3.3.5. Estabilidade de encostas naturais e taludes em solos residuais .......................... 45

3.4. Metodologia GPR (Ground Penetrating Radar) ............................................. 49

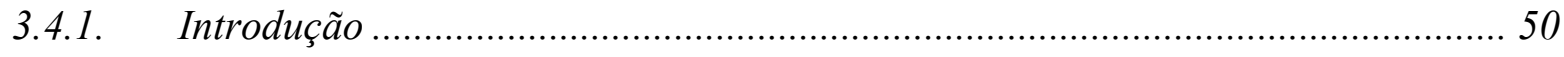

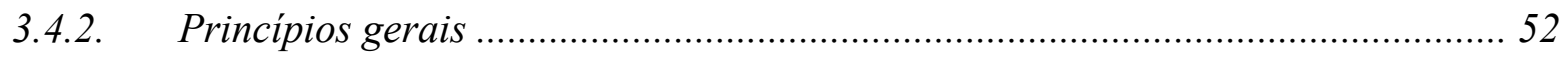

3.4.3. Propagação de ondas eletromagnéticas .......................................................... 54 
3.4.4. Relação entre a permissividade e o teor de umidade do solo .............................. 58

3.4.5. Medição do teor de umidade do solo com métodos eletromagnéticos .................. 60

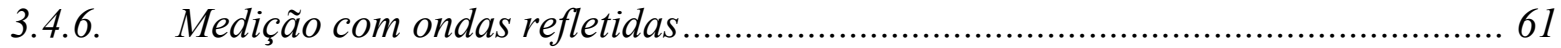

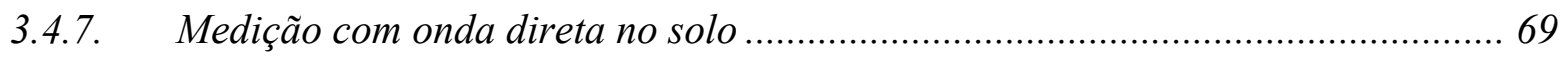

3.4.8. Medição com furo de sondagem GPR ..................................................... 72

3.4.9. Medição com ondas refletidas em superfície ............................................... 76

4. ASPECTOS GERAIS DAS ÁREAS ESTUDADAS ............................................. 79

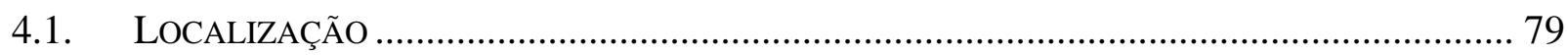

4.2. MotIVAÇÃo PARA A ESCOLHA DAS ÁREAS DE ESTUdO .............................................. 81

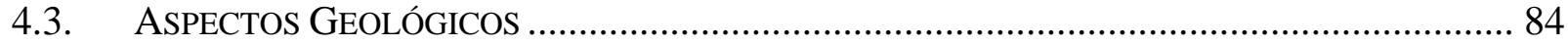

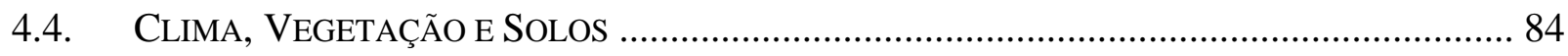

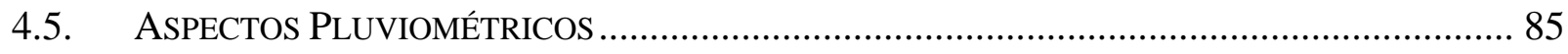

5. CARACTERIZAÇÃO DOS SOLOS E ENSAIOS DE LABORATÓRIO...................... 89

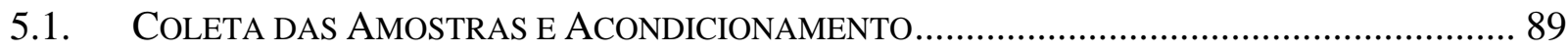

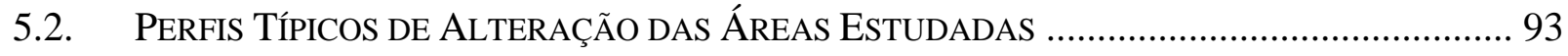

5.3. ENSAIOS DE CARACTERIZAÇÃO GEOTÉCNICA …...................................................... 95

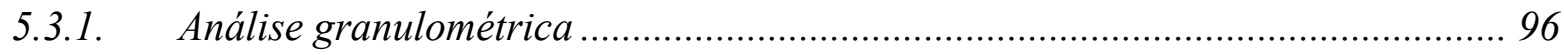

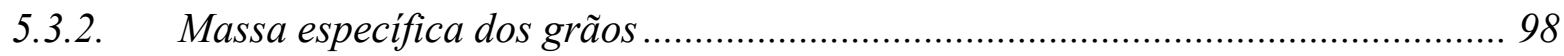

5.3.3. Massa especifica natural e massa específica seca ......................................... 98

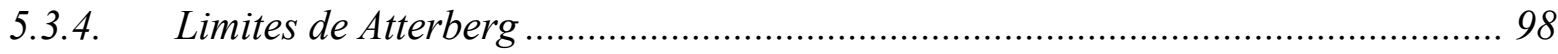

5.4. CARACTERIZAÇÃo MinERALÓGICA E MiCROESTRUTURAL........................................... 102

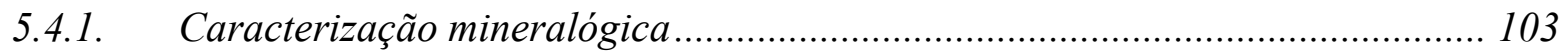

5.4.2. Caracterização microestrutural .................................................................. 110

5.4.3. Síntese da evolução dos perfis de alteração estudados..................................... 113

5.5. OBTENÇÃo dAs CURVAS DE RETENÇÃo DE ÁGUA (CRA).......................................... 116

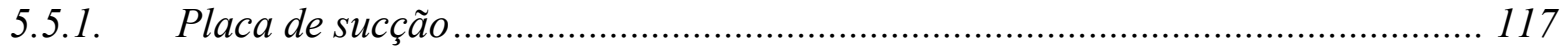

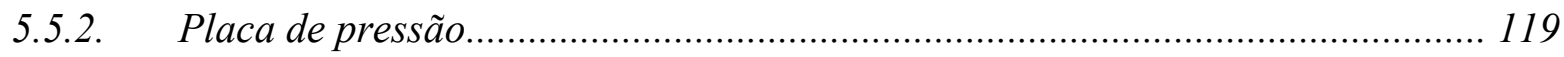

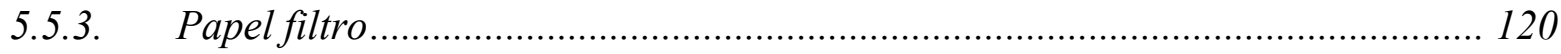

5.5.4. Resultados das curvas de retenção de água (CRAs) ...................................... 123

5.6. ENSAIOS DE POROSIMETRIA POR INTRUSÃo DE MERCÚRIO ....................................... 136

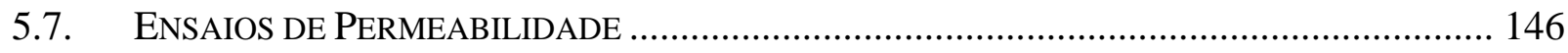


6. INVESTIGAÇÕES DE CAMPO

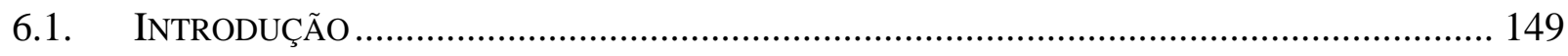

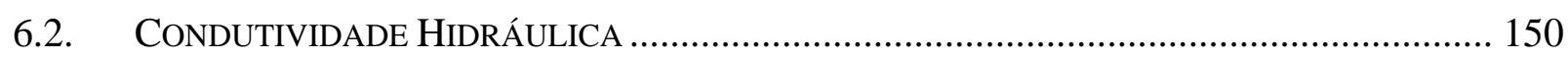

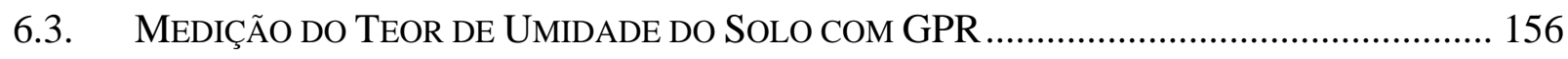

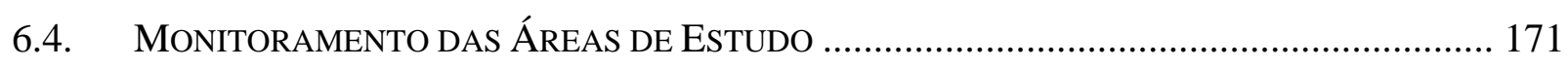

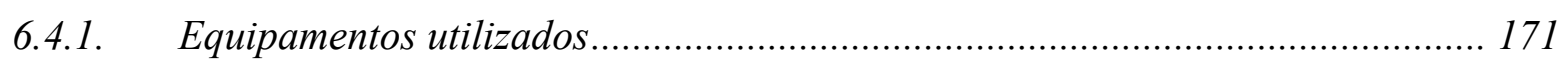

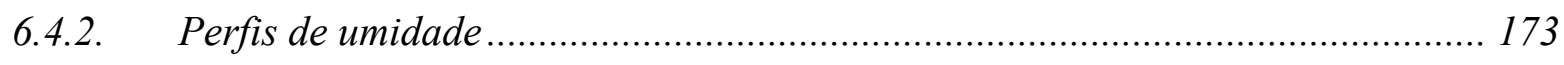

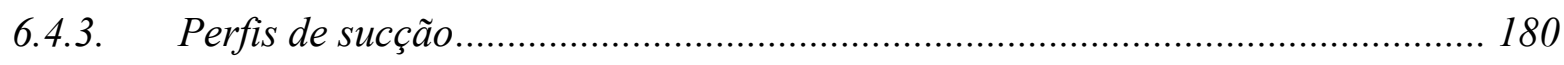

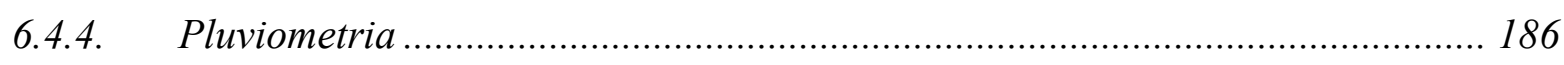

7. CONCLUSÕES E RECOMENDAÇÕES PARA FUTURAS PESQUISAS .................. 195

8. REFERÊNCIAS BIBLIOGRÁFICAS _................................................................ 202

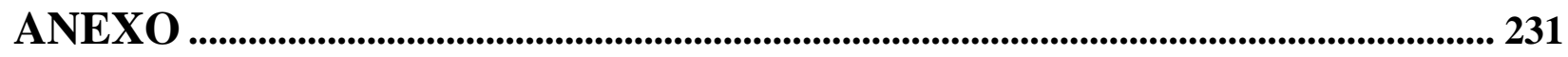




\section{LISTA DE FIGURAS}

\section{CAPÍTULO 2:}

FIgURA 2.1 - ÁREA ESTUdAdA E MONITORADA NO BAIRRO DO PEREQUÊ-MIRIM........................... 6

\section{CAPÍTULO 3:}

FIGURA 3.1 - MODELO FÍSICO RELACIONADO AO FENÔMENO DA CAPILARIDADE. 11

FIGURA 3.2 - CARACTERÍSTICAS PRINCIPAIS DA CRA DURANTE A SECAGEM E UMEDECIMENTO (MODIFICADO DE FREDLUND \& XING 1994). 12

FIgURA 3.3 - ESTÁgIOS DA CRA PARA UM MEIO POROSO HIPOTÉTICO (MOdifiCAdO DE VANAPALLI ET AL. 1996). 13

Figura 3.4 - CuRVAs DE RETENÇÃo DE ÁGUA PARA SOlO ARGILOSO, Siltoso E ARENOSO (MODIFICADO DE FREDLUND \& XING 1994). 14

FIGURA 3.5 - CURVAS DE RETENÇÃO DE ÁGUA E CONDUTIVIDADE HIDRÁULICA PARA UM SOLO ARENOSO (MODIFICADO DE FREDLUND ET AL. 1994). 17

FIGURA 3.6 - VARIÁVEIS DE ESTADO DE TENSÕES PARA SOLOS SATURADOS................................ 19

FIGURA 3.7 - VARIÁVEIS DE ESTADO DE TENSÕES PARA SOLOS NÃO SATURADOS. 20

FIGURA 3.8 - ENVOLTÓRIA DE RUPTURA LINEAR COMO UMA SUPERFÍCIE PLANAR PARA SOLOS NÃO SATURADOS. 22

FIGURA 3.9 - ENVOLTÓRIA DE RUPTURA NÃO LINEAR COMO UMA SUPERFÍCIE CURVA PARA SOLOS NÃO SATURADOS. 23

FIgURA 3.10 - SUPERFÍCIE DA ENVOLTÓRIA DE RESISTÊNCIA DE SOLOS NÃO SATURAdOS (DE CAMPOS 1997). 24

FIGURA 3.11 - ESCORREGAMENTO PLANAR RASO OCORRIDO NUMA ENCOSTA DA SERRA DO MAR (FONTE: ACERVO IG-SMA). 40

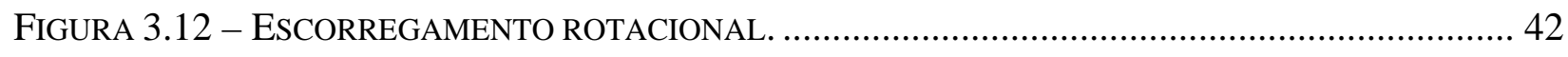

FIGURA 3.13 - ESCORREGAMENTO EM TALUDE DE CORTE (FONTE: ACERVO IG-SMA)............... 44 FIgURA 3.14 - EFEITO DA FRENTE DE “SATURAÇÃO” E DURAÇÃO DA CHUVA NO FATOR DE SEGURANÇA DE UM TALUDE (MODIFICADO YONG ET AL 1982).

FIGURA 3.15 - CAMINHOS DE PROPAGAÇÃO DA ONDA ELETROMAGNÉTICA NO SOLO CONSTITUÍDO POR DUAS CAMADAS COM PERMISSIVIDADE DIELÉTRICA DISTINTA (MODIFICADO DE SPERL 1999). 
Figura 3.16 - EXEMPlo do MODElo DE DEBye PARA A PARTE REAL (LiNHA AZUL) E PARTE IMAGINÁRIA (LINHA VERMELHA) DA PERMISSIVIDADE (MODIFICADO DE HUISMAN ET AL. 2003). 56 FIGURA 3.17 - ARRANJO DAS ANTENAS DO GPR NO MÉTODO DE AFASTAMENTO CONSTANTE. ..... 61 FIGURA 3.18 - RADARGRAMA OBTIDO NUMA SITUAÇÃO IDEALIZADA (MODIFICADO DE DAVIS \& ANNAN 1989). 62

FIGURA 3.19 - ARRANJO DAS ANTENAS DO GPR NO MÉTODO CMP. 64 FIGURA 3.20 - ARRANJO DAS ANTENAS DO GPR NO MÉTODO WARR 65

FIGURA 3.21 - RADARGRAMA DE AQUISIÇÃO CMP OU WARR (1-ONDA DIRETA NO SOLO, 2-ONDA REFLETIDA NO SOLO E 3-ONDA DIRETA NO AR). 66

FIGURA 3.22 - ESPECTRO DE VELOCIDADE DE UMA MEDIDA CMP PARA ILUSTRAR A OBTENÇÃO AUTOMÁTICA DA VELOCIDADE VERSUS TEMPO - A COR AZUL INDICA A MÁXIMA COERÊNCIA (HUISMAN ET AL. 2003).

FIGURA 3.23 - AJUSTE DA EQUAÇÃO DE CALIBRAÇÃO ENTRE O TEOR DE UMIDADE VOLUMÉTRICO

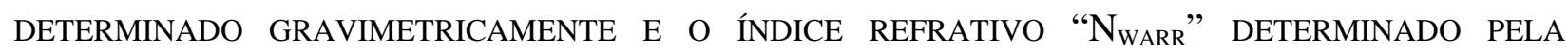
VELOCIDADE DA ONDA DIRETA NO SOLO (HUISMAN ET AL. 2003)............................................. 70 Figura 3.24 - COMPARAÇÃO DE $\mathrm{N}_{\text {TDR }}$ E $\mathrm{N}_{\text {WARr }}$ PARA AS MEDIDAS MOSTRADAS NA FigURA 3.23 (HUISMAN ET AL. 2003).

FigurA 3.25 - PERFIL ESQUEMÁTICO DOS FUROS DE SONDAGEM ZOP E MOP E O PERCURSO DA ONDA DIRETA NO SOLO TRANSMITIDA ENTRE AS ANTENAS TRANSMISSORA $\mathrm{T}_{\mathrm{X}}$ E RECEPTORA $\mathrm{R}_{\mathrm{X}}$ (MODIFICADO DE HUISMAN ET AL. 2003). 73

FIGURA 3.26 - ESQUEMA DAS TRAJETÓRIAS DAS ONDAS DO RADAR E MEDIDAS DE FUROS DE SONDAGEM GPR REALIZADAS NUM SOLO COM CAMADA DE ALTA VELOCIDADE (MODIFICADO DE

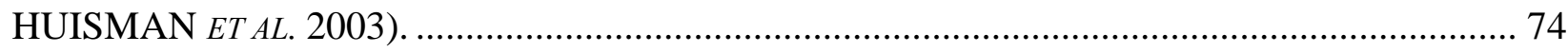

FIGURA 3.27 - SISTEMA GPR USADO PARA MEDIR A AMPLITUDE DE REFLEXÃO EM SUPERFÍCIE (HUISMAN ET AL. 2003)...... 76

FIGURA 3.28 - DAdOS DO TEOR DE UMIDADE DO SOLO MEDIDO COM O MÉTODO DE REFLEXÃO DE SUPERFÍCIE E COM SENSORES TDR (HUISMAN ET AL. 2003). 77

\section{CAPÍTULO 4:}

FIGURA 4.1 - LOCALIZAÇÃO DAS ÁREAS DE ESTUDO NO MUNICÍPIO DE UBATUBA........................ 79

FIGURA 4.2 - LOCALIZAÇÃO DAS ÁREAS DE ESTUDO (FONTE: ACERVO IG-SMA)....................... 80 FIgURA 4.3 - DistribuiÇÃO DAS ÁREAS DE RISCO A ESCORREGAMENTO NO MUNICÍPIO DE UBATUBA-SP (FONTE: MODIFICADO DE MARCHIORI FARIA ET AL. 2005).............................. 82 
FigurA 4.4 - ÁREAS DE RISCO A ESCORREgAMENTO SITUADAS NO BAIRRO DE MARANDUBA (FONTE: MODIFICADO DE MARCHIORI FARIA ET AL. 2005). 83

FIgURA 4.5 - ÁreAs DE RISCO A ESCORREGAMENTO SITUADAS NO BAIRRO DO PEREQUÊ-MiRIM (FONTE: MODIFICADO DE MARCHIORI FARIA ET AL. 2005) ................................................. 83

FIgURA 4.6 - LOCALIZAÇÃO DOS POSTOS PLUVIOMÉTRICOS NO MUNICÍPIO DE UBATUBA-SP......... 86

FIGURA 4.7 - DADOS DE PRECIPITAÇÃO MENSAL E ANUAL DO POSTO IAC................................... 87

FIGURA 4.8 - DADOS DE PRECIPITAÇÃO MENSAL E ANUAL DO POSTO IO/USP.............................. 87

FIgURA 4.9 - DADOS DE PRECIPITAÇÃO MENSAL E ANUAL DO POSTO MATA DENTRO (DAEE). .... 87

FIgURA 4.10 - DADOS DE PRECIPITAÇÃO MENSAL E ANUAL DO POSTO UBATUBA (DAEE)............ 87

\section{CAPÍTULO 5:}

FIGURA 5.1 - VISÃO GERAL DOS PERFIS VERTICAIS ESCOLHIDOS PARA A COLETA DAS AMOSTRAS NA

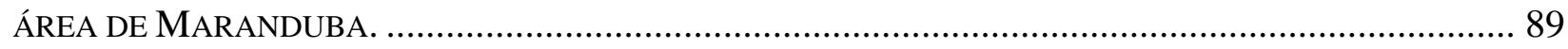

FIGURA 5.2 - VISÃO GERAL DO PERFIL VERTICAL ESCOLHIDO PARA A COLETA DAS AMOSTRAS NA

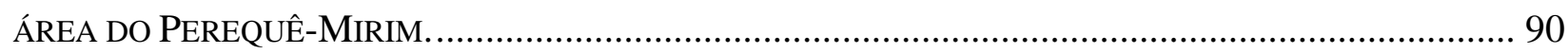

FiguRA 5.3 - COLETA DOS BLOCOS INDEFORMAdOS NA ÁREA DE MARANDUBA........................... 92

Figura 5.4 - Coleta dos Blocos INDEFORMAdos NA ÁREA Do PEREQUÊ-Mirim. ..................... 93

FIGURA 5.5 - PERFIL DE ALTERAÇÃO DA ÁREA DE ESTUDO DE MARANDUBA................................ 94

FIgURA 5.6 - PERFIL DE ALTERAÇÃo DA ÁREA DE ESTUdO SITUADA NO PEREQUÊ-MiRIM.............. 95

FigurA 5.7 - CURVAS GRANULOMÉTRICAS DAS AMOSTRAS COLETADAS NA ÁREA DE MARANDUBA. 96

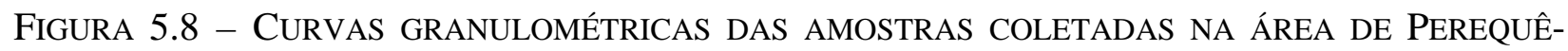

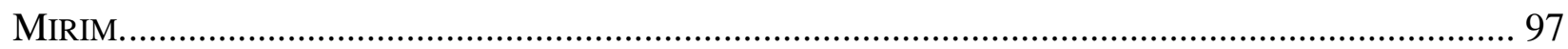

FIGURA 5.9 - CARTA DE PLASTICIDADE DAS AMOSTRAS DE SOLO ANALISADAS. ........................... 99

FIGURA 5.10 - GRÁFICO DE ATIVIDADE DAS AMOSTRAS DE SOLO ANALISADAS.......................... 100

FIgURA 5.11 - DifRATOGRAMAS CARACTERÍSTICOS DOS SOlOS DE ALTERAÇÃO DE MARANDUBA. 105

Figura 5.12 - Difratograma CARACTERÍstico DA ROCHA ALTERADA (GRANITO-GNAisSE) DE

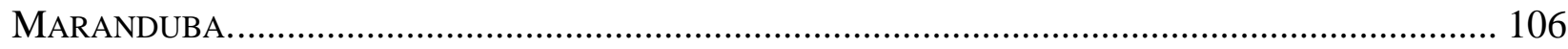

Figura 5.13 - Difratogramas CARActerísticos dos solos DE ALTERAÇÃo do PerequÊ-

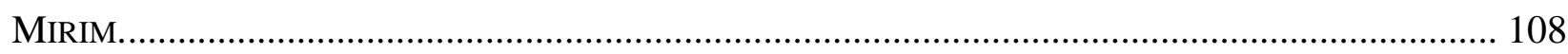

Figura 5.14 - Difratogramas CARActerísticos DA ROCHA (Charnockito) DO Perequê-

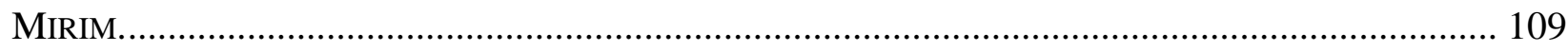


FIGURA 5.15 - MiCROFOTOGRAFIAS E FEIÇÕES MICROMORFOLÓGICAS OBSERVADAS NOS HORIZONTES DE SOLO CARACTERÍSTICOS DO PERFIL DE ALTERAÇÃO DE MARANDUBA.................. 114 FIGURA 5.16 - MICROFOTOGRAFIAS E FEIÇÕES MICROMORFOLÓGICAS OBSERVADAS NOS HORIZONTES DE SOLO CARACTERÍSTICOS DO PERFIL DE ALTERAÇÃO DO PEREQUÊ-MIRIM. ........... 115

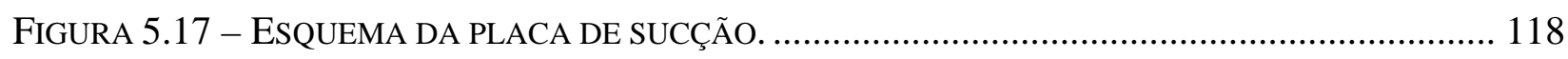

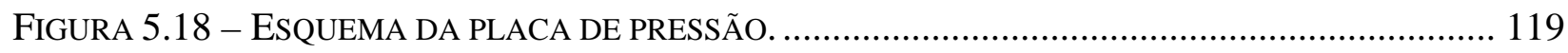

FIGURA 5.19 - TÉCNICA DO PAPEL FILTRO .......................................................................... 122

Figura 5.20 - CURVAS DE RETENÇÃO DE ÁGUA DOS SOLOS DE MARANDUBA............................ 124

Figura 5.21 - CuRVAS DE RETENÇÃo DE ÁGUA dOS SOLOS DO PEREQUÊ-Mirim. ...................... 125

FIGURA 5.22 - CURVAS DE RETENÇÃO DE ÁGUA DO HORIZONTE DE SOLO A............................... 127

FIGURA 5.23 - CURVAS DE RETENÇÃO DE ÁGUA DO HORIZONTE I-B........................................ 128

FIGURA 5.24 - CURVAS DE RETENÇÃO DE ÁGUA DO HORIZONTE I-C......................................... 129

Figura 5.25 - Modelos de AJUSTE PARA As CURVAS DE RETENÇÃo DE ÁGUA dos SOlOS DE

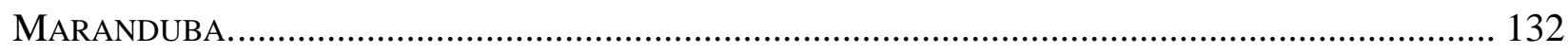

Figura 5.26 - Modelos de AJUSTE para As CURVAS DE RETENÇÃo DE ÁGUA dos SOlOS DE

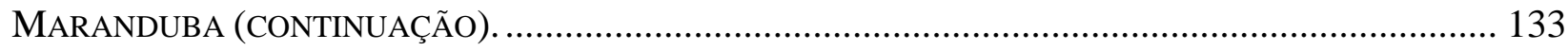

Figura 5.27 - Modelos de AJUSTE PARA AS CURVAS DE RETENÇÃo DE ÁGUA DOS SOLOS DO

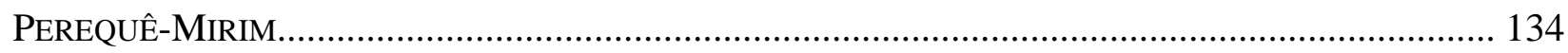

Figura 5.28 - Modelos de AJUSTE PARA AS CURVAS DE RETENÇÃo DE ÁGUA DOS SOLOS DO

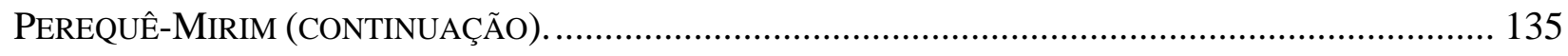

FIGURA 5.29 - DisTRIBUIÇÃO ACUMULADA DE POROS DOS SOLOS DE MARANDUBA..................... 138

FIGURA 5.30 - DisTRIBUIÇÃO INCREMENTAL DE POROS DOS SOLOS DE MARANDUBA. ................ 139

FIgURA 5.31 - DisTRIBUiÇÃO ACUMULAdA DE POROS DAS AMOSTRAS DO PEREQUÊ-MiriM........ 140

FIgURA 5.32 - DisTRIBUIÇÃO INCREMENTAL DE POROS DAS AMOSTRAS DO PEREQUÊ-MiRIM..... 141

FIGURA 5.33 - CURVAS DE RETENÇÃO OBTIDAS A PARTIR DOS MÉTODOS CONVENCIONAIS E DOS DADOS DE POROSIMETRIA PARA AS AMOSTRAS DE MARANDUBA.............................................. 143

FIGURA 5.34 - CURVAS DE RETENÇÃO OBTIDAS A PARTIR DOS MÉTODOS CONVENCIONAIS E DOS DADOS DE POROSIMETRIA PARA AS AMOSTRAS DE MARANDUBA - CONTINUAÇÃO. ...................... 144

FIGURA 5.35 - CURVAS DE RETENÇÃO OBTIDAS A PARTIR DOS MÉTODOS CONVENCIONAIS E DOS DADOS DE POROSIMETRIA PARA AS AMOSTRAS DO PEREQUÊ-MIRIM. ....................................... 145

FigurA 5.36 - PERMEÂMETRO DE CARGA CONSTANTE E PAREDE FLEXÍVEL ACOPLADO AO SISTEMA

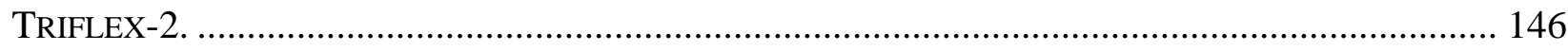


FIgURA 5.37 - CURVAS DE RETENÇÃo (A) E DE CONDUTIVIDADE HIDRÁULICA (B) PARA OS SOLOS RESIDUAIS REPRESENTATIVOS DAS ÁREAS ESTUDADAS. 148

\section{CAPÍTULO 6:}

FIGURA 6.1 - PERFIL ESQUEMÁTICO DO INFILTRÔMETRO DE MINI-DISCO. 150

FIgURA 6.2 - EXEMPLO DE GRÁFICO OBTIDO COM OS DADOS DO INFILTRÔMETRO (DECAGON DEVICES 2005).

FIGURA 6.3 - ENSAIOS NO CAMPO COM O INFILTRÔMETRO DE MINI-DISCO EM DIFERENTES PROFUNDIDADES DOS PERFIS DE ALTERAÇÃO ESTUDADOS. 153

FigurA 6.4 - CURVAS DE INFILTRAÇÃO OBTIDAS COM OS DADOS DO INFILTRÔMETRO DE MINIDISCO NAS CONDIÇÕES DE CAMPO. 154

FIGURA 6.5 - ENSAIOS NO LABORATÓRIO COM O INFILTRÔMETRO DE MINI-DISCO SOBRE OS CORPOS DE PROVA. 155

FIGURA 6.6 - SISTEMA GPR UTILIZADO PARA DETERMINAR O TEOR DE UMIDADE DO SOLO NO CAMPO. 157

FIGURA 6.7 - LOCAIS ESTUDADOS COM O SISTEMA GPR NA ÁREA DE MARANDUBA. 157

FIgURA 6.8 - ARRANJOS EMPREGADOS COM O SISTEMA GPR NA ÁREA DO PEREQUÊ-MIRIM. ..... 158 FIGURA 6.9 - IDENTIFICAÇÃO DOS TEMPOS DE CHEGADA DA ONDA DIRETA (1) E DA ONDA REFLETIDA (2) NO RADARGRAMA OBTIDO A PARTIR DE UM CONJUNTO DE MEDIDAS CMP. . 159

FIGURA 6.10 - ESQUEMA ILUSTRATIVO DA DETERMINAÇÃO DAS CONSTANTES DIELÉTRICAS MÉDIAS OU DE EMPILHAMENTO $\left(K_{M E ́ D .}\right)$ E INTERVALARES $\left(K_{I N T}\right)$...... 160

FIGURA 6.11 - VALORES DA CONSTANTE DIELÉTRICA MÉDIA OBTIDA SOBRE O PERFIL DE SOLO DE ALTERAÇÃO NA ÁREA DE MARANDUBA. 161

FIGURA 6.12 - VALORES DA CONSTANTE DIELÉTRICA MÉDIA OBTIDA SOBRE O PERFIL DE SAPROLITO NA ÁREA DE MARANDUBA. 162

FIgURA 6.13 - VALORES DA CONSTANTE DIELÉTRICA MÉDIA OBTIDA SOBRE O PERFIL DE ALTERAÇÃO NA ÁREA DO PEREQUÊ-MIRIM. 163

Figura 6.14 - COLETA DE AMOSTRAS DEFORMADAS DE SOLO PARA DETERMINAÇÃO DO TEOR DE UMIDADE GRAVIMÉTRICO EM LABORATÓRIO. 164

Figura 6.15 - PERFIS DE UMIDAdE VOlumÉtRiCA DA ÁREA DE MARANDUBA. 165

FIGURA 6.16 - PERFIS DE UMIDADE VOLUMÉTRICA DA ÁREA DO PEREQUÊ-MIRIM. 166

FIGURA 6.17 - RELAÇÃO ENTRE UMIDADE VOLUMÉTRICA OBTIDA COM TRADO E CONSTANTES DIELÉTRICAS MÉDIA E INTERVALAR PARA ANTENA DE 100MHZ. 
FIGURA 6.18 - RELAÇÃO ENTRE UMIDADE VOLUMÉTRICA OBTIDA COM TRADO E CONSTANTES DIELÉTRICAS MÉDIA E INTERVALAR PARA ANTENA DE 200MHZ. 168

FIGURA 6.19 - RELAÇÕES ENTRE UMIDADE VOLUMÉTRICA E CONSTANTE DIELÉTRICA MÉDIA PARA ANTENAS DE 100 E 200MHz. 168

FIGURA 6.20 - COMPARAÇÃO ENTRE OS TEORES DE UMIDADE VOLUMÉTRICA OBTIDOS COM GPR E TÉCNICA GRAVIMÉTRICA (TRADO) PARA ANTENAS DE 100 E 200 MHz. 169

FIGURA 6.21 - SENSOR DE MATRIZ GRANULAR GMS. 171

FIGURA 6.22 - SENSOR DE UMIDADE FDR. 173

FIGURA 6.23 - LOCALIZAÇÃO DOS SENSORES INSTALADOS NA ÁREA DE MARANDUBA................ 174

FIgURA 6.24 - LOCALIZAÇÃO DOS SENSORES INSTALAdOS NA ÁREA DO PEREQUÊ-MIRIM. .......... 175

FIGURA 6.25 - INSTALAÇÃO DOS SENSORES FDR COM EQUIPAMENTOS ESPECÍFICOS DE CRAVAÇÃO. 176

FIgURA 6.26 - DADOS DE MONITORAMENTO DO TEOR DE UMIDADE NA ÁREA DE MARANDUBA. . 177 Figura 6.27 - DAdOS DE MONITORAMENTO DO TEOR DE UMIDADE NA ÁREA DO PEREQUÊ-MiRIM. 178

FIGURA 6.28 - PERFIS DO TEOR DE UMIDADE DAS ÁREAS ESTUDADAS. 179

FIGURA 6.29 - PROCEDIMENTOS UTILIZADOS PARA A INSTALAÇÃO DOS SENSORES GMS. 181

FIGURA 6.30- DADOS DE MONITORAMENTO DA SUCÇÃO NA ÁREA DE MARANDUBA. 182

FIgURA 6.31 - DAdOS DE MONITORAMENTO DA SUCÇÃO NA ÁREA DO PEREQUÊ-MIRIM. 183

FIGURA 6.32 - PERFIS DE SUCÇÃO DAS ÁREAS ESTUDADAS. 184

FIGURA 6.33 - CURVAS DE RETENÇÃO OBTIDAS NO LABORATÓRIO E DADOS DE CAMPO DOS PERFIS DE UMIDADE E SUCÇÃO DAS ÁREAS ESTUDADAS. 185

FIGURA 6.34 - LOCAL DE INSTALAÇÃO DO PLUVIÔMETRO NA ÁREA DE MARANDUBA. 186

FIgURA 6.35 - LOCAL DE INSTALAÇÃO DO PLUVIÔMETRO NA ÁREA DO PEREQUÊ-Mirim............. 187

FIGURA 6.36 - DAdOS DE MONITORAMENTO DA PRECIPITAÇÃO NA ÁREA DE MARANDUBA.......... 188

Figura 6.37 - DAdOS DE MONITORAMENTO DA PRECIPITAÇÃO NA ÁREA DO PEREQUÊ-MiRIM. .. 189

FIGURA 6.38 - AGRUPAMENTO DOS DADOS DE MONITORAMENTO DA ÁREA DE MARANDUBA. .... 190

Figura 6.39 - AgruPAMENTO dos DAdOS DE MONITORAMENTO DA ÁREA DO PEREQUÊ-MiRIM.191

FIgURA 6.40 - REgISTROS DE UMIDADE E PRECIPITAÇÃO HORÁRIA DA ÁREA DE MARANDUBA... 193

FIGURA 6.41 - REGISTROS DE SUCÇÃO E PRECIPITAÇÃO HORÁRIA DA ÁREA DE MARANDUBA. .... 194 


\section{LISTA DE TABELAS}

\section{CAPÍTULO 3:}

TABELA 3.1 - PRINCIPAIS EQUAÇÕES PARA REPRESENTAR AS CRAS DE SOLOS BRASILEIROS. ........ 15 TABELA 3.2 - RESOLUÇÃO VERTICAL DA IMAGEM EM FUNÇÃO DA FREQÜÊNCIA DE OPERAÇÃO DAS

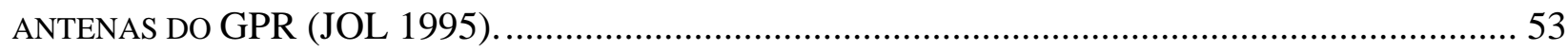

\section{CAPÍTULO 5:}

TABELA 5.1 - RESULTADOS DOS ENSAIOS DE CARACTERIZAÇÃO. .............................................. 101

TABELA 5.2 - MinERALOGIA DO PERFIL DE ALTERAÇÃO DE MARANDUBA. ................................ 104

TABEla 5.3 - Mineralogia do PERFIL DE ALTERAÇÃo DO PEREQUÊ-MiriM............................. 107

TABELA 5.4 - PRINCIPAIS FEIÇÕES MINERALÓGICAS E MICROMORFOLÓGICAS DO PERFIL DE ALTERAÇÃO DA ÁREA DE ESTUdO DE MARANDUBA............................................................... 111 TABELA 5.5 - PRINCIPAIS FEIÇÕES MINERALÓGICAS E MICROMORFOLÓGICAS DO PERFIL DE

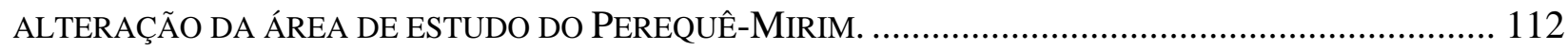

TABELA 5.6 - SUCÇÕES INICIAIS DE CAMPO DOS CORPOS DE PROVA. ........................................ 116 TABELA 5.7 - TEMPO DE EQUILÍBRIO SUGERIDO PARA O PAPEL FILTRO (MARINHO 1994)........ 121 TABELA 5.8 - PARÂMETROS UTILIZADOS PARA AJUSTAR OS PONTOS EXPERIMENTAIS. ................. 131 TABELA 5.9 - VALORES DO COEFICIENTE DE PERMEABILIDADE E CARACTERÍSTICAS INICIAIS DOS CORPOS DE PROVA UTILIZADOS NOS ENSAIOS DE PERMEABILIDADE 147

\section{CAPÍTULO 6:}

TABela 6.1 - PARÂMetros de VAN GenuChten E VALORES DE A PARA 12 TIPOS DE SOLO...... 152 TABELA 6.2 - VALORES DA CONDUTIVIDADE HIDRÁUliCA SATURADA E DOS PARÂMETROS UTILIZADOS PARA OS SOLOS INVESTIGADOS. 154

TABELA 6.3 - VALORES DA CONDUTIVIDADE HIDRÁUliCA SATURADA E DOS PARÂMETROS UTILIZADOS PARA OS CORPOS DE PROVA ENSAIADOS. 156 


\section{LISTA DE SÍMBOLOS}

\section{Alfabeto latino}

a - parâmetro de ajuste na equação proposta por Fredlund e Xing (1994) e representa também o afastamento entre antenas GPR (transmissora-receptora)

$\mathrm{a}_{\mathrm{w}}$ - área de água normalizada

$\mathrm{A}_{\mathrm{w}}$ - área de contato de água efetiva

c - velocidade de propagação de ondas eletromagnéticas no vácuo

$\mathrm{C}^{\prime}$ - intercepto de coesão efetiva

$\mathrm{d}$ - profundidade da camada refletora

e - índice de vazios

$\mathrm{f}_{\text {rel }}$ - freqüência de relaxação.

g - aceleração da gravidade

$\mathrm{h}_{\mathrm{c}}$ - máxima altura de ascensão da água

$\mathrm{I}_{\mathrm{a}}$ - índice de atividade de Skempton

IP - índice de plasticidade

$\mathrm{k}$ - coeficiente de permeabilidade

$\mathrm{K}$ - permissividade dielétrica relativa ou constante dielétrica

$\mathrm{K}^{*}$ - constante dielétrica complexa

K'- parte real da constante dielétrica

K”- parte imaginária da constante dielétrica

$\mathrm{K}_{\text {sat }}$ - condutividade hidráulica saturada

m - parâmetro de ajuste nas equações de Fredlund e Xing (1994) e Van Genuchten (1980)

$\mathrm{m}_{\mathrm{i}}$ - parâmetro de ajuste das sub-curvas na equação de Durner (1994)

n - porosidade e parâmetro de ajuste nas equações de Fredlund e Xing (1994) e Van Genuchten (1980)

$\mathrm{n}_{\mathrm{i}}$ - parâmetro de ajuste das sub-curvas na equação de Durner (1994)

$\mathrm{R}_{\mathrm{S}}$ - raio de curvatura do menisco

$S$ - grau de saturação

$\mathrm{S}_{\mathrm{e}}$ - grau de saturação efetivo

$\mathrm{S}_{\mathrm{R}}$ - grau de saturaçao residual 
$t_{a}$ - tempo de chegada da onda refletida para um determinado afastamento "a"

$\mathrm{T}_{\mathrm{S}}$ - tensão superficial da água

$\mathrm{u}_{\mathrm{a}}-$ poro-pressão do ar

$\left(\mathrm{u}_{\mathrm{a}}-\mathrm{u}_{\mathrm{w}}\right)$ - sucção matricial

$\mathrm{u}_{\mathrm{w}}$ - poro-pressão da água

v - velocidade de propagação de ondas eletromagnéticas

$\mathrm{w}$ - teor de umidade gravimétrica

$\mathrm{W}_{\mathrm{i}}$ - peso atribuído a cada sub-curva na equaçõa de Durner (1994)

$\mathrm{w}_{\mathrm{l}}$ - limite de liquidez

$\mathrm{w}_{\mathrm{p}}$ - limite de plasticidade

\section{Alfabeto grego}

$\chi$ - parâmetro função do grau de saturação

$\varepsilon_{\mathrm{a}}$ - deformação axial e permissividade do ar

$\varepsilon_{\mathrm{w}}$ - permissividade da água

$\varepsilon_{\mathrm{s}}$ - permissividade das partículas sólidas do solo

$\varepsilon$ - permissividade aparente do material

$\varepsilon_{0}$ - permissividade do espaço livre

$\phi '$ - ângulo de atrito interno efetivo

$\phi^{\mathrm{b}}$ - ângulo correspondente ao incremento da resistência ao cisalhamento com a sucção matricial

К - parâmetro de forma função do grau de saturação

$\Theta$ - relação entre a umidade volumétrica para um dado valor de sução e a umidade volumétrica na saturação $\left(\theta / \theta_{S}\right)$

$\theta_{\mathrm{R}}$ - umidade volumétrica residual

$\theta_{\mathrm{S}}$ - umidade volumétrica na saturação

$\theta$ - umidade volumétrica

$\rho_{d}$ - massa específica seca

$\rho$ - massa específica natural

$\rho_{\mathrm{s}}-$ massa específica dos sólidos 
$\rho_{\mathrm{w}}$ - massa específica da água

$\alpha$ - ângulo de contato entre o menisco de água e o tubo de vidro, e representa também o parâmetro de ajuste na equação de Van Genuchten (1980)

$\alpha_{i}$ - parâmetro de ajuste das sub-curvas na equação de Durner (1994)

$\psi_{\mathrm{m}}$ - sucção matricial

$\sigma$ - tensão normal total

б’- tensão normal efetiva

$\sigma_{\mathrm{dc}}-$ condutividade elétrica dos solos

$\left(\sigma-\mathrm{u}_{\mathrm{a}}\right)$ - tensão normal líquida

$\tau$ - tensão cisalhante

$\mu_{\mathrm{r}}$ - permeabilidade magnética relativa

$\lambda$ - comprimento da onda eletromagnética 


\section{INTRODUÇÃO}

\subsection{Estudos em Solos Não Saturados}

Ultimamente o estudo das propriedades de solos não saturados vem tomando destaque no âmbito da engenharia geotécnica nacional e internacional, principalmente porque a grande maioria das obras de engenharia é feita em solos na condição não saturada e a consideração deste estado pode proporcionar alguns benefícios técnicos e econômicos.

No Brasil, tanto o clima quanto certas peculiaridades dos solos residuais inerentes à mineralogia e à macro e microestrutura geram a necessidade de estudos específicos, onde a associação das características climáticas com o tipo de solo é fundamental quando se pretende entender seu comportamento hidro-mecânico. Considera-se que uma forma adequada de se avaliar este comportamento é por meio do monitoramento do perfil de sucção e umidade nas condições de campo.

A sucção é uma variável de tensão necessária para a definição do comportamento mecânico dos solos não saturados. A resistência destes solos é, em parte, governada pela pressão negativa de sua água intersticial. Deste modo, a medição da sucção matricial em solos não saturados se torna de grande importância para a compreensão do seu comportamento.

Nas análises de estabilidade de taludes e encostas é fundamental se estudar a variação sazonal da sucção devida a variações de teor de umidade do solo causadas por períodos de chuvas e estiagem. Para uma adequada associação dos aspectos climáticos com o comportamento hidromecânico do solo é essencial monitorar tanto os eventos pluviométricos quanto o seu efeito no perfil de sucção e umidade. Este monitoramento deve ser feito por meio de estações metereológicas e por núcleos de instrumentos que monitoram a sucção e o teor de umidade ao longo do perfil a ser investigado.

Se por um lado o uso destes instrumentos para o acompanhamento dos perfis de sucção e umidade é precisa por outro é problemática quando se trata de monitorar grandes áreas. A instalação de instrumentação com o objetivo de identificar periodicamente áreas de riscos é 
custosa e demanda grande esforço de manutenção. Desta forma, um dos objetivos do presente trabalho foi avaliar o desempenho de uma metodologia alternativa para o monitoramento do perfil de sucção, que permita auxiliar as análises de estabilidade de taludes em áreas de risco a escorregamentos.

Os escorregamentos em solo que ocorrem na Serra do Mar geralmente estão associados ao período de chuvas intensas. Uma das causas que explica a ocorrência dos escorregamentos é o efeito do desenvolvimento de pressões neutras positivas geradas pela infiltração de água das chuvas (VARGAS 1999). Porém, em outras circunstâncias, o mecanismo de instabilização envolve a redução ou eliminação do componente de resistência ao cisalhamento, que é devido à sucção do solo. Estudos que abordam o efeito da sucção na estabilidade de taludes e encostas em solos não saturados podem ser encontrados na literatura (e.g. MORGENSTERN \& MATTOS 1975, WOLLE et al. 1978, WOLLE 1985, ABRAMENTO \& CARVALHO 1989, WOLLE \& CARVALHO 1989, WOLLE \& HACHICH 1989, BRESSANI et al. 1997, CANCINO CALLE 2000, VIEIRA \& MARINHO 2001, SANTOS \& VILLAR 2004a, 2004b).

Os períodos de chuva e estiagem não ocorrem de maneira uniforme ao longo dos anos, fazendo com que o solo atinja valores de sucção diferentes, a depender do seu histórico de umedecimento e secagem (BENEVELI \& DE CAMPOS 2004). Neste contexto, torna-se bastante relevante o estudo dos fenômenos ligados ao movimento da água no solo.

O monitoramento do movimento de água em solos pode ser feito tanto por meio de medições de teor de umidade quanto a partir de valores de sucção. A medição do teor de umidade, in situ, não é simples e exige técnicas sofisticadas tais como: sonda de nêutrons, reflectômetro com domínio temporal (TDR) ou de freqüência (FDR), entre outras. Tanto o TDR quanto o FDR exige a instalação prévia no campo de hastes-guia que servem de “sensores” para a determinação da constante dielétrica do solo e posterior conversão para teor de umidade por meio de uma curva de calibração. No entanto, na geotecnia brasileira, a utilização da técnica FDR para medição do teor de umidade do solo, assim como sua associação com medições de sucção, ainda é uma abordagem inovadora. Desta forma, um dos objetivos do presente estudo é avaliar o estado de saturação do solo em diferentes épocas do ano utilizando-se duas técnicas inovadoras no meio geotécnico, ou seja, a técnica FDR e o método GPR (Ground Penetrating Radar) que se baseia 
nos mesmos princípios de funcionamento da técnica do TDR (TOPP et al. 1980, TOPP \& DAVIS 1985, TOPP 1987) sem, no entanto, necessitar de instalação prévia de sensores dentro do solo.

O método GPR vem sendo freqüentemente aplicado para identificação qualitativa da morfologia de perfis de solo em diversas áreas, tais como: geologia, hidrogeologia, geotecnia, meio ambiente, ciências do solo, arqueologia, etc. O reflexo da grande aplicabilidade desse método pode ser verificado nos inúmeros trabalhos científicos publicados na literatura internacional e nacional, envolvendo aplicações em diferentes áreas (e.g. ANNAN et al. 1991, BERES \& HAENI 1991, SCAIFE \& ANNAN 1991, ANNAN \& COSWAY 1992, FENNER \& VENDI 1992, LANZ et al. 1994, MAEKAWA \& FENNER 1994, ULRYCH et al. 1994, VAN OVERMEEREN 1994, ROBILLARD et al. 1994, SIGURDSSON 1994, JOL 1995, GREENHOUSE et al. 1995, LINER \& LINER 1995, OWEN 1995, PORSANI \& RODRIGUES 1995, SMITH \& JOL 1995, OLHOEFT 1996, SCAIFE 1997, ANNAN \& DAVIS 1997, RODRIGUES \& PORSANI 1997, AQUINO et al. 1998, SATO \& VERSTEEG 1998, PORSANI 1999, AQUINO 2000, DEHAINI 2001, GANDOLFO 2003).

Alguns trabalhos nacionais e internacionais demostram a possibilidade de se avaliar o teor de umidade do solo com base nos efeitos causados pela presença de água na velocidade de propagação do pulso eletromagnético do GPR (e.g. GREAVES et al. 1996, HUISMAN et al. 2001, HUISMAN et al. 2002, BOHIDAR \& HERMANCE 2002, DAVIS \& ANNAN 2002, GALAGEDARA et al. 2003, GROTE et al. 2003, HUISMAN et al. 2003, LUNT et al. 2004, BANO 2004, MACHADO et al. 2004a, PAIXÃO et al 2004, MACHADO et al. 2005, PAIXÃO \& PRADO 2006, AMPARO et al. 2007).

Os resultados promissores alcançados com o uso do GPR para medição do teor de umidade em outras circunstâncias são um estímulo para se investigar suas potencialidades e limitações para as condições geológicas e geotécnicas brasileiras. Neste sentido, utilizou-se a metodologia GPR com o intuito de estudar e avaliar sua eficiência para a determinação do teor de umidade em perfis de solos residuais não saturados da Serra do Mar (SP).

O presente estudo integra três linhas de pesquisas de diferentes instituições: a primeira do grupo de pesquisa sobre solos não saturados do Programa de Engenharia Geotécnica da Escola Politécnica da USP, onde foram estudadas as propriedades hidro-mecânicas dos solos residuais 
não saturados; a segunda do Departamento de Geofísica Aplicada do IAG-USP, responsável pela investigação geofísica com o radar de penetração no solo (GPR) e a terceira associa-se ao Programa de Geotecnia e Meio Ambiente do Instituto Geológico (IG-SMA), que desenvolve pesquisas na área de riscos geológico-geotécnicos e atua na operação de Planos Preventivos de Defesa Civil (PPDC), destinados à prevenção de escorregamentos nas encostas da Serra do Mar, entre outros municípios do Estado de São Paulo.

\subsection{Organização da Tese}

A apresentação da Tese de Doutoramento está dividida em 8 capítulos. No Capítulo 1 é feito um breve relato sobre a importância das condições climáticas e da sazonalidade do perfil de umidade e sucção nos estudos que envolvem análise de estabilidade de encostas e taludes em solos residuais tropicais. No Capítulo 2 são apresentadas as justificativas e hipóteses inicialmente adotadas na pesquisa e os objetivos gerais do presente trabalho.

No Capítulo 3 é feita uma revisão bibliográfica sobre os temas associados ao desenvolvimento da presente tese, sendo dividivos em quatro tópicos principais, a saber: 1) propriedades de solos não saturados, 2) características de solos residuais tropicais, 3) principais processos de instabilização de taludes e encostas naturais e 4) metodologia para definição do teor de umidade. No primeiro tópico são comentados os aspectos principais relacionados com a curva de retenção de água, condutividade hidráulica e resistência ao cisalhamento de solos. O segundo tópico trata da importância dos aspectos mineralógicos e microestruturais no comportamento dos solos residuais tropicais em termos de permeabilidade e resistência ao cisalhamento. O terceiro tópico relata brevemente os tipos de processos de instabilização predominantes no município onde estão situadas as áreas de estudo. O quarto tópico apresenta uma revisão geral do estado da arte, no âmbito internacional, sobre os métodos utilizados para a medição do teor de umidade do solo de forma não invasiva.

O Capítulo 4 descreve de forma sucinta os principais aspectos das áreas estudadas, destacando as condições geológicas, geomorfológicas, pluviométricas, o clima, a vegetação e o solo, em termos regionais e locais, retratando, sobretudo os motivos para a escolha das áreas estudadas. No Capítulo 5 são descritos os perfis típicos de alteração das áreas estudadas, assim como as técnicas 
e os métodos utilizados para a caracterização dos solos estudados, em termos geotécnicos e micromorfológicos. São apresentados os resultados obtidos nos diversos ensaios realizados, tais como: granulometria, massa específica natural e dos grãos, limites de Atterberg, caracterização mineralógica e microestrututal, curvas de retenção de água, distribuição dos poros por porosimetria, coeficientes de condutividade hidráulica e parâmetros de resistência ao cisalhamento dos solos.

No Capítulo 6 são apresentadas e descritas as técnicas utilizadas para a instalação dos equipamentos de monitoramento das variáveis geotécnicas (perfis de sucção e umidade do solo) e climatológica (precipitação). Apresenta-se também a metodologia empregada para a medição do teor de umidade nas condições de campo e os dados gerais do monitoramento realizado no período de novembro de 2006 a janeiro de 2008.

No Capítulo 7 são apresentadas as conclusões derivadas das análises dos diversos resultados obtidos na presente pesquisa e relatadas algumas recomendações para o desenvolvimento de pesquisas futuras. No Capítulo 8 são apresentadas as referências bibliográficas citadas no presente trabalho. 


\section{JUSTIFICATIVAS E OBJETIVOS}

Atualmente a região litorânea do Estado de São Paulo apresenta expressivo desenvolvimento regional, caracterizado principalmente pelas elevadas demandas para utilização de seus recursos naturais. Neste contexto, destaca-se o município de Ubatuba (SP) por apresentar crescente uso dos seus recursos naturais, mais especificamente pela utilização de saibro na infraestrutura civil e na manutenção da rede viária.

Segundo FERREIRA (2004), existem atualmente 118 áreas mineradas envolvendo extração de saibro e rocha ornamental no município de Ubatuba, sendo que 44\% destas áreas encontram-se em situação de instabilidade geotécnica associada a processos geodinâmicos, e 9\% das áreas encontram-se em situação de risco. Ainda segundo o autor op cit., tais áreas apresentam condições ambientais bastante sensíveis, caracterizadas principalmente pela elevada suscetibilidade a movimentos gravitacionais de massa, onde predominam severas restrições para uso e ocupação dos recursos naturais. A Figura 2.1 ilustra a referida situação de degradação ambiental numa das áreas de estudo.

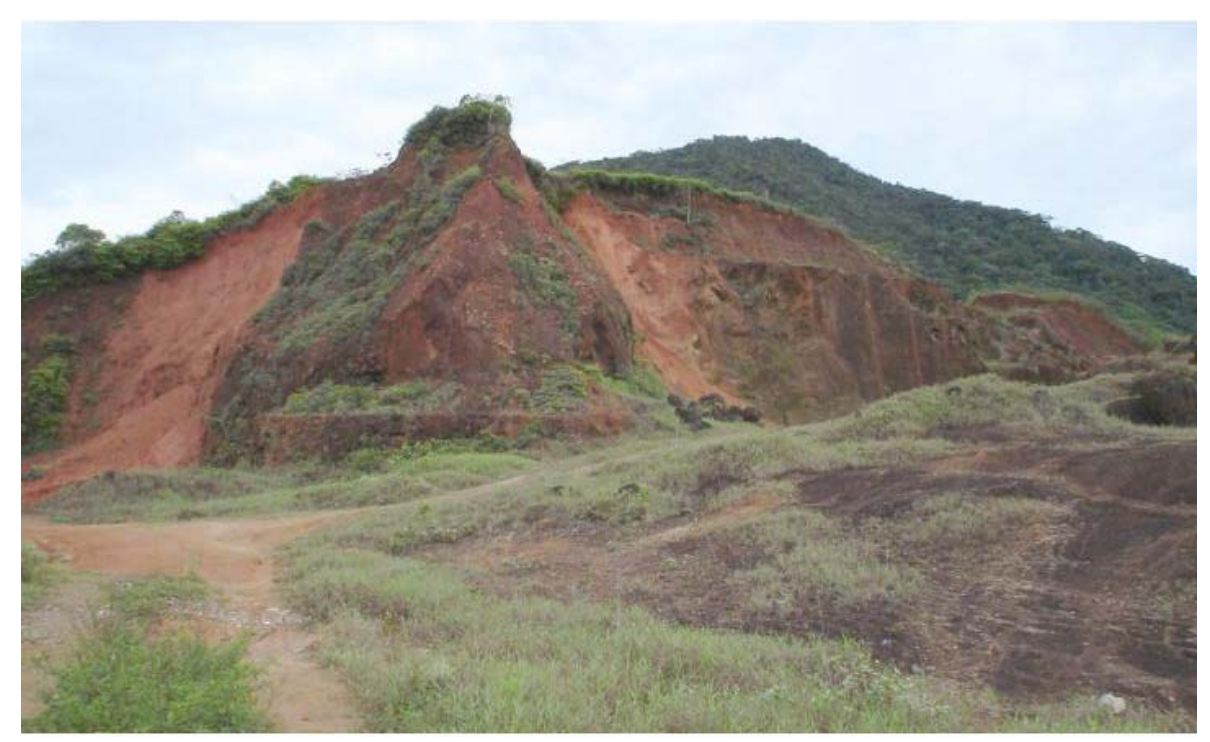

FIGURA 2.1 - ÁrEA ESTUDADA E MONITORADA NO BAIRRO DO PEREQUÊ-MIRIM.

Logo, a proposta da presente tese partiu da constatação dos processos geodinâmicos ocorrentes nessas áreas parcialmente degradadas, caracterizando, deste modo, a relevância de se estudar detalhadamente as propriedades geotécnicas dos perfis de solos residuais não saturados 
encontrados nesses locais, bem como avaliar novas técnicas e/ou métodos que permitam o monitoramento simultâneo de variáveis climatológicas e geotécnicas fundamentais para as análises de estabilidade de encostas e taludes.

O estudo das propriedades geotécnicas dos solos residuais não saturados foi efetuado através de uma abordagem macro e micromorfológica, buscando estabelecer a relação existente entre a água presente no solo e sua variação sazonal.

A hipótese de partida da presente tese foi que no interior dos solos residuais existe uma importante diferenciação dos microagregados, dos argilominerais e da distribuição espacial dos poros. Acredita-se que tais variáveis influenciam, de uma maneira bem distinta, a circulação de água nos solos residuais e, conseqüentemente, a relação entre água presente nos poros e a sucção matricial que, por sua vez, controla os parâmetros de resistência ao cisalhamento.

Os procedimentos e técnicas necessários aos estudos macro e micromorfológicos permitiram identificar variações nos "horizontes do solo" quanto à microestrutura e porosidade, e caracterizar seu comportamento físico-hídrico. Os ensaios geotécnicos, in situ e em laboratório, forneceram informações importantes sobre as propriedades dos materiais, tais como: índices físicos, distribuição granulométrica, limites de Atterberg, curva de retenção de água, parâmetros de resistência ao cisalhamento sob diferentes condições de umidade e condutividade hidráulica saturada. Os equipamentos instalados no campo (pluviômetros, sensores GMS e FDR) permitiram o monitoramento contínuo das variáveis climatológicas (chuva) e geotécnicas (perfis de umidade e sucção). O método GPR foi utilizado para a determinação do teor de umidade volumétrico ao longo dos perfis de alteração estudados nas condições de campo.

O objetivo geral do trabalho foi estudar as propriedades geotécnicas de solos residuais não saturados ocorrentes nas encostas da Serra do Mar, com o intuito de estabelecer critérios e procedimentos de monitoramento de variáveis climatológicas e geotécnicas que permitam fornecer subsídios para o aperfeiçoamento dos parâmetros técnicos utilizados em Planos Preventivos de Defesa Civil (PPDC), implantados em áreas de risco associadas com escorregamentos de encostas e taludes. 
Para alcançar o objetivo da presente tese, foram executadas as seguintes etapas de estudo:

1. Caracterização geológico-geotécnica dos perfis de alteração em duas áreas de estudo situadas no município de Ubatuba-SP;

2. Caracterização da porosidade e da micromorfologia dos solos que compõem os perfis de alteração das áreas de estudo;

3. Avaliação da influência da sucção matricial na resistência ao cisalhamento dos solos residuais não saturados;

4. Estudo da influência da micromorfologia dos solos residuais tropicais no comportamento da curva de retenção de água;

5. Determinação dos parâmetros geotécnicos necessários para as análises de estabilidade de encostas e taludes;

6. Monitoramento dos eventos pluviométricos simultaneamente com os perfis de sucção e umidade para compreender melhor o processo de infiltração das águas da chuva nos solos residuais não saturados;

7. Avaliação do método GPR para a determinação do perfil de umidade em solos residuais tropicais não saturados; 


\section{REVISÃO BIBLIOGRÁFICA}

\subsection{Propriedades de Solos Não Saturados}

\subsubsection{Introdução}

O clima desempenha um papel importante quer o solo esteja na condição saturada ou não saturada. A água é removida do solo por evaporação na superfície do terreno ou pela evapotranspiração da cobertura vegetal. Estes processos acabam produzindo um fluxo ascendente de água para fora do solo. Em contrapartida, a chuva e outras formas de precipitação fornecem um fluxo descendente de água por dentro do solo. O balanço entre essas duas situações de fluxo impõe a condição de poro-pressão da água num determinado tipo de solo (FREDLUND 1995).

Variações climáticas influenciam o teor de umidade do solo próximo à superfície do terreno. Quando umedecido, a poro-pressão da água aumenta, tendendo a valores positivos. Como resultado, ocorrem mudanças na resistência ao cisalhamento do solo. Alguns solos são conhecidos pela sua significativa capacidade de perder a resistência ao cisalhamento quando umedecidos. Mudanças na poro-pressão negativa da água associada com períodos de chuvas intensas e prolongadas são as causas de numerosas rupturas de encostas e taludes. Este fenômeno, em particular, indica o papel importante que a poro-pressão negativa da água ou sucção matricial desempenha no controle do comportamento mecânico dos solos não saturados (FREDLUND \& RAHARDJO 1993).

\subsubsection{Curva de retenção de água (CRA)}

A existência de suç̧ão em solos não saturados é reconhecida como decorrente dos efeitos combinados de capilaridade e de adsorção. O valor da sucção matricial é devido à atuação das forças de adsorção e de capilaridade, sendo representada pela diferença entre a poro-pressão do ar e da água $\left(u_{a}-u_{w}\right)$. A sucção osmótica é função da quantidade de sais dissolvidos no interior de 
solo. A parcela de sucção matricial devido à capilaridade tem importância maior no domínio das baixas sucções, em poros de diâmetros relativamente grandes. As forças de adsorção são mais atuantes no domínio dos altos valores de sucção, em poros de menor diâmetro, onde há predominância dos fenômenos de superfície, relacionados com a atividade do argilomineral (FREDLUND \& RAHARDJO 1993).

O aparecimento de meniscos nos poros do solo proporciona a ocorrência da sucção matricial. Estes meniscos são similares aos formados pela interface água-ar no interior de um tubo capilar. Tanto a altura de ascensão da água quanto o raio de curvatura do menisco têm relações diretas com a curva de retenção de água. Utilizando o modelo do tubo capilar ilustrado na Figura 3.1 e considerando o equilíbrio de forças na vertical, pode-se obter a máxima altura de ascensão da água, $h_{c}$ :

$$
h_{c}=\frac{2 T_{S}}{\rho_{w} g R_{S}}
$$

onde: $T_{s}$ é a tensão superficial da água; $g$ é a aceleração da gravidade; $R_{S}$ é o raio de curvatura do menisco.

Os pontos $A, B$ e $C$, na Figura 3.1, estão em equilíbrio hidrostático. Nessa condição, a pressão da água no ponto $C$ é dada por:

$$
u_{w}=-\rho_{w} g h_{c}
$$

A pressão da água no tubo capilar acima do ponto $A$ é negativa. A pressão da água abaixo do ponto $A$ é positiva devido às condições de pressão hidrostática. No ponto $C$, a pressão do ar é atmosférica (isto é, $\left.u_{a}=0\right)$, e a pressão de água é negativa. A sucção matricial $\left(u_{a}-u_{w}\right)$ no ponto $C$ pode, então, ser expressa da seguinte forma:

$$
\left(u_{a}-u_{w}\right)=\rho_{w} g h_{c}
$$


Substituindo a Equação 3.1 na Equação 3.3, obtém-se uma relação entre a sucção matricial e o raio de curvatura do menisco de água formado entre as partículas do solo:

$$
\left(u_{a}-u_{w}\right)=\frac{2 T_{S}}{R_{S}}
$$
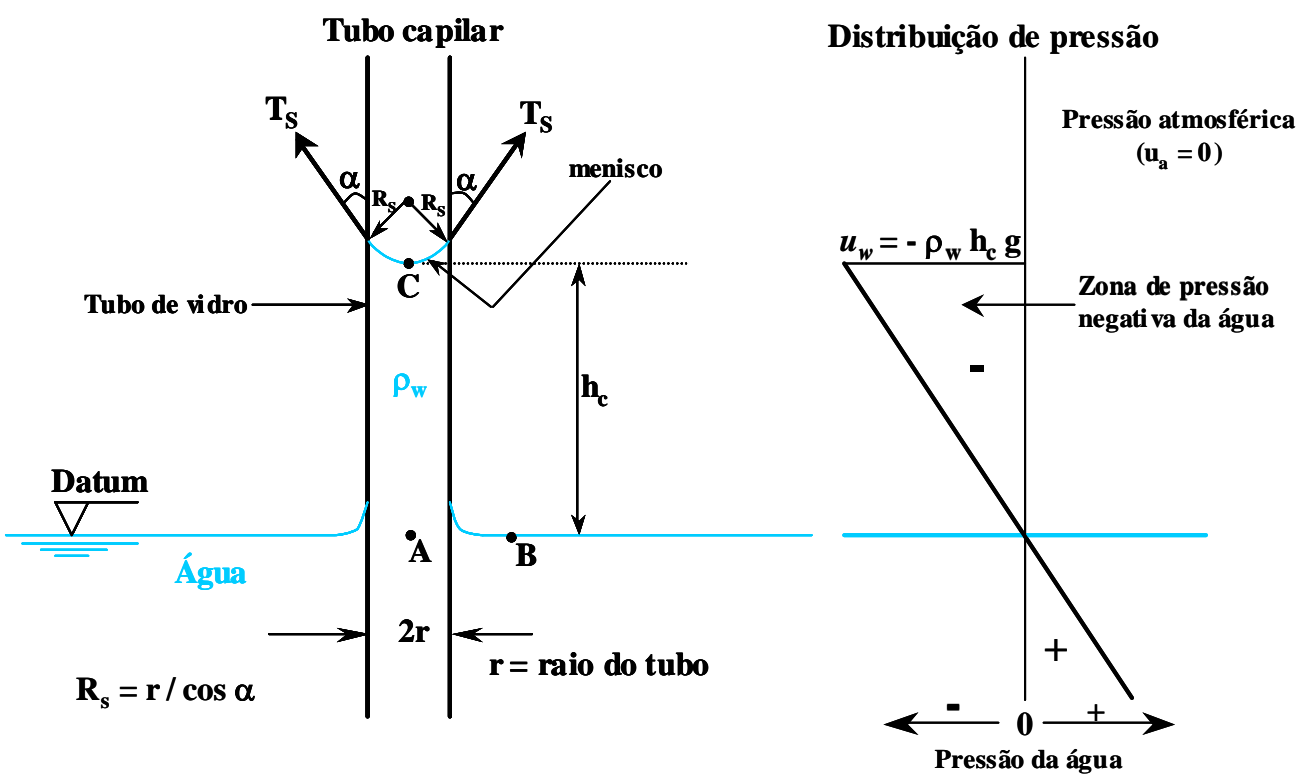

FIGURA 3.1 - MODELO FÍSICO RELACIONADO AO FENÔMENO DA CAPILARIDADE.

O raio de curvatura do menisco, $R_{s}$, pode ser considerado semelhante ao raio dos poros de um solo. Como resultado, quanto menor for o raio dos poros, maior será a sucção matricial do solo. O aumento da sucção matricial proporciona uma maior atração entre as partículas dos solos, aumentando o componente normal das forças que atuam sobre elas, gerando um aumento na resistência ao cisalhamento.

A sucção matricial pode ser medida de maneira direta ou indireta. As principais técnicas de medição e aplicação da sucção são: tensiômetros, placa de sucção e a técnica de translação de eixos (HILF 1956). Entre as técnicas indiretas, destacam-se os sensores de blocos porosos e a técnica do papel filtro (CHANDLER et al. 1992, MARINHO 1994, 1995 e 1997, MARINHO \& OLIVEIRA 2006). 
A curva de retenção de água (CRA) ou curva característica solo-água expressa a relação entre a quantidade de água retida no solo e a sucção matricial. A quantidade de água pode ser representada pelo teor de umidade gravimétrico $(w)$, volumétrico $(\theta)$ ou pelo grau de saturação $(S)$. Alguns modelos matemáticos que utilizam a CRA vem sendo amplamente empregados para a obtenção de algumas propriedades de solos não saturados. Por exemplo, utiliza-se a CRA para se avaliar a função condutividade hidráulica e também a envoltória de resistência ao cisalhamento (e.g. FREDLUND et al. 1994 e 1995).

Partindo do valor da sucção matricial para a condição saturada $\left(\theta_{\mathrm{S}}\right)$ e percorrendo a CRA durante o procedimento de secagem, à medida que o valor da sucção aumenta chega-se primeiramente ao valor de entrada de ar e depois ao valor residual de sucção, conforme observado na Figura 3.2. A CRA pode apresentar histerese, ou seja, os valores de sucção e umidade obtidos ao longo da curva de secagem não são os mesmos daqueles obtidos na curva de umedecimento. Este fenômeno pode ser atribuído a diversas causas, destacando-se entre elas, a geometria não uniforme dos poros e o ar aprisionado nos vazios do solo durante o processo de umedecimento (FREDLUND \& XING 1994).

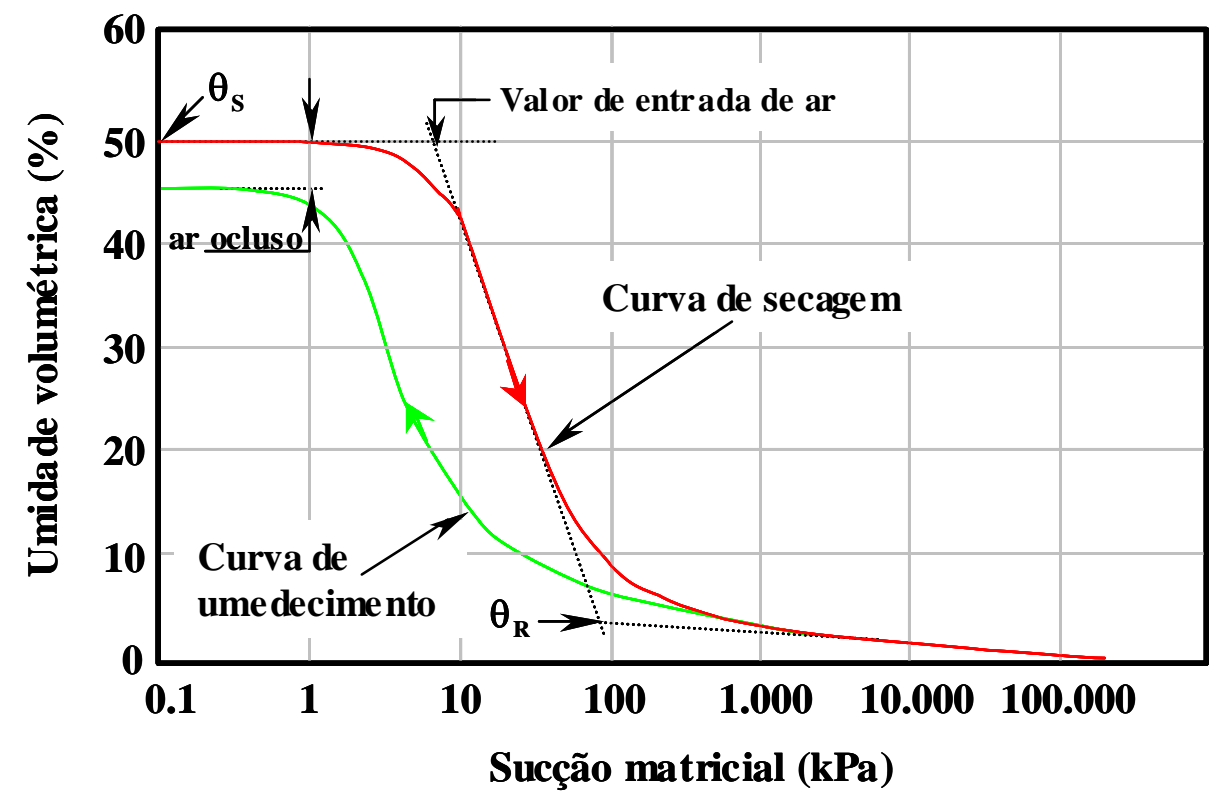

FIGURA 3.2 - CARACTERÍSTICAS PRINCIPAIS DA CRA DURANTE A SECAGEM E UMEDECIMENTO (MODIFICADO DE FREDLUND \& XING 1994). 
Podem ser identificados três estágios de desaturação ao longo da CRA: estágio de efeito de fronteira, estágio de transição (primária e secundária) e estágio residual de não saturação, conforme é mostrado na Figura 3.3. No primeiro estágio, todos os poros do solo estão preenchidos com água, isto é, os meniscos de água estão em contato contínuo com os grãos ou agregados do solo, até a sucção atingir o valor de entrada de ar. Este valor de sucção identifica o ponto no qual o ar entra nos poros de diâmetros maiores. O solo começa a dessaturar no estágio de transição primária e aumenta ainda mais no estágio de transição secundária. Neste estágio, o teor de umidade no solo reduz significativamente com o aumento da sucção. A área do menisco de água em contato com os grãos ou agregados do solo não é mais contínua e começa a reduzir. No estágio final, grandes aumentos nos valores de sucção provocam pequenas mudanças no teor de umidade ou grau de saturação do solo.

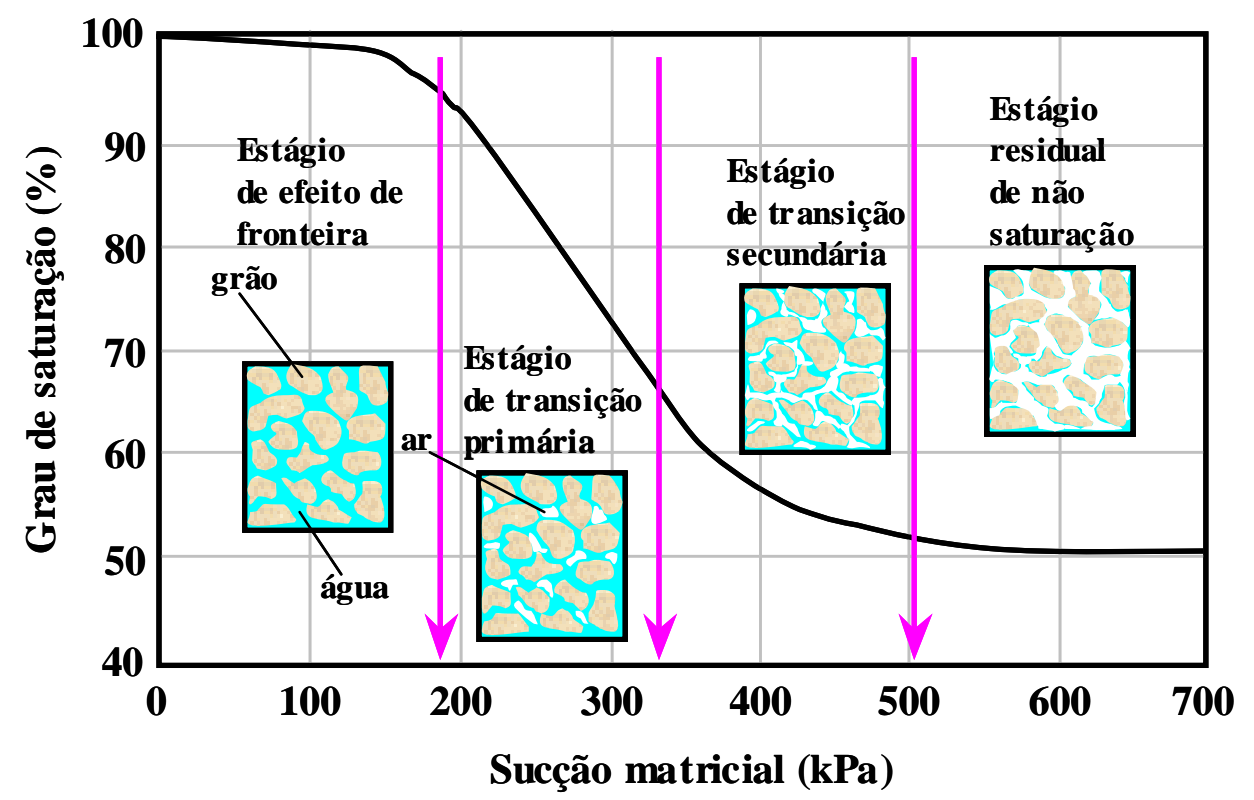

FIGURA 3.3 - ESTÁGIOS DA CRA PARA UM MEIO POROSO HIPOTÉTICO (MODIFICADO DE VANAPALLI ET AL. 1996).

Na literatura existem procedimentos gráficos para a determinação dos valores de sucção correspondentes a entrada de ar e ao valor residual (e.g. FREDLUND \& XING 1994, VANAPALLI et al. 1998). No entanto, verifica-se que ainda não há consenso na comunidade científica sobre o valor exato da sucção residual a ser adotado. A forma da CRA depende sobremaneira de algumas peculiariedades dos solos relacionadas principalmente aos seguintes aspectos: estrutura, tamanho e geometria dos poros, textura e mineralogia. 
Em relação à textura, observa-se que para solos argilosos o desenvolvimento da sucção é maior do que para solos mais arenosos, conforme se observa na Figura 3.4. Os solos argilosos tendem a reter mais água para um certo valor de sucção, ao contrário dos solos arenosos que perdem água de seus vazios mais rapidamente devido à existência de poros de maior diâmetro em sua estrutura. Os valores de entrada de ar e teor de umidade saturada $\left(\theta_{\mathrm{S}}\right)$ geralmente aumentam com a plasticidade do solo. Outros fatores, como o histórico de tensões do solo, também influenciam o formato da CRA (FREDLUND \& XING 1994).

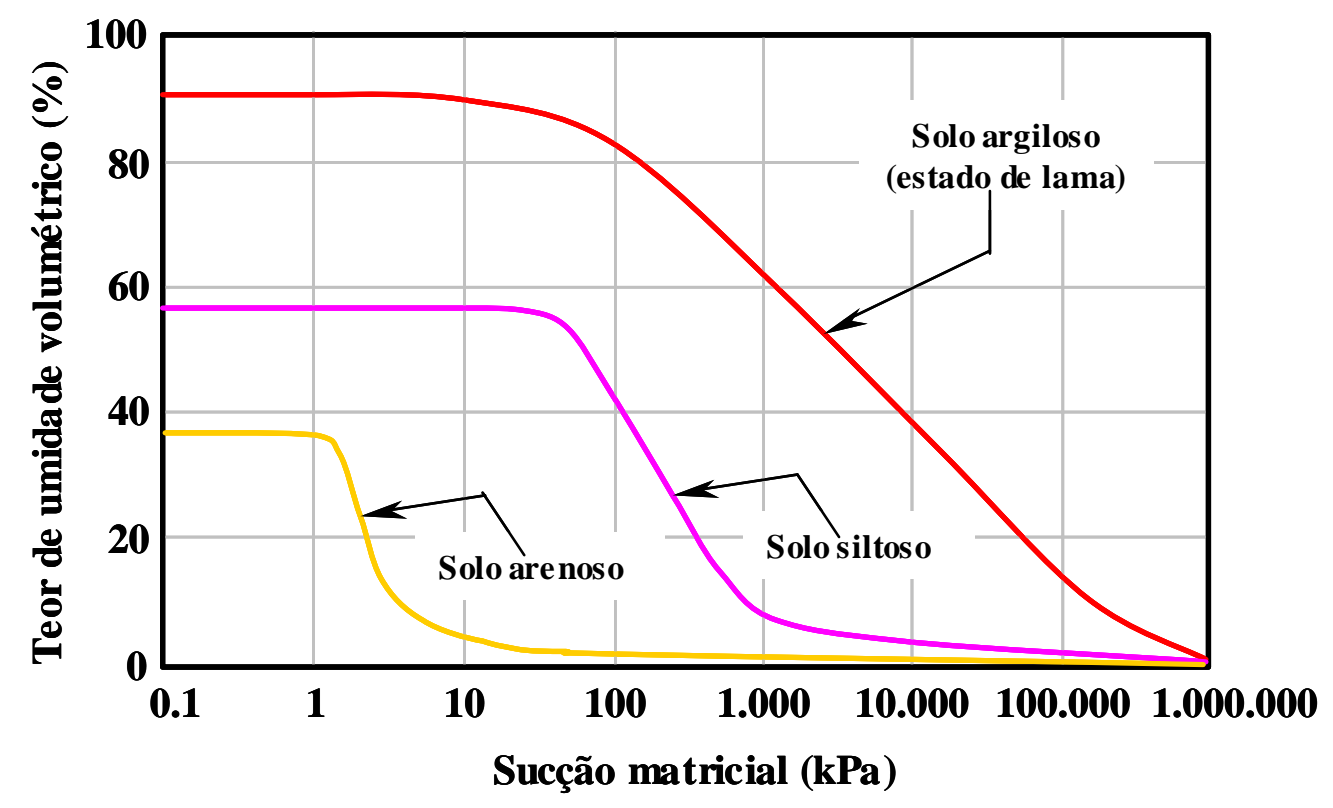

FiguRA 3.4 - CURVAS DE RETENÇÃo DE ÁGUA PARA SOLO ARGILOSO, SILTOSO E ARENOSO (MODIFICADO DE FREDLUND \& XING 1994).

Os valores experimentais da CRA podem ser ajustados e posteriormente representados por equações matemáticas. Existem diversas equações matemáticas que podem ser utilizadas para ajustar as curvas de retenção de água, destacando os modelos de ajuste propostos por BURDINE (1953), GARDNER (1958), BROOKS \& COREY (1964), MUALEM (1976), VAN GENUCHTEN (1980) e FREDLUND \& XING (1994). Em termos gerais, todas essas equações ajustam razoavelmente os pontos experimentais da CRA, para valores baixos e médios de sucção. Segundo GERSCOVICH \& SAYÃO (2002), os pontos experimentais das CRAs de solos brasileiros são melhor ajustados pelas equações matemáticas propostas por GARDNER (1958), VAN GENUCHTEN (1980) e FREDLUND \& XING (1994). Na Tabela 3.1 são apresentadas essas equações com seus respectivos parâmetros de ajuste. 
Tabela 3.1 - Principais equações para representar as CRAs de solos brasileiros.

\begin{tabular}{|c|c|c|c|}
\hline Autor (es) & Ano & Equação & Parâmetros de ajuste \\
\hline GARDNER & 1958 & $\Theta=\frac{1}{1+q \psi^{n}}$ & $\begin{array}{l}q \text {-valor da sucção de entrada de } \\
\text { ar. } \\
n \text {-inclinação do ponto de } \\
\text { inflexão da CRA. }\end{array}$ \\
\hline VAN GENUCHTEN & 1980 & $\begin{array}{l}\Theta=\frac{1}{\left[1+(\alpha \psi)^{n}\right]^{m}} \\
\Theta=S_{e}=\frac{\theta-\theta_{R}}{\theta_{s}-\theta_{R}}\end{array}$ & $\begin{array}{l}\Theta \text { - teor de umidade volumétrica } \\
\text { normalizada ou grau de saturação } \\
\text { relativo. } \\
\psi \text { - sucção matricial. } \\
\alpha, \text { n e } m \text { - parâmetros de ajuste. }\end{array}$ \\
\hline FREDLUND \& XING & 1994 & $\theta=C(\psi) \frac{\theta_{s}}{\ln \left[e+\left(\frac{\psi}{a}\right)^{n}\right]^{m}}$ & $\begin{array}{l}\psi \text { - sucção matricial. } \\
\theta_{s} \text { - umidade volumétrica saturada } \\
\text { a, n e } m \text { - parâmetros de ajuste. }\end{array}$ \\
\hline
\end{tabular}

Entretanto, tais equações podem ser aplicadas somente para ajustar pontos experimentais da CRA de solos que apresentem uma distribuição de poros do tipo monomodal. No caso de solos constituídos por uma porosidade dupla, pode-se utilizar o modelo dual porosity sugerido por DURNER (1994), empregando-se a seguinte equação:

$$
S_{e}=w_{1} \cdot \frac{1}{\left[1+\left(\alpha_{1}|\psi|\right)^{n_{1}}\right]^{n_{1}}}+w_{2} \cdot \frac{1}{\left[1+\left(\alpha_{1}|\psi|\right)^{n_{2}}\right]^{n_{2}}},
$$

onde: $w_{i}$ é o peso atribuído a cada sub-curva, onde $0<w_{i}<1$ e $\Sigma w_{i}=1$. Os valores $\alpha_{\mathrm{i}}, n_{i}, m_{i}$ são os parâmetros das sub-curvas que estão sujeitas as seguintes condições $\alpha_{\mathrm{i}}>0, n_{i}>1$ e $m_{i}>0$; $\psi$ é a sucção matricial; $S_{e}$ é a saturação efetiva definida por:

$$
S_{e}=\frac{\left(\theta-\theta_{R}\right)}{\left(\theta_{S}-\theta_{R}\right)}
$$

com $\theta_{S}$ e $\theta_{R}$,representando os teores de umidade volumétrica saturada e residual, respectivamente. 


\subsubsection{Condutividade hidráulica}

No campo da engenharia geotécnica não há propriedade que possa ser mais variável do que a condutividade hidráulica. Quando os solos se encontram na condição saturada, a condutividade hidráulica pode variar mais de $10^{6}$ vezes para solos que possuem uma textura muito heterogênea, variando desde pedregulhos até argilas. Esta ampla variabilidade na condutividade hidráulica tem sido o maior obstáculo em análises que envolvem problemas de percolação (FREDLUND et al. 1994).

Num solo saturado, a condutividade hidráulica é constante devido o teor de umidade do solo não variar. Num solo não saturado, a condutividade hidráulica não é mais constante, pois depende do teor de umidade volumétrico ou do grau de saturação que, por sua vez, está relacionado com a sucção do solo. A curva de condutividade hidráulica é utilizada para representar o relacionamento entre o coeficiente de permeabilidade e a sucção dos solos “ $k(\psi)$ ”.

O termo coeficiente de permeabilidade representa uma condição particular na curva de condutividade hidráulica, quando o solo está na condição saturada. A curva de condutividade hidráulica de um solo não saturado pode ser obtida a partir de equações empíricas e modelos estatísticos. No entanto, para se utilizar uma equação empírica é necessário obter diversos dados experimentais sobre medidas de permeabilidade. Em contrapartida, os modelos estatísticos podem ser facilmente utilizados para a previsão da curva de condutividade hidráulica, quando se dispõem do coeficiente de permeabilidade e da curva de retenção de água (CRA) do solo.

Os modelos estatísticos se baseiam no fato de que, tanto a condutividade hidráulica quanto a CRA, são obtidas a partir da distribuição dos tamanhos de poros de um determinado tipo de solo. Atualmente existem vários modelos estatísticos propostos para a previsão da condutividade hidráulica de solos não saturados (e.g. GARDNER 1958, BROOKS \& COREY 1968, ARBHABHIRAMA \& KRIDAKORN 1968, MUALEM 1976, VAN GENUCHTEN 1980 e FREDLUND et al. 1994, VANAPALLI \& LOBBEZOO 2002). 
Em geral, todos os modelos propostos necessitam do conhecimento prévio do teor de umidade volumétrico saturado $\left(\theta_{\mathrm{s}}\right)$ e residual $\left(\theta_{\mathrm{R}}\right)$, do valor da sucção de entrada de ar e do coeficiente de permeabilidade. A Figura 3.5 mostra uma curva de retenção de água típica para um solo superficial arenoso e sua respectiva curva de condutividade hidráulica.

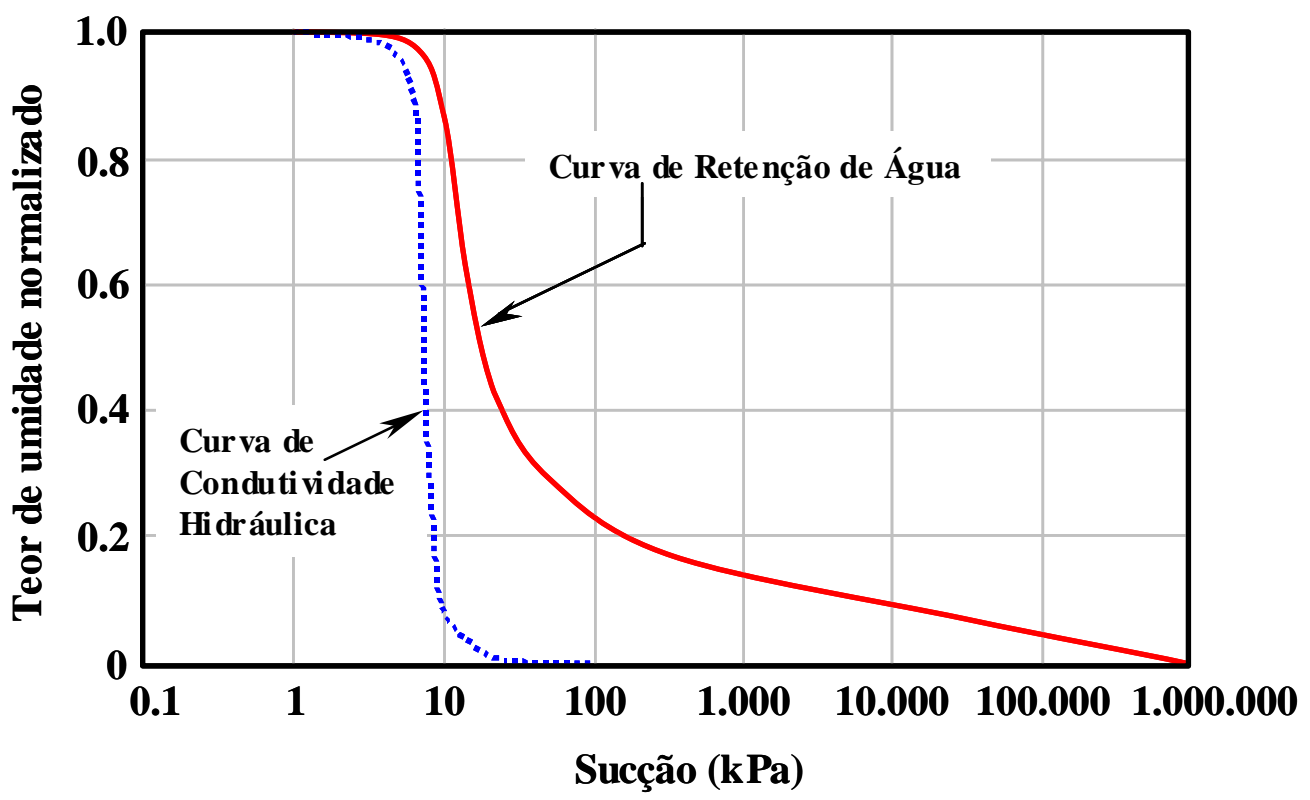

FIGURA 3.5 - CURVAS DE RETENÇÃO DE ÁGUA E CONDUTIVIDADE HIDRÁULICA PARA UM SOLO ARENOSO (MODIFICADO DE FREDLUND ET AL. 1994).

Segundo avaliações realizadas por GERSCOVICH \& GUEDES (2004), os modelos de condutividade hidráulica baseados na variação de sucção (BROOKS \& COREY 1968, ARBHABHIRAMA \& KRIDAKORN 1968) forneceram os melhores ajustes para os dois solos brasileiros estudados.

A maioria dos modelos propostos apresentam ajustes razoáveis entre os valores previstos e medidos para a condutividade hidráulica. As comparações podem ser realizadas a partir de resultados de ensaios de laboratório, apesar de consumir muito tempo. As pesquisas sugerem que as peculiaridades estruturais do maciço devem estar muito bem representadas em laboratório, visando garantir uma adequada avaliação do comportamento de fluxos em solos não saturados (FREDLUND \& RAHARDJO 1993). 
O modelo estatístico proposto por VAN GENUCHTEN (1980) para a previsão da curva de condutividade hidráulica é representado pela seguinte expressão:

$$
k(\theta)=k_{s} \cdot \Theta^{l}\left[1-\left(1-\Theta^{\frac{1}{m}}\right)^{m}\right]^{2}
$$

onde: $m$ é o parâmetro de ajuste; $l$ é um valor adotado igual a 0,5 ; e $\Theta$ é o teor de umidade volumétrica normalizada ou grau de saturação efetivo, dado por:

$$
\Theta=S_{e}=\frac{\theta-\theta_{R}}{\theta_{s}-\theta_{R}}
$$

Outro modelo estatístico bastante utilizado combina a equação de ajuste da curva de retenção proposta por DURNER (1994), com o modelo de distribuição de tamanho de poros sugerido por MUALEM (1976). Desta forma, para um solo com distribuição de poros do tipo bimodal, o modelo estatístico para previsão da condutividade hidráulica é dado por:

$$
k\left(S_{e}\right)=k_{s} \cdot \frac{\left(w_{1} S_{e_{1}}+w_{2} S_{e_{2}}\right)^{l} \cdot\left(w _ { 1 } \alpha _ { 1 } \left[1-\left(1-S_{e_{1}}^{\left.\left.\frac{1}{m_{1}}\right)^{m_{1}}\right]}{ }^{m_{2}} w_{2} \alpha_{2}\left[1-\left(1-S_{e_{2}} \frac{1}{m_{2}}\right)^{m_{2}}\right]\right)^{2}\right.\right.}{\left(w_{1} \alpha_{1}+w_{2} \alpha_{2}\right)} \text { [Equação 3.9] }
$$

onde: $w_{i}$ é o peso atribuído a cada sub-curva; $l, \alpha_{\mathrm{i}}, m_{i}$ são os parâmetro de ajuste; $S_{e}$ é o teor de umidade volumétrica normalizada ou grau de saturação relativo.

\subsubsection{Variáveis de estado de tensão}

O comportamento mecânico de solos é controlado por algumas variáveis de tensão que controlam o equilíbrio da estrutura do solo. Portanto, as variáveis de tensão requeridas para descrever o equilíbrio da estrutura de um solo podem ser consideradas como as variáveis de estado de tensão para o solo. As variáveis de estado de tensão para um solo saturado foram completamente definidas por TERZAGHI (1936), na forma da seguinte equação: 


$$
\sigma^{\prime}=\sigma-u_{w}
$$

onde: $\sigma$ ' é a tensão normal efetiva; $\sigma$ é a tensão normal total; $u_{w}$ é a poro-pressão de água.

A Equação 3.10 é definida como a equação das tensões efetivas. Tem-se mostrado que somente uma variável de estado de tensão, isto é $\left(\sigma-u_{w}\right)$, é necessária para descrever o comportamento mecânico de um solo saturado. A descrição mais completa do estado de tensão envolve a consideração das tensões efetivas em cada uma das três direções ortogonais, incluindo as componentes de cisalhamento conforme apresentado na Figura 3.6. O conceito de tensões efetivas forma a base fundamental para os estudos da mecânica dos solos saturados (FREDLUND \& RAHARDJO 1993).

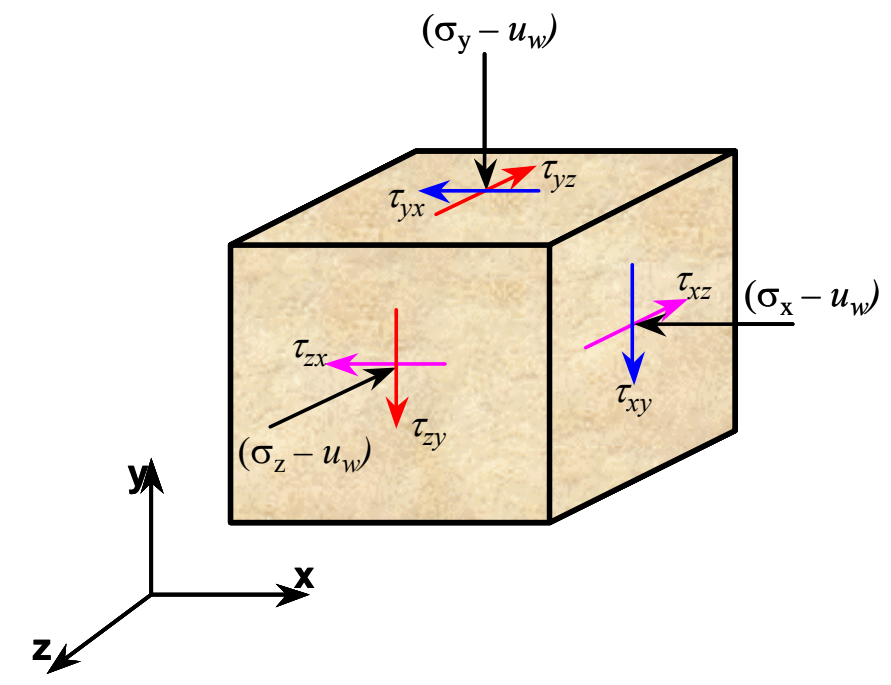

FIGURA 3.6 - VARIÁVEIS DE ESTADO DE TENSÕES PARA SOLOS SATURADOS.

O comportamento de solos não saturados é mais complexo que o comportamento de solos saturados. Os solos não saturados geralmente têm sido considerados como um sistema de três fases (ar, água, grãos de solo). FREDLUND \& MORGENSTERN (1977) concluíram que três variáveis de estado de tensão $\left(\sigma_{\mathrm{y}}-u_{a}\right),\left(u_{a}-u_{w}\right),\left(u_{a}\right)$, são necessárias para descrever o estado de tensão de um solo não saturado. A variável de tensão, $u_{a}$, pode ser eliminada quando as partículas de solo e a água forem consideradas incompressíveis. Logo, as componentes $\left(\sigma-u_{a}\right)$ e $\left(u_{a}-u_{w}\right)$ são consideradas como as variáveis de estado de tensão para um solo não saturado. A Figura 3.7 mostra um elemento de solo não saturado onde são indicadas as variáveis de estado de tensão para os solos não saturados. 
As variáveis $\left(\sigma-u_{a}\right)$ e $\left(u_{a}-u_{w}\right)$ mostram-se mais satisfatórias para a prática da engenharia geotécnica, com a vantagem adicional de que a variação na tensão normal pode ser separada do efeito causado pela variação na poro pressão de água (FREDLUND \& RAHARDJO 1993).

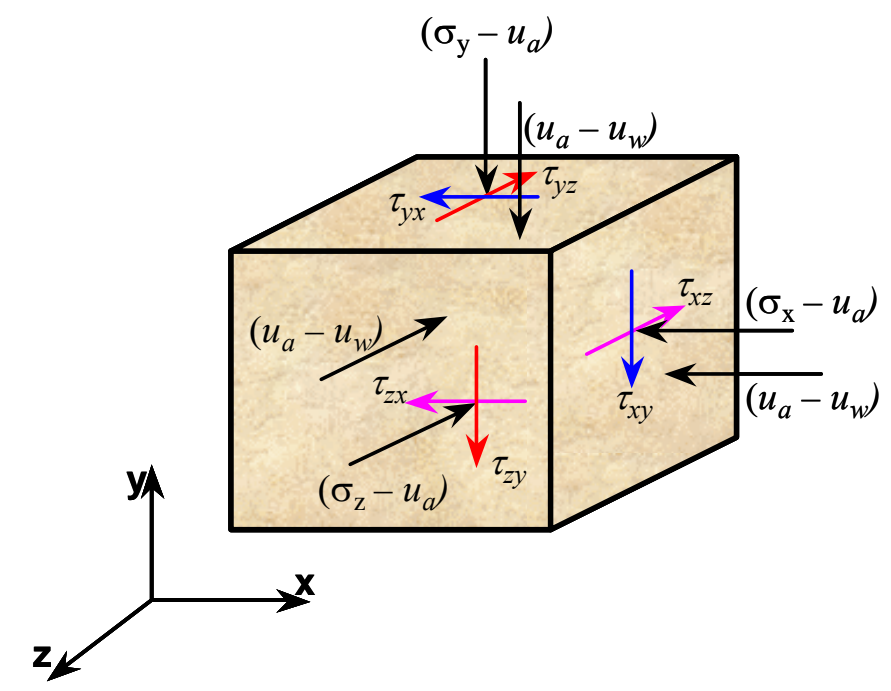

FIGURA 3.7 - VARIÁVEIS DE ESTADO DE TENSÕES PARA SOLOS NÃO SATURADOS.

\subsubsection{Resistência ao cisalhamento dos solos não saturados}

Um dos trabalhos pioneiros na definição das leis de comportamento de solos não saturados, em relação à resistência ao cisalhamento, foi o de BISHOP (1959). Aplicando o critério de Mohr-Coulomb, BISHOP et al. (1960) propôs a primeira equação de resistência ao cisalhamento em solos não saturados, representada pela seguinte expressão:

$$
\tau=c^{\prime}+\left(\sigma-u_{a}\right) \tan \phi^{\prime}+\chi\left(u_{a}-u_{w}\right) \tan \phi^{\prime}
$$

onde: c' e $\phi$ ' são os parâmetros de resistência do solo na condição saturada; $\left(\sigma-u_{a}\right)$ é a tensão normal liquida; $\left(u_{a}-u_{w}\right)$ é a sucção matricial e $\chi$ é um parâmetro dependente do grau de saturação do solo. O parâmetro $\chi$ é igual a 1 para o solo na condição saturada, e igual a zero para o solo totalmente seco. 
No entanto, JENNINGS \& BURLAND (1962) e BURLAND (1965) mostraram que o parâmetro $\chi$ varia muito devido à estrutura e ao tipo de solo, e que a proposição só era satisfatória para a condição de ruptura, não representando bem o comportamento do solo em função das variações volumétricas. Tais autores enfatizaram a importância de separar duas variáveis de estado de tensões: a primeira denominada de "tensão normal líquida $\left(\sigma-u_{a}\right)$ e a segunda de sucção matricial $\left(u_{a}-u_{w}\right)$. Além disso, BLIGHT (1967), reconhecendo os problemas em relação à equação de Bishop, apontou dificuldades para a obtenção do parâmetro $\chi$, principalmente devido às diferentes formas como poderiam ser interpretados os resultados dos ensaios realizados para sua determinação.

Mais tarde, reconhecendo a necessidade de utilizar duas variáveis de estado de tensões, MATHIAS \& RADHAKRISHNA (1968) introduzem o conceito de superfície de estado. Os autores estabeleceram que o estado de tensões num solo não saturado é completamente descrito pelas variáveis $\left(\sigma-u_{a}\right)$ e $\left(u_{a}-u_{w}\right)$. No entanto, o conceito de variáveis de estado de tensões para descrever o comportamento de solos não saturados foi introduzido por FREDLUND \& MORGENSTERN (1977).

Em seguida, FREDLUND et al. (1978) apresentaram uma equação para a resistência ao cisalhamento de solos não saturados baseada nas duas variáveis de estado de tensão, $\left(\sigma-u_{a}\right)$ e $\left(u_{a}\right.$ $\left.-u_{w}\right)$ :

$$
\tau=c^{\prime}+\left(\sigma-u_{a}\right) \tan \phi^{\prime}+\left(u_{a}-u_{w}\right) \tan \phi^{b}
$$

onde: c' é a coesão efetiva; $u_{a}$ é a poro-pressão do ar; $u_{w}$ é a poro-pressão da água; $\left(u_{a}-u_{w}\right)$ é a sucção matricial; $\phi$ ' é o ângulo de atrito interno efetivo; $\phi^{b}$ é a razão do incremento da resistência ao cisalhamento com a sucção matricial.

A resistência ao cisalhamento dada pela Equação 3.12 pode ser representada na forma gráfica tridimensional, onde nos eixos horizontais estão os valores da tensão normal líquida e da sucção matricial. Considerando que os ângulos $\phi^{\prime}$ e $\phi^{b}$ não variam com a acréscimo de sucção, a superfície tangente aos círculos de Mohr na ruptura define um plano. A Figura 3.8 mostra a superfície de ruptura baseada no critério no critério de Mohr-Coulomb. 


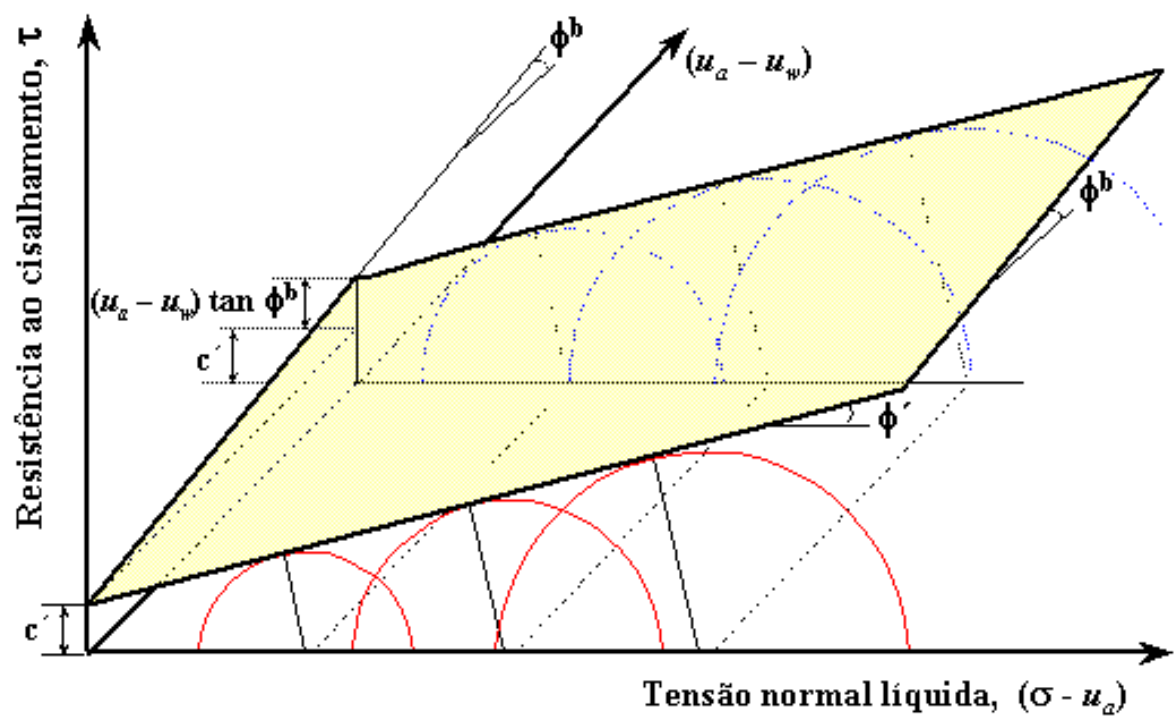

FIGURA 3.8 - ENVOLTÓRIA DE RUPTURA LINEAR COMO UMA SUPERFÍCIE PLANAR PARA SOLOS NÃO SATURADOS.

Comparando as equações propostas por Bishop (Equação 3.11) e Fredlund et al. (Equação 3.12), para a resistência ao cisalhamento de solos não saturados temos que o valor do parâmetro $\chi$ se relaciona com o ângulo $\phi^{b}$ da seguinte maneira:

$$
\tan \phi^{b}=\chi \cdot \tan \phi^{\prime}
$$

A Equação 3.13 indica, portanto, que a variabilidade encontrada para $\chi$ pode também ser verificada em $\phi^{b}$. Resultados experimentais obtidos recentementes indicam que o parâmetro c' é constante, enquanto que os parâmetros $\phi^{\prime}$ e $\phi^{b}$ podem variar em função do nível de sucção aplicado (ESCARIO \& SAEZ 1986, GAN \& FREDLUND 1988, ESCARIO \& JUCA 1989, ABRAMENTO \& CARVALHO 1989, WHEELER \& SIVAKUMAR 1992, DE CAMPOS \& CARRILLO 1995, ROHM \& VILAR 1995, BRESSANI et al. 1997, FUTAI et al. 2004, REIS \& VILAR 2004, LOPES et al. 2007). 
A Figura 3.9 apresenta a proposta de variação não linear do parâmetro de resistência ao cisalhamento $\phi^{b}$, em função dos níveis de sucção aplicados. Quando a sucção for menor que o valor de entrada de ar (solo na condição saturada) o valor do parâmetro $\phi^{b}$ é igual a $\phi^{\prime}$. Com o aumento da sucção o solo começa a dessaturar e o parâmetro $\phi^{b}$ diminui de forma não linear até estabilizar-se a partir de um determinado valor de sucção. CAMAPUM DE CARVALHO (1985), utilizando resultados de curvas de retenção de água de um solo de calcário, já mostrava, que a partir de um certo valor de sucção, o parâmetro $\phi^{b}$ apresentava tendência de tornar-se constante. A natureza não linear da envoltória de resistência ao cisalhamento no plano $\tau$ versus $\left(u_{a}-u_{w}\right)$ depende, sobretudo, das características de dessaturação do solo que podem ser diferentes devido, principalmente, aos aspectos estruturais e mineralógicos do solo (VANAPALLI et al. 1996).

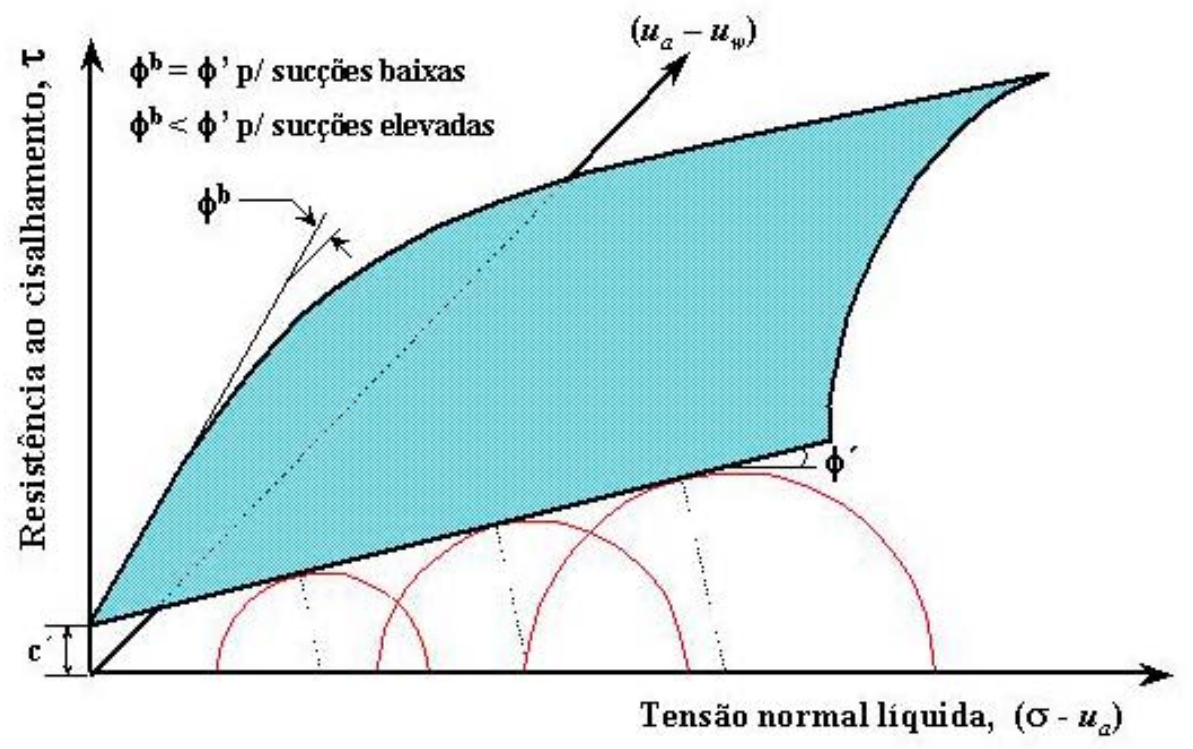

FIGURA 3.9 - ENVOLTÓRIA DE RUPTURA NÃO LINEAR COMO UMA SUPERFÍCIE CURVA PARA SOLOS NÃO SATURADOS.

Apesar de existir um consenso entre a grande maioria dos trabalhos encontrados na literatura de que o ângulo $\phi^{b}$ é menor que o ângulo $\phi$ ', alguns autores têm apresentado resultados experimentais, onde o valor do parâmetro $\phi^{b}$ foi maior que $\phi^{\prime}$ (e.g. ESCARIO 1988, ROHM 1992, ABRAMENTO \& PINTO 1993, MACHADO \& VILAR 1998, LOPES et al. 2007), provavelmente devido ao fato de que o comportamento do solo depende também do estado físico 
e não apenas das interações físico-químicas do sistema solo-água. Além disso, imprecisões na definição de valores experimentais de $\phi$ ' podem gerar apreciáveis erros de interpretação dos valores de $\phi^{b}$.

Para DE CAMPOS (1997) as variações nos parâmetros $\phi$ ' e $\phi^{b}$ sugerem que a envoltória geral de resistência ao cisalhamento de solos não saturados deve ser representada por uma superfície curva, conforme apresentado na Figura 3.10.

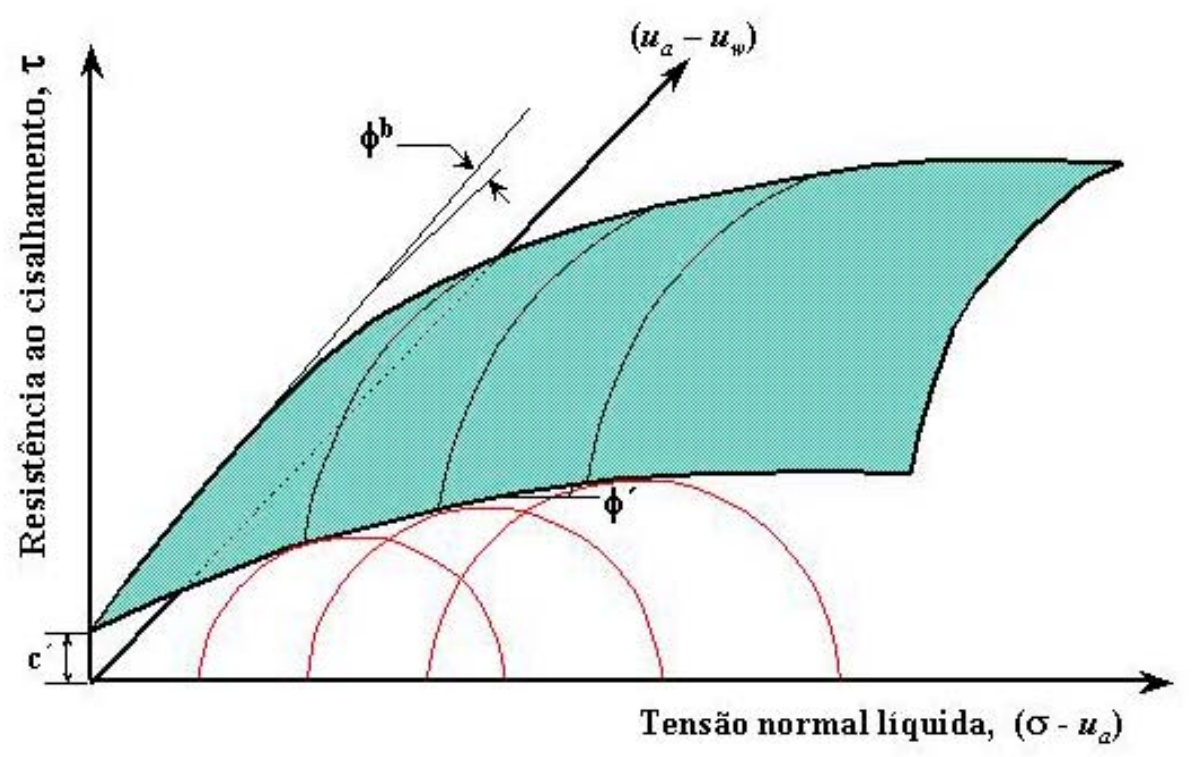

FIGURA 3.10 - SUPERFÍCIE DA ENVOLTÓRIA DE RESISTÊNCIA DE SOLOS NÃO SATURADOS (DE CAMPOS 1997).

A idéia implícita no modelo proposto por FREDLUND et al. (1978), de que a resistência ao cisalhamento pode ser representada pelos parâmetros c', $\phi^{\prime}$ e $\phi^{b}$, quer sejam constantes ou não, permite uma modelagem adequada da resistência ao cisalhamento de solos não saturados, e por isso esta proposta tem grande aceitação.

Segundo FREDLUND et al. (1996), o modelo não linear é mais realístico e deverá fornecer uma aproximação melhor. Apesar de existirem diversos modelos de previsão de resistência, verificase que muito pouco se conhece sobre a validação desses modelos para dados experimentais obtidos de solos residuais tropicais não saturados. 


\subsubsection{Modelos de previsão da resistência em função da curva de retenção}

Os dados de resistência ao cisalhamento dos solos em condições não saturadas são de fundamental importância em estudos sobre análise de estabilidade de encosta e taludes, pois permitem considerar a influência das mudanças climáticas no comportamento geomecânico do maciço.

No entanto, verifica-se que a necessidade de equipamentos específicos e o consumo de tempo com os ensaios dessa natureza têm motivado a busca por modelos ou funções empíricas que permitam a previsão da resistência ao cisalhamento de solos não saturados de forma rápida e precisa para fins práticos de engenharia.

A relação entre a sucção e a resistência ao cisalhamento de um solo não saturado é definida como a função de resistência ao cisalhamento. Esta relação pode ser prevista para aplicação em muitos problemas de engenharia, a partir do conhecimento dos parâmetros de resistência ao cisalhamento na condição saturada e da curva de retenção de água (CRA).

Verifica-se que os modelos de previsão de resistência ao cisalhamento de solos não saturados propostos por FREDLUND et al. (1995), OBERG \& SALLFORS (1995), VANAPALLI et al. (1996), VILAR (2006) estão entre os mais estudados na literatura.

O modelo proposto por FREDLUND et al. (1995) assume que o incremento de resistência ao cisalhamento, $\mathrm{d} \tau$, devido a um incremento de sucção matricial, $\mathrm{d}\left(\mathrm{u}_{\mathrm{a}}-\mathrm{u}_{\mathrm{w}}\right)$, é proporcional ao produto da variação da sucção e da área de contato de água efetiva no solo, dado por:

$$
d \tau=C A_{w} d\left(u_{a}-u_{w}\right)
$$

onde: $A_{w}$ é a área de contato de água efetiva; $C$ é uma constante proporcionalidade. $A_{w}$ é também representada pelo denominado "grau de saturação efetivo”, definido como:

$$
S_{e}=\frac{S-S_{R}}{1-S_{R}}
$$


onde: $S_{R}$ é o grau de saturação residual, correspondente ao valor de sucção residual. FREDLUND et al. (1995) propõem a seguinte relação entre $A_{w}$ e $S_{R}$ :

$$
A_{w}=\left[S_{e}\right]^{p}
$$

sendo “p” um parâmetro de ajuste. Substituindo a Equação 3.16 em 3.14 e integrando esta última, tem-se:

$$
\tau=C_{1}+C \cdot \int_{0}^{\left(u_{a}-u_{w}\right)}\left[S_{e}\right]^{p} \cdot d\left(u_{a}-u_{w}\right)
$$

onde: $C_{1}$ é uma constante de integração. Quando a sucção matricial for igual a zero, o segundo termo na Equação 3.17 será igual a zero, e então:

$$
C_{1}=\tau(0)=c^{\prime}+\left(\sigma_{n}-u_{a}\right) \cdot \tan \phi^{\prime}
$$

A Equação 3.18 representa a resistência ao cisalhamento do solo na condição saturada. Abaixo do valor de entrada de ar, a resistência ao cisalhamento aumenta numa razão linear igual a tan $\phi$; e desta maneira:

$$
C=\tan \phi^{\prime}
$$

Substituindo as Equações 3.18 e 3.19 na Equação 3.17, a expressão resultante para a resistência ao cisalhamento em função da sucção matricial é:

$$
\tau=c^{\prime}+\left(\sigma_{n}-u_{a}\right) \cdot \tan \phi^{\prime}+\tan \phi^{\prime} \cdot \int_{0}^{\psi}\left[S_{e}\right]^{p} \cdot d\left(u_{a}-u_{w}\right)
$$

onde: $\psi$ é a variável de integração que representa a sucção presente no solo. 
Segundo os autores, para areias, siltes e alguns solos finos inativos e para valores de sucção matricial inferiores a $500 \mathrm{kPa}$, é possível considerar p=1. Deste modo, a expressão da resistência ao cisalhamento é dada por (VANAPALLI et al. 1996):

$$
\tau=c^{\prime}+\left(\sigma_{n}-u_{a}\right) \cdot \tan \phi^{\prime}+\left(u_{a}-u_{w}\right) \cdot \tan \phi^{\prime} \cdot\left(\frac{S-S_{R}}{1-S_{R}}\right)
$$

Para a aplicação do modelo proposto por FREDLUND et al. (1995) é necessário conhecer os parâmetros efetivos de resistência ao cisalhamento, a curva de retenção de água do solo e o valor do grau de saturação residual " $S_{R}$ ”.

OBERG \& SALLFORS (1995) propõem um modelo denominado de aproximação racional para a determinação da resistência ao cisalhamento de siltes e areias na condição não saturada. A hipótese básica do modelo consiste em assumir o parâmetro “ $\chi$ ” de Bishop como a representação da fração da área total dos poros ocupado por água. Baseados em estudos com “solos ideais”, os autores admitem que, para solos arenosos e siltosos e para valores do grau de saturação maiores que $50 \%$, esta fração de áreas seja equivalente a S, de tal forma que $\chi=S$.

Segundo os autores, erros associados a esta hipótese de igualdade são menores que 20\%, sendo ainda menores em relação à previsão da resistência ao cisalhamento. Aplicando a expressão proposta por Bishop (Equação 3.11) ao critério de ruptura de Mohr-Coulomb, a equação de resistência ao cisalhamento para solos não saturados adquire a seguinte forma:

$$
\tau=c^{\prime}+\left(\sigma_{n}-u_{a}\right) \cdot \tan \phi^{\prime}+\chi \cdot\left(u_{a}-u_{w}\right) \cdot \tan \phi^{\prime}
$$

onde: c' e $\phi$ ' são os parâmetros de resistência ao cisalhamento efetivos do solo. Substituindo a igualdade $\chi=\mathrm{S}$, tem-se:

$$
\tau=c^{\prime}+\left(\sigma_{n}-u_{a}\right) \cdot \tan \phi^{\prime}+S \cdot\left(u_{a}-u_{w}\right) \cdot \tan \phi^{\prime}
$$


Para a aplicação do modelo de OBERG \& SALLFORS (1995) é necessário conhecer os parâmetros de resistência efetivos, obtidos em ensaios convencionais, e também a curva de retenção de água do solo.

VANAPALLI et al. (1996) propõem um modelo cujo desenvolvimento teórico é análogo àquele proposto por FREDLUND et al. (1995). Entretanto diferem na hipótese básica que relaciona a área de contato de água efetiva. No modelo proposto por Vanapalli et al., a área de água normalizada " $\mathrm{a}_{\mathrm{w}}$ " é assumida como sendo diretamente proporcional ao teor de umidade volumétrica normalizada “ $\Theta$ ”, e a seguinte expressão pode ser adotada:

$$
a_{w}=(\Theta)^{\kappa}
$$

onde: $\kappa$ é um parâmetro de ajuste; $\Theta$ é a relação entre a umidade volumétrica (para um dado valor de sucção) e a umidade volumétrica na saturação $\left(\theta / \theta_{\mathrm{s}}\right)$. Desta forma, a equação que representa a variação da resistência ao cisalhamento com a sucção é dada por:

$$
\tau=\left[c^{\prime}+\left(\sigma_{n}-u_{a}\right) \cdot \tan \phi^{\prime}\right]+\left(u_{a}-u_{w}\right) \cdot\left[(\Theta)^{\kappa} \cdot\left(\tan \phi^{\prime}\right)\right]
$$

O parâmetro $\kappa$ foi utilizado para se obter uma melhor correlação entre os valores dados pelo modelo e os valores experimentais dos ensaios de resistência. Os valores de umidade volumétrica e sucção são obtidos da curva de retenção de água. Os parâmetros $\phi$ ' e c' são considerados constantes e podem ser obtidos a partir de ensaios triaxiais ou de cisalhamento direto na condição saturada. O parâmetro $\kappa$ deve ser aplicado de forma a se obter o melhor ajuste aos dados experimentais. VANAPALLI \& FREDLUND (2000) constataram que este parâmetro pode ser influenciado pelo índice de plasticidade e estrutura do solo, e propuseram uma correlação entre o parâmetro $\kappa$ e o índice de plasticidade. Com a possibilidade de se estimar o valor de $\kappa$, a partir dessa correlação, o modelo de VANAPALLI et al. (1996) deixa de ser uma proposta de ajuste para ser um modelo de previsão de resistência ao cisalhamento em função da sucção. 


\subsection{Características dos Solos Residuais Tropicais}

\subsubsection{Introdução}

Os solos residuais geralmente são definidos como "um material terroso proveniente do processo de intemperização e decomposição da rocha in situ e que não tenha sido transportado de sua posição original” (BLIGHT 1997).

Os solos residuais podem possuir características geotécnicas completamente distintas daquelas observadas em solos transportados. Por exemplo, a permeabilidade de um solo transportado pode usualmente estar relacionada à sua granulometria (e.g. pela conhecida fórmula de Hazen), o que diferentemente ocorre em solos residuais. Nos solos residuais a permeabilidade é geralmente governada pela sua macro e micro-estrutura, e por características adicionais, tais como falhas, juntas e outros bio-canais (BLIGHT 1997).

Os solos residuais são formados por diferentes processos de intemperismo. Os processos intempéricos agem a partir de mecanismos modificadores das propriedades físicas dos minerais e rochas (intemperismo físico), e de suas características químicas (intemperismo químico). O intemperismo e a pedogênese levam à formação de um "perfil de alteração” ou "perfil de solo”. A pedogênese atua no processo de reorganização estrutural do perfil de solo e permite a transferência dos minerais formadores dos níveis superiores do manto de alteração (TOLEDO et al. 2000).

A ação do intemperismo é controlada pelos seguintes fatores: variação sazonal da temperatura, distribuição das chuvas, relevo, fauna, flora, rocha matriz e o tempo de exposição da rocha aos agentes intempéricos. Sendo dependentes do clima e do relevo, o intemperismo e a pedogênese atuam de maneira bem distinta nos diferentes compartimentos morfo-climáticos do planeta, e conseqüentemente levam à formação de perfis de alteração compostos por horizontes de diferente espessura e composição (TOLEDO et al. 2000). 
Como se pode observar, o processo de formação de um perfil de solo residual é extremamente complexo, o que dificulta seu entendimento e sua generalização. Com exceção de algumas generalizações válidas, nota-se que é difícil relacionar diretamente as propriedades geotécnicas de um solo residual com a sua rocha de origem. Cada situação requer considerações individuais e raramente se podem extrapolar experiências de uma área para prever condições geotécnicas em outras, mesmo se a formação geológica nas duas áreas forem similares.

Outro aspecto importante a ser destacado é sobre a existência de incompatibilidade entre o comportamento geotécnico dos solos residuais tropicais e aqueles previstos por métodos convencionais de classificação dos solos de clima temperado. Existem algumas características específicas dos solos residuais tropicais que não são adequadamente consideradas pelos métodos convencionais de classificação dos solos (e.g. Sistema Unificado de Classificação dos Solos SUCS).

Um exemplo particular é o caso que ocorre com os solos posicionados na região $\mathrm{MH}$ da carta de plasticidade, segundo a classificação SUCS. Muitos solos residuais tropicais ricos em alofana (mineral não cristalino com modelo estrutural semelhante ao da caulinita) ou caulinita dispostos no grupo MH são classificados como solos de características mais argilosas e conseqüentemente considerados inapropriados para várias aplicações geotécnicas. No entanto, na prática, tais solos freqüentemente possuem boas propriedades geotécnicas (BLIGHT 1997).

Dentre as diversas características específicas dos solos residuais tropicais que não são levadas em consideração pelos métodos convencionais de classificação, destacam-se as seguintes:

1. A existência de argilominerais incomuns em alguns solos tropicais faz com que seu comportamento geotécnico não seja compatível com aquele normalmente previsto para o grupo ao qual o solo foi classificado;

2. O perfil de solo residual tropical pode apresentar uma seqüência apreciável de materiais, dependendo do grau de intemperismo, o qual não pode ser adequadamente descrito pelos sistemas de classificação atualmente utilizados na engenharia geotécnica, pois foram originariamente desenvolvidos para a classificação de solos de climas temperados; 
3. Os sistemas de classificação de solos de clima temperado tratam primeiramente das propriedades dos solos em seu estado amolgado. Tais propriedades são freqüentemente enganosas para solos residuais tropicais, cujas propriedades geotécnicas são preponderantemente influenciadas pelas características macro e microestruturais herdadas da rocha matriz ou pela evolução do perfil de solo, como conseqüência do processo de intemperismo.

\subsubsection{Aspectos mineralógicos e microestruturais}

A mineralogia e a microestrutura dos solos residuais tropicais estão associadas com o modo de ocorrência e formação do solo. A microestrutura pode ser considerada em duas escalas relativas:

I. Grumos e vazios internos entre grumos;

II. Grãos e vazios intergranulares.

Os grumos são agregações naturais de grãos do solo que podem existir numa escala centimétrica até micrométrica. Eles são as unidades naturais de interação mecânica entre os grãos do solo e podem quebrar-se ou formar novas estruturas em resposta a uma secagem, umedecimento ou devido a vários tipos de perturbação mecânica (CARVALHO \& SIMMONS 1997).

A desagregação física e as reações químicas são os processos de intemperismo que levam à formação dos solos residuais tropicais. As desagregações físicas são controladas pela exposição e energia transmitida ao material de origem através do meio ambiente local. Os processos de reações químicas podem ser resumidos em:

- Decomposição;

- Lixiviação;

- Desidratação.

O processo de decomposição inclui a desagregação física da estrutura da rocha e a desagregação química de minerais constituintes, usualmente minerais primários que formam a rocha. O processo de decomposição em clima tropical tende a favorecer a formação dos argilominerais 
cauliníticos, sendo esse o tipo de argilomineral mais comum ocorrente em solos residuais tropicais. Geralmente, os óxidos de ferro presentes e/ou remanescentes são suficientes para formar goetita e hematita. Os óxidos de ferro formarão um mineral dependendo das condições in situ. Por exemplo, a hematita é formada somente em condições extremamente oxidantes, ao passo que a goetita e a limonita são formadas onde há condições contínuas de aeração e umidade (CARVALHO \& SIMMONS 1997).

O processo de lixiviação, que inclui os processos de laterização, envolve a remoção combinada das sílicas, álcalis e alcalinos terrosos. Há uma conseqüente acumulação de óxidos e hidróxidos de sesquióxidos. Os materiais lixiviados podem ser depositados e acumulados em outro lugar no perfil de solo (CARVALHO \& SIMMONS 1997).

O processo de desidratação (parcial ou completa) modifica a composição e distribuição dos materiais ricos em sesquióxidos de uma maneira que geralmente não é reversível com o processo de umedecimento. A desidratação também influencia o processo de formação dos argilominerais. No caso de uma desidratação total, podem ser formados solos fortemente cimentados com uma única estrutura granular.

Os argilominerais geralmente se concentram na fração fina do solo. Os minerais de óxidos de ferro, tais como a goetita e/ou hematita e também o quatzo, tendem estar concentrados na fração grosseira. A gibsita é freqüentemente encontrada como material de preenchimento concrecionário nos poros dos solos (CARVALHO 1981, 1985, 1991).

A estrutura, o arcabouço e a textura do solo são termos que se referem ao arranjo físico dos grumos e grãos. Estes arranjos, junto com a mineralogia, determinam o comportamento geotécnico. Na mecânica dos solos convencional, a importância do arcabouço foi reconhecida há muito tempo e resumida por ROWE (1974).

Muitos aspectos do arcabouço relevantes ao comportamento geotécnico são macroestruturais. No entanto, a microestrutura dos solos residuais pode revelar cimentações e arranjos de pequenos contatos que levam a um melhor entendimento da ocorrência e desempenho geotécnico de tais solos. As investigações da microestrutura do solo geralmente são realizadas usando a microscopia óptica e/ou a microscopia eletrônica de varredura (CARVALHO \& SIMMONS 1997). 
A mineralogia do solo pode ser avaliada por difração de raios-X. A técnica da difração de raios-X é amplamente utilizada, mas somente é apropriada para minerais com nítida cristalografia. Ela pode ser realizada a partir de amostras de solo selecionadas casualmente ou orientadas, que são posteriormente colocadas num recipiente com ou sem resina para fixação das amostras.

A microscopia óptica é utilizada para investigar finas seções (lâminas delgadas) com polarização cruzada, sendo um processo de avaliação bem consagrado para minerais primários de rocha. A preparação da amostra pode envolver impregnação com resina e, neste caso, deve ser feita com extremo cuidado para não danificar a microestrutura original da amostra indeformada de solo.

A microscopia eletrônica de varredura (MEV) envolve técnicas de preparação que podem retirar total ou parcialmente a água existente nos poros e, portanto, danificar a microestrutura original. Este problema pode ser evitado ou minimizado a partir da utilização de microscópios ambientais (MEV ambiental) que não requer a secagem prévia da amostra. O estudo com o MEV pode ser realizado a partir de amostras de solo em pedaços (pequenos blocos) ou cortadas em finas seções (lâminas delgadas).

As influências mineralógicas e microestruturais sobre as propriedades geotécnicas são evidentes. Por exemplo, solos que apresentam caulinita como argilomineral exibem um comportamento bem distinto dos solos constituídos por montmorilonita, em termos de plasticidade e permeabilidade.

Estudos realizados por FONSECA et al. (2005) mostram que argilominerais de mica exercem apreciável influência na resistência ao cisalhamento residual, ou seja, quanto maior o teor de mica menor é o ângulo de atrito residual.

Estudo desenvolvido por MARTINEZ et al. (2004), em solos residuais tropicais, mostra que a presença de sesquióxidos de ferro exerce influência considerável na resistência ao cisalhamento e na compressibilidade. Segundo os autores, quando o solo está na condição saturada, o efeito da cimentação cria pontes entre partículas, preenche os vazios e gera estabilidade dos microagregados, contribuindo na rugosidade e no intertravamento entre as partículas. Na condição não saturada, a cimentação proporciona uma melhor distribuição dos mesoporos, aumento da sucção matricial e conseqüentemente elevação da resistência ao cisalhamento. 
FROTA et al. (2001) realizaram diversos ensaios em solos tropicais provenientes de dois taludes de boçorocas, e concluíram que as modificações de condutividade hidráulica devem estar associadas com as mudanças das estruturas ou das porosidades presentes nos solos investigados, e ainda ressaltam a importância de se estudar a ação do intemperismo em taludes para compreender melhor os processos de instabilização.

SOUSA NETO et al. (2001), ao tentarem correlacionar parâmetros mecânicos (compressibilidade e resistência) com propriedades índices de alguns solos residuais brasileiros, mencionam que raramente as correlações obtidas foram consistentes devido, provavelmente, à grande dipersão existente na composição mineralógica e estrutural dos solos analisados.

Segundo COLLINS (1985), a presença de hematita/goetita como agente cimentante pode contribuir para o aumento da resistência ao cisalhamento do solo em termos de coesão aparente.

Em termos gerais, deve-se esperar que as propriedades geotécnicas de solos residuais tropicais sejam influenciadas por suas características mineralógicas e microestruturais específicas. O aspecto mais importante é que os solos residuais tropicais geralmente apresentam comportamento geotécnico muito melhor do que aqueles indicados por métodos de classificação desenvolvidos para solos de clima temperado.

\subsubsection{Permeabilidade}

Apesar da enorme influência da percolação de água sobre a estabilidade de encostas e taludes, a literatura geotécnica fornece informações muito limitadas sobre a permeabilidade (ou condutividade hidráulica saturada) de solos residuais. A variação na macroestrutura de um perfil de intemperismo de solo residual pode resultar em grandes variações na permeabilidade, tanto lateralmente quanto em profundidade (GARGA \& BLIGHT 1997).

Generalizações dos valores típicos de permeabilidade para outros tipos de solos residuais podem ser enganosas e, portanto, devem ser evitadas. Perfis de intemperismo típicos de solos residuais apresentados por LUMB (1962), DEERE \& PATTON (1971), VARGAS (1974), BLIGHT 
(1988) e outros colaboradores, mostram que as variações nos tamanhos dos grãos, índice de vazios, mineralogia e certas estruturas herdadas da rocha matriz (e.g. grau de fraturamento e descontinuidades) podem afetar os valores de permeabilidade.

Os métodos usados na prática para determinar a permeabilidade de solos residuais, tanto no campo quanto no laboratório, são similares àqueles usados para solos transportados. Os métodos de campo mais comuns são os ensaios de permeabilidade de carga constante e variável em furos de sondagem, furos de trado e poços de inspeção. Entre os métodos de campo mais difundidos no meio geotécnico, destaca-se a utilização de infiltrômetros tais como o permeâmetro Guelph (MACHADO et al. 2004b) e o infiltrômetro de mini-disco (DANE \& TOPP 2002).

A revisão realizada por BRAND \& PHILLIPSON (1985) sobre a prática internacional dos ensaios de permeabilidade em solos residuais indica uma forte preferência pelos métodos de campo e rassalta as limitações dos ensaios de laboratório para representar as variações macro e microestruturais encontradas nas condições de campo.

A permeabilidade de um saprolito é controlada principalmente pela estrutura reliquiar da rocha de origem. A maior parte dos fluxos ocorre ao longo de juntas reliquiares, veios de quartzo e outras descontinuidades. Por causa da permeabilidade ser governada pelas características de macroescala, ela não pode ser usualmente avaliada de forma confiável no laboratório, pois a escala das amostras indeformadas utilizadas nos ensaios é muito pequena. A única maneira completamente confiável de se avaliar a permeabilidade é por meio de ensaios de campo em grande escala (GARGA \& BLIGHT 1997).

Apesar disso, observa-se existirem poucos trabalhos na literatura que realizaram medidas de permeabilidade no campo voltadas, por exemplo, para estudos e análises de infiltração de chuva em taludes e encostas naturais (e.g. SCHILLING et al. 1992, CAMPOS et al. 1992, LACERDA \& LOPES 1992, DA ROCHA et al. 1992, AVELAR \& NETO 1992, DE CAMPOS et al. 1992, VARGAS JR. et al. 1992, MOLINARI 2005). 


\subsubsection{Resistência ao cisalhamento}

Em países com solos residuais, a prática de ensaios de resistência ao cisalhamento tem adotado principalmente procedimentos padrões utilizando-se, no laboratório, ensaios de cisalhamento direto e triaxial, e no campo, algum tipo de ensaio de penetração ou ensaio de carga em placa (BRAND \& PHILLIPSON 1985).

O conhecimento da origem dos solos residuais e os fatores que afetam sua resistência permitem compreender melhor suas peculiaridades quanto à deformação e ao cisalhamento. Solos residuais desenvolvem in situ uma estrutura específica de grãos de diferente graduação, que os tornam fundamentalmente diferentes dos solos transportados (BRENNER et al. 1997). A Tabela 3.6 mostra as principais características encontradas em solos residuais que são responsáveis pela diferença no comportamento mecânico em comparação com os solos transportados.

Tabela 3.6 - Comparação entre as características especiais de solos residuais e transportados que afetam sua resistência (BRENNER et al. 1997).

\begin{tabular}{|c|c|c|}
\hline Fatores que afetam a resistência & Efeitos sobre o solo residual & Efeitos sobre o solo transportado \\
\hline Histórico de tensões & Geralmente não importante. & $\begin{array}{l}\text { Muito importante, modifica o confinamento } \\
\text { inicial do grão, causa efeito de sobreadensamento }\end{array}$ \\
\hline Resistência do grão/partícula & $\begin{array}{l}\text { Muito variável, depende da mineralogia } \\
\text { e da fragilidade do grão. }\end{array}$ & $\begin{array}{l}\text { Mais uniforme, poucos grãos frágeis devido a } \\
\text { eliminação das partículas frágeis pelo transporte. }\end{array}$ \\
\hline Aderência & $\begin{array}{l}\text { Componente importante de resistência } \\
\text { devido principalmente às ligações ou } \\
\text { cimentações; causa o intercepto de } \\
\text { coesão e resulta numa tensão de campo; } \\
\text { pode ser destruída por amolgamento. }\end{array}$ & $\begin{array}{l}\text { Ocorre em depósitos geologicamente antigos, } \\
\text { produz intercepto de coesão e tensões de campo, } \\
\text { pode ser destruída por amolgamento. }\end{array}$ \\
\hline $\begin{array}{l}\text { Estrutura reliquiar e } \\
\text { descontinuidades }\end{array}$ & $\begin{array}{l}\text { Desenvolve a partir de estrutura pré- } \\
\text { existente ou de características estruturais } \\
\text { da rocha matriz, incluindo estratificações, } \\
\text { juntas, estrias de fricção, etc. }\end{array}$ & $\begin{array}{l}\text { Desenvolve a partir de ciclos de deposição e } \\
\text { histórico de tensões, formação de possíveis } \\
\text { superfícies de cisalhamento. }\end{array}$ \\
\hline
\end{tabular}

A seguir são apresentadas detalhadamente as principais características que afetam o comportamento mecânico dos solos residuais: 
- Histórico de tensões.

Solos residuais podem sofrer um ligeiro desconfinamento vertical e lateral devido à perda de diversos minerais durante o seu processo de formação (intemperismo). Isto significa uma alteração progressiva no estado das tensões in situ que modifica o efeito de tensões anteriores sobre a estrutura do material intemperizado. Desta forma, pode ser quase desprezível o efeito do histórico de tensões aos quais os solos residuais estão sujeitos durante o seu processo de formação (VAUGHAN 1988).

- Resistência das partículas/grãos.

As partículas do solo são produtos do intemperismo com diferentes graus de deterioração (grãos minerais ou aglomerações de grãos). As partículas podem, portanto, apresentar uma enorme variabilidade na resistência ao esmagamento em relação àquelas usualmente encontradas em solos transportados.

- Cimentação.

Uma das características de um solo residual é a existência de cimentação entre as partículas. Esta cimentação representa uma componente de resistência ao cisalhamento denominada de “coesão” (BRENNER et al. 1997). Segundo VAUGHAN (1988), as possíveis causas para o desenvolvimento das cimentações (ou coesão) entre as partículas (ou grãos) dos solos residuais são:

- Cimentação por meio da deposição de carbonatos, óxidos/hidróxidos de ferro, matrix orgânica, etc;

- Solução e nova precipitação de agentes cimentantes, tais como silicatos;

- Aparecimento de ligações durante o processo de alteração química dos minerais.

Estudos realizados por alguns autores tem constatado a importância da parcela de coesão aparente decorrente da não saturação no aumento significativo da resistência ao cisalhamento de solos residuais tropicais (e.g. LACERDA \& 
SILVEIRA 1992, CLEMENTINO \& LACERDA 1992, BEVILAQUA et al. 2004, MARTINEZ et al. 2004).

- Estruturas reliquiares e descontinuidades.

Solos residuais constituídos por estruturas reliquiares geralmente podem romper ao longo desses planos de fraqueza. Muitos autores têm concluído que a resistência de saprolitos pode ser governada quase que totalmente por suas estruturas ou características mineralógicas herdadas da rocha matriz (BRENNER et al. 1997). Ensaios realizados por LACERDA \& SILVEIRA (1992) indicam que a resistência ao cisalhamento dos solos residuais estudados foi sensivelmente menor ao longo dos planos de estruturas reliquiares. Segundo GOBBI et al. (2005), os solos residuais de gnaisse estudados apresentaram anisotropia de resistência ao cisalhamento devido principalmente à presença de partículas micáceas (biotita), conferindo valores mais baixos de resistência. SOUSA NETO et al. (2001) constataram comportamento semelhante, ou seja, que os solos micáceos tendem a ser menos resistentes à medida que aumenta o teor de mica em suas frações. No entanto, a resistência global do maciço de solos é governada pela freqüência e orientação predominante das estruturas reliquiares em relação à direção de aplicação das tensões, e pela resistência peculiar dessas caracteríticas estruturais (COWLAND \& CARBRAU 1988, IRFAN \& WOODS 1988, LO et al. 1988).

- Anisotropia.

Nos solos residuais o comportamento anisotrópico se deve principalmente à herança estrutural da rocha matriz, embora as tensões in situ também possam desempenhar um certo papel. Isto particularmente se aplica em solos originados de rochas metamórficas, onde a mica está presente. As placas de mica presentes em alguns solos residuais podem, por exemplo, se orientar durante o processo de cisalhamento e gerar uma superfície mais frágil e preferencial de cisalhamento.

- Índice de vazios inicial (in situ) ou densidade.

O índice de vazios num solo residual depende do estágio do processo de intemperismo alcançado, e geralmente não está diretamente relacionado ao 
histórico de tensão. Ele pode variar muito e depender das características da rocha matriz. Num solo pouco coesivo, o índice de vazios tem uma forte influência sobre a resistência drenada, que aumenta com o aumento da densidade (HOWATT \& CATER 1985, HOWATT 1988).

\subsection{Principais Processos de Instabilização em Taludes e Encostas Naturais}

\subsubsection{Introdução}

Embora sejam citados na literatura diversos tipos de processo de instabilização, ressalta-se que a presente revisão aborda apenas os processos de instabilização que ocorrem com maior freqüência em taludes e encostas naturais da região estudada (município de Ubatuba-SP), ou seja, escorregamentos em taludes de corte, planares rasos e rotacionais.

No presente trabalho, os escorregamentos foram tratados como "movimentos rápidos que mobilizam volumes variados e bem definidos de solo e/ou rocha, cujo centro de gravidade se desloca para baixo e para fora de uma encosta natural ou de um talude de corte, ao longo de uma ou mais superfícies de ruptura”. A classificação dos escorregamentos em encostas naturais depende de duas características principais: a geometria ou forma do escorregamento da massa mobilizada de solo e/ou rocha e a velocidade de sua movimentação.

Existem dois tipos principais de geometria de escorregamento que são abordados a seguir: i) se a cobertura de solo for rasa em comparação com o comprimento da encosta, pode ocorrer um escorregamento planar raso; ii) se a cobertura de solo for profunda, pode ocorrer tanto um escorregamento rotacional quanto um escorregamento planar raso que, dependendo das circusntâncias geológicas locais, pode até remover materiais menos intemperizados (saprolito, rocha alterada e blocos de rocha). 


\subsubsection{Escorregamentos planares rasos}

Os escorregamentos planares ou translacionais rasos são caracterizados pelo envolvimento de uma fina camada de solo, da ordem de 1,0 a 2,0 metros de espessura, que desliza sobre uma superfície de ruptura plana, geralmente paralela à encosta. Estes tipos de escorregamentos geralmente ocorrem em encostas retilíneas de grande amplitude e com inclinações maiores que $30^{\circ}$, envolvendo na maioria das vezes, os horizontes superficiais e, em algumas circunstâncias peculiares, os horizontes mais profundos constituídos por saprolito.

Os escorregamentos planares rasos são os processos de instabilização que mais ocorrem nas porções médias e altas das encostas naturais da Serra do Mar, no Estado de São Paulo. A Figura 3.11 apresenta um escorregamento planar raso que ocorreu em Caraguatatuba-SP, na rodovia Rio-Santos, próximo à divisa com Ubatuba-SP.

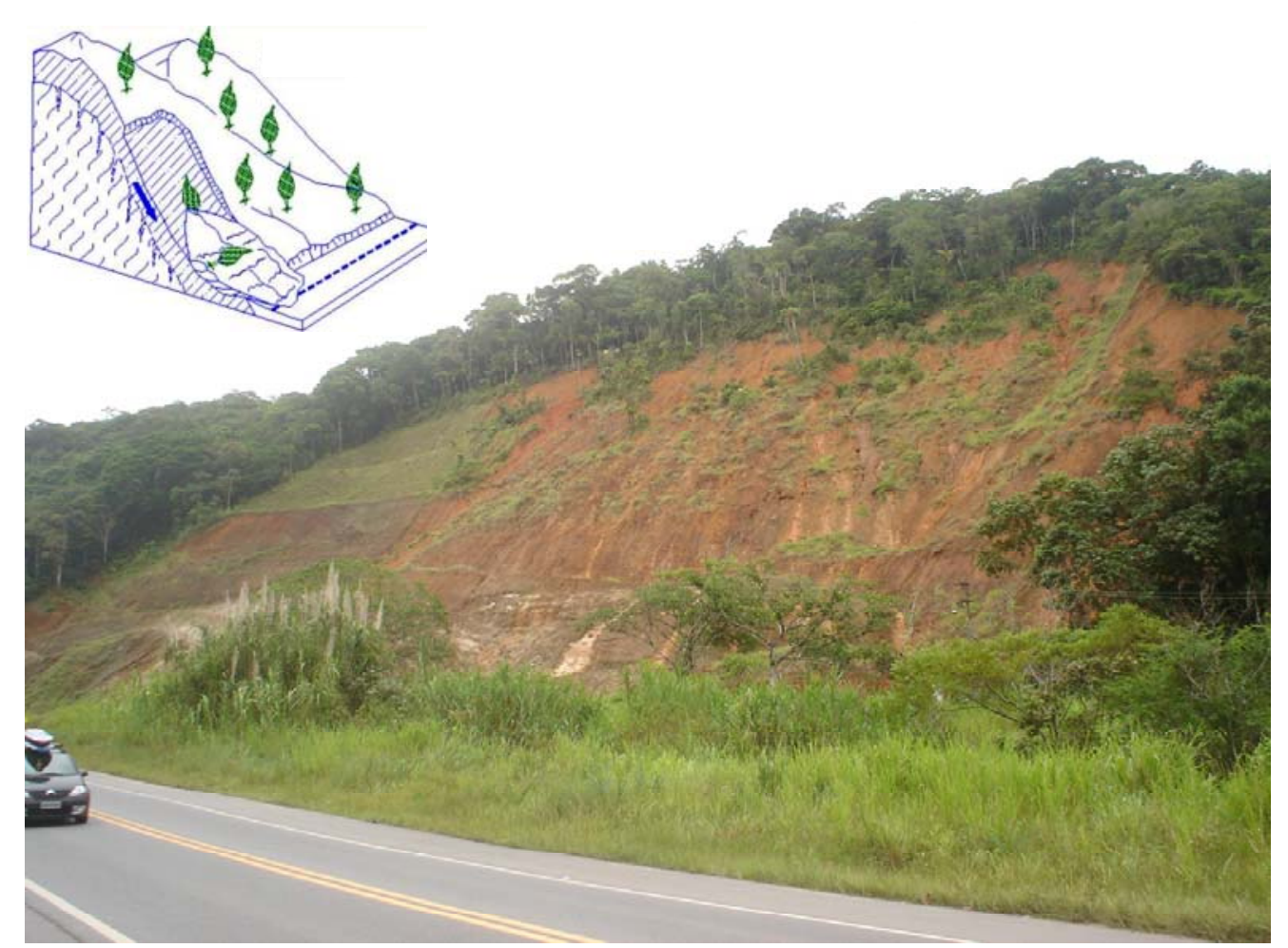

FIGURA 3.11 - ESCORREGAMENTO PLANAR RASO OCORRIDO NUMA ENCOSTA DA SERRA DO MAR (FONTE: ACERVO IG-SMA). 
Os escorregamentos planares rasos que ocorrem nas encostas naturais da Serra do Mar estão, na maioria dos casos, associados ao período da estação de chuvas. Segundo VARGAS (1999), uma das causas que explica a ocorrência destes escorregamentos é o efeito do desenvolvimento de poro-pressões positivas pela infiltração das águas de chuva. Conforme mencionado por outros autores (WOLLE et al. 1978, WOLLE \& CARVALHO 1989, WOLLE \& HACHICH 1989), existem dois tipos prováveis de mecanismos que podem explicar a deflagração desses escorregamentos.

O primeiro tipo de mecanismo envolve o aparecimento de uma rede de fluxo paralela a encosta e de poro-pressões positivas no interior do maciço, ocasionado por chuvas intensas e prolongadas. Neste caso, o maciço apresenta uma diminuição da condutividade hidráulica com o aumento da profundidade ao longo do perfil de alteração, que proporciona o aparecimento de poro-pressões positivas. No segundo tipo de mecanismo, ocorre um aumento da condutividade hidráulica com o aumento da profundidade, e a direção do fluxo, devido à infiltração das águas de chuva, é praticamente vertical. Nesta situação, não se verifica a ocorrência de poro-pressões positivas, e a deflagração dos escorregamentos é proveniente da redução ou eliminação da componente de resistência ao cisalhamento devido à sucção matricial do solo, proporcionado pela infiltração de água da chuva através dos horizontes superficiais do perfil de alteração.

No entanto, acredita-se que para deflagrar os escorregamentos nestas circunstâncias, deve existir uma certa combinação entre as intensidades pluviométricas acumulada e do evento. As primeiras chuvas, ocorridas em dias anteriores (acumulada), promovem a elevação do teor de umidade nos horizontes mais superficiais dos perfis de alteração, e as chuvas seguintes (durante o evento), aumentam ainda mais o teor de umidade nos horizontes superficiais, proporcionando o avanço da frente de saturação para os horizontes mais profundos.

O escorregamento do Morro da Caneleira citado por VARGAS \& PICHLER 1957, pode ser considerado como do tipo planar raso. Outro escorregamento planar típico em encosta de solo residual ocorreu em Tresna, na qual a superfície de escorregamento foi convexa (BUJAK 1967). 


\subsubsection{Escorregamentos rotacionais}

Este tipo de processo de instabilização é definido como um movimento de massas instabilizada sobre uma superfície de ruptura curva, cilíndrica ou conchoidal, com concavidade voltada para cima, conforme mostrado na Figura 3.12. A geometria da superfície de ruptura, geralmente, está associada com as condições de heterogeneidades presentes no maciço, como falhas preenchidas por material de baixa resistência, planos de fraqueza, planos de acamamento, entre outros.

Antes da efetiva deflagração deste tipo de escorregamento, é comum se observar alguns indícios de movimentação do maciço, na região da crista ou porção superior do escorregamento, tais como trincas de tração e degraus de abatimento, voltados para a direção do movimento. Observase, muitas vezes, que uma parte considerável da massa escorregada deposita-se no pé ou base da própria cicatriz de escorregamento.

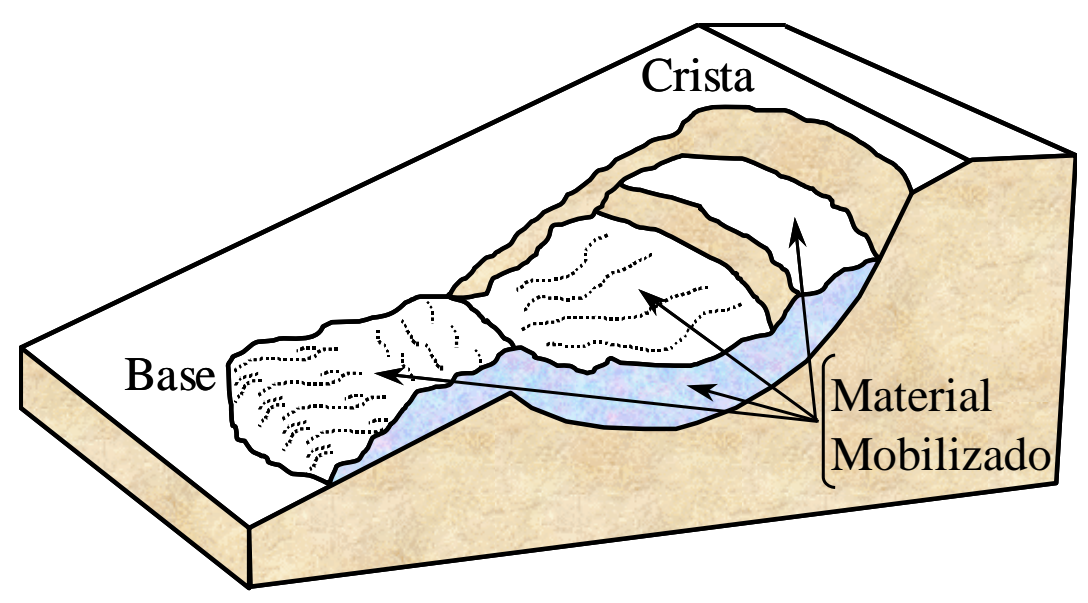

FIGURA 3.12 - ESCORREGAMENTO ROTACIONAL.

Os escorregamentos rotacionais podem ocorrer tanto em maciços isotrópicos quanto em maciços anisotrópicos. Nas encostas naturais constituídas por solos residuais, tem-se observado que eles ocorrem, na maioria das vezes, em horizontes superficiais evoluídos pedologicamente e nos horizontes de solos de alteração de algumas rochas mais homogêneas e isotrópicas, por exemplo, como os granitos (CARVALHO 1996). Segundo VARGAS (1999), os escorregamentos 
rotacionais que ocorrem na Serra do Mar, se dão preferencialmente nos topos dos morros, onde as espessuras dos solos de alteração de rocha são mais profundas.

Existem dois tipos de mecanismos de ruptura que explicariam o processo de instabilização de escorregamento rotacionais, conforme relatado por VARGAS (1999). O primeiro envolve a redução ou eliminação do componente de resistência ao cisalhamento (coesão “aparente”), devido ao aumento expressivo do teor de umidade ao longo do perfil de alteração por uma frente de umedecimento. O segundo tipo está relacionado com o desenvolvimento de poro-pressões positivas devido às deformações por cisalhamento sofridas pelo solo durante o processo de ruptura ou devido às poro-pressões positivas geradas pela percolação de água das chuvas.

VARGAS (1999) cita casos de escorregamentos rotacionais ocorridos na cidade de Santos, no alto do morro Monte Serrat, o primeiro em março de 1928 e outro em 1956, após período de chuvas intensas; e no Morro da Tapera, próximo ao pé da Serra de Cubatão, em julho de 1963, durante tentativas de estabilização de um talude, após período de chuva intensa.

\subsubsection{Escorregamentos em taludes de corte}

Os escorregamentos em taludes de cortes são comuns em muitas áreas urbanas, onde existem favelas e outros tipos de moradias em condições precárias, desprovidas de infraestrutura adequada e de acompanhamento técnico qualificado. Mesmo em residências construídas em alvenaria, onde se julga ter um acompanhamento técnico mínimo durante sua construção, podem ocorrer escorregamentos nos cortes executados, caso medidas corretivas não sejam adotadas para garantir a estabilidade permanente do maciço.

A Figura 3.13 mostra um escorregamento num talude de corte realizado na base de uma encosta situada no bairro Lagoinha, município de Ubatuba-SP, após período de chuvas intensas. O referido talude foi executado numa inclinação excessiva, da ordem de $70^{\circ}$, e não havia sido realizada nenhuma estrutura de contenção. 


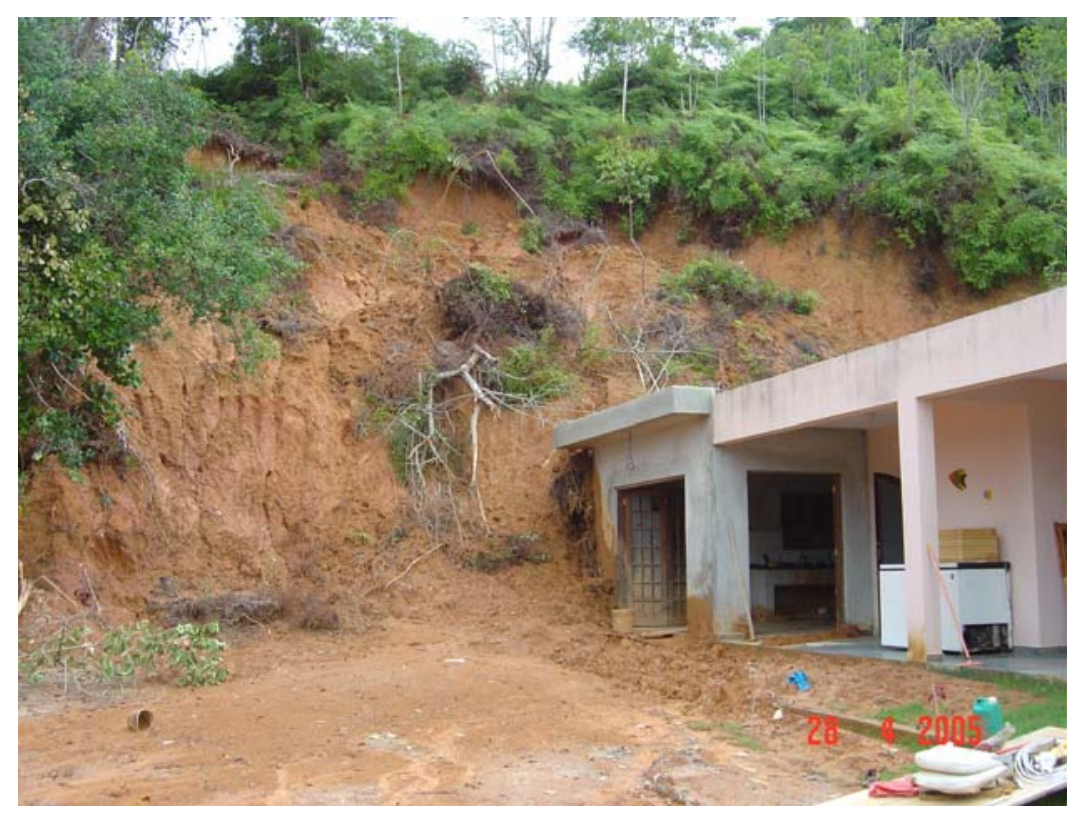

Figura 3.13 - EsCorregamento EM TALUdE DE CORTE (FONTE: ACERVO IG-SMA).

Os escorregamentos em talude de corte podem ocorrer tanto sobre uma superfície de ruptura cilíndrica, quanto sobre uma superfície de ruptura plana. A geometria da superfície de ruptura, nestes tipos de escorregamentos, é condicionada pelas condições de alteração do maciço de solo e/ou rocha e pela inclinação do talude de corte. No caso de cortes com inclinações excessivas em maciços pouco alterados, a superfície de ruptura tende a ser plana. À medida que diminui a inclinação do talude de corte e aumenta as condições de alteração do maciço, a superfície de ruptura tende a ficar mais próxima de uma geometria cilíndrica.

Segundo FEIJÓ et al. (2001), que estudaram 542 laudos de vistoria técnica da Fundação GEORIO correspondentes ao triênio 1998/2000, o tipo de processo de instabilização mais comum nas encostas do Rio de Janeiro é o escorregamento de solo em talude de corte, normalmente de pequeno volume, responsável por aproximadamente $41 \%$ de todas as ocorrências.

VARGAS (1999) relata um caso de escorregamento em talude de corte no Morro da Tapera, na Serra de Cubatão. O talude de corte, com cerca de 100 metros de altura foi realizado num maciço composto por solo de alteração de gnaisse sobreposto a um afloramento de rocha gnáissica, com taludes íngremes, chegando a cerca de $45^{\circ}$. Esse material começou a mover-se, durante a escavação do corte até romper, quando o talude escavado atingiu cerca de 30 metros de altura e inclinação de $35^{\circ}$. 


\subsubsection{Estabilidade de encostas naturais e taludes em solos residuais}

Encostas naturais constituídas por solo residual geralmente são estáveis e tendem a permanecer nesse estado, a menos que condições internas das encostas sejam alteradas pela ação de eventos naturais excepcionais ou por interferência humana. Segundo BLIGHT (1997), as principais ações naturais e antrópicas que podem deflagar os escorregamentos em encostas naturais são as chuvas prolongadas e de intensidades excepcionais e as interferências humanas.

Muitas encostas naturais formadas por solos residuais ocorrem na condição não saturada e sua margem de segurança contra os escorregamentos depende da sucção matricial, que proporciona um significativo aumento na parcela de resistência ao cisalhamento do solo. No entanto, as infiltrações de água que ocorrem durante períodos de chuvas prolongadas podem reduzir a sucção matricial num determinado ponto da encosta natural e torná-la instável.

Os efeitos das chuvas excepcionais sobre a estabilidade de encostas em solos residuais têm sido investigado por diversos pesquisadores nacionais e internacionais (e.g. COSTA NUNES 1969, LUMB 1975, MORGENSTERN \& DE MATOS 1975, BRAND 1982, MALONE \& SHELTON 1982, VARGAS JR. et al. 1986, SCHILLING et al. 1992, ELBACHÁ et al. 1992, DE CAMPOS et al. 1992, PRADEL \& RAAD 1993, LIM et al. 1996, AFFENDI \& FAISAL 1996).

Investigações de campo e análises de fluxo tridimensionais realizadas por GERSCOVICH et al. (2006), revelaram que a quantidade de infiltração das águas de chuva não foi suficiente para produzir poro-pressão de água positiva. Segundo os autores op cit, o desenvolvimento de caminhos preferenciais para a infiltração da chuva poderia explicar as condições hidrológicas das encostas naturais durante os escorregamentos. O estudo revelou ainda que a infiltração da chuva difere do mecanismo de fluxo ao longo da superfície da encosta, podendo desempenhar um papel importante no modelo hidrológico das encostas.

Experimentos conduzidos por LI et al. (2005), numa encosta natural de saprolito instrumentada com sensores de umidade e sucção, mostram que a "frente de umedecimento" formada durante a estação chuvosa atingiu 3,0 metros de profundidade. Os resultados dos experimentos também 
indicam que a infiltração da chuva foi de aproximadamente $70 \%$ do total precipitado, e que a água infiltrada aumentou principalmente o teor de umidade do horizonte superficial de solo.

Segundo resultados obtidos por RAHARDJO et al. (2005), as chuvas de pequena intensidade contribuem mais para a infiltração de água nas encostas do que as chuvas de grande intensidade, além da quantidade de infiltração diminuir com o aumento da intensidade das chuvas. $\mathrm{O}$ estudo também revelou que os teores de umidade tendem a ser mais elevados no sopé das encostas naturais do que no topo, independentemente dos eventos pluviométricos, indicando circulação de água em direção à jusante.

Estudos conduzidos por KIM et al. (2004), a partir de curvas de retenção de água obtidas com papel filtro e tensiômetros, revelaram que a magnitude da sucção na região da "frente de umedecimento" desempenha um papel importante na estabilidade das encostas naturais em solos intemperizados. Constatou-se também que, para solos coreanos intemperizados, o fator de segurança diminui rapidamente ao longo da "frente de umedecimento", que geralmente alcança uma profundidade de $1,2 \mathrm{~m}$.

O estudo sobre as características de infiltração em encostas de solo residual realizado por TSAPARAS et al. (2003), apresenta dados de chuva, escoamento superficial e poro-pressão de água obtidos ao longo de 12 meses de monitoramento. As análises das medições de campo revelaram que tanto a chuva acumulada quanto a poro-pressão de água inicial são responsáveis pelas mudanças de poro-pressão de água nas encostas naturais durante a infiltração das águas de chuva.

LUMB (1975) sugere que a velocidade máxima de infiltração da chuva dentro de um solo homogêneo, na ausência de camadas impermeáveis, é numericamente igual à permeabilidade saturada do solo. Usando valores típicos de permeabilidade do solo e intensidade de chuva, Lumb mostrou que a frente de umedecimento pode alcançar uma profundidade potencialmente crítica numa encosta em poucas horas (tal como no contato solo/rocha). Trincas e fissuras abertas podem acelerar o avanço da frente de umedecimento.

YONG et al. (1982) apresentaram resultados de redução do fator de segurança de um talude devido às variações na duração da chuva (de intensidade igual à permeabilidade saturada). A 
Figura 3.14 mostra alguns dos resultados de suas análises representados pelo fator de segurança versus a profundidade alcançada pela "frente de saturação" e duração da chuva. No exemplo em questão, a ruptura ocorre após 20 horas no primeiro caso e após 36 horas no outro caso.
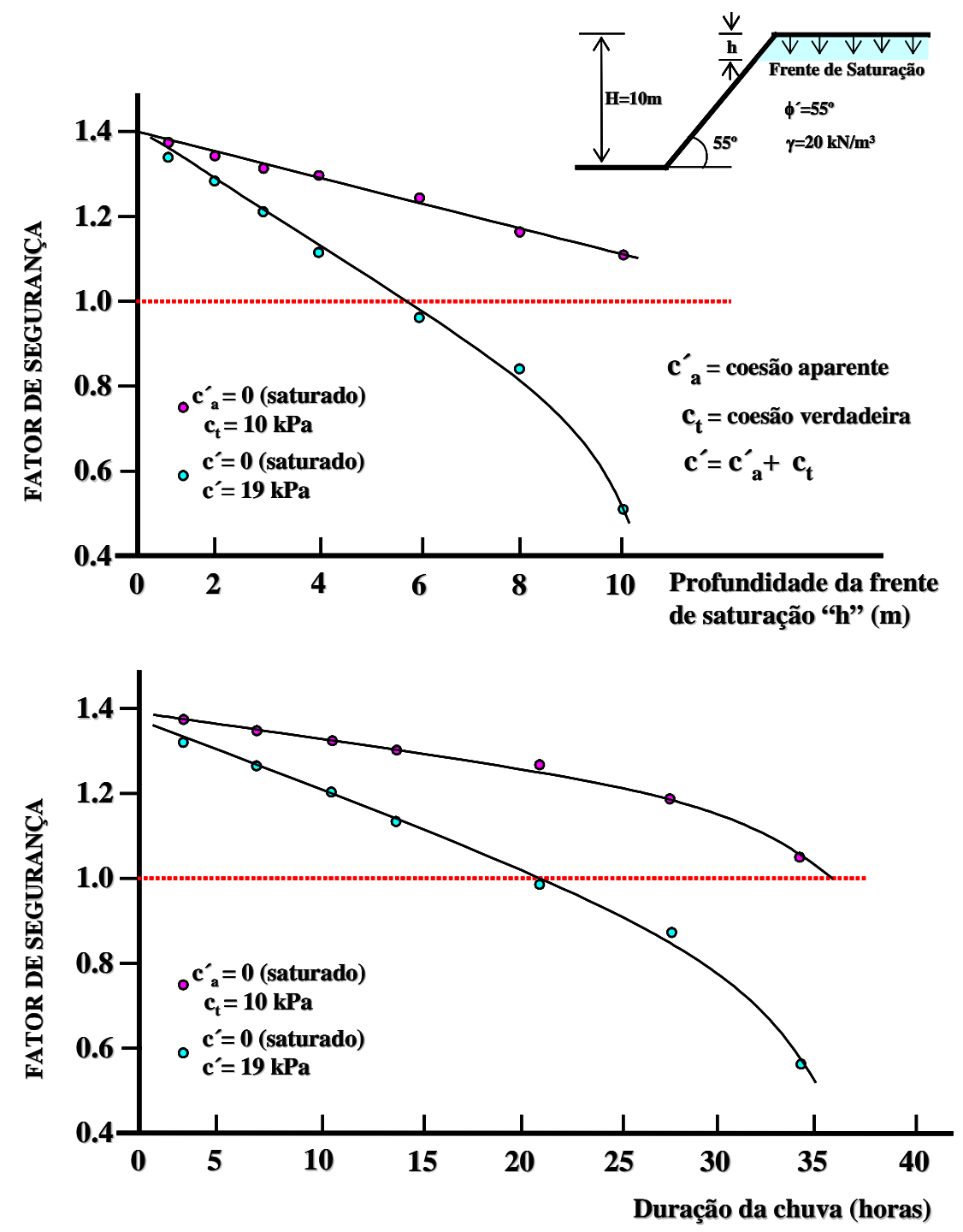

FiguRA 3.14 - EFEITO DA FRENTE DE “SATURAÇÃO” E DURAÇÃO DA CHUVA NO FATOR DE SEGURANÇA DE UM TALUDE (MODIFICADO YONG ET AL 1982).

As interferências humanas também podem afetar a estabilidade de encostas naturais. A execução de taludes de corte na base de uma encosta natural extensa pode acelerar um processo de instabilização. Mudanças no regime d’água no interior de uma encosta pode causar instabilidade. Se o regime for drasticamente alterado por irrigação, remoção da vegetação ou inundação parcial por água confinada, poderá acontecer um processo de instabilização (RICHARDS 1985). 
Segundo FERREIRA \& LIMA (2005), a precipitação somada às interferências humanas são as principais causas de escorregamentos nas encostas dos morros do Recife. Para os autores, o componente antrópico é o mais importante desencadeador das situações de risco de deslizamentos na cidade do Recife.

O efeito do desmatamento também pode afetar a estabilidade de encostas naturais, pois as raízes profundas reforçam mecanicamente o solo (BLIGHT 1987). O sistema de raízes ancoradas em estratos firmes pode contribuir para o aumento de sua resistência. No entanto, o sistema de ancoragem das raízes depende da capacidade de penetração das mesmas no maciço de solos e/ou rocha, ou ainda, em último caso, nas suas descontinuidades.

Para SILVEIRA et al. (2001) as raízes desempenham um papel fundamental na manutenção da sucção matricial e, portanto, devem interferir na estabilidade dos maciços de solo. Entretanto, segundo os autores op cit., a rápida entrada de água nos maciços através de fluxos preferenciais durante as chuvas pode ser um fator agravante e condicionante de rupturas por saturação em profundidade.

A papel da vegetação na estabilidade das encostas ainda é um assunto muito contraditório na literatura. Estudos conduzidos por O’LOUGHLIN (1974), PRANDINI et al. (1976), GREENWAY et al. (1984), WU (1984), ZIEMER (1978 e 1981) e GUSMÃO FILHO et al. (1997) destacam o aspecto estabilizador da vegetação, enquanto os trabalhos de FLACCUS (1959), SHAW (1978) e SUÁREZ (1997) demonstram que a vegetação contribui para o processo de instabilização das encostas.

Estudos conduzidos por ANDRADE et al. (1992) revelaram que o efeito das raízes no aumento da resistência foi irrelevante para o processo de ruptura analisado. Resultados obtidos por NUNES et al. (1992), destacam a importância da vegetação no controle das variações espaciais e temporais de poro-pressão de água nos solos florestados. Segundo esses autores, os sistemas radiculares atuam no controle das rotas preferenciais de percolação e concentração de água nos solos, e sua ação mecânica na estabilidade das encostas parece ser variável em função não apenas do padrão de enraizamento, mas das próprias condições mecânicas dos solos onde estas se ancoram. 


\subsection{Metodologia GPR (Ground Penetrating Radar)}

Neste item, apresenta-se uma revisão geral dos métodos disponíveis para medição do teor de umidade do solo com GPR. Apesar da metodologia GPR ter sido desenvolvida no mesmo período da bem sucedida técnica TDR há, entretanto, uma grande diferença na aceitação entre tais métodos para a determinação do teor de umidade do solo. Isto pode ser parcialmente atribuído a adequabilidade limitada da primeira geração de instrumentos GPR para a medida precisa do teor de umidade do solo. No entanto, a atual geração de instrumentos GPR fornece medidas muito mais precisas, o qual tem resultado num restabelecimento do uso de GPR para a determinação do teor de umidade como evidenciado pelo aumento significativo de publicações recentes (HUISMAN et al 2003).

As limitações e o potencial de cada método GPR para determinação do teor de umidade do solo é discutido detalhadamente nesta revisão. Particularmente, são ressaltadas duas questões importantes que atualmente limitam o desenvolvimento e a aceitação da metodologia GPR como um sensor de umidade do solo, conforme questionado por HUISMAN et al (2003).

A primeira questão trata da relação petrofísica entre permissividade dielétrica (ou constante dielétrica) e teor de umidade volumétrico. Embora a comunidade científica aparenta ter uma alta confiabilidade nesta relação por causa dos excelentes resultados obtidos com a técnica TDR, parece existir uma certa dependência desta relação em função da freqüência adotada, principalmente para aplicações com antenas de baixa freqüência em solos muito argilosos que necessitem de uma calibração específica local para a determinação do teor de umidade do solo.

Nesse sentido, acredita-se que novas investigações sobre a dependência da permissividade dielétrica do solo, a partir de estudos de campo que comparam diretamente as medições de umidade do solo realizadas com a técnica TDR e a metodologia GPR, usando antenas de baixa freqüência em solos com alto teor de argila, devem contribuir para resolver esta questão.

A segunda questão é o volume de amostragem e a resolução espacial dos métodos GPR, particularmente sob condições heterogêneas de campo. Neste ponto, tanto a modelagem numérica quanto os estudos de campo são fundamentais para se determinar tais valores. 


\subsubsection{Introdução}

A primeira pesquisa utilizando a metodologia GPR foi realizada na Austrália em 1929 para determinar a profundidade de uma geleira. No entanto, foi somente na década de 80 que seu reconhecimento foi estabelecido como método de exploração geofísica no âmbito da comunidade geocientífica mundial (OLHOEFT 2003).

Na década de 90 a metodologia GPR passou a ser utilizada de forma mais intensiva na resolução de diversos problemas, tais como: localização de objetos enterrados (galerias de águas pluviais, canos e dutos), sítios arqueológicos, determinação da profundidade da rocha sã para assentamentos de pontes e edifícios, determinação da profundidade do lençol freático, localização de pluma de contaminação, etc.

Atualmente encontram-se na literatura nacional e internacional diversos trabalhos abordando as potencialidades e limitações do método GPR em muitas áreas de aplicação, destacando-se:

- Geologia Ambiental - localização de plumas de contaminação e resíduos da indústria de hidrocarbonetos (ANNAN et al. 1984, DAVIS \& ANNAN 1988 e 1989, SCAIFE \& ANNAN 1991, FENNER \& VENDI 1992, RODRIGUES \& PORSANI 1995, AQUINO et al. 1998, NASCIMENTO et al. 1998);

- Geologia Básica - estudo estratigráfico detalhado e localização de estruturas tectônicas e fraturas em rochas graníticas (DAVIS \& ANNAN 1986, 1988 e 1989, LINER \& LINER 1995, SMITH \& JOL 1995, PORSANI \& RODRIGUES 1995, RODRIGUES \& PORSANI 1997);

- Geotecnia - determinação do topo da rocha sã e localização de cavernas e de vazios em estruturas de concreto (DANIELS et al. 1988, DAVIS \& ANNAN 1988, SCAIFE \& ANNAN 1991, MAEKAWA \& FENNER 1994);

- Hidrogeologia - determinação da profundidade do nível freático e estudos sobre a intrusão salina em áreas litorâneas e assoreamentos (ANNAN et al. 1991, BERES \& HAENI 1991, SCAIFE \& ANNAN 1991, ANNAN \& COSWAY 1992, VAN OVERMEEREN 1994); 
- Ciências do Solo - determinação do conteúdo de água presente no solo (DAVIS \& ANNAN 1977, TOPP et al. 1980, DU et al. 1994, GREAVES et al. 1996, HUISMAN et al. 2001, 2002 e 2003, BOHIDAR \& HERMANCE 2002, DAVIS \& ANNAN 2002, GALAGEDARA et al. 2003, GROTE et al. 2003, LUNT et al. 2004, BANO 2004);

- $\quad$ Planejamento Urbano - localização de galerias de águas pluviais, dutos enterrados e disposição de resíduos sólidos (BEVAN 1984, ANNAN et al. 1984, OLHOEFT 1996, MALAGUTTI FILHO et al.1997);

- Pesquisas Arqueológicas - localização de túneis e fundações de igrejas históricas (VAUGHAN 1986, SAUCK et al. 1995);

- Exploração Mineral - localização de jazidas para o desenvolvimento de minas (ANNAN \& DAVIS 1976, STEWART \& UNTERBERGER 1976, DAVIS et al. 1984, DANIELS 1988, SIGURDSSON 1994).

Embora haja atualmente um número expressivo de instituições de pesquisas e universidades brasileiras empregando a metodologia GPR (PUC-Rio, IPT, UFBA, UFF, UERJ, IAG/USP, IGc/USP, IGCE/UNESP, UFRGS, UFMG, UFRN, entre outras) voltados para diversas finalidades verifica-se, no entanto, que os trabalhos realizados no Brasil freqüentemente estão concentrados somente em algumas áreas de aplicação. Neste sentido, observa-se que ainda não foram realizados trabalhos sobre a aplicação da metodologia GPR na determinação do teor de umidade do solo para fins geotécnicos.

Os bons resultados recentemente alcançados com o uso do GPR para a medição do teor de umidade do solo em outros paises (e.g. HUISMAN et al. 2001, 2002 e 2003, DAVIS \& ANNAN 2002, GALAGEDARA et al. 2002, GROTE et al. 2003, BANO 2004) é um estímulo para se investigar suas potencialidades e limitações para as condições geológico-geotécnicas brasileiras. 


\subsubsection{Princípios gerais}

O radar penetrante no solo (Ground Penetrating Radar - GPR) é um método de medida geofísica que tem sido extensivamente usado para mapear de modo não invasivo as características de subsuperfície em diversas escalas de trabalho. O método GPR é similar, em princípio, ao método de reflexão sísmica e à técnica de sonar. No caso da maioria dos sistemas geralmente usados, uma antena transmissora $T_{x}$ irradia pulsos curtos de ondas eletromagnéticas de alta freqüência (normalmente entre $10 \mathrm{MHz}$ a $1 \mathrm{GHz}$ ), e uma outra antena receptora $R_{x}$ registra o sinal da antena transmissora em função do tempo de percurso da onda eletromagnética (HUISMAN et al. 2003).

Quando uma antena transmissora $T_{x}$ está posicionada sobre a superfície do terreno, ondas eletromagnéticas esféricas são irradiadas tanto para dentro do maciço quanto para o ar. Se as condições do solo forem adequadas para o GPR e a antena estiver bem acoplada com o solo, a maior parte do sinal irradiado (cerca de 90\%) é transmitida para dentro do maciço e somente uma pequena parcela (aproximadamente 10\%) vai para o ar (ANNAN 1992).

A Figura 3.15 mostra possíveis caminhos de propagação de uma onda eletromagnética para antenas GPR localizadas na superfície do terreno. Na aquisição de dados no campo com GPR, as ondas normalmente observadas são: onda direta no ar, onda direta no solo e onda refletida e refratada.

O produto final da aquisição no campo é uma seção contínua representada no eixo horizontal pela distância ao longo da linha medida em superfície e no eixo vertical pelo tempo de ida e volta do sinal emitido por reflexão, medida em nano-segundos (desde o refletor até a antena receptora). 


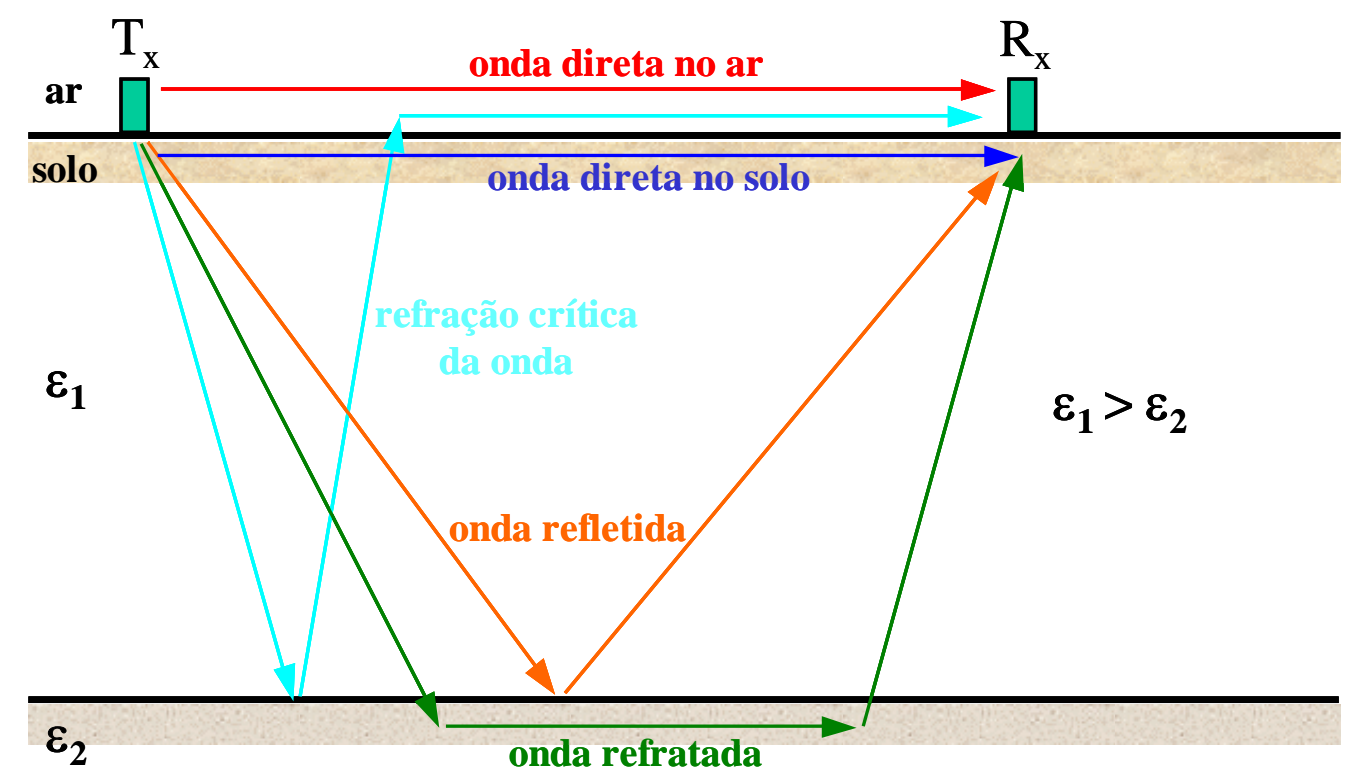

FIGURA 3.15 - CAMINHOS DE PROPAGAÇÃO DA ONDA ELETROMAGNÉTICA NO SOLO CONSTITUÍDO POR DUAS CAMADAS COM PERMISSIVIDADE DIELÉTRICA DISTINTA (MODIFICADO DE SPERL 1999).

Na metodologia GPR existem dois aspectos importantes que precisam ser destacados: a resolução da imagem de subsuperfície e a profundidade de penetração da onda eletromagnética. A resolução da imagem é determinada pela duração do pulso emitido, que é controlada pela largura de banda da freqüência do sistema GPR. Como normalmente os sistemas de pulso do radar são projetados para atingir larguras de banda equivalentes à freqüência central, a resolução vertical da imagem aumenta com o aumento da freqüência central das antenas, conforme apresentado na Tabela 3.2 (DAVIS \& ANNAN 1989).

Tabela 3.2 - Resolução vertical da imagem em função da freqüência de operação das antenas do GPR (JOL 1995).

\begin{tabular}{|c|c|}
\hline Freqüência central da antena (MHz) & Resolução vertical (metros) \\
\hline 25 & 0,76 \\
\hline 50 & 0,37 \\
\hline 100 & 0,21 \\
\hline 200 & 0,15 \\
\hline 400 & 0,05 \\
\hline
\end{tabular}


Em termos gerais, a freqüência central de operação é definida de maneira a fornecer a relação mais vantajosa entre a penetração e a resolução vertical para atender a um determinado objetivo. Deste modo, pode-se adequar o sistema GPR às características peculiares de um determinado local variando-se apenas a freqüência de operação. A profundidade de penetração da onda transmitida pelo GPR é controlada pelas propriedades eletromagnéticas do meio (condutividade elétrica e permissividade dielétrica relativa) em combinação com a freqüência central das antenas.

Em meios de baixa condutividade, tais como pedregulhos e areias secas, um sistema GPR com antenas de baixa freqüência pode alcançar penetrações de vários metros, enquanto que um sistema de alta freqüência pode alcançar penetrações de apenas poucos metros ou centímetros. Para areias siltosas e argilas, a profundidade de penetração será significativamente menor devido principalmente aos elevados valores da condutividade elétrica desses materiais.

Assim, verifica-se que as propriedades eletromagnéticas dos materiais geológicos são os principais fatores que afetam as medidas do sistema GPR, uma vez que proporcionam reflexões e atenuações dos sinais nas interfaces de subsuperfície (refletores), influenciando sobremaneira a velocidade de propagação das ondas eletromagnéticas.

\subsubsection{Propagação de ondas eletromagnéticas}

A velocidade e a atenuação são os fatores que descrevem a propagação de ondas eletromagnéticas de alta freqüência no solo. Para descrever as propriedades eletromagnéticas de altas freqüências dos materiais utiliza-se a permissividade dielétrica relativa ou constante dielétrica, $K$, a qual fornece a razão da permissividade do material $(\varepsilon)$ em relação à permissividade do espaço livre $\left(\varepsilon_{0}=8,854 \times 10^{-12} \mathrm{~F} / \mathrm{m}\right)$ e define uma quantidade adimensional:

$$
K=\frac{\varepsilon}{\varepsilon_{0}}
$$


A constante dielétrica apresenta valores que variam desde 1 (para o ar) até 81 (para a água). Para solos e rochas, a constante dielétrica $K$ é significativamente influenciada pelo conteúdo de água existente nos poros e/ou fraturas desses materiais, sendo insignificante a influência da temperatura (TOPP et al. 1980).

Quando se considera simultaneamente propagação e atenuação de ondas eletromagnéticas, tem-se que citar a constante dielétrica complexa, a qual é dada pela soma das partes real e imaginária:

$$
K^{*}=K^{\prime}-j K^{\prime \prime}
$$

onde: $K^{\prime}$ é a parte real da constante dielétrica, e $K^{\prime \prime}$ é a parte imaginária da constante dielétrica ou a parte de perda elétrica.

A velocidade de propagação de ondas eletromagnéticas é determinada pela constante dielétrica complexa,

$$
v=\frac{c}{\sqrt{K^{\prime} \cdot \mu_{r} \cdot \frac{1+\sqrt{1+\tan ^{2} \delta}}{2}}}
$$

com a parte de perda elétrica definida como:

$$
\tan \delta=\frac{K^{\prime \prime}+\frac{\sigma_{d c}}{2 \pi \cdot f \cdot \varepsilon_{0}}}{K^{\prime}}
$$

onde: $c$ é a velocidade de propagação de ondas eletromagnéticas no vácuo $\left(3 \times 10^{8} \mathrm{~m} / \mathrm{s}\right), f$ é a freqüência do campo eletromagnético $(\mathrm{Hz}), \mu_{r}$ é a permeabilidade magnética relativa, e $\sigma_{d c}$ é a condutividade DC (S/m). Para solos não magnéticos, $\mu_{r}$ é igual a 1,0 na faixa de freqüência do GPR (VAN DAM et al. 2002). 
A parte imaginária da constante dielétrica está associada com a dissipação de energia, e a parte real está associada com a capacidade de armazenamento de energia quando um campo elétrico é aplicado. A constante dielétrica complexa da maioria dos materiais varia consideravelmente em função da freqüência do campo elétrico aplicado. Um processo importante que contribui para essa dependência da constante dielétrica é o surgimento de polarização a partir da orientação das moléculas impostas pelo campo elétrico. A formulação matemática que representa este processo para materiais polares puros é dada por (DEBYE 1929):

$$
K^{*}=\varepsilon_{\infty}+\frac{\varepsilon_{s}-\varepsilon_{\infty}}{1+\left(i \cdot \frac{f}{f_{r e l}}\right)}-\frac{j \cdot \sigma_{d c}}{2 \pi \cdot f \cdot \varepsilon_{0}}
$$

onde: $\varepsilon_{\infty}$ é a permissividade para altas freqüências, $\varepsilon_{s}$ é a permissividade estática, isto é, o valor na freqüência zero; e $f_{\text {rel }}$ a a freqüência de relaxação, definida como a freqüência em que a permissividade é igual a $\left(\varepsilon_{s}+\varepsilon_{\infty} / 2\right)$.

Na Figura 3.16 é mostrado a separação da Equação 3.30 em parte real e imaginária, para um meio idealizado com $\varepsilon_{s}=20, \varepsilon_{\infty}=15, f_{r e l}=10^{8,47} \mathrm{~Hz}(300 \mathrm{MHz})$ e $\sigma_{d c}=0 \mathrm{~S} / \mathrm{m}$.

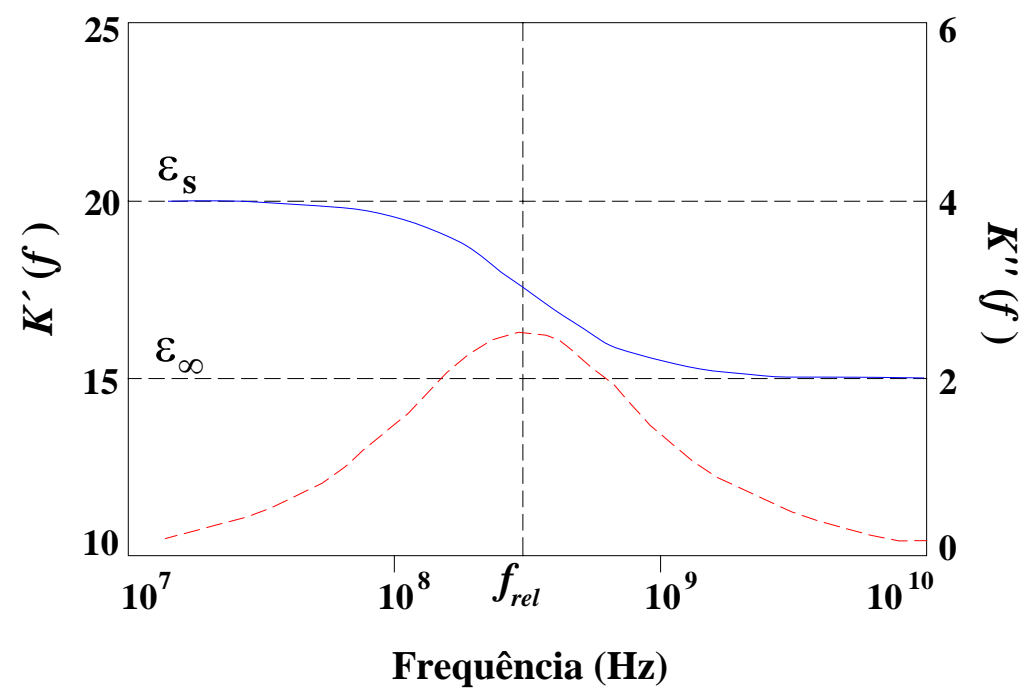

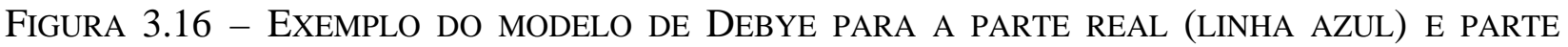
IMAGINÁRIA (LINHA VERMELHA) DA PERMISSIVIDADE (MODIFICADO DE HUISMAN ET AL. 2003). 
A Figura 3.16 mostra que em freqüências muito baixas e muito altas em relação ao processo de relaxação, a permissividade tem valores constantes e nenhuma perda. Em freqüências intermediárias, a permissividade sofre uma dispersão e as perdas dielétricas ocorrem com o pico da perda em $f=f_{r e l}$. A água em seu estado líquido é um bom exemplo de um dielétrico polar. Os parâmetros utilizados por DEBYE (1929) para a água são $\varepsilon_{s}=80,1, \quad \varepsilon_{\infty}=4,2 \mathrm{e}$ $f_{\text {rel }}=10^{10,2} \mathrm{~Hz}(17,1 \mathrm{GHz})$ à $25^{\circ} \mathrm{C}$.

Em solos arenosos, a maior parte da água está efetivamente em seu estado líquido livre. Em solos com teor elevado de argila, a água nos poros não está necessariamente em seu estado líquido livre. Às vezes ela se apresenta fisicamente absorvida por capilares, limitada em movimento pela interação eletrostática com partículas de argila. A relaxação dielétrica das moléculas de água absorvida ocorre em freqüências mais baixas do que a relaxação das moléculas de água livre (HASTED 1973).

Na maioria dos sistemas GPR, que geralmente operam numa faixa de freqüência entre $10 \mathrm{MHz}$ a $1 \mathrm{GHz}$, a parte de perda da constante dielétrica $K^{\prime \prime}$ é freqüentemente pequena quando comparada com sua parte real $K^{\prime}$. Além disso, muitos solos não apresentam relaxação de permissividade na faixa de freqüência de operação do GPR, e nessas condições a Equação 3.28 se reduz a seguinte expressão para solos não salinos (WYSEURE et al. 1997):

$$
v=\frac{c}{\sqrt{K^{\prime}}}
$$

onde: $c$ é a velocidade de propagação de ondas eletromagnéticas no vácuo $\left(3 \times 10^{8} \mathrm{~m} / \mathrm{s}\right)$.

Dentro da faixa de operação do GPR, a parte real da constante dielétrica da água é de aproximadamente 80, uma vez que a constante dielétrica do ar é de 1, e de muitos outros constituintes comuns do solo estão entre 3 e 10. Este grande contraste entre os valores da constante dielétrica explica, por exemplo, o sucesso em medições do teor de umidade dos solos utilizando-se técnicas eletromagnéticas (HUISMAN et al. 2003). 


\subsubsection{Relação entre a permissividade e o teor de umidade do solo}

A relação entre a permissividade aparente, $\varepsilon$, e o teor de umidade volumétrico do solo, $\theta$ $\left(\mathrm{m}^{3} \cdot \mathrm{m}^{-3}\right)$, que vem sendo mais utilizada foi proposta por TOPP et al. (1980):

$$
\theta=-5,3 \times 10^{-2}+2,92 \times 10^{-2} \varepsilon-5,5 \times 10^{-4} \varepsilon^{2}+4,3 \times 10^{-6} \varepsilon^{3}
$$

Esta equação foi determinada empiricamente para diversas composições mineralógicas de solos e tem uma precisão de $0,022 \mathrm{~m}^{3} \cdot \mathrm{m}^{-3}$. O termo “aparente” é usado porque a permissividade adotada nessa equação foi determinada a partir de medidas da velocidade de propagação de ondas eletromagnéticas no solo, utilizando-se a técnica do TDR nas freqüências de $20 \mathrm{MHz}$ a $1 \mathrm{GHz}$.

Esta relação não é apropriada para solos com alto teor de argila ou matéria orgânica, devendo ser calibrada para novos materiais. No entanto, é interessante notar que a equação de TOPP se aplica a materiais consolidados (rochas alteradas) com baixo teor de umidade, e se ajusta muito bem para materiais inconsolidados (solos) com alto teor de umidade (BANO 2004).

Uma aproximação mais teórica a respeito da relação entre a permissividade e o teor de umidade volumétrica do solo está fundamentada em combinações de modelos dielétricos que utilizam as frações de cada tipo de solo, em volume, e a permissividade dielétrica (e.g. DOBSON et al. 1985, ROTH et al. 1990, FRIEDMAN 1998, JONES \& FRIEDMAN 2000).

Nas combinações de modelos dielétricos, a permissividade volumétrica de um sistema solo-águaar, $\varepsilon_{b}$, pode ser representada pelo Modelo do Índice Refrativo Complexo (CRIM):

$$
\varepsilon_{b}=\left[\theta \cdot \varepsilon_{w}^{\alpha}+(1-n) \cdot \varepsilon_{s}^{\alpha}+(n-\theta) \cdot \varepsilon_{a}^{\alpha}\right]^{\frac{1}{\alpha}}
$$

onde: $n$ é a porosidade do solo; $\varepsilon_{w}, \varepsilon_{s}, \varepsilon_{a}$ são as permissividades da água, das partículas sólidas e do ar, respectivamente; $\alpha$ é um fator que leva em consideração a orientação do campo elétrico em relação à geometria do meio ( $\alpha=1$ para um campo elétrico paralelo às camadas de solo, $\alpha=-1$ para um campo elétrico perpendicular às camadas de solo e $\alpha=0,5$ para um meio isotrópico). 
Após reorganizar a Equação 3.33, a seguinte expressão pode ser obtida para o teor de umidade volumétrico do solo:

$$
\theta=\frac{\varepsilon_{b}^{\alpha}-(1-n) \cdot \varepsilon_{s}^{\alpha}-n \cdot \varepsilon_{a}^{\alpha}}{\varepsilon_{w}^{\alpha}-\varepsilon_{a}^{\alpha}}
$$

Após a substituição de $\varepsilon_{a}=1$ e assumindo $\alpha=0,5$; a Equação 3.34 se reduz a:

$$
\theta=\frac{1}{\sqrt{\varepsilon_{w}}-1} \cdot \sqrt{\varepsilon_{b}}-\frac{(1-n) \cdot \sqrt{\varepsilon_{s}}-n}{\sqrt{\varepsilon_{w}}-1}
$$

que dá uma interpretação física simples a partir da relação entre o teor de umidade volumétrico do solo e a permissividade aparente $\varepsilon$, conforme sugerido por LEDIEU et al. (1986) e HERKELRATH et al. (1991):

$$
\theta=a \cdot \sqrt{\varepsilon_{b}}-b
$$

onde: $a$ e $b$ são parâmetros de calibração e $\sqrt{\varepsilon_{b}}$ também referido como índice refrativo $\left(n_{a}\right)$. Esta relação tem uma precisão de $0,0188 \mathrm{~m}^{3} \cdot \mathrm{m}^{-3}$, conforme determinado por uma validação independente para alguns minerais de solos.

BANO (2004) realizou um estudo numa camada de arenito siltoso inconsolidado em ambiente desértico, onde comparou a resposta da permissividade aparente da equação de TOPP et al. (1980), plotada em função do teor de umidade volumétrico do solo, com a expressão do índice refrativo complexo (CRIM) para $\varepsilon_{s}=4$ e $\varepsilon_{w}=81$. Observou que para valores baixos do teor de umidade (<30\%), os valores da permissividade aparente “ $\varepsilon$ ” calculados pela equação de Topp são menores do que aqueles determinados pela expressão do CRIM.

Segundo BANO (2004), uma possível explicação para essa discrepância é que, para baixos teores de umidade, a curva de Topp se ajusta melhor para materiais com maior grau de consolidação (densidade), que não é o caso do material estudado. 
È importante salientar que a maioria das equações de calibração disponíveis relacionando permissividade e teor de umidade foi obtida usando TDR, o qual funciona na faixa de freqüência de $500 \mathrm{MHz}$ a $1 \mathrm{GHz}$. Adicionalmente, sabe-se que solos com alto teor de argila apresentam significativas dispersões de permissividade em baixas freqüências (OLHOEFT 1987). Isto significa que uma calibração específica local pode ser necessária para aplicações que exigem uma certa precisão na medida do teor de umidade utilizando-se antenas de freqüências mais baixas.

De qualquer maneira, mesmo quando se utilizam relações petrofísicas determinadas pelo TDR, tal como a Equação 3.32, associadas com valores de permissividade obtidos de dados GPR, informações razoáveis sobre a variação espacial do teor de umidade podem ser obtidas.

\subsubsection{Medição do teor de umidade do solo com métodos eletromagnéticos}

Os métodos eletromagnéticos de alta freqüência, tais como o TDR e o GPR, são atualmente os melhores métodos para a medição do teor de umidade do solo, pois dispõem de uma série de técnicas que permitem medir o teor de umidade do solo a partir do conhecimento da permissividade dielétrica do meio, em diferentes escalas espaciais (HUISMAN et al. 2003).

Apesar da técnica TDR ser amplamente utilizada para o monitoramento do teor de umidade do solo com uma alta resolução temporal, observa-se que o pequeno volume envolvido no processo de medição $\left(<\mathrm{dm}^{3}\right)$ torna a técnica sensível a pequenas variações do teor de umidade dentro deste volume (e.g. macroporos, folgas devido à inserção das hastes do TDR - FERRÉ et al. 1996). Além disso, o uso do TDR para determinar a variação espacial do teor de umidade do solo em grandes áreas exige muito trabalho, pois além de requerer uma quantidade significativa de sensores, os mesmos precisam ser instalados em diversos pontos na área de interesse tornando-o, desta forma, num método tecnicamente impraticável.

Em contrapartida, a metodologia GPR (Ground Penetrating Radar) que se baseia nos mesmos princípios de funcionamento do TDR, vem sendo adotada com grande sucesso em diversos estudos que necessitam obter informações sobre a variação espacial do teor de umidade do solo em grandes áreas (HUISMAN et al. 2003). 
Apesar do aumento significativo nos últimos 20 anos de aplicações usando a técnica TDR, notase que paralelamente muitos trabalhos envolvendo medições do teor de umidade do solo com GPR também foram realizados com sucesso (e.g. GREAVES et al. 1996, HUISMAN et al.2001, 2002 e 2003, BOHIDAR \& HERMANCE 2002, DAVIS \& ANNAN 2002, GROTE et al. 2003, HUISMAN \& BOUTEN 2003, GALAGEDARA et al. 2003, BANO 2004, LUNT et al. 2004).

De um modo geral, todas as ondas irradiadas pelo GPR para dentro do terreno (conforme apresentado na Figura 3.15) podem ser utilizadas para medir o teor de umidade do solo. A seguir, são apresentados os principais métodos de medição do teor de umidade do solo a partir do tempo de percurso das ondas refletida e direta no solo, além dos métodos que utilizam os dados do tempo de percurso das ondas propagadas em furos de sondagens GPR e os dados de amplitude de reflexão na superfície do terreno.

\subsubsection{Medição com ondas refletidas}

Existem três métodos para se determinar o teor de umidade do solo a partir de dados do tempo de percurso de ondas refletidas. O primeiro método, denominado de "arranjo de afastamento constante” ou common offset, utiliza a mesma distância $n_{x}$ de separação entre as antenas, onde a cada medida deslocam-se as antenas em conjunto, conforme apresentado na Figura 3.17.

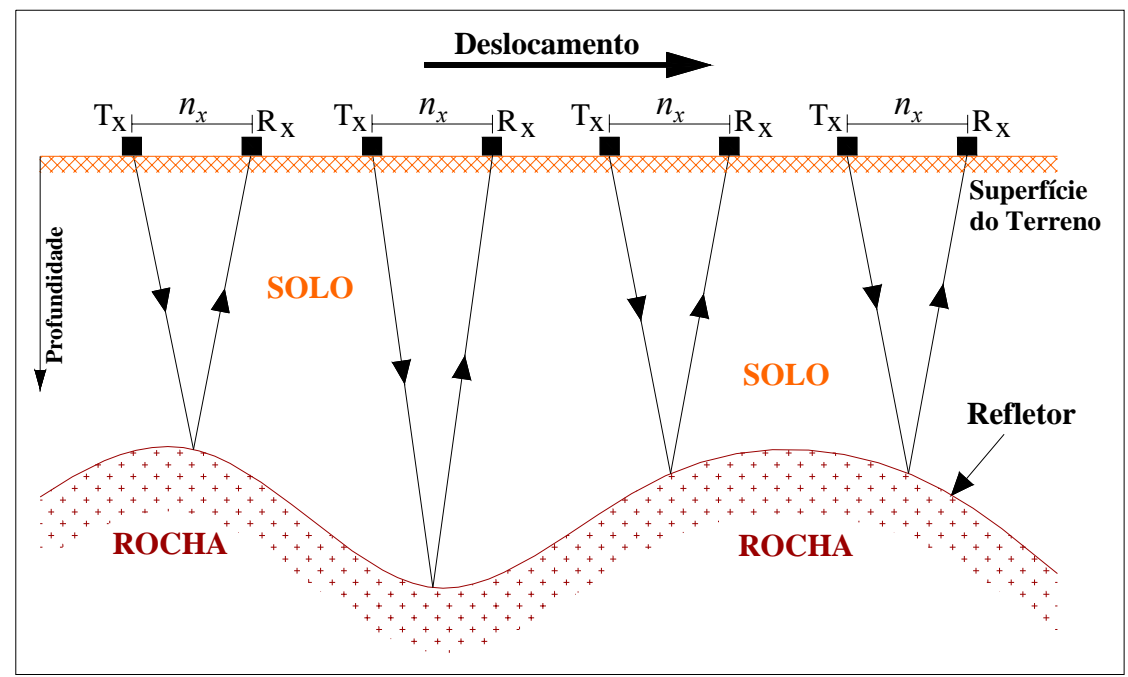

FIGURA 3.17 - ARRANJO DAS ANTENAS DO GPR NO MÉTODO DE AFASTAMENTO CONSTANTE. 
Nesse método, as ondas eletromagnéticas irradiadas pelo GPR para dentro do solo serão parcialmente refletidas ao se chocarem com estratos geológicos (rochas) ou camadas de solo com permissividades dielétricas distintas. A Figura 3.18 apresenta uma situação idealizada para o método de afastamento constante (lado esquerdo) e um radargrama (lado direito), adquirido num terreno onde ocorre lençol freático e zona anômala de umidade. No radargrama pode-se observar o sinal da onda direta no ar (A), o sinal de reflexão da zona anômala (B) e do nível freático (C).
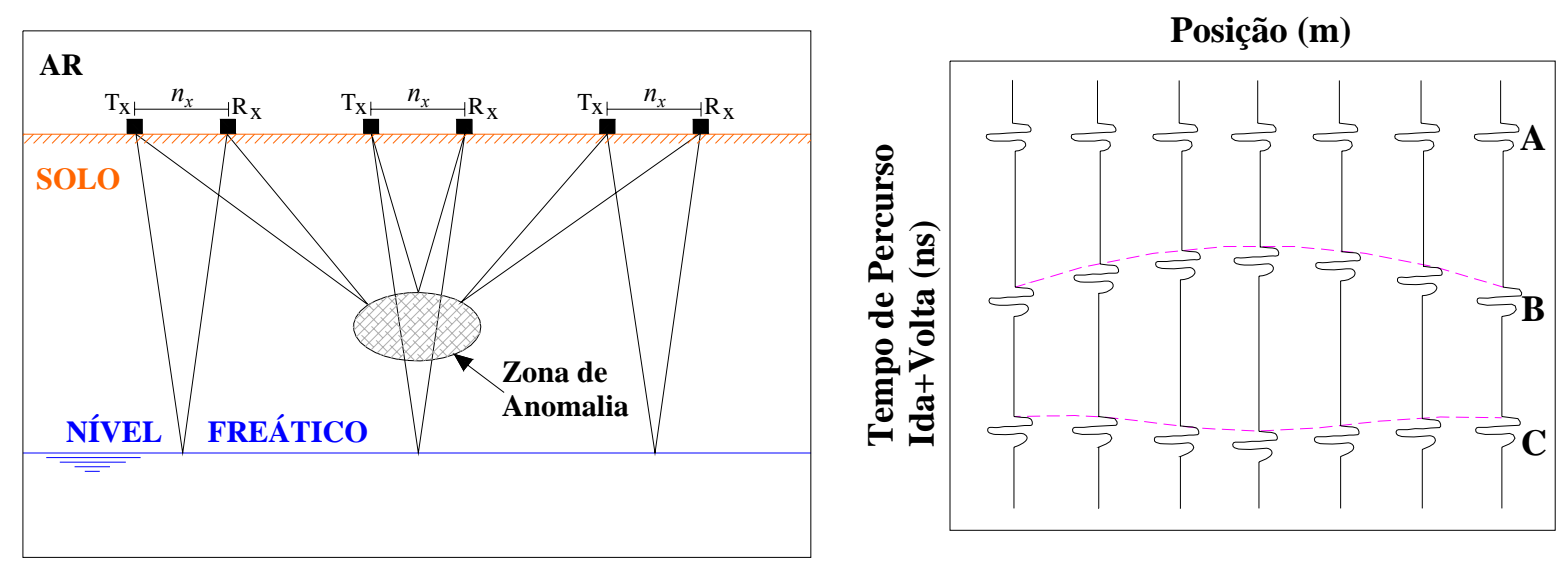

FIGURA 3.18 - RADARGRAMA OBTIDO NUMA SITUAÇÃO IDEALIZADA (MODIFICADO DE DAVIS \& ANNAN 1989).

Devido o GPR emitir ondas em todas as direções, a energia refletida é detectada antes do GPR estar próximo ou sobre a zona de anomalia. Os eventos refletidos em subsuperfície são detectados pela antena receptora e registrados em forma de hipérbole no radargrama (ponto “B”). A velocidade média da onda no solo determina a convexidade da hipérbole de reflexão “B”. A velocidade média entre a superfície do terreno e a zona de anomalia, $v_{\text {solo }}$, pode ser determinada a partir da análise do radargrama, ajustando-se a hipérbole para medir os tempos de chegada das ondas refletidas em várias posições:

$$
v_{\text {solo }}=\frac{2 \cdot \sqrt{x^{2}+d^{2}}}{t_{x}}
$$

onde: $x$ representa a posição em relação ao ápice da hipérbole, $d$ é a profundidade da zona de anomalia e $t_{x}$ é o tempo de chegada da onda refletida na posição $x$. 
Se o radargrama for obtido por um afastamento entre antenas significativo, $a$, este também deverá ser incluído na determinação da velocidade como segue:

$$
v_{\text {solo }}=\frac{\sqrt{(x-0.5 a)^{2}+d^{2}}+\sqrt{(x+0.5 a)^{2}+d^{2}}}{t_{x}}
$$

A maioria dos softwares de análise de dados GPR dispõe de rotinas simples, onde a velocidade pode ser determinada interativamente por ajuste manual da hipérbole de reflexão presente no radargrama. Esta velocidade pode então ser usada para calcular a permissividade do solo (Equação 3.31) e o teor de umidade volumétrico do solo (Equação 3.32).

Embora sua aplicação seja simples, o método por afastamento constante não tem sido aplicado com freqüência na determinação do teor de umidade do solo, sendo utilizado somente em algumas situações para investigações exploratórias do subsolo. A principal desvantagem deste método é que ele somente pode ser usado em terrenos onde são observados significativos contrastes na permissividade dielétrica. A reflexão de ondas no topo da zona saturada, imediatamente acima do lençol freático, é um bom exemplo de contraste na permissividade do solo (marcado com “C” no radargrama).

Para se tornar vantajoso, em relação à estimativa do teor de umidade do solo, o método de reflexão por afastamento constante necessita primeiramente de uma penetração de sinal suficiente e da presença de um contraste dielétrico em subsuperfície que produza um nítido refletor, e ainda um bom controle sobre a profundidade deste refletor.

A aplicação deste método tem obtido êxito em alguns estudos que utilizaram refletores enterrados até pequenas profundidades. GROTE et al. (2002) enterraram refletores dentro de um poço arenoso em pequena profundidade $(<1,0$ metro), e utilizaram o tempo de percurso das ondas refletidas para estimar os valores do teor de umidade do solo. Suas estimativas variaram em até $0,01 \mathrm{~m}^{3} \cdot \mathrm{m}^{-3}$ quando comparadas com valores medidos por técnicas gravimétricas. 
STOFFREGEN et al. (2002) estimaram sazonalmente o teor de umidade volumétrico na base de um lisímetro pouco profundo (1,5 metros) que foi preenchido com solo arenoso, usando antenas de $1 \mathrm{GHz}$. Os autores encontraram um desvio padrão médio de $0,01 \mathrm{~m}^{3} \cdot \mathrm{m}^{-3}$ entre os teores de umidade obtidos com o método GPR e as medidas realizadas com o lisímetro.

No entanto, a precisão do método por afastamento constante em relação à estimativa do teor de umidade sob condições naturais ainda não está bem consagrada. Alguns pesquisadores têm testado este método para estimar o teor de umidade do solo a partir de refletores naturais detectados em diferentes profundidades (e.g. observações do nível d’água - WEILER et al. 1998 ou limites de transição litológica durante sondagem - VAN OVERMEEREN et al. 1997). A utilização do método de reflexão por afastamento constante para estimar espacialmente o teor de umidade do solo sob condições naturalmente heterogêneas na escala de campo, ainda é um assunto de pesquisa em atividade.

Os outros dois métodos para se determinar o teor de umidade do solo são: Commom Mid Point (CMP) e Wide Angle Reflection and Refraction (WARR), conforme apresentado nas Figuras 3.19 e 3.20, respectivamente.

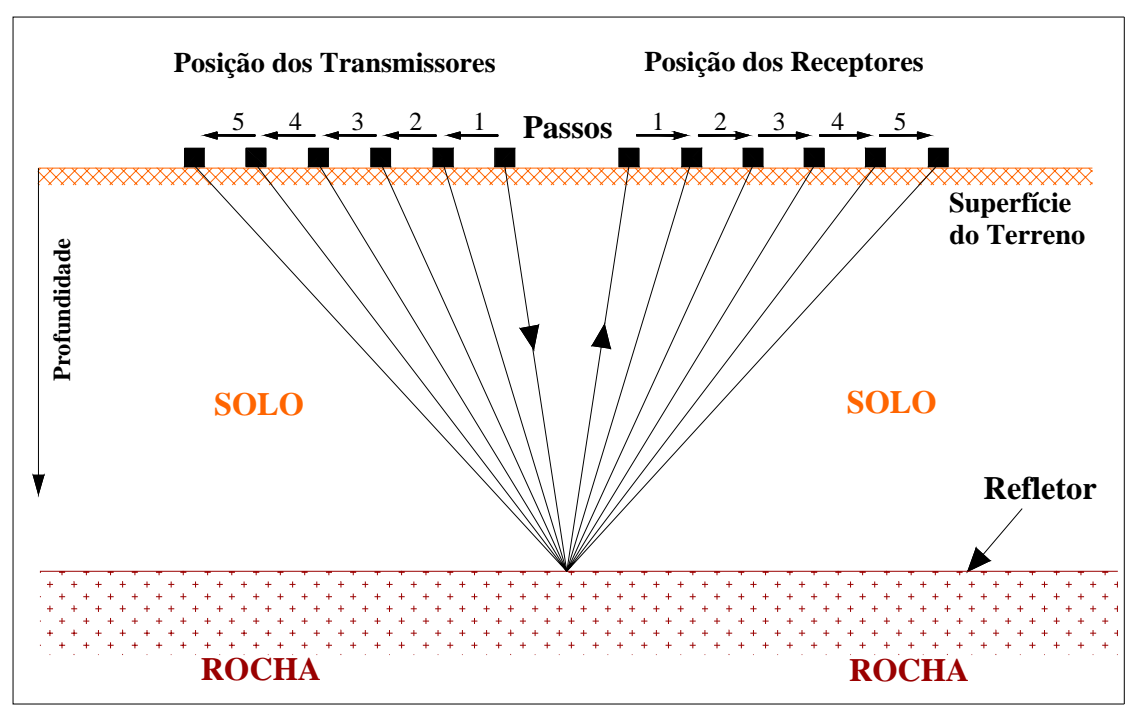

FIGURA 3.19 - ARRANJO DAS ANTENAS DO GPR NO MÉTODO CMP. 


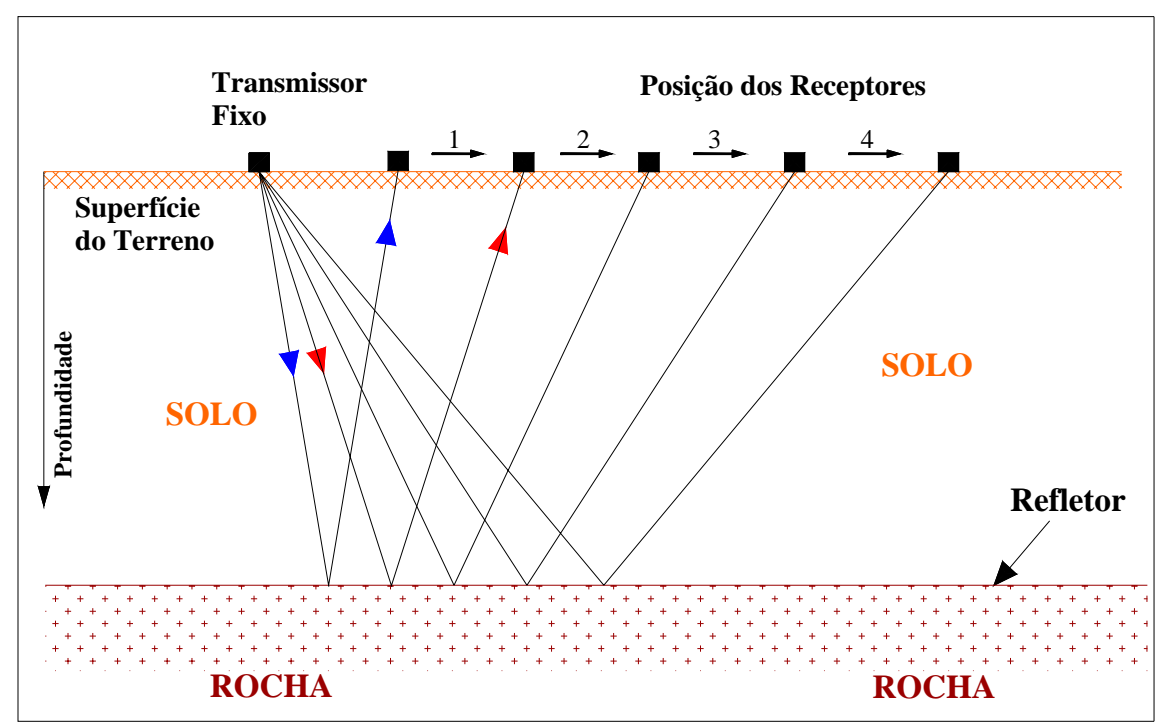

FIGURA 3.20 - ARRANJO DAS ANTENAS DO GPR NO MÉTODO WARR.

A diferença entre um método e outro é que no CMP ambas as antenas são movidas a cada passo e no WARR somente uma das antenas se move. Apesar do método WARR ser mais prático ele não é aconselhável, pois seus resultados apresentam irregularidades em relação ao refletor e podem gerar erros na fase de ajuste da hipérbole de reflexão.

Nos dois métodos aumenta-se gradativamente a distância entre as antenas transmissora e receptora sempre num intervalo fixo pré-determinado. A aquisição se inicia com as antenas dispostas paralelamente, uma em relação à outra, segundo a direção do seu comprimento e ambas dispostas perpendicularmente em relação à direção do perfil de caminhamento. O modelo de radiação nesta posição de antenas irá permitir uma maior cobertura do alvo em subsuperfície.

O resultado final será o radargrama mostrado na Figura 3.21 do qual, através da análise de velocidade das hipérboles identificadas, pode-se estimar os valores de propagação das ondas eletromagnéticas nas diversas camadas presentes e conseqüentemente, as espessuras envolvidas. 


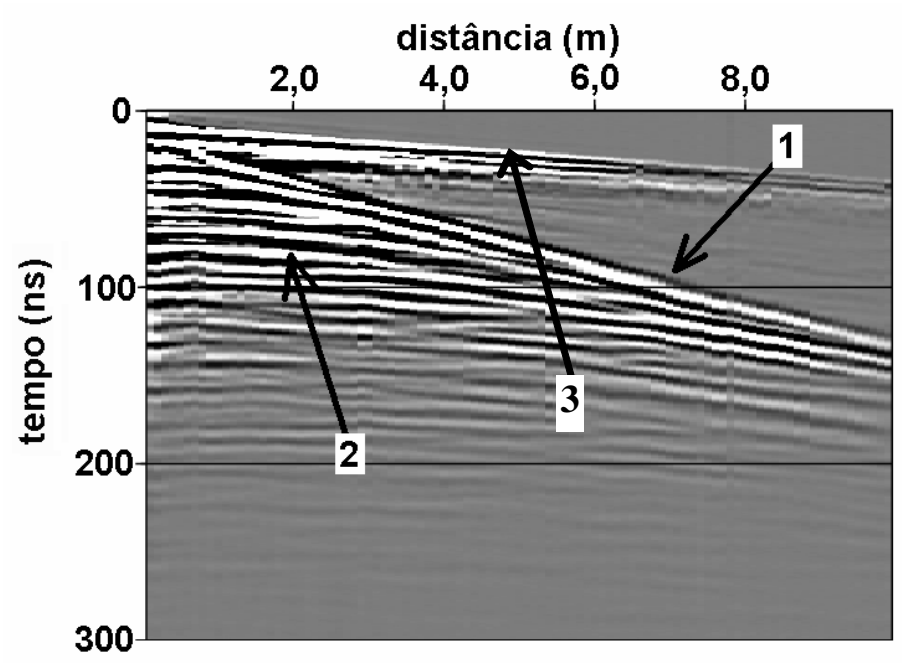

FIGURA 3.21 - RADARGRAMA DE AQUISIÇÃO CMP OU WARR (1-ONDA DIRETA NO SOLO, 2-ONDA REFLETIDA NO SOLO E 3-ONDA DIRETA NO AR).

A obtenção das velocidades de propagação da onda direta no solo pode ser feita através de ajuste linear dos tempos de percurso identificados nos radargramas. O valor da velocidade média de propagação da onda refletida no solo numa medida CMP ou WARR pode ser obtido a partir da seguinte expressão:

$$
v_{\text {solo }}=\frac{2 \cdot \sqrt{d^{2}+(0.5 a)^{2}}}{t_{a}}
$$

onde: $a$ representa o afastamento entre as antenas (transmissora-receptora), $d$ é a profundidade da camada refletora e $t_{a}$ é o tempo de chegada da onda refletida para um determinado afastamento entre as antenas.

Softwares de análise de dados GPR fornecem rotinas simples, onde a velocidade média de propagação pode ser obtida via radargrama por ajuste manual da hipérbole de reflexão para vários afastamentos entre as antenas. A velocidade média pode então ser usada para calcular o teor de umidade volumétrico do solo.

Para evitar estimativas subjetivas do teor de umidade do solo e para acelerar o processo de análise, têm sido desenvolvidas aproximações semi-automatizadas visando a determinação da 
velocidade a partir de ondas refletidas, que são análogas às aproximações de análises de velocidade voltadas para uso com dados sísmicos (e.g. YILMAZ 1987).

Um método bem conhecido é a análise da máxima coerência no espectro de velocidade, conforme apresentado na Figura 3.22. O objetivo dessa análise é descobrir a velocidade e o tempo de percurso para o qual a energia de reflexão de uma onda refletida numa medida CMP se concentre num determinado ponto. Isto é feito a partir do gráfico de espectro de velocidade, que é construído por reavaliação do tempo de chegada da onda refletida numa medida CMP para uma determinada faixa de velocidade, assumindo a energia normalizada para cada tempo de chegada e velocidade.

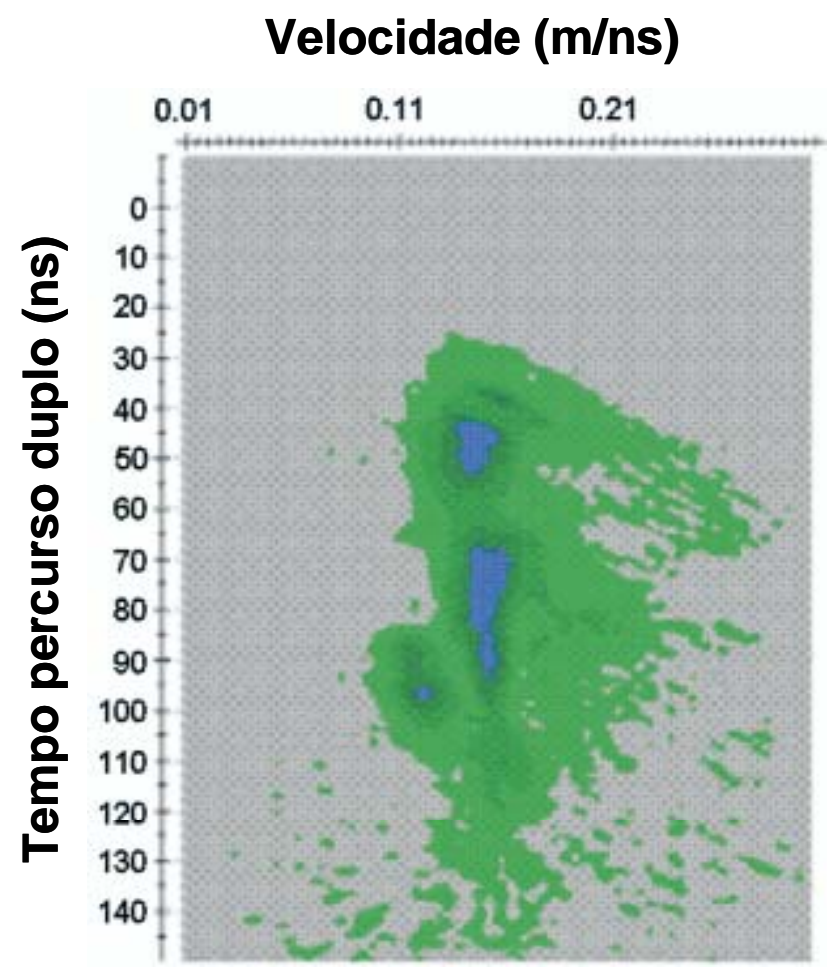

FIGURA 3.22 - ESPECTRO DE VELOCIDADE DE UMA MEDIDA CMP PARA ILUSTRAR A OBTENÇÃO AUTOMÁTICA DA VELOCIDADE VERSUS TEMPO - A COR AZUL INDICA A MÁXIMA COERÊNCIA (HUISMAN ET AL. 2003).

Na Figura 3.22, as manchas em azul indicam os respectivos valores do tempo de chegada e da velocidade para os quais as ondas refletidas estão bem caracterizadas. As velocidades determinadas manualmente ou semi-automaticamente a partir de medidas CMP ou WARR, são 
consideradas velocidades médias para a profundidade do refletor. Para converter essas velocidades médias em velocidade intervalares de cada camada, $v_{i n t, n}$, pode-se utilizar a fórmula de Dix (DIX 1955, YILMAZ 1987):

$$
v_{\mathrm{int}, n}=\sqrt{\frac{t_{n} \cdot v^{2}{ }_{\text {solo }, n}-t_{n-1} \cdot v^{2}{ }_{\text {solo }, n-1}}{t_{n}-t_{n-1}}}
$$

onde: $v_{s o l o, n}$ é a velocidade média a partir da superfície do terreno até a base da camada $n, v_{\text {solo,n-1 }}$ é a velocidade média até a base da camada $n-1, t_{n}$ é o tempo de percurso duplo (ida+volta) até a base da camada $n, t_{n-1}$ é o tempo de percurso duplo até a base da camada $n-1$, e $n=1$ é a camada superior do terreno.

As necessidades para se empregar os métodos de reflexão CMP e WARR para estimativas do teor de umidade do solo é similar às requeridas no método por afastamento constante (common offset): penetração de sinal adequado e a presença de contraste dielétrico em subsuperfície que seja capaz de produzir refletores nítidos no radargrama.

Há numerosos trabalhos envolvendo a determinação do teor de umidade do solo a partir dos métodos de reflexão CMP e WARR (e.g. TILLARD \& DUBOIS 1995, GREAVES et al. 1996, VAN OVERMEEREN et al. 1997, DANNOWSKI \& YARAMANCI 1999, ENDRES et al. 2000, NAKASHIMA et al. 2001, BOHIDAR \& HERMANCE 2002, GARAMBOIS et al. 2002).

Embora sejam extremamente usados no processamento de dados GPR para a determinação dos perfis de velocidade com a profundidade, os métodos CMP e WARR apresentam algumas dificuldades operacionais ao serem utilizados em determinadas situações de campo (e.g. regiões com alta densidade de vegetação e com alta declividade); 


\subsubsection{Medição com onda direta no solo}

O princípio de medição do teor de umidade com a onda direta no solo está ilustrado na Figura 3.15. A onda direta no solo é a parte da energia radiada que se propaga entre as antenas transmissora e receptora através da superfície do terreno. A onda direta no solo é detectada pela antena receptora do GPR, mesmo na ausência de camadas de solo nitidamente reflexivas (DU 1996, BERKTOLD et al. 1998, SPERL 1999). O caráter instável ou passageiro da onda direta no solo medido pela antena receptora do GPR na superfície do terreno necessita que ambas as antenas (receptora e transmissora) sejam colocadas tão próximas quanto possível da superfície do terreno.

A onda direta no solo pode ser facilmente reconhecida num radargrama de aquisição CMP ou WARR, pela relação linear observada entre a separação das antenas e os tempos de percurso da onda direta no solo, que começa na origem do ajuste de medida CMP ou WARR (ver Figura 3.21). A inclinação da onda direta no solo numa medida CMP ou WARR está diretamente relacionada com sua velocidade e pode, portanto, ser usada para a determinação do teor de umidade do solo.

A velocidade da onda direta no solo pode também ser determinada pelo método do arranjo de afastamento constante ou common off set, desde que o tempo de chegada da onda direta no solo seja obtido inicialmente por uma medida CMP ou WARR. Por essa razão, DU (1996) e SPERL (1999) propuseram o seguinte método para medição do teor de umidade do solo usando a onda direta no solo:

1. Identificar o tempo de chegada aproximado da onda direta no solo para diferentes separações das antenas numa medida CMP ou WARR;

2. Escolher uma separação da antena para a qual a onda direta no solo possa ser nitidamente separada das ondas aérea e refletida;

3. Usar esta separação de antena em medidas por afastamento constante e relacionar as mudanças do tempo de chegada da onda direta no solo com as mudanças na permissividade do solo. 
A precisão deste método para medição do teor de umidade do solo foi determinada por HUISMAN et al. (2001), a partir da análise de um conjunto de 24 medidas WARR usando antenas de $225 \mathrm{MHz}$ e dados gravimétricos de umidade obtidos independentemente. A equação de calibração resultante $\left(\theta_{\text {Grav. }}=0,1087 . \mathrm{N}_{\text {WARR }}-0,1076\right)$ é mostrada na Figura 3.23 e tem uma precisão de $0,024 \mathrm{~m}^{3} \cdot \mathrm{m}^{-3}$.

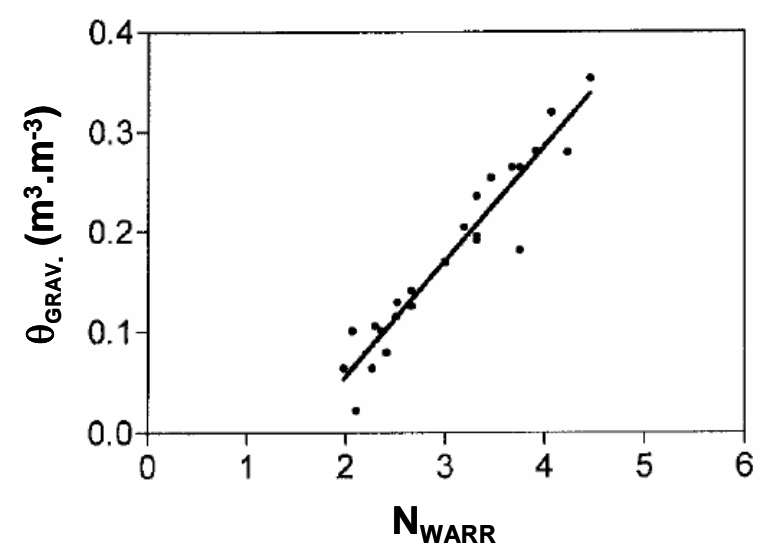

FIGURA 3.23 - AJUSTE DA EQUAÇÃO DE CALIBRAÇÃO ENTRE O TEOR DE UMIDADE VOLUMÉTRICO DETERMINADO GRAVIMETRICAMENTE E O ÍNDICE REFRATIVO “N $\mathrm{N}_{\text {WARR" DETERMINADO PELA }}$ VELOCIDADE DA ONDA DIRETA NO SOLO (HUISMAN ET AL. 2003).

GROTE et al. (2003) compararam 29 medições do teor de umidade do solo obtidas a partir do método WARR com medidas gravimétricas de umidade. Eles apresentaram imprecisões médias de 0,022 e $0,015 \mathrm{~m}^{3} \cdot \mathrm{m}^{-3}$ usando antenas de 450 e $900 \mathrm{MHz}$, respectivamente, para equações de calibração do tipo da Equação 3.36. Tanto HUISMAN et al. (2001) quanto GROTE et al. (2003) encontraram uma boa correlação entre a permissividade obtida a partir da velocidade da onda direta no solo com as medidas de TDR nessas freqüências, conforme ilustrado na Figura 3.24. 


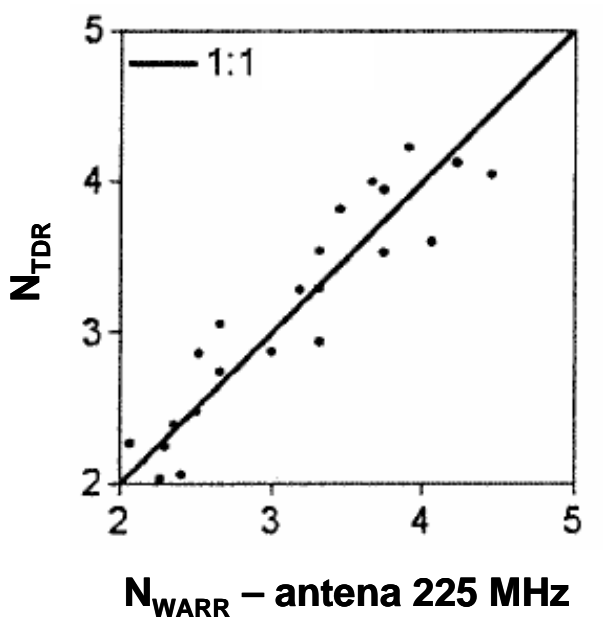

Figura 3.24 - COMPARAÇÃo DE $\mathrm{N}_{\text {TDR }}$ E $\mathrm{N}_{\text {WARR }}$ PARA AS MEDidAS MOSTRAdAS NA FigURA 3.23 (HUISMAN ET AL. 2003).

Experimentos realizados em alguns trabalhos (e.g. LESMES et al. 1999, HUBBARD et al. 2002, HUISMAN et al. 2002 e 2003, GROTE et al. 2003) tem confirmado ótimos resultados de medição do teor de umidade do solo com dados do tempo de percurso da onda direta no solo.

Embora os resultados com dados de ondas direta no solo sejam geralmente promissores há, entretanto, algumas incertezas associadas com este método. Uma importante questão ainda não solucionada é como definir o volume efetivamente atingido pela onda direta no solo. DU (1996) sugeriu que a influência da profundidade é aproximadamente metade do comprimento da onda $\left(\lambda=c /(f . \varepsilon)^{1 / 2}\right)$. Isto significa, por exemplo, que para uma antena de freqüência central de 225 $\mathrm{MHz}$, a profundidade de influência poderá variar de 0,50 metro $(\varepsilon=4,0)$ a 0,22 metro $(\varepsilon=20,0)$.

Contudo, observa-se que novas pesquisas são necessárias para melhor compreender a zona de influência da onda direta no solo. As principais desvantagens do uso da onda direta no solo para estimar o teor de umidade são:

1. Dificuldade para identificar e separar a chegada da onda direta no solo das demais interferências (ondas refletidas e refratadas); 
2. Dificuldade para escolher uma separação adequada entre as antenas de modo que os tempos de chegada das ondas direta no solo e aérea possam ser diferenciados em função do deslocamento das antenas;

3. A onda direta no solo é atenuada mais rapidamente do que outras ondas, o que limita a faixa de separação das antenas para a qual a onda direta possa ser observada.

\subsubsection{Medição com furo de sondagem GPR}

Para aplicações em furos de sondagem GPR, a antena transmissora $\left(\mathrm{T}_{\mathrm{X}}\right)$ e receptora $\left(\mathrm{R}_{\mathrm{X}}\right)$ são abaixadas através de um par de tubos com acesso vertical. No modo ZOP (zero offset profile - perfil sem afastamento), as antenas são abaixadas de tal modo que seus pontos centrais estão sempre na mesma profundidade, conforme apresentado na Figura 3.25 (lado esquerdo). Os dados do tempo de chegada da onda direta no solo e a distância entre os furos de sondagem são usados para calcular a velocidade e a permissividade ou constante dielétrica do solo.

O método ZOP é uma técnica interessante para se medir o perfil de umidade do solo na zona vadosa com alta resolução espacial e grande volume de amostragem (GILSON et al. 1996, KNOLL \& CLEMENT 1999, PARKIN et al. 2000, BINLEY et al. 2001 e 2002, RUCKER \& FERRÉ 2003). Além disso, cada medida do furo de sondagem GPR somente necessita de alguns segundos e, portanto, o método ZOP é potencialmente capaz de medir processos transientes no interior da zona não saturada. 


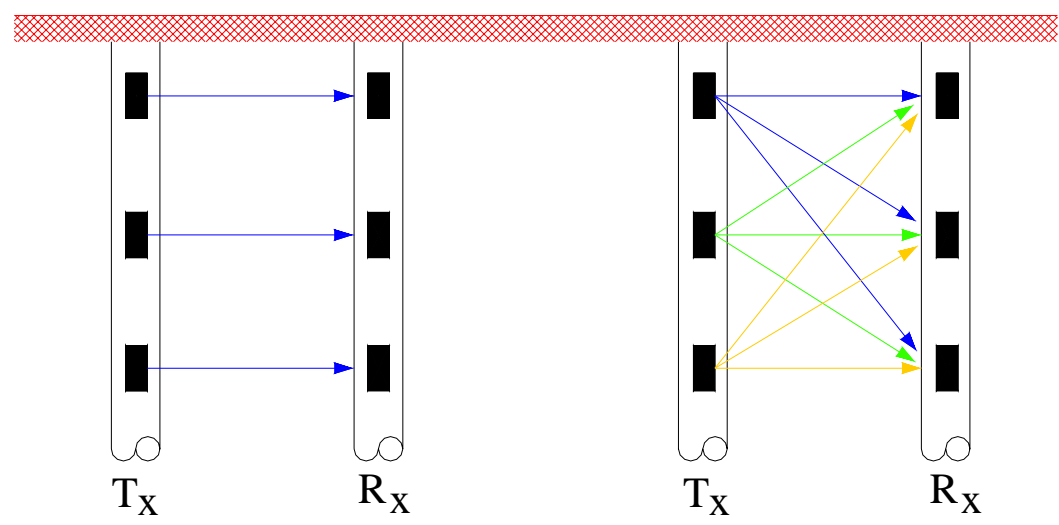

Figura 3.25 - Perfil ESQUemÁtico dos FuROS DE SONDAGEM ZOP E MOP E O PERCURSO DA ONDA DIRETA NO SOLO TRANSMITIDA ENTRE AS ANTENAS TRANSMISSORA $T_{X}$ E RECEPTORA $R_{X}$ (MODIFICADO DE HUISMAN ET AL. 2003).

O teor de umidade do solo também pode ser determinado pelo método MOP (multi-offset profile - perfil com afastamentos múltiplos), conforme perfil esquemático mostrado na Figura 3.25 (lado direito). O tempo de chegada de todas as primeiras medidas com afastamentos múltiplos podem ser utilizados para reconstruir uma imagem bidimensional (tomográfica) da distribuição do teor de umidade do solo entre os furos de sondagem (HUBBARD et al. 1997, PARKIN et al. 2000, BINLEY et al. 2001, ALUMBAUGH et al. 2002). Para se conseguir uma alta resolução de imagem tomográfica é importante que durante o processo de tomografia as informações sejam obtidas com a maior precisão possível. Maiores detalhes sobre o procedimento para inversão dos dados tomográficos podem ser obtidos em PETERSON (2001).

Vários estudos têm comparado medições do teor de umidade do solo obtidas a partir de dados do tempo de propagação de ondas entre furos de sondagem GPR, com medidas unidimensionais obtidas de dados coletados dentro dos furos de sondagem correspondentes (e.g. HUBBARD et al. 1997, BINLEY et al. 2001, ALUMBAUGH et al. 2002).

ALUMBAUGH et al. (2002) constataram que as medidas do teor de umidade volumétrica obtidas a partir de dados de velocidade de tomografia de radar apresentaram um erro quadrático médio de 0,02 a $0,03 \mathrm{~m}^{3} \cdot \mathrm{m}^{-3}$, quando comparado com valores obtidos diretamente dos furos de sondagem correspondentes, e que os erros foram maiores nas zonas úmidas. 
BINLEY et al. (2002), usando um modelo de combinação dielétrica, converteram a variação do tempo de um conjunto de dados ZOP para obter uma estimativa na mudança do teor de umidade volumétrico. A mudança no teor de umidade estimado variou entre 0,005 e 0,02 $\mathrm{m}^{3} \cdot \mathrm{m}^{-3}$, correspondendo favoravelmente com as medidas de chuvas mensais.

PETERSON (2001) sugere que deve ser tomado muito cuidado na determinação do tempo zero quando se pretende utilizar dados de furos de sondagem GPR para monitoramento da variação da umidade em função do tempo. O referido autor sugere ainda, coletar dados ZOP antes e após a aquisição dos dados MOP para se avaliar o desvio do tempo zero que ocorre durante a aquisição e posteriormente para sua consideração na etapa de processamento MOP.

A correta identificação da trajetória de chegada da primeira onda é crucial para as análises das medidas de furos de sondagem GPR (HAMMON et al. 2003, RUCKER \& FERRÉ 2003, FERRÉ et al. 2003). No lado esquerdo da Figura 3.26 são apresentadas possíveis trajetórias da onda para medidas ZOP num solo com uma camada de alta velocidade (condição seca) subjacente a um solo com uma velocidade mais baixa. No lado direito da Figura 3.26 é mostrado um esquema de medida ZOP.
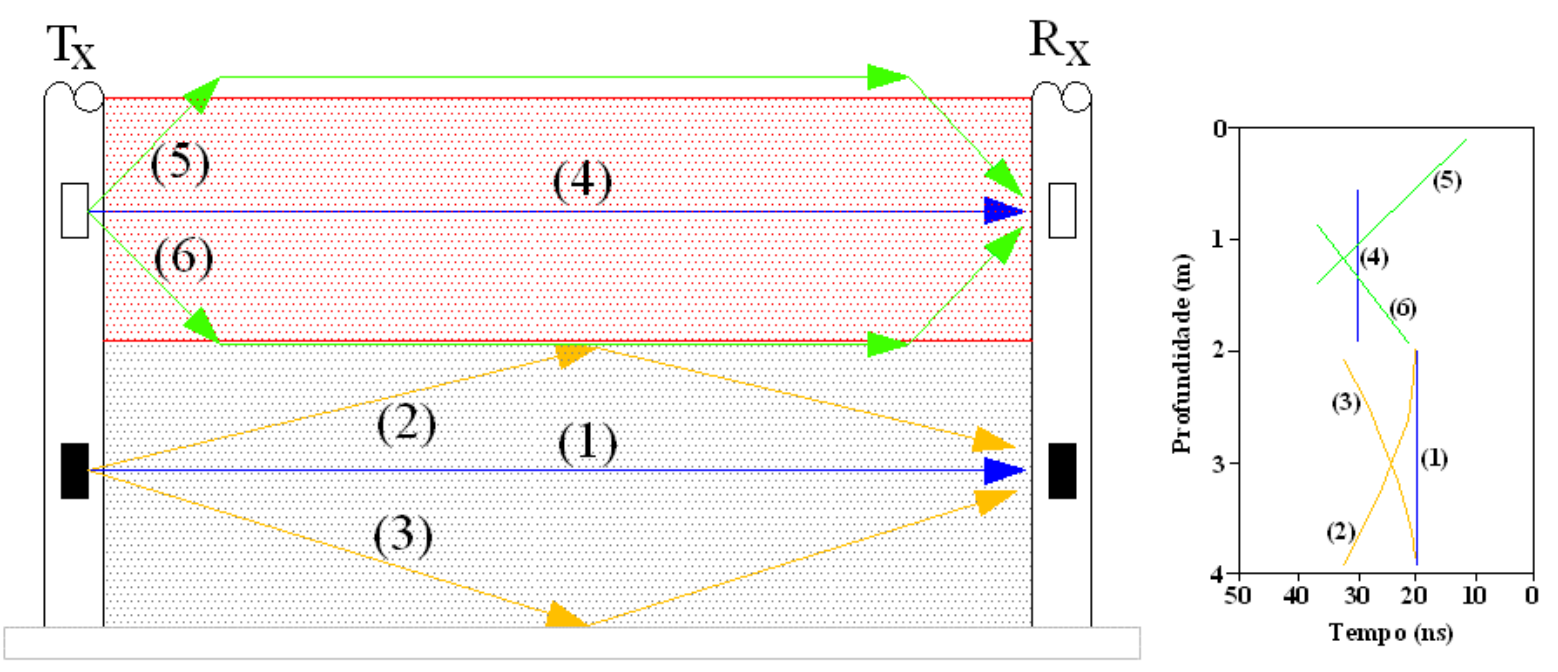

FIGURA 3.26 - ESQUEMA DAS TRAJETÓRIAS DAS ONDAS DO RADAR E MEDIDAS DE FUROS DE SONDAGEM GPR REALIZADAS NUM SOLO COM CAMADA DE ALTA VELOCIDADE (MODIFICADO DE HUISMAN ET AL. 2003). 
Para a zona de alta velocidade, a onda direta no solo (onda 1) chega primeiro, e o conhecimento prévio da separação dos furos de sondagem pode ser usada para calcular a velocidade. As reflexões das ondas no topo e na base da zona de alta velocidade (ondas 2 e 3 ) chegam depois. Quando as antenas estão na zona de baixa velocidade, as ondas refratadas (ondas 5 e 6) podem chegar primeiro em relação a onda direta (onda 4) até certo ponto, e a velocidade estimada estará errada caso seja assumida a trajetória da onda direta (onda 4). Esta situação é de particular importância para furos de sondagem GPR medidos muito próximos da superfície, onde a maioria das ondas refratadas no ar (onda 5) provavelmente deverão chegar primeiro.

Os métodos de furos de sondagem ZOP e MOP não têm sido usados somente na posição vertical. Alguns pesquisadores usaram furos de sondagem horizontais para monitorar o teor de umidade do solo no plano horizontal bidimensional em baixo de uma fossa (e.g. PARKIN et al. 2000, GALAGEDARA et al. 2002).

Apesar do significativo aumento das aplicações com furos de sondagem GPR, há vários pontos que requerem atenção quando se pretende utilizar esta técnica, destacando-se:

1. Para se obter informações quantitativas é importante identificar e corrigir erros provenientes dos procedimentos de aquisição de dados, conforme sugerido por PETERSON (2001);

2. É importante considerar a interferência das ondas refratadas na precisão das medidas do teor de umidade com furos de sondagem GPR, especialmente as ondas refratadas no interior do solo (onda 6);

3. A distância entre os furos de sondagem GPR, o comprimento e a freqüência das antenas tem uma influência apreciável na resolução espacial máxima que pode ser obtida;

4. A heterogeneidade do solo afeta consideravelmente o volume de amostragem nos furos de sondagem GPR. 
O princípio do método das ondas refletidas em superfície para medição do teor de umidade do solo é apresentado na Figura 3.27.

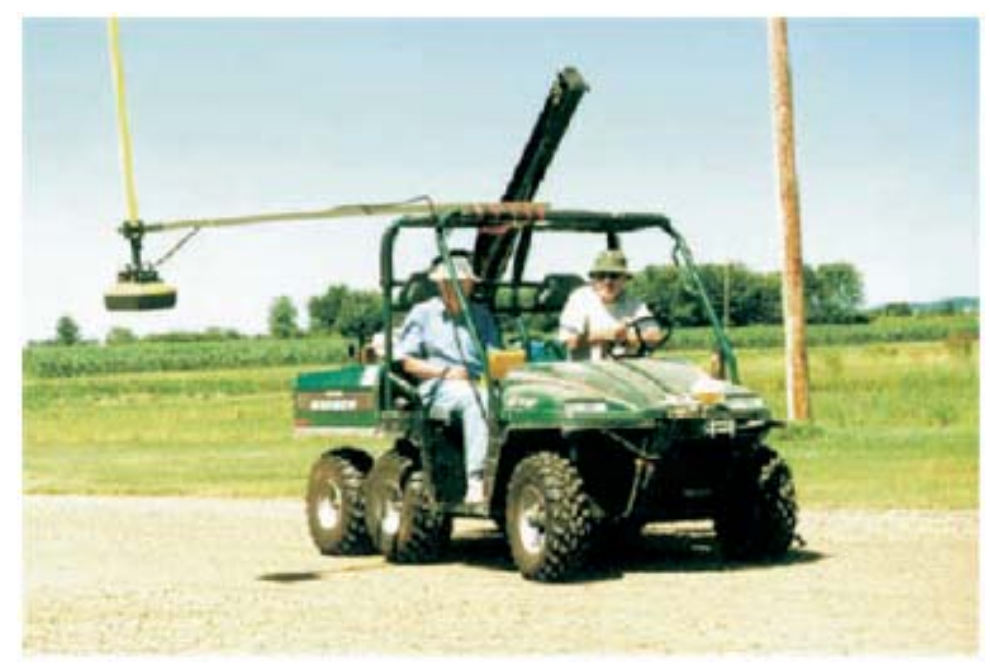

FIGURA 3.27 - SISTEMA GPR USADO PARA MEDIR A AMPLITUDE DE REFLEXÃO EM SUPERFÍCIE (HUISMAN ET AL. 2003).

Neste método, as antenas do GPR são fixadas sobre um veículo ou uma plataforma aérea de baixa altitude e operadas com uma certa distância acima do solo. A propriedade do solo a ser medida será o coeficiente de reflexão da interface solo-ar, $R$, que é relacionada com a permissividade dielétrica do solo, $\varepsilon_{\text {solo }}$, dada por:

$$
R=\frac{1-\sqrt{\varepsilon_{\text {solo }}}}{1+\sqrt{\varepsilon_{\text {solo }}}}
$$

O coeficiente de reflexão é determinado a partir da medida de amplitude, $A_{r}$, relacionada com a amplitude de um refletor perfeito, $A_{m}$, tal como uma chapa metálica maior que a cobertura do radar (DAVIS \& ANNAN 2002, REDMAN et al. 2002): 


$$
\varepsilon_{\text {solo }}=\left(\frac{1+\frac{A_{r}}{A_{m}}}{1-\frac{A_{r}}{A_{m}}}\right)^{2}
$$

$\mathrm{O} \varepsilon_{\text {solo }}$ obtido a partir do método da reflexão em superfície é uma média não linear da variação da permissividade dielétrica do solo com a profundidade.

A Figura 3.28 apresenta uma seqüência de dados adquiridos pelo método de reflexão de superfície usando antenas de $500 \mathrm{MHz}$. Geralmente, o teor de umidade do solo medido com GPR é similar ao teor de umidade medido com sensores TDR longos (0,20 metro). No entanto, neste caso, parece haver uma variação significativa do teor de umidade do solo para distâncias relativamente curtas (HUISMAN et al. 2003).

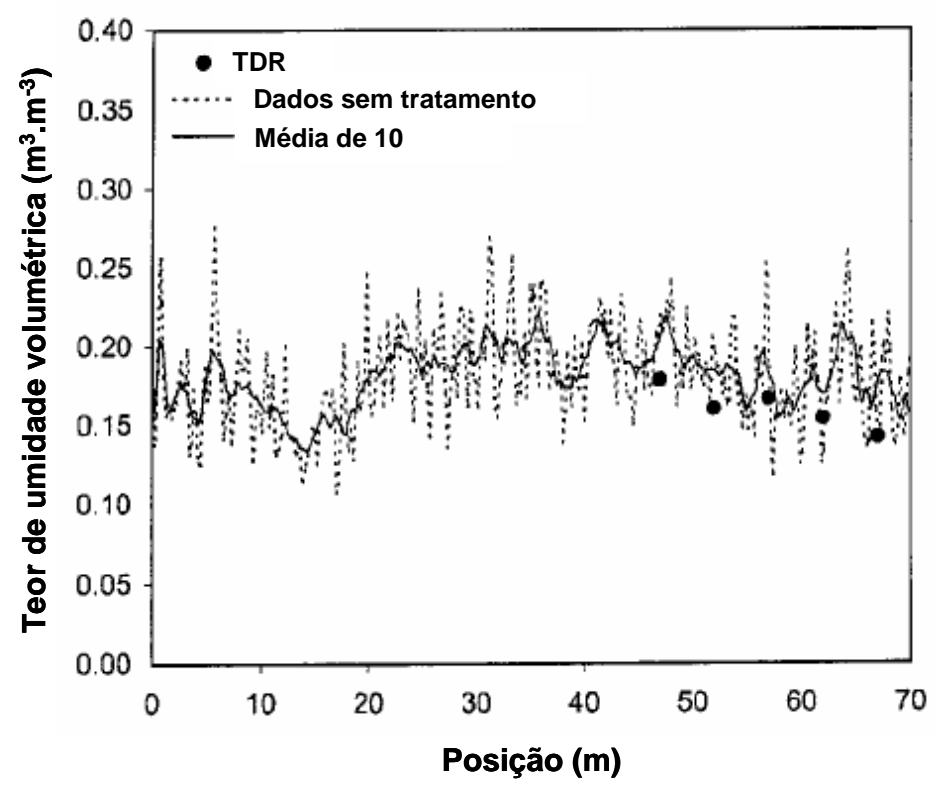

FIGURA 3.28 - DADOS DO TEOR DE UMIDADE DO SOLO MEDIDO COM O MÉTODO DE REFLEXÃO DE SUPERFÍCIE E COM SENSORES TDR (HUISMAN ET AL. 2003).

Segundo REDMAN et al. (2002), as três prováveis explicações para as variações observadas no teor de umidade do solo $\left( \pm 0,10 \mathrm{~m}^{3} \cdot \mathrm{m}^{-3}\right)$ são: i) o conflito do perfil de umidade do solo com a profundidade sobre o coeficiente de reflexão, ii) o conflito da rugosidade da superfície sobre o coeficiente de reflexão, iii) a confiabilidade e a precisão das medidas de amplitude. Tanto a 
rugosidade da superfície quanto a variação do perfil de umidade do solo com a profundidade são os responsáveis pela significativa dispersão, o qual leva à diminuição no coeficiente de reflexão e conseqüentemente numa subestimação do teor de umidade do solo.

A medida efetiva da profundidade e do conflito de variações do teor de umidade do solo com a profundidade são tópicos de pesquisas em atividades, mas ainda pouco divulgado até o momento. Certamente, o conflito da rugosidade de superfície e do perfil de umidade do solo sobre o coeficiente de reflexão na superfície do terreno são dois temas chaves que precisam ser enfocados quando se aplica esta técnica. 


\section{ASPECTOS GERAIS DAS ÁREAS ESTUDADAS}

\subsection{Localização}

O município de Ubatuba está situado no litoral norte do Estado de São Paulo, ocupando uma área total de $748 \mathrm{Km}^{2}$, sendo que 80\% desta área pertencem ao Parque Estadual da Serra do Mar, dos quais $617 \mathrm{Km}^{2}$ são formados por áreas rurais e $131 \mathrm{Km}^{2}$ correspondem à zona urbana (FERREIRA 2004). A localização das áreas de estudo no município de Ubatuba está indicada na Figura 4.1.

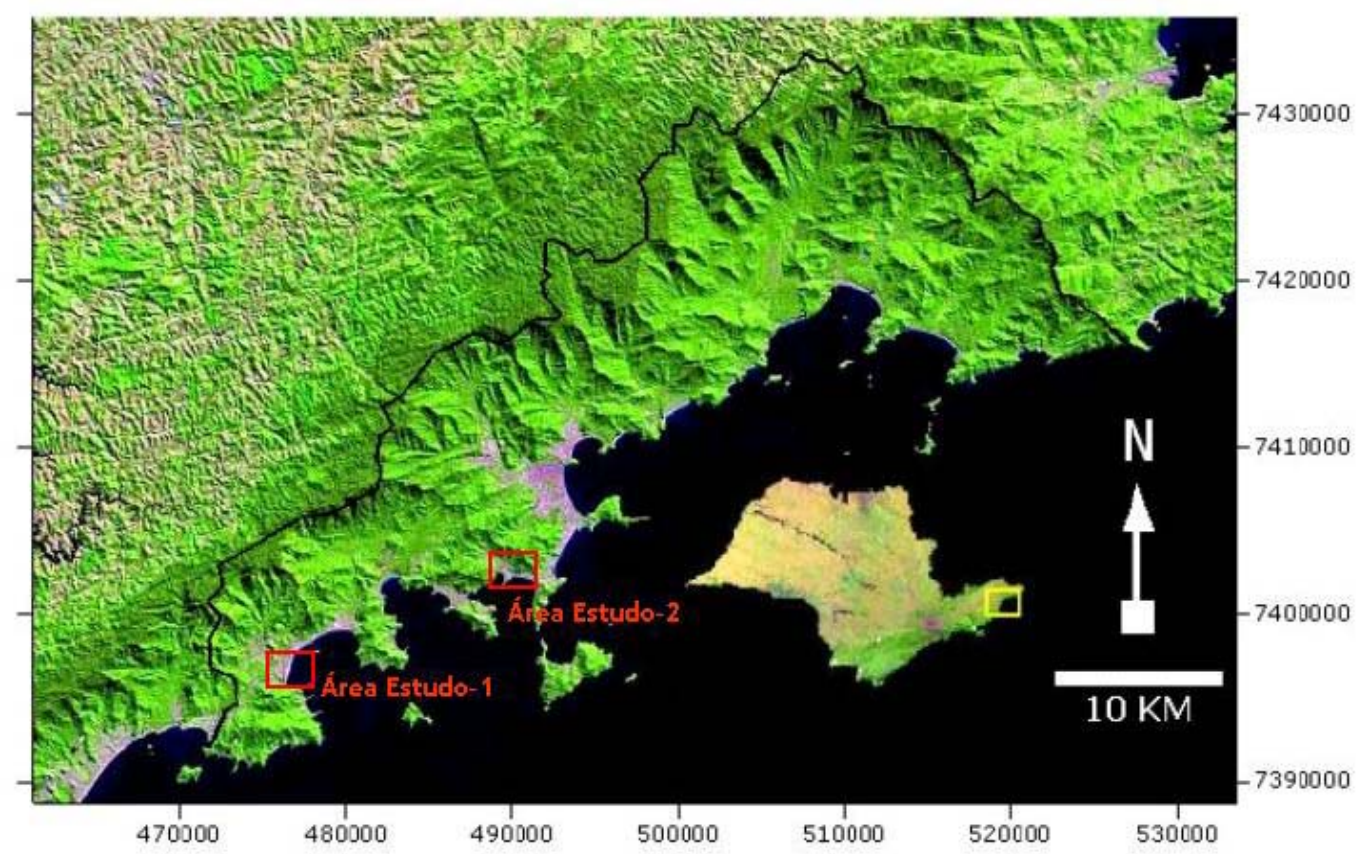

FIGURA 4.1 - LOCALIZAÇÃO DAS ÁREAS DE ESTUDO NO MUNICÍPIO DE UBATUBA.

Na Figura 4.2 são apresentadas as duas áreas estudadas, onde se percebe a considerável extensão da degradação ambiental ocasionada pela retirada de saibros e rochas ornamentais, a partir da escavação das porções superiores das encostas, destacados em vermelho. 
A área de estudo - 1 (praia de Maranduba), está situada na meia encosta de um morro isolado com declividades médias de 15 a 20\%, amplitudes locais de 100 metros e topo predominantemente arrendondado com vertentes de perfis convexos a retilíneos. Trata-se de uma antiga área de empréstimo de saibro em estágio avançado de degradação ambiental, caracterizada geologicamente pela presença de migmatitos homogêneos com estruturas embrechítica e nebulítica que conferem ao solo de alteração um aspecto geotécnico de característica granitognáissica.

A área de estudo - 2 (praia do Perequê-Mirim), está localizada no topo de uma encosta parcialmente degradada por mineração de saibro, situada nas extremidades de uma serra alongada, onde predominam declividades altas (>20\%) e amplitude locais da ordem de 200 metros. Geologicamente esta área é caracterizada pela ocorrência de granulitos parcialmente migmatizados denominados “charnockitos”.
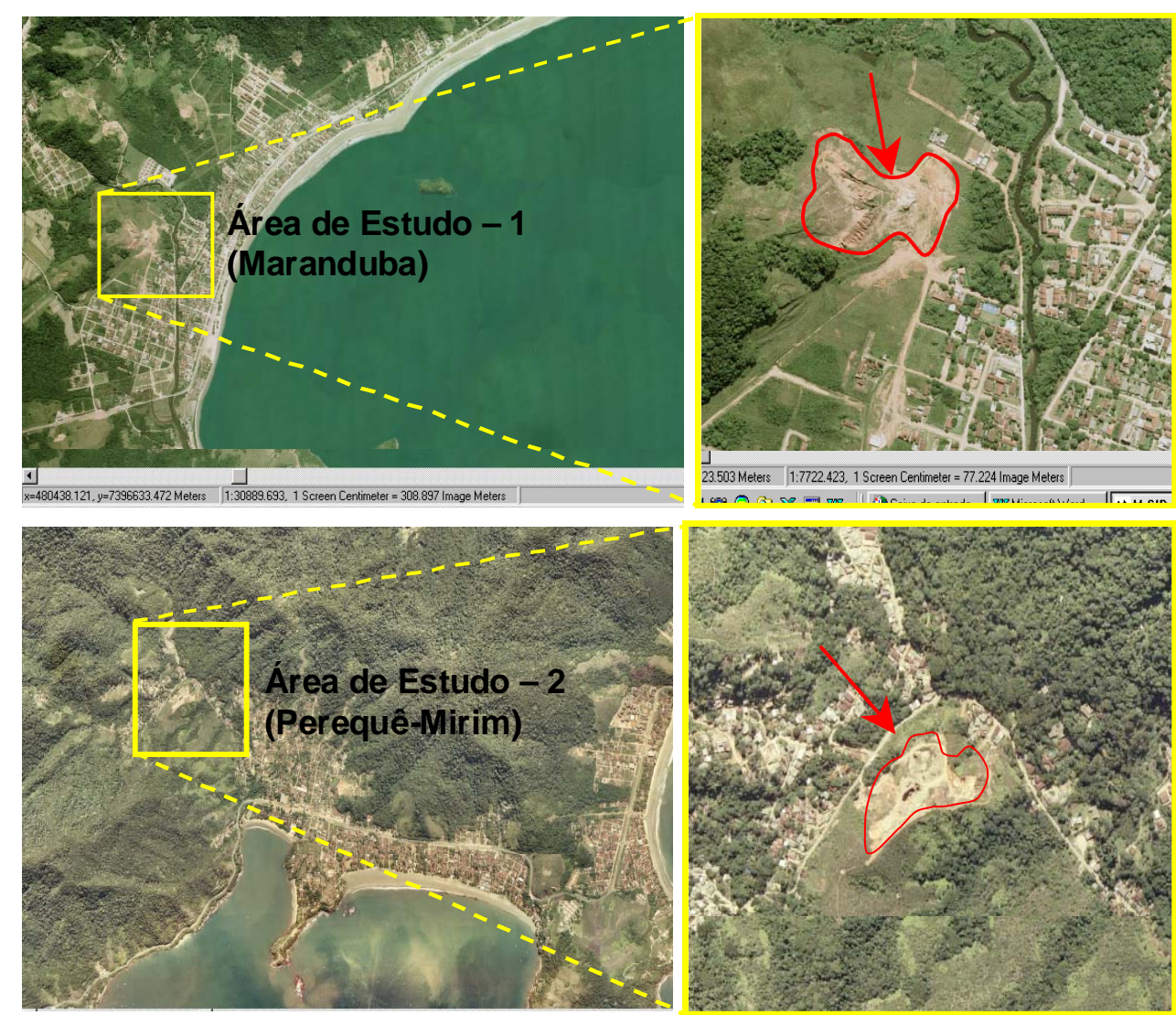

FIGURA 4.2 - LOCALIZAÇÃO DAS ÁREAS DE ESTUDO (FONTE: ACERVO IG-SMA). 


\subsection{Motivação para a Escolha das Áreas de Estudo}

As motivações que levaram à escolha das áreas estudadas foram: os atuais estágios de degradação ambiental e os riscos associados aos processos de instabilização geotécnica nas áreas mineradas, a representatividade local dos perfis de alteração em relação aos aspectos geológicogeotécnicos regionais e a facilidade de acesso para a realização de trabalhos de campo e instalação dos equipamentos de monitoramento.

Entre essas motivações, destaca-se a preocupante ocupação das áreas mineradas por moradias de baixa renda, as quais estão sujeitas a diferentes situações de risco a escorregamentos de encostas e/ou taludes. Esta situação vem-se tornando um problema cada vez mais caótico para o gestor público municipal, pois em muitos bairros de Ubatuba (SP) as moradias já se encontram próximas ou junto às encostas, geralmente ocupando áreas de mineração inativas que apresentam condições geotécnicas preocupantes, inclusive com riscos de queda de blocos rochosos.

A situação das áreas mineradas no município de Ubatuba foi analisada por FERREIRA (2004) e revela que das 118 áreas mineradas visitadas, 44\% apresentam algum grau de instabilidade geotécnica associada a processos geodinâmicos, das quais 9\% foram classificadas como áreas de risco. Mais recentemente o Instituto Geológico - SMA, a partir do Termo de Cooperação Técnica com a Coordenadoria Estadual de Defesa Civil (CEDEC) da Casa Militar do Governo do Estado de São Paulo, efetuou o mapeamento das áreas de risco no município de Ubatuba-SP (MARCHIORI-FARIA et al. 2005).

O mapeamento das áreas de risco realizado pelo Instituto Geológico utiliza metodologias e técnicas já consagradas em situações similares, descritas em FUNDUNESP (2003), CERRI et al. (2004), CANIL et al. (2004), MACEDO et al. (2004a, 2004b), MARCHIORI FARIA et al. (2005). Nesses estudos, os fatores que compõem a avaliação e análise de risco são simplificados, agrupados e avaliados de forma qualitativa a partir de observações realizadas no campo.

O mapeamento das áreas de risco no município de Ubatuba foi realizado a partir de 54 áreas-alvo definidas e indicadas previamente pela Defesa Civil Municipal (COMDEC), resultando na identificação de 122 setores associados com risco a escorregamentos em encostas e taludes. Desse total de setores mapeados, 19 apresentaram grau de risco baixo, 52 grau de risco médio, 36 
grau de risco alto e 15 grau de risco muito alto. Ao todo 2.252 moradias estão situadas em áreas sujeitas a escorregamentos, das quais 266 em áreas com grau de risco baixo, 874 em áreas com grau de risco médio, 912 em áreas com grau de risco alto e 199 em áreas com grau de risco muito alto. A Figura 4.3 apresenta a distribuição das áreas de risco a escorregamentos mapeadas no município de Ubatuba-SP.

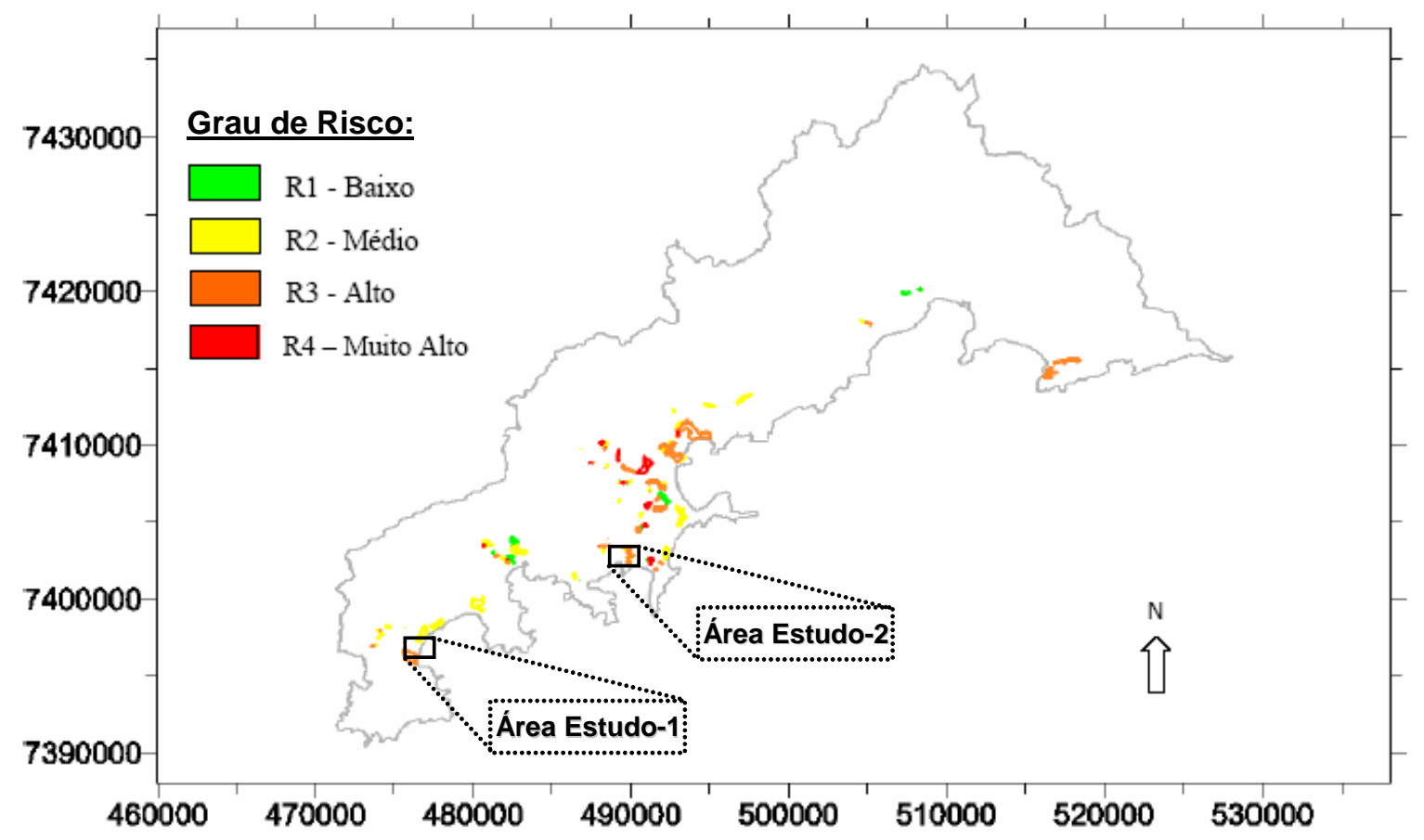

FIgURA 4.3 - DistribUIÇÃO DAS ÁREAS DE RISCO A ESCORREGAMENTO NO MUNICÍPIO DE UBATUBA-SP (FONTE: MODIFICADO DE MARCHIORI FARIA ET AL. 2005).

No bairro de Maranduba, onde está localizada a Área de Estudo-1, foram identificadas duas áreas em situação de risco a escorregamento, distribuídas em 7 setores da seguinte forma: 5 setores com risco médio (108 moradias) e 2 setores com risco alto (33 moradias), totalizando 141 moradias em risco. A Figura 4.4 apresenta uma área no bairro de Maranduba com diferentes graus de risco a escorregamento. 


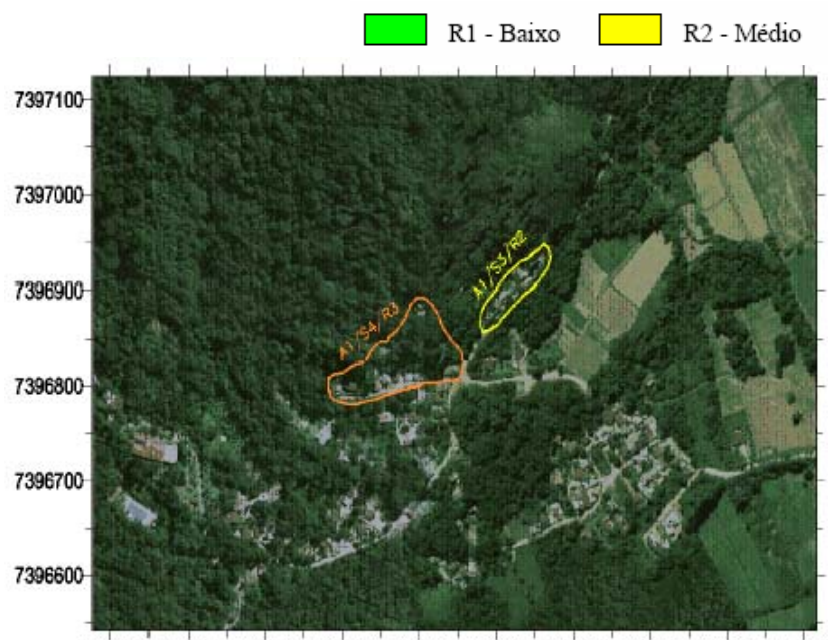

$\begin{array}{llllllllll}473200 & 473300 & 473400 & 473500 & 473600 & 473700 & 473800 & 473900 & 474000 & 474100\end{array}$
R3 - Alto $\square$ R4 - Muito Alto

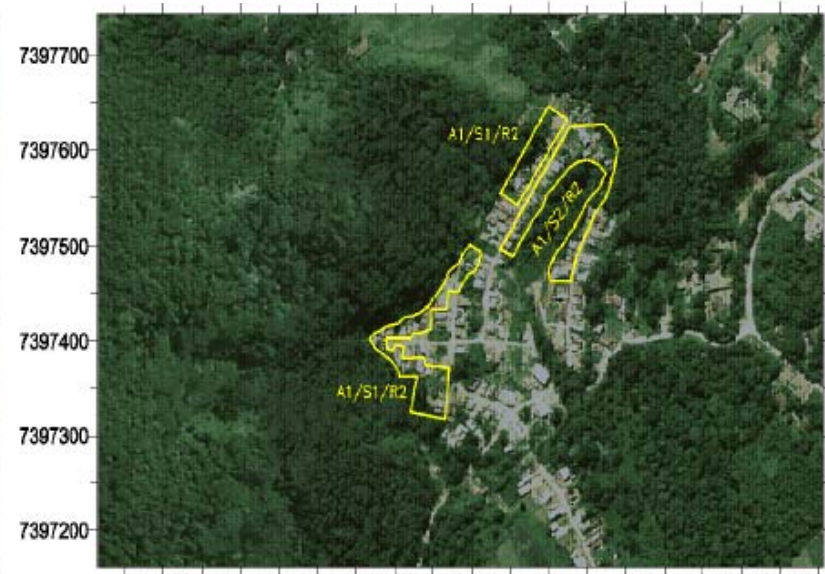

$\begin{array}{llllllllll}473600 & 473700 & 473800 & 473900 & 474000 & 474100 & 474200 & 474300 & 474400\end{array}$

Figura 4.4 - ÁREAs DE RISCO A ESCORREgAmENTO SITUAdAS NO BAIRRO DE MARANDUBA (FONTE: MODIFICADO DE MARCHIORI FARIA ET AL. 2005).

No bairro do Perequê-Mirim foram identificadas seis áreas em situação de risco a escorregamento, distribuídas em 11 setores da seguinte forma: 1 setor com risco baixo (3 moradias), 4 setores com risco médio (78 moradias) e 6 setores com risco alto (165 moradias), totalizando 246 moradias em risco. A Figura 4.5 mostra algumas áreas com grau de risco "Médio a Muito Alto” muito próximas da Área de Estudo-2.
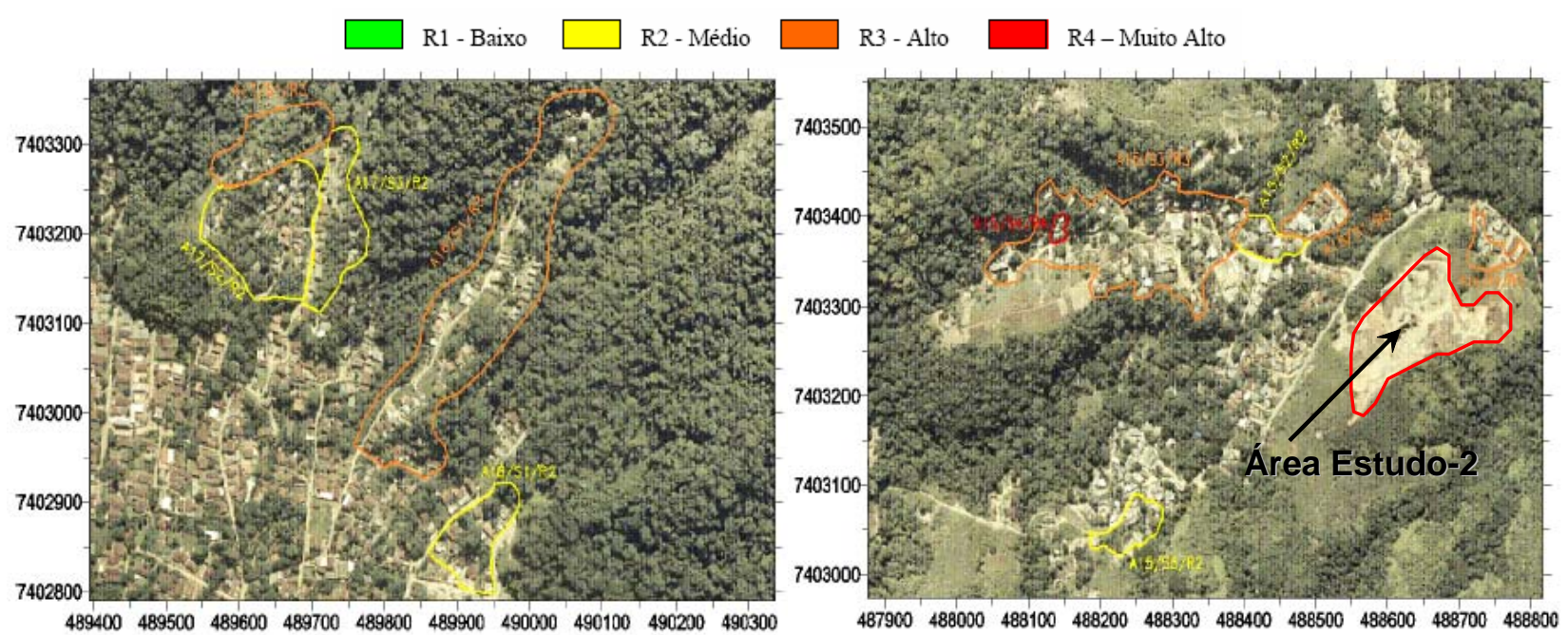

FiguRA 4.5 - ÁREAS DE RISCO A ESCORREGAMENTO SITUADAS NO BAIRRO DO PEREQUÊ-MIRIM (FONTE: MODIFICADO DE MARCHIORI FARIA ET AL. 2005). 


\subsection{Aspectos Geológicos}

A área de estudo de Maranduba é representada geologicamente por unidades compostas por migmatitos homogêneos com estruturas embrechítica e nebulítica, classificadas petrograficamente como gnaisses e granitos de anatexia. Tais estruturas são constituídas predominantemente por microclínio, oligoclásio, quartzo e biotita, tendo como acessórios a muscovita, hornblenda, granada, zircão, apatita, clorita e opacos (IG-IPT 1992).

Na área de estudo do Perequê-Mirim ocorrem unidades geológicas formadas por granulitos parcialmente migmatizados denominados de “charnockitos". Os tipos de charnockitos encontrados na área de estudo são constituídos de microclínio, quartzo, oligoclásio, hiperstênio, hornblenda e traços de biotita, muscovita, zircão e apatita. Na sua textura observa-se albitização nas bordas dos feldspatos e substituição do hiperstênio pela hornblenda e desta pela biotita. Os tipos de charnockitos derivados por granitização apresentam maior quantidade de biotita à medida que diminuem o hiperstênio e a hornblenda, resultando, como tipo extremo, rochas da mesma composição dos granitóides (IG-IPT 1992).

Segundo observações de BITAR et al. (1985), o que se denomina no campo de charnockitos são, na verdade, núcleos que resistiram a uma série de eventos metamórfico-magmáticos ao longo do tempo geológico. A ação diferenciada do intemperismo sobre os maciços rochosos expostos tende a isolar tais núcleos em blocos de matacões de dimensões variadas. Trata-se, portanto, de um processo de alteração in situ peculiar a esta unidade, que preserva os materiais mais homogêneos e mais resistentes.

\subsection{Clima, Vegetação e Solos}

Em termos gerais, a região apresenta um clima tropical úmido, com temperaturas altas ao longo de todo o ano, pequena amplitude térmica e índices pluviométricos com médias anuais superiores a $2.000 \mathrm{~mm}$. Os maiores índices pluviométricos são registrados durante os meses de verão, geralmente com maior concentração no mês de janeiro. É de notório conhecimento a existência do estreito vínculo entre as chuvas intensas e os escorregamentos no município, já sendo possível a quantificação desta correlação (IG-IPT 1992). 
O município de Ubatuba apresenta aproximadamente 80\% de todo o seu território coberto por vegetação nativa nas áreas pertencentes ao Parque Estadual da Serra do Mar. De forma geral, as áreas mais preservadas são encontradas nas encostas mais acentuadas da Serra do Mar (IG-IPT 1992). A área de estudo de Maranduba encontra-se atualmente em estágio avançado de degradação ambiental, caracterizada pela supreção total da vegetação nativa nas porções superiores e médias das encostas. Na área de estudo do Perequê-Mirim, as vegetações nativas ocupam apenas as porções do topo da encosta investigada. Deve-se considerar que a constante remoção da vegetação local pode induzir ou acelerar, em algumas circunstâncias, os processos de instabilização de encostas naturais e taludes.

Os morros isolados apresentam declividades entre 30 a $60 \%$, sendo caracterizados por perfis predominantemente côncavos e convexos, constituídos por camada de solo de alteração de diferentes espessuras, a depender do perfil de alteração associado basicamente às condições geológicas e morfológicas locais.

As encostas suaves representadas por morros isolados com declividade inferior a 30\% são formadas por diferentes tipos de solo de alteração de rocha. Geralmente tendem a apresentar um perfil de alteração de solo mais evoluído em relação às demais compartimentações.

\subsection{Aspectos Pluviométricos}

O comportamento pluviométrico tem papel fundamental na compreensão da dinâmica da paisagem, sendo que suas diferenças de distribuição ao longo do tempo e espaço são relevantes em estudos de natureza geotécnica, visto que ele apresenta maior probabilidade de desencadear processos de instabilização em encostas naturais e taludes.

No entanto, verifica-se que a coleta de dados de chuva não é uma tarefa fácil, pois sua realização depende da instalação de instrumentos de monitoramento ou da existência de postos pluviométricos na região onde se pretende estudar. Atualmente existem somente dois postos pluviométricos em atividade no município de Ubatuba: posto do Instituto Agronônico de Campinas (IAC) e do Instituto Oceanográfico (IO-USP). Os postos do DAEE (Ubatuba e Mata 
Dentro) estão atualmente desativados, mas existem dados pluviométricos destes postos que foram coletados no período de 1958 a 2000 (IG-IPT 1992 e DAEE 2004).

A Figura 4.6 indica a localização destes quatro postos pluviométricos no município de Ubatuba. Ressalta-se que os dados desses postos pluviométricos não permitem traçar isoietas para fins de previsão da distribuição espacial das chuvas com aceitável grau de precisão, pois a região apresenta significativo grau de variação pluviométrica entre áreas próximas devido às diferenças dos atributos geográficos.

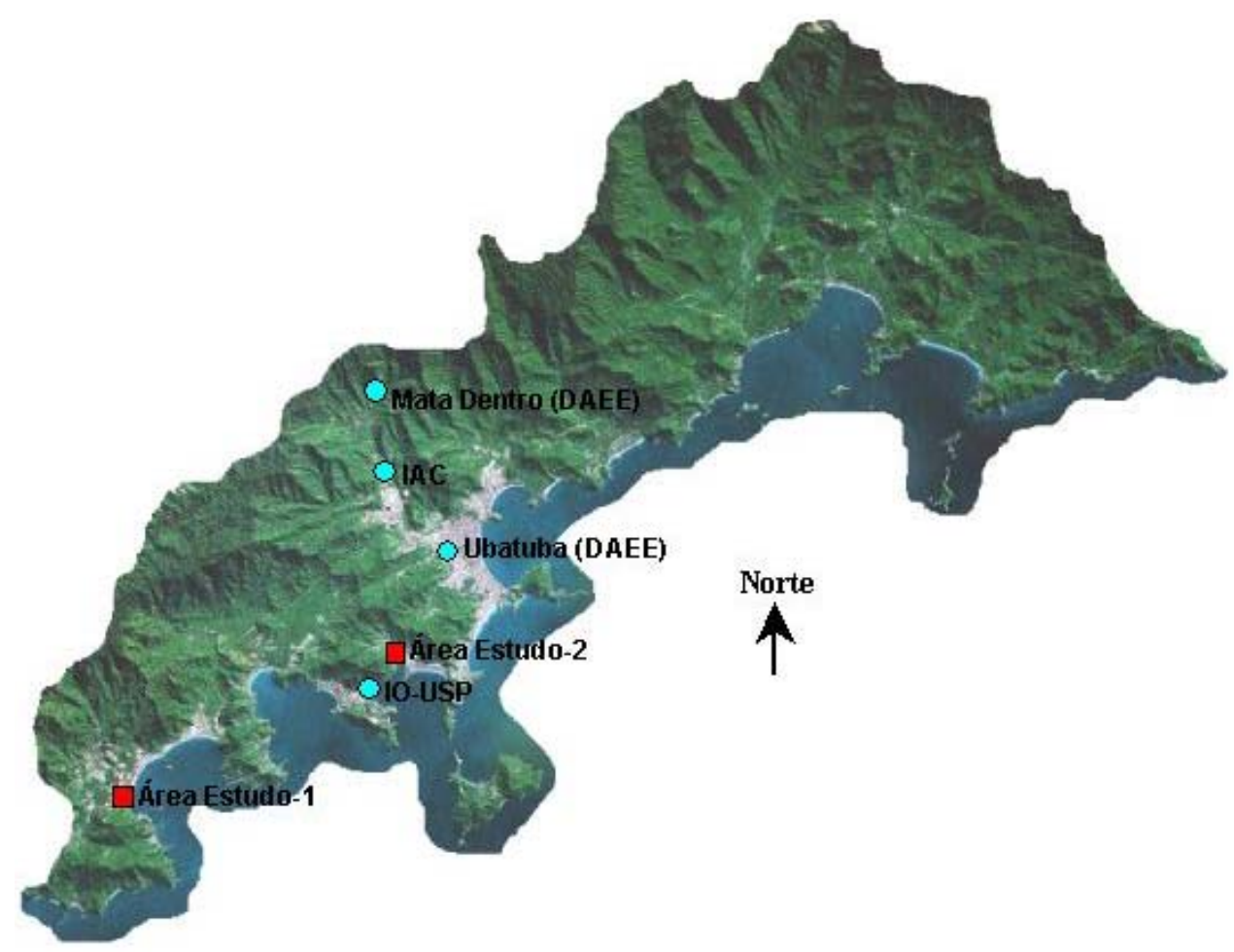

FIGURA 4.6 - LOCALIZAÇÃO DOS POSTOS PLUVIOMÉTRICOS NO MUNICÍPIO DE UBATUBA-SP.

Os postos pluviométricos que se encontram em operação estão instalados na Estação Experimental do Instituto Agronômico de Campinas (IAC), localizado às margens da Rodovia

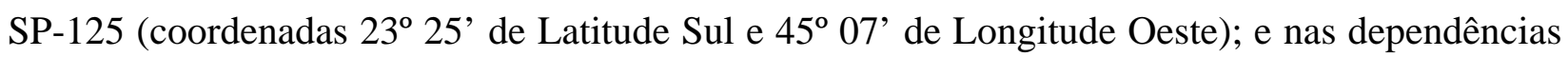
do Instituto Oceanográfico da Universidade de São Paulo (IO-USP), localizada às margens da Rodovia Manoel Hyppolito Rego (coordenadas $23^{\circ} 30^{\prime}$ de Latitude Sul e $45^{\circ} 07^{\prime}$ de Longitude Oeste). Tratam-se de estações de primeira classe, constituídas de pluviômetro, pluviógrafo e outros instrumentos. 

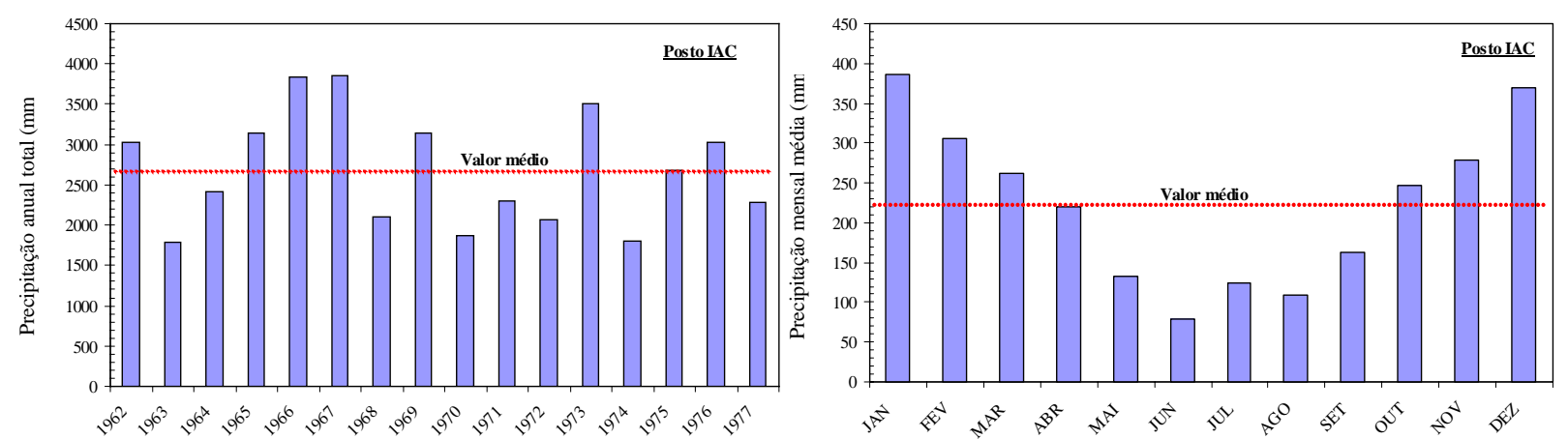

FIGURA 4.7 - DADOS DE PRECIPITAÇÃO MENSAL E ANUAL DO POSTO IAC.
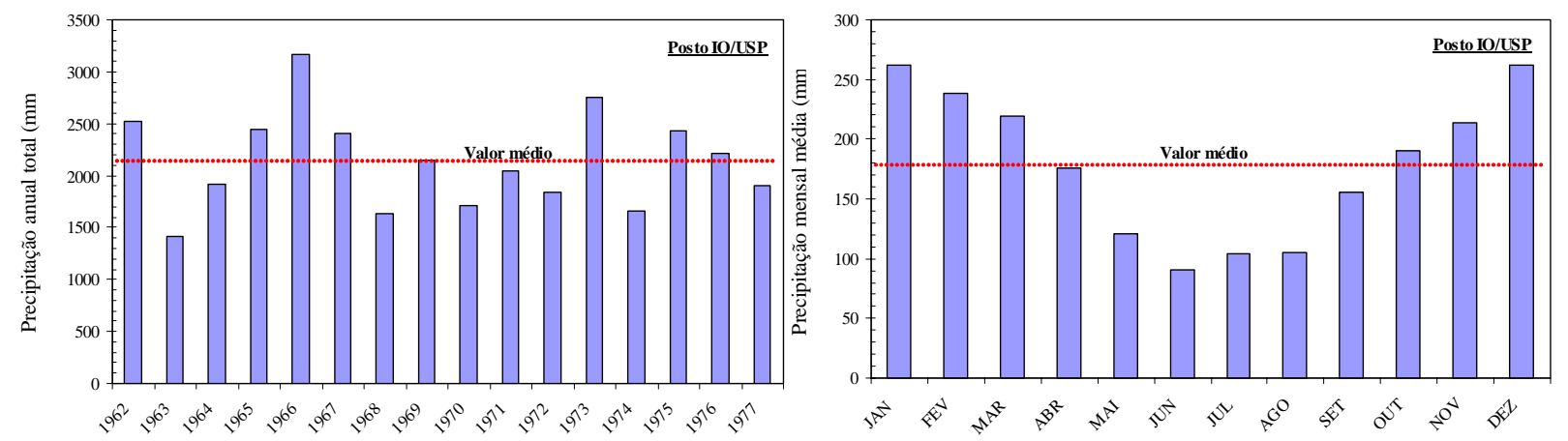

FIGURA 4.8 - DADOS DE PRECIPITAÇÃO MENSAL E ANUAL DO POSTO IO/USP.
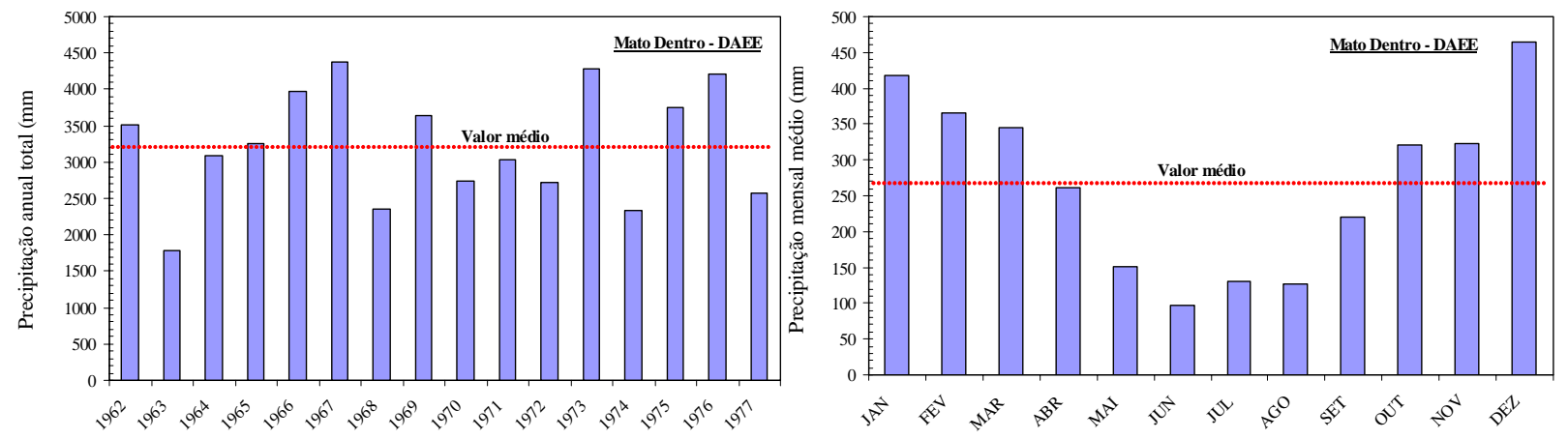

Figura 4.9 - DADOS DE PRECIPITAÇÃo MENSAL E ANUAL DO POSTO MATA DENTRO (DAEE).
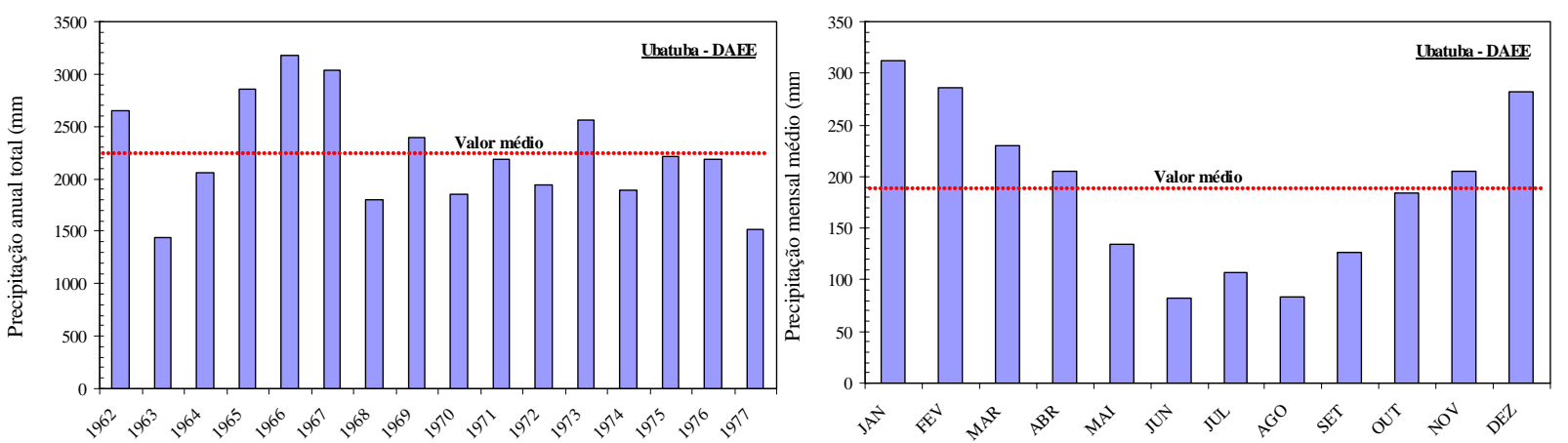

FiguRA 4.10 - DAdOS DE PRECIPITAÇÃO MENSAL E ANUAL DO POSTO UBATUBA (DAEE). 
Os quatro postos pluviométricos tiveram início de medição em diferentes épocas, determinando séries de períodos diferenciados, além de apresentarem interrupções, da ordem de um mês até vários anos. Nas Figuras 4.7 a 4.10 são apresentadas as séries de dados pluviométricos destes quatro postos que foram registrados entre o período de 1962 a 1977 (IG-IPT 1992).

Ao analisar os dados pluviométricos dos quatro postos, observa-se que existem algumas diferenças em relação à distribuição espacial das precipitações na região estudada. Por exemplo, o posto de Mato Dentro (DAEE) registrou, no período considerado, dados de precipitação anual maiores, com valor médio de $3.226 \mathrm{~mm}$. Ao contrário, os postos pluviométricos do Instituto Oceanográfico (IO/USP) e de Ubatuba (DAEE) registraram dados anuais de precipitação menores, com valores médios de 2.138 e 2.236 mm, respectivamente.

Os meses mais chuvosos registrados coincidentemente por todos os postos pluviométricos, para o período considerado, são: dezembro, janeiro, fevereiro e março, sendo janeiro o mês mais chuvoso. Ao analisar todos esses dados, fica evidente a existência de uma distribuição espacial consideravelmente heterogênea na região estudada, ocasionada principalmente por condicionantes do meio físico local.

Logo, verifica-se a necessidade de um monitoramento puntual das condições pluviométricas nas áreas de estudo, no sentido de garantir uma interpretação mais confiável durante a etapa de análise dos dados de chuva associados aos parâmetros geotécnicos estudados, principalmente nas análises de estabilidade de encostas naturais e taludes que levam em consideração o histórico de chuva. 


\section{CARACTERIZAÇÃO DOS SOLOS E ENSAIOS DE LABORATÓRIO}

\subsection{Coleta das Amostras e Acondicionamento}

As amostras deformadas e indeformadas de solo utilizadas na presente pesquisa foram coletadas ao longo de taludes verticais existentes em duas encostas naturais parcialmente degradadas por mineração de saibro. Na área de estudo de Maranduba, devido à grande extensão do talude e da apreciável variabilidade lateral do perfil de alteração, escolheu-se dois perfis verticais para a realização da coleta de amostras de solo conforme indicado na Figura 5.1.

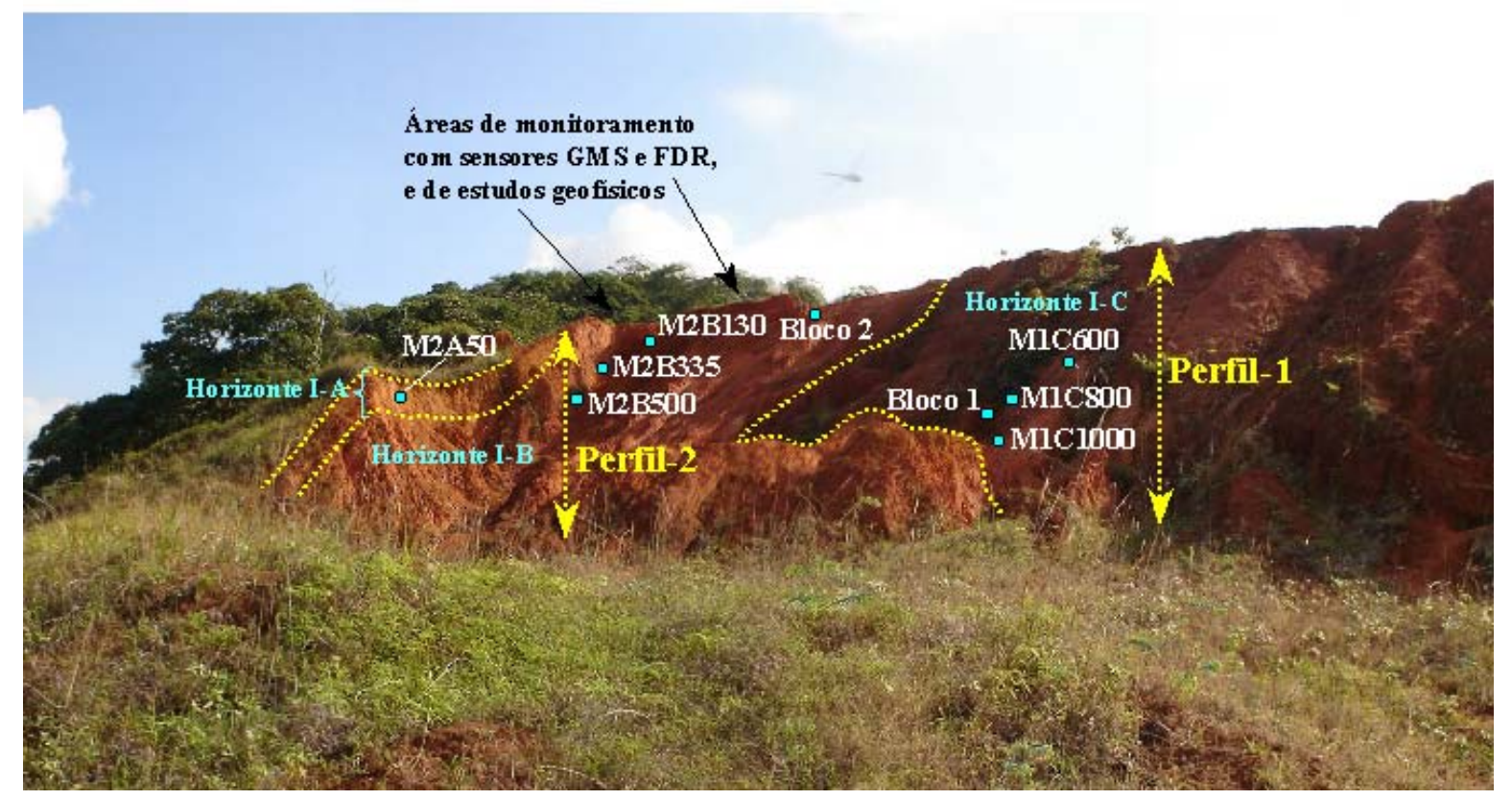

FIGURA 5.1 - VISÃO GERAL DOS PERFIS VERTICAIS ESCOLHIDOS PARA A COLETA DAS AMOSTRAS NA ÁREA DE MARANDUBA.

Em termos gerais, no primeiro perfil escolhido (Perfil-1), cuja altura é de aproximadamente 14,0 metros, ocorre apenas um único horizonte de solo residual constituído por saprolito de textura areno-siltosa de cor variegada com presença de estrutura reliquiar, representado pelas amostras M1C600, M1C800 e Bloco 1. Na base desse perfil ocorre uma pequena fratura que está 
preenchida com solo de textura silto-argilosa de cor predominantemente amarelada com pontos pretos, representado pela amostra M1C1000.

No segundo perfil (Perfil-2) ocorrem dois horizontes de solo residual ao longo dos seus 10,0 metros de altura. O primeiro horizonte de solo, compreendido entre o topo do perfil até aproximadamente 0,8 metro de profundidade, é composto por solo de textura argilo-arenosa de coloração amarela com presença de material orgânico e raízes, representado pelas amostras M2A50 e M2A30 (coletada no topo da encosta natural). O segundo horizonte de solo apresenta uma textura areno-siltosa com muitos minerais micáceos de coloração predominantemente marrom, sendo representado pela amostras Bloco2, M2B130, M2B335 e M2B500.

Na área de estudo do Perequê-Mirim, apesar da pequena extensão do talude e da aparente homogeneidade do perfil de intemperismo, foram necessários dois locais para a realização da coleta de amostras de solo, conforme apresentado na Figura 5.2, pois em algumas circunstâncias a condição natural do talude de corte dificultou a retirada dos blocos indeformados.

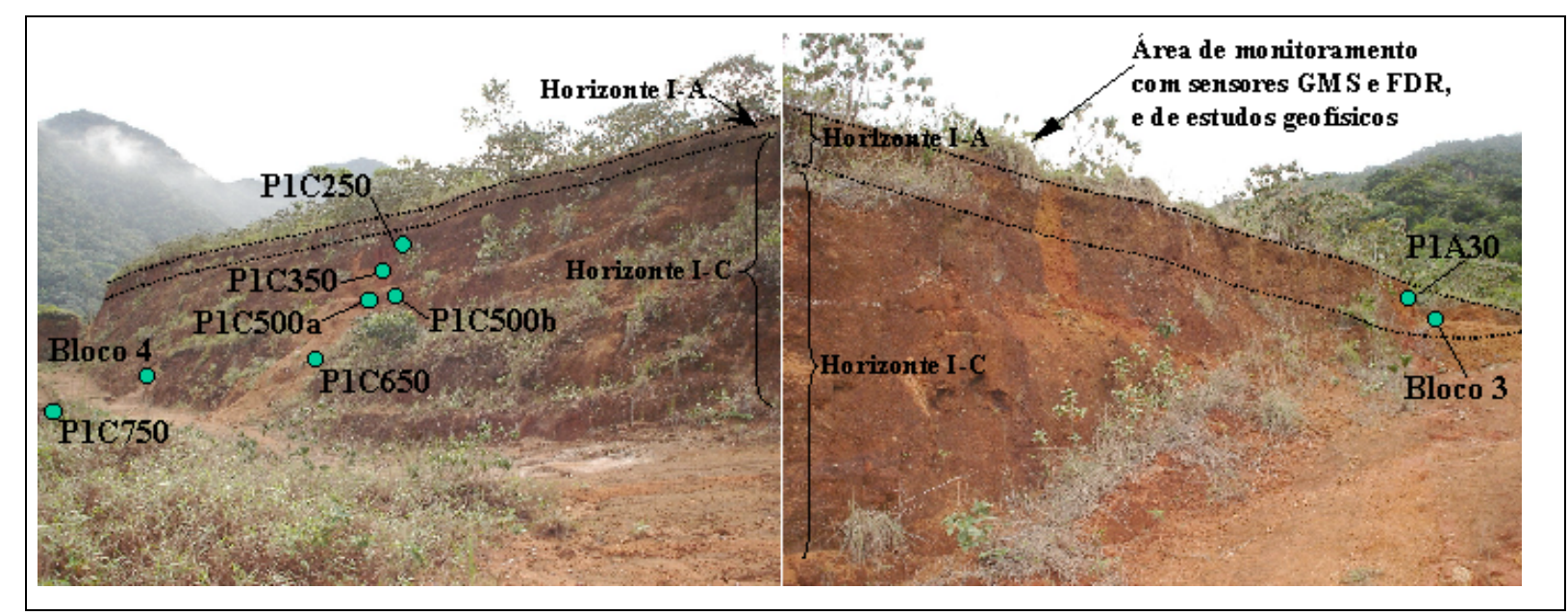

FIGURA 5.2 - VISÃO GERAL DO PERFIL VERTICAL ESCOLHIDO PARA A COLETA DAS AMOSTRAS NA ÁREA DO PEREQUÊ-MIRIM.

No entanto, considerou-se, para fins práticos, que a coleta das amostras de solo foi realizada em apenas um perfil vertical devido principalmente à pequena extensão do talude. $\mathrm{O}$ talude vertical na área de estudo do Perequê-Mirim possui uma altura média de 8,0 metros e o seu perfil de alteração pode ser dividido basicamente em dois horizontes de solo residual. O primeiro horizonte de solo possui uma espessura de aproximadamente 1,0 metro a partir do topo da 
encosta natural, sendo constituído por solo de textura areno-argilosa de coloração amarela e presença de material orgânico e raízes, representado pelas amostras P1A30 e Bloco 3.

O segundo horizonte de solo possui uma espessura de 7,0 a 8,0 metros, sendo formado por saprolito de textura areno-argilo-siltosa e areno-siltosa com pedregulhos e coloração variegada, presença de estrutura reliquiar e apreciável variação de textura, tanto vertical quanto lateralmente, representado pelas amostras P1C250, P1C350, P1C500a, P1C500b, P1C650, Bloco 4 e P1C750.

Ao todo foram coletadas 18 amostras deformadas de solo para a realização de ensaios de caracterização, retirados 4 blocos indeformados de dimensões $30 \times 30 \times 30 \mathrm{~cm}$ para a realização dos ensaios de permeabilidade e resistência ao cisalhamento, e talhados 16 corpos de prova em anéis cilíndricos biselados de PVC com 5,0 cm de altura e 4,0 cm de diâmetro interno para determinação das curvas de retenção de água.

Após a coleta, as amostras deformadas foram acondicionadas em sacos plásticos devidamente identificados e armazenadas em caixas plásticas no Laboratório de Mecânica dos Solos da Escola Politécnica-USP, para aguardar a realização dos seguintes ensaios de caracterização: análise granulométrica, determinação da massa específica dos grãos $\left(\rho_{\mathrm{S}}\right)$, massa específica natural $(\rho)$, massa específica aparente seca $\left(\rho_{\mathrm{d}}\right)$ e limites de Atterberg (limites de liquidez e plasticidade).

As amostras indeformadas (4 blocos) foram muito bem acondicionadas buscando-se evitar ganho ou perda de umidade, para depois serem utilizadas nos ensaios de resistência (cisalhamento direto inundado e triaxial CW não saturado com medida de sucção), condutividade hidráulica, curvas de retenção de água, porosimetria por intrusão de mercúrio e ensaios mineralógicos (microscopia óptica e difração de raios-X). Os corpos de prova talhados em anéis cilíndricos foram devidamente identificados e lacrados com filme plástico e papel alumínio, sendo depois acondicionados em caixa de isopor para serem utilizados na obtenção das curvas de retenção de água e nos ensaios de porosimetria por intrusão de Hg.

Os blocos indeformados foram coletados a partir da face exposta dos taludes verticais em diferentes horizontes de intemperismo. Na área de estudo de Maranduba os Blocos 1 e 2 foram coletados nos horizontes de solo residual I-C e I-B, nas profundidades 9,0 e 1,10 metros, respectivamente, conforme mostrado na Figura 5.3. 
O Bloco 1 apresenta algumas feições características de saprolito, ou seja, encontra-se estruturas reliquiares da rocha de origem (por exemplo, veios brancos orientados que se destacam na Figura 5.3a), a textura é areno-siltosa com grandes grãos de quartzo dispersos, apresenta uma considerável variação de cores (róseo, amarelo, branco e pontos pretos). O Bloco 2 é caracterizado por sua aparente homogeneidade textural e de coloração, com aspecto tátil-visual de solo de alteração. Este solo merece ser destacado por apresentar uma apreciável quantidade de mica em sua composição, sendo constituído por uma textura areno-siltosa de coloração marromavermelhada, com algumas feições localizadas que lembram as estruturas reliquiares encontradas no Bloco 1.

a) Bloco-1 - coletado no horizonte I-C

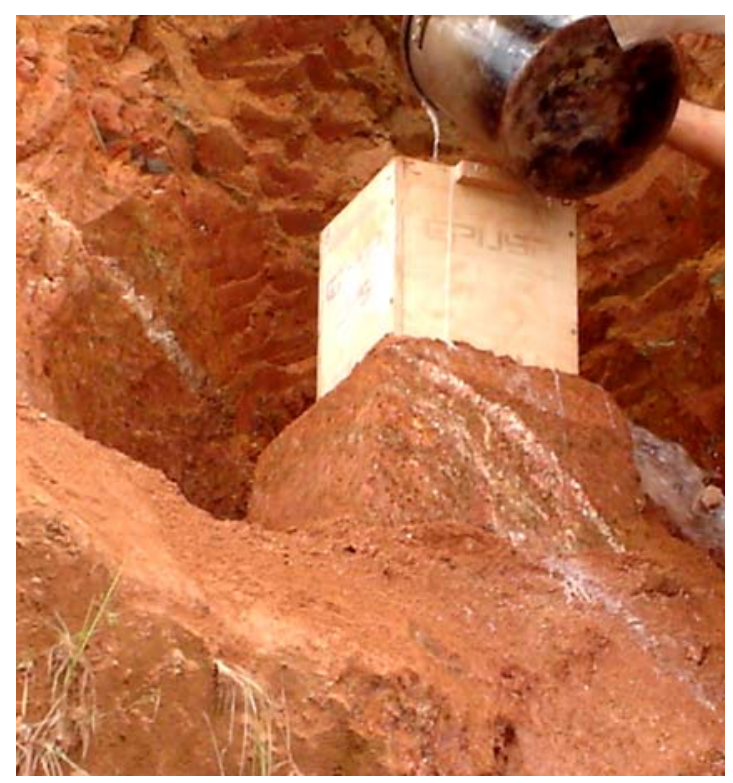

b) Bloco-2 - coletado no horizonte I-B

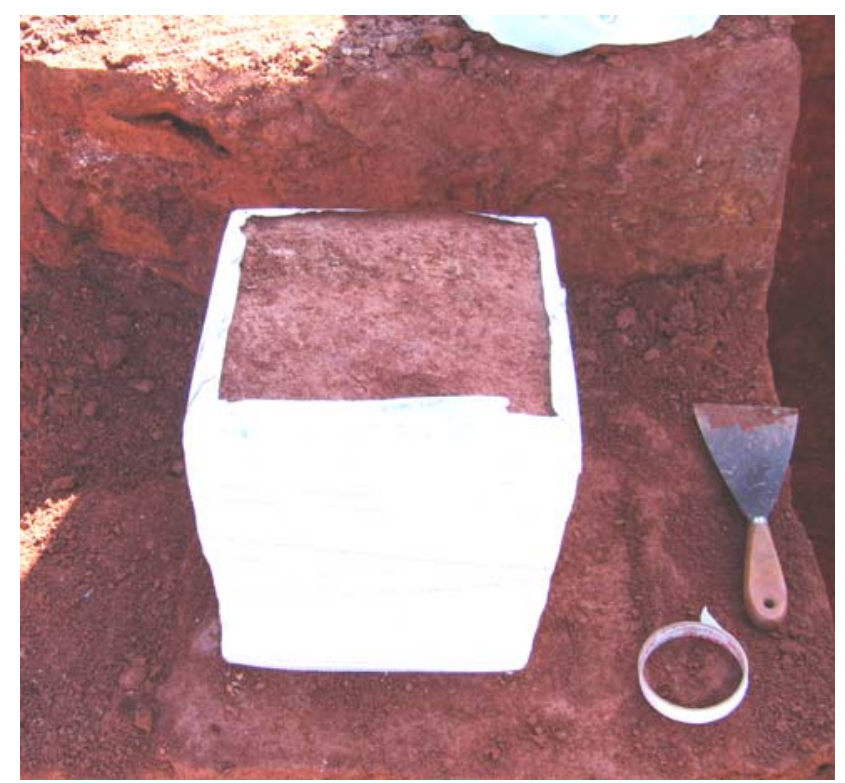

FiguRA 5.3 - COLETA DOS BLOCOS INDEFORMAdOS NA ÁREA DE MARANDUBA.

Na área de estudo do Perequê-Mirim os blocos foram coletados nos horizontes de solo residual IA e I-C, nas profundidades 0,50 e 6,70 metros, respectivamente, conforme mostrado na Figura 5.4. O Bloco 3 é composto por material de textura argilo-arenosa com grânulos de quartzo de diversos tamanhos dispersos na matriz do solo, apresenta poros e canalículos de tamanhos variados em sua estrutura com traços de material orgânico e raízes, e coloração predominantemente amarelada. O Bloco 4 apresenta uma estrutura com baixa coesão, sendo composto por material de textura areno-siltosa com muitos minerais micáceos, sua coloração 
predominantemente é o marrom com alguns traços bege a branco, e apresenta estruturas reliquiares da rocha de origem, onde se observa veios de quartzo e algumas estruturas orientadas.

a) Bloco-3 - coletado no horizonte I-A

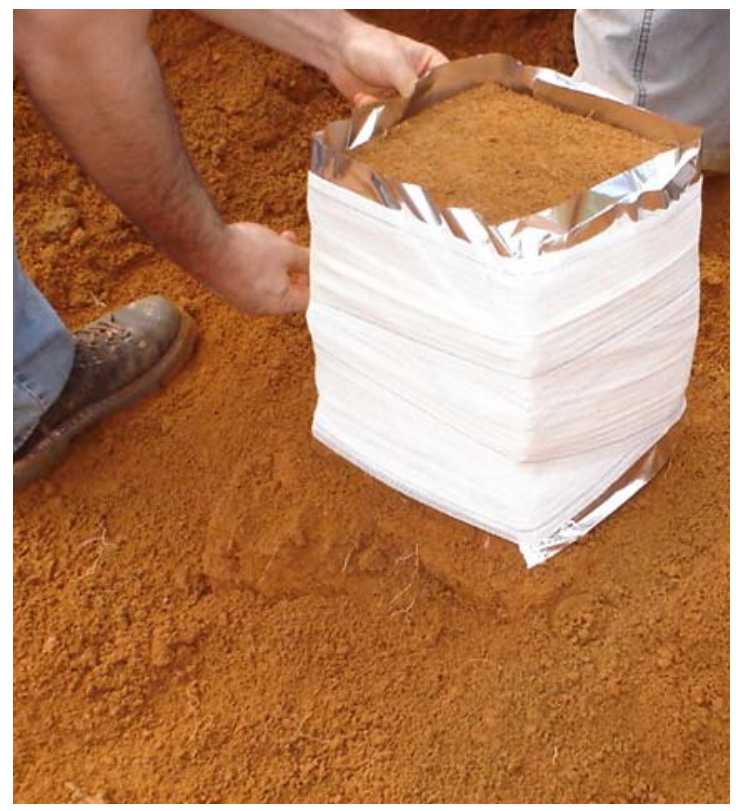

b) Bloco-4 - coletado no horizonte I-C

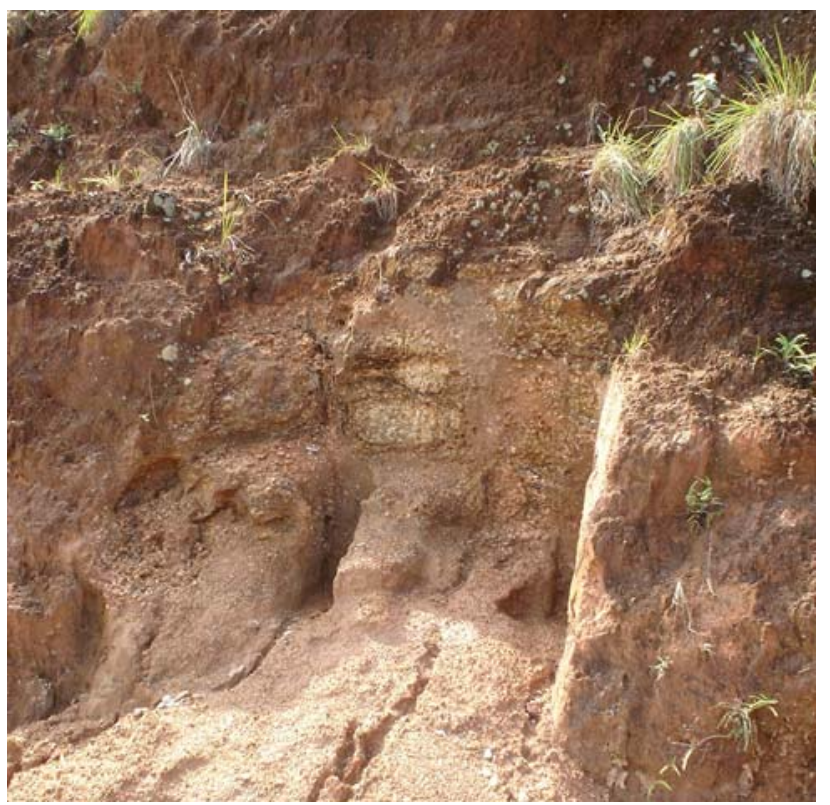

FigurA 5.4 - COLETA dOS BlOCOS INDEFORMAdOS NA ÁREA DO PEREQUÊ-MIRIM.

Em relação à coleta no campo, encontrou-se muita dificuldade na retirada dos Blocos 3 e 4 . A retirada do Bloco 3 foi dificultada pela quantidade espressiva de raízes, grãos de quartzo e pela abundância de canalículos e poros distribuídos na estrutura do solo que dificultaram a moldagem do bloco. Foi possível observar canalículos da ordem de milímetros distribuídos em todas as direções, provavelmente devido à presença de raízes decompostas. Na retirada do bloco-4, encontraram-se problemas devido à ocorrência de material muito friável associado com as estruturas reliquiares da rocha.

\subsection{Perfis Típicos de Alteração das Áreas Estudadas}

A partir da utilização de critérios de inspeção tátil-visual aplicado no campo e das informações encontradas nos perfis de alteração propostos por VAZ (1996) e DEERE \& PATTON (1971), foi possível estabelecer algumas divisões de classes para os horizontes de solos encontrados e propor um perfil de alteração típico para cada uma das áreas estudadas. 
As amostras coletadas no campo foram identificadas conforme sua localização no perfil de alteração típico de cada área de estudo. Para isso, adotaram-se siglas compostas por duas letras e um número, onde a primeira letra representa a área de estudo (“M” para a área de estudo de Maranduba e "P” para a área de estudo do Perequê-Mirim), a segunda letra representa a posição de coleta no perfil de alteração típico (horizontes $\mathrm{A}, \mathrm{B}$ ou $\mathrm{C}$ - correspondentes às respectivas divisões do horizonte I), e o número representa a profundidade aproximada de coleta (em centímetros) em relação ao nível do terreno natural. As Figuras 5.5 e 5.6 mostram os perfis de alteração típicos com a localização das amostras deformadas e indeformadas coletadas nas áreas de estudo.

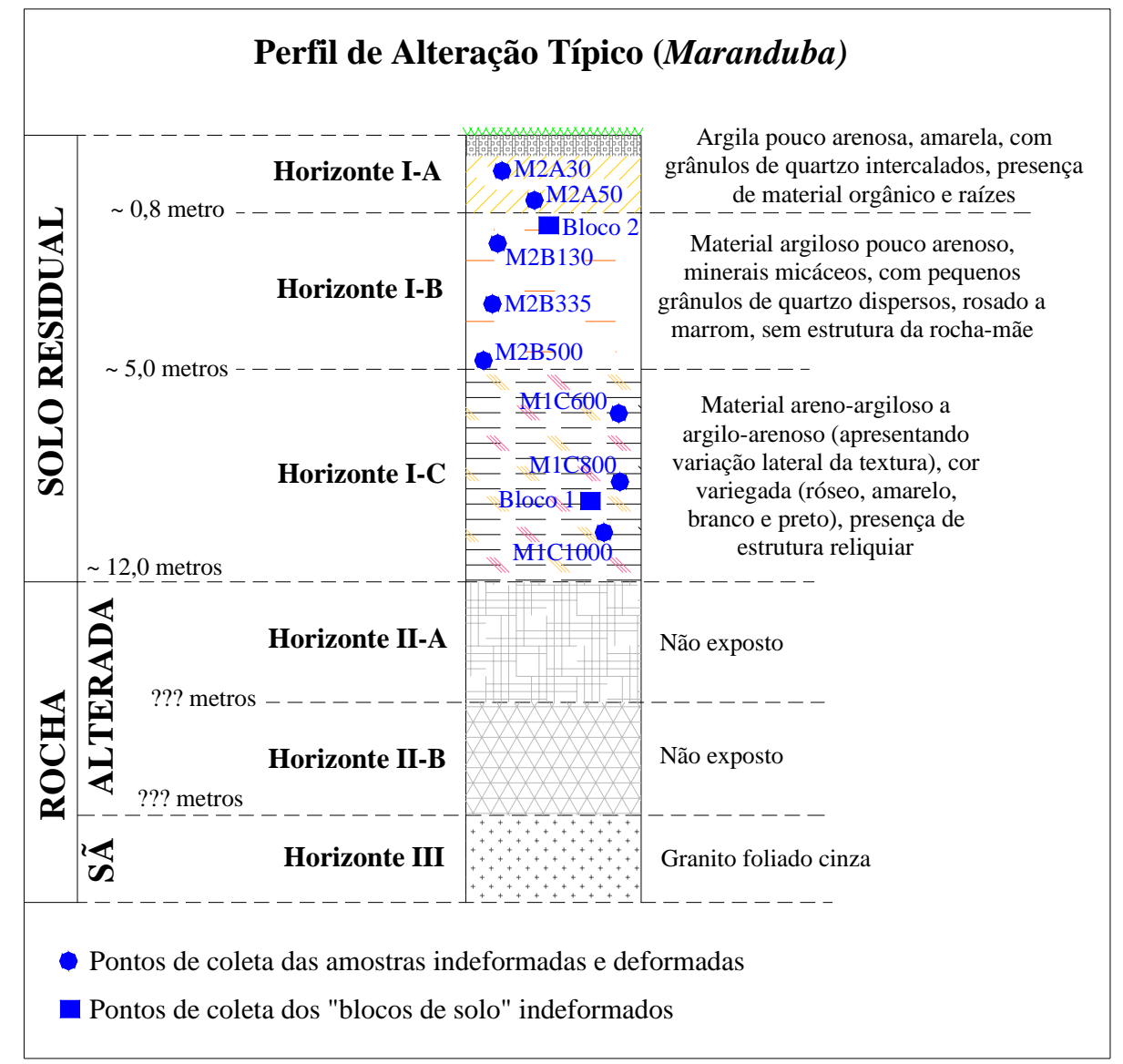

FIGURA 5.5 - PERFIL DE ALTERAÇÃO DA ÁREA DE ESTUDO DE MARANDUBA. 


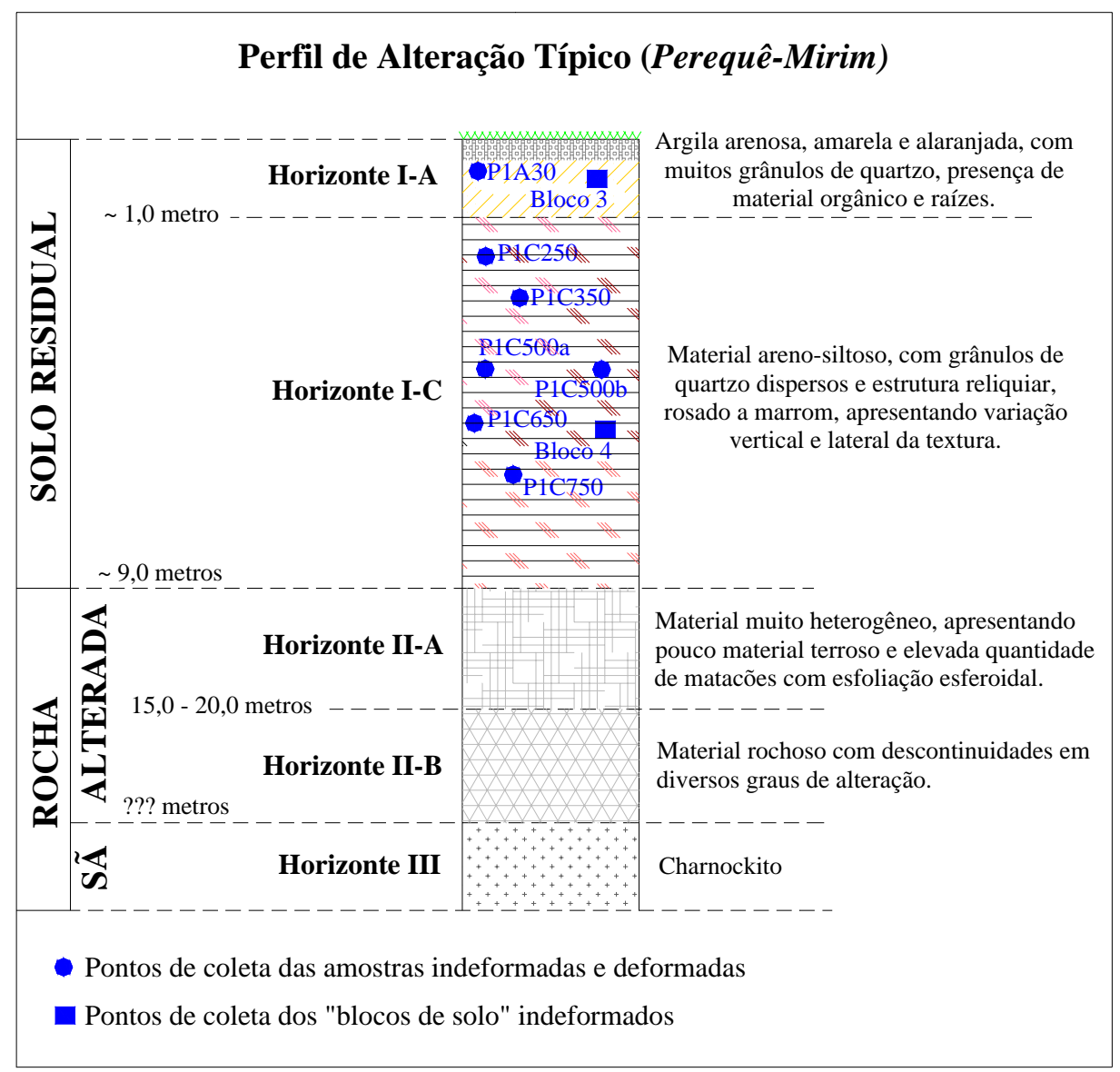

FiguRA 5.6 - PERFIL DE ALTERAÇÃo DA ÁREA DE ESTUdO SITUADA NO PEREQUÊ-Mirim.

A seguir são abordados e comentados os ensaios realizados que proporcionaram caracterizar os solos residuais não saturados coletados nas duas áreas de estudo.

\subsection{Ensaios de Caracterização Geotécnica}

A partir das amostras deformadas coletadas nas duas áreas de estudo, foram realizados os seguintes ensaios de caracterização: análise granulométrica, determinação da massa específica dos grãos $\left(\rho_{s}\right)$, massa específica natural $(\rho)$, massa específica aparente seca $\left(\rho_{d}\right)$ e limites de Atterberg (limite de liquidez e limite de plasticidade). 


\subsubsection{Análise granulométrica}

A análise granulométrica foi realizada conforme norma da ABNT (NBR-7181/84), e consistiu de duas fases: peneiramento e sedimentação. A escala granulométrica utilizada para a classificação textural dos solos seguiu a norma da ABNT (NBR-6502/95). As Figuras 5.7 e 5.8 mostram as curvas granulométricas obtidas a partir de ensaios de laboratório para as amostras de solos coletadas nas áreas de estudo. Comparando-se estas curvas com os limites que identificam as diversas faixas de tamanho dos grãos, pôde-se estabelecer a composição textural do solo a partir da porcentagem de cada fração.

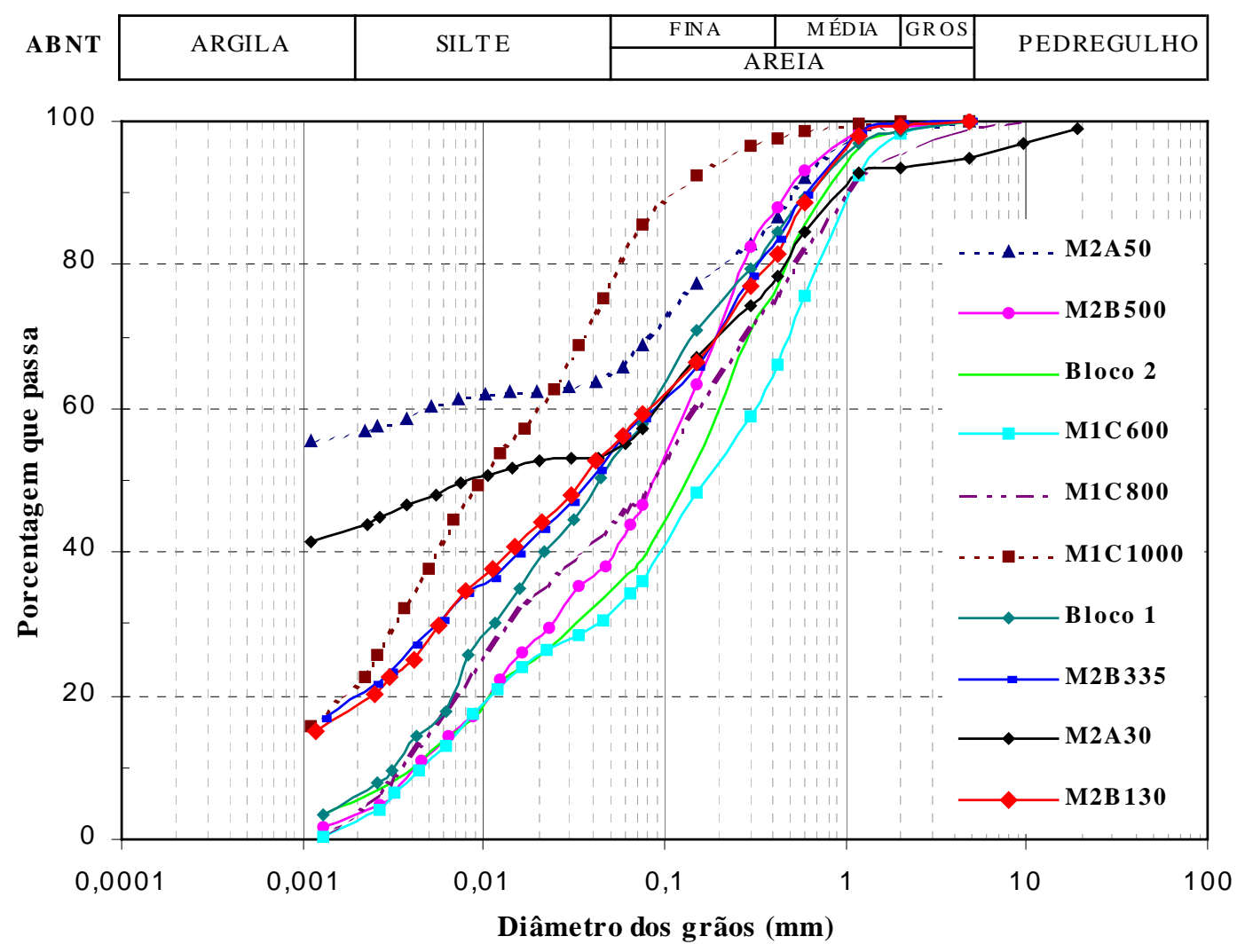

FIGURA 5.7 - CURVAS GRANULOMÉTRICAS DAS AMOSTRAS COLETADAS NA ÁREA DE MARANDUBA. 


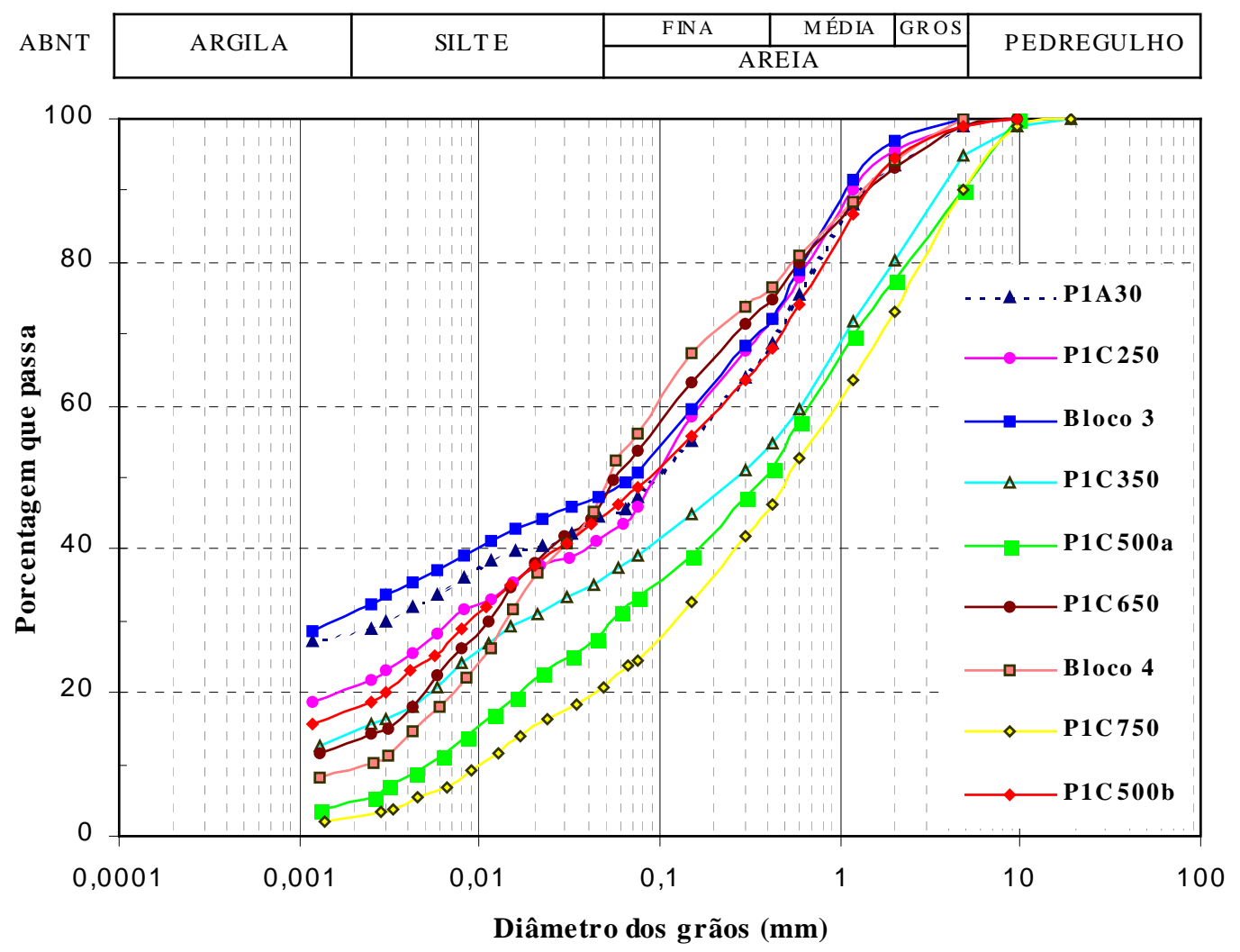

Figura 5.8 - CURVAS GRANUlOMÉTRICAS DAS AMOSTRAS COLETADAS NA ÁREA DE PEREQUÊMIRIM.

De uma maneira geral, as amostras coletadas nos horizontes mais superficiais (M2A50, M2A30, P1A30 e Bloco 3) das áreas estudadas apresentaram um percentual maior da fração argila; enquanto que as amostras do horizonte I-C, correspondente ao saprolito, apresentaram um percentual menor da fração argila e maiores proporções de areia e silte. Analisando as curvas granulométricas das Figuras 5.7 e 5.8, observa-se de um modo geral que os horizontes de solo das duas áreas estudadas tendem a apresentar uma diminuição do teor de argila com o aumento da profundidade. 


\subsubsection{Massa específica dos grãos}

O método utilizado para a determinação da massa específica dos grãos de solos que passam na peneira de 4,8 mm foi feito por meio de picnômetro conforme recomendação da norma da ABNT (NBR-6508/84). O valor da massa especifica foi obtido a partir da média simples de pelo menos dois ensaios considerados satisfatórios (ensaios que apresentaram diferenças menores que $0,02 \mathrm{~g} / \mathrm{cm}^{3}$ em comparação com os seus resultados).

\subsubsection{Massa especifica natural e massa especifica seca}

Os valores da massa específica natural das amostras foram obtidos pelo método da balança hidrostática conforme norma da ABNT (NBR-10838). Para a determinação da massa específica natural foram utilizadas pequenas amostras indeformadas de solo de aproximadamente 5,0 cm de diâmetro. Tais amostras foram extraídas de blocos com formatos irregulares coletados ao longo do perfil de alteração das áreas estudadas. O valor adotado para a massa específica natural corresponde ao valor médio encontrado para duas amostras ensaiadas nas mesmas condições. Os valores da massa específica seca foram obtidas a partir da seguinte equação:

$$
\rho_{d}=\frac{\rho}{(1+w)} \quad\left(\mathrm{g} / \mathrm{cm}^{3}\right)
$$

onde: $\rho$ é a massa específica do solo, determinado pelo método da balança hidrostática; $w$ é o teor de umidade da amostra.

\subsubsection{Limites de Atterberg}

Os limites de Atterberg foram realizados segundo as normas da ABNT (NBR-6459/84 e NBR-7180/84), e serviram de procedimento para a definição dos Limites de Liquidez e de Plasticidade, respectivamente. 
Os limites de Atterberg foram utilizados conjuntamente com as frações granulométricas dos solos para a realização da classificação das amostras estudadas segundo o Sistema Unificado de Classificação de Solos - SUCS (OLIVEIRA \& BRITO 1998).

Para a identificação do grau de participação dos argilominerais das amostras analisadas foi utilizado o conceito de atividade de SKEMPTON (1953), que é a razão entre o índice de plasticidade (IP) e o percentual da fração argila $(\%<2 \mu)$ presente nas amostras de solo analisadas. Conforme observações relatadas por VARGAS (1993), é necessário que se faça uma análise comparativa da plasticidade dos solos utilizando-se para isso a carta de plasticidade em conjunto com o gráfico de atividade, principalmente quando as amostras em análise se tratarem de solos tropicais.

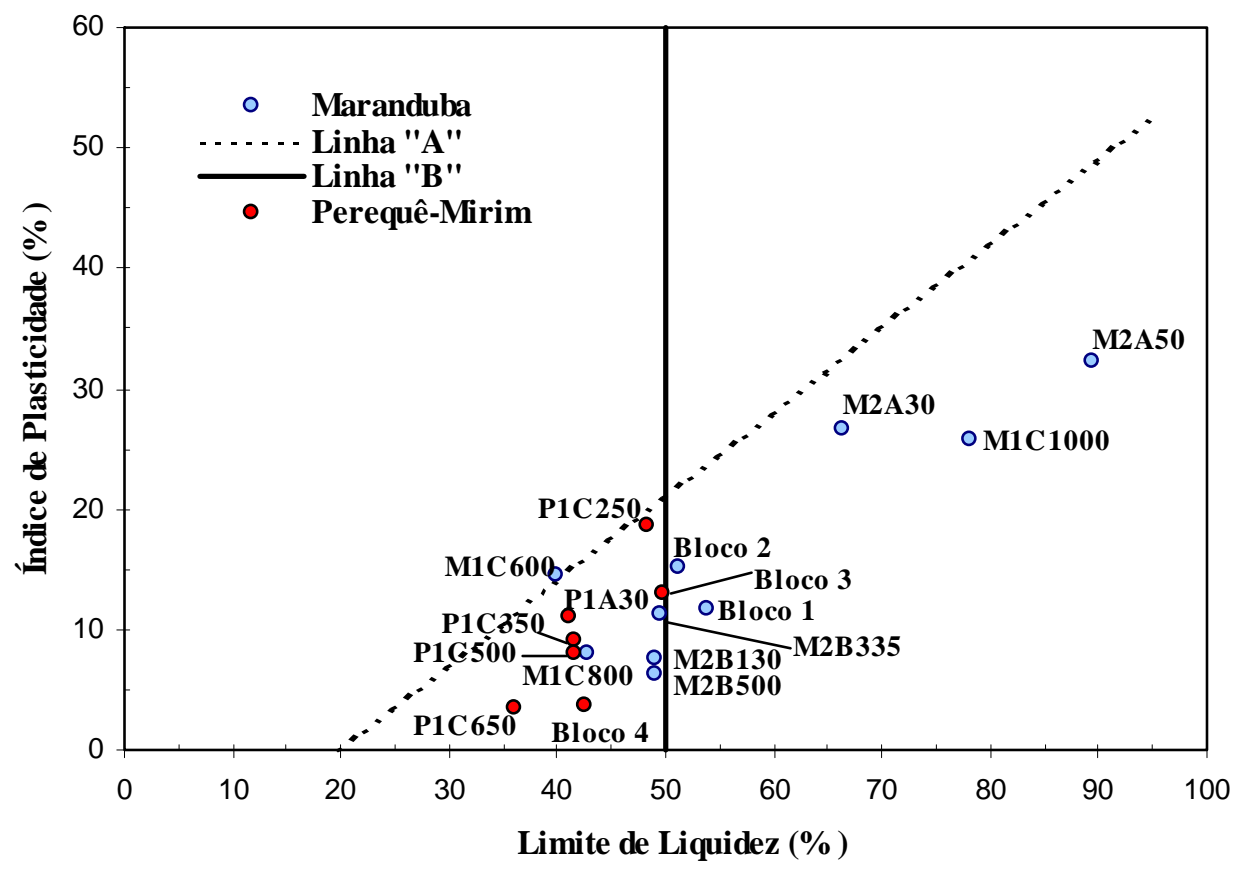

FIGURA 5.9 - CARTA DE PLASTICIDADE DAS AMOSTRAS DE SOLO ANALISADAS.

As Figuras 5.9 e 5.10 mostram, respectivamente, a carta de plasticidade e o gráfico de atividade para as amostras de solo coletadas nas áreas estudadas. Observando a posição dos solos na carta de plasticidade, nota-se que todas as amostras ensaiadas estão localizadas abaixo da "Linha A", 
com exceção de uma única amostra de solo - M1C600, que se encontra ligeiramente acima da "Linha A".

Em relação ao gráfico de atividade, observa-se que cinco amostras estão situadas acima da linha de atividade 1,25 (M1C600, Bloco 2, Bloco 1, M1C800 e M2B500). Duas amostras estão situadas entre as linhas de atividade 1,25 e 0,75 (M1C1000 e PC250). As demais amostras estão localizadas abaixo da linha de atividade 0,75 .

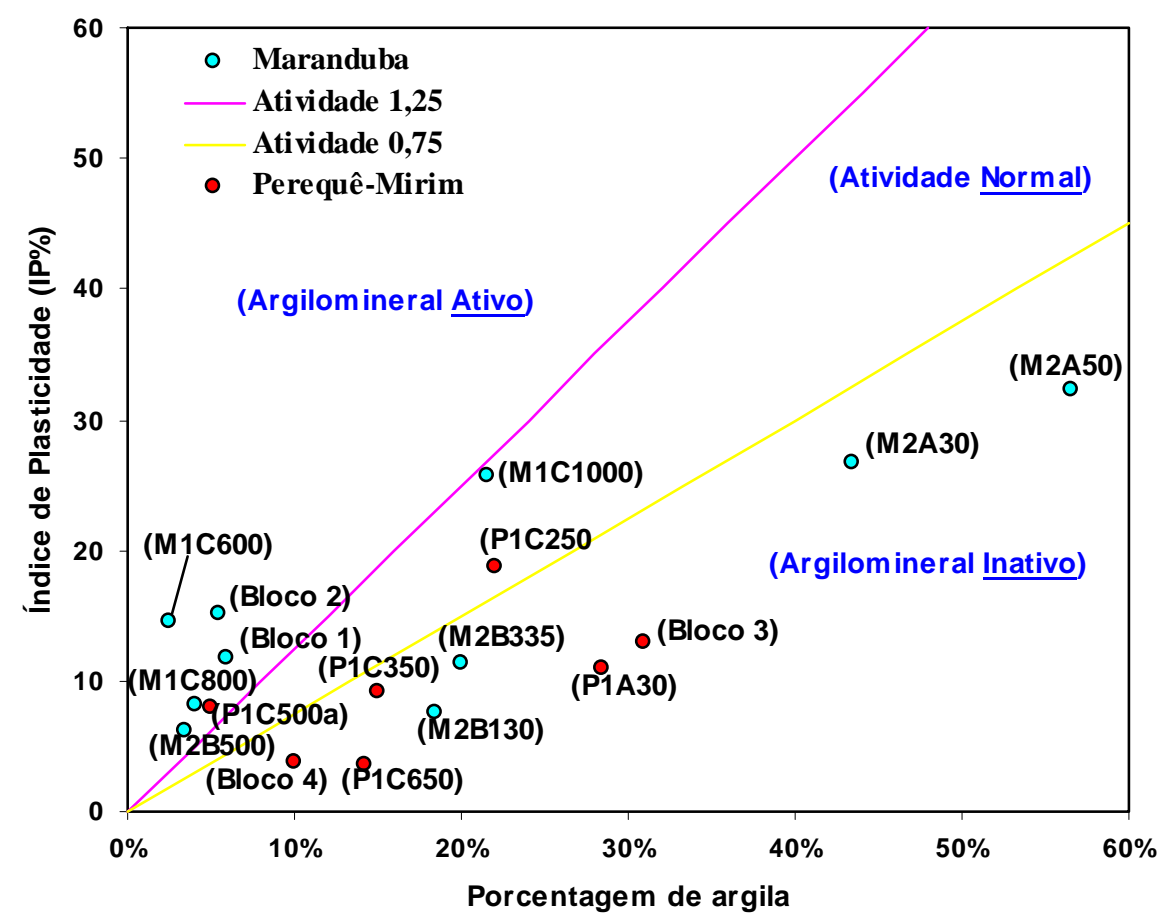

FIGURA 5.10 - GRÁFICO DE ATIVIDADE DAS AMOSTRAS DE SOLO ANALISADAS.

Na Tabela 5.1 são apresentados todos os resultados dos ensaios de caracterização realizados para as amostras coletadas nas duas áreas de estudo, bem como a classificação dos solos investigados conforme o Sistema Unificado de Classificação de Solos - SUCS. 
Tabela 5.1 - Resultados dos ensaios de caracterização.

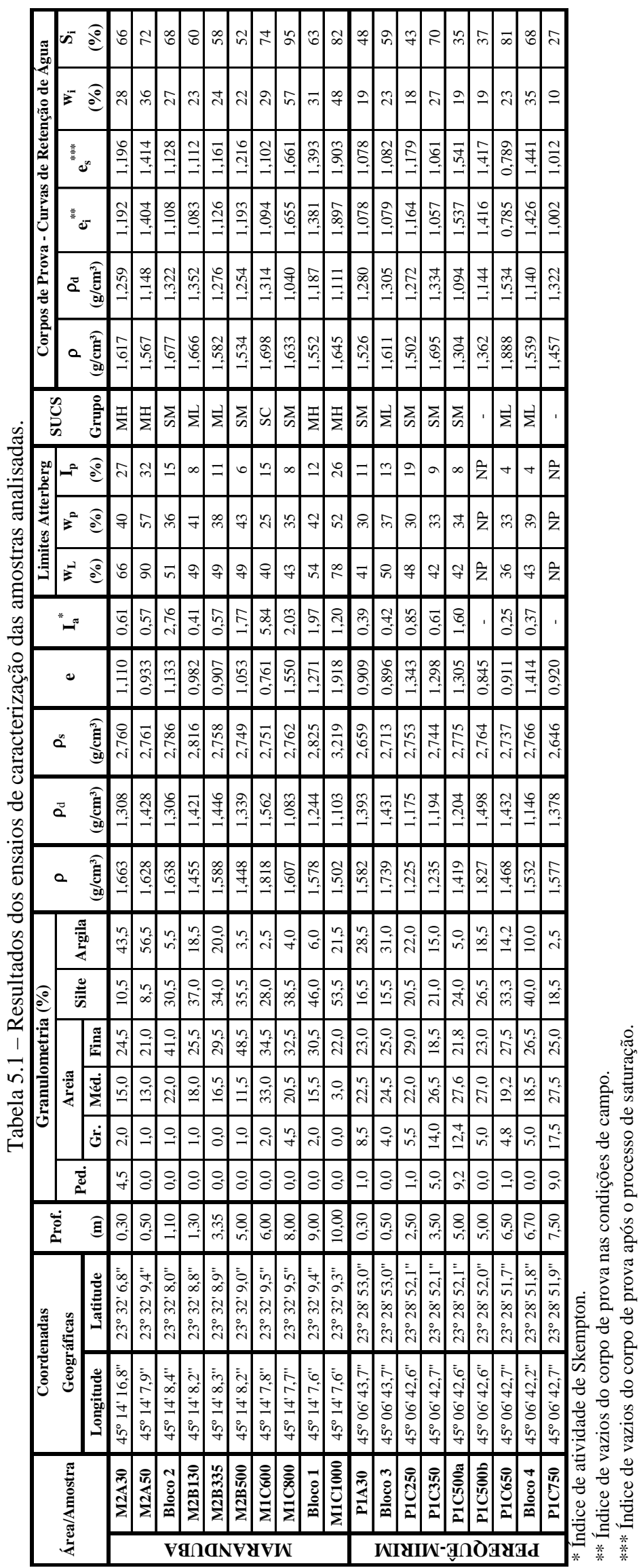




\subsection{Caracterização Mineralógica e Microestrutural}

O estudo micromorfológico, que envolve aspectos mineralógicos e microestruturais, foi realizado sobre amostras indeformadas (lâminas delgadas obtidas de pequenos blocos indeformados de solo impregnados com resina acrílica) e amostras deformadas (pó de solo) com o intuito de identificar as diferentes organizações morfológicas que compõem os horizontes dos perfis de alteração típicos das áreas de estudo. A abordagem micromorfológica foi baseada nos trabalhos de BOULET et al. (1982), BOULET (1978), BREWER (1964) e DELVIGNE (1998).

Os estudos mineralógicos e microscópicos tiveram como objetivo principal identificar e caracterizar os constituintes do solo, verificando os níveis de organização dentro de cada conjunto dos horizontes (natureza, forma, arranjo dos microagregados e porosidade associada), contribuindo para um melhor entendimento das propriedades geotécnicas dos solos residuais tropicais. Deste modo, buscou-se evidenciar similaridades e diferenças mineralógicas, texturais e microestruturais nas amostras de solo coletadas ao longo dos perfis de alteração das áreas estudadas, para posterior correlação com o comportamento de retenção de água e de resistência ao cisalhamento.

O estudo micromorfológico foi realizado conjuntamente por microscópio óptico de polarização e análises de difração de raios-X, para caracterizar a composição mineralógica de algumas fases mineralógicas. A seguir são apresentados os termos adotados (BREWER 1964, BOULANGÉ 1984) nos estudos micromorfológicos e as técnicas utilizadas no presente estudo.

Terminologia:

Alterita: é o material inconsolidado resultante do processo de intemperismo;

Minerais primários (minerais I): são os minerais derivados diretamente de rochas ígneas ou metamórficas (e.g. biotita, feldspato e quartzo) e que ocorrem, principalmente, nas frações de areia e de silte;

Minerais supérgenos (minerais II): são os minerais formados pelo processo de intemperismo atuante nos minerais primários (e.g. argilominerais como caolinita e montmorilonita, além de hematita, goethita e gibbsita) e que predominam na fração argila; 
Isalterita: alterita com conservação das texturas petrográficas e estruturas litológicas originais, na qual os minerais supérgenos formaram-se a partir do intemperismo químico dos minerais primários resistentes, mas sem destruir a estruturação original da rocha inicial;

Aloterita: alterita sem conservação das texturas e estruturas originais da rocha matriz, material com maior densidade que a isalterita e menor quantidade de vazios;

Estrutura porfirosquélica: é constituída por uma massa de materiais muito finos com grãos de minerais primários resistentes dispersos e com microporos mais ou menos abundantes, além de fissuras irregulares mais ou menos longas;

Estrutura aglomeroplásmica: é formada por pequenos volumes irregulares de massa do solo que se individualizam pela abertura de fissuras em maior quantidade, entre os agregados formados pela evolução pedogenética;

Plasma primário: conjunto de minerais supérgenos que preservam as texturas petrográficas e estruturas litológicas da rocha original (pseudomorfos dos minerais primários);

Plasma secundário: parte do solo que já foi mobilizada, reorganizada e/ou concentrada pelos processos de formação da alterita e do solo. Inclui todo o material, orgânico ou mineral, de tamanho coloidal e relativamente solúvel não mais relacionado aos grãos do esqueleto originários da rocha matriz.

\subsubsection{Caracterização mineralógica}

Os minerais presentes nos materiais estudados foram identificados mediante aplicação da técnica de difração de raios-X. No entanto, deve-se ressaltar que alguns minerais presentes em quantidades não muito grandes, não aparecem nos difratogramas de raios-X, sendo, contudo, reconhecíveis ao microscópio óptico. Além disso, os produtos ferruginosos, mesmo bem cristalizados como hematita e goethita, podem não aparecer nos difratogramas devido principalmente aos aspectos técnicos do equipamento (cátodo utilizado) e às características peculiares dos minerais. Já a presença de produtos ferruginosos mal cristalizados, geralmente encontrados em ambientes de clima tropical e de grande importância na agregação das partículas dos solos, não é passível de detecção ao difratômetro, que detecta apenas fases bem cristalizadas. 
As amostras foram analisadas no Laboratório de Raios-X do Instituto de Geociências da Universidade de São Paulo (USP). As amostras de solo coletadas em diferentes profundidades ao longo dos perfis de alteração foram secas, destorroadas e passadas na peneira $\mathrm{N}^{0} 100$ (abertura 0,149 mm) para serem analisadas na forma de pó. Posteriormente as amostras de solo foram colocadas em porta-amostras de modo a evitar a orientação preferencial dos grãos. As lâminas assim preparadas foram submetidas à análise de difratometria de raios- $\mathrm{X}$ no seu estado seco ao ar.

Para o perfil de alteração de Maranduba foram analisadas 12 amostras de solo por difração de raios-X e para o perfil de alteração do Perequê-Mirim 16 amostras, obtendo-se um total de 28 difratogramas. Os resultados das análises mineralógicas para os solos que compõem o perfil de alteração de Maranduba são apresentados na Tabela 5.2. Os difratogramas representativos dos horizontes que compõem o perfil de alteração de Maranduba são apresentados nas Figuras 5.11 e 5.12 .

Tabela 5.2 - Mineralogia do perfil de alteração de Maranduba.

\begin{tabular}{|c|c|c|c|c|c|c|c|c|c|c|c|c|}
\hline \multirow[b]{2}{*}{ Amostra } & \multirow[b]{2}{*}{$\begin{array}{l}\text { Profundidade } \\
\text { (metros) }\end{array}$} & \multirow[b]{2}{*}{ Tipo de Material } & \multicolumn{10}{|c|}{ MINERAIS PRESENTES } \\
\hline & & & 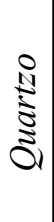 & 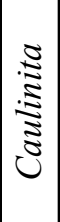 & 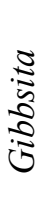 & $\stackrel{\Xi}{:}$ & 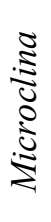 & 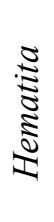 & 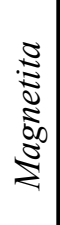 & 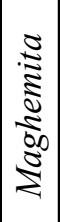 & 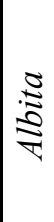 & 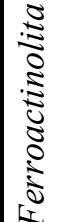 \\
\hline M2A50 & 0,50 & $\begin{array}{l}\text { solo superficial } \\
\text { (Horizonte I-A) }\end{array}$ & & & & & & & & & & \\
\hline BLOCO 2 & 1,10 & $\begin{array}{c}\text { solo de alteração } \\
\text { (Horizonte I-B) }\end{array}$ & & & & & & & & & & \\
\hline M2B130 & 1,30 & $\begin{array}{c}\text { solo de alteração } \\
\text { (Horizonte I-B) }\end{array}$ & & & & & & & & & & \\
\hline M2B335 & 3,35 & $\begin{array}{c}\text { solo de alteração } \\
\text { (Horizonte I-B) }\end{array}$ & & & & & & & & & & \\
\hline M2B500 & 5,00 & $\begin{array}{c}\text { solo de alteração } \\
\text { (Horizonte I-B) }\end{array}$ & & & & & & & & & & \\
\hline M2B500 & 5,00 & $\begin{array}{l}\text { solo de alteração } \\
\text { (variação lateral) }\end{array}$ & & & & & & & & & & \\
\hline M1C600 & 6,00 & $\begin{array}{c}\text { saprolito } \\
\text { (Horizonte I-C) }\end{array}$ & & & & & & & & & & \\
\hline BLOCO 1 & 9,00 & $\begin{array}{c}\text { saprolito } \\
\text { (Horizonte I-C) }\end{array}$ & & & & & & & & & & \\
\hline M1C1000 & 10,00 & $\begin{array}{c}\text { saprolito } \\
\text { (Horizonte I-C) }\end{array}$ & & & & & & & & & & \\
\hline $\begin{array}{c}\text { ROCHA } \\
\text { ALTERADA }\end{array}$ & $\sim 15,00$ & (Horizonte II-A) & & & & & & & & & & \\
\hline $\begin{array}{c}\text { ROCHA } \\
\text { ALTERADA }\end{array}$ & $\sim 20,00$ & (Horizonte II-B) & & & & & & & & & & \\
\hline
\end{tabular}




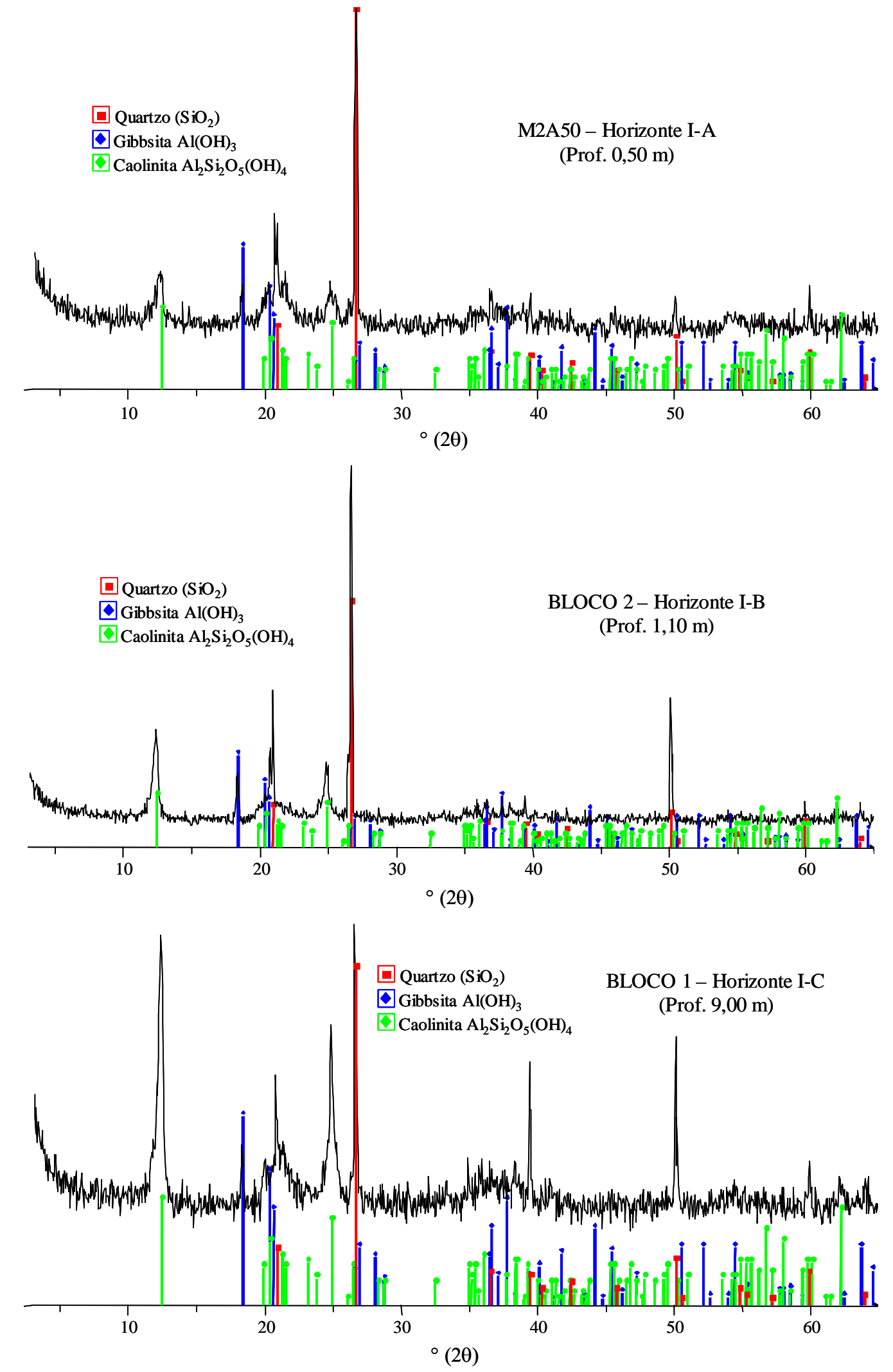

FiguRA 5.11 - DifRATOGRAMAS CARACTERÍSTICOS DOS SOLOS DE ALTERAÇÃo DE MARANDUBA. 


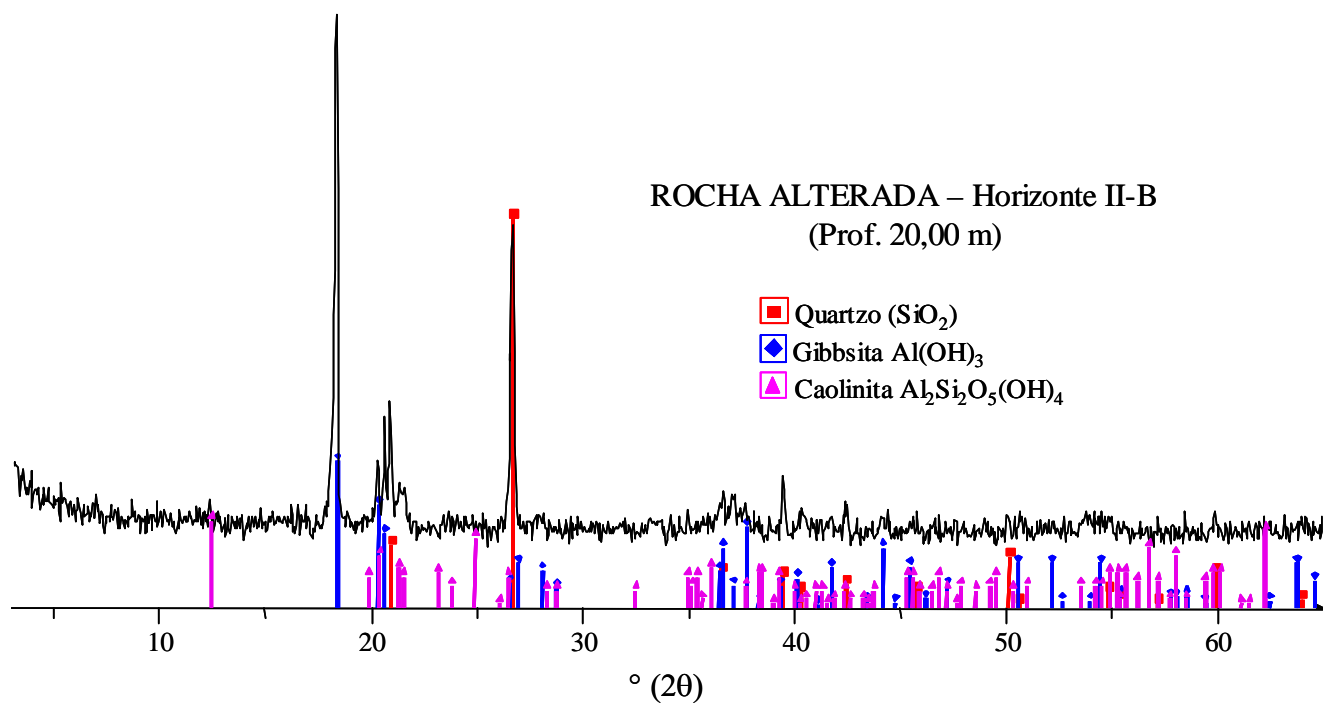

FigurA 5.12 - DifRATOGRAMA CARACTERÍSTICO DA ROCHA ALTERADA (GRANITO-GNAISSE) DE MARANDUBA.

Os resultados das análises mineralógicas apresentadas na Tabela 5.2 indicam a presença predominante de quartzo $\left(\mathrm{SiO}_{2}\right)$, caolinita $\left(\mathrm{Al}_{2} \mathrm{Si}_{2} \mathrm{O}_{5}(\mathrm{OH})_{4}\right)$ e gibbsita $\left(\mathrm{Al}(\mathrm{OH})_{3}\right)$ em praticamente todos os horizontes de solo que compõem o perfil de alteração da área de estudo de Maranduba. Observa-se também a presença em menor proporção de illita $\left(\mathrm{K}, \mathrm{H}_{3} \mathrm{O}\right) \mathrm{Al}_{2} \mathrm{Si}_{3} \mathrm{AlO}_{10}(\mathrm{OH})_{2}$ e microclínio ( $\mathrm{KAlSi}_{3} \mathrm{O}_{8}$ ), tanto nos horizontes mais intemperizados (horizonte I-B) quanto no horizonte de rocha alterada. Magnetita $\left(\mathrm{Fe}^{+2} \mathrm{Fe}_{2}{ }^{+3} \mathrm{O}_{4}\right)$ está presente em pequena quantidade e foi detectada por DRX num dos horizontes menos alterados (horizonte I-C, na amostra de solo M1C1000). Os minerais supérgenos ferruginosos representados pela hematita $\left(\mathrm{Fe}_{2} \mathrm{O}_{3}\right)$ e maghemita $\left(\mathrm{Fe}_{2} \mathrm{O}_{3}\right)$ ocorrem apenas num dos horizontes mais intemperizados (horizonte I-B).

Comparando os difratogramas dos horizontes que compõem o perfil de alteração de Maranduba, conforme apresentado nas Figuras 5.11 e 5.12, observa-se nitidamente a ocorrência predominante dos minerais de quartzo $\left(\mathrm{SiO}_{2}\right)$, caolinita $\left(\mathrm{Al}_{2} \mathrm{Si}_{2} \mathrm{O}_{5}(\mathrm{OH})_{4}\right)$ e gibbsita $\left(\mathrm{Al}(\mathrm{OH})_{3}\right)$, desde o horizonte de solo mais superficial (horizonte I-A) até o horizonte de rocha alterada. A rocha alterada apresenta maior variedade de minerais presentes que, uma vez intemperizados quimicamente, transformam-se num conjunto menos variado de minerais supérgenos. 
Os resultados das análises mineralógicas para os solos que compõem o perfil de alteração da área de estudo do Perequê-Mirim são apresentados na Tabela 5.3. Analisando a Tabela 5.3, nota-se que o quartzo $\left(\mathrm{SiO}_{2}\right)$ e a caolinita $\left(\mathrm{Al}_{2} \mathrm{Si}_{2} \mathrm{O}_{5}(\mathrm{OH})_{4}\right)$ ocorrem de maneira preponderante ao longo de todo o perfil de alteração da área de estudo do Perequê-Mirim. A gibbsita $\left(\mathrm{Al}(\mathrm{OH})_{3}\right)$ ocorre tanto no horizonte de solo mais intemperizado (horizonte I-A) quanto no horizonte de saprolito (horizonte I-C) e também no horizonte de rocha alterada mais profundo (horizonte II-B). Já a illita $\left(\mathrm{K}_{3} \mathrm{H}_{3} \mathrm{O}\right) \mathrm{Al}_{2} \mathrm{Si}_{3} \mathrm{AlO}_{10}(\mathrm{OH})_{2}$ e microclínio $\left(\mathrm{KAlSi}_{3} \mathrm{O}_{8}\right)$ ocorrem apenas nos horizontes de saprolito mais profundos (horizonte I-C, Bloco 4 e P1C750) e nos horizontes de rocha alterada (horizonte II-A e B). Os difratogramas representativos dos horizontes de solos que compõem esse perfil de alteração são apresentados nas Figuras 5.13 e 5.14 .

Tabela 5.3 - Mineralogia do perfil de alteração do Perequê-Mirim.

\begin{tabular}{|c|c|c|c|c|c|c|c|}
\hline \multirow[b]{2}{*}{ Amostra } & \multirow[b]{2}{*}{$\begin{array}{l}\text { Profundidade } \\
\text { (metros) }\end{array}$} & \multirow[b]{2}{*}{ Tipo de Material } & \multicolumn{5}{|c|}{ MINERAIS PRESENTES } \\
\hline & & & 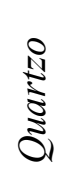 & 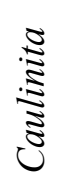 & $\begin{array}{l}\frac{\sigma}{5} \\
\frac{0}{0} \\
\dot{0}\end{array}$ & 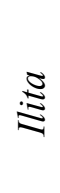 & 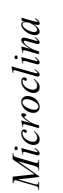 \\
\hline BLOCO 3 & 0,50 & $\begin{array}{l}\text { solo superficial } \\
\text { (Horizonte I-A) }\end{array}$ & & & & & \\
\hline P1C350 & 3,50 & $\begin{array}{c}\text { saprolito } \\
\text { (Horizonte I-C) }\end{array}$ & & & & & \\
\hline P1C350 & 3,50 & $\begin{array}{c}\text { saprolito } \\
\text { (variação lateral) } \\
\end{array}$ & & & & & \\
\hline BLOCO 4 & 6,70 & $\begin{array}{c}\text { saprolito (Horizonte } \\
\text { I-C) }\end{array}$ & & & & & \\
\hline P1C750 & 7,50 & $\begin{array}{c}\text { saprolito (Horizonte } \\
\text { I-C) }\end{array}$ & & & & & \\
\hline $\begin{array}{c}\text { ROCHA } \\
\text { ALTERADA }\end{array}$ & $\sim 11,00$ & (Horizonte II-A) & & & & & \\
\hline $\begin{array}{c}\text { ROCHA } \\
\text { ALTERADA }\end{array}$ & $\sim 15,00$ & (Horizonte II-B) & & & & & \\
\hline
\end{tabular}



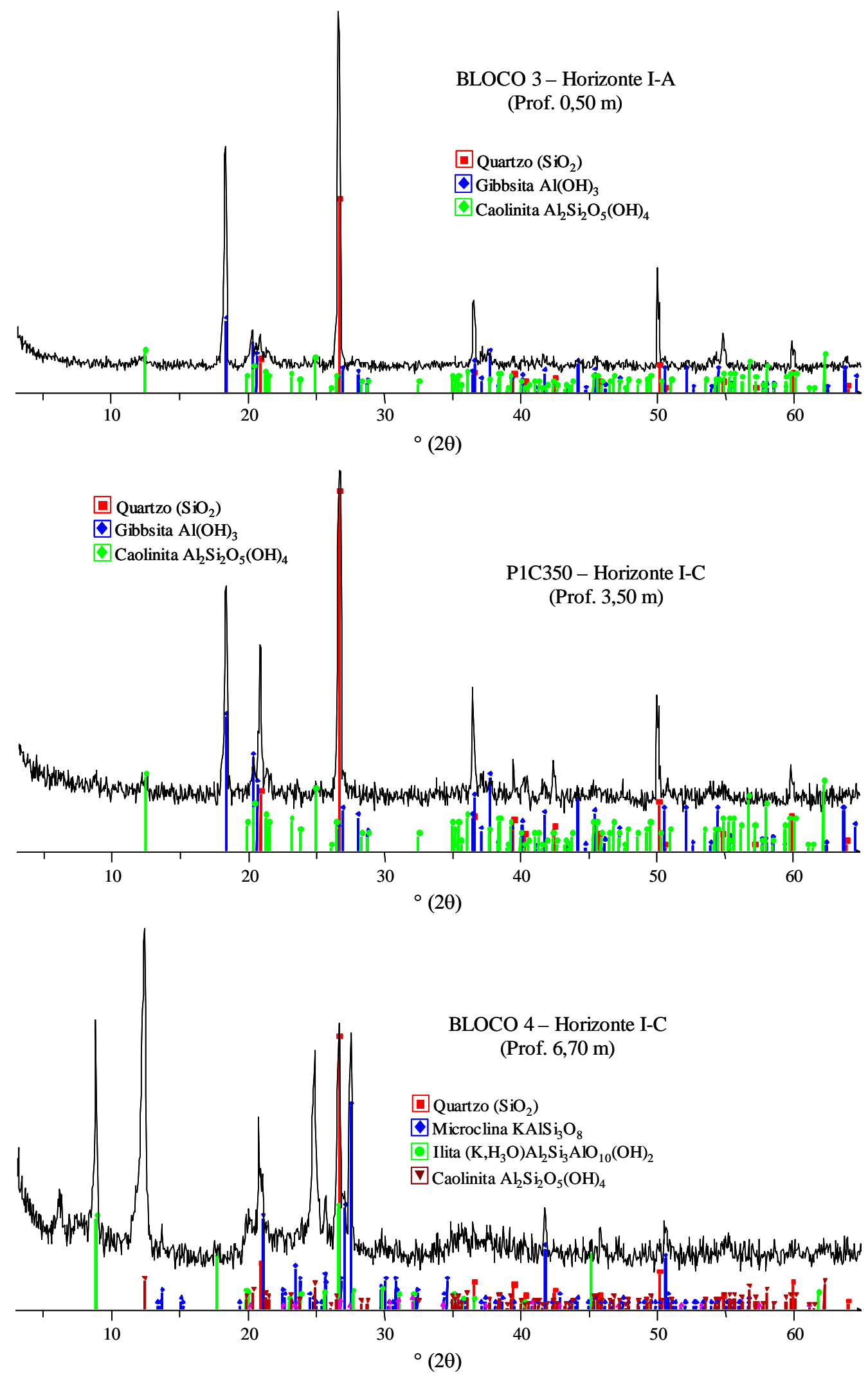

Figura 5.13 - DifRATOgRAMAS CARACTERÍsticos DOS SOlOS DE ALTERAÇÃo DO PEREQUÊMIRIM. 

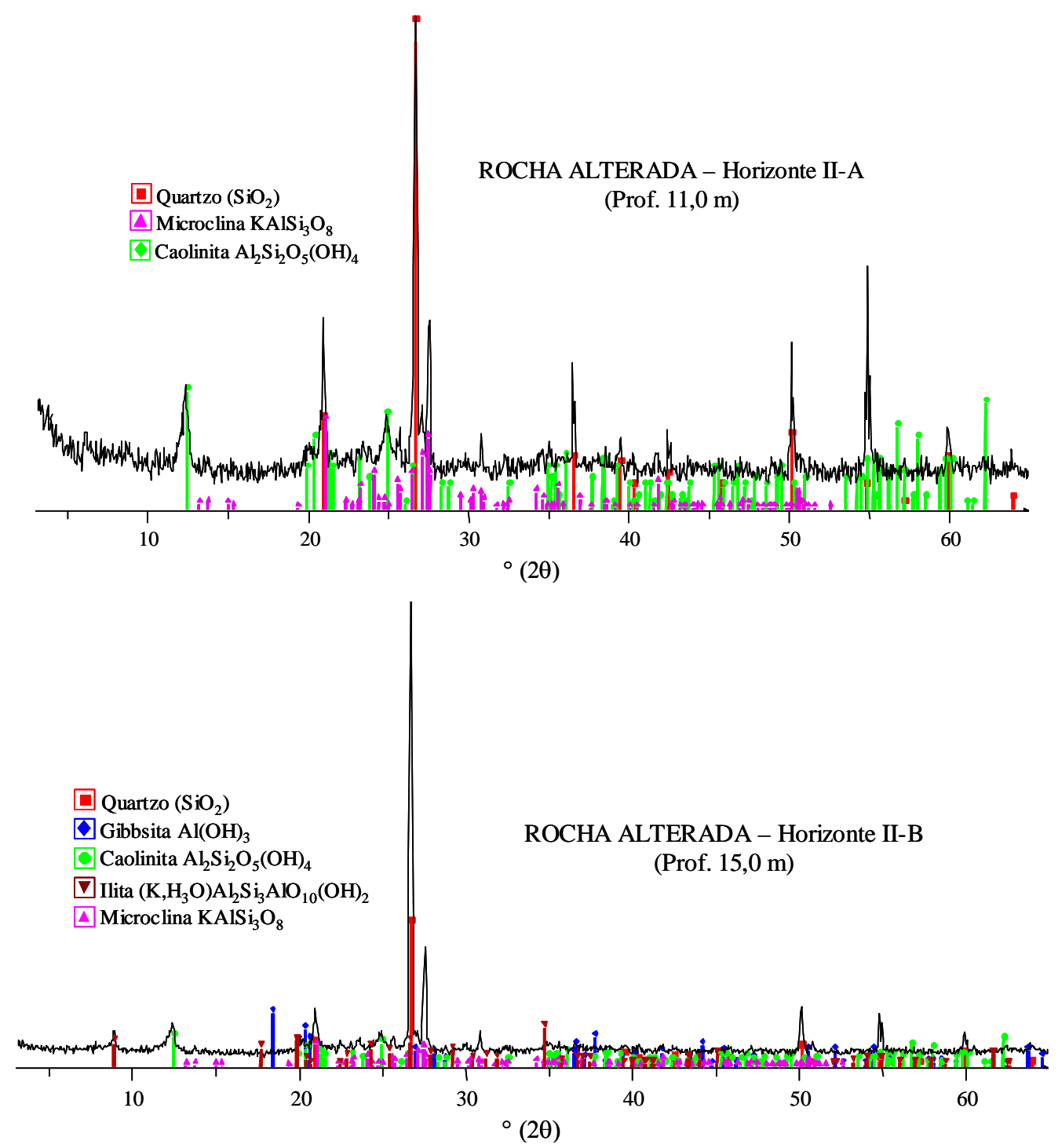

Figura 5.14 - Difratogramas CARACTERÍsticos DA ROCHA (ChaRnOCKITO) DO PEREQUÊMIRIM.

Os difratogramas apresentados nas Figuras 5.13 e 5.14, mostram a ocorrência predominante de quartzo $\left(\mathrm{SiO}_{2}\right)$ e caolinita $\left(\mathrm{Al}_{2} \mathrm{Si}_{2} \mathrm{O}_{5}(\mathrm{OH})_{4}\right)$ em todos os horizontes que compõem o perfil de alteração. Com o aumento da profundidade do horizonte de saprolito (horizonte I-C), gibbsita $\left(\mathrm{Al}(\mathrm{OH})_{3}\right)$ não é mais detectada até reaparecer no horizonte de rocha alterada (horizonte II-B). Analisando os difratogramas observa-se que os picos mais intensos de illita $\left(\mathrm{K}, \mathrm{H}_{3} \mathrm{O}\right) \mathrm{Al}_{2} \mathrm{Si}_{3} \mathrm{AlO}_{10}(\mathrm{OH})_{2}$ e microclínio $\left(\mathrm{KAlSi}_{3} \mathrm{O}_{8}\right)$ são identificados nos solos do horizonte de saprolito (horizonte I-C) e diminuem gradativamente de intensidade até o horizonte de rocha alterada (horizonte II-B). 


\subsubsection{Caracterização microestrutural}

A microestrutura dos solos foi estudada por meio de lâminas delgadas analisadas no microscópio óptico de polarização. As lâminas delgadas foram obtidas a partir da impregnação com resina acrílica em pequenos blocos indeformados de alterita e solo. Os pequenos blocos indeformados foram coletados ao longo dos dois perfis de alteração estudados, envolvendo amostras de rocha sã e de materiais inconsolidados em diversos estágios de intemperismo e pedogênese. Na etapa de preparo das lâminas delgadas, os pequenos blocos indeformados foram previamente sêcos em estufa a $40^{\circ} \mathrm{C}$, e posteriormente impregnados com resina acrílica endurecedora utilizando-se um dessecador a vácuo. A preparação das lâminas delgadas foi realizada no Laboratório de Laminação do Instituto de Geociências da Universidade de São Paulo (USP).

$\mathrm{Na}$ área de estudo de Maranduba, a rocha matriz que deu origem ao perfil de alteração (granitognaisse) apresenta variações significativas na proporção relativa dos minerais essenciais. Os minerais claros (quartzo e feldspato) e escuros (principalmente biotita e hornblenda) distribuemse de forma irregular, formando uma rocha de coloração heterogênea, sendo que a fase acessória (illita ou sericita) também pode variar. As características estruturais também variam com ou sem bandamento. A granulometria da rocha é grossa, com abundância de grãos minerais da ordem de 1,0 centímetro.

A área de estudo de Maranduba apresenta cortes na topografia, permitindo a observação do perfil de intemperismo e de solo, que é incompleto (truncado), pois na área funcionava uma mineração de saibro, tendo havido, portanto, retirada de material superficial (talvez cerca de 5,0 metros no topo do perfil de alteração original), tanto pela extração de saibro quanto pelo processo de erosão laminar. Durante a coleta das amostras foi possível observar a rocha sã e alterada, na base (cerca de 20,0 metros abaixo da superfície do terreno atual), seguida, em direção ao topo, por isalterita até cerca de 10,0 metros, depois material de transição ou aloterítico até cerca de 6,0 metros, e a partir daí observa-se material aloterítico, com feições de solo stricto sensu nos decímetros do topo. 
A Tabela 5.4 apresenta as principais feições mineralógicas e micromorfológicas do perfil de alteração típico da área de Maranduba. Os minerais indicados incluem não apenas os detectados pelas análises de difração de raios-X, mas também aqueles observados nas lâminas delgadas ao microscópio óptico.

Tabela 5.4 - Principais feições mineralógicas e micromorfológicas do perfil de alteração da área de estudo de Maranduba.

\begin{tabular}{|c|c|c|c|c|}
\hline Amostra & Prof. (m) & Mineral I & Mineral II & Feições Micromorfológicas \\
\hline M2A50 & 0,50 & Quartzo e Magnetita & $\begin{array}{l}\text { Gibbsita, Caolinita e Oxi- } \\
\text { hidróxido de Ferro }\end{array}$ & $\begin{array}{l}\text { Presença de fissuras separando volumes de fundo matricial, instalação da } \\
\text { estrutura aglomeroplásmica, predomínio de plasma II e argilo-minerais } \\
\text { ferruginosos; quase não há pseudomorfos micáceos. Há pequenos } \\
\text { agregados de gibbsita e caolinita. Material poroso. }\end{array}$ \\
\hline BLOCO 2 & 1,10 & Quartzo e Magnetita & $\begin{array}{l}\text { Gibbsita, Caolinita e Oxi- } \\
\text { hidróxido de Ferro }\end{array}$ & $\begin{array}{l}\text { Aloterita. Plasma II muito ferruginoso, também com abundância de } \\
\text { fragmentos de quartzo e magnetita e pseudomorfos de mica; proporção de } \\
\text { esqueleto, plasma I e plasma II praticamente equilibrada. Material poroso. }\end{array}$ \\
\hline $\begin{array}{l}\text { M2B335 } \\
\text { M2B500 }\end{array}$ & $\begin{array}{l}3,35 \\
5,00\end{array}$ & Quartzo e Magnetita & $\begin{array}{l}\text { Gibbsita, Caolinita e Oxi- } \\
\text { hidróxido de Ferro }\end{array}$ & $\begin{array}{l}\text { Aloterita. Plasma II caolinítico/ferruginoso com abundância de fragmentos } \\
\text { de quartzo e magnetita, e de pseudomorfos micáceos caolinizados e } \\
\text { ferruginizados (mais esqueleto e plasma I que plasma II). Porosidade } \\
\text { variável. }\end{array}$ \\
\hline M1C600 & 6,00 & Quartzo e Magnetita & $\begin{array}{l}\text { Gibbsita, Caolinita e Oxi- } \\
\text { hidróxido de Ferro }\end{array}$ & $\begin{array}{l}\text { Aloterita. Plasma II caolinítico (talvez também gibbsítico) porfirosquélico, } \\
\text { com abundância de fragmentos de quartzo e magnetita, pseudomorfos } \\
\text { micáceos caolinizados e pouco ferruginizados, com manchas e faixas } \\
\text { vermelhas de oxi-hidróxidos de ferro. Porosidade variável. }\end{array}$ \\
\hline BLOCO 1 & 9,00 & Quartzo e Magnetita & $\begin{array}{l}\text { Gibbsita, Caolinita e Oxi- } \\
\text { hidróxido de Ferro }\end{array}$ & $\begin{array}{l}\text { Transição aloterita/isalterita. Abundância de biotita caolinizada e } \\
\text { ferruginizada, com abertura e deformação das lamelas. Grandes grãos de } \\
\text { quartzo fragmentados e um pouco dissolvidos. Restos de magnetita, alguns } \\
\text { pseudomorfos de piroxênio e alguns domínios muito finos, talvez de } \\
\text { caolinita. Material poroso. }\end{array}$ \\
\hline M1C1000 & 10,00 & Quartzo e Magnetita & $\begin{array}{l}\text { Gibbsita, Caolinita e Oxi- } \\
\text { hidróxido de Ferro }\end{array}$ & $\begin{array}{l}\text { Isalterita. Predomínio de plasma argilo-ferruginoso (porfirosquélico, } \\
\text { iniciando evolução para aglomeroplásmico, com formação de agregados e } \\
\text { abertura de fissuras). Esqueleto de quartzo (pouco abundante e } \\
\text { fragmentado) e magnetita. Agregados de gibbsita. Longas fissuras com } \\
\text { caolinita bem cristalizada, o que parece diminuir a porosidade fissural. } \\
\text { Material medianamente poroso. }\end{array}$ \\
\hline $\begin{array}{c}\text { ROCHA } \\
\text { ALTERADA } \\
\text { Horizonte II-A }\end{array}$ & $\sim 15,0$ & $\begin{array}{l}\text { Quartzo, Feldspato e } \\
\text { Magnetita }\end{array}$ & $\begin{array}{l}\text { Gibbsita, Caolinita e Oxi- } \\
\text { hidróxido de Ferro }\end{array}$ & $\begin{array}{l}\text { Material pouco intemperizado, com feldspato e biotita semi-alterados, } \\
\text { pouca mica branca ainda preservada. Material pouco poroso. }\end{array}$ \\
\hline $\begin{array}{c}\text { ROCHA } \\
\text { ALTERADA } \\
\text { Horizonte II-B }\end{array}$ & $\sim 20,0$ & $\begin{array}{l}\text { Quartzo, Feldspato, } \\
\text { Biotita, Hornblenda e } \\
\text { Magnetita }\end{array}$ & $\begin{array}{l}\text { Gibbsita, Caolinita e Oxi- } \\
\text { hidróxido de Ferro }\end{array}$ & $\begin{array}{l}\text { Granito intemperizado com as seguintes filiações mineralógicas: feldspato } \\
\text { resultando em gibbsita, hornblenda e biotita transformado em oxi- } \\
\text { hidróxidos de ferro e gibbsita (talvez em caolinita); quartzo parcialmente } \\
\text { dissolvido e invadido por produtos supérgenos (ferruginosos e aluminosos). } \\
\text { A porosidade já é bastante significativa (macroporos presentes nos vazios } \\
\text { dos pseudomorfos e nas fissuras transminerais, e microporos presentes nos } \\
\text { volumes formados pelos minerais supérgenos). }\end{array}$ \\
\hline ROCHA SÃ & $?$ & $\begin{array}{l}\text { Quartzo, Feldspato, } \\
\text { Biotita, Hornblenda e } \\
\text { Magnetita }\end{array}$ & & $\begin{array}{l}\text { Granito inalterado, praticamente sem orientação, com textura grossa dos } \\
\text { grãos de quartzo, feldspato, biotita, hornblenda e magnetita. Apesar da } \\
\text { rocha ser sã, já se observa leve ferruginização das descontinuidades dos } \\
\text { ferromagnesianos, mostrando que já há percolação de água. Porosidade não } \\
\text { visível ao microscópio óptico. }\end{array}$ \\
\hline
\end{tabular}

Na área de estudo do Perequê-Mirim, a rocha de origem do perfil de alteração é um tipo peculiar de granito, conhecido como “Charnockito de Ubatuba” ou “Granito Verde de Ubatuba”. Esse tipo de rocha difere dos granitos comuns por sua cor escura, devido à presença de feldspato do tipo anortoclásio, que algumas vezes assume a cor verde, quase preta. A rocha possui granulometria 
grosseira, com os grãos minerais variando de 1,0 a 10,0 milímetros, sendo constituída basicamente por quartzo, feldspato e piroxênio (do tipo hiperstênio). A origem dessas rochas é controversa entre o magmatismo e o metamorfismo de alto grau. A tendência atual é considerar este tipo de rocha como de origem ígnea, devido à ausência ou raridade de minerais máficos hidratados como biotita e anfibólio.

Na área de estudo do Perequê-Mirim o perfil de alteração é completo, ao contrário do perfil de Maranduba. Durante a coleta das amostras foi possível observar a rocha sã e alterada, na base do perfil (aproximadamente 15,0 a 20,0 metros de profundidade), seguida, em direção ao topo, por isalterita até cerca de 3,5 metros, depois material aloterítico com feições de solo stricto sensu nos decímetros do topo.

A Tabela 5.5 apresenta as principais feições mineralógicas e micromorfológicas do perfil de alteração típico da área do Perequê-Mirim, identificados pelas análises de difração de raios-X e observados em lâminas delgadas ao microscópio óptico.

Tabela 5.5 - Principais feições mineralógicas e micromorfológicas do perfil de alteração da área de estudo do Perequê-Mirim.

\begin{tabular}{|c|c|c|c|c|}
\hline Amostra & Prof. (m) & Mineral I & Mineral II & Feições Micromorfológicas \\
\hline P1A30 & 0,30 & Quartzo & $\begin{array}{l}\text { Gibbsita, Caolinita e Oxi- } \\
\text { hidróxido de Ferro }\end{array}$ & $\begin{array}{l}\text { Aloterita. Material muito poroso, com quartzo e pequenos domínios } \\
\text { preservando as estruturas e o plasma primário (ferruginoso e/ou gibbsítico). }\end{array}$ \\
\hline BLOCO 3 & 0,50 & Quartzo & $\begin{array}{l}\text { Gibbsita, Caolinita e Oxi- } \\
\text { hidróxido de Ferro }\end{array}$ & $\begin{array}{l}\text { Aloterita. Material com estrutura porfirosquélica tendendo a } \\
\text { aglomeroplásmica, apresenta fragmentos de quartzo, magnetita e de } \\
\text { agregados de gibbsita. Material muitíssimo poroso com macroporosidade } \\
\text { visível. }\end{array}$ \\
\hline P1C350 & 3,50 & Quartzo & $\begin{array}{l}\text { Gibbsita, Caolinita e Oxi- } \\
\text { hidróxido de Ferro }\end{array}$ & $\begin{array}{l}\text { Aloterita. Plasma II argilo-ferruginoso, porfirosquélico tendendo a } \\
\text { aglomeroplásmico; grande quantidade de fragmentos de quartzo com } \\
\text { tamanhos variados, fragmentos de magnetita e de pseudomorfos micáceos, } \\
\text { pequenos agregados de gibbsita. Material com significativa porosidade, } \\
\text { mas menor que o horizonte superior. }\end{array}$ \\
\hline $\begin{array}{l}\text { P1C350 } \\
\text { (variação } \\
\text { lateral) }\end{array}$ & & Quartzo e Magnetita & & $\begin{array}{l}\text { Isalterita. Presença de quartzo e magnetita fragmentados, gibbsita em } \\
\text { pseudomorfos porosos de feldspatos. Pseudomorfos de mica ferruginizados } \\
\text { e/ou caolinizados e/ou gibbsitizados. Alta porosidade. }\end{array}$ \\
\hline BLOCO 4 & 6,70 & $\begin{array}{l}\text { Quartzo, Ilita e } \\
\text { Feldspato }\end{array}$ & $\begin{array}{l}\text { Gibbsita, Caolinita e Oxi- } \\
\text { hidróxido de Ferro }\end{array}$ & $\begin{array}{l}\text { Isalterita. Plasma II de caolinita, com esqueleto (quartzo + magnetita) e } \\
\text { plasma I de pseudomorfos micáceos totalmente caolinizados ou não, mais } \\
\text { ou menos ferruginizados (muito abundante). Os grãos de quartzo estão } \\
\text { muito fragmentados e com sinais de dissolução. Pseudomorfos irregulares } \\
\text { de piroxênio, em oxi-hidróxidos de ferro. Material com elevada quantidade } \\
\text { de micro e macroporos. }\end{array}$ \\
\hline P1C750 & 7,50 & $\begin{array}{l}\text { Quartzo, Ilita, } \\
\text { Feldspato, Biotita e } \\
\text { Magnetita }\end{array}$ & $\begin{array}{l}\text { Gibbsita, Caolinita e Oxi- } \\
\text { hidróxido de Ferro }\end{array}$ & $\begin{array}{l}\text { Isalterita. Todos os minerais primários encontram-se afetados pelo } \\
\text { intemperismo, com exceção do quartzo. Plasma II com fragmentos de } \\
\text { quartzo e também de magnetita (abundantes), feldspato semi- } \\
\text { intemperizado. Abundância de pseudomorfos micáceos em caolinita e oxi- } \\
\text { hidróxido de ferro (preservados, deformados ou fragmentados). Material } \\
\text { muito impregnado por produtos ferruginosos e com elevada } \\
\text { microporosidade. }\end{array}$ \\
\hline ROCHA SÃ & ? & $\begin{array}{l}\text { Quartzo, Feldspato, } \\
\text { Anfibólio, Biotita e } \\
\text { Magnetita }\end{array}$ & & $\begin{array}{l}\text { Charnockito de granulometria grosseira, com volumes restritos mais finos. } \\
\text { Início da alteração de piroxênio, com formação de produtos ferruginosos } \\
\text { nas descontinuidades e início de formação de porosidade. }\end{array}$ \\
\hline
\end{tabular}




\subsubsection{Síntese da evolução dos perfis de alteração estudados}

As rochas de origem dos dois perfis de alteração são semelhantes do ponto de vista geoquímico e mineralógico, pois são rochas graníticas (granito-gnaisse na área de Maranduba e charnockito na área do Perequê-Mirim). Esta condição contribui sobremaneira para a semelhança encontrada entre os minerais formados nos dois perfis de alteração, que são basicamente quartzo, caolinita e gibbsita, além de certa quantidade variável de oxi-hidróxidos de ferro (e.g. hematita, magnetita e maghemita).

Ambas as rochas possuem textura grossa e porosidade quase nula no início do processo de intemperismo. O granito-gnaisse apresenta mais heterogeneidade na distribuição dos minerais primários, com bandas mais ou menos micáceas e quartzosas, o que tem reflexos no grau de ferruginização e na proporção de argila, em função da condição inicial de cada porção da rocha parental.

O intemperismo atua primeiramente nos minerais mais frágeis entre aqueles presentes nos perfis estudados (ferromagnesianos, inclusive biotita; feldspatos e depois o quartzo). Da base para o topo dos perfis de alteração, os materiais encontram-se progressivamente mais intemperizados, chegando à pedogênese, com evolução das características associadas aos processos naturais. A porosidade passa de praticamente nula (na rocha sã) a alta (na isalterita), depois diminui (na aloterita) e volta aumentar no solo stricto sensu.

Os teores de argila aumentam em direção ao topo dos perfis de alteração, mas de forma não linear, o que é facilmente compreendido quando se destaca a heterogeneidade da rocha sã, ora mais quartzosa (resultando em materiais intemperizados menos argilosos), ora mais micácea (resultando em materiais mais argilosos e ferruginosos). Os minerais supérgenos (minerais II) ocorrem desde a base dos perfis, sendo a gibbsita aparentemente mais abundante que a caolinita entre os minerais aluminosos. Já os produtos ferruginosos (hematita e magnetita), que também são abundantes, ocorrem disseminados ao longo dos perfis, geralmente nas zonas de maior circulação de água e também nas regiões onde ocorrem pseudomorfos micáceos ou associados ao plasma secundário. Nas Figuras 5.15 e 5.16 são apresentadas resumidamente todas as informações sobre os estudos micromorfológicos dos perfis de alteração das áreas de estudo. 


\section{Horizonte I-A (Amostra M2A50)}

Presença de fissuras separando volumes de fundo matricial e insta lação da estrutura aglomeroplásmica. Predomínio de plasma II (argilo-ferruginoso) e quase não há pseudomorfos micáceos. Há alguns pequenos agregados de gibbsita na forma de nódulos ou altero-relíquias). Material poroso.

\section{Horizonte I-B (Amostra Bloco 2)}

Aloterita. Plasma II muito ferruginoso com abundância de fragmentos de quartzo e magnetita e pseudomorfos de mica; proporção de grãos do esqueleto, plasma I e plasma II praticamente equilibrada. Material poroso.

\section{Horizonte I-C (Amostra Bloco 1)}

Aloterita em estágio de transição. Plasma II caolinítico (talvez também gibbsítico) porfirosquélico, com abundância de fragmentos de quartzo e magnetita parcialmente dissolvida, pseudomorfos micáceos caolinizados e pouco ferruginizados, com manchas e faixas vermelhas de oxi-hidróxidos de ferro. Porosidade variável em função do caráter de transição isalterita/aloterita.

\section{Horizonte II-A (Rocha Alterada)}

Granito intemperizado com estrutura conservada (isalterita), com as seguintes filiações mineralógicas observadas: feldspato resultando em gibbsita, hornblenda e biotita em oxi-hidróxidos de ferro e gibbsita; quartzo parcia lmente dissolvido. Apresenta macroporosidade nos vazios dos pseudomorfos e em fissuras transminerais; a microporosidade é inferida pela textura nos volumes formados pelos minerais supérgenos em textura mais maciça.
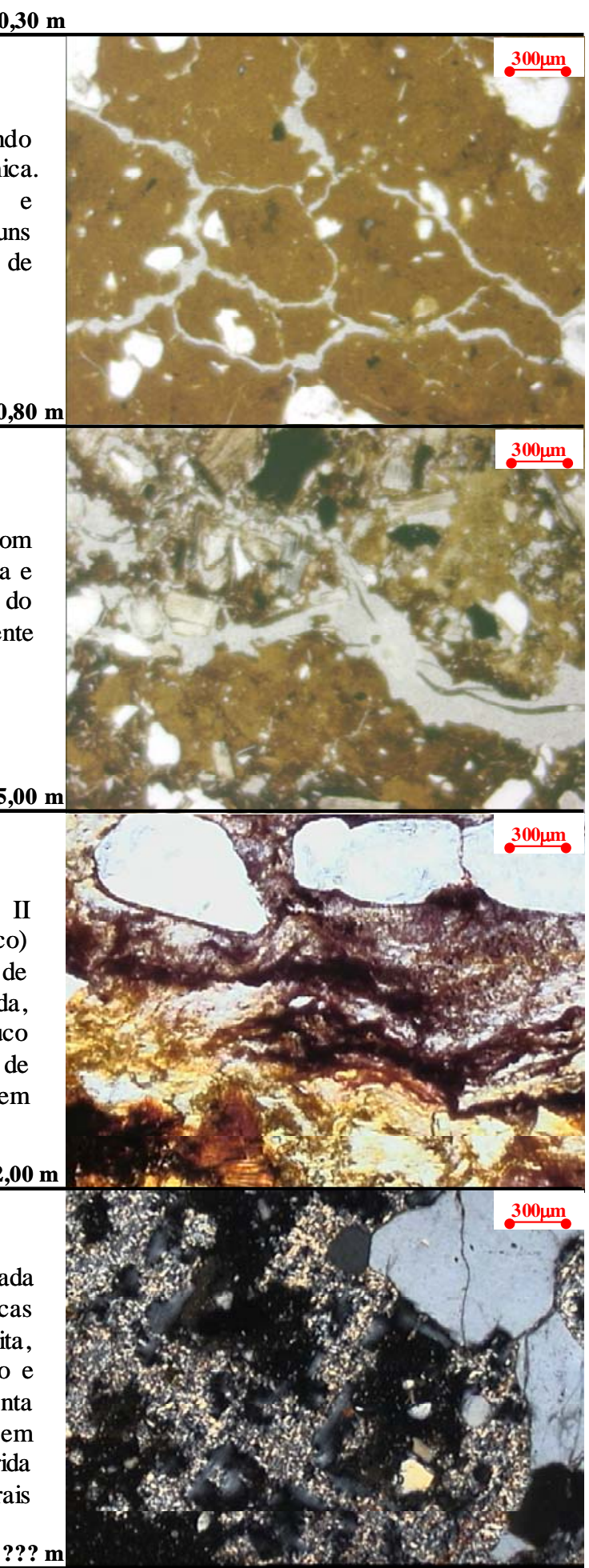

\section{FIGURA 5.15 - MICROFOTOGRAFIAS E FEIÇÕES MICROMORFOLÓGICAS OBSERVADAS NOS} HORIZONTES DE SOLO CARACTERÍSTICOS DO PERFIL DE ALTERAÇÃO DE MARANDUBA. 


\section{Horizonte I-A (Amostra Bloco 3)}

Material com estrutura porfirosquélica tendendo a aglomeroplásmica. Apresenta fragmentos de quartzo, magnetita e de agregados de gibbsita. Material muitíssimo poroso com macroporosidade visível.

\section{Horizonte I-C (Amostra P1 C350)}

Aloterita. Plasma II argilo-ferruginoso com grande quantidade de fragmentos de quartzo de tamanhos variados, fragmentos de magnetita e pseudomorfos micáceos; pequenos agregados de gibbsita. Material com significativa porosidade, mas menor que 0 horizonte superior.

\section{Horizonte I-C (Amostra Bloco 4)}

Isalterita. Plasma II de caulinita com esqueleto (quartzo+magnetita) e Plasma I de pseudomorfos micáceos totalmente caulinizados ou não, mais ou menos ferruginizados (em abundância). Os grãos de quartzo estão muito fragmentados e com sinais de dissolução. Material com elevada quantidade de micro e macroporos.

\section{Horizonte III (Rocha Sã)}

Charnockito de granulometria grosseira, com volumes restritos mais finos. Início da alteração de piroxênio, com formação de produtos ferruginosos nas descontinuidades e início de formação de porosidade.
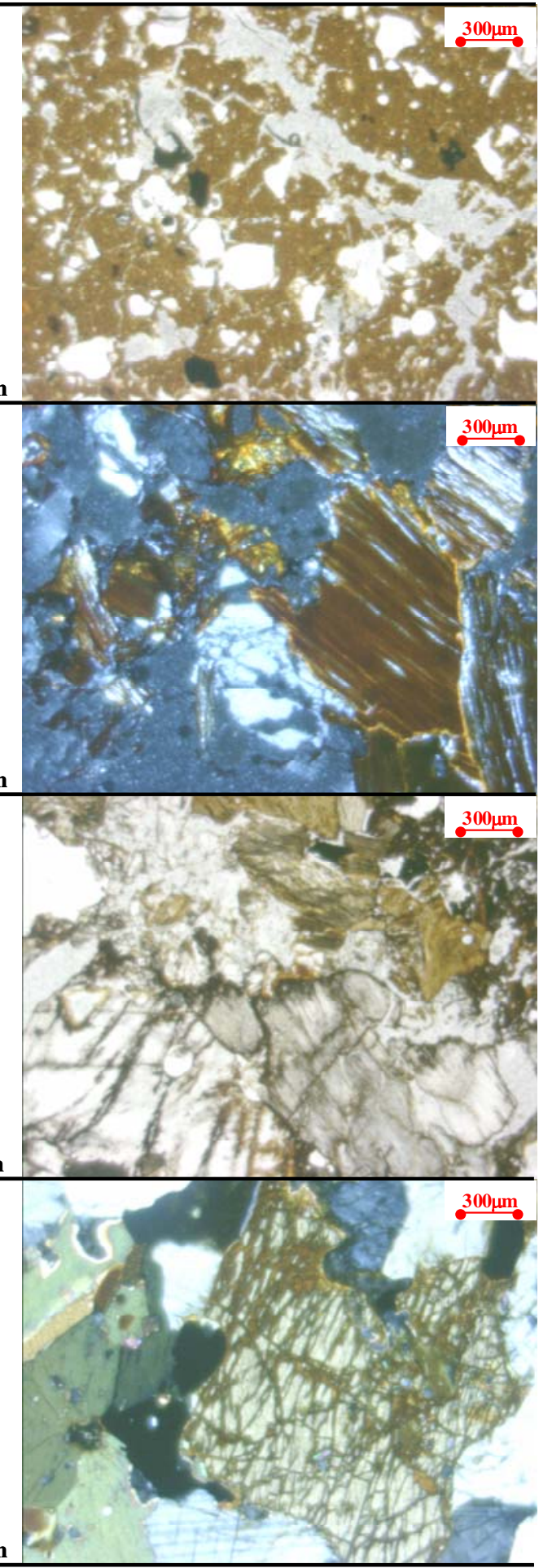

FIGURA 5.16 - MICROFOTOGRAFIAS E FEIÇÕES MICROMORFOLÓGICAS OBSERVADAS NOS HORIZONTES DE SOLO CARACTERÍSTICOS DO PERFIL DE ALTERAÇÃO DO PEREQUÊ-MIRIM. 


\subsection{Obtenção das Curvas de Retenção de Água (CRA)}

Antes de iniciar os ensaios para a obtenção das curvas de retenção de água foram medidas as sucções inicias de campo dos corpos de prova com o auxílio do tensiômetro de alta capacidade (TAC). Essa medição foi realizada colocando-se sobre a pedra porosa do TAC uma pasta feita com o mesmo tipo de solo do corpo de prova. A pasta foi preparada com material passante na peneira n40 e consistência próxima ao seu limite de liquidez. Em seguida, o corpo de prova foi envolvido por filme plástico e colocado sobre a pasta.

Como a superfície inferior de alguns corpos de prova continha certas irregulares, apresentando uma notável quantidade de vazios, optou-se por preenchê-las com a mesma pasta que foi utilizada sobre a pedra porosa do TAC. A Tabela 5.6 indica os valores das sucções iniciais de campo dos corpos de prova medidas com o TAC. Os valores marcados com asterisco $(*)$ indicam que a sucção não se estabilizou durante o processo de medição.

Tabela 5.6 - Sucções iniciais de campo dos corpos de prova.

\begin{tabular}{cc}
\hline Solo & Sucção (kPa) \\
\hline${ }^{*}$ M2A30 & 15 \\
${ }^{*}$ M2A50 & 490 \\
M2B130 & 200 \\
M2B335 & 470 \\
M2B500 & 162 \\
M1C600 & 27 \\
${ }^{*}$ M1C800 & 148 \\
M1C1000 & 56 \\
P1C650 & 40 \\
P1C350 & 12 \\
P1C750a & 9 \\
P1C750b & 4 \\
Bloco 1 & 39 \\
Bloco 2 & 37 \\
Bloco 3 & 22 \\
Bloco 4 & 12 \\
\hline *alor da sucção não estabilizou
\end{tabular}


Após a etapa de medição das sucções iniciais, os corpos de prova foram levados para o início do processo de saturação. Durante o processo de saturação, alguns corpos de prova constituídos por solo muito pouco coesivo (M1C600, P1C750 e P1C500a) apresentaram significativa perda de consistência, dificultando o seu manuseio e as determinações de suas medidas, tais como diâmetro e altura.

O tempo necessário para o equilíbrio da "saturação aparente" dos corpos de prova variou de acordo com o tipo de solo. Em termos gerais, o tempo necessário verificado para atingir a saturação aparente foi de 8 a 12 dias. Para o levantamento dos pontos experimentais das CRAs foram utilizados diferentes equipamentos e técnicas. Na presente pesquisa utilizaram-se os seguintes métodos: placa de sucção, placa de pressão (translação de eixos) e a técnica do papel filtro.

\subsubsection{Placa de sucção}

A placa de sucção é formada por uma base circular metálica constituída de uma pedra porosa de $15 \mathrm{~cm}$ de diâmetro e 0,7 cm de espessura, com entrada de ar de $100 \mathrm{kPa}$. A placa fica apoiada em um suporte metálico que pode ser encaixado em pinos espaçados de 0,5 metro contidos na haste principal do equipamento, conforme apresentado na Figura 5.17. No Laboratório de Mecânica dos Solos da POLI-USP a altura dessa haste se limita a três metros, limitando a imposição da sucção em $30 \mathrm{kPa}$. O sistema base/pedra é conectado por um tubo plástico flexível à um pequeno reservatório de água. A altura desse reservatório pode ser regulada ao longo de uma haste metálica secundária situada ao lado da haste principal.

Esse equipamento foi utilizado para impor sucções entre 0 e $30 \mathrm{kPa}$, aumentando-se o desnível compreendido entre a metade da altura da amostra (colocado sobre a pedra porosa) e o topo do reservatório de água. A imposição do desnível pode ser feita tanto pelo rebaixamento do reservatório de água através da haste metálica secundária, como pela ascensão do suporte metálico nos pinos espaçados de meio metro na haste principal. Dessa forma, um desnível de $10 \mathrm{~cm}$ corresponde a uma sucção de $1 \mathrm{kPa}$. 

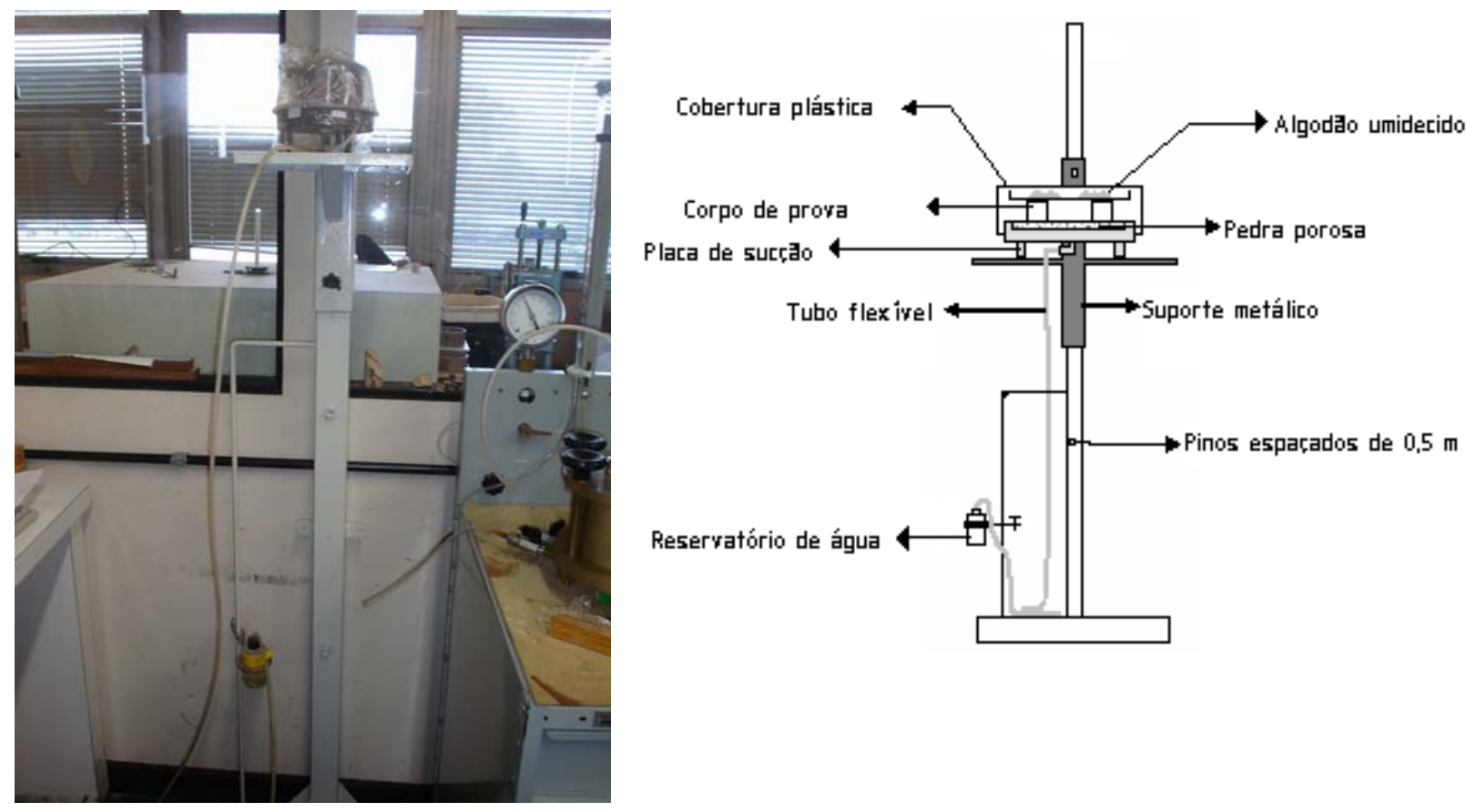

FIGURA 5.17 - ESQUEMA DA PLACA DE SUCÇÃO.

Durante a preparação dos corpos de prova foram obtidas diversas medidas como diâmetro, altura e massa. Posteriormente os corpos de prova foram colocados sobre a pedra porosa para início do processo de saturação. Nesta etapa foi aplicada uma carga positiva, impondo-se um desnível de $1 \mathrm{~cm}$ na base do corpo de prova. Assim os corpos de prova passaram a absorver água do reservatório e apresentar aumento de volume e massa. Colocou-se um pedaço de papel filtro entre a pedra porosa e a superfície inferior dos corpos de prova com o intuito de melhorar o contato e evitar a perda de solo para a pedra durante a retirada dos mesmos.

Visando evitar a perda de umidade do sistema interno (formado pela placa de sucção e pelos corpos de prova), colocou-se um recipiente com algodão umedecido em cima dos corpos de prova e depois o sistema foi isolado do ambiente externo por meio de um filme plástico, conforme apresentado na Figura 5.17.

Depois que os corpos de prova atingiram a "saturação aparente", foram impostos os seguintes incrementos de sucções: 1, 2, 4, 6, 8, 10, 12, 14, 16, 18, 20, 25 e 30kPa. Após os corpos de prova terem atingido o equilíbrio (que ocorreu para um intervalo de tempo superior a 2 dias, indicando 
que sua sucção tornou-se igual à sucção imposta pela pedra porosa), os mesmos foram levados para pesagem e anotação de suas medidas (altura e diâmetro).

\subsubsection{Placa de pressão}

A placa de pressão é composta por uma câmara metálica formada por três partes principais: uma tampa dotada de uma válvula para a entrada e pressurização de ar, um cilindro metálico que forma o corpo da câmara e uma base de latão, semelhante à placa de sucção. A base contém uma pedra porosa de $15 \mathrm{~cm}$ de diâmetro e 0,7 cm de espessura, com entrada de ar de 500 $\mathrm{kPa}$, sobre a qual são colocados os corpos de prova (Figura 5.18). Na parte inferior da base encontram-se duas válvulas, uma ligada a bureta graduada e outra destinada à circulação de água na base, por onde se pode extrair bolhas de ar eventualmente alojadas na câmara de água. O conjunto cilindro/base é fechado por seis parafusos juntamente com a tampa garantindo um ambiente capaz de suportar elevadas pressões. Nas extremidades das peças temos “o-rings” para garantir a estanqueidade do conjunto.
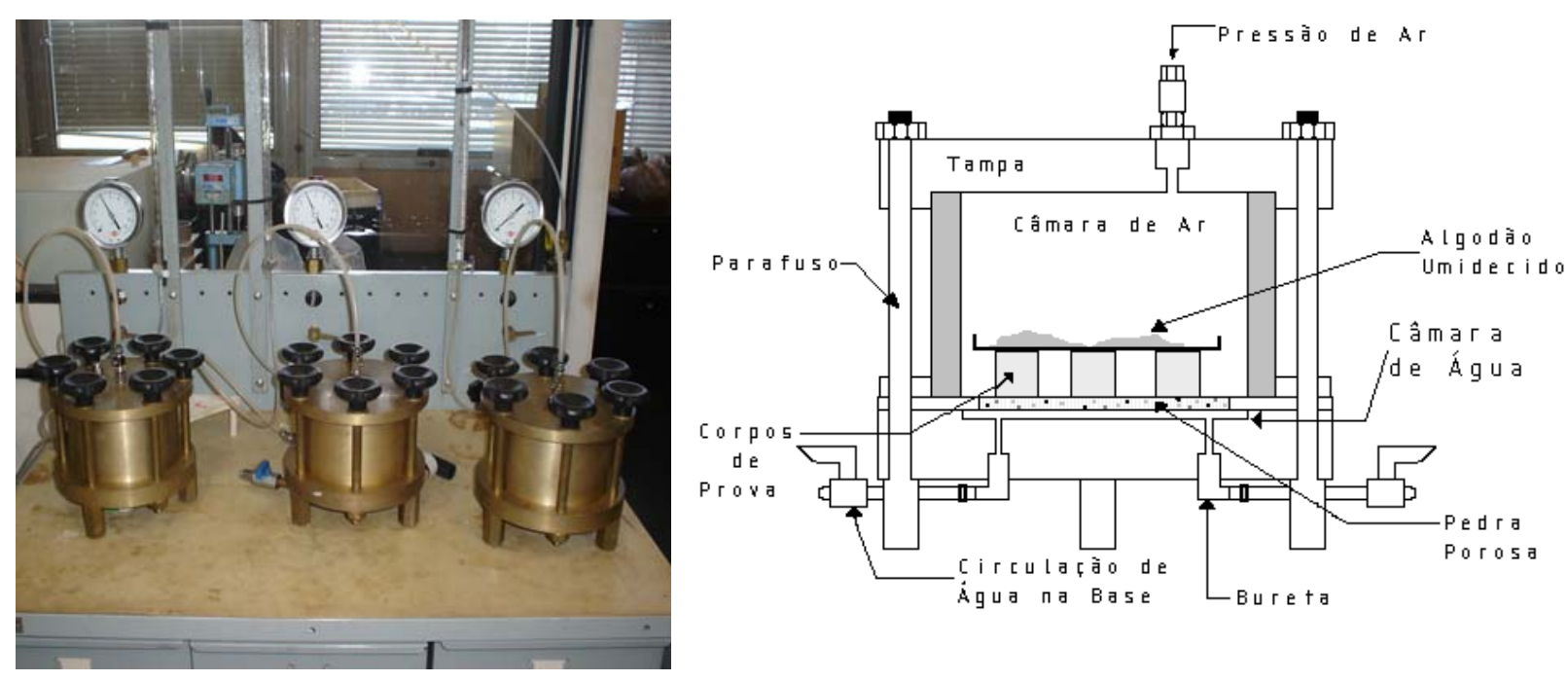

FIGURA 5.18 - ESQUEMA DA PLACA DE PRESSÃO.

A faixa de sucção sob a qual a placa pode trabalhar depende da pedra porosa e da capacidade de aplicação de pressão de ar do sistema. No equipamento utilizado a sucção máxima imposta foi de $500 \mathrm{kPa}$, sendo utilizada a técnica da translação de eixos proposta por HILF (1956). 
Conforme abordado anteriormente, uma das válvulas da base está diretamente conectada a bureta graduada, proporcionando uma coluna de água contínua entre a pedra porosa e a bureta. Dessa forma, pode-se dizer que a pedra porosa está com o mesmo valor da pressão atmosférica (pressão relativa igual a zero) e conseqüentemente, a sucção imposta neste equipamento corresponde ao valor da pressão de ar aplicada. Assim, caso se pretenda impor uma trajetória de secagem dos corpos de prova, aumenta-se a pressão de ar e no caso de uma trajetória de umedecimento diminui-se a pressão de ar.

Antes de iniciar os ensaios na placa de pressão, foi necessário realizar a saturação da pedra porosa. A saturação foi realizada inundando-se a base da câmara de ar com água destilada até aproximadamente a metade de sua altura, e em seguida aplicando-se uma determinada pressão no interior da câmara. Após esse procedimento, realizou-se a remoção de ar na parte inferior da pedra porosa a partir da circulação de água pela base. Após o término dessa etapa, o excesso de água da pedra porosa foi removido com auxílio de um pano e os corpos de prova foram colocados sobre a mesma e submetidos a sucções de 50, 100, 150, 200, 300 e 400 kPa.

O equilíbrio da sucção dos corpos de prova foi acompanhado por leituras diárias da variação do volume de água na bureta. Após essa variação de volume permanecer constante, considerou-se que as amostras atingiram a sucção imposta e em seguida os corpos de prova foram levados para pesagem e anotação de suas medidas (altura e diâmetro). Em média, verificou-se que são necessários 3 dias para que os mesmos atinjam o equilíbrio.

\subsubsection{Papel filtro}

A técnica do papel filtro tem sido muito utilizada para obtenção da CRA por ser um método fácil, de baixo custo e que consegue cobrir uma faixa de sucção relativamente grande. Entretanto, esta técnica apresenta desvantagens como a necessidade de extremo cuidado em sua execução e na interpretação dos resultados.

O método consiste em colocar um pedaço de papel filtro em contato direto com o solo. O papel, por ser um material poroso irá absorver água, tanto por meio do contato físico direto como pela absorção do vapor de água, até que seja estabelecido o equilíbrio entre ambos. 
O estado de equilíbrio entre ambos irá nos fornecer a mesma sucção no solo e no material poroso, porém com conteúdos de umidades diferentes. Dentre os vários pontos importantes da técnica do papel filtro, o tempo de equilíbrio de sucção entre a amostra de solo e o papel filtro é um dos mais importantes. No caso do presente trabalho o tempo de equilíbrio adotado variou de acordo com o valor de sucção aplicada. O tempo de equilíbrio adotado foi sugerido por MARINHO (1994), conforme apresentado na Tabela 5.7.

Tabela 5.7 - Tempo de equilíbrio sugerido para o papel filtro (MARINHO 1994).

\begin{tabular}{|c|c|}
\hline Nível de sucção $(\mathrm{kPa})$ & Tempo de equilíbrio (dias) \\
\hline $0-100$ & Indeterminado $(>30)$ \\
\hline $100-250$ & 15 \\
\hline $250-1000$ & 7 \\
\hline$>1000$ & \\
\hline
\end{tabular}

O valor da sucção imposta e o teor de umidade do papel correspondem a um ponto da curva de calibração. A determinação da sucção do solo a partir da umidade do papel filtro é feita com base nessa curva. Os papéis filtros mais utilizados são Whatman n²42 e o Scheicher \& Schell n589.

A técnica do papel filtro foi utilizada para valores de sucção superiores a $400 \mathrm{kPa}$. As equações de calibração em função da umidade para o papel filtro Whatman foram propostas por CHANDLER et al. (1992). No entanto, MARINHO \& OLIVEIRA (2006) observaram que ao se aplicar as equações propostas por Chandler op cit, num determinado lote do papel filtro Whatman, os resultados da curva de retenção apresentaram uma significativa descontinuidade no trecho inicial. Dessa forma, foi necessário o uso das equações de calibração para o papel filtro Whatman propostas por MARINHO \& OLIVEIRA (2006):

- $\quad$ Para $W<33 \%$ :

$$
\operatorname{Sucção}(k P a)=10^{(4,83-0,0839 . W)}
$$

- $\quad$ Para $W \geq 33 \%$ :

$$
\operatorname{Sucção~}(k P a)=10^{(2,57-0,0154 . W)}
$$


Depois de finalizadas as medições na placa de pressão, os corpos de prova foram secos ao ar até atingirem um teor de umidade pré-estabelecido. Enquanto isso, o papel filtro foi cortado em duas partes de modo a terem praticamente o mesmo diâmetro dos corpos de prova. Após atingir o teor de umidade desejado, colocou-se uma das partes do papel na superfície superior do corpo de prova e a outra na superfície inferior conforme indicado na Figura 5.19. Deve-se ressaltar que durante a manipulação com o papel filtro utilizou-se uma pinça metálica para evitar qualquer tipo de alteração em suas características originais.
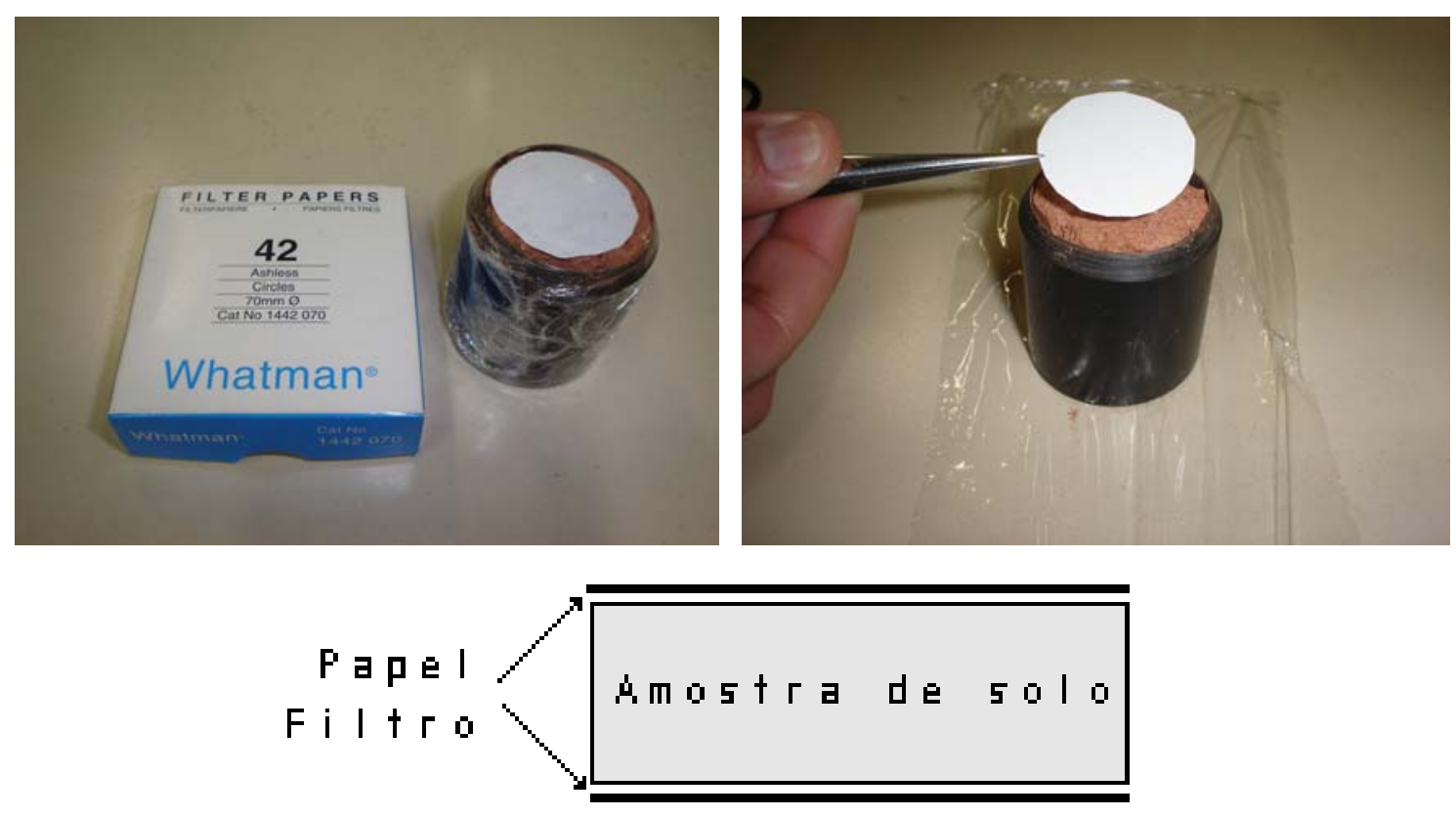

FIGURA 5.19 - TÉCNICA DO PAPEL FILTRO

Em seguida os corpos de prova com os papéis foram envolvidos por filme plástico e papel alumínio e deixados em repouso no interior de uma caixa de isopor por um período de 7 a 15 dias. Esse procedimento foi realizado para garantir que o fluxo de água ocorra somente entre o solo e o papel, evitando a interferência do ambiente externo.

Com o equilíbrio supostamente atingido, os papéis filtro foram retirados rapidamente dos corpos de prova (tempo de exposição ao ar menor que 5 segundos) e colocados em sacos plásticos auto selantes. Após a pesagem e determinação do peso úmido, os papéis foram colocados em cápsulas e conduzidos à estufa, onde permaneceram por no mínimo 4 horas. Depois de seco, o papel filtro 
foi rapidamente retirado da estufa e colocado em sacos plásticos para a determinação de sua massa.

A partir dos valores do teor de umidade do papel filtro e das equações de calibração propostas por MARINHO \& OLIVEIRA (2006), os valores de sucção dos corpos de prova foram obtidos. Para a obtenção de outros pontos experimentais das curvas de retenção, os mesmos procedimentos foram adotados.

\subsubsection{Resultados das curvas de retenção de água (CRAs)}

Neste item são apresentados e analisados todos os resultados das CRAs obtidas nesta pesquisa. As CRAs foram analisadas utilizando-se os valores da sucção matricial em função do grau de saturação, teor de umidade gravimétrico e índices de vazios. Os pontos experimentais das CRA foram obtidos a partir da combinação das seguintes técnicas: placa de sucção, placa de pressão e papel filtro. As CRAs foram obtidas a partir de corpos de prova talhados em anéis cilíndricos biselados de PVC com 5,0 cm de altura e 4,0 cm de diâmetro interno. Utilizou-se apenas um corpo de prova para a obtenção de todos os pontos experimentais da CRA representativa de cada tipo de solo.

Na Figura 5.20 são apresentadas as CRAs dos corpos de prova coletados na área de estudo de Maranduba. As CRAs dos corpos de prova M2A30, M2A50, Bloco2, M2B500, M1C600 e Bloco1, indicam existir um comportamento de distribuição dos tamanhos de poros do tipo bimodal, fato este que foi confirmado pelos ensaios de porosimetria por intrusão de mercúrio, conforme apresentado mais adiante. Em relação ao formato das CRAs, nota-se que os solos do horizonte superficial (M2A30 e M2A50) apresentaram curvas com "patamares” mais evidentes em relação aos solos dos demais horizontes. Esses "patamares” representam trechos, onde uma grande variação do grau de saturação ou teor de umidade gera uma pequena alteração da sucção matricial do solo. Nota-se também que praticamente não houve uma expressiva variação do índice de vazios durante a obtenção das CRAs dos solos de Maranduba para sucções impostas de até $700 \mathrm{kPa}$, com exceção da amostra M1C800. 

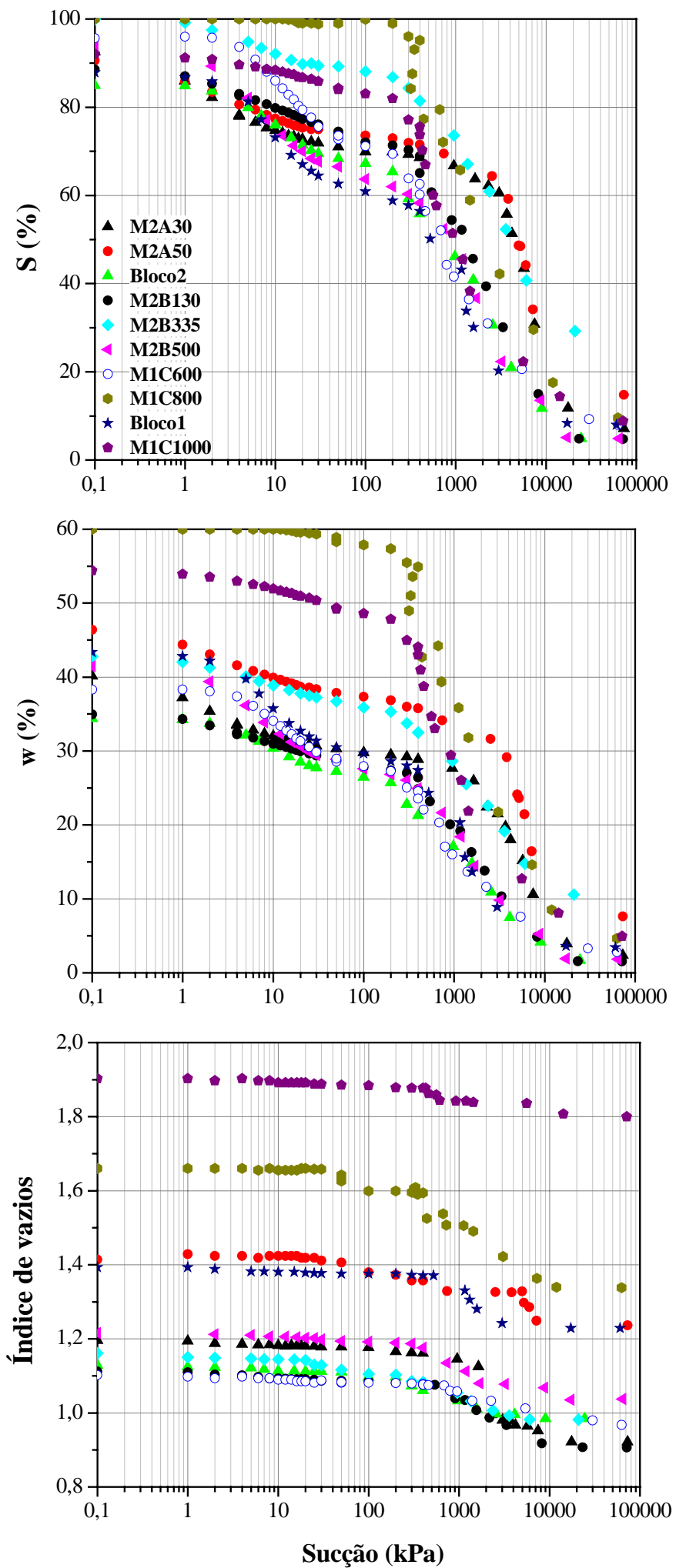

FigurA 5.20 - CURVAS DE RETENÇÃo DE ÁGUA DOS SOLOS DE MARANDUBA. 

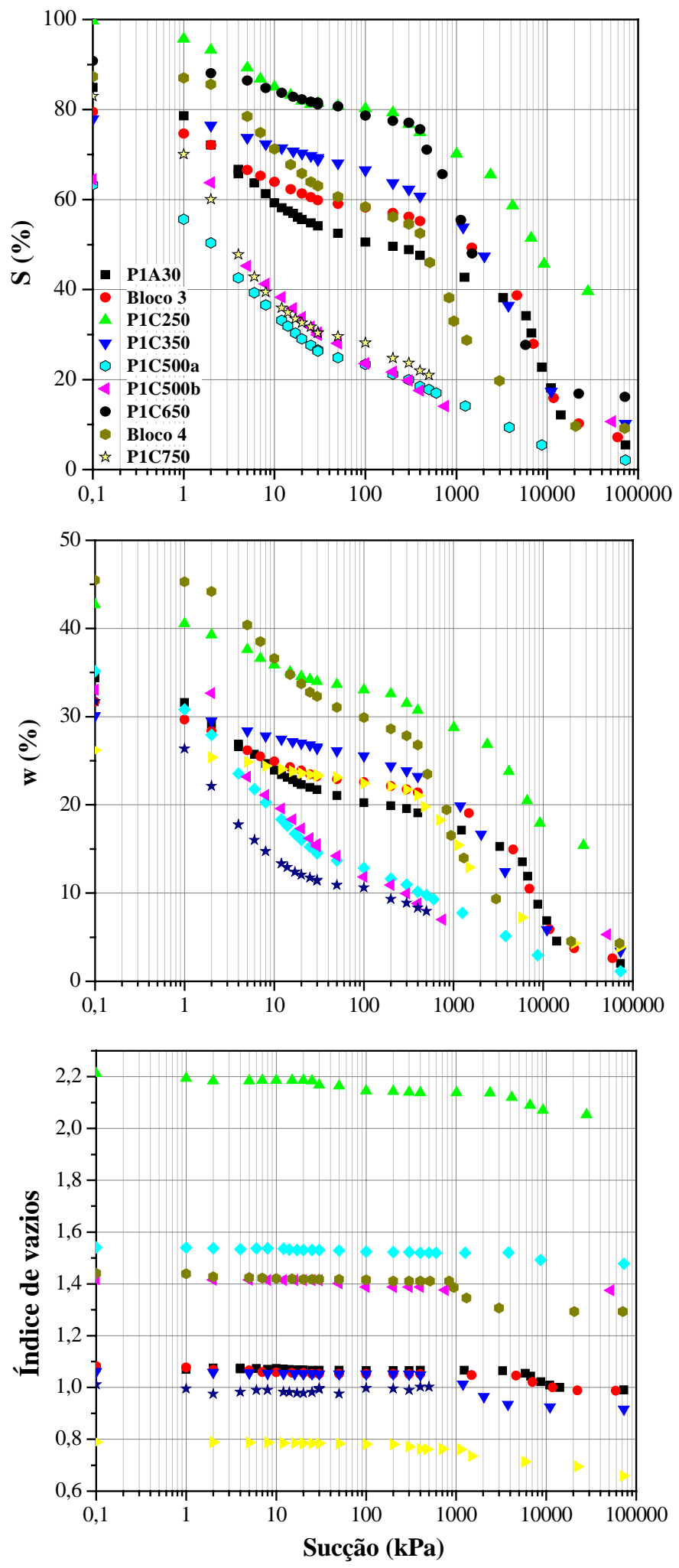

Figura 5.21 - CURVAS DE RETENÇÃo DE ÁGUA DOS SOlOS DO PEREQUÊ-MiRIM. 
Na Figura 5.21 são apresentadas as CRAs dos corpos de prova coletados na área de estudo do Perequê-Mirim. Nessa figura, algumas CRAs indicam claramente existir um comportamento de distribuição dos tamanhos de poros do tipo bimodal (P1A30, Bloco3, P1C250 e Bloco4), que também foi confirmado pelos ensaios de porosimetria por intrusão de mercúrio, conforme apresentado no próximo item. Nota-se também que as CRAs dos solos do horizonte superficial (P1A30 e Bloco3), apresentam um aspecto de “sela” mais pronunciado em relação aos solos dos demais horizontes, revelando trechos pequenos para solos mais arenosos e/ou siltosos (e.g. P1C250 e Bloco4).

Assim como ocorreu para os solos de Maranduba, o índice de vazios dos corpos de prova do Perequê-Mirim praticamente não variou durante a obtenção das CRAs, para sucções aplicadas de até $1.000 \mathrm{kPa}$.

Analisando as curvas de retenção de água dos solos estudados, apresentadas nas Figuras 5.20 e 5.21, observa-se que a maior parte dos corpos de prova não atingiu a saturação. Isto pode estar relacionado à tendência decrescente de retenção de água, em resposta à distribuição de microporos e à própria composição granulométrica e mineralógica dos solos que leva a uma dificuldade em preencher todos os poros com água. Por exemplo, os maiores graus de saturação foram atingidos pelos corpos de prova M1C800, M2B335, M1C600 e P1C250. Verifica-se que estes solos geralmente apresentam baixas quantidades de microporos e grandes quantidades de macroporos, além de baixos teores de argila, com exceção do solo M2B335. Essas características ressaltam a importância de se levar em consideração a distribuição de poros e da quantidade da fração fina na capacidade de retenção de água dos solos residuais tropicais.

Na Figura 5.22 são apresentadas as CRAs dos solos do horizonte mais superficial das duas áreas estudadas. Primeiramente, destaca-se a semelhança no comportamento de retenção de água para os dois solos de Maranduba (M2A30 e M2A50), apesar deles serem provenientes de diferentes locais ao longo da encosta. O corpo de prova M2A30 foi coletado em cota topográfica mais baixa, praticamente na porção inferior média da encosta, enquanto que o corpo de prova M2A50 foi coletado no topo da encosta. Esta semelhança caracteriza a origem residual das camadas que compõem o perfil de alteração típico adotado para esta área de estudo, pois dificilmente tem-se, no topo da encosta, camadas de solo cuja origem esteja relacionada com solos transportados. 


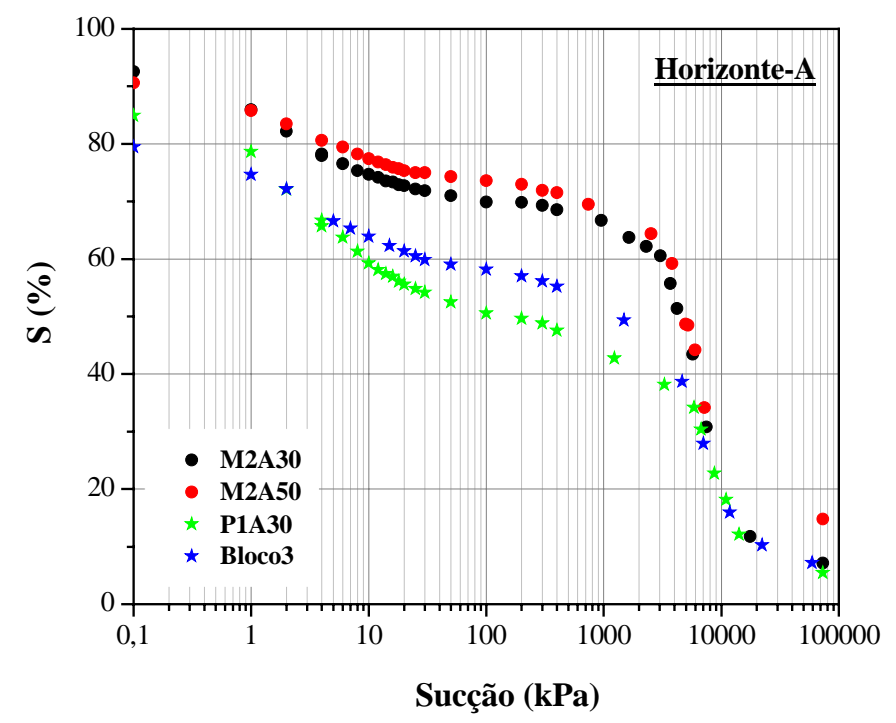

FIGURA 5.22 - CURVAS DE RETENÇÃO DE ÁGUA DO HORIZONTE DE SOLO A.

As curvas representativas do horizonte superficial da área de estudo do Perequê-Mirim apresentadas na Figura 5.22 (P1A30 e Bloco3), também apresentam o mesmo comportamento de retenção de água, o que era de se esperar, pois ambos os corpos de prova foram coletados no mesmo horizonte de solo, em profundidades muito próximas $(0,30$ e 0,50 metros, respectivamente). Comparando-se as CRAs do horizonte superficial das duas áreas de estudo, verifica-se comportamentos de retenção de água muito semelhantes, principalmente relacionado com a presença de “patamares”, que indica uma distribuição de poros do tipo bimodal.

Na Figura 5.23 são apresentadas as CRAs representativas do horizonte intermediário (horizonte IB), que ocorre somente no perfil de alteração típico de Maranduba. Observa-se que praticamente todas as curvas apresentam "patamares”, indicando uma distribuição de poros do tipo bimodal. Além disso, pode-se constatar que os solos desse horizonte possuem o mesmo comportamento de retenção de água, ou seja, apresentam valores de sucção muito próximos para um dado valor do grau de saturação ou teor de umidade gravimétrico, com exceção da curva M2B335. Tal curva difere apreciavelmente das demais pela sua capacidade de reter mais água para um dado nível de sucção. Esse comportamento provavelmente deve estar relacionado comparativamente com a quantidade de argila e de microporos presentes em seu arcabouço, conforme apresentado nas Figuras 5.7 e 5.30, respectivamente. 


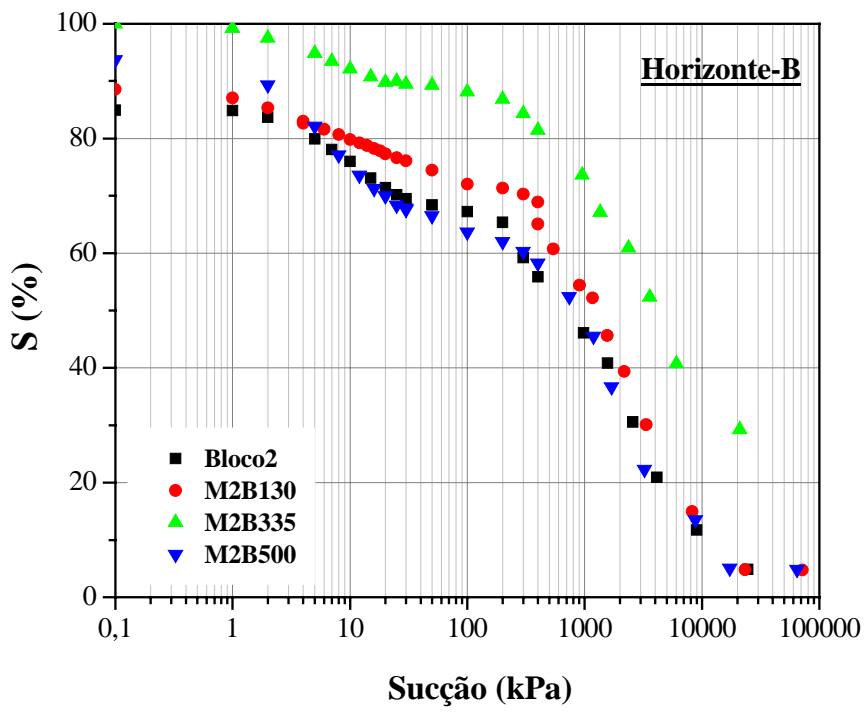

FIGURA 5.23 - CURVAS DE RETENÇÃO DE ÁGUA DO HORIZONTE I-B.

Na Figura 5.24 são apresentadas as CRAs dos solos do horizonte mais profundo que ocorre nos perfis de alteração das duas áreas de estudo. As curvas de retenção dos solos de Maranduba apresentam "patamares”, com exceção para as curvas dos solos M1C800 e M1C1000. O solo M1C1000 foi coletado numa anomalia geológica (falha geológica preenchida por material de composição básica de origem intrusiva) que ocorre num determinado trecho do primeiro perfil desta área de estudo e, portanto, seria irrelevante comparar sua CRA com as dos demais solos representativos do perfil de alteração. O solo M1C800 mostra uma maior capacidade de retenção d’água que os demais solos, principalmente para valores de sucção entre 10 a 300 kPa. Acreditase que esse comportamento esteja diretamente relacionado com o tipo de argilomineral presente na fração argila, pois os demais solos apresentam praticamente a mesma porcentagem de argila, e com a quantidade de macro e microporos presentes na estrutura deste solo.

Observa-se também, na Figura 5.24, que as CRAs do horizonte mais profundo da área do Perequê-Mirim apresentam diferenças significativas na capacidade de reter água. A ocorrência de “patamar” somente se verifica nas curvas do solo P1C250, P1C350, P1C650 e Bloco4. Estes solos também apresentaram maior capacidade de retenção de água para todos os níveis de sucção aplicados, em comparação com os demais tipos de solo. Verifica-se que este comportamento está relacionado com o conteúdo de argila e com a quantidade de microporos presente no arcabouço do solo. Por exemplo, o percentual de argila nestes solos são, respectivamente: 22.0, 15.0, 14.2 e 10.0, seguindo praticamente a mesma ordem da capacidade de retenção de água, ou seja, quanto 
menor o teor de argila, menor a capacidade de retenção d’água. Além disso, a presença de microporos na estrutura de tais amostras de solo tende a diminuir consideravelmente, conforme apresentado na Figura 5.32.
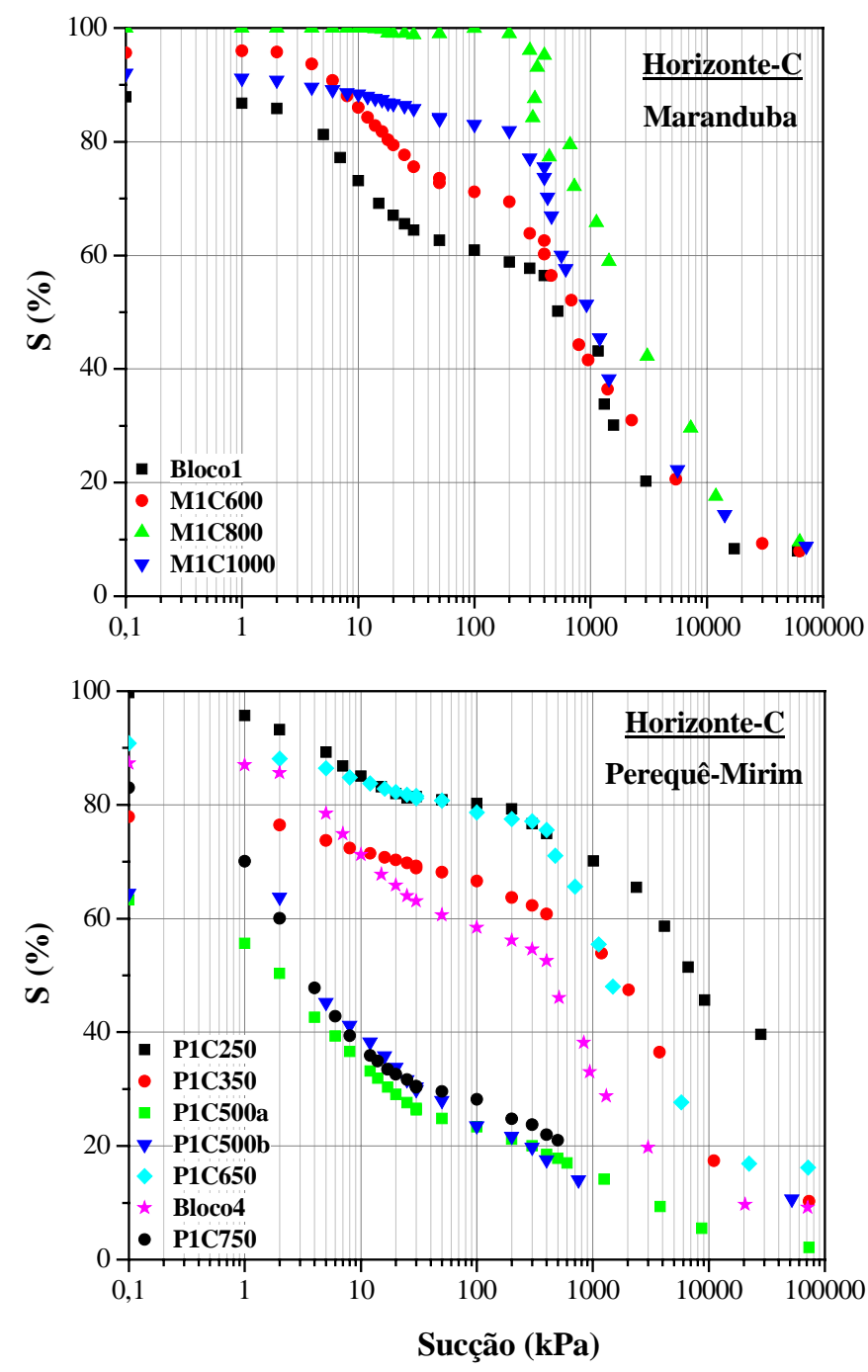

FIGURA 5.24 - CURVAS DE RETENÇÃO DE ÁGUA DO HORIZONTE I-C.

Em termos gerais, as curvas de retenção de água apresentaram diferentes tipos de comportamento ao longo dos perfis de alteração das áreas estudadas. Essas diferenças de comportamento devem estar relacionadas com o grau de intemperismo aos quais os solos estiveram submetidos, pois se observa uma nítida tendência de diminuição do teor de argila e aumento da quantidade de macroporos com o aumento da profundidade no perfil de alteração de Maranduba. Nota-se, nesse perfil, que o horizonte I-A é caracterizado por uma alta quantidade de argila e de microporos; e à 
medida que se avança em direção ao horizonte I-B ocorre uma diminuição apreciável do teor de argila e da quantidade de microporos, até que no horizonte I-C o teor de argila passa a ser muito baixo e a quantidade de macroporos no arcabouço do solo é praticamente dominante. Observa-se que no perfil de alteração do Perequê-Mirim, o comportamento é semelhante, porém com algumas diferenças entre as proporções de macro e microporos e do teor de argila.

Ressalta-se a importância do formato bi-modal das CRAs obtidas para a maioria dos solos estudados, pois permite identificar dois trechos distintos nas curvas de retenção: o primeiro comporta-se como uma CRA de um solo arenoso até um determinado valor de sucção, e o segundo trecho da CRA apresenta um comportamento similar à de um solo mais argiloso. Dependendo das variações do teor de umidade observadas no campo e do tipo de CRA, estes trechos poderão influenciar positiva ou negativamente o comportamento de resistência ao cisalhamento dos solos e, conseqüentemente, a condição de estabilidade das encostas ou taludes.

Quanto à variação de volume, pode-se dizer que praticamente não houve diminuição dos índices de vazios durante o procedimento de secagem dos corpos de prova, para valores de sucção de até $1.000 \mathrm{kPa}$, na área do Perequê-Mirim, e de até 700 kPa, na área de Maranduba.

Com o objetivo de se obter os parâmetros de ajuste das CRAs dos solos estudados utilizou-se o software RETC-versão 6.0, desenvolvido no U.S. Salinity Laboratory, USDA, Riverside, CA. Os parâmetros dos modelos matemáticos que melhor ajustaram os pontos experimentais são mostrados na Tabela 5.8.

Conforme indicado na Tabela 5.8, a maior parte das amostras foi ajustada pelo modelo dual porosity de DURNER (1994) que, para um meio constituído por uma porosidade dupla, sugere o emprego da seguinte função:

$$
S_{e}=w_{1} \cdot \frac{1}{\left[1+\left(\alpha_{1}|\psi|\right)^{n_{1}}\right]^{n_{1}}}+w_{2} \cdot \frac{1}{\left[1+\left(\alpha_{1}|\psi|\right)^{n_{2}}\right]^{n_{2}}},
$$

onde: $w_{i}$ é o peso atribuído a cada sub-curva, onde $0<w_{i}<1$ e $\sum w_{i}=1$. Os valores $\alpha_{\mathrm{i}}, n_{i}, m_{i}$ são os parâmetros das sub-curvas que estão sujeitas as seguintes condições $\alpha_{\mathrm{i}}>0, n_{i}>1$ e $m_{i}>0$; $\psi$ é a sucção matricial; $S_{e}$ é a saturação efetiva definida por: 


$$
S_{e}=\frac{\left(\theta-\theta_{R}\right)}{\left(\theta_{S}-\theta_{R}\right)}
$$

com $\theta_{S}$ e $\theta_{R}$, representando os teores de umidade volumétrica saturada e residual, respectivamente.

Tabela 5.8 - Parâmetros utilizados para ajustar os pontos experimentais.

\begin{tabular}{|c|c|c|c|c|c|c|c|c|c|c|c|c|}
\hline Amostras & Modelo de Ajuste & $\begin{array}{c}\theta_{\mathrm{R}} \\
(\%)\end{array}$ & $\begin{array}{c}\theta_{\mathrm{S}} \\
(\%)\end{array}$ & $\begin{array}{c}\alpha_{1} \\
(1 / \mathrm{cm})\end{array}$ & $\begin{array}{l}\mathbf{n}_{1} \\
(-)\end{array}$ & $\begin{array}{l}\mathbf{m}_{1} \\
(-)\end{array}$ & $\begin{array}{l}\mathrm{W}_{1} \\
(-)\end{array}$ & $\begin{array}{c}\alpha_{2} \\
(1 / \mathrm{cm})\end{array}$ & $\begin{array}{l}\mathbf{n}_{2} \\
(-)\end{array}$ & $\begin{array}{l}\mathbf{m}_{2} \\
(-)\end{array}$ & $\begin{array}{l}\mathrm{w}_{2} \\
(-)\end{array}$ & $\begin{array}{l}\mathbf{R}^{2} \\
(-)\end{array}$ \\
\hline M2A30 & Durner (dual porosity) & 0,00 & 60,59 & 0,0021 & 2,6942 & 0,6288 & 0,5000 & 1041,7450 & 1,1524 & 0,1323 & 0,5000 & 0,9968 \\
\hline M2A50 & Durner (dual porosity) & 0,00 & 54,91 & 0,0018 & 3,7449 & 0,7330 & 0,5000 & 155,7186 & 1,0791 & 0,0733 & 0,5000 & 0,9967 \\
\hline Bloco 2 & Durner (dual porosity) & 0,00 & 45,79 & 0,0075 & 2,1626 & 0,5376 & 0,5000 & 2,5728 & 1,2246 & 0,1834 & 0,5000 & 0,9954 \\
\hline M2B130 & Durner (dual porosity) & 0,00 & 47,04 & 3,4160 & 1,1652 & 0,1418 & 0,5000 & 0,0066 & 2,5107 & 0,6017 & 0,5000 & 0,9910 \\
\hline M2B335 & Durner (dual porosity) & 0,00 & 54,20 & 0,0070 & 1,8508 & 0,4597 & 0,5000 & 10,3504 & 1,0797 & 0,0738 & 0,5000 & 0,9974 \\
\hline M2B500 & Durner (dual porosity) & 0,00 & 52,26 & 6,8365 & 1,2690 & 0,2120 & 0,5000 & 0,0072 & 2,1304 & 0,5306 & 0,5000 & 0,9972 \\
\hline M1C600 & Durner (dual porosity) & 0,00 & 51,31 & 0,0149 & 1,8068 & 0,4465 & 0,5000 & 3,2641 & 1,2244 & 0,1832 & 0,5000 & 0,9944 \\
\hline M1C800 & Van Genuchten (original) & 0,00 & 62,66 & 0,0171 & 1,5434 & 0,3521 & 1,0000 & - & - & - & - & 0,9867 \\
\hline Bloco 1 & Durner (dual porosity) & 0,04 & 52,09 & 0,0082 & 2,8342 & 0,6472 & 0,5000 & 3,4364 & 1,3607 & 0,2651 & 0,5000 & 0,9949 \\
\hline M1C1000 & Van Genuchten (original) & 0,05 & 57,63 & 0,0210 & 1,7722 & 0,3750 & 1,0000 & - & - & - & - & 0,9911 \\
\hline P1A30 & Durner (dual porosity) & 0,00 & 44,30 & 0,0015 & 2,4858 & 0,5977 & 0,5000 & 10,3229 & 1,3891 & 0,2801 & 0,5000 & 0,9959 \\
\hline Bloco 3 & Durner (dual porosity) & 0,00 & 42,03 & 0,0018 & 2,9156 & 0,6570 & 0,5000 & 28,3560 & 1,1614 & 0,1390 & 0,5000 & 0,9980 \\
\hline P1C250 & Durner (dual porosity) & 0,20 & 51,94 & 0,0027 & 2,6996 & 0,6296 & 0,5000 & 2,4200 & 1,3500 & 0,2593 & 0,5000 & 0,9868 \\
\hline P1C350 & Durner (dual porosity) & 0,00 & 40,01 & 0,0041 & 2,4607 & 0,5936 & 0,5000 & 1,9777 & 1,1357 & 0,1195 & 0,5000 & 0,9975 \\
\hline$\overline{P 1 C 500 a}$ & Van Genuchten (original) & 0,00 & 39,86 & 20,3508 & 1,2032 & 0,1689 & 1,0000 & - & - & - & - & 0,9871 \\
\hline P1C500b & Van Genuchten (original) & 0,00 & 39,38 & 7,1926 & 1,2432 & 0,1956 & 1,0000 & - & - & - & - & 0,9684 \\
\hline P1C650 & Durner (dual porosity) & 0,00 & 40,33 & 0,0088 & 2,7057 & 0,6304 & 0,5000 & 4,0665 & 1,0981 & 0,0893 & 0,5000 & 0,9961 \\
\hline Bloco 4 & Durner (dual porosity) & 0,00 & 52,67 & 0,0150 & 1,8056 & 0,4462 & 0,5000 & 5,8517 & 1,2714 & 0,2135 & 0,5000 & 0,9903 \\
\hline P1C750 & Van Genuchten & 0,00 & 42,24 & 33,7490 & 2,2100 & 0,0950 & 1,0000 & - & - & - & - & 0,9696 \\
\hline
\end{tabular}

As demais amostras foram ajustadas pelo modelo de VAN GENUCHTEN (1980):

$$
S_{e}=\frac{1}{\left[1+(\alpha|\psi|)^{n}\right]^{m}} \text {, }
$$

[Equação 5.7]

onde: $\alpha, n$ e $m$ são os parâmetros de ajuste das curvas, para $\alpha>0, n>1$ e $m>0$.

As Figuras 5.25 a 5.28 mostram as curvas ajustadas, conforme os modelos matemáticos utilizados, para os pontos experimentais que compõem as CRAs de todos os solos analisados. No geral, observa-se que os modelos utilizados ajustaram muito bem os pontos experimentais para todas as CRAs dos solos estudados. 

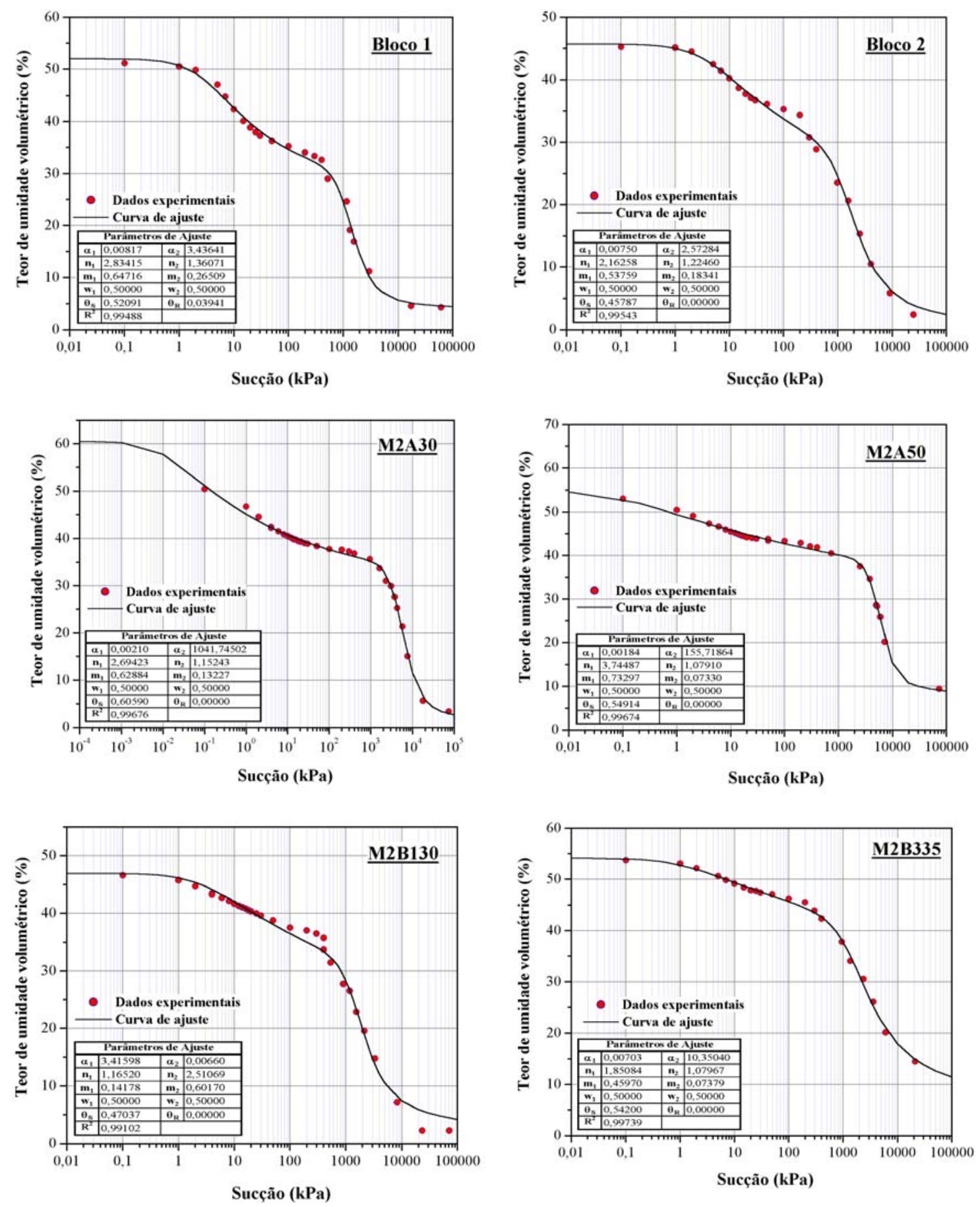

Figura 5.25 - Modelos De AJUSte PARA AS CURVAS DE RETENÇÃo DE ÁGUA dOS SOlOS DE MARANDUBA. 

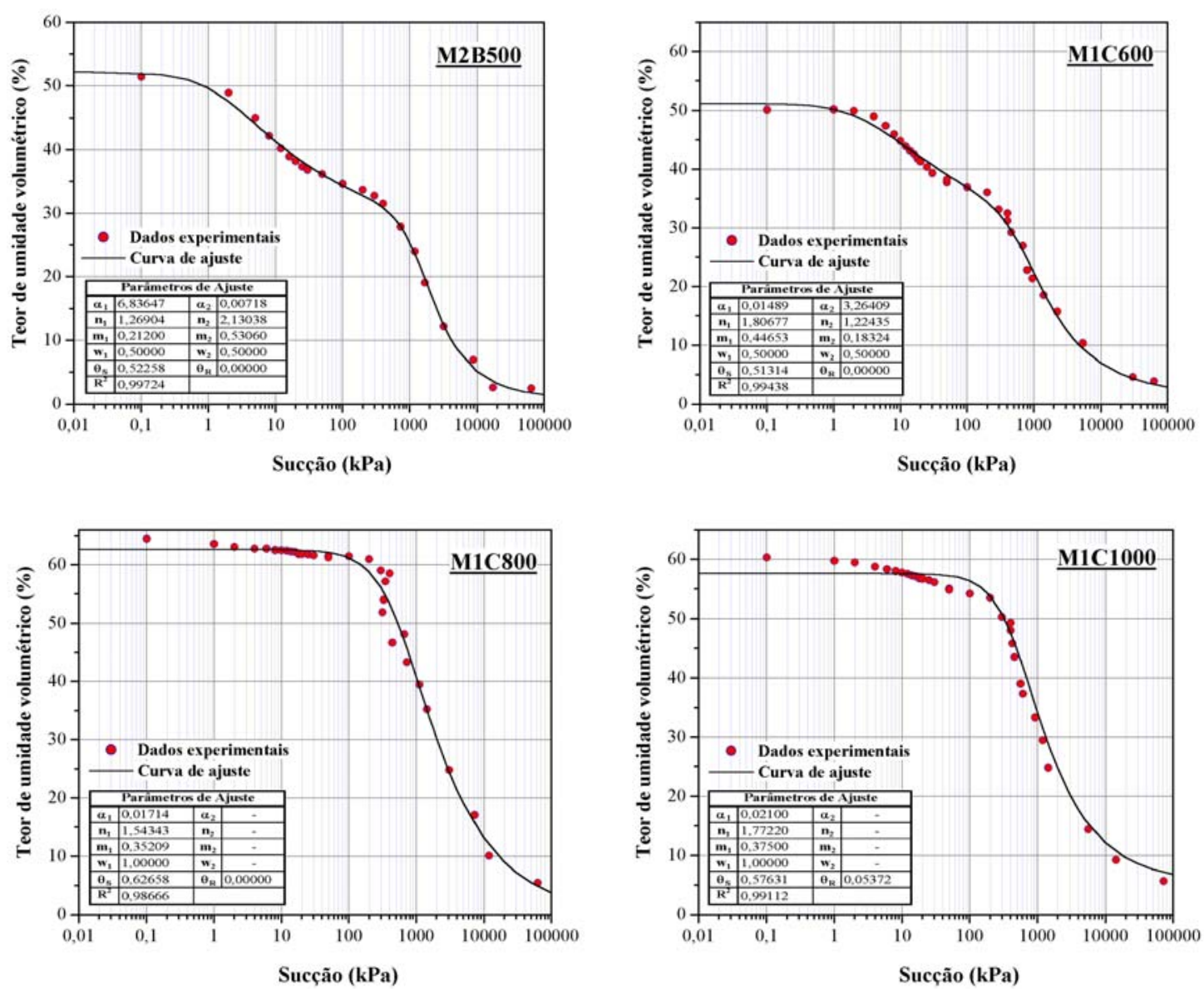

Figura 5.26 - Modelos De AJUSte PARA AS CURVAS DE RETENÇÃo DE ÁGUA dOS SOlOS DE MARANDUBA (CONTINUAÇÃO). 

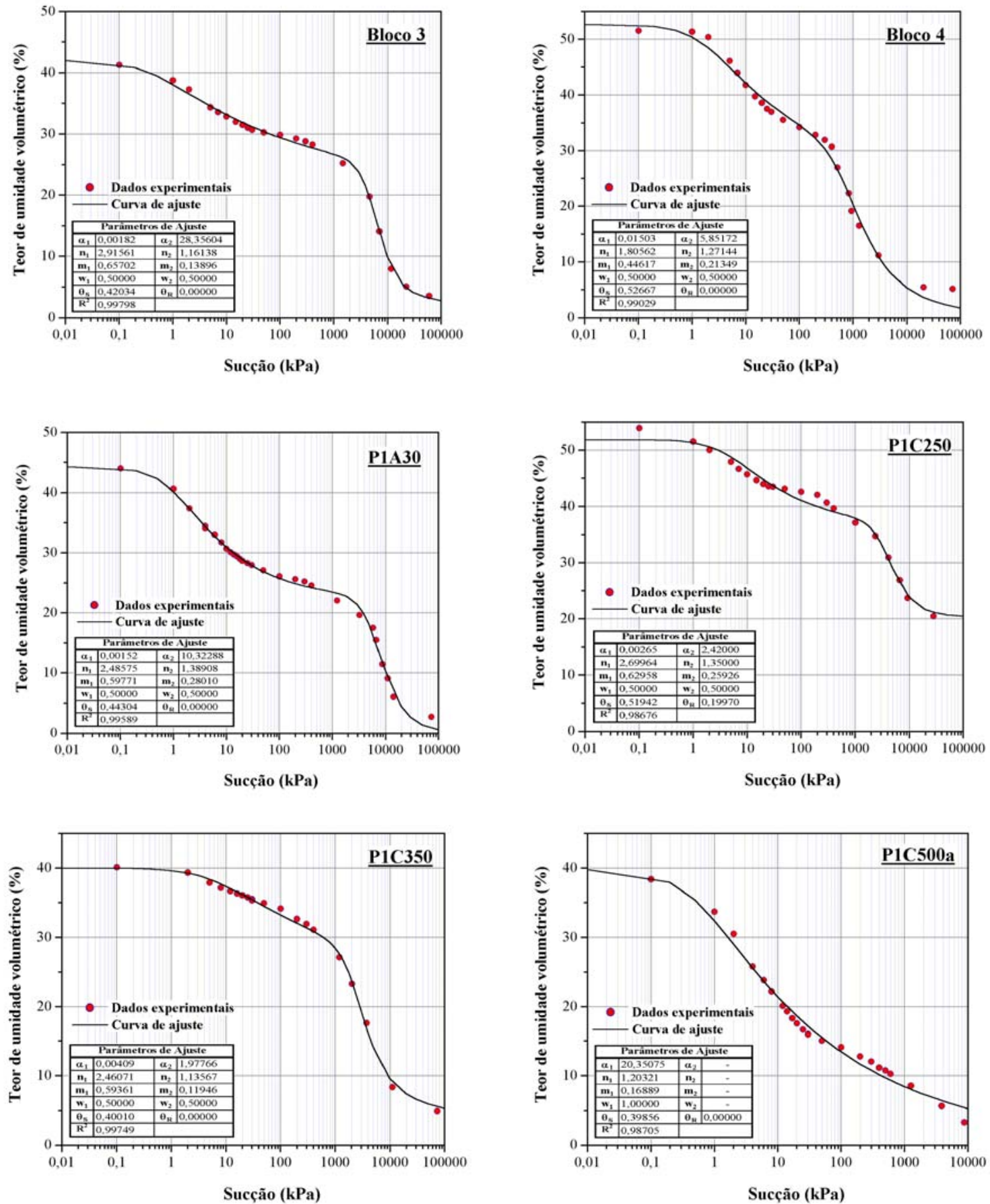

Figura 5.27 - Modelos DE AJUSTE PARA AS CURVAS DE RETENÇÃO DE ÁGUA DOS SOLOS DO PEREQUÊ-MIRIM. 

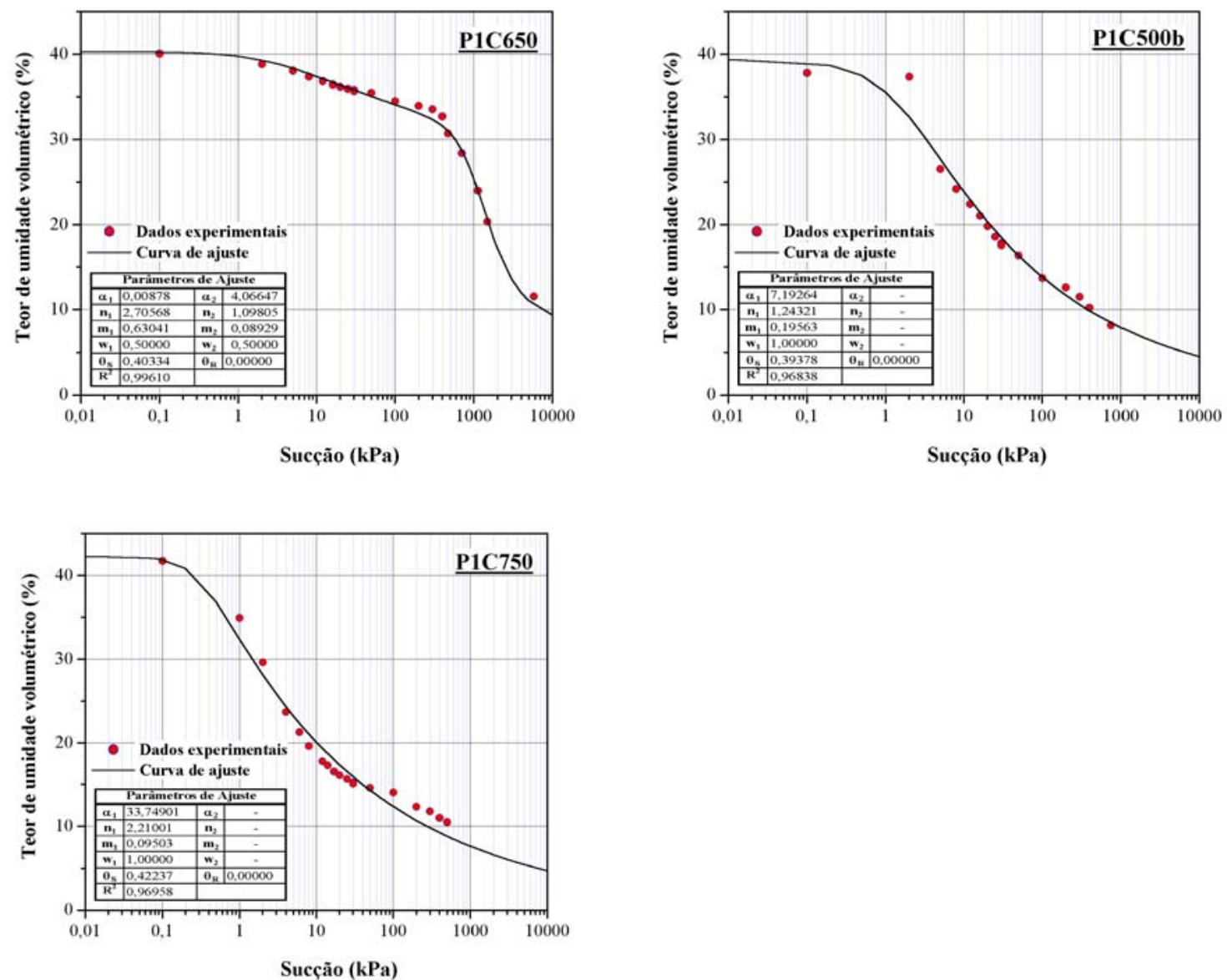

Figura 5.28 - MOdelos DE AJUSTE PARA AS CURVAS DE RETENÇÃO DE ÁGUA DOS SOLOS DO PEREQUÊ-MIRIM (CONTINUAÇÃO). 


\subsection{Ensaios de Porosimetria por Intrusão de Mercúrio}

O uso da técnica de injeção de mercúrio ou ensaio de porosimetria constitui uma importante ferramenta no estudo da microestrutura do solo. Este ensaio fornece a distribuição dos diversos tamanhos de poros e suas porcentagens relativas ao volume de vazios do solo analisado.

O ensaio de porosimetria fornece basicamente dois gráficos: a) Curva de volume acumulado permite obter, a partir de um determinado valor de diâmetro de poro, as percentagens dos poros de diâmetro maior ou menor do que aquele considerado em relação ao volume de vazios total da amostra; b) Curva de $\mathrm{d}_{\mathrm{V}} / \mathrm{d}_{(\operatorname{logd})}$ ou histograma de freqüência dos diâmetros de poros - esta curva permite observar os intervalos de diâmetros de poros que aparecem com mais freqüência na estrutura do solo (BRUAND \& PROST 1987).

A curva de volume injetado acumulado versus o diâmetro dos poros pode ser transformada em uma curva de retenção. A grande característica diferenciadora desta curva em relação à obtida nos métodos tradicionais (e.g. placa de sucção e de pressão), é que os valores de sucção obtidos a partir da porosimetria são devidos somente à ação da capilaridade, uma vez que a molécula de mercúrio é apolar e, portanto não pode apresentar o fenômeno de adsorção (MACHADO 1995).

No presente trabalho foram realizados ensaios de porosimetria por intrusão de mercúrio com os seguintes objetivos:

- Para se estudar a influência da distribuição dos tamanhos dos poros no comportamento de retenção de água em solos residuais tropicais, e conseqüentemente analisar o seu grau de interferência sobre a resistência ao cisalhamento dos solos;

- Para se avaliar a técnica de obtenção da curva de retenção a partir dos dados de volume injetado acumulado de mercúrio obtidos nos ensaios de porosimetria, e analisar se a secagem prévia das amostras, condição requerida por este ensaio, pode afetar a distribuição de poros quando comparados com as curvas de retenção obtidas por métodos convencionais. 
Os ensaios de porosimetria foram realizados no Laboratório da Fundação de Apoio à Física e à Química da Universidade de São Paulo, em São Carlos - SP. Utilizou-se o porosímetro Micromeritics Poresizer 9320. Com este equipamento é possível investigar poros de diâmetro a partir de $0,7 \mathrm{~mm}$ até poros de $0,6 \cdot 10^{-5} \mathrm{~mm}$ ou 6 ângstrons de diâmetro.

As amostras de solo usadas na realização dos ensaios de porosimetria foram obtidas dos próprios corpos de prova utilizados para a obtenção das CRAs e também dos blocos indeformados. Após obter os últimos pontos experimentais das CRAs, os corpos de prova foram revestidos com papel alumínio e plástico bolha, sendo posteriormente acondicionados numa caixa de isopor e, juntamente com as demais amostras, enviados ao Laboratório de Física da USP/São Carlos.

A análise da porosidade dos solos exige a adoção de uma classificação dos tamanhos dos mesmos em intervalos pré-estabelecidos. Nesse aspecto, muitos conceitos têm surgido no sentido de estabelecer um padrão para a classificação dos poros quanto ao tamanho, considerando a geometria e a configuração do espaço poroso. Apesar de não existir nos solos uma nítida separação entre poros pequenos e grandes, inúmeras classificações do diâmetro de poros são citadas na literatura, sendo que uma forma mais simplificada separa os poros em duas classes: micro e macroporos. Por exemplo, a escala proposta por KIEHL (1979) classifica como macroporos, os poros com diâmetro maior que 0,06 mm e como microporos, aqueles com diâmetro menor que 0,06 mm; enquanto RICHARDS (1965) utiliza diâmetro igual a 0,05 mm como limite de separação entre macro e microporos.

Vários autores incluem os mesoporos na classificação como uma classe intermediária, tal como LUXMOORE (1981), que sugeriu uma classificação na qual os microporos apresentam diâmetro menor que 0,01 mm; os mesoporos com diâmetro entre 0,01 e 1,0 mm; e os macroporos, diâmetro maior que 1,0 mm. Já KLEIN \& LIBARDI (2002), classificam como macroporos, os poros com diâmetro maior que 0,05 mm (que perdem água para tensões menores que $6 \mathrm{kPa}$ ), microporos, aqueles com diâmetro entre 0,05 e 0,0002 mm (que perdem água para tensões entre 6 e $1500 \mathrm{kPa}$ ) e criptoporos, poros com diâmetro menor que 0,0002 mm (que perdem água apenas para tensões maiores que $1500 \mathrm{kPa}$ ).

Deste modo, observa-se que existe uma variação muito grande na definição dos limites de diâmetro entre uma classe e outra, verificando-se que não foi estabelecida, até o momento, uma 
terminologia padronizada para classificar o tamanho dos poros do solo. No entanto, como um dos objetivos da presente pesquisa é de comparar as diferentes curvas de distribuição de poros dos diferentes materiais analisados, buscou-se uma classificação de tamanhos de poros que possa representar de maneira satisfatória as condições de distribuição de poros dos solos estudados.

Logo, verifica-se que a classificação que se adapta melhor aos resultados de porosimetria é aquela definida em função dos níveis de sucção encontrados nas curvas de retenção de água. Assim, a classificação dos tamanhos dos poros adotada foi estabelecida em função da distribuição de poros (porosimetria por Hg) e dos níveis de sucção médios estabelecidos para a entrada de ar generalizada nos micro e macroporos (curvas de retenção de água), resultando nas seguintes classes: microporos (diâmetro $<0,2 \mu \mathrm{m}$ - para sucções maiores que $3.000 \mathrm{kPa})$, mesoporos $(0,2$ $\mu \mathrm{m}<$ diâmetro $<20 \mu \mathrm{m}$ - para sucções entre 3.000 e $50 \mathrm{kPa}$ ) e macroporos (diâmetro $>20$ m para sucções menores que $50 \mathrm{kPa}$ ). Tal classificação foi adotada nas análises das curvas de distribuição incremental dos poros.

Na Figura 5.29 é apresentada a distribuição acumulada dos diâmetros de poros dos solos representativos da área de estudo de Maranduba.

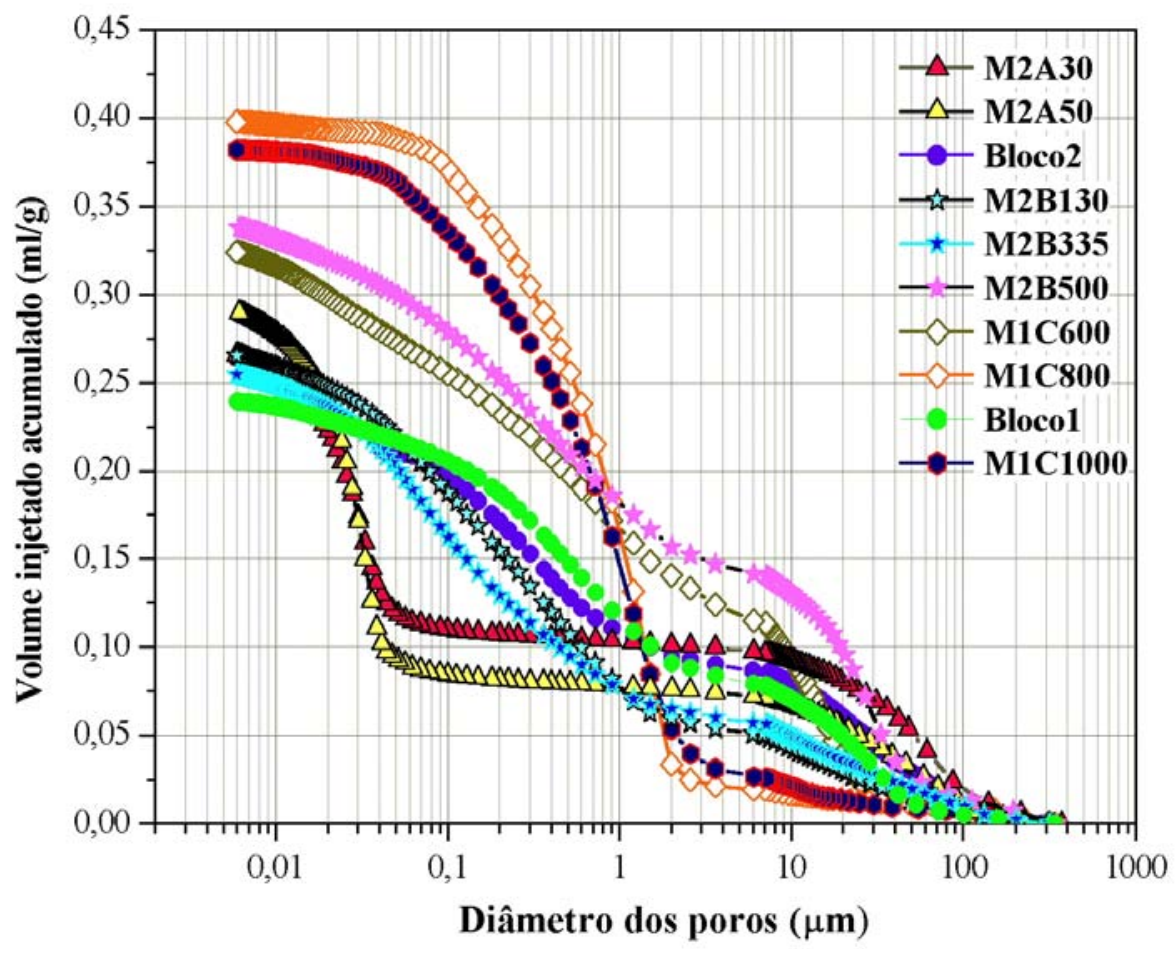

FiguRA 5.29 - DistRIBUIÇÃO ACUMULADA DE POROS DOS SOLOS DE MARANDUBA. 
A Figura 5.29 mostra claramente que o volume de poros é maior nos solos do horizonte mais profundo - correspondente ao saprolito (M1C800 e M1C1000), com exceção da amostra do Bloco1, que apresentou a menor quantidade de volume de poros. Este comportamento divergente entre os volumes de poros dos solos de um mesmo horizonte, pode estar relacionado com a distribuição de micro e macroporos no arcabouço do solo. Em termos gerais, os solos que apresentaram uma curva de distribuição acumulada de poros em formato de "sela” (Bloco1, Bloco2, M2A30 e M2A50), foram as que tiveram os menores volumes de poros.

Na Figura 5.30 é apresentada a distribuição incremental dos diâmetros de poros dos solos representativos da área de estudo de Maranduba.

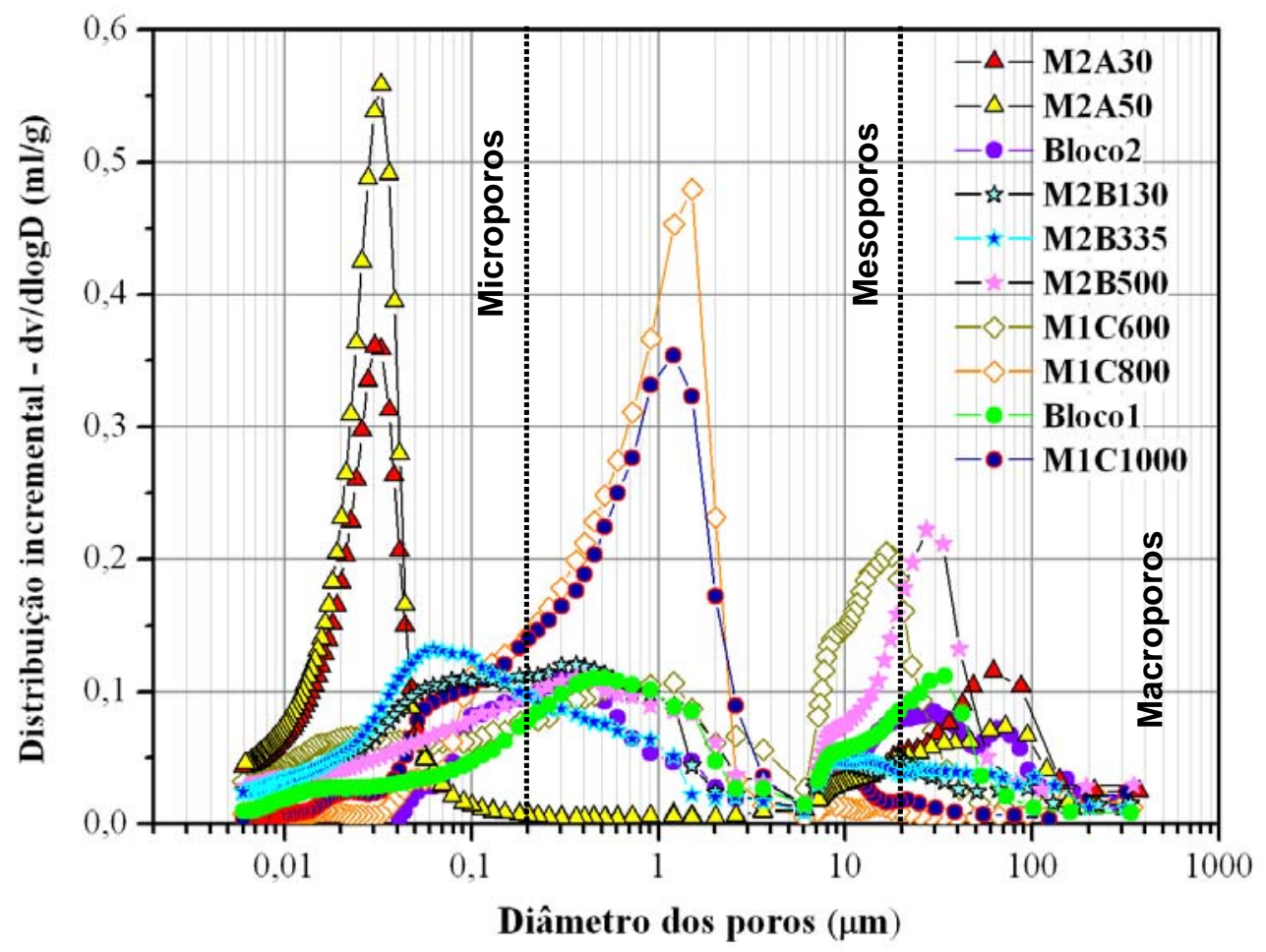

FigURA 5.30 - DisTRIBUIÇÃO INCREMENTAL DE POROS DOS SOLOS DE MARANDUBA.

Analisando a Figura 5.30, verifica-se o predomínio de solos que apresentam uma distribuição de poros do tipo bi-modal (e.g. amostras M2A30, M2A50, Bloco2, M2B500, M1C600 e Bloco1), ou seja, possuem dois tamanhos predominantes de poros. Os solos do horizonte mais superficial (M2A30 e M2A50) se destacam por apresentar uma quantidade maior de microporos (diâmetro 
dos poros igual a 0,03 $\mu \mathrm{m}$ ), enquanto que os solos dos horizontes mais profundos (M1C800 e M1C1000) apresentam uma quantidade maior de mesoporos (diâmetro dos poros igual a 1,5 ㅆm). Os demais solos que compõem o perfil de alteração de Maranduba apresentam uma distribuição mais uniforme entre as quantidades de micro, meso e macroporos (e.g. Bloco1, Bloco2, M2B500).

Na Figura 5.31 é apresentada a distribuição acumulada dos diâmetros de poros dos solos representativos da área de estudo do Perequê-Mirim, onde se observa que o volume de poros foi consideravelmente maior no solo do horizonte mais profundo - correspondente ao saprolito (Bloco4). Os demais tipos de solos apresentaram volumes de poros muito próximos, entre 0,20 a $0,25 \mathrm{ml} / \mathrm{g}$. Nota-se também que algumas curvas de distribuição acumulada de poros apresentam um nítido formato de "sela” (P1A30, Bloco3, P1C350 e P1C400).

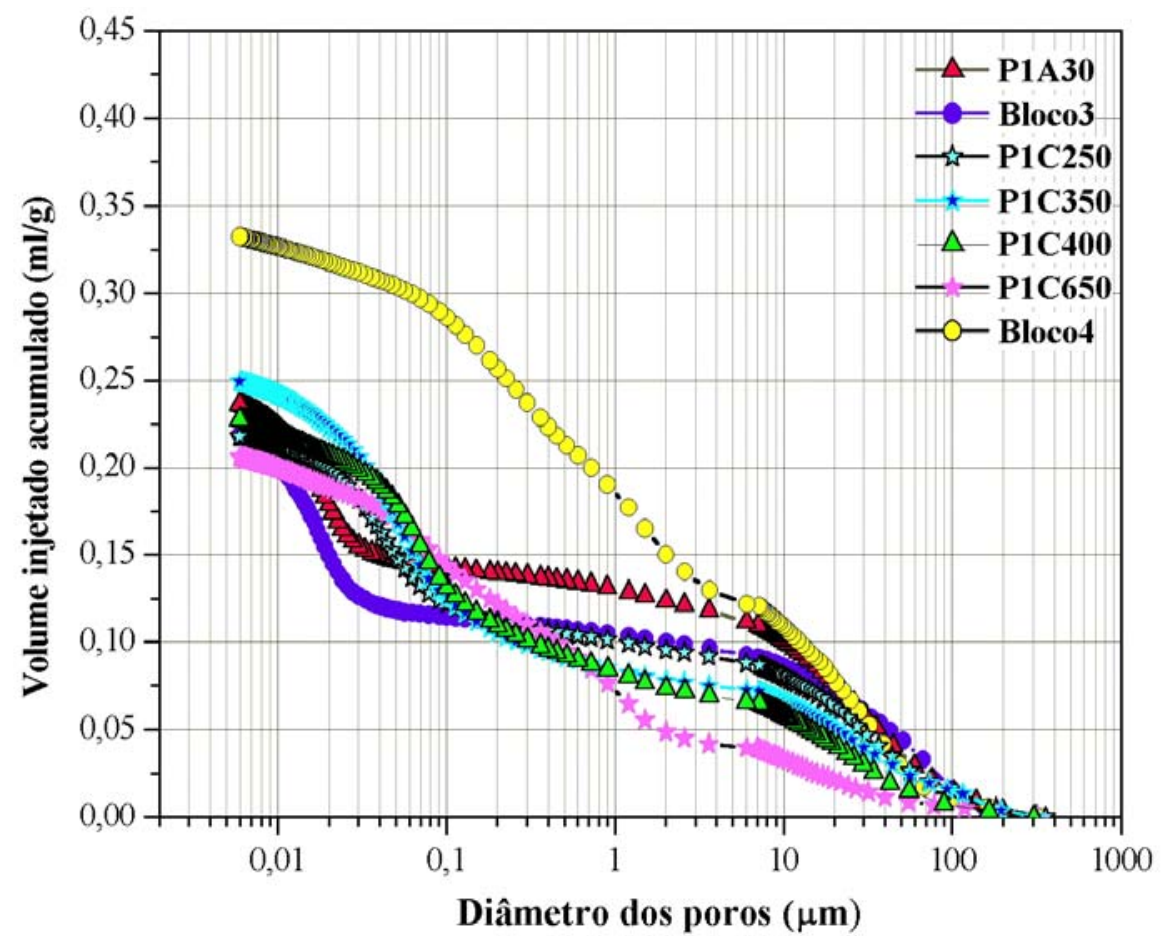

Figura 5.31 - DistribuiçÃo ACUMULADA DE POROS DAS AMOSTRAS DO PEREQUÊ-MiRIM.

Na Figura 5.32 é apresentada a distribuição incremental dos diâmetros de poros dos solos representativos da área de estudo do Perequê-Mirim, onde se observa que a maioria dos solos também apresenta uma distribuição de poros do tipo bi-modal, embora com uma freqüência de distribuição menos pronunciada em comparação com os solos de Maranduba. 
Na área de estudo do Perequê-Mirim, nota-se que tanto os solos do horizonte mais superficial (P1A30 e Bloco3) quanto os solos do horizonte C, correspondente ao saprolito (P1C250, P1C350 e P1C400), apresentam apreciáveis concentrações de microporos (diâmetro dos poros de 0,02 e 0,06 $\mu \mathrm{m}$, respectivamente) e uma baixa quantidade de mesoporos. Nota-se também que alguns solos apresentam significativa quantidade de mesoporos (Bloco4 e P1C650) e de macroporos (Bloco4, P1A30, Bloco3).

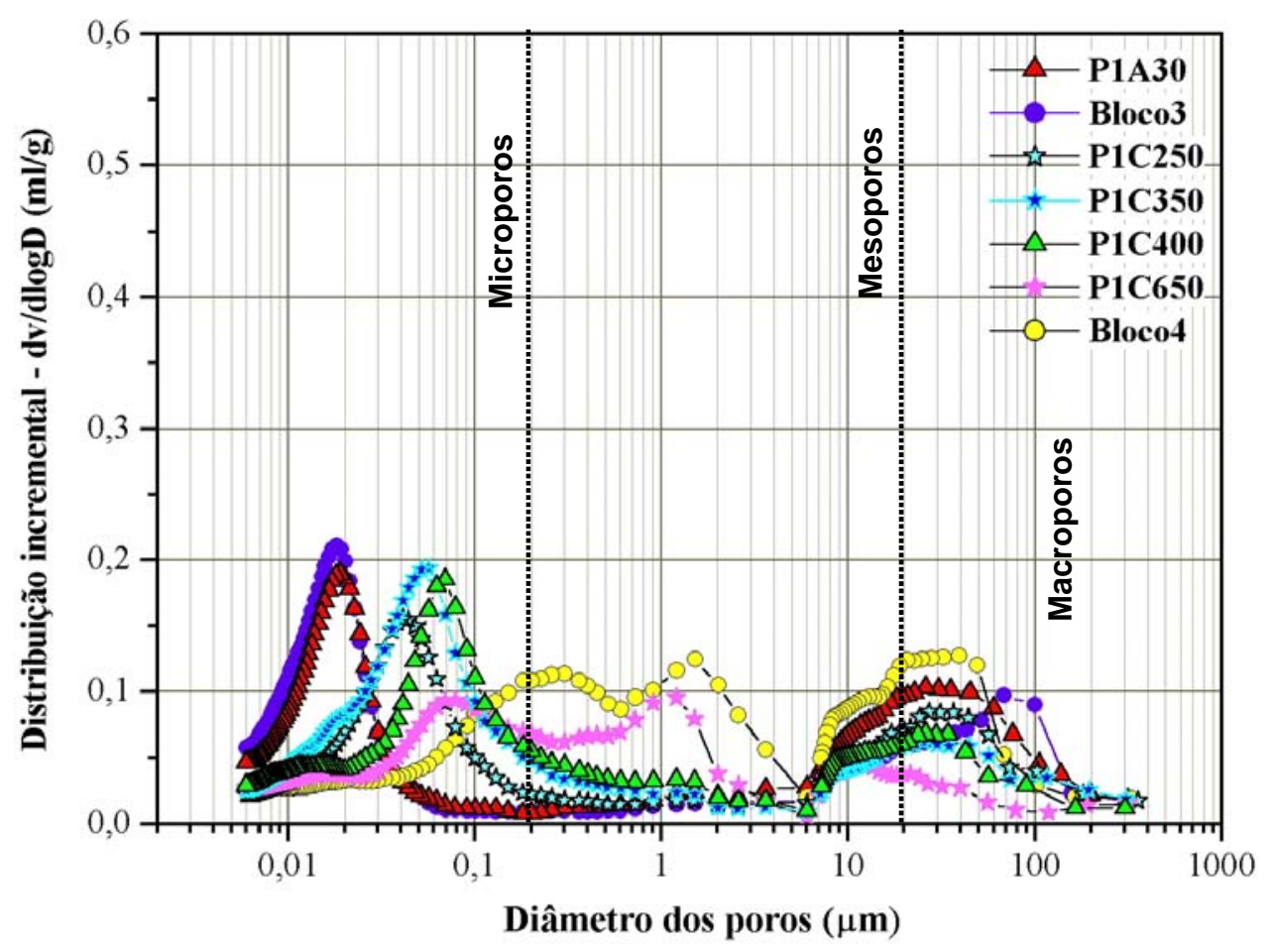

FiguRA 5.32 - DistRIBUIÇÃo INCREMENTAL DE POROS DAS AMOSTRAS DO PEREQUÊ-MirIM.

O volume acumulado de mercúrio injetado $\left(V_{A, H g}\right)$, obtido durante a realização do ensaio de porosimetria, foi convertido para "grau de saturação aparente" (S), considerando-se o volume total de vazios da amostra igual ao volume total de mercúrio injetado $\left(V_{T, H g}\right)$. Desta forma, a expressão $\left(V_{T, H g}-V_{A, H g}\right)$ representa o volume de ar existente nos vazios da amostra de solo, e a expressão final de " $S$ " é dada por:

$$
S=\left(\frac{V_{T, H g}-V_{A, H g}}{V_{T, H g}}\right) \times 100
$$


Nas Figuras 5.33 a 5.35 são apresentadas as curvas de retenção obtidas pelos métodos convencionais (placa de sucção, placa de pressão e papel filtro) juntamente com as curvas obtidas a partir dos dados dos ensaios de porosimetria por intrusão de mercúrio.

Analisando as Figuras 5.33, 5.34 e 5.35, nota-se que algumas curvas de retenção obtidas com os dados de porosimetria tendem a sobreestimar consideravelmente a capacidade de retenção de água dos solos analisados, para todos os níveis de sucção impostos. Contudo, não se verifica essa tendência para as amostras M2B335, M2B500, M1C600, M1C800, P1C250 e P1C650. Nessas amostras, as curvas de retenção tendem a sobreestimar a capacidade de retenção somente para alguns trechos de sucção (e.g. M2B335 - para sucções entre 1 a 30kPa; M2B500 - para sucções entre 0,1 a $70 \mathrm{kPa}$; M1C600 - sucções entre 0,1 a $100 \mathrm{kPa}$ e P1C650 - sucções entre 0,1 a 200 $\mathrm{kPa}$ ). Em outras circunstâncias, as curvas de retenção da porosimetria tendem a subestimar, para alguns níveis de sucção aplicada, a capacidade de retenção de alguns solos analisados (M2A30 para sucções entre 50 a 2.000 kPa; M2B335 - para sucções entre 50 a 1.000 kPa e P1C250 - para sucções entre 40 a $6.000 \mathrm{kPa})$.

Nota-se que nos trechos (geralmente entre 0,1 a $100 \mathrm{kPa}$ ) onde ocorre uma tendência de sobreestimativa da capacidade de retenção, as sucções impostas correspondem aos valores de entrada de ar dos macroporos. Este fato pode explicar o motivo pelo qual tais solos apresentam um ganho na capacidade de retenção. Por exemplo, durante o processo de secagem prévia de uma amostra (por aplicação de vácuo), condição requerida pelo ensaio de porosimetria, o arcabouço do solo pode sofrer algum tipo de rearranjo estrutural, e consequentemente os vazios maiores (macroporos) acabarem sendo ocupados por partículas que irão conferir ao solo uma nova estrutura, constituída por poros de diâmetros menores do que aqueles originalmente existentes no solo. Além disso, deve-se ressaltar que nos pontos iniciais das curvas, para valores de sucção igual a $0,1 \mathrm{kPa}$, o grau de saturação aparente calculado a partir dos dados de porosimetria é constantemente assumido como saturado, fazendo com que tais curvas apresentem sempre um “ganho aparente” na capacidade de retenção para baixas sucções. 

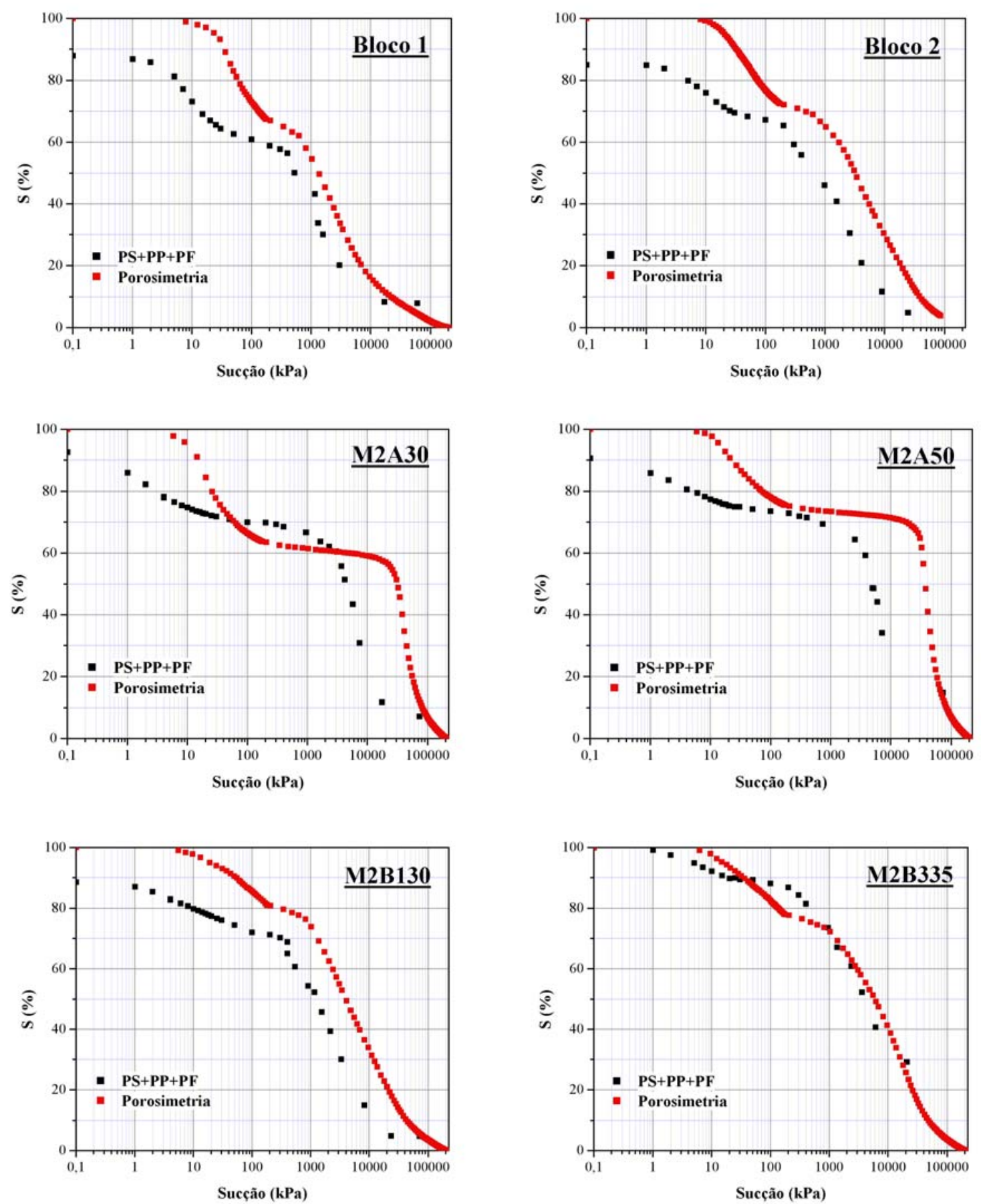

FIGURA 5.33 - CURVAS DE RETENÇÃO OBTIDAS A PARTIR DOS MÉTODOS CONVENCIONAIS E DOS DADOS DE POROSIMETRIA PARA AS AMOSTRAS DE MARANDUBA. 
As curvas obtidas com os dados de porosimetria que melhor se aproximam, em termos de capacidade de retenção de água, dos resultados obtidos com os métodos tradicionais (PS+PP+PF), são as curvas das amostras M2B335, M1C600, M1C800 e P1C650. Apesar dessas curvas não terem apresentado, de modo satisfatório, o mesmo comportamento de retenção d’água das CRAs obtidas tradicionalmente, observa-se que elas apresentaram o mesmo formato em relação aos "patamares” verificados nas CRAs. Acredita-se que as diferenças entre as curvas possam estar associadas, primeiramente, com o modo ao qual as sucções são impostas pelos líquidos molhantes, em segundo lugar, com a secagem prévia das amostras requerida pelo ensaio de porosimetria, e o último e mais importante, relacionado com o grau de saturação aparente adotado no início das curvas.
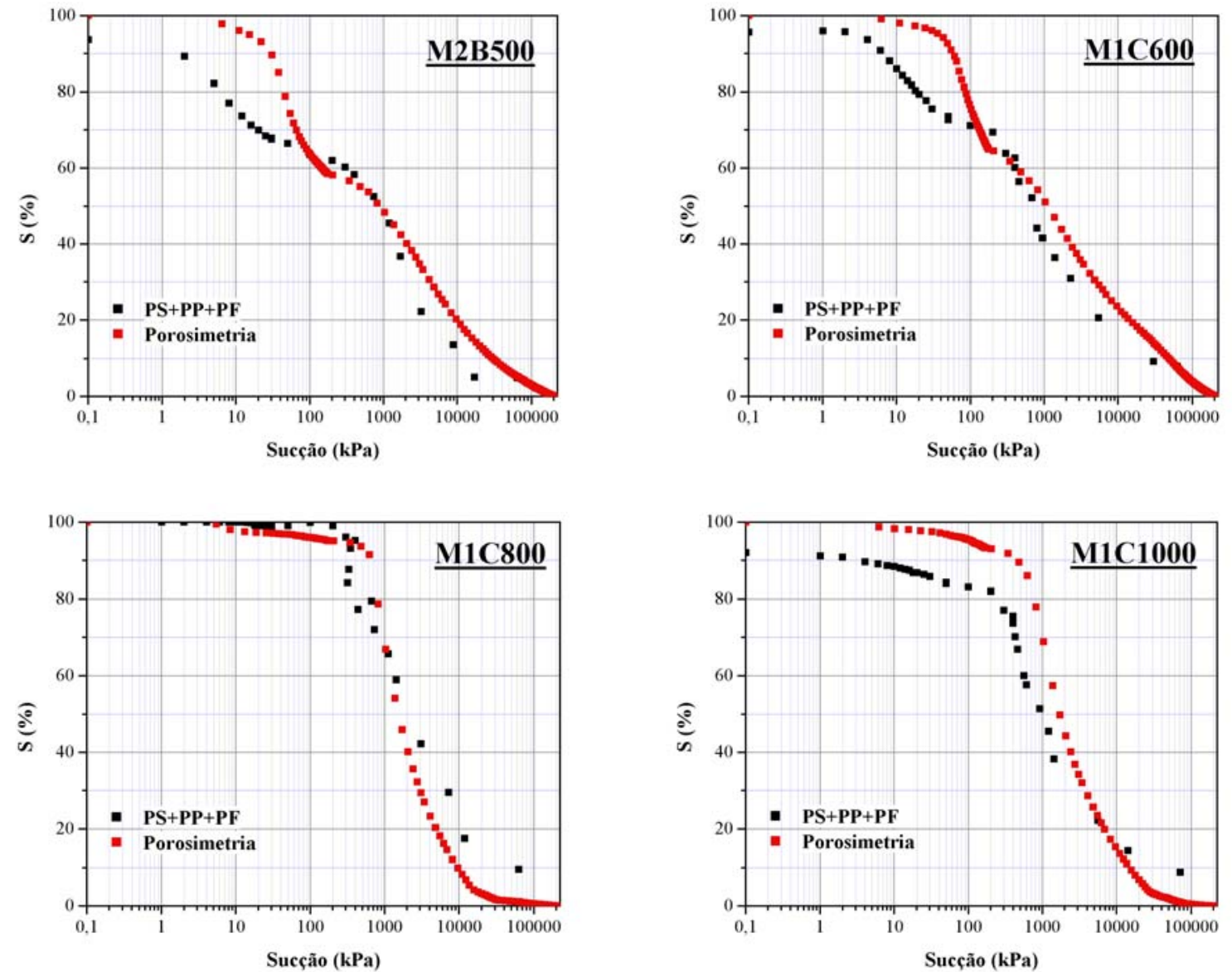

FiguRA 5.34 - CURVAS DE RETENÇÃO OBTIDAS A PARTIR DOS MÉTODOS CONVENCIONAIS E DOS DADOS DE POROSIMETRIA PARA AS AMOSTRAS DE MARANDUBA - CONTINUAÇÃO. 

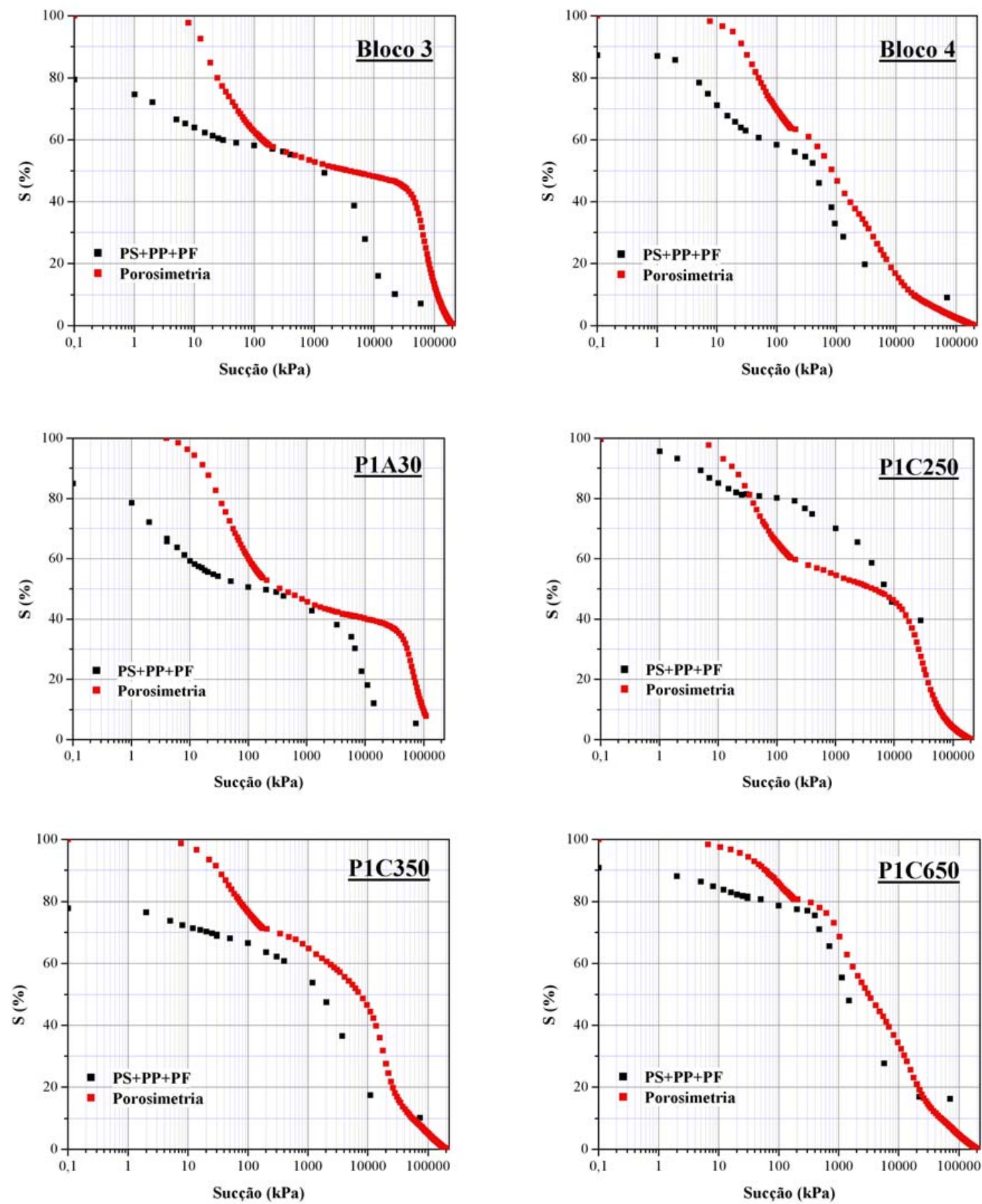

FIGURA 5.35 - CURVAS DE RETENÇÃO OBTIDAS A PARTIR DOS MÉTODOS CONVENCIONAIS E DOS DADOS DE POROSIMETRIA PARA AS AMOSTRAS DO PEREQUÊ-MIRIM. 


\subsection{Ensaios de Permeabilidade}

Os ensaios de permeabilidade foram realizados num permeâmetro de carga constante e parede flexível, acoplado a um sistema Triflex-2. Inicialmente foram talhados corpos de prova cilíndricos diretamente dos blocos indeformados de solos representativos da área estudada. Em seguida, cada corpo de prova foi montado sobre a base da câmara triaxial e vedado com membrana plástica para a realização do ensaio de condutividade hidráulica com o infiltrômetro de mini-disco, sendo posteriormente saturado no término desse ensaio (maiores detalhes do ensaio são apresentados no item 6.2). Depois o corpo de prova foi confinado com uma pressão de 50 $\mathrm{kPa}$, e posteriormente, aplicada uma pressão na base e no topo, estabelecendo-se uma percolação d’água ascendente (fluxo da base para o topo do C.P.). O volume de água $\left(\mathrm{cm}^{3}\right)$ percolado através do corpo de prova foi determinado a partir dos medidores de variação volumétrica do sistema Triflex-2, conectados na base e no topo do C.P. A Figura 5.36 apresenta os principais componentes do permeâmetro de parede flexível utilizado para a determinação do coeficiente de permeabilidade dos solos estudados.

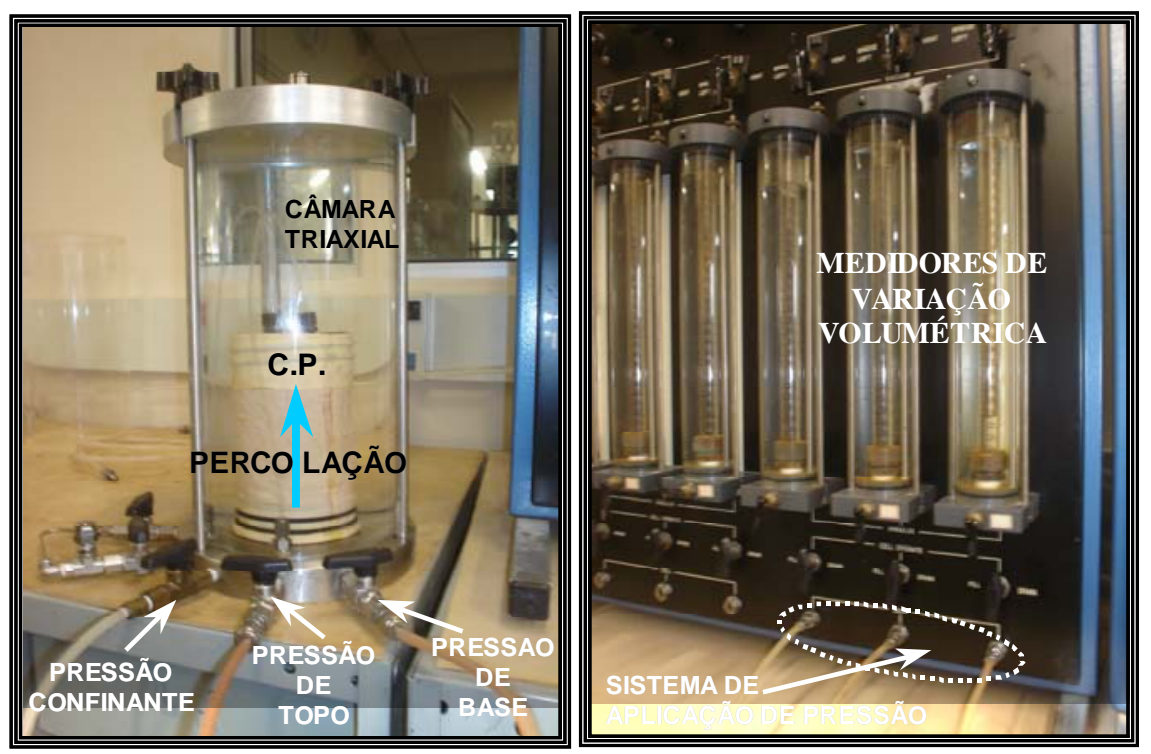

Figura 5.36 - PERMEÂMETRO DE CARGA CONSTANTE E PAREDE FLEXÍVEL ACOPLADO AO SISTEMA TRIFLEX-2.

Nos ensaios de permeabilidade realizados no sistema Triflex-2, antes de iniciar a percolação de água, o corpo de prova está submetido a um gradiente hidráulico, que é resultante da diferença entre as pressões aplicadas no topo e na base, e da altura do corpo de prova. No entanto, no decorrer do ensaio, os níveis de água em ambos os medidores variam, conforme o sentido do 
fluxo. Essa variação provoca uma pequena alteração no gradiente hidráulico durante o ensaio. Dessa maneira, deve-se corrigir os valores do gradiente hidráulico para cada incremento de variação volumétrica registrado no sistema Triflex-2. Logo, o coeficiente de permeabilidade foi determinado levando-se em consideração essa correção. A Tabela 5.9 apresenta os valores dos coeficientes de permeabilidade, assim como as características iniciais dos corpos de prova e as pressões aplicadas durante os ensaios de permeabilidade.

Tabela 5.9 - Valores do coeficiente de permeabilidade e características iniciais dos corpos de prova utilizados nos ensaios de permeabilidade.

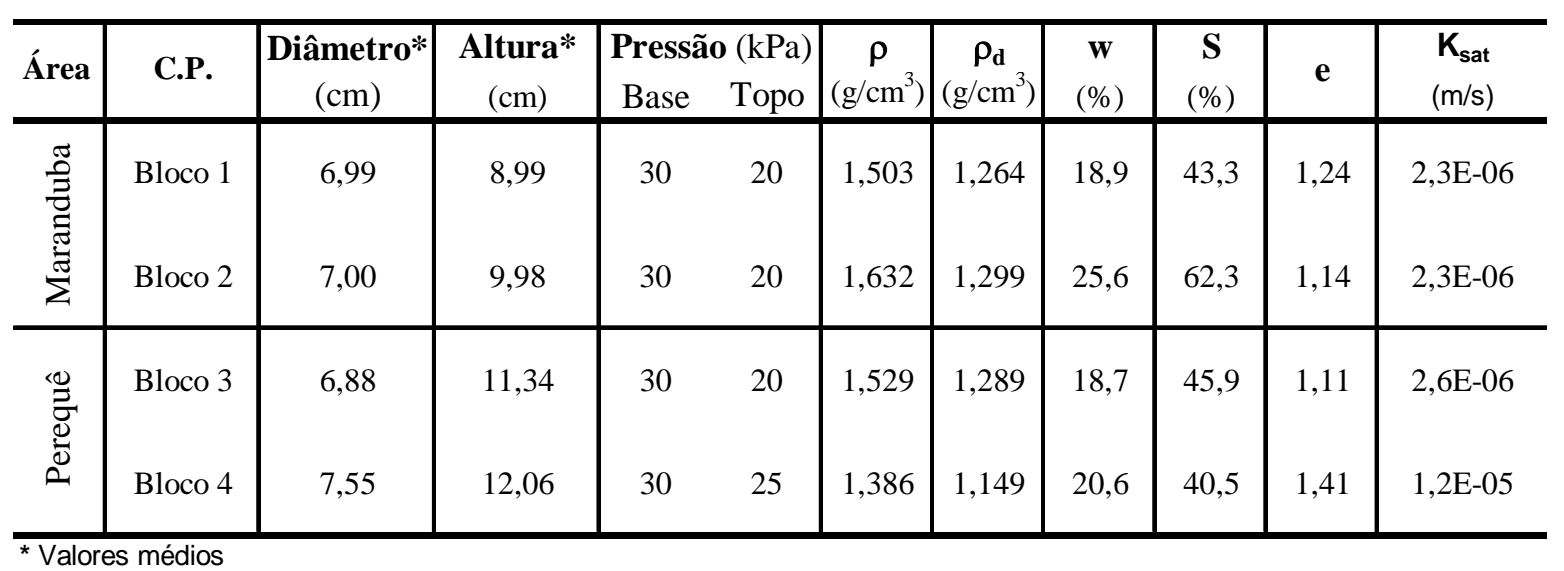

Analisando os dados apresentados na Tabela 5.9, nota-se que os solos representativos da área de Maranduba apresentam os mesmos valores de $\mathrm{K}_{\text {sat }}$, enquanto que os solos de alteração e saprolito representativos do Perequê-Mirim, apresentam valores muito próximos, onde o saprolito (Bloco4) mostrou ser ligeiramente mais permeável que o solo de alteração (Bloco3).

A partir das análises dos valores de $\mathrm{K}_{\text {sat, }}$, verifica-se a possibilidade de associação entre os valores de permeabilidade dos solos de Maranduba com sua distribuição de poros, pois os Blocos 1 e 2 apresentam distribuição de poros muito parecida, ou seja, são constituídos predominantemente por meso e macroporos, conforme apresentado anteriormente na Figura 5.30. Já os solos representativos da área de estudo do Perequê-Mirim (Blocos 3 e 4) apresentam distribuição de poros consideravelmente distintas, ou seja, o Bloco 3 possui uma quantidade maior de microporos apesar de possuir uma quantidade significativa de macroporos, enquanto que o Bloco 4 é constituído predominantemente por meso e macroporos, conforme apresentado na Figura 5.32. Os valores do coeficiente de permeabilidade $\left(\mathrm{K}_{\mathrm{sat}}\right)$ foram utilizados juntamente com os dados experimentais das curvas de retenção de água para estimar as curvas de condutividade 
hidráulica dos solos representativos das áreas estudadas (Blocos 1, 2, 3 e 4). As estimativas foram realizadas a partir do software RETC (US Salinity Laboratory, USDA, Riverside, CA), adotandose uma função condutividade hidráulica que combina a equação bimodal proposta por DURNER (1994) para ajustar os dados experimentais das curvas de retenção, com o modelo de distribuição de poros sugerido por MUALEM (1976). Na Figura 5.37 são apresentadas as curvas de retenção juntamente com as curvas de condutividade hidráulica estimadas para os solos estudados.

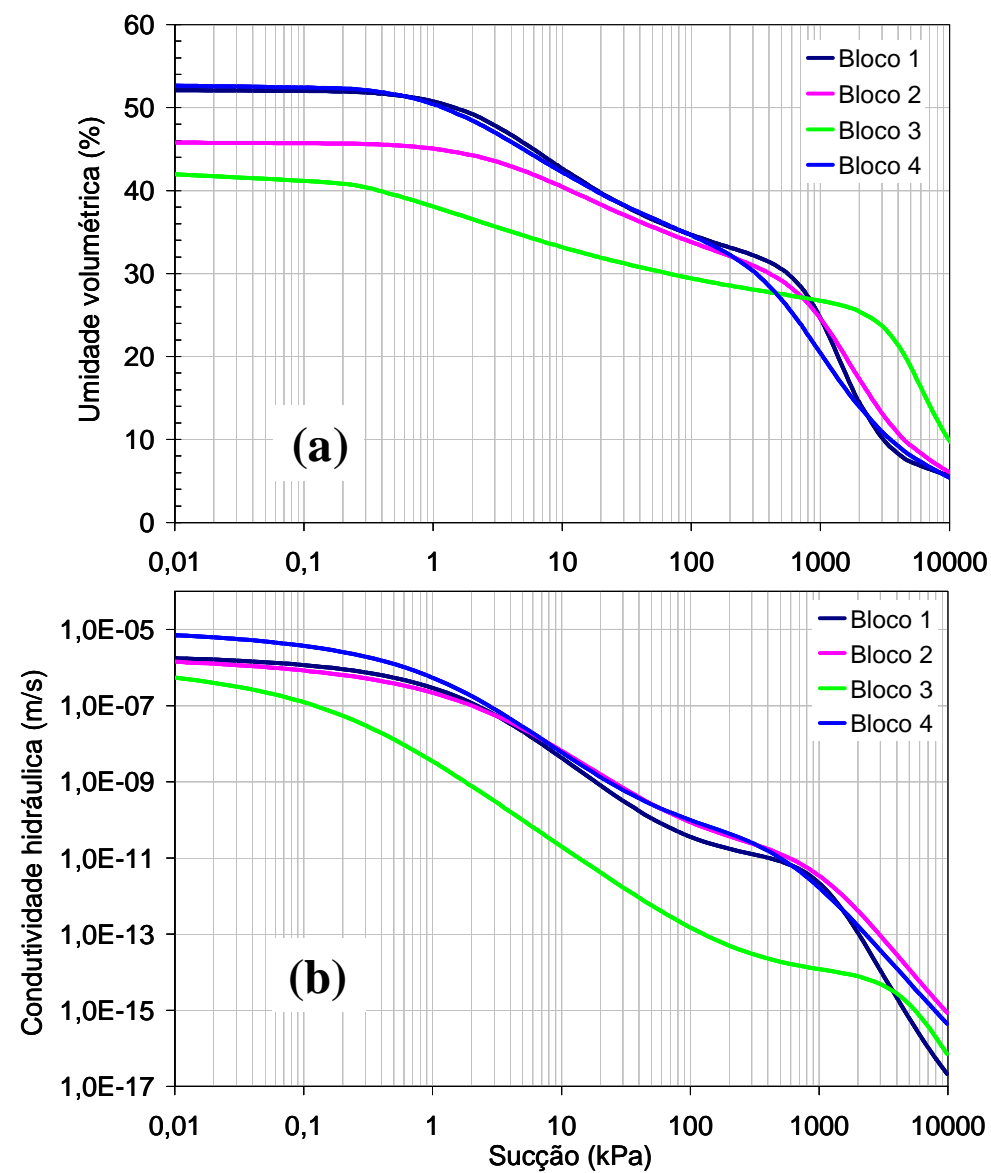

FIGURA 5.37 - CURVAS DE RETENÇÃO (A) E DE CONDUTIVIDADE HIDRÁULICA (B) PARA OS SOLOS RESIDUAIS REPRESENTATIVOS DAS ÁREAS ESTUDADAS.

Na Figura 5.37 nota-se uma certa similaridade no formato das curvas de condutividade hidráulica estimadas para os Blocos 1, 2 e 4, com uma ligeira discordância para o trecho inicial (sucção < 1 $\mathrm{kPa}$ - em relação ao Bloco 4) e para o trecho final (sucção > $1000 \mathrm{kPa}$ - em relação ao Bloco 1). Para o Bloco 3, a curva de condutividade hidráulica estimada apresentou um formato bem distinto em relação às curvas dos outros solos. 


\section{INVESTIGAÇÕES DE CAMPO}

\subsection{Introdução}

As investigações de campo foram realizadas a partir do emprego dos seguintes ensaios e métodos: condutividade hidráulica, medição do teor de umidade do solo com GPR, monitoramento dos perfis de umidade com sensores FDR, monitoramento da sucção do solo com sensores GMS e monitoramento dos índices pluviométricos com pluviômetros automatizados.

Os ensaios de condutividade hidráulica de campo foram realizados com o intuito de comparar seus resultados com aqueles obtidos nos ensaios de laboratório, além de utilizá-los nas estimativas das respectivas curvas de condutividade hidráulica dos solos estudados, juntamente com as curvas de retenção de água (CRAs). Os teores de umidade obtidos com os métodos GPR foram comparados com os valores obtidos com a técnica gravimétrica. A análise destes dados possibilitou verificar a viabilidade e precisão do método não invasivo (GPR) para medir o teor de umidade em solos residuais tropicais nas condições de campo, podendo inclusive contribuir para avaliações futuras das condições de umidade das encostas e taludes em áreas de risco.

Os dados de monitoramento dos perfis de sucção, umidade e índices pluviométricos foram utilizados para o estabelecimento das faixas de valores a serem adotados em futuras análises de estabilidade de taludes na região estudada. Os resultados também permitem uma avaliação sobre o comportamento dos perfis de sucção e umidade associados com os períodos de chuvas e estiagem. Esses dados também foram utilizados conjuntamente com os demais resultados obtidos no presente trabalho, com o objetivo de propor procedimentos que permitam o monitoramento das variáveis climatológicas e geotécnicas em áreas sujeitas a escorregamentos. 


\subsection{Condutividade Hidráulica}

A condutividade hidráulica saturada dos solos estudados foi determinada a partir de ensaios de laboratório e de campo. No laboratório foram realizados ensaios de condutividade hidráulica com permeâmetro de parede flexível e no campo ensaios de condutividade hidráulica com o infiltrômetro de mini-disco. O infiltrômetro de mini-disco apresentado na Figura 6.1 é ideal para medidas no campo, pois necessita de pouca quantidade de água durante sua operação e, além disso, o seu tamanho reduzido permite a realização de diversos ensaios num período curto de tempo.

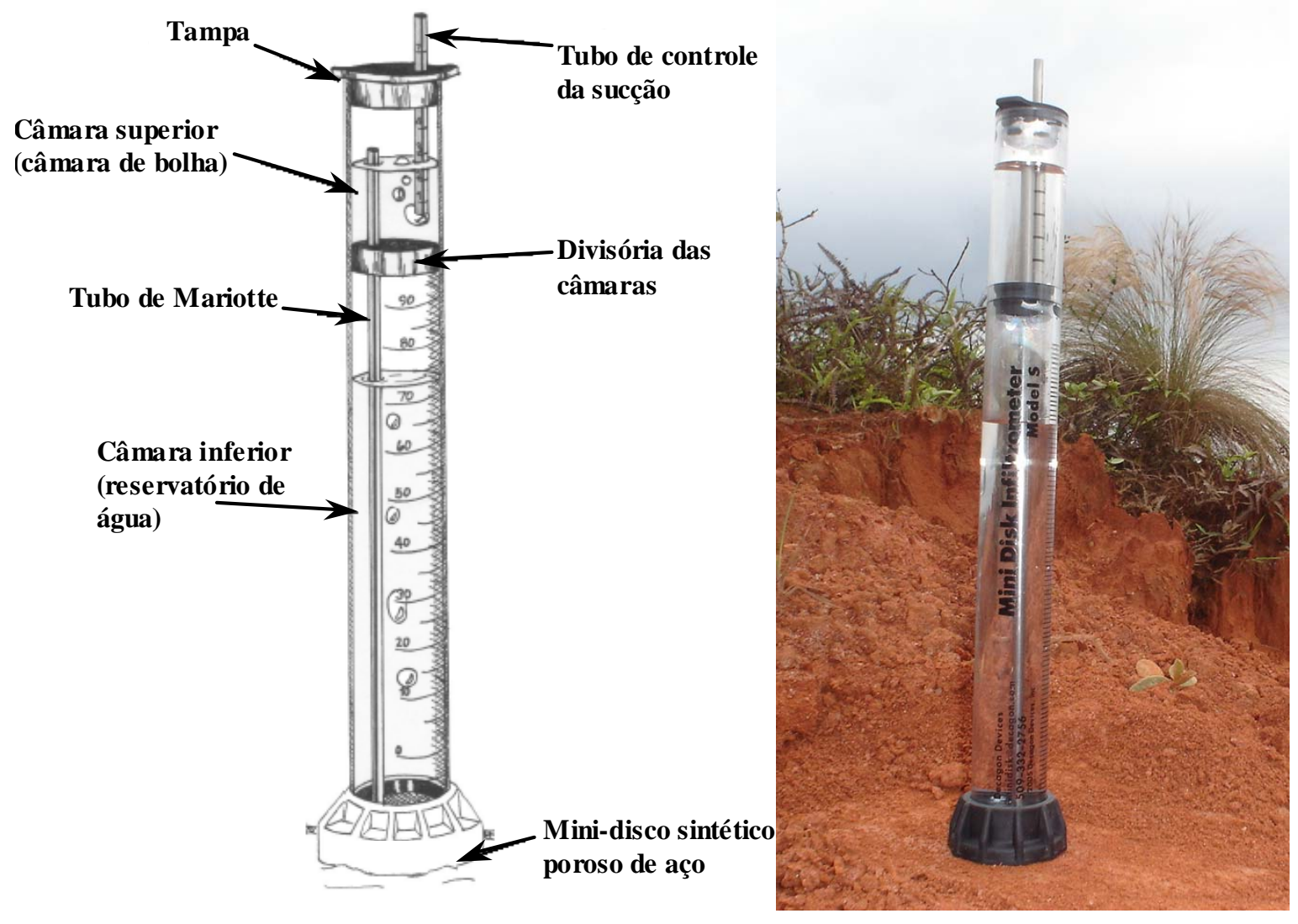

FIGURA 6.1 - PERFIL ESQUEMÁTICO DO INFILTRÔMETRO DE MINI-DISCO.

A câmara superior e inferior do infiltrômetro são preenchidas com água. A câmara superior (ou câmara de bolha) controla a sucção. A câmara inferior contém um certo volume de água que infiltra no solo numa determinada quantidade, que depende da sucção imposta na câmara superior. A câmara inferior é graduada em intervalos de volume (mililitros). 
A base do infiltrômetro é composta por um mini-disco sintético e poroso de aço inoxidável que não permite o vazamento de água para a atmosfera. O pequeno diâmetro do mini-disco permite a realização de medidas não invasivas sobre o nível do terreno.

Após colocar o infiltrômetro sobre o terreno, a água começa a fluir da câmara inferior e infiltra no terreno numa quantidade determinada pelas propriedades hidráulicas do solo. A cada rebaixamento do nível de água, é anotado o volume de água consumido pelo solo, para intervalos de tempo específicos (por exemplo, 30 segundos para um solo siltoso ou 60 segundos para um solo argiloso). Pode-se então, plotar estes dados num gráfico (raiz quadrada do tempo versus infiltração cumulativa) que permite a obtenção dos parâmetros para calcular a condutividade hidráulica do solo, conforme apresentado na Figura 6.2.

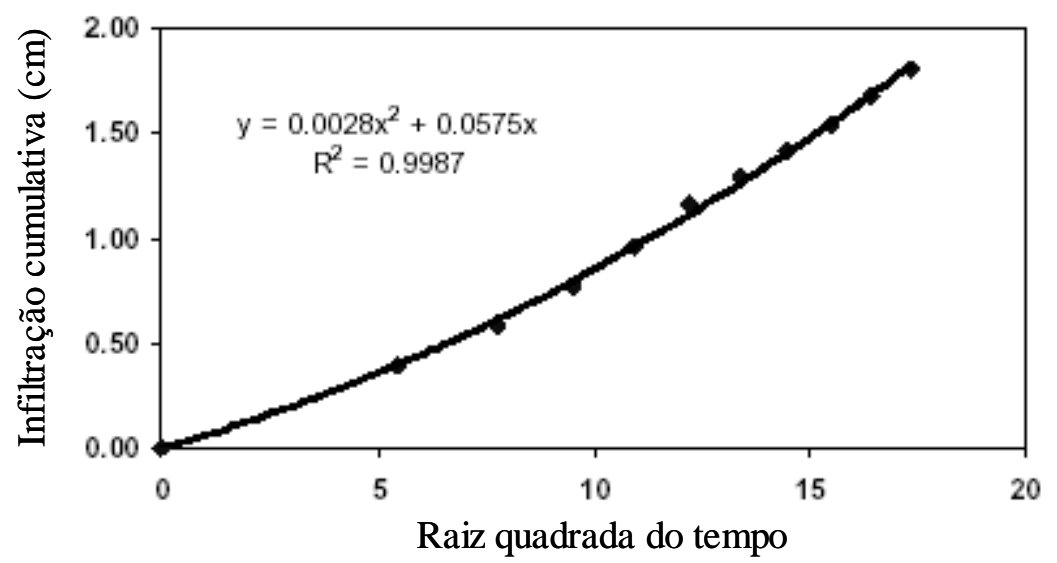

FIGURA 6.2 - EXEMPLO DE GRÁFICO OBTIDO COM OS DADOS DO INFILTRÔMETRO (DECAGON DEVICES 2005).

O cálculo da infiltração de água nos solos é feito pelo método proposto por ZHANG (1997). O método requer a medição da infiltração cumulativa em função do tempo (conforme indicado na Figura 6.2) e os resultados são ajustados com a função:

$$
I=C_{1} \cdot t+C_{2} \cdot \sqrt{t}
$$

onde: $C_{1}\left(\mathrm{~m} . \mathrm{s}^{-1}\right)$ e $C_{2}\left(\mathrm{~m} . \mathrm{s}^{-1 / 2}\right)$ são parâmetros. $C_{1}$ está relacionado com a condutividade hidráulica, e $C_{2}$ está relacionado com a absorção do solo. A condutividade hidráulica do solo $(k)$ é calculada a partir da expressão: 


$$
k=\frac{C_{1}}{A}
$$

onde: $C_{l}$ é a inclinação da curva de infiltração cumulativa versus a raiz quadrada do tempo (e.g. representado pelo valor 0,0028 na equação da Figura 6.2), e $A$ é um valor relacionado com os parâmetros de Van Genuchten, e que depende do tipo de solo, do valor da sucção imposta e do raio do mini-disco. $\mathrm{O}$ valor de $A$ pode ser obtido pelas seguintes expressões:

$$
\begin{aligned}
& A=\frac{11,65\left(n^{0,1}-1\right) \exp \left[2,92(n-1,9) \alpha \cdot h_{0}\right]}{\left(\alpha \cdot r_{0}\right)^{0,91}} ; \operatorname{para} n \geq 1,9 \\
& A=\frac{11,65\left(n^{0,1}-1\right) \exp \left[7,5(n-1,9) \alpha \cdot h_{0}\right]}{\left(\alpha \cdot r_{0}\right)^{0,91}} ; \operatorname{para} n<1,9
\end{aligned}
$$

[Equação 7.3]

onde: $n$ e $\alpha$ são os parâmetros de Van Genuchten para um determinado tipo de solo, $r_{0}$ é o raio do mini-disco, e $h_{0}$ é a sucção imposta na superfície do mini-disco.

O infiltrômetro é capaz de impor sucções entre -0,5 a -6,0 cm, e o mini-disco possui um raio de $2.2 \mathrm{~cm}$. Os parâmetros de Van Genuchten juntamente com os valores de $A$ para 12 tipos de solos, foram obtidos por CARSEL \& PARRISH (1988), conforme mostrado na Tabela 6.1.

Tabela 6.1 - Parâmetros de Van Genuchten e valores de A para 12 tipos de solo.

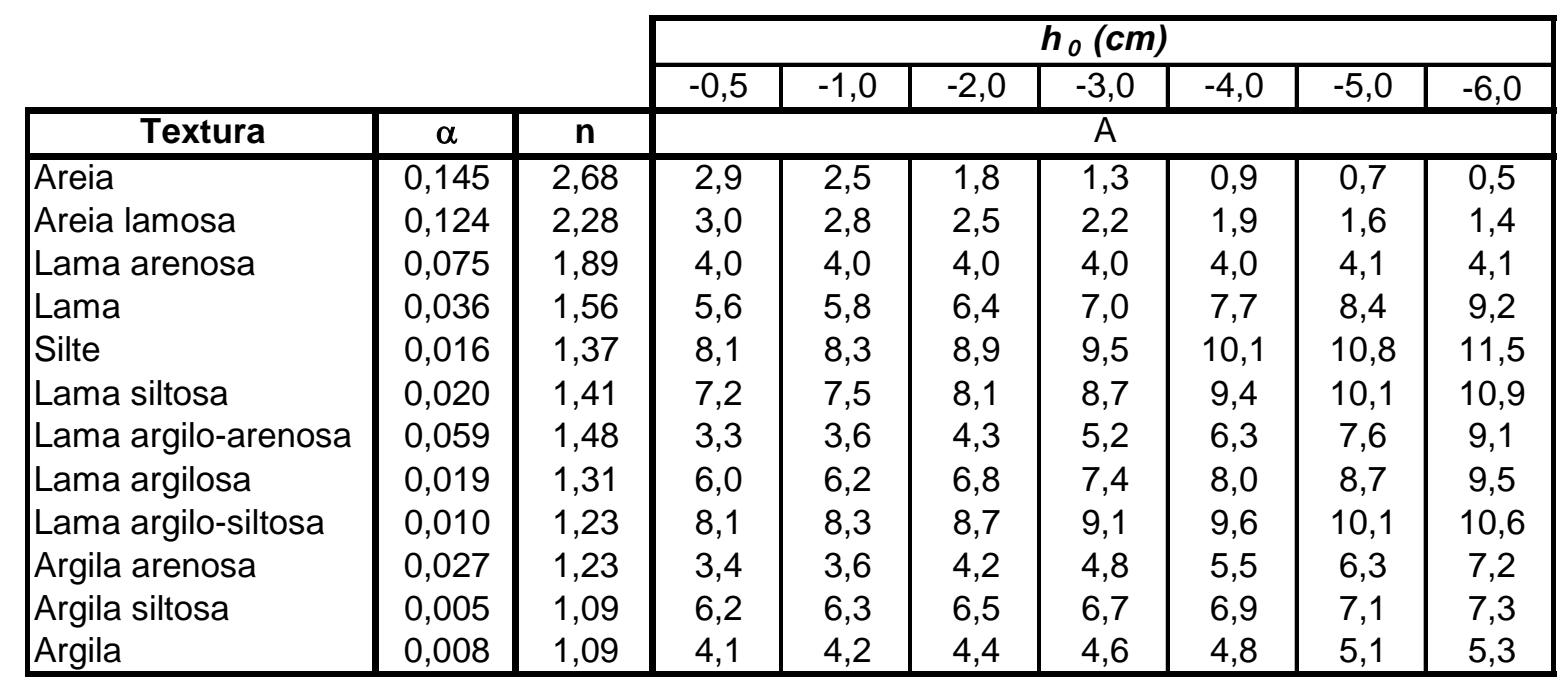


No exemplo da Figura 6.2, o valor do $C_{l}$ é $0,0028 \mathrm{~cm} . \mathrm{s}^{-1}$. O solo é classificado como uma lama siltosa, assim da Tabela 6.1, para a sucção de $-2,0 \mathrm{~cm}, A=8,1$. A condutividade hidráulica saturada é conseqüentemente $k_{s}=0,0028 / 8,1=3,45 \times 10^{-4} \mathrm{~cm} / \mathrm{s}$. Uma discussão mais detalhada sobre a medida e da análise do infiltrômetro de tensão pode ser encontrada em DANE \& TOPP (2002).

Os ensaios de campo para a determinação da condutividade hidráulica saturada $\left(\mathrm{K}_{\text {sat }}\right)$ com o infiltrômetro de mini-disco foram realizados em diferentes profundidades do perfil de alteração, conforme apresentado na Figura 6.3.
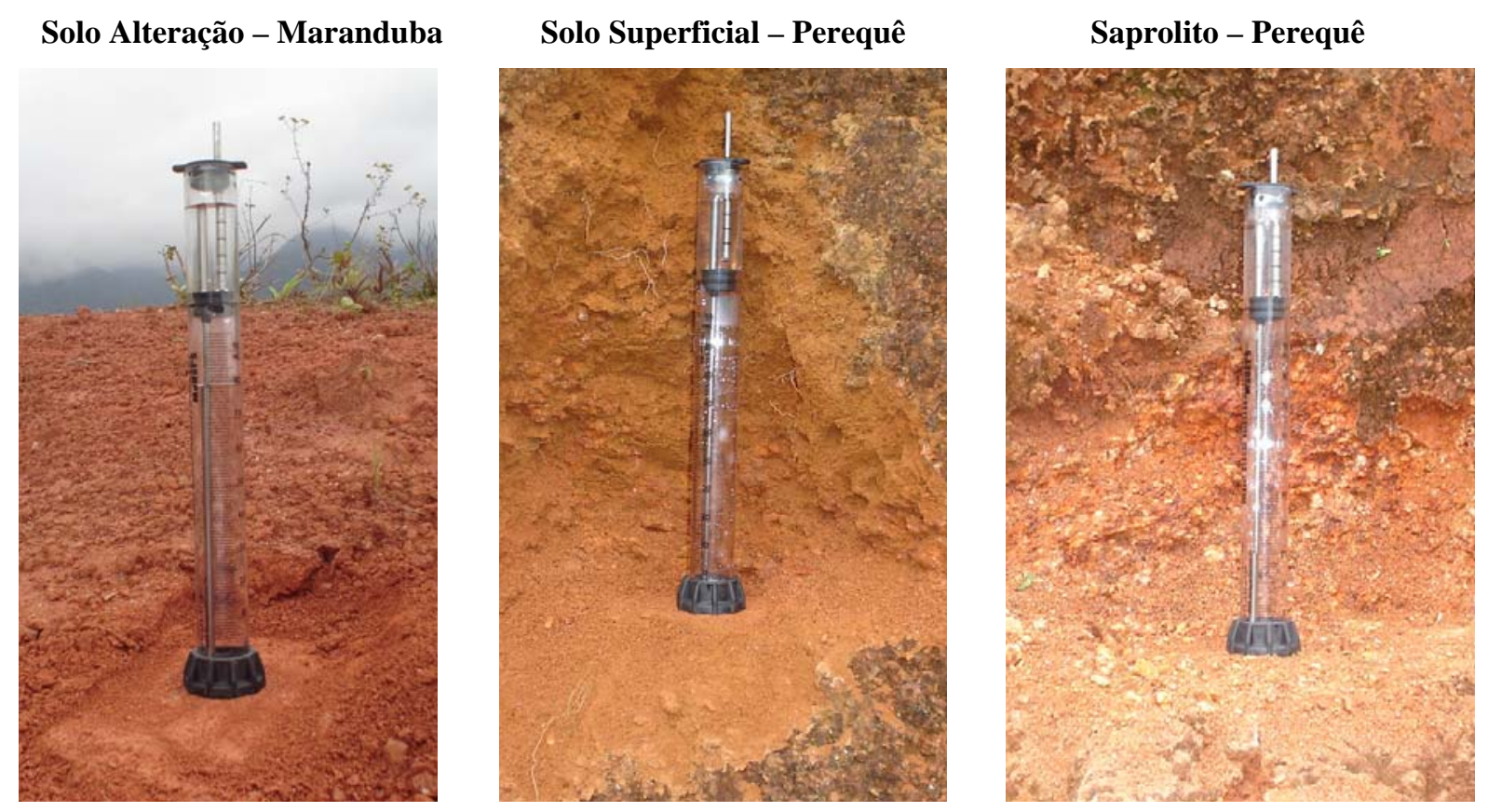

FIGURA 6.3 - ENSAIOS NO CAMPO COM O INFILTRÔMETRO DE MINI-DISCO EM DIFERENTES PROFUNDIDADES DOS PERFIS DE ALTERAÇÃO ESTUDADOS.

Os valores correspondentes ao parâmetro $C_{1}$ foram obtidos diretamente da inclinação das curvas de infiltração cumulativa versus a raiz quadrada do tempo, conforme apresentado na Figura 6.4. Os valores de “ $A$ ” foram calculados pela Equação 7.3 com base nos parâmetros de Van Genuchten adotados em função dos perfis de solos ensaiados. 

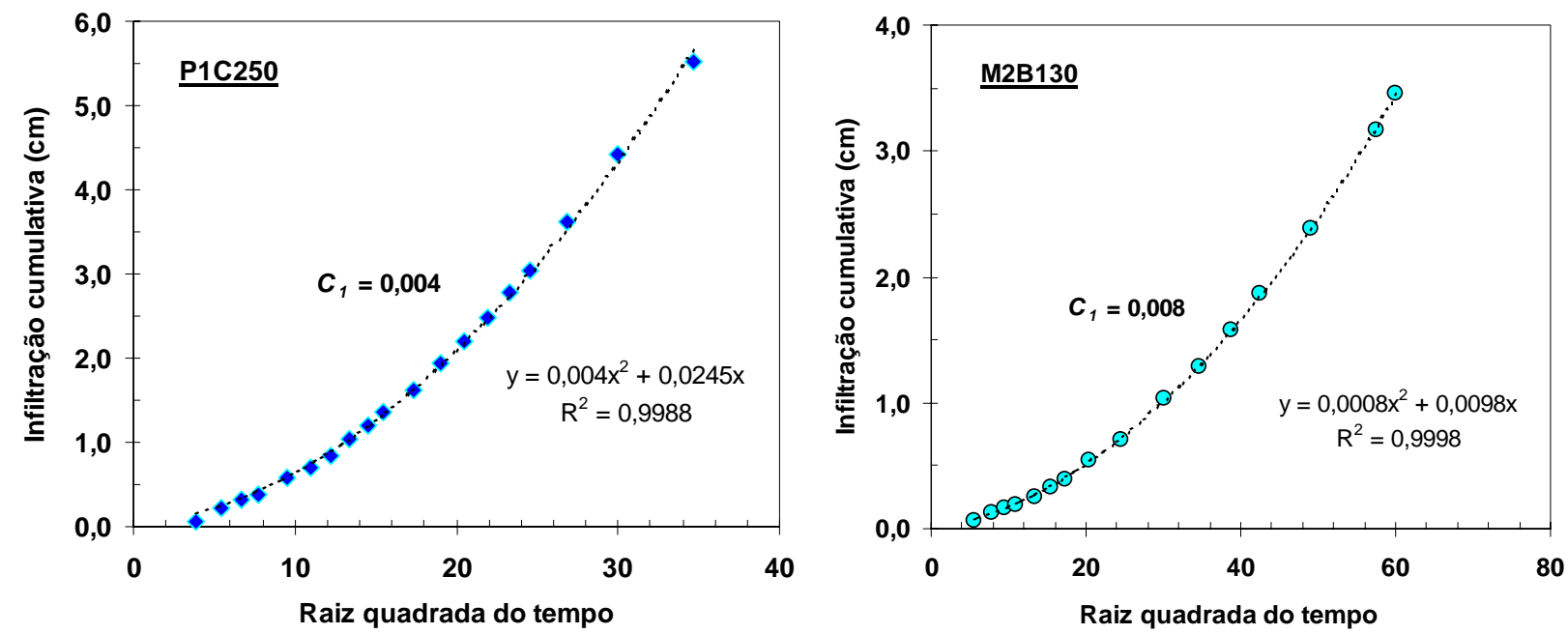

FIgURA 6.4 - CURVAS DE INFILTRAÇÃO OBTIDAS COM OS DADOS DO INFILTRÔMETRO DE MINIDISCO NAS CONDIÇÕES DE CAMPO.

Os parâmetros de Van Genuchten “ $\alpha$ ” e “ $n$ ” necessários para calcular os valores da condutividade hidráulica saturada $\left(\mathrm{K}_{\text {sat }}\right)$, foram obtidos diretamente dos parâmetros utilizados para ajustar os pontos experimentais das curvas de retenção de água, conforme apresentado na Tabela 5.8. Como a maior parte dessas curvas foi ajustada por modelo matemático para meio de porosidade dupla "dual porosity”, optou-se preferencialmente pelos parâmetros de ajuste da primeira curva $\left(\alpha_{1}\right.$ e $\left.n_{1}\right)$, pois representam a condição mais próxima da infiltração. Na Tabela 6.2 são apresentados os valores da condutividade hidráulica saturada obtidos nas condições de campo com o infiltrômetro de mini-disco, juntamente com os respectivos parâmetros de ajuste das curvas de retenção de água.

Tabela 6.2 - Valores da condutividade hidráulica saturada e dos parâmetros utilizados para os solos investigados.

\begin{tabular}{|c|c|c|c|c|c|c|c|}
\hline \multicolumn{2}{|c|}{ Área/Amostra } & $\begin{array}{l}\text { Prof. } \\
\text { (m) }\end{array}$ & $\begin{array}{c}\alpha \\
(1 / \mathrm{cm})\end{array}$ & $\begin{array}{c}n \\
(-)\end{array}$ & $\begin{array}{c}\mathrm{h}_{0} \\
(\mathrm{~cm})\end{array}$ & $\begin{array}{c}r_{0} \\
(\mathrm{~cm})\end{array}$ & $\begin{array}{c}\mathrm{K}_{\mathrm{sat}} \\
(\mathrm{m} / \mathrm{s})\end{array}$ \\
\hline \multirow{4}{*}{ 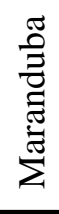 } & M2B130 & 1,30 & 6,6E-03 & 2,511 & $-5,0$ & 2,2 & $1,6 \mathrm{E}-07$ \\
\hline & M2B250 & 2,50 & 7,0E-03 & 1,851 & $-5,0$ & 2,2 & $2,4 \mathrm{E}-07$ \\
\hline & M2B335 & 3,35 & 7,0E-03 & 1,851 & $-5,0$ & 2,2 & $3,0 \mathrm{E}-07$ \\
\hline & M2B500 & 5,00 & 7,2E-03 & 2,130 & $-5,0$ & 2,2 & $8,0 \mathrm{E}-07$ \\
\hline \multirow{3}{*}{ 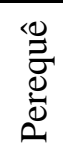 } & P1A30 & 0,30 & $1,5 \mathrm{E}-03$ & 2,486 & $-1,0$ & 2,2 & $1,0 \mathrm{E}-07$ \\
\hline & P1A90 & 0,90 & $1,5 \mathrm{E}-03$ & 2,486 & $-5,0$ & 2,2 & 8,8E-07 \\
\hline & P1C250 & 2,50 & 2,7E-03 & 2,699 & $-5,0$ & 2,2 & $3,2 \mathrm{E}-07$ \\
\hline
\end{tabular}


Analisando a Tabela 6.2, constata-se que os valores de condutividade hidráulica saturada ( $\left.\mathrm{K}_{\text {sat }}\right)$ dos solos representativos do Horizonte-B de Maranduba e do Horizonte-A do Perequê-Mirim variaram da ordem de até 8,0 vezes, havendo tendência de um ligeiro aumento da condutividade hidráulica com o aumento da profundidade em ambas as áreas estudadas.

O infiltrômetro de mini-disco também foi utilizado no laboratório com a finalidade de comparar seus resultados com os valores da condutividade hidráulica saturada $\left(\mathrm{K}_{\text {sat }}\right)$ obtidos com o permeâmetro de carga variável e parede flexível. Os ensaios foram realizados sobre os corpos de prova cilíndricos talhados diretamente dos blocos indeformados representativos das áreas estudadas. Antes de serem submetidos ao procedimento de saturação por contrapressão, os corpos de prova foram revestidos com uma membrana de borracha e, em seguida, ensaiados com o infiltrômetro de mini-disco apoiado no topo dos corpos de prova, conforme apresentado na Figura 6.5.
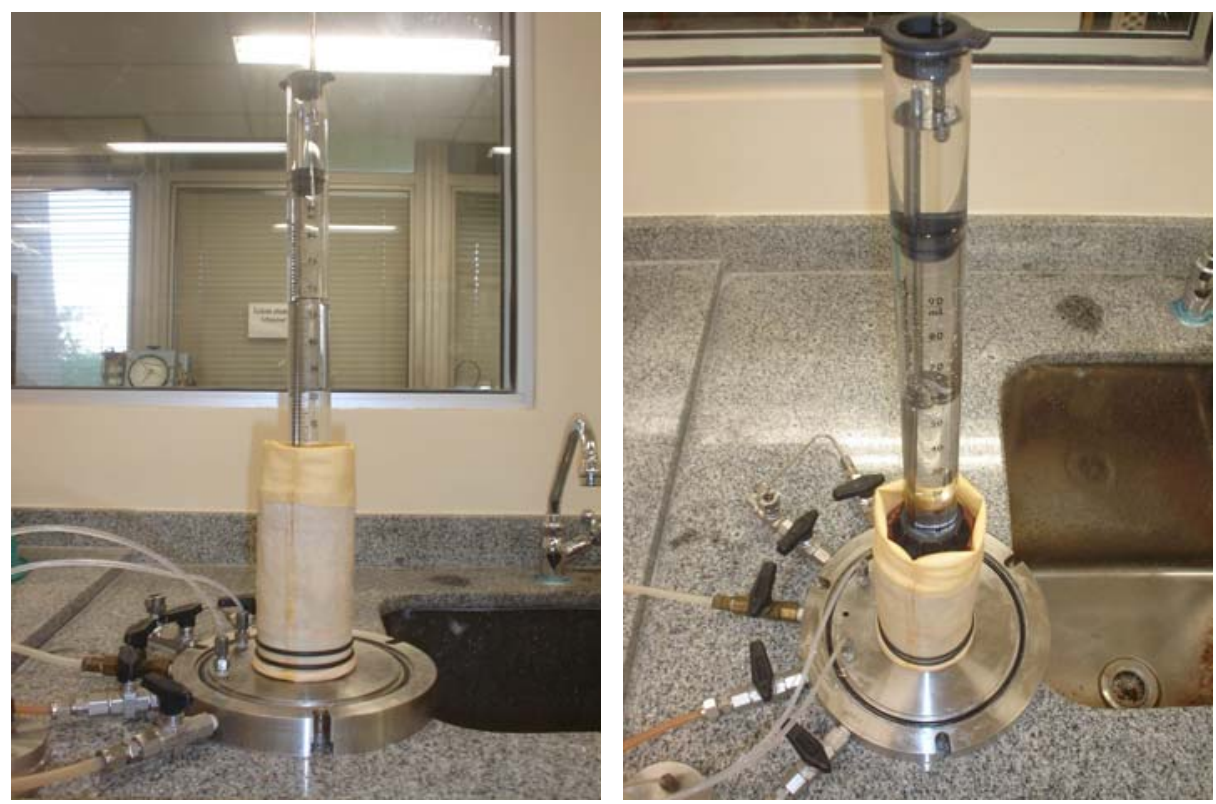

FIGURA 6.5 - ENSAIOS NO LABORATÓRIO COM O INFILTRÔMETRO DE MINI-DISCO SOBRE OS CORPOS DE PROVA.

Os valores da condutividade hidráulica saturada $\left(\mathrm{K}_{\mathrm{sat}}\right)$ obtidos pelos ensaios realizados no laboratório com o infiltrômetro de mini-disco e o permeâmetro de parede flexível são apresentados na Tabela 6.3. 
Tabela 6.3 - Valores da condutividade hidráulica saturada e dos parâmetros utilizados para os corpos de prova ensaiados.

\begin{tabular}{|c|c|c|c|c|c|c|c|c|}
\hline Área & C.P. & $\begin{array}{l}\text { Prof. } \\
\text { (m) }\end{array}$ & $\begin{array}{c}\alpha \\
(1 / \mathrm{cm})\end{array}$ & $\begin{array}{l}n \\
(-)\end{array}$ & $\begin{array}{c}\mathrm{h}_{0} \\
(\mathrm{~cm})\end{array}$ & $\begin{array}{c}r_{0} \\
(\mathrm{~cm})\end{array}$ & $\begin{array}{c}\mathrm{K}_{\text {sat }}(\mathrm{m} / \mathrm{s}) \\
\text { Infiltrômetro }\end{array}$ & $\begin{array}{c}\mathrm{K}_{\text {sat }}(\mathrm{m} / \mathrm{s}) \\
\text { Permeâmetro }\end{array}$ \\
\hline 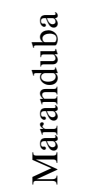 & $\begin{array}{l}\text { Bloco } 1 \\
\text { Bloco } 2\end{array}$ & 9,00 & $\begin{array}{l}\text { 8,2E-03 } \\
7,5 \mathrm{E}-03\end{array}$ & $\begin{array}{l}2,834 \\
2,163\end{array}$ & $\begin{array}{l}-5,0 \\
-2,0\end{array}$ & 2,2 & $\begin{array}{l}\text { 1,4E-07 } \\
\text { 3,6E-07 }\end{array}$ & $\begin{array}{l}\text { 2,3E-06 } \\
\text { 2,3E-06 }\end{array}$ \\
\hline . & $\begin{array}{l}\text { Bloco } 3 \\
\text { Bloco } 4\end{array}$ & $\begin{array}{l}0,50 \\
6,70\end{array}$ & $1,8 \mathrm{E}-03$ & 2,916 & $-1,0$ & 2,2 & 2,5E-07 & $\begin{array}{l}\text { 2,6E-06 } \\
\text { 1,2E-05 }\end{array}$ \\
\hline
\end{tabular}

Na Tabela 6.3 observa-se que os valores de condutividade hidráulica saturada obtidos com o infiltrômetro de mini-disco tendem ser 10 vezes menores em relação aos valores obtidos com o permeâmetro de carga variável. Acredita-se que essa diferença esteja associada com o teor de umidade inicial do solo nas condições de campo e que influencia sobremaneira o avanço da frente de saturação durante a realização dos ensaios com o infiltrômetro de mini-disco, o que não ocorre nos ensaios de permeabilidade com carga variável, pois o solo já se encontra previamente saturado.

\subsection{Medição do Teor de Umidade do Solo com GPR}

O sistema de radar utilizado consiste basicamente de uma unidade de controle que gera um pulso de alta voltagem e de curtíssima duração, dentro de uma banda de freqüência prédeterminada. Este sinal elétrico é transformado (via antenas) em ondas eletromagnéticas que se propagam no solo. No presente estudo empregou-se antenas não blindadas, biestáticas (transmissora e receptora), de freqüências centrais de 50, 100 e $200 \mathrm{MHz}$. Esses equipamentos são mostrados em detalhe na Figura 6.6. 
Unidade de controle e notebook

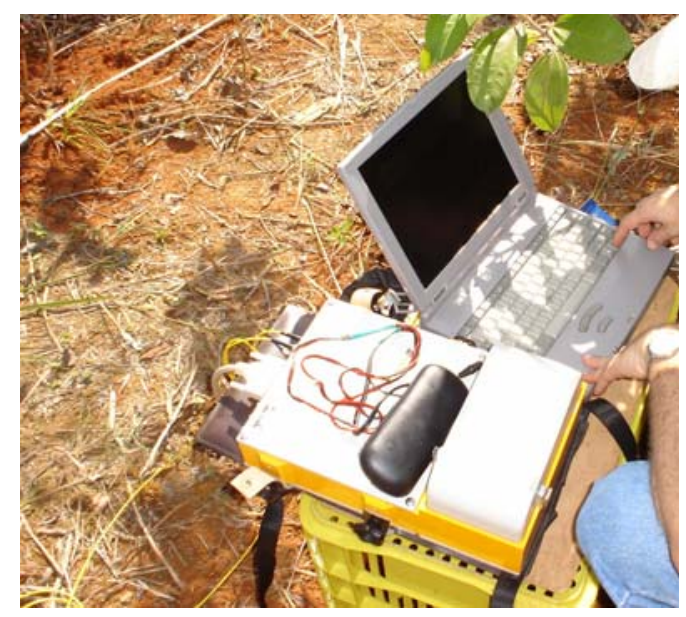

Antenas

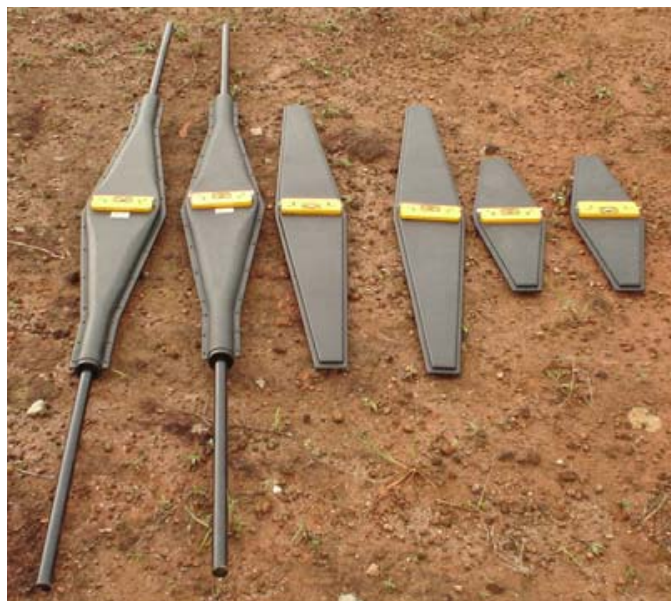

FigURA 6.6 - SISTEMA GPR UTILIZADO PARA DETERMINAR O TEOR DE UMIDADE DO SOLO NO CAMPO.

Nas duas áreas de estudo foram realizados ensaios de GPR empregando-se o arranjo CMP (common mid point) ao longo da superfície do terreno, e apenas na área de estudo do PerequêMirim foram realizados ensaios GPR com arranjo do tipo "common off set”, ao longo do talude adjacente ao local de realização do ensaio CMP, conforme descrito no item 3.4.6. Na área de Maranduba foram realizados ensaios em dois locais distintos, ambos sobre a superfície do terreno, sendo um sobre o solo de alteração e outro sobre o saprolito, conforme mostrado na Figura 6.7.

Solo de alteração

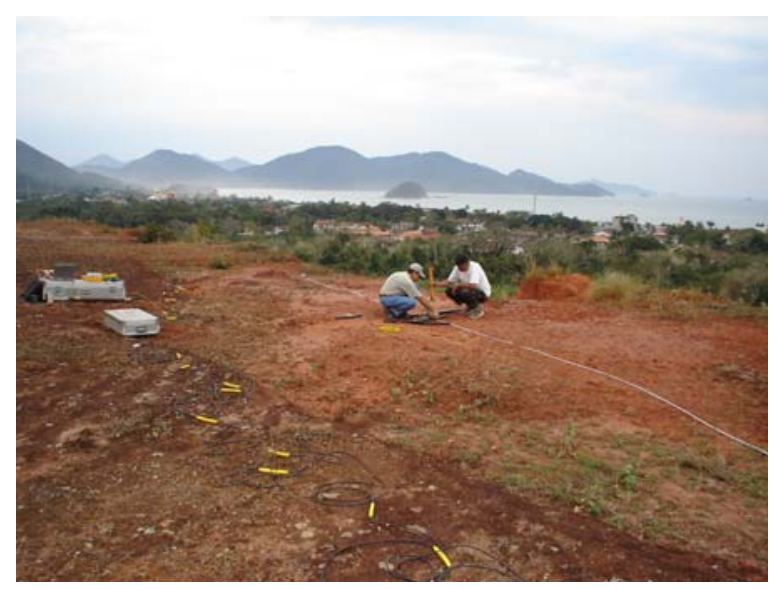

\section{Saprolito}

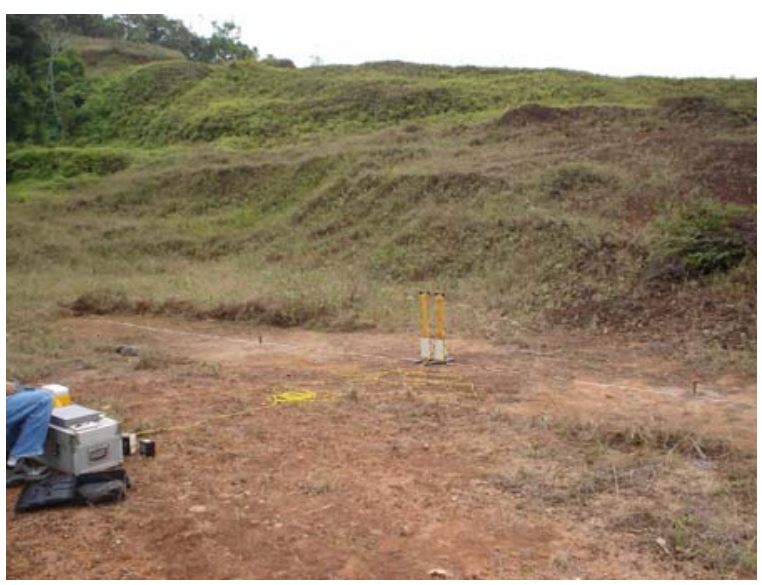

FIGURA 6.7 - LOCAIS ESTUDADOS COM O SISTEMA GPR NA ÁREA DE MARANDUBA. 
Na área de estudo do Perequê-Mirim, foram realizados ensaios em apenas um local, mas empregando-se dois tipos de arranjos. O primeiro tipo de arranjo (CMP) foi empregado sobre a superfície do terreno e o segundo (common offset) ao longo de um talude vertical (4,5 metros) próximo ao local de realização do ensaio CMP, conforme mostrado na Figura 6.8.

Arranjo CMP - sobre a superfície do terreno.

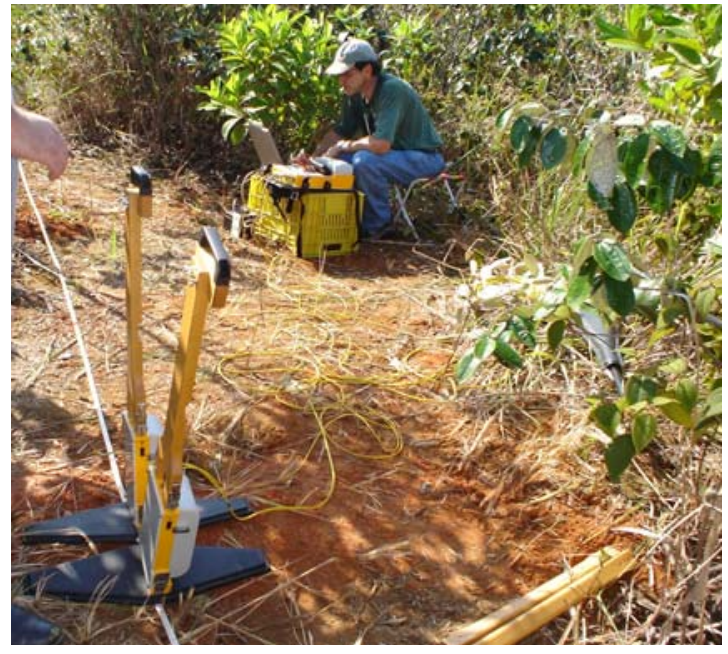

Arranjo common offset - talude vertical.

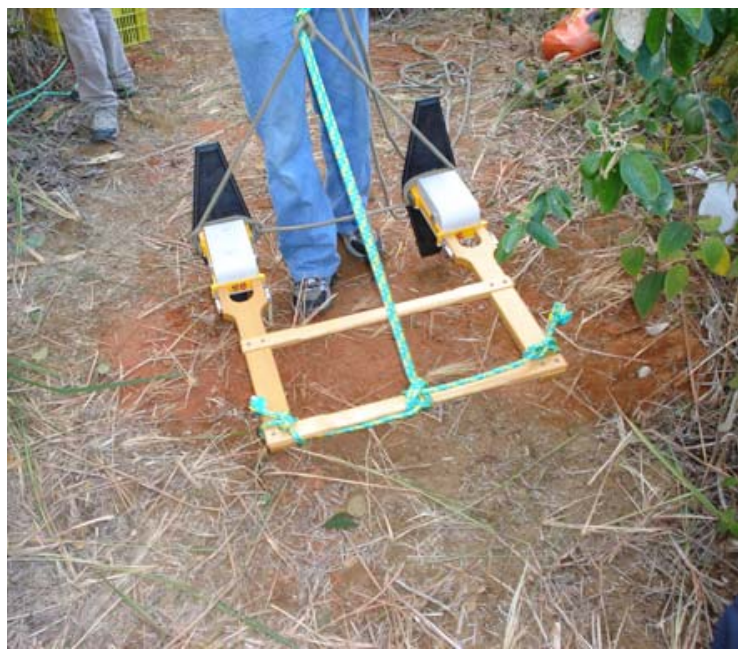

Figura 6.8 - ARRANJOS EMPREGADOS COM O SISTEMA GPR NA ÁREA DO PEREQUÊ-MIRIM.

Nos arranjos CMP adotou-se incrementos entre as aquisições de 0,1 metro, partindo de um afastamento inicial de zero metro até afastamentos máximos da ordem de 10 metros, dependendo das condições de cada local. No arranjo "common offset”" empregou-se somente a antena de 200 $\mathrm{MHz}$, com afastamento constante de 0,8 metro entre as antenas transmissora e receptora.

A partir das identificações dos tempos de percurso das ondas direta e refletida no radargrama CMP, buscou-se determinar as velocidades de propagação da onda eletromagnética nos diversos estratos geológicos ocorrentes nas áreas de estudo. Considerando o mesmo material geológico, as velocidades mais baixas indicam um aumento na quantidade de água, ou seja, acréscimo no teor de umidade do solo; velocidades mais altas implicam num teor de umidade mais baixo. Para se ter uma estimativa do teor de umidade volumétrico com o método GPR, primeiramente é necessário obter o valor da constante dielétrica das camadas $(K)$, a partir das leituras dos tempos de chegada das ondas direta e/ou refletida no radargrama. 
No caso de um solo homogêneo, parte da energia radiada que se propaga através do solo, entre a antena transmissora e a receptora, descreve uma relação linear entre o tempo de percurso e a separação da antena que permite a determinação da velocidade da onda direta no solo, e consequentemente a obtenção da constante dielétrica do meio atravessado.

De forma aproximada, a velocidade da onda eletromagnética é dada pela Equação 3.31, apresentada anteriormente. A obtenção das velocidades de propagação da onda direta é feita através do ajuste linear dos tempos de percurso identificados no radargrama, conforme ilustrado na Figura 6.9. No radargrama são registrados os tempos de chegada (em nanosegundos) das ondas aérea, direta no terreno e refletidas em função da distância " $n_{x}$ " (em metros) entre as antenas transmissora e receptora.

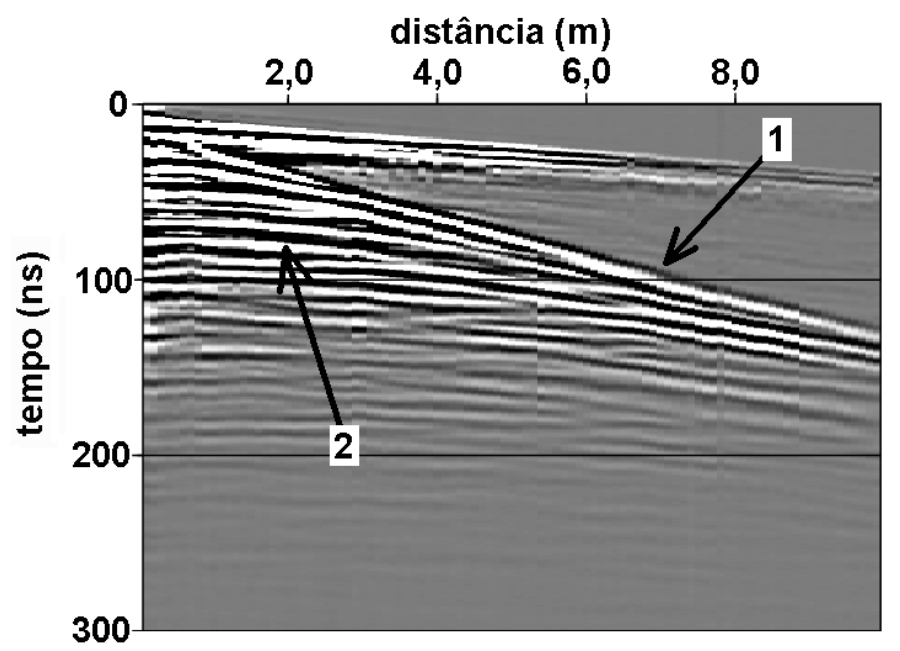

FiguRA 6.9 - IDENTIFICAÇÃO DOS TEMPOS DE CHEGADA DA ONDA DIRETA (1) E DA ONDA REFLETIDA (2) NO RADARGRAMA OBTIDO A PARTIR DE UM CONJUNTO DE MEDIDAS CMP.

Para a onda refletida identificada na Figura 6.9, o valor da velocidade média de propagação da onda eletromagnética é obtido pela Equação 3.39, conforme visto anteriormente. Mesmo para um meio com várias camadas, essa equação descreve com relativa precisão os tempos de percurso das ondas refletidas em cada interface (ou refletor). Neste caso, porém, a velocidade " $V$ " representará a velocidade média do pacote acima da interface considerada. As velocidades de propagação das ondas refletidas nas diferentes interfaces detectadas foram obtidas pela análise 
das hipérboles de reflexão presentes no radargrama CMP, conforme mostrado na Figura 6.9. O método adotado foi o da medida da máxima coerência no espectro de velocidade (YILMAZ 1987).

A velocidade obtida desta forma é denominada velocidade de empilhamento e representa a velocidade média do pacote superior a cada interface analisada, como já mencionado. Para um meio composto por diversas camadas é possível obter, a partir das velocidades de empilhamento presentes, as velocidades de cada camada denominada velocidade intervalar. Para converter as velocidades de empilhamento em velocidades intervalares de cada camada, $v_{\text {int, } n}$, utilizou-se a Equação 3.40 apresentada anteriormente.

A partir da velocidade média de cada pacote (ou de empilhamento) e da velocidade intervalar, obteve-se as respectivas constantes dielétricas do meio considerado, ou seja, $K_{\text {méd. }}$ e $K_{\text {int. }}$, conforme ilustrado na Figura 6.10. Os valores das constantes dielétricas foram obtidos em diferentes épocas do ano, com o intuito de se estudar e avaliar a eficiência da metodologia GPR para determinação do teor de umidade volumétrico em perfis de solos residuais não saturados.

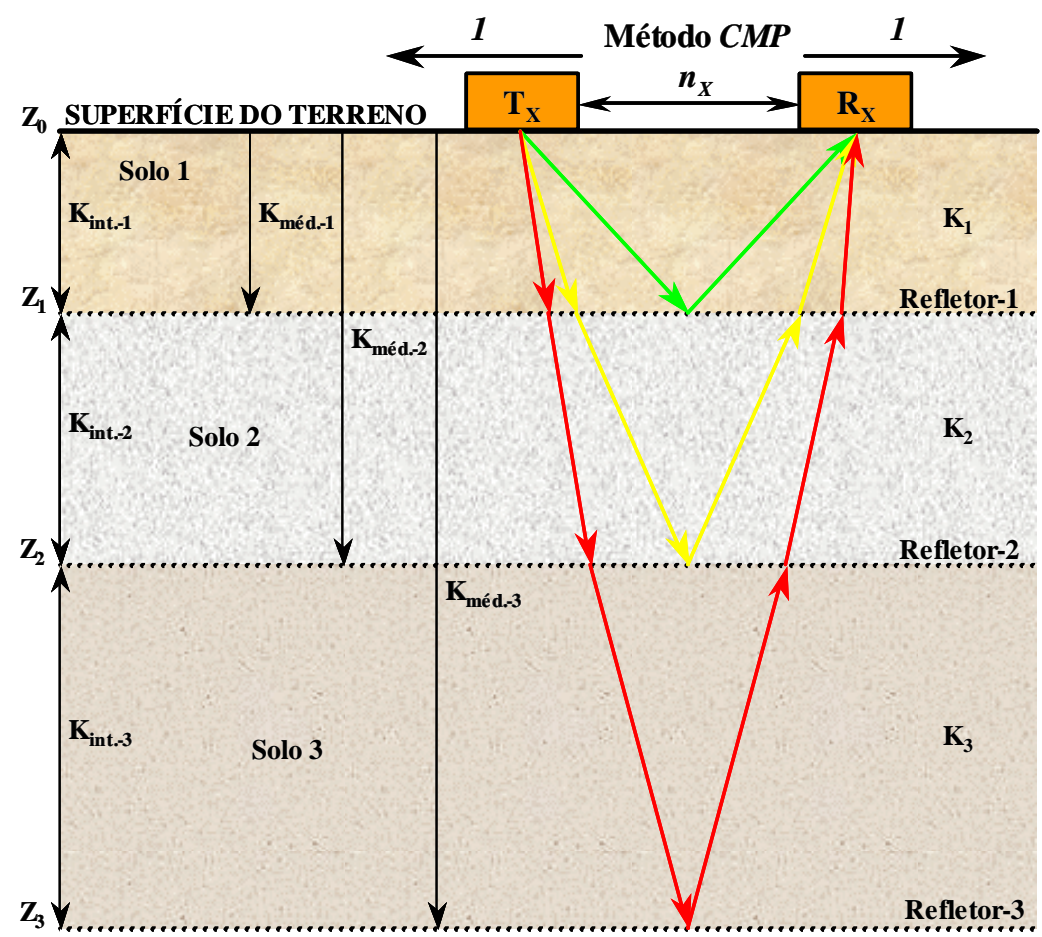

FIGURA 6.10 - ESQUEMA ILUSTRATIVO DA DETERMINAÇÃO DAS CONSTANTES DIELÉTRICAS MÉDIAS OU DE EMPILHAMENTO $\left(K_{M E ́ D .}\right)$ E INTERVALARES $\left(K_{I N T}\right)$. 
Após analisar cuidadosamente todos os valores das constantes dielétricas obtidas com GPR, verificou-se que os valores médios, obtidos com as antenas de 100 e $200 \mathrm{MHz}$, representam melhor a variação da constante dielétrica ao longo dos perfis de solo estudados, pois tais antenas apresentaram maior acurácia que as antenas de menor freqüência (antena de $50 \mathrm{MHz}$ ). Portanto, deve-se ressaltar que todos os valores de $K_{\text {méd }}$ apresentados em seguida foram obtidos a partir da análise de velocidades dos eventos de reflexão detectados no radargrama com as antenas de maior freqüência.

Os valores das constantes dielétricas médias $\left(K_{\text {méd}}\right.$. $)$ obtidos em diferentes épocas do ano e distribuídas ao longo dos perfis de alteração na área de Maranduba são mostrados nas Figuras 6.11 e 6.12 .
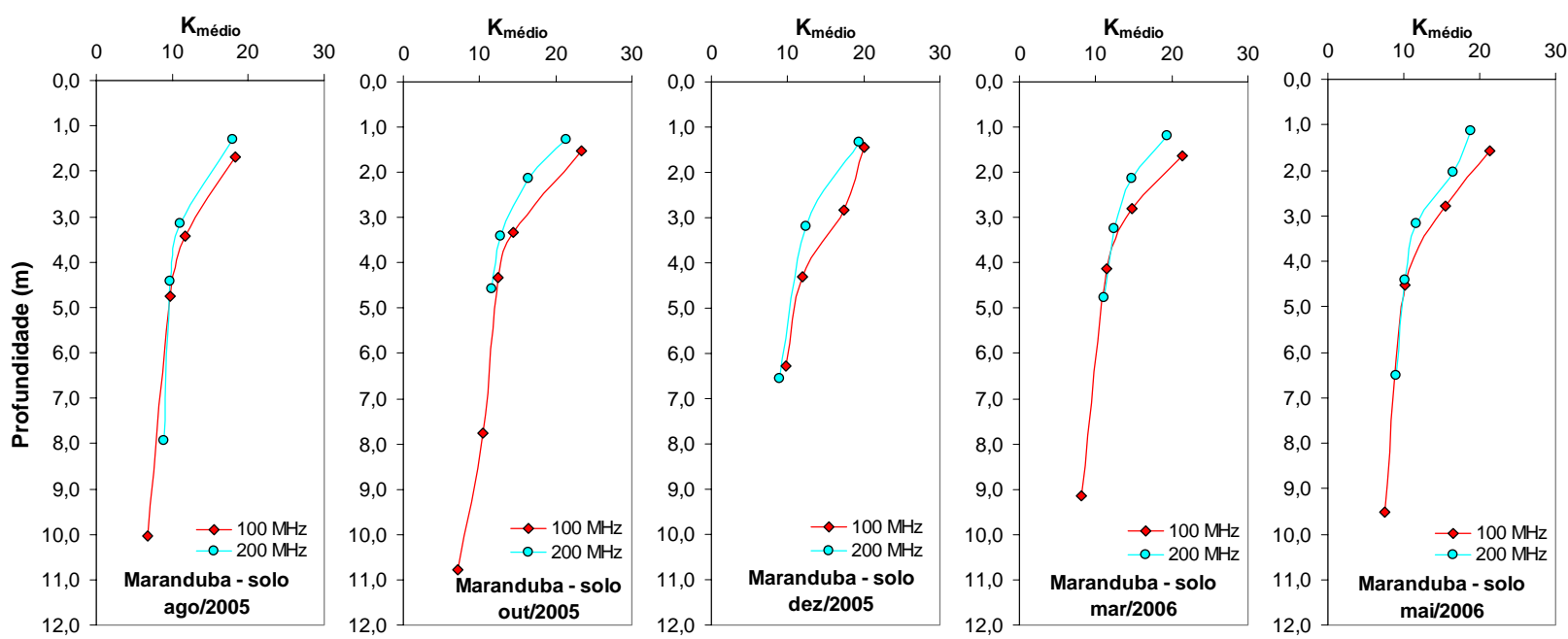

FIGURA 6.11 - VALORES DA CONSTANTE DIELÉTRICA MÉDIA OBTIDA SOBRE O PERFIL DE SOLO DE ALTERAÇÃO NA ÁREA DE MARANDUBA. 

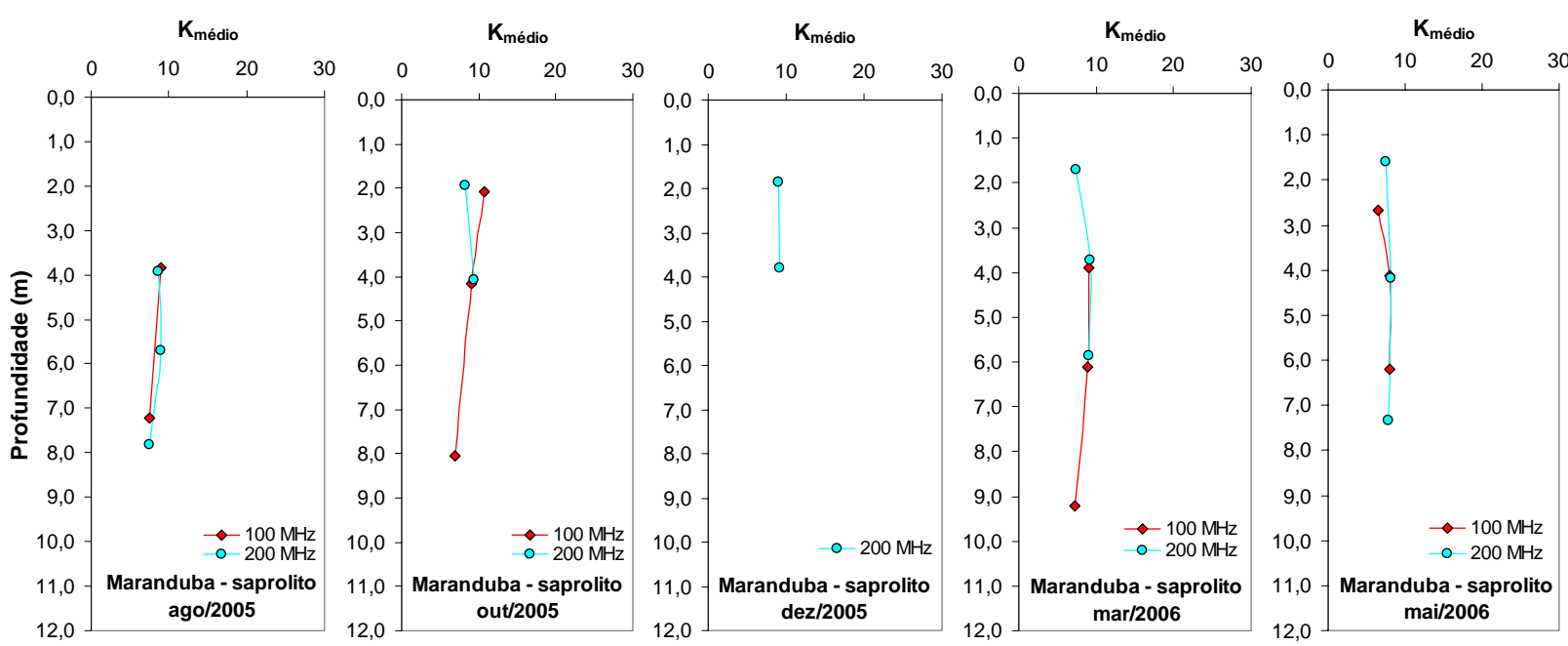

FIGURA 6.12 - VALORES DA CONSTANTE DIELÉTRICA MÉDIA OBTIDA SOBRE O PERFIL DE SAPROLITO NA ÁREA DE MARANDUBA.

Na Figura 6.11 são apresentadas as composições dos valores obtidos com as antenas de 100 e 200 MHz sobre o perfil de solo de alteração, onde se observa que os valores de $K_{\text {méd }}$ variaram aproximadamente de 23 a 7, tendendo a diminuir com o aumento da profundidade durante todo o período investigado. Essa mesma tendência não ocorreu para os valores de $K_{\text {méd }}$ obtidos sobre o perfil de saprolito, conforme está indicado na Figura 6.12. Nesse perfil os valores da constante dielétrica variaram muito pouco, apresentando valores máximos da ordem de 11 para o mês de outubro/2005 a 6 para o mês de dezembro/2005. Analisando conjuntamente os dados apresentados nas Figuras 6.11 e 6.12, observa-se que foi possível obter valores das constantes dielétricas para profundidades de até 11,0 metros sobre o perfil de solo de alteração, e de até 9,0 metros sobre o perfil de saprolito.

Os valores das constantes dielétricas médias $\left(K_{\text {méd }}\right.$ ) obtidos em diferentes épocas do ano e distribuídas ao longo do perfil de alteração na área do Perequê-Mirim são apresentados nas Figuras 6.13. 


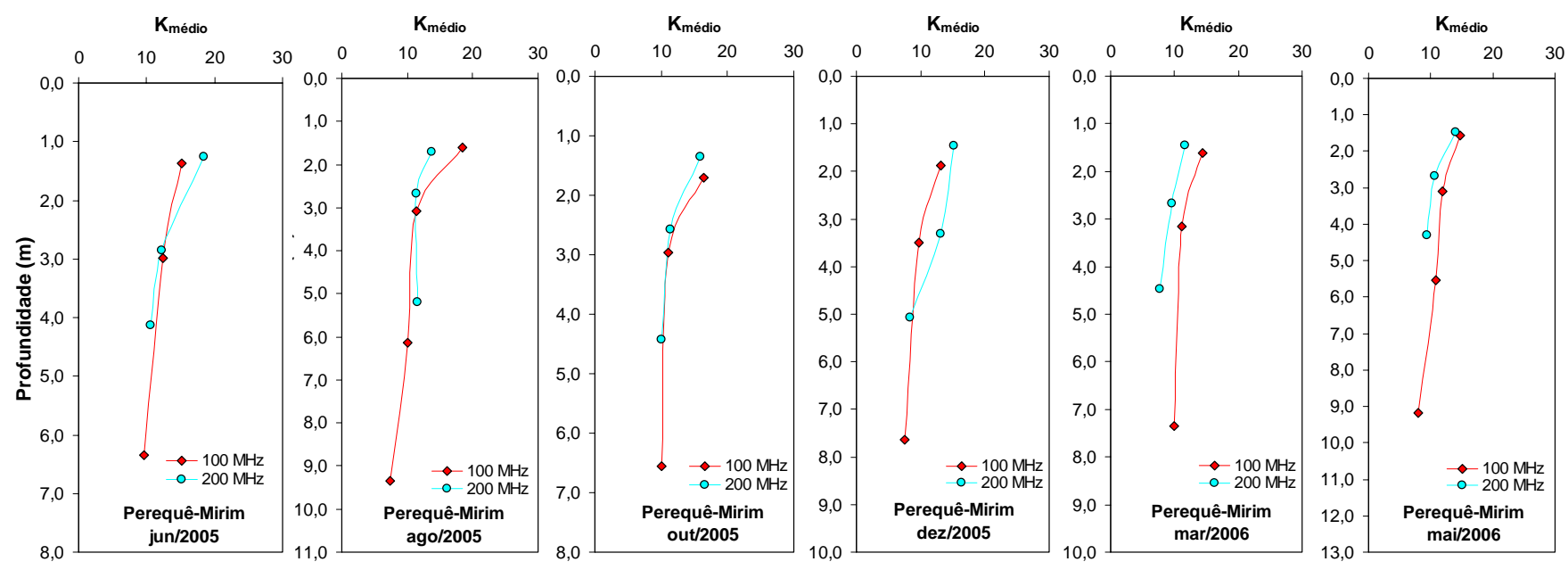

FIGURA 6.13 - VALORES DA CONSTANTE DIELÉTRICA MÉDIA OBTIDA SOBRE O PERFIL DE ALTERAÇÃO NA ÁREA DO PEREQUÊ-MIRIM.

Na Figura 6.13 observa-se que os valores de $K_{\text {méd }}$ variaram em média de 19 a 8, numa tendência de diminuição com o aumento da profundidade durante todo o período investigado. Verifica-se que as maiores variações de $K_{\text {méd }}$ ocorreram durante as medidas realizadas nos meses de junho, agosto e dezembro de 2005, e que foi possível obter valores das constantes dielétricas para profundidades de até 9,0 metros.

Na mesma época em que foram realizados os ensaios GPR, também foram coletadas amostras deformadas de solo com trado a cada 0,25 metros, até a profundidade de 3,0 metros, para determinação do teor de umidade gravimétrico. Os furos com o trado foram feitos sobre ou muito próximo $(\approx 0,10 \mathrm{~m})$ do início da linha de afastamento (espaçamento igual a zero), onde foram realizados os caminhamentos com as antenas GPR. A Figura 6.14 mostra o procedimento utilizado durante a coleta das amostras deformadas nas duas áreas de estudo. 
Área de Maranduba - sobre o perfil de saprolito

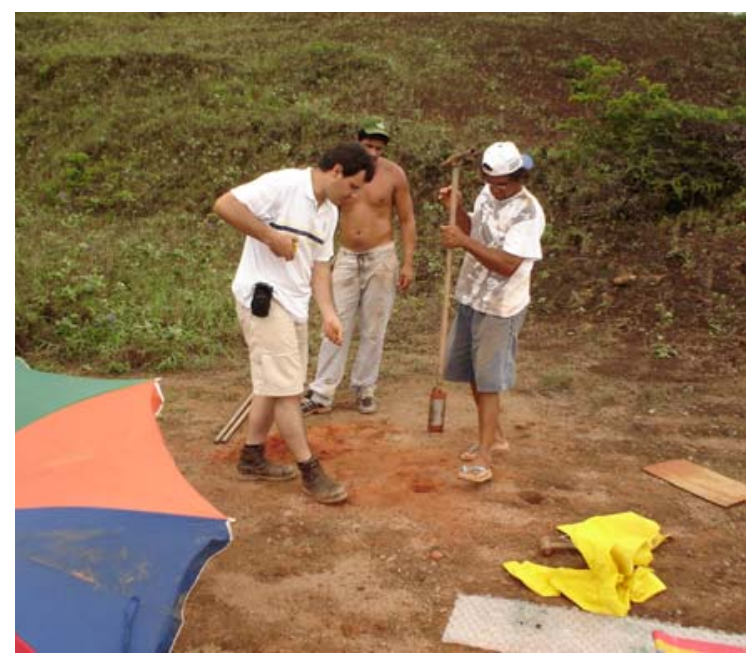

\section{Área do Perequê-Mirim}

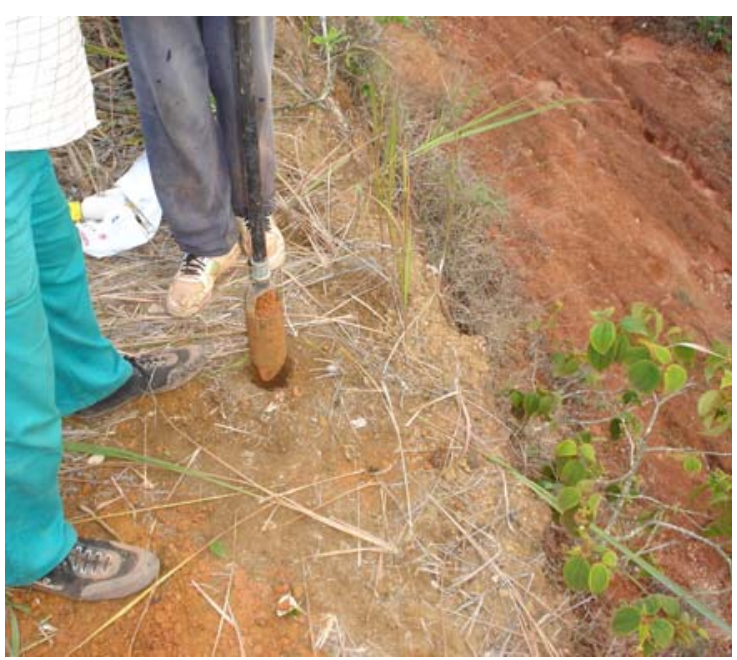

Figura 6.14 - COLETA DE AMOSTRAS DEFORMADAS DE SOLO PARA DETERMINAÇÃO DO TEOR DE UMIDADE GRAVIMÉTRICO EM LABORATÓRIO.

Os teores de umidade obtidos pela técnica gravimétrica foram posteriormente convertidos em teores de umidade volumétricos. Para isso, utilizou-se os valores da massa específica aparente seca $\left(\rho_{\mathrm{d}}\right)$, das amostras de solo que constituem o perfil de alteração de cada área estudada (ver resultados dos ensaios de caracterização na Tabela 5.1), e a seguinte expressão:

$$
\theta=w \times \rho_{d} \quad\left(\mathrm{~m}^{3} \cdot \mathrm{m}^{-3}\right)
$$

Os perfis de umidade volumétrica obtidos na área de Maranduba, durante o período de jun/2005 a mai/2006, são apresentados na Figura 6.15. 

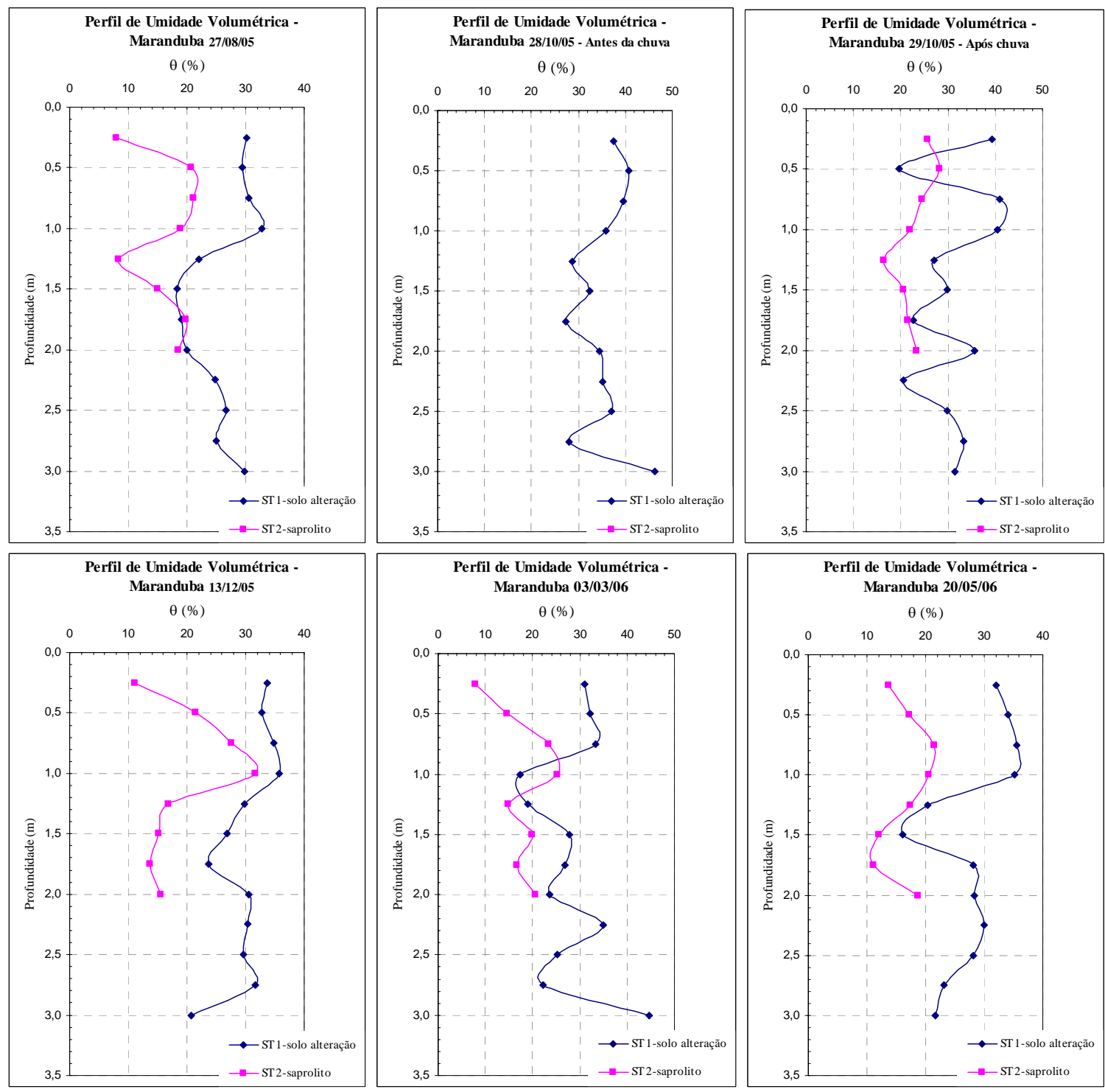

FIGURA 6.15 - PERFIS DE UMIDADE VOLUMÉTRICA DA ÁREA DE MARANDUBA.

Analisando os perfis de umidade apresentados na Figura 6.15, nota-se que não ocorre uma nítida tendência de diminuição da umidade volumétrica com a profundidade ao longo dos perfis de alteração, contrariamente ao que ocorreu para os valores da constante dielétrica apresentados na Figura 6.11, o que não era esperado, pois tais valores se relacionam empiricamente e são diretamente proporcionais. 
Os perfis de umidade volumétrica obtidos na área de estudo do Perequê-Mirim, durante o período de jun/2005 a mai/2006, são apresentados na Figura 6.16. Nesta figura verifica-se uma tendência de diminuição da umidade volumétrica com o aumento da profundidade, principalmente para os perfis de umidade obtidos durante os meses de junho, agosto e dezembro de 2005.
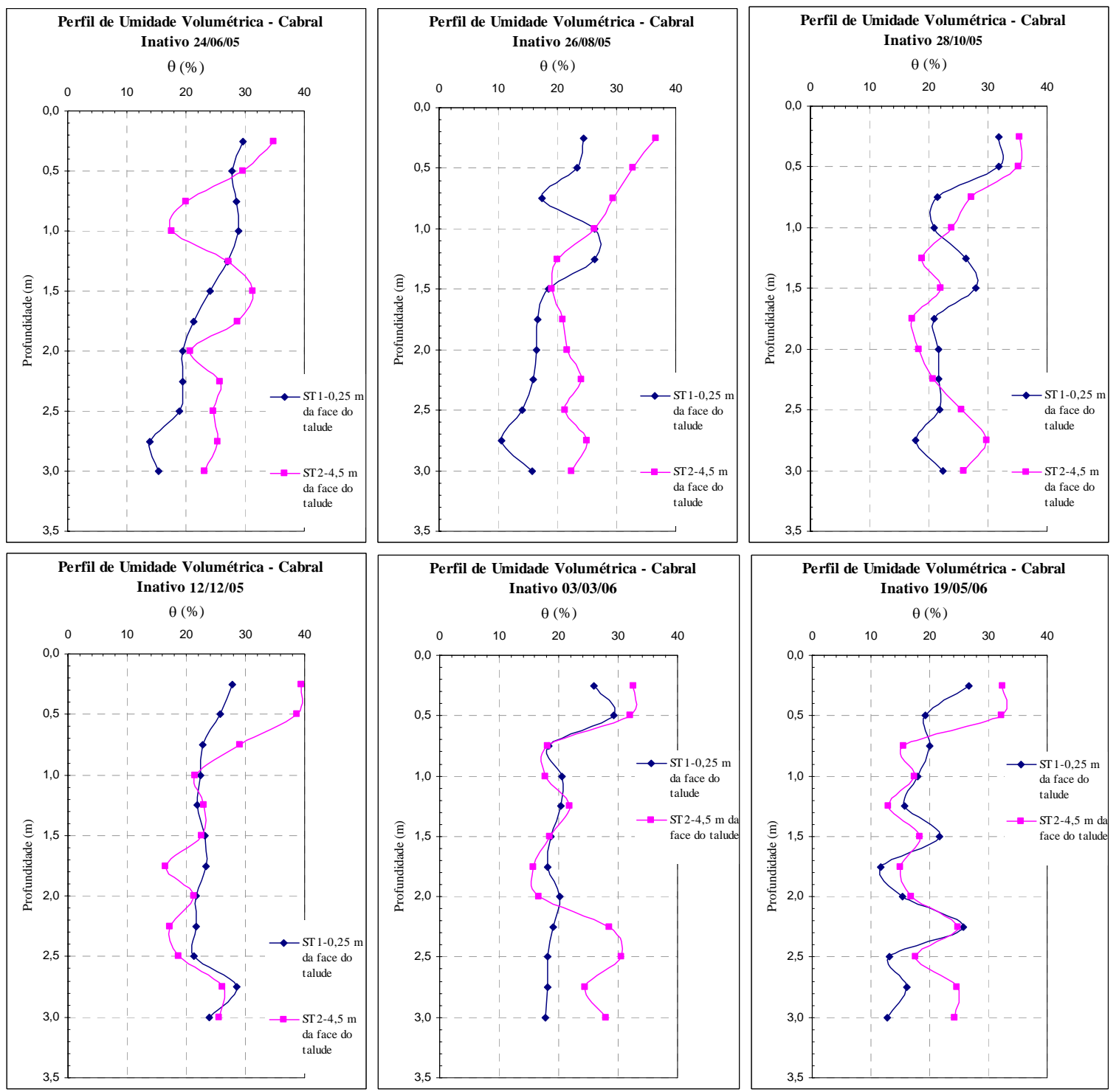

Figura 6.16 - PERFIS DE UMIDAdE VOLUMÉTRICA DA ÁREA DO PEREQUÊ-Mirim.

Os valores dos perfis de umidade volumétrica, obtidos a partir da técnica gravimétrica, foram utilizados para se avaliar a eficiência da metodologia GPR na determinação do teor de umidade do solo nas condições de campo. Deste modo, foram plotados os gráficos das constantes dielétricas obtidas com as antenas de 100 e $200 \mathrm{MHz}\left(K_{\text {méd }}\right.$ e $\left.K_{\text {int }}\right)$ versus as umidades 
volumétricas obtidas com a técnica gravimétrica $\left(\theta_{\text {Trado }}\right)$. Os dados da antena de $50 \mathrm{MHz}$ foram descartados, pois apresentaram apreciáveis dispersões durante as medidas de velocidades das ondas.

As Figuras 6.17 e 6.18 mostram os gráficos que relacionam as umidades volumétricas obtidas com o trado (técnica gravimétrica) com as constantes dielétricas do GPR, para as antenas de 100 e $200 \mathrm{MHz}$, juntamente com a relação proposta por TOPP et al. (1980).
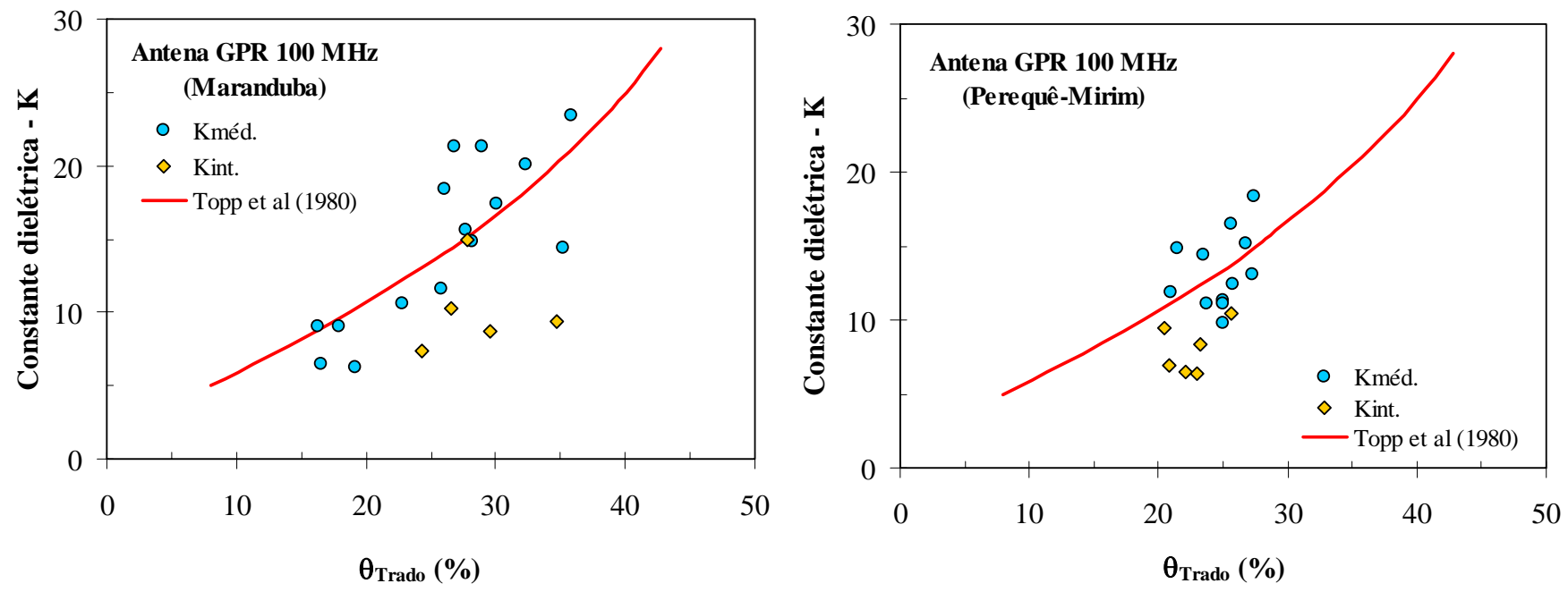

FIGURA 6.17 - RELAÇÃO ENTRE UMIDADE VOLUMÉTRICA OBTIDA COM TRADO E CONSTANTES DIELÉTRICAS MÉDIA E INTERVALAR PARA ANTENA DE 100MHz.

A partir da análise das Figuras 6.17 e 6.18, observa-se que, apesar da dispersão, os valores medidos estam muito próximos da relação proposta por Topp, principalmente os valores das constantes dielétricas médias $\left(K_{\text {méd. }}\right)$. Os valores das constantes dielétricas intervalares $\left(K_{\text {int. }}\right)$ apresentam uma significativa tendência de afastamento em relação a equação de Topp, apesar da análise ser realizada para um intervalo de umidade considerado relativamente pequeno $(15 \%<$ $\left.\theta_{\text {Trado }}<35 \%\right)$. 

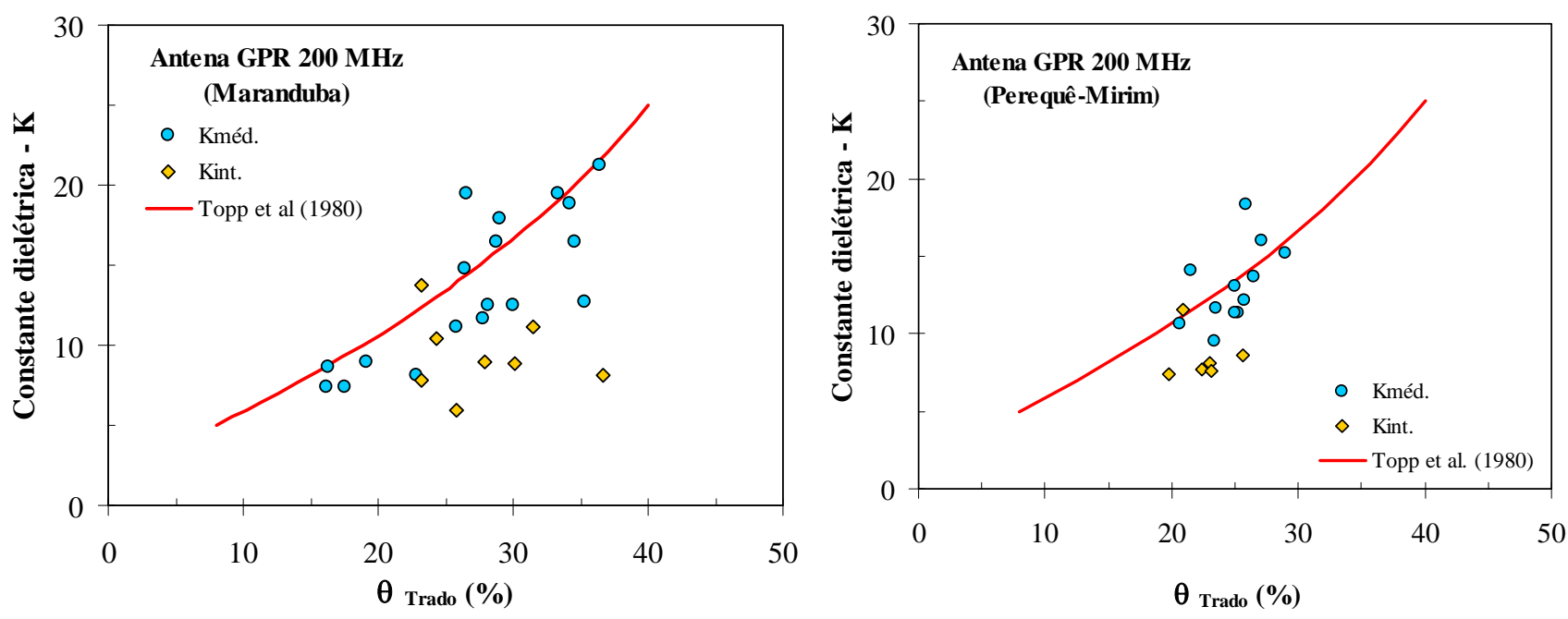

FIGURA 6.18 - RELAÇÃO ENTRE UMIDADE VOLUMÉTRICA OBTIDA COM TRADO E CONSTANTES DIELÉTRICAS MÉDIA E INTERVALAR PARA ANTENA DE 200MHZ.

Agrupando-se os valores das constantes dielétricas médias das duas áreas estudadas, obtém-se uma boa relação com os teores de umidade volumétrica determinados com a técnica gravimétrica, conforme apresentado na Figura 6.19.
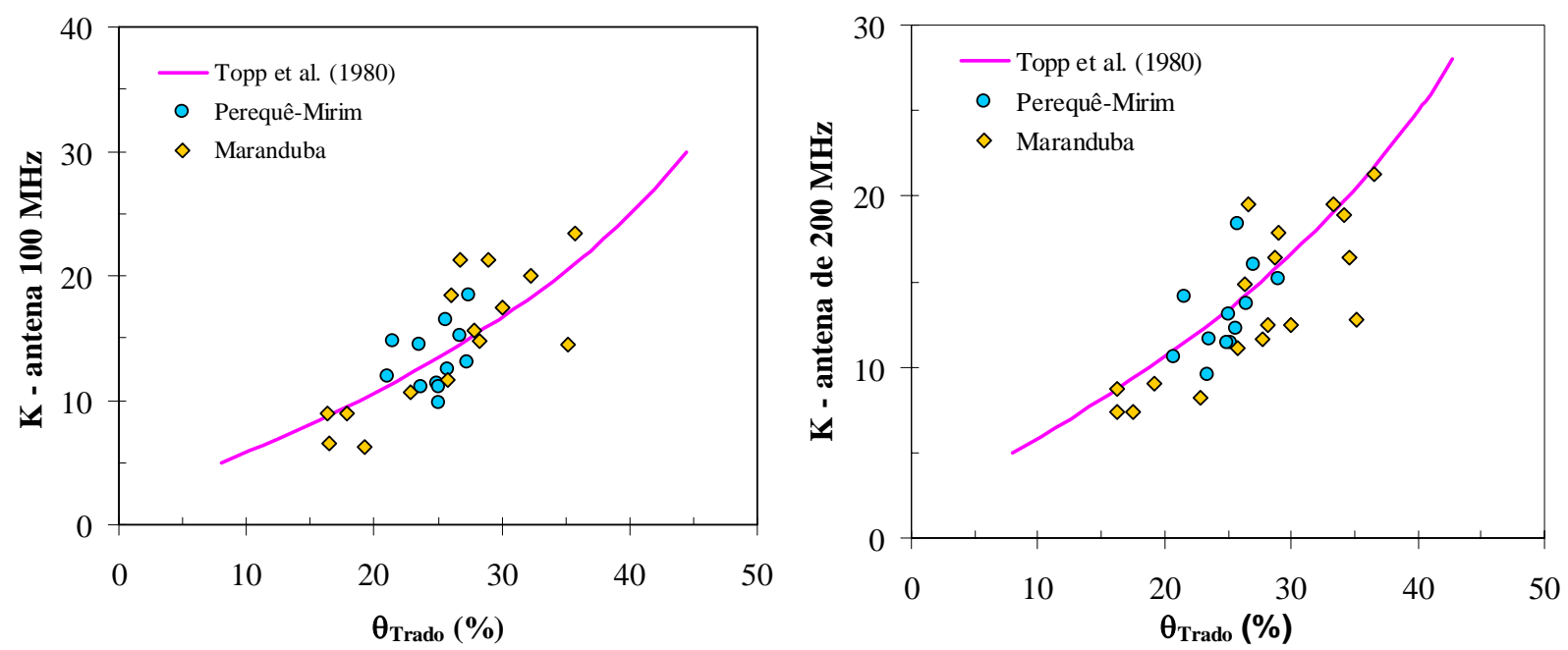

FIGURA 6.19 - RELAÇÕES ENTRE UMIDADE VOLUMÉTRICA E CONSTANTE DIELÉTRICA MÉDIA PARA ANTENAS DE 100 E 200MHz. 
Analisando a Figura 6.19, verifica-se que as antenas de $100 \mathrm{MHz}$ fornecem um melhor ajuste entre os pares de valores $K_{\text {méd. }}$ e $\theta_{\text {Trado }}$, apesar das antenas de $200 \mathrm{MHz}$ terem apresentado maior precisão durante as determinações das velocidades de reflexão. Contudo, a relação obtida com as antenas de $200 \mathrm{MHz}$ também mostra uma boa precisão com os valores medidos, e ambas as relações se aproximam significativamente da relação proposta por Topp.

Os valores de umidade volumétrica obtidos a partir da técnica gravimétrica ( $\left.\theta_{\text {Trado }}\right)$ foram comparados com os valores de umidade volumétrica estimados pela correlação empírica proposta por TOPP et al. (1980). Para isso, foram utilizados os valores da constante dielétrica média “ $K_{\text {méd }}$ " obtidos com as antenas de 100 e $200 \mathrm{MHz}$ e a equação 3.34, apresentada anteriomente no item 3.4.4. A Figura 6.20 mostra a comparação entre os valores da umidade volumétrica obtidos pelas duas técnicas (GPR e gravimétrica).
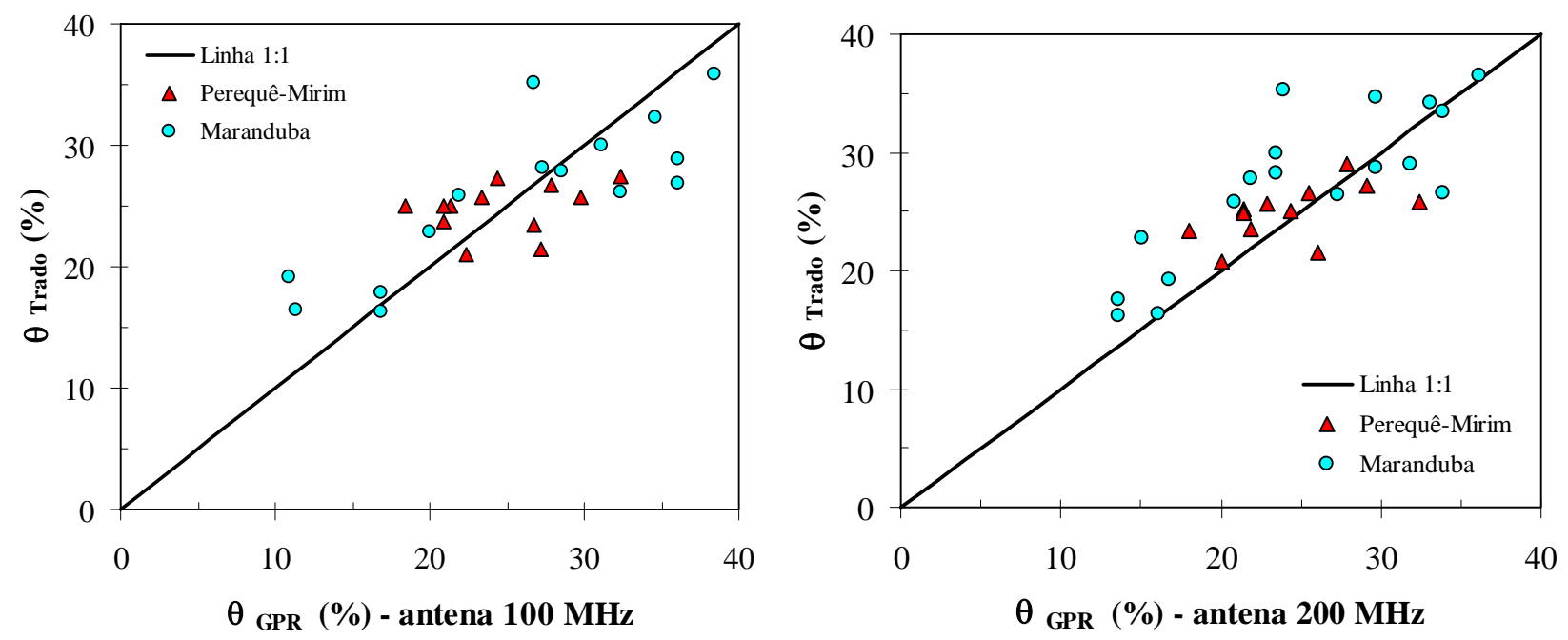

FiguRA 6.20 - COMPARAÇÃO ENTRE OS TEORES DE UMIDADE VOLUMÉTRICA OBTIDOS COM GPR E TÉCNICA GRAVIMÉTRICA (TRADO) PARA ANTENAS DE 100 E 200 MHz.

Observando a Figura 6.20, nota-se que os teores de umidade volumétrica obtidos com a metodologia GPR, para ambas as antenas, apresentam valores muito próximos dos teores de umidade obtidos com a técnica gravimétrica. Apesar dessa constatação preliminar, a real precisão da metodologia GPR para determinação dos teores de umidade volumétrica nas condições de campo, é melhor avaliada através da expressão da raiz do erro médio quadrático: 


$$
R M S E=\sqrt{\frac{\sum_{i=1}^{N}\left(\theta_{\text {Trado }}-\theta_{G P R}\right)^{2}}{N}}
$$

A partir desta expressão, encontrou-se uma precisão de $0,0458 \mathrm{~m}^{3} \cdot \mathrm{m}^{-3}$ (média RMSE obtida de 27 medições) para a antena de $100 \mathrm{MHz}$ e uma precisão de $0,0435 \mathrm{~m}^{3} \cdot \mathrm{m}^{-3}$ (média RMSE obtida de 30 medições) para a antena de $200 \mathrm{MHz}$. Comparativamente, encontra-se na literatura (e.g. HUISMAN et al. 2001) precisões de 0,0281 e 0,0308 $\mathrm{m}^{3} \cdot \mathrm{m}^{-3}$ (média RMSE obtida de 15 medições) para umidades volumétricas obtidas a partir de arranjos WARR, utilizando antenas de 225 e $450 \mathrm{MHz}$, respectivamente. LUNT et al. (2004) encontraram uma precisão média de $0,0180 \mathrm{~m}^{3} \cdot \mathrm{m}^{-3}$ (média RMSE obtida de 18 medições) para umidades volumétricas obtidas a partir de arranjos “common offset”, utilizando antenas de $100 \mathrm{MHz}$.

Nota-se que, além da diferença entre os tipos de arranjos e freqüências das antenas empregadas nestes trabalhos, existem ainda as incertezas relacionadas com o método utilizado para determinar as umidades volumétricas no campo - por exemplo, HUISMAN et al. (2001) e LUNT et al. (2004) utilizaram a técnica TDR e sonda de nêutron, respectivamente, para comparar com as umidades volumétricas obtidas com o GPR; e as incertezas relacionadas com a profundidade e quantidade de refletores (interfaces) considerada na análise, pois nos trabalhos mencionados as profundidades dos refletores não ultrapassam 1,35 metro. 


\subsubsection{Equipamentos utilizados}

Os perfis de alteração das duas áreas de estudo foram também monitorados por equipamentos capazes de medir a sucção matricial e o teor de umidade volumétrico do solo continuamente. A sucção matricial do solo foi medida por sensores GMS (Sensor de Matriz Granular). O GMS é um sensor do tipo resistivo, originalmente desenvolvido para controlar sistemas de irrigação com base na medição da sucção do solo. O sensor permite a medição da condutividade elétrica do solo feita por meio de dois eletrodos acoplados em um bloco de gesso compactado que está envolvido por uma matriz granular (areia quartzosa), conforme ilustrado na Figura 6.21.
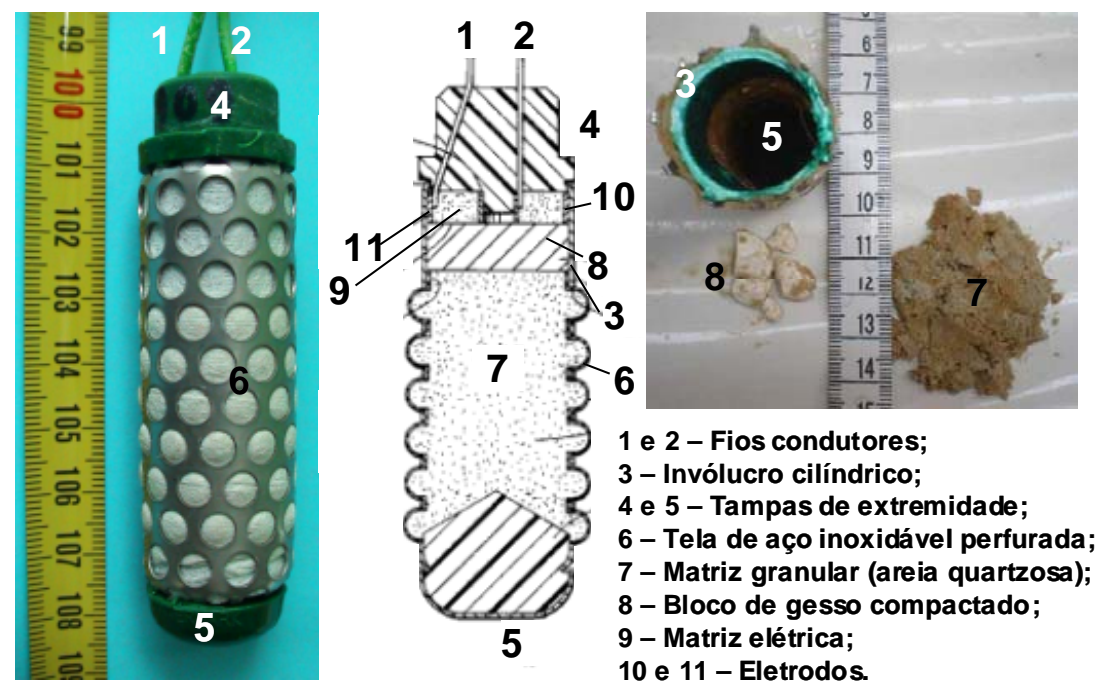

FIGURA 6.21 - SENSOR DE MATRIZ GRANULAR GMS.

A condutividade elétrica varia com o teor de umidade da matriz granular. Estando o sensor em equilíbrio com a sucção do solo ao seu redor, é possível obter a sucção do solo por meio de uma calibração. A estrutura do sensor GMS é de forma cilíndrica, envolvida com uma tela de aço inoxidável perfurada sobre uma manta sintética que possibilita o contato com o solo. Os dois eletrodos no interior do sensor GMS fazem a medição da condutividade elétrica. Estas medições 
são lidas e armazenadas num dataloger da Watermark, que possui a capacidade para leitura de até 8 sensores e de armazenamento dos dados de forma automatizada.

Os sensores GMS foram avaliados preliminarmente no laboratório de mecânica dos solos da EPUSP, antes de serem instalados no campo. Para isso, foram realizados ensaios experimentais visando avaliar quais os melhores procedimentos para a saturação, instalação e, ainda, comparar o tempo de resposta dos sensores GMS para medição da sucção nas condições de campo.

Em relação aos procedimentos para a saturação, foram avaliados seis sensores GMS a partir de ciclos de submersão em água seguidos por secagem, e uma submersão final de 16 horas e 30 minutos (submersão longa). Após serem submetidos aos diferentes procedimentos de saturação, os sensores foram instalados numa caixa plástica retangular preenchida com solo compactado da área de estudo de Maranduba, correspondente ao solo M2B500.

O tempo de resposta dos sensores GSM foi avaliado por comparação com o tempo de resposta de um tensiômetro convencional. O tensiômetro foi instalado próximo aos sensores GMS utilizandose uma broca de pequeno diâmetro. Maiores detalhes sobre os procedimentos de saturação e instalação dos sensores GMS podem ser obtidos em MENDES et al. (2007).

Os resultados obtidos revelaram que os procedimentos de saturação utilizados praticamente não interferem no desempenho dos sensores GMS para a medição da sucção, tanto na fase de secagem quanto na fase de umedecimento do solo. Apesar disso, adotou-se como procedimento padrão para a saturação dos sensores GMS, aquele consistido por 5 ciclos de submersão/secagem e uma submersão longa, sendo este o mesmo procedimento recomendado pelo fabricante. $\mathrm{O}$ tempo de resposta do sensor GMS mostrou ser da ordem de 6 (seis) vezes maior que o de um tensiômetro convencional, para a fase de secagem do solo. Para a fase de umedecimento por irrigação do solo, os sensores GMS apresentaram maior sensibilidade quando comparados com a fase de secagem e, portanto, foram mais rápidos para a detecção da frente de umedecimento ou saturação do solo. 
O teor de umidade volumétrico foi medido com sensores do tipo FDR (Frequency Domain Reflectometry). O sensor FDR possui princípio de funcionamento semelhante ao da técnica TDR. A diferença básica entre as técnicas está na faixa de freqüência utilizada para operação dos equipamentos. No FDR, a freqüência é mantida constante durante todo o processo de aquisição dos dados, daí o termo reflectometria no domínio da freqüência; já no TDR a freqüência de operação não é controlada durante a aquisição dos dados. Na Figura 6.22 é apresentado o sensor de umidade FDR dentro do sistema de cravação.

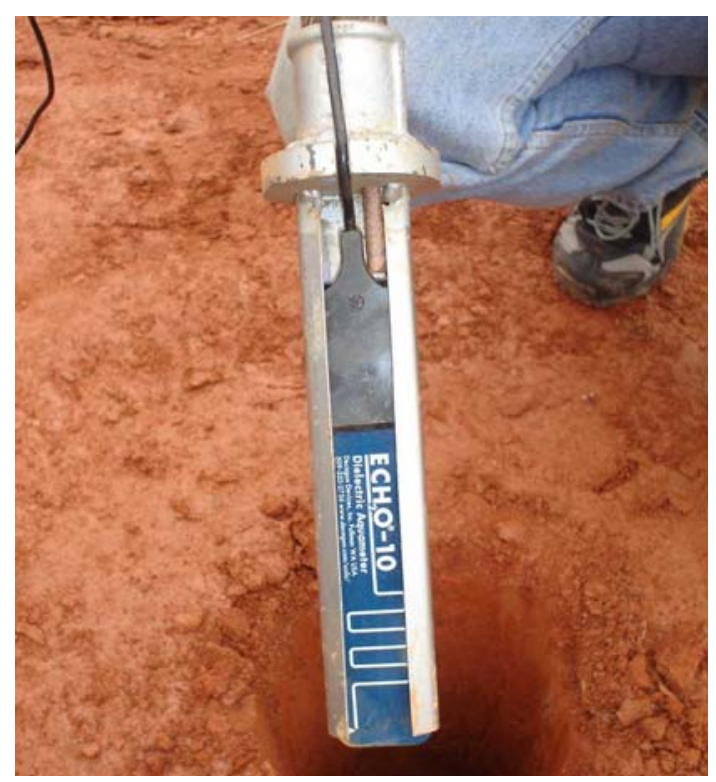

FIGURA 6.22 - SENSOR DE UMIDADE FDR.

\subsubsection{Perfis de umidade}

Os perfis de umidade das áreas estudadas foram obtidos a partir da instalação de 4 sensores FDR em diferentes profundidades. Na área de Maranduba, os sensores foram instalados nas profundidades 0.25 , 0.50 e 0.75 metros, em conjunto com os sensores GMS (distantes aproximadamente de 5,0 centímetros), no horizonte do solo de alteração (horizonte I-B), conforme apresentado na Figura 6.23. 


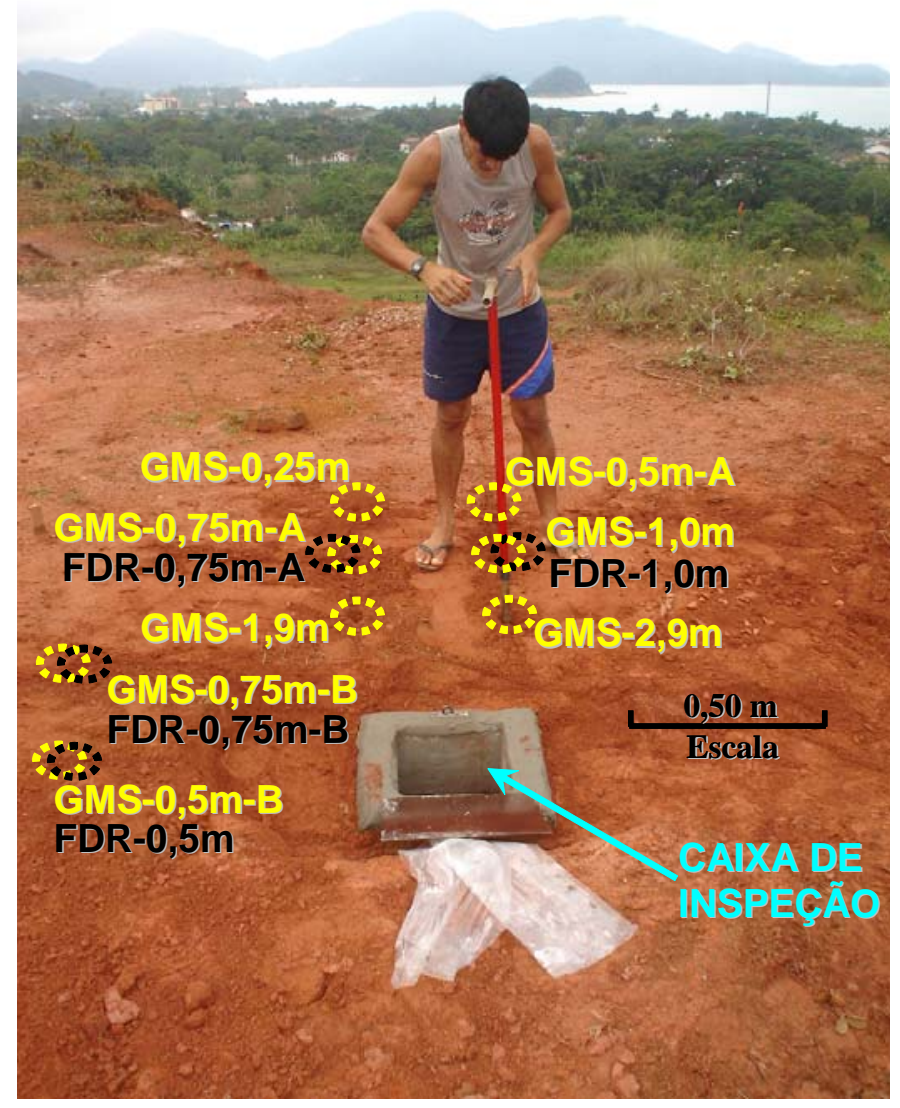

FIGURA 6.23 - LOCALIZAÇÃO DOS SENSORES INSTALADOS NA ÁREA DE MARANDUBA.

Na área do Perequê-Mirim, os sensores foram instalados nas profundidades de 0,25 e 0,45 metro, no horizonte superficial de solo alterado (horizonte I-A) e na profundidade de 0,90 metro, correspondente ao horizonte de transição entre o solo alterado (horizonte I-A) e o saprolito (horizonte I-C). Foram instalados dois sensores na produndidade de 0.45 metro, um próximo da face do talude vertical $(0,45 \mathrm{~m}-\mathrm{A})$ e outro na porção interna do talude $(0,45 \mathrm{~m}-\mathrm{B})$, distante aproximadamente 2,0 metros da face do mesmo, conforme apresentado na Figura 6.24. Nessa área de estudo não foi possível instalar os sensores de umidade e sucção no mesmo local. Isto fez com que cada sensor fosse instalado próximo um do outro, mas não exatamente na mesma posição. 


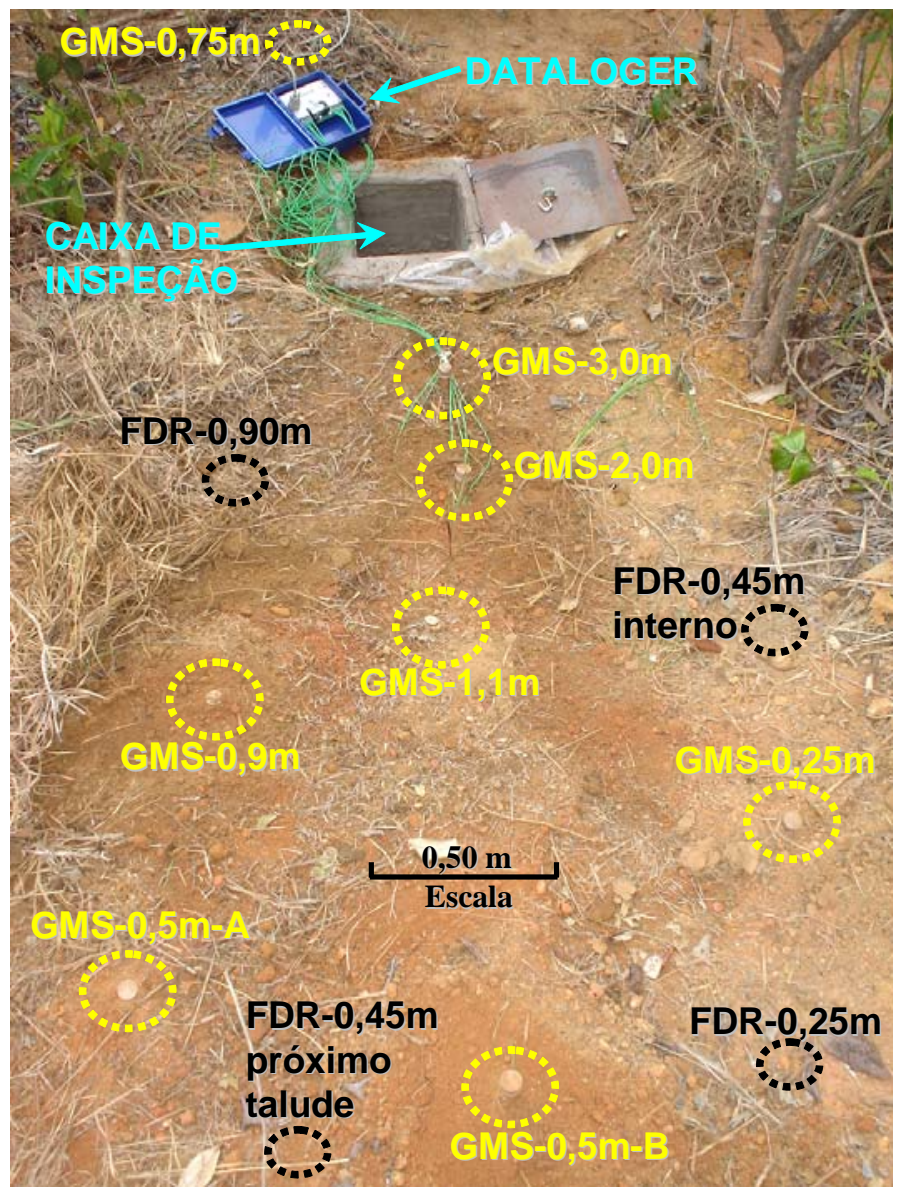

FIGURA 6.24 - LOCALIZAÇÃO DOS SENSORES INSTALADOS NA ÁREA DO PEREQUÊ-MIRIM.

Para a instalação dos sensores FDR, foram desenvolvidos equipamentos específicos que viabilizaram sua cravação, pois a haste do sensor é composta por material muito flexível que impossibilita a cravação direta no terreno. Para a instalação dos equipamentos, primeiramente foi aberto um furo com trado helicoidal de diâmetro ligeiramente superior ao diâmetro dos equipamentos de cravação dos sensores FDR. Em seguida, foi introduzido no furo um tubo metálico de 1 1⁄2”'dotado de uma lâmina de pré-cravação na ponta que realizou uma abertura no final do furo, com a mesma largura do sensor, permitindo posteriormente a instalação dos sensores no solo através de uma haste guia de acoplagem dos sensores, conforme mostrado na Figura 6.25a. Na Figura 6.25a também se observa a lâmina do equipamento de pré-cravação danificada durante abertura do furo, devido à elevada compacidade do horizonte superficial da área do Perequê-Mirim, além do fato de haver uma quantidade expressiva de pedregulhos e raízes nesse horizonte de solo. 

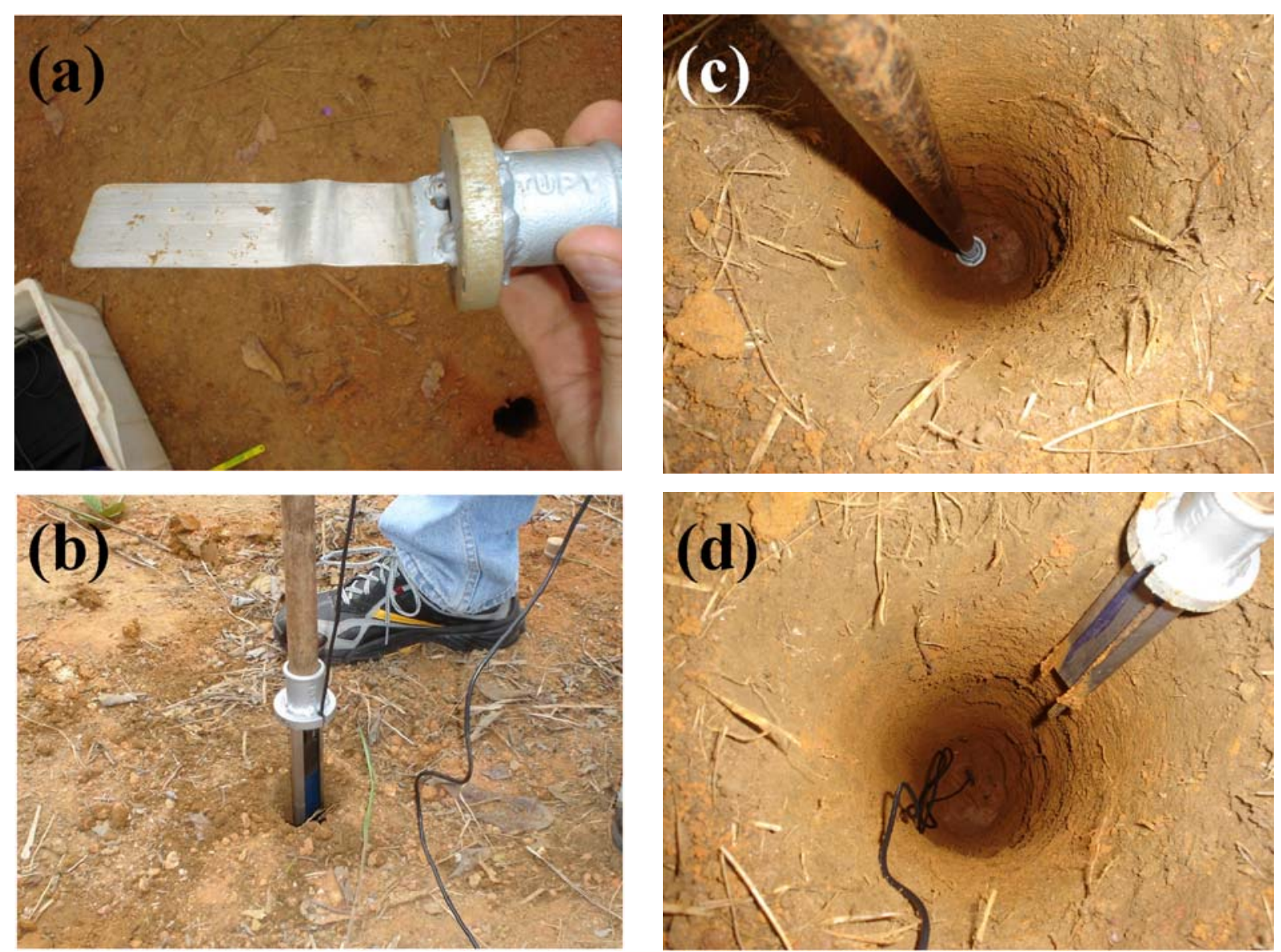

FIGURA 6.25 - INSTALAÇÃO DOS SENSORES FDR COM EQUIPAMENTOS ESPECÍFICOS DE CRAVAÇÃO.

Após realizar os furos com o equipamento de pré-cravação, os sensores de umidade FDR foram acoplados dentro do sistema de cravação, conforme ilustrado na Figura 6.25b, sendo posteriormente inseridos dentro do furo com o auxílio da haste guia mostrada na Figura 6.25c e cravados no fundo do mesmo conforme ilustrado na Figura 6.25d. Em algumas circunstâncias, quando houve dificuldade na abertura do furo com trado helicoidal para a instalação dos equipamentos, utilizou-se uma cavadeira de aproximadamente 0,20 m de diâmetro.

Os sensores FDR entraram em operação em datas distintas nas áreas de estudo por motivos operacionais apresentados pelos sistemas de registro (dataloggers), defasados em aproximadamente dois meses. Desta forma, adotou-se uma data inicial comum para a apresentação dos dados dos sensores FDR instalados em ambas as áreas de estudo. Os dados de umidade volumétrica registrados pelos sensores FDR na área de estudo de Maranduba, durante o período de dezembro/2006 a janeiro/2008, são apresentados na Figura 6.26. 
Analisando os dados da Figura 6.26, observa-se que os sensores instalados nas profundidades de 1,0 e 0,75 metro registraram um comportamento semelhante em relação à variação do teor de umidade no decorrer do período de monitoramento. Para o sensor instalado a 0,50 metro de profundidade, a umidade volumétrica variou consideravelmente no decorrer do período de monitoramento, caracterizado principalmente pelas constantes oscilações e "picos de umidade” registrados em diversos momentos do período, sempre associados a picos nas demais profundidades. Em relação aos valores absolutos, os sensores instalados na profundidade de 0,50 e 0,75 metro apresentaram teores de umidade mais elevados, da ordem de 23 a $27 \%$, enquanto o sensor instalado a 1,0 metro de profundidade registrou valor de umidade de no máximo 19\%, entre o período de dezembro/2006 a janeiro/2007.

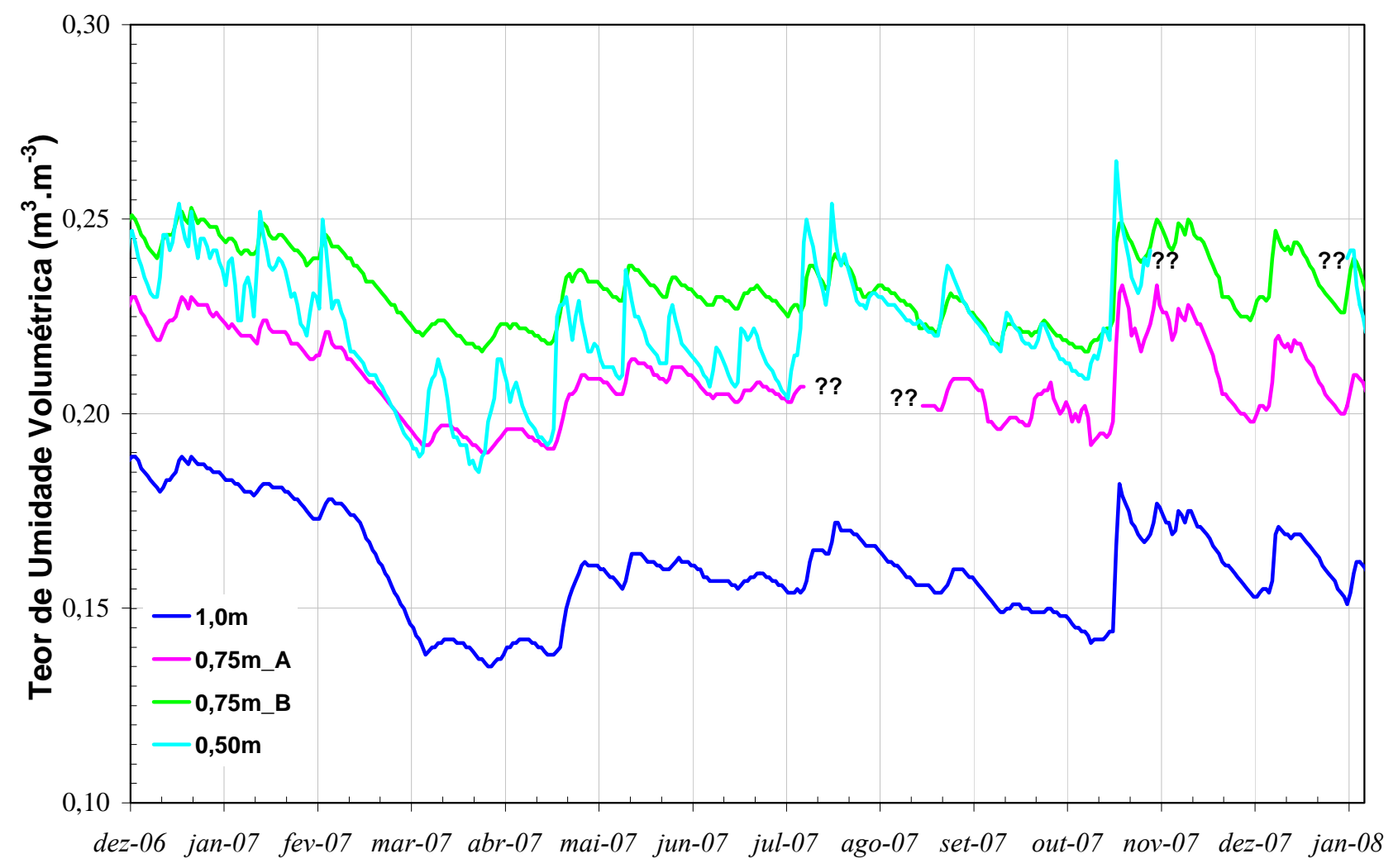

FIGURA 6.26 - DADOS DE MONITORAMENTO DO TEOR DE UMIDADE NA ÁREA DE MARANDUBA.

Analisando a Figura 6.26, observa-se que o teor de umidade do solo é sempre menor a maiores profundidades durante a maior parte do tempo. Nota-se também pequenas diferenças na distribuição de umidade para os sensores instalados na mesma profundidade durante todo o 
período de monitoramento. Na Figura 6.26 os pontos de interrogação (??) representam períodos de interrupção dos registros de umidade, ocasionada por atos de vandalismo que acabaram danificando permanentemente os sensores que foram substituídos posteriormente por apresentarem falhas geradas pelo sistema de aquisição de dados (datalogger).

Os dados de monitoramento do teor de umidade na área do Perequê-Mirim são apresentados na Figura 6.27. Assim como na área de Maranduba, verifica-se a interrupção dos registros de umidade representados pelos pontos de interrogação (??), que nesse caso foi devido exclusivamente aos atos de vandalismo que danificou permanentemente o sensor instalado na profundidade de 0,25 metro, conforme apresentado na Figura 6.27.

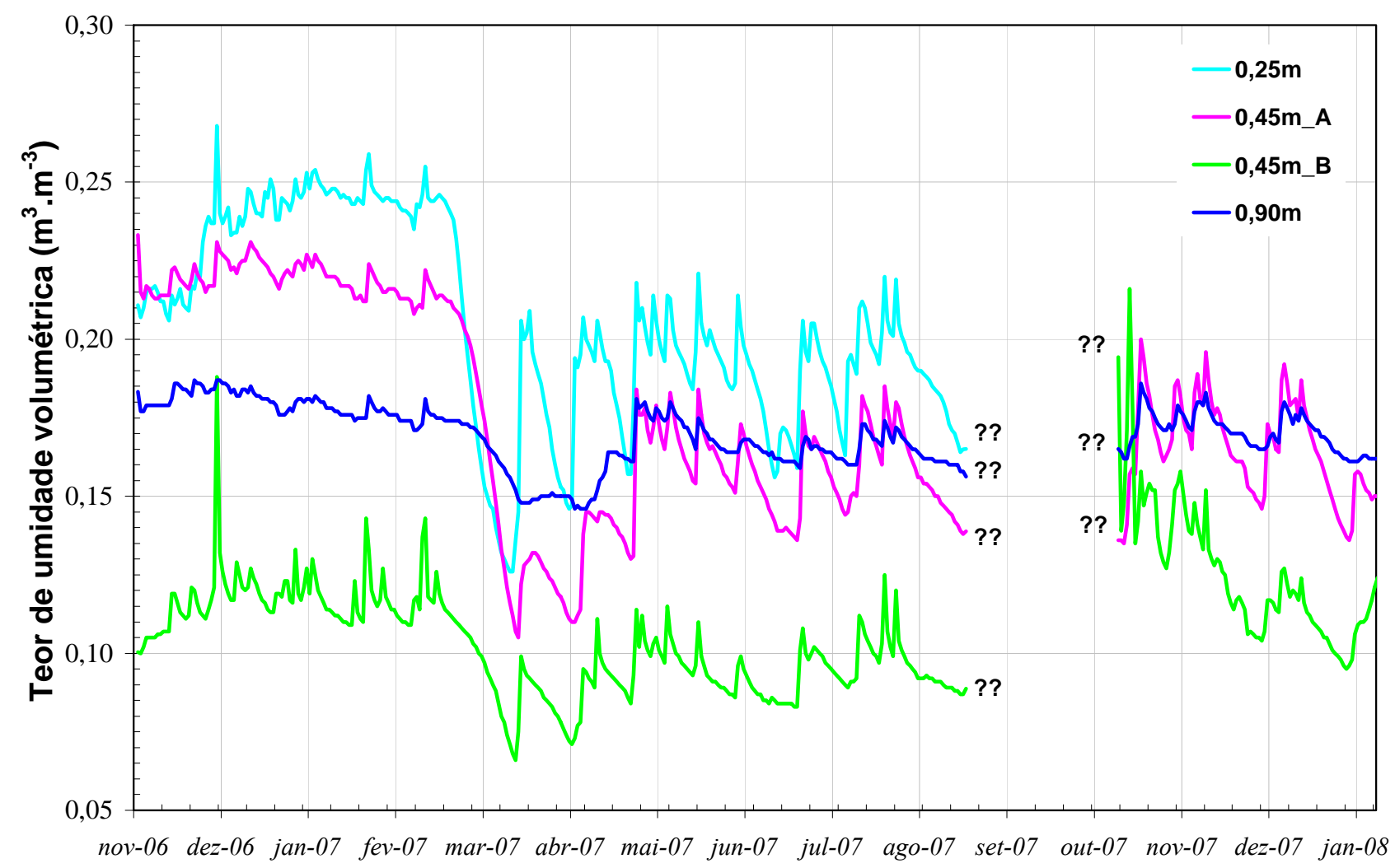

Figura 6.27 - DAdOS DE MONITORAMENTO DO TEOR DE UMIDADE NA ÁREA DO PEREQUÊ-MiRIM.

Na Figura 6.27 nota-se que o sensor instalado na profundidade de 0,25 metro apresentou teor de umidade mais elevado em relação aos demais sensores, com medições do teor de umidade de até $27 \%$ em dezembro/2006. Os sensores instalados na profundidade de 0,45 metro apresentaram medições de umidade consideravelmente distintas. O sensor instalado na parte interna do talude 
(0,45m-B) apresentou valores de umidade significativamente menores em relação ao sensor instalado próximo ao talude $(0,45 \mathrm{~m}-\mathrm{A})$ durante praticamente todo o período monitorado. O sensor instalado a 0,90 metro de profundidade apresentou oscilações significativamente menores em relação aos demais sensores, com variações de umidade entre 14,5 e 18,5\%.

Em termos gerais, nota-se na Figura 6.27, que há uma tendência de diminuição da umidade do solo com o aumento da profundidade em alguns períodos (por exemplo, entre dezembro/2006 a março/2007), e que alguma característica peculiar do talude pode ter contribuído para o comportamento da distribuição sazonal de umidade para os sensores instalados a 0,45 metro. Acredita-se que tal comportamento esteja relacionado com a presença de vegetação na porção interna do talude que, por meio das raízes existentes em profundidades de até 0,50 metro, tenderia diminuir a umidade do solo e conseqüentemente do sensor instalado nessa profundidade.

Na Figura 6.28 são apresentados os perfis de umidade das áreas estudadas. Nessa figura, os teores de umidade nas profundidades 0,75 e 0,45 metro das áreas de Maranduba e Perequê-Mirim, respectivamente, correspondem aos valores médios de umidade registrados nessas profundidades durante o período de monitoramento, conforme apresentado nas Figuras 6.26 e 6.27.
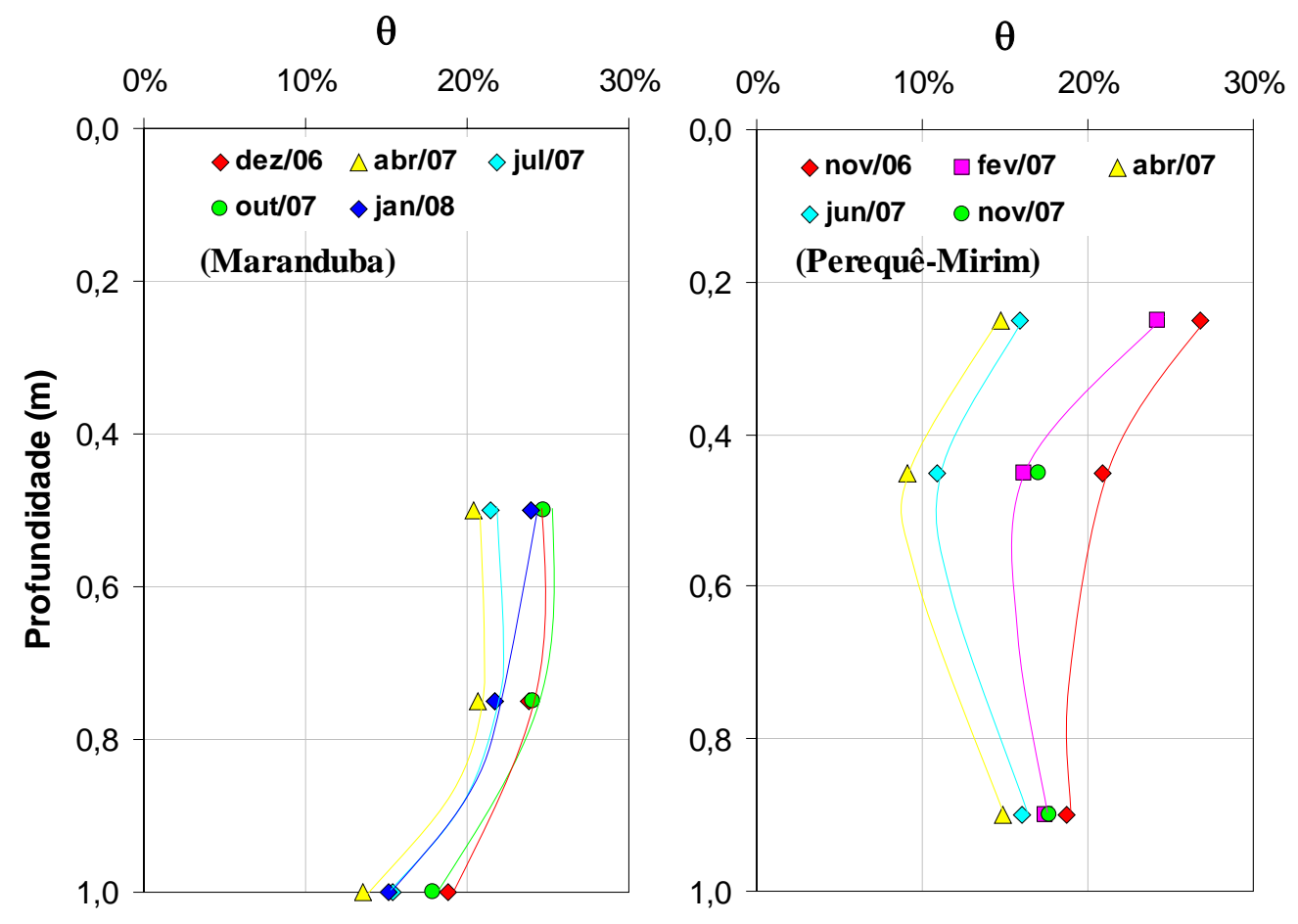

FIGURA 6.28 - PERFIS DO TEOR DE UMIDADE DAS ÁREAS ESTUDADAS. 
Na Figura 6.28, para o perfil de umidade de Maranduba, observa-se que os teores de umidade tendem a diminuir com o aumento da profundidade no decorrer do período de monitoramento (dezembro/2006 a janeiro/2008). Para o perfil de umidade do Perequê-Mirim, em termos gerais, nota-se que os teores de umidade tendem a diminuir até cerca de 0,50 metro de profundidade e depois tendem a aumentar gradativamente até 0,90 metro de profundidade, exceto para o perfil de umidade referente ao mês de novembro/2006. Observa-se também na Figura 6.28, que os perfis das áreas estudadas apresentaram teores de umidade mais elevados nos meses de outubro/2007, novembro/2006 e 2007, dezembro/2006, janeiro/2008 e fevereiro/2007.

\subsubsection{Perfis de sucção}

Para a obtenção da variação de sucção com o tempo em diversas profundidades nas duas áreas de estudo, foram instalados 8 sensores GMS em diferentes profundidades. Na área do Perequê-Mirim, os sensores foram instalados nas profundidades de 0.25, 0.50, 0.75, 0.90, 1.10, 2.0 e 3.0 metros, dentro dos horizontes de solo alterado e saprolito (horizonte I-A e I-C, respectivamente). Foram instalados dois sensores na produndidade de 0,50 metro, ambos próximos da face do talude vertical, distante aproximadamente 1,5 metro da face do mesmo, conforme apresentado na Figura 6.24. Na área de Maranduba, os sensores GMS foram instalados nas profundidades 0.25, 0.50, 0.75, 1.0, 1.9 e 2.9 metros, próximos aos sensores FDR, nos horizontes do solo de alteração e saprolito (horizonte I-B e I-C, respectivamente) conforme apresentado na Figura 6.23.

Para a instalação dos sensores GMS, primeiramente foram realizados furos com trado helicoidal de aproximadamente 3/4"de diâmetro até a profundidade desejada. Em algumas circunstâncias, quando houve dificuldade na abertura do furo com trado helicoidal, utilizou-se uma cavadeira de aproximadamente 0,20 m de diâmetro. Em seguida, os sensores foram inseridos e colados permanentemente em tubos de PVC de 3/4" de diâmetro, conforme apresentado seqüencialmente nas Figuras 6.29a e 6.29b. Os cabos dos sensores passaram por dentro do tubo de PVC até a outra extremidade, que depois recebeu uma tampa de PVC. Uma lama foi então preparada com o solo retirado dos furos e depois despejada dentro dos mesmos, em quantidade suficiente para garantir um bom contato entre o solo envolvente e os sensores, conforme apresentado na Figura 6.29c. 
Em seguida, os conjuntos formados pelos tubos de PVC e sensores foram inseridos nos furos conforme apresentado na Figura 6.29d. Ressalta-se que todos os sensores GMS, antes de serem instalados no campo, foram submetidos a cinco ciclos de secagem e umedecimento, conforme procedimentos de saturação realizados no laboratório de Mecânica dos Solos da EPUSP. Estes procedimentos estão descritos detalhadamente em MENDES et al. (2007) - ANEXO. Além disso, os sensores permaneceram imersos em água antes de sua instalação no campo.
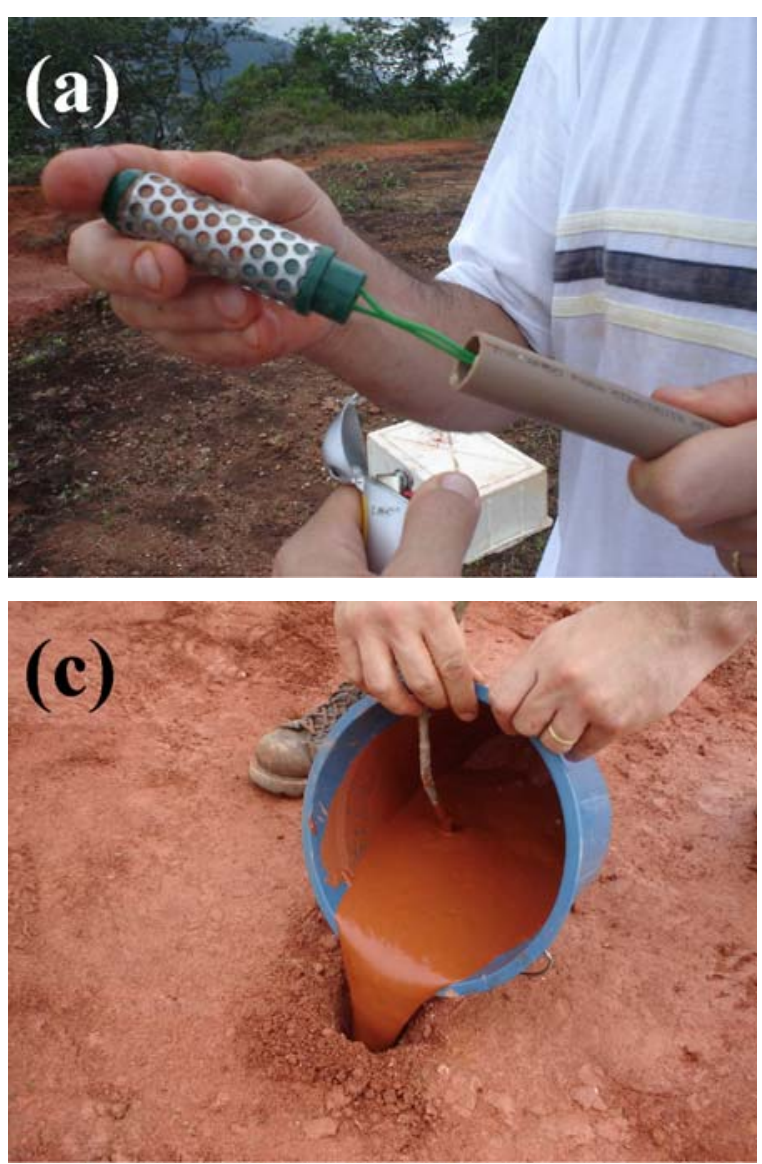
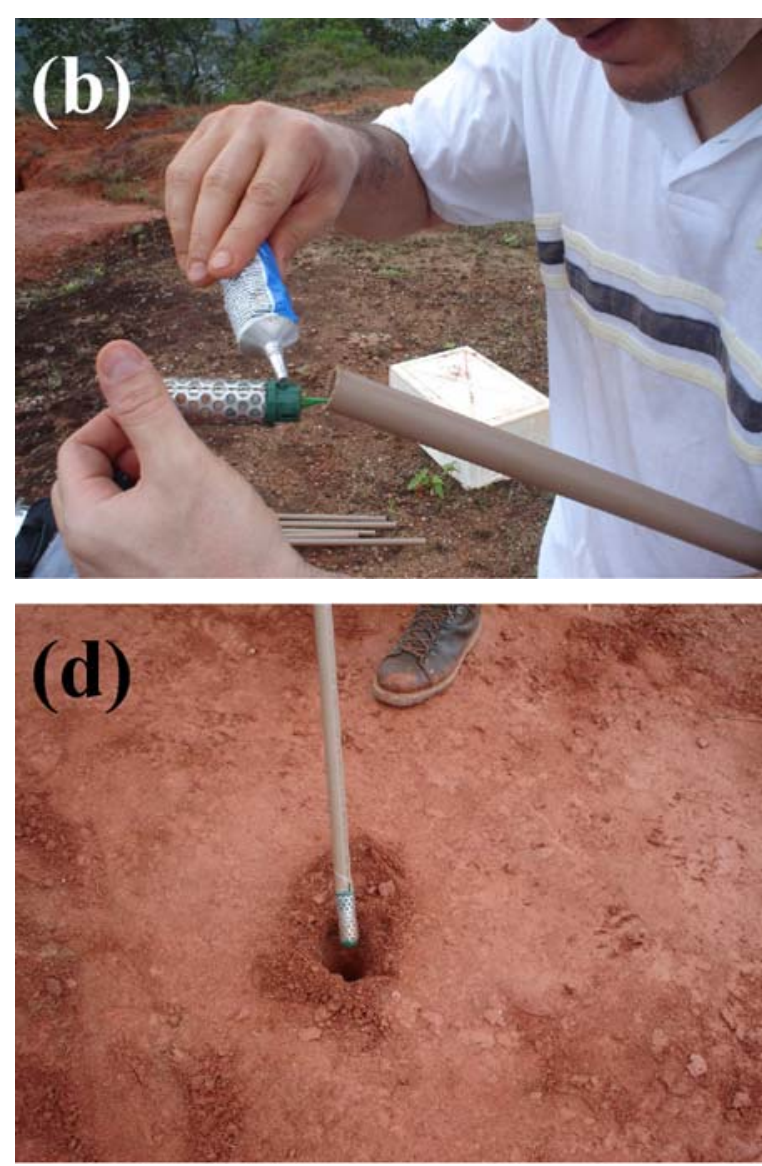

FigURA 6.29 - PROCEDIMENTOS UTILIZADOS PARA A INSTALAÇÃO DOS SENSORES GMS.

O monitoramento do perfil de sucção na área de Maranduba teve início em novembro/2006, mas devido a problemas técnicos com o datalogger, os dados começaram a ser registrados somente a partir de dezembro/2006, conforme apresentado na Figura 6.30. Analisando essa figura, nota-se que o sensor instalado na profundidade de 0,25 metro registrou valores de sucção mais elevados em comparação com os demais sensores, durante a maior parte do período monitorado. Na Figura 
6.30, observa-se também uma nítida tendência de diminuição dos valores e da magnitude de oscilação da sucção com o aumento da profundidade.

Os sensores instalados no horizonte de saprolito, nas profundidades de 1,9 e 2,9 metros, apresentam um comportamento de variação sazonal da sucção bem diferente dos sensores instalados no horizonte do solo de alteração. Na Figura 6.30 nota-se que os valores de sucção oscilam muito pouco para os sensores mais profundos, com valores variando de 8,0 a 36,0 kPa, durante a maior parte do período de monitoramento. Na Figura 6.30 constata-se, durante o período de outubro/2007 a janeiro/2008, que os sensores instalados nas profundidades de 1,9 e 0,75 metro apresentaram valores e variações de sucção consideravelmente maiores do que todo o período anteriormente monitorado.

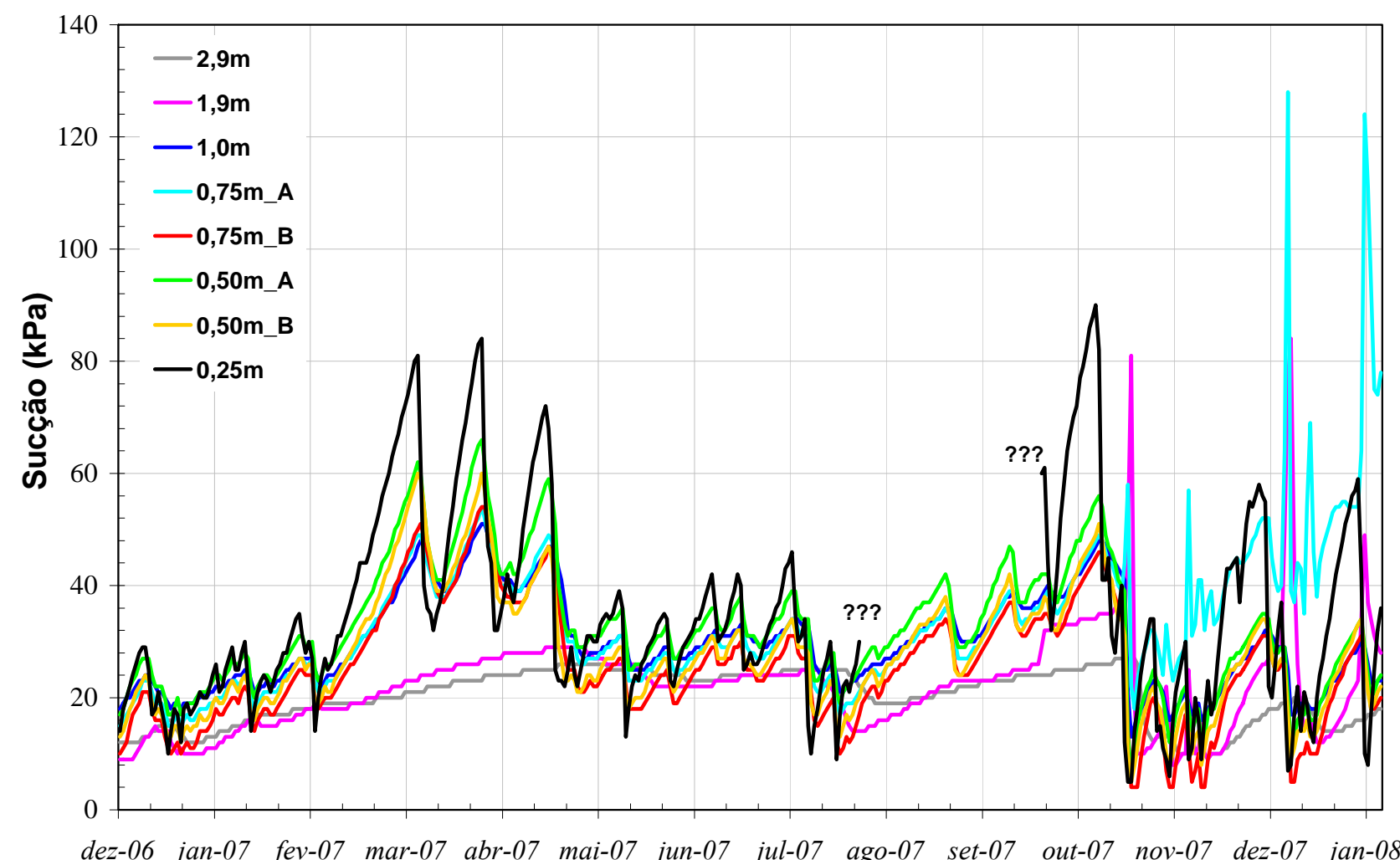

FiguRA 6.30- DAdOS DE MONITORAMENTO DA SUCÇÃO NA ÁREA DE MARANDUBA.

Analisando a Figura 6.30, verifica-se, em termos gerais, que os valores de sucção mais baixos foram registrados nos períodos compreendidos entre dezembro/2006 a fevereiro/2007 e outubro/2007 a janeiro/2008. As sucções mais elevadas foram registradas predominantemente durante os meses de março a maio/2007 e no mês de outubro/2007. 
Para aqueles sensores que registraram altos valores de sucção durante o período chuvoso (1,9m e 0,75m-A), entre os meses de outubro/2007 a janeiro/2008, acredita-se que tanto a intensidade da chuva quanto a precipitação acumulada podem ter influenciado de alguma maneira o fluxo de água no perfil de alteração. Além disso, destaca-se que foram realizados reparos nos sensores no final do mês de setembro/2007 por motivos de depredação do sensor instalado a 0,25 metro de profundidade, conforme indicado na Figura 6.30 pelos pontos de interrogação.

Na área do Perequê-Mirim, os dados do GMS começaram a ser registrados em novembro/2006, mas devido à oxidação e conseqüente perda de carga das baterias do datalogger, a seqüência de leituras de dados foi interrompida em diversas ocasiões até a substituição do equipamento, conforme indicado na Figura 6.31 pelos pontos de interrogação. Além disso, todos os fios dos sensores foram cortados entre agosto e setembro/2007 que, após reparos técnicos, voltaram a operar no início de outubro /2007. Deste modo, a série de registros do perfil de sucção da área do Perequê-Mirim ficou bastante comprometida.

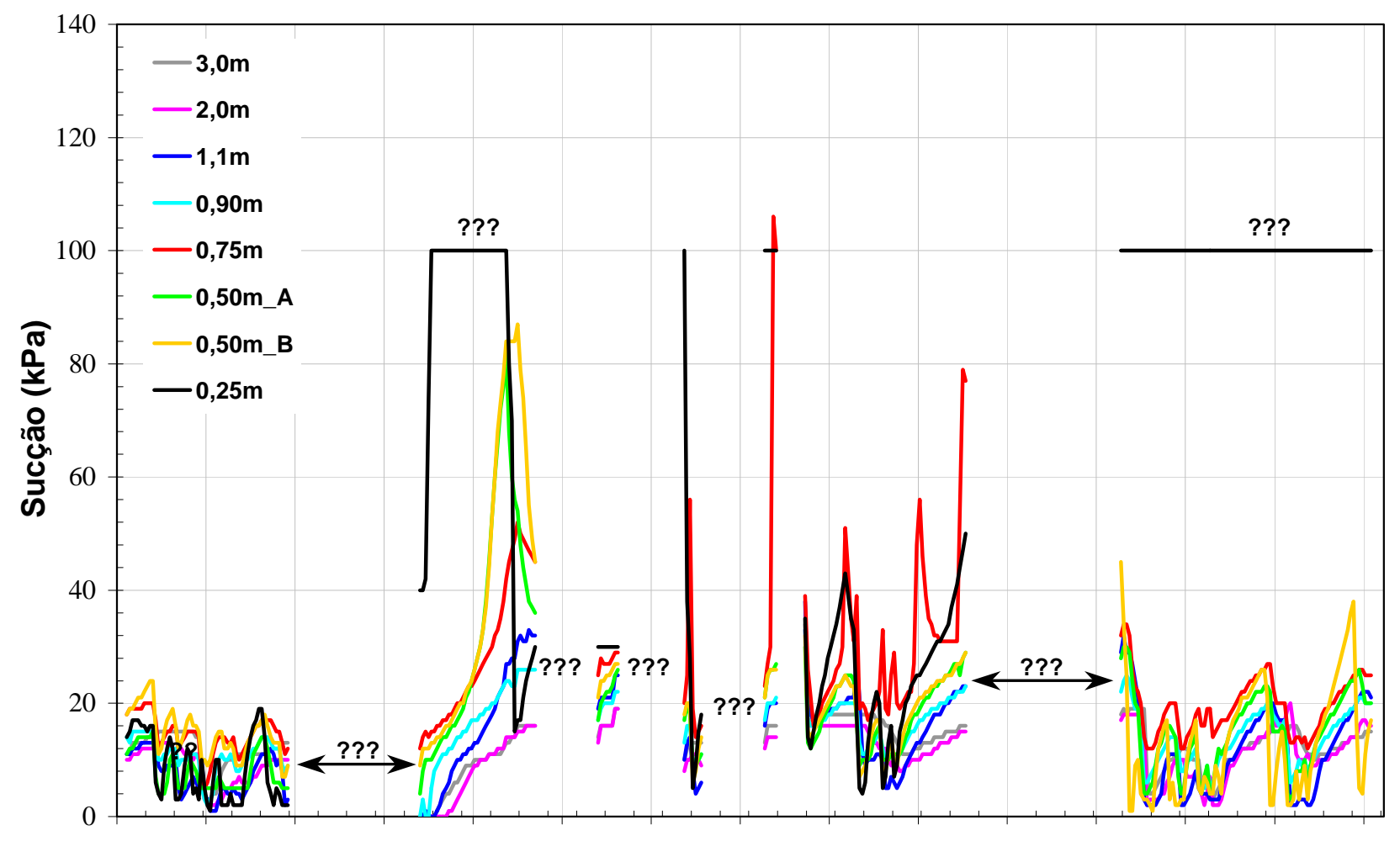

nov-06 dez-06 jan-07 fev-07 mar-07 abr-07 mai-07 jun-07 jul-07 ago-07 set-07 out-07 nov-07 dez-07 jan-08

Figura 6.31 - DAdOS DE MONITORAMENTO DA SUCÇÃO NA ÁREA DO PEREQUÊ-MiRIM. 
Os poucos dados de sucção registrados para a área do Perequê-Mirim, conforme apresentado na Figura 6.31, permitem observar que praticamente não houve apreciáveis variações de sucção entre os sensores GMS para os períodos entre novembro/2006 a janeiro/2007 e outubro/2007 a janeiro/2008. Nota-se que nos meses considerados chuvosos (novembro, dezembro e janeiro), os valores de sucção de todos os sensores permaneceram a maior parte do tempo abaixo de $20 \mathrm{kPa}$. Os valores de sucção mais elevados, da ordem de $100 \mathrm{kPa}$, foram registrados pelos sensores instalados a 0.25 , 0.50 e 0.75 metro de profundidade. Na Figura 6.31, verifica-se que em alguns períodos do monitoramento há uma tendência de diminuição da sucção com o aumento da profundidade. Em termos gerais, os acréscimos de sucção em função do tempo foram maiores para os sensores instalados no horizonte de solo de alteração (horizonte I-A), quando comparados com os acréscimos de sucção registrados pelos sensores instalados no saprolito (horizonte I-C profundidades de 3.0, 2.0, 1.1 e 0.9 metros).

Ao comparar os perfis de sucção das áreas estudadas, conforme apresentado na Figura 6.32, observa-se que o perfil de Maranduba apresenta valores de sucção relativamente maiores ao longo do período de monitoramento (dezembro/2006 a janeiro/2008).
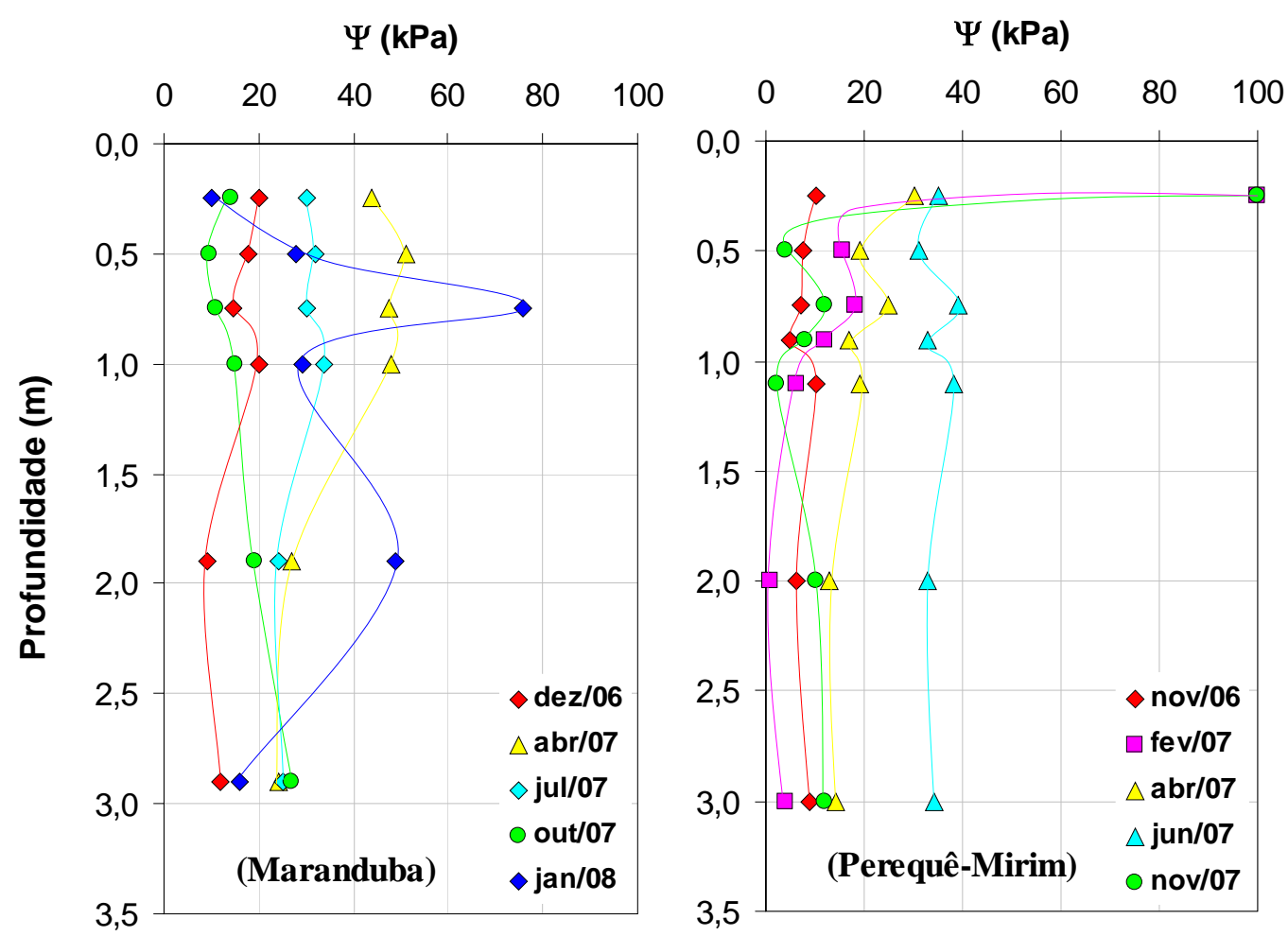

FIGURA 6.32 - PERFIS DE SUCÇÃO DAS ÁREAS ESTUDADAS. 
Observa-se também na Figura 6.32, que os perfis das áreas estudadas apresentam valores de sucção mais elevados nos meses de abril/2007, junho/2007 e julho/2007. Além disso, nota-se que foram registrados valores muito elevados de sucção (> $70 \mathrm{kPa}$ ) nos meses de fevereiro e novembro de 2007 e janeiro de 2008.

Na Figura 6.33 são apresentados os dados de monitoramento de campo, referente aos perfis de umidade e sucção, juntamente com as curvas de retenção de água representativas do perfil de alteração (Bloco 2 e M2B130) onde foram instalados os sensores de umidade (FDR) e sucção (GMS).

Analisando a Figura 6.33, verifica-se que os pares de valores de sucção e umidade obtidos no campo, representados pelos pontos azuis, estão situados abaixo da curva de retenção obtida em laboratório. Supõe-se que essa apreciável diferença possa estar relacionada com os valores de umidade medidos no campo, associada principalmente com a técnica de instalação dos sensores de umidade FDR, uma vez que os sensores de sucção GMS foram previamente avaliados em laboratório (maiores detalhes em MENDES et al 2007 - ANEXO).

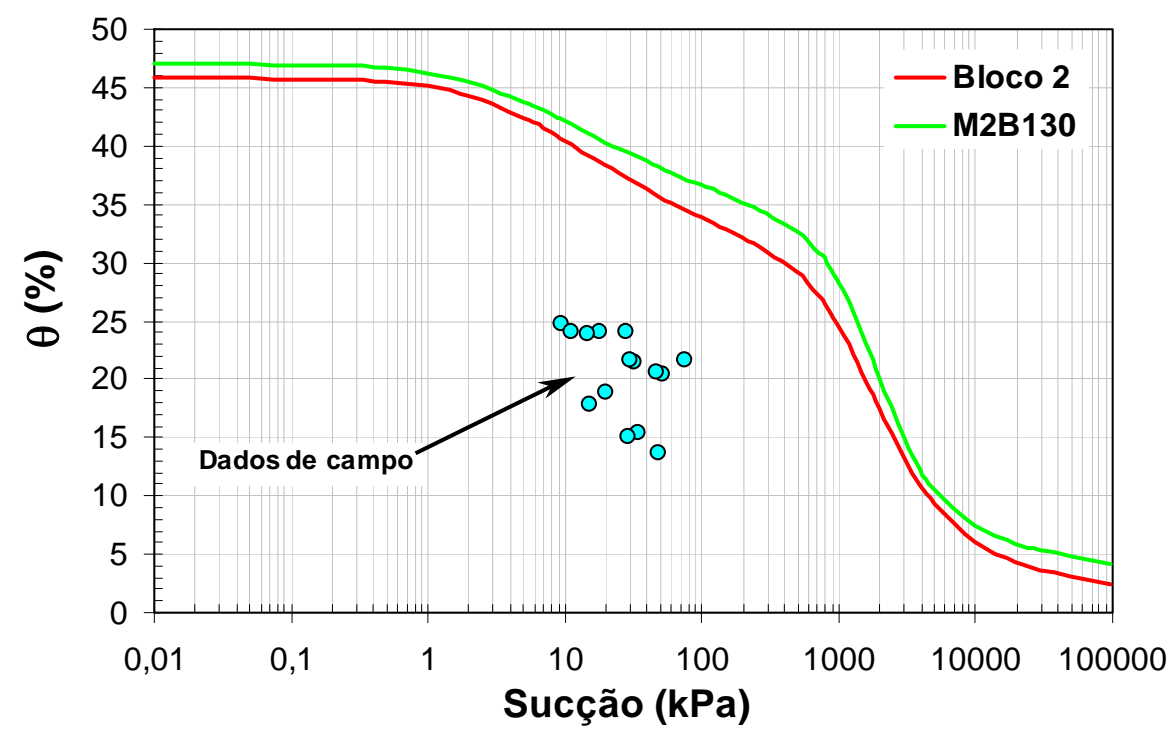

FIGURA 6.33 - CURVAS DE RETENÇÃO OBTIDAS NO LABORATÓRIO E DADOS DE CAMPO DOS PERFIS DE UMIDADE E SUCÇÃO DAS ÁREAS ESTUDADAS. 


\subsubsection{Pluviometria}

Os dados de chuva foram obtidos a partir da instalação de dois pluviômetros próximos às duas áreas de estudo. Na área de Maranduba, o pluviômetro está situado a menos de 200 metros de distância do local onde foram instalados os sensores de monitoramento do teor de umidade e sucção do solo, conforme apresentado na Figura 6.34. O pluviômetro foi instalado sobre a cobertura de uma residência particular com o intuito de evitar possíveis depredações e garantir que as leituras de chuva durante o período de monitoramento não sejam prejudicadas pela interferência de folhas de árvores ou galhos que possam eventualmente cair dentro do equipamento.
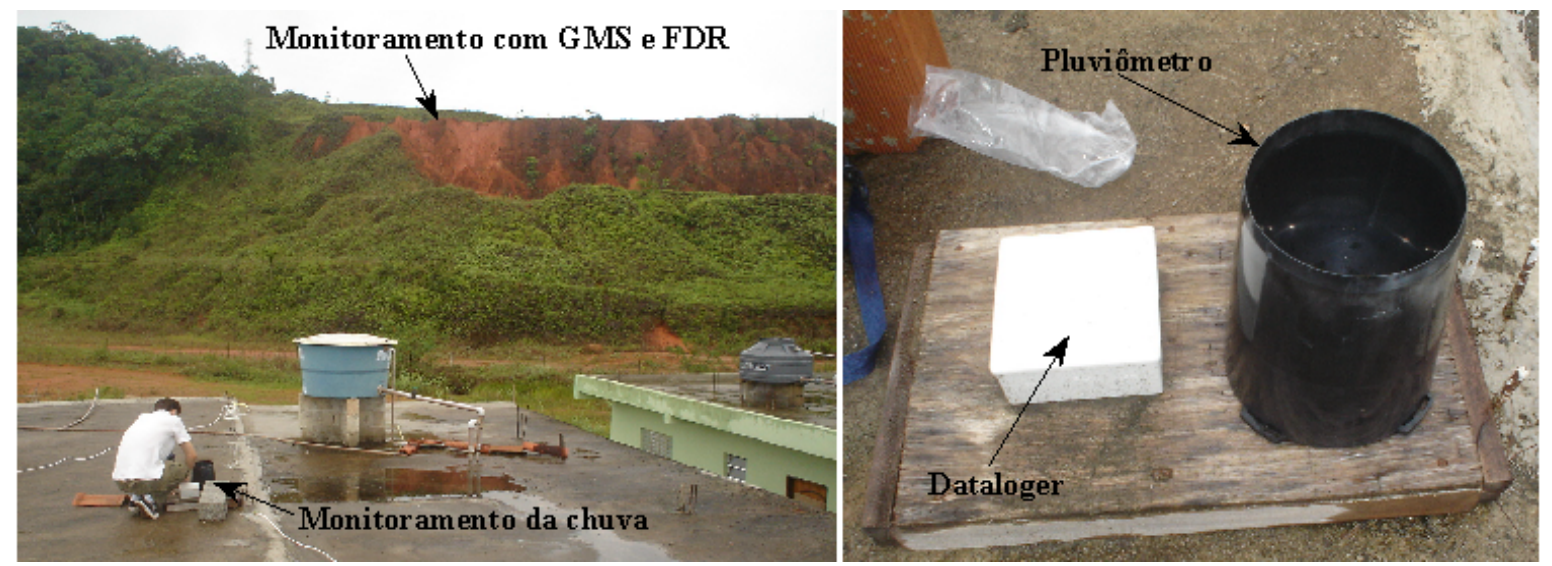

FIGURA 6.34 - LOCAL DE INSTALAÇÃO DO PLUVIÔMETRO NA ÁREA DE MARANDUBA.

Na área do Perequê-Mirim, o pluviômetro foi instalado a menos de 300 metros de distância do local onde foram instalados os sensores de monitoramento do teor de umidade e sucção do solo, conforme apresentado na Figura 6.35. O pluviômetro foi instalado numa área desocupada e livre de galhos de árvores, próximo de uma residência particular. No entanto, constata-se a presença de algumas árvores ao seu redor e a constante presença de pássaros. 


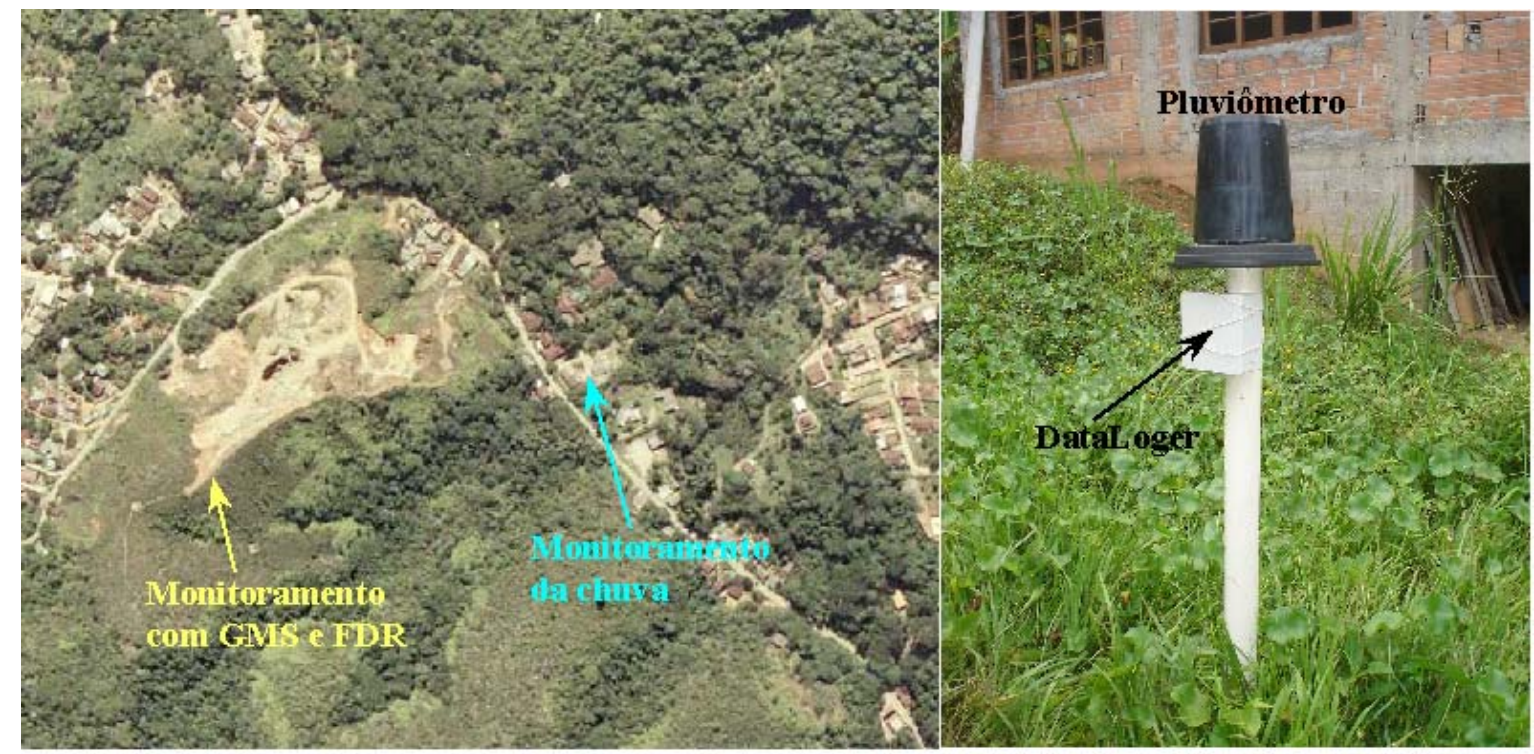

FiguRA 6.35 - LOCAL DE INSTALAÇÃO DO PLUVIÔMETRO NA ÁREA DO PEREQUÊ-MiRIM.

Os dados de monitoramento da chuva das áreas estudadas foram coletados durante o período de novembro/2006 a janeiro/2008, conforme apresentados nas Figuras 6.36 e 6.37. Analisando os dados da Figura 6.36, observa-se que as maiores intensidades de precipitação diária foram registradas no mês de fevereiro/2007 e também entre o período de outubro a novembro/2007. A precipitação total acumulada para o período monitorado (14 meses) na área de Maranduba foi de $1.721 \mathrm{~mm}$ e a precipitação mensal média de aproximadamente $123 \mathrm{~mm}$. Os meses de dezembro/2006 e novembro/2007 foram os mais chuvosos, com precipitação total acumulada de 253 e $239 \mathrm{~mm}$, respectivamente, e os meses de agosto e setembro/2007 os mais secos, com precipitação total acumulada de 34 e $37 \mathrm{~mm}$, respectivamente.

Nos meses considerados chuvosos (novembro, dezembro, janeiro e fevereiro), a precipitação total acumulada foi de aproximadamente $1.000 \mathrm{~mm}$, ou seja, correspondente a 58\% da precipitação total acumulada no período de monitoramento. Analisando esses dados conjuntamente com os dados pluviométricos dos postos distribuídos no município de Ubatuba, conforme apresentados nas Figuras 4.7 a 4.10, verifica-se que tanto a precipitação total acumulada quanto a precipitação mensal média na área de Maranduba ficaram significativamente abaixo dos valores médios registrados no período de 1962 a 1977. 


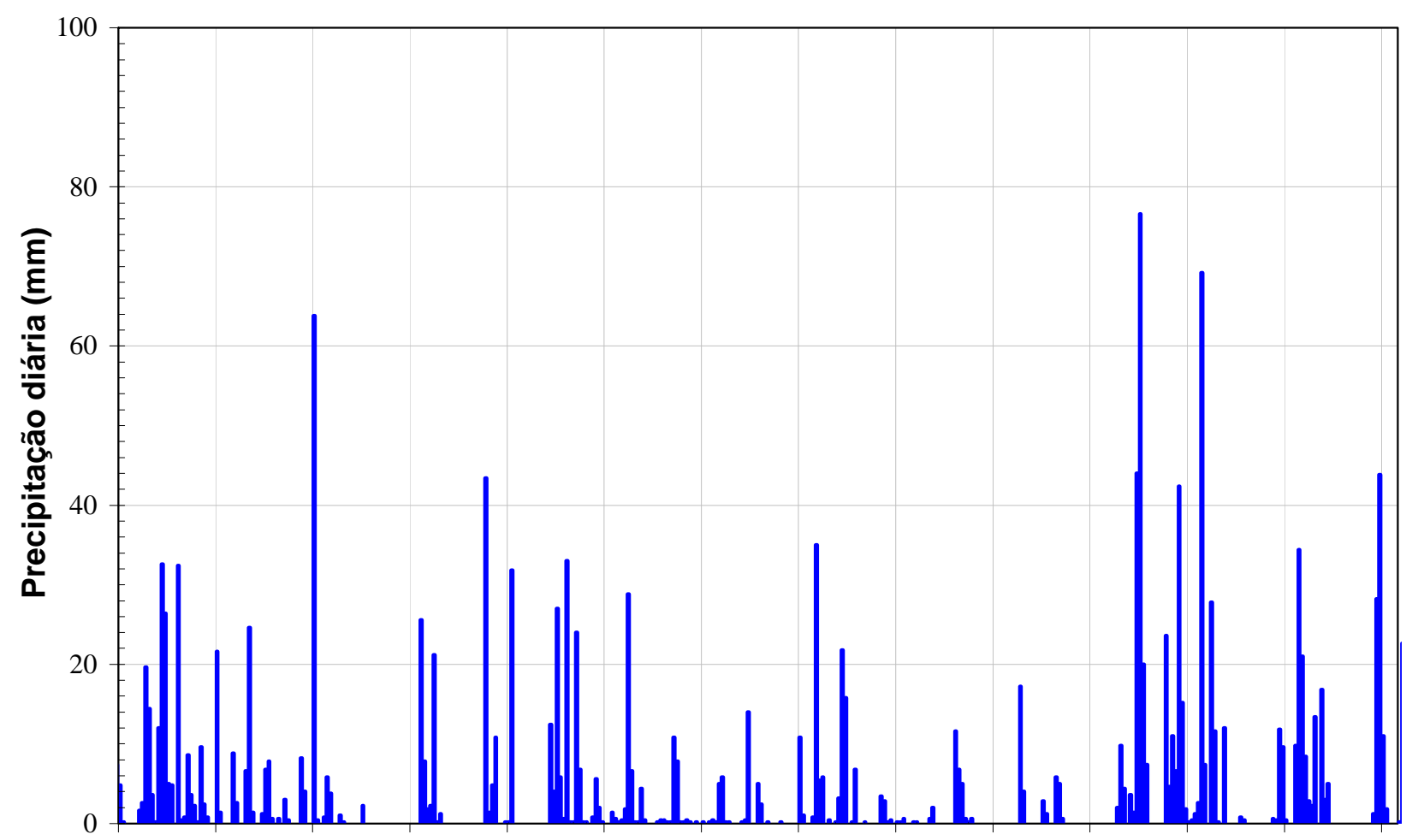

dez-06 jan-07 fev-07 mar-07 abr-07 mai-07 jun-07 jul-07 ago-07 set-07 out-07 nov-07 dez-07 jan-08

FIGURA 6.36 - DADOS DE MONITORAMENTO DA PRECIPITAÇÃO NA ÁREA DE MARANDUBA.

Na área do Perequê-Mirim, antes de realizar qualquer tipo de análise com os dados de precipitação, deve-se observar o problema técnico ocasionado pelo entupimento do pluviômetro durante o período de dezembro/2006 a janeiro/2007, conforme indicado na Figura 6.37 pelos pontos de interrogação (???). Além disso, deve-se ressaltar que os dados de precipitação correspondentes ao mês de janeiro/2008 estão incompletos, ou seja, apresentam registros de precipitação somente até o dia 10/01/2008.

Analisando os dados da Figura 6.37, constata-se que as maiores intensidades de precipitação diária foram registradas no mês de fevereiro/2007 e também entre o período de outubro a novembro/2007. A precipitação total acumulada para o período monitorado na área do PerequêMirim foi de $1.758 \mathrm{~mm}$ e a precipitação mensal média de aproximadamente $117 \mathrm{~mm}$. Os meses de outubro e novembro/2007 foram os mais chuvosos, com precipitação total acumulada de 210 e $251 \mathrm{~mm}$, respectivamente, e os meses de março, agosto e setembro/2007 os mais secos, com precipitação total acumulada de 47, 53 e $54 \mathrm{~mm}$, respectivamente. Nos meses considerados chuvosos (novembro, dezembro, janeiro e fevereiro), a precipitação total acumulada foi de 
aproximadamente $825 \mathrm{~mm}$, ou seja, correspondente a 47\% da precipitação total acumulada no período de monitoramento. Analisando esses dados conjuntamente com os dados pluviométricos dos postos distribuídos no município de Ubatuba, conforme apresentados nas Figuras 4.7 a 4.10, verifica-se que tanto a precipitação total acumulada quanto a precipitação mensal média na área de Maranduba também ficaram significativamente abaixo dos valores médios registrados no período de 1962 a 1977.

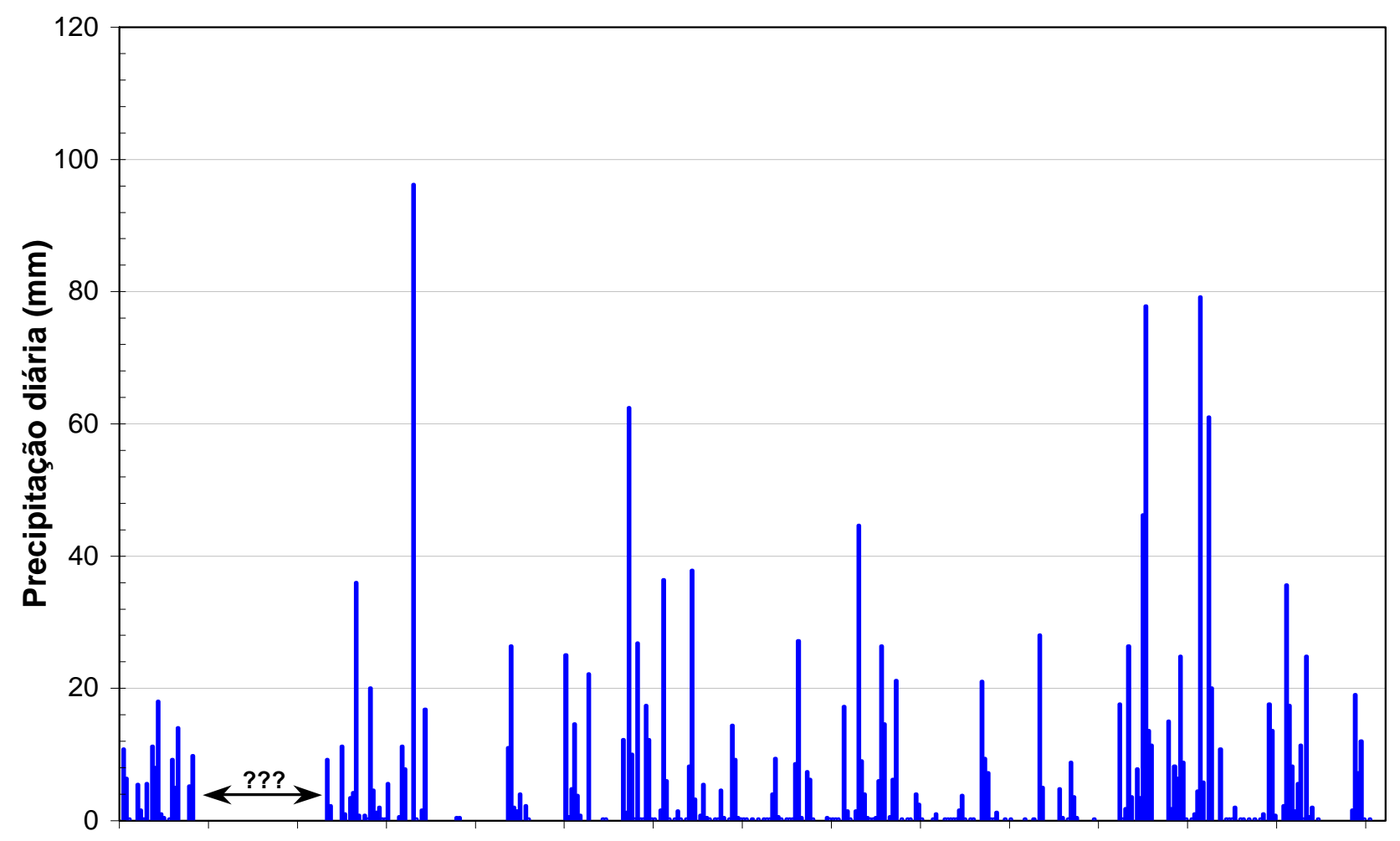

nov-06 dez-06 jan-07 fev-07 mar-07 abr-07 mai-07 jun-07 jul-07 ago-07 set-07 out-07 nov-07 dez-07 jan-08

Figura 6.37 - DADOS DE MONITORAMENTO DA PRECIPITAÇÃO NA ÁREA DO PEREQUÊ-MiRIM.

Ao analisar os dados de monitoramento da precipitação, do teor de umidade e da sucção do solo da área de Maranduba, conforme apresentado na Figura 6.38, percebe-se que as respostas dos sensores de umidade (FDR) e sucção (GMS) correspondem às variações de precipitação diariamente. Por exemplo, para a precipitação diária de $64 \mathrm{~mm}$ ocorrida no mês de fevereiro/2007, os sensores FDR registraram aumento de umidade da ordem de até 2,5\% (sensor instalado a 0,50m), enquanto os sensores GMS registraram diminuição de sucção de até $16 \mathrm{kPa}$ (sensor instalado a 0,25m). Na Figura 6.38, observa-se também que tanto a intensidade de chuva diária quanto a precipitação mensal acumulada contribuíram sobremaneira para o avanço da frente de umedecimento ao longo do perfil de alteração da área de Maranduba. 

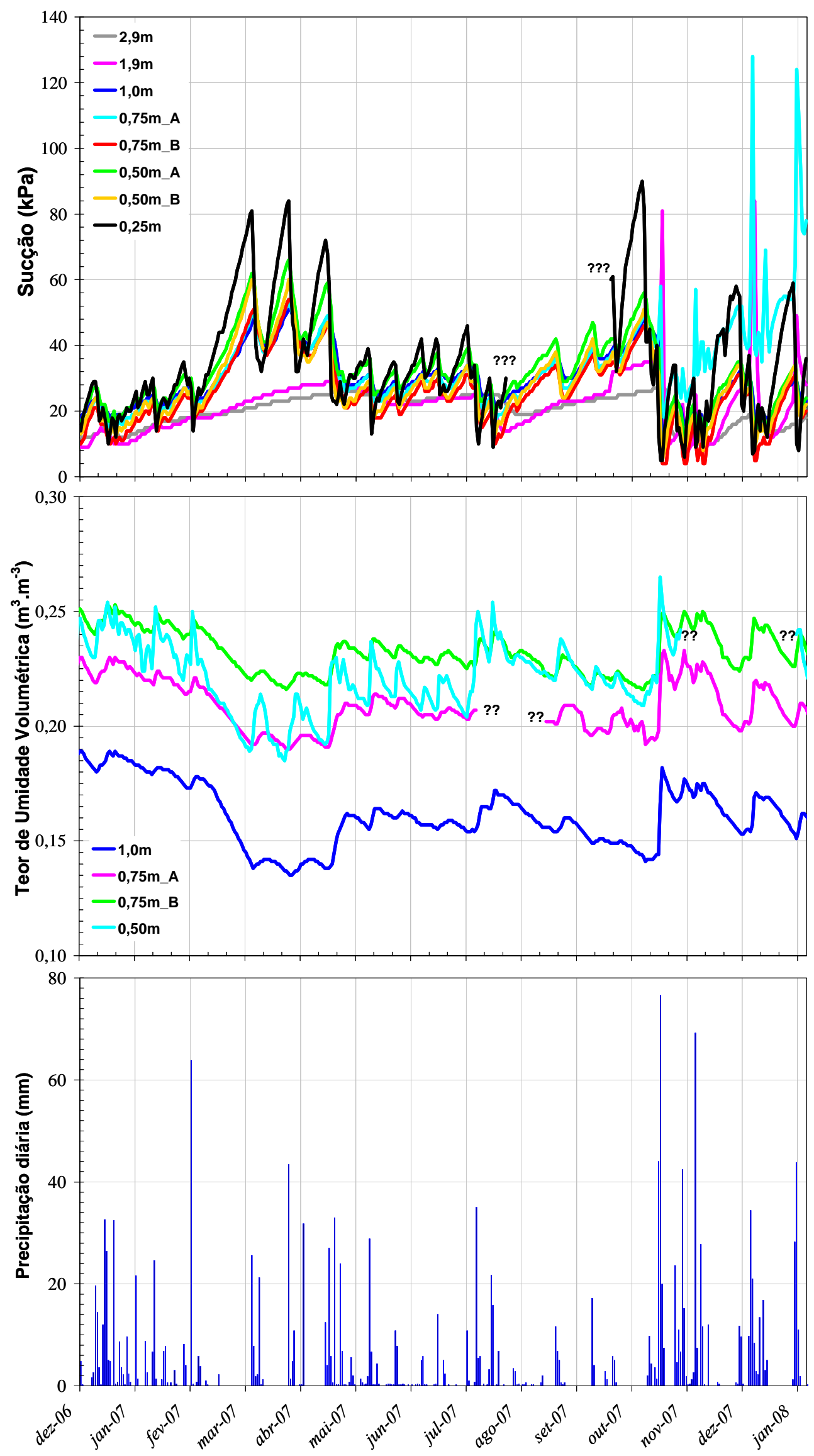

FiguRA 6.38 - AGRUPAMENTO DOS DADOS DE MONITORAMENTO DA ÁREA DE MARANDUBA. 

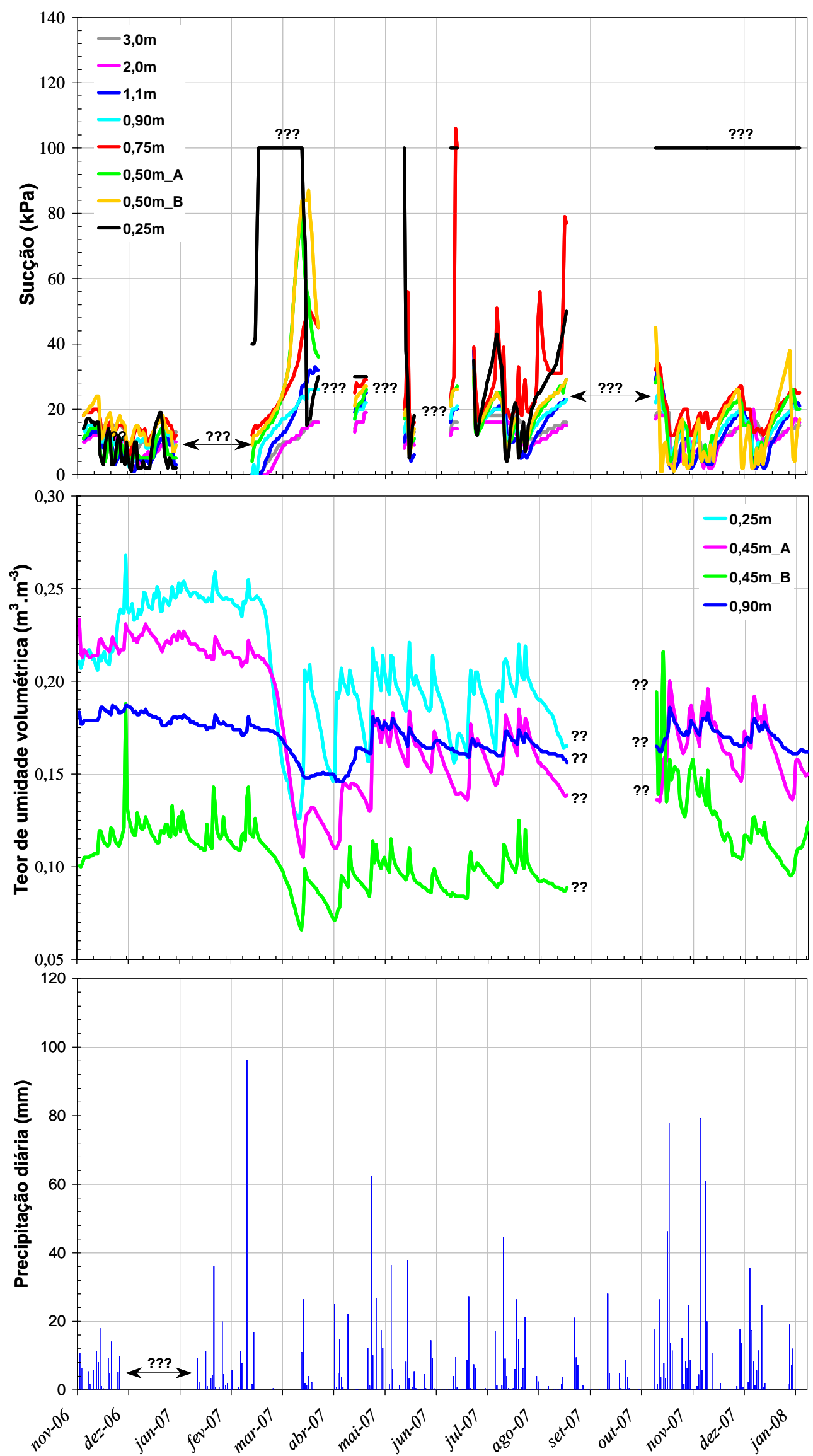

FigurA 6.39 - Agrupamento dos DAdOS DE MONITORAMENTO DA ÁREA DO PEREQUÊ-MiRIM. 
Por exemplo, observa-se, na Figura 6.38, que o aumento de umidade mais significativo registrado pelo sensor FDR instalado a 1,0 metro, da ordem 4\%, ocorreu no dia 24/10/2007, no qual também foi registrada a maior intensidade de chuva no período de monitoramento (76,6 mm). O sensor FDR mais profundo (1,0m) também registrou aumento de umidade considerado relevante durante os períodos de abril a maio/2007, julho a agosto/2007 e dezembro/2007, durante os quais ocorreram precipitações acumuladas de 262, 142 e 140 mm, respectivamente, ou seja, bem acima da precipitação mensal média registrada para todo o período monitorado (123 mm). Além disso, nota-se, na Figura 6.38, que as chuvas acumuladas no período de dezembro/2006 a fevereiro/2007 (460 mm) não foram suficientes para promover um expressivo aumento de umidade do solo a 1,0 metro de profundidade.

Ao analisar os dados de monitoramento da precipitação, do teor de umidade e da sucção do solo da área do Perequê-Mirim, conforme apresentado na Figura 6.39, percebe-se que as respostas dos sensores de umidade (FDR) e sucção (GMS) também correspondem às variações de precipitação registradas diariamente. Por exemplo, para a precipitação diária de 96 mm ocorrida no mês de fevereiro/2007, os sensores FDR registraram aumento de umidade da ordem de até 3,0\% (sensor instalado a 0,45m-B), enquanto os sensores GMS não registraram dados devido a problemas técnicos. Na Figura 6.39, observa-se que a intensidade de chuva diária e a precipitação mensal acumulada também contribuem para o avanço da frente de umedecimento na área do PerequêMirim, embora de maneira mais tênue.

Por exemplo, observa-se, na Figura 6.36, que o aumento de umidade mais significativo registrado pelo sensor FDR instalado a 0,90 metro é da ordem de 2\% , e que ocorreu no dia 27/04/2007, no qual também foi registrada uma das maiores intensidades de chuva no período de monitoramento $(62,4 \mathrm{~mm})$. O sensor FDR mais profundo $(0,90 \mathrm{~m})$ também registrou aumento de umidade considerado relevante durante os períodos de abril a maio/2007 e outubro a novembro/2007, durante os quais ocorreram precipitações acumuladas de 323 e 461 mm, respectivamente, ou seja, bem acima da precipitação mensal média registrada para todo o período monitorado (117 mm). Nota-se também, na Figura 6.36, que as chuvas acumuladas no período de novembro/2006 a março/2007 (438 mm) não foram suficientes para promover um aumento significativo de umidade do solo a 0,90 metro de profundidade. 
Nas Figuras 6.40 e 6.41 são apresentados os registros de monitoramento do teor de umidade e sucção com os dados de precipitação horária da área de Maranduba, com a finalidade de avaliar o tempo de resposta dos sensores FDR e GMS para detectar a frente de umedecimento no terreno.

Analisando os dados da Figura 6.40, nota-se que o tempo de resposta do sensor FDR instalado na profundidade de 0,50 m é menor em relação ao tempo de resposta dos demais sensores FDR, ou seja, nessa profundidade o sensor FDR foi mais sensível às variações de umidade do solo. Nessa figura, observa-se também que os sensores FDR instalados nas profundidades de 0,75 e 1,0 metro registraram variações de umidade pouco significativas, mesmo para os períodos onde a intensidade de chuva horária foi expressiva (entre 16 a 31/12/2006 e 16 a 23/03/2007).
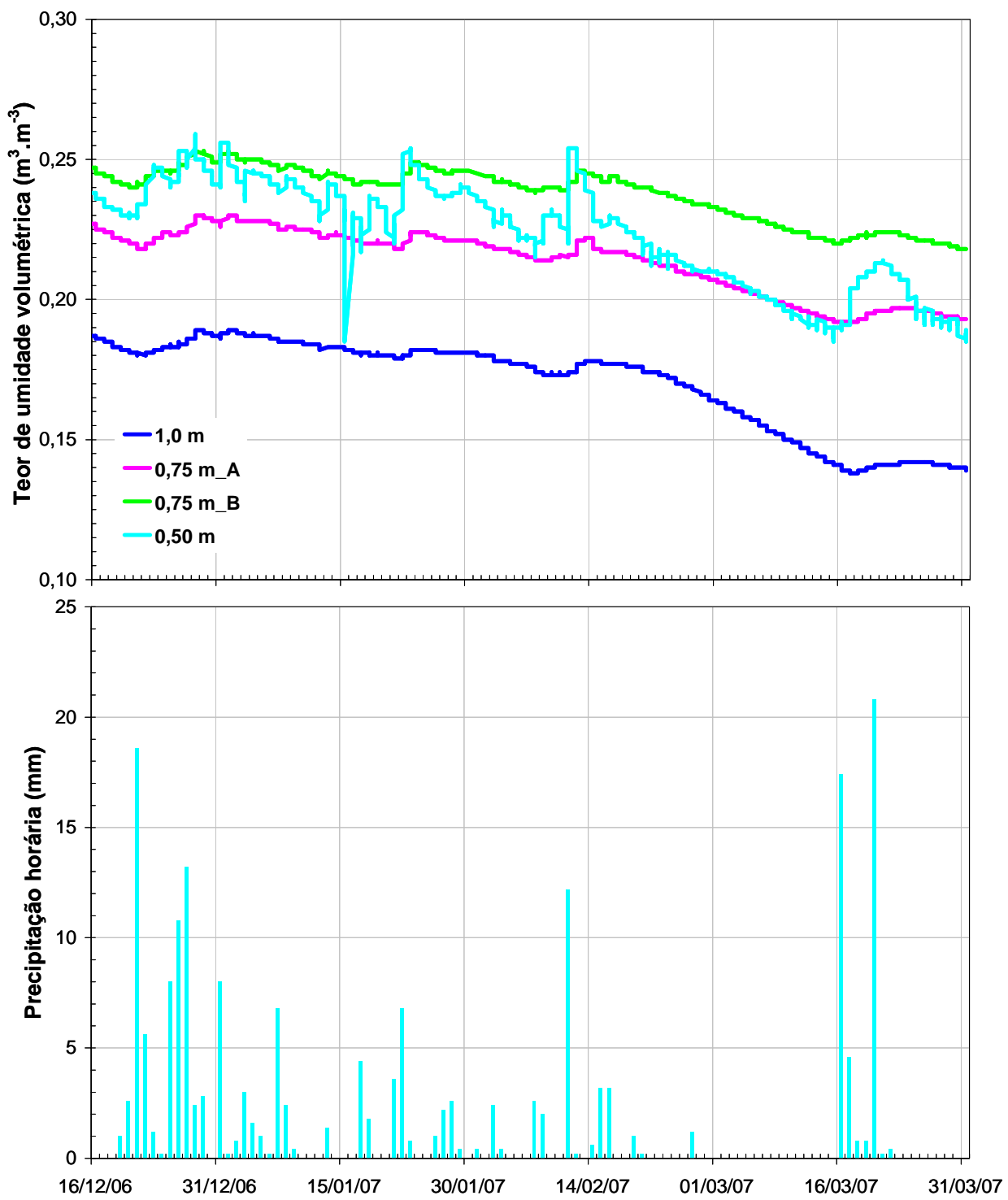

FIGURA 6.40 - REGISTROS DE UMIDADE E PRECIPITAÇÃO HORÁRIA DA ÁREA DE MARANDUBA. 
Analisando os dados da Figura 6.41, verifica-se que o tempo de resposta dos sensores GMS instalados nas profundidades 0,25 e 0,50 metro são menores em relação aos demais sensores. Os sensores GMS instalados no horizonte de solo mais profundo (1,9 e 2,9 metros) não registraram variações significativas de sucção, mesmo em períodos sem chuva (01 a 16/03/2007) ou com intensidade de precipitação horária significativa (16 a 23/03/2007). Na Figura 6.41 nota-se também que o sensor GMS instalado na profundidade de 0,25 metro foi capaz de detectar a frente de umedecimento do solo num tempo relativamente pequeno, da ordem de algumas horas, principalmente durante os períodos de chuvas intensas (entre os dias 11 e 12/02/2007 e entre os dias 16 a 21/03/2007).

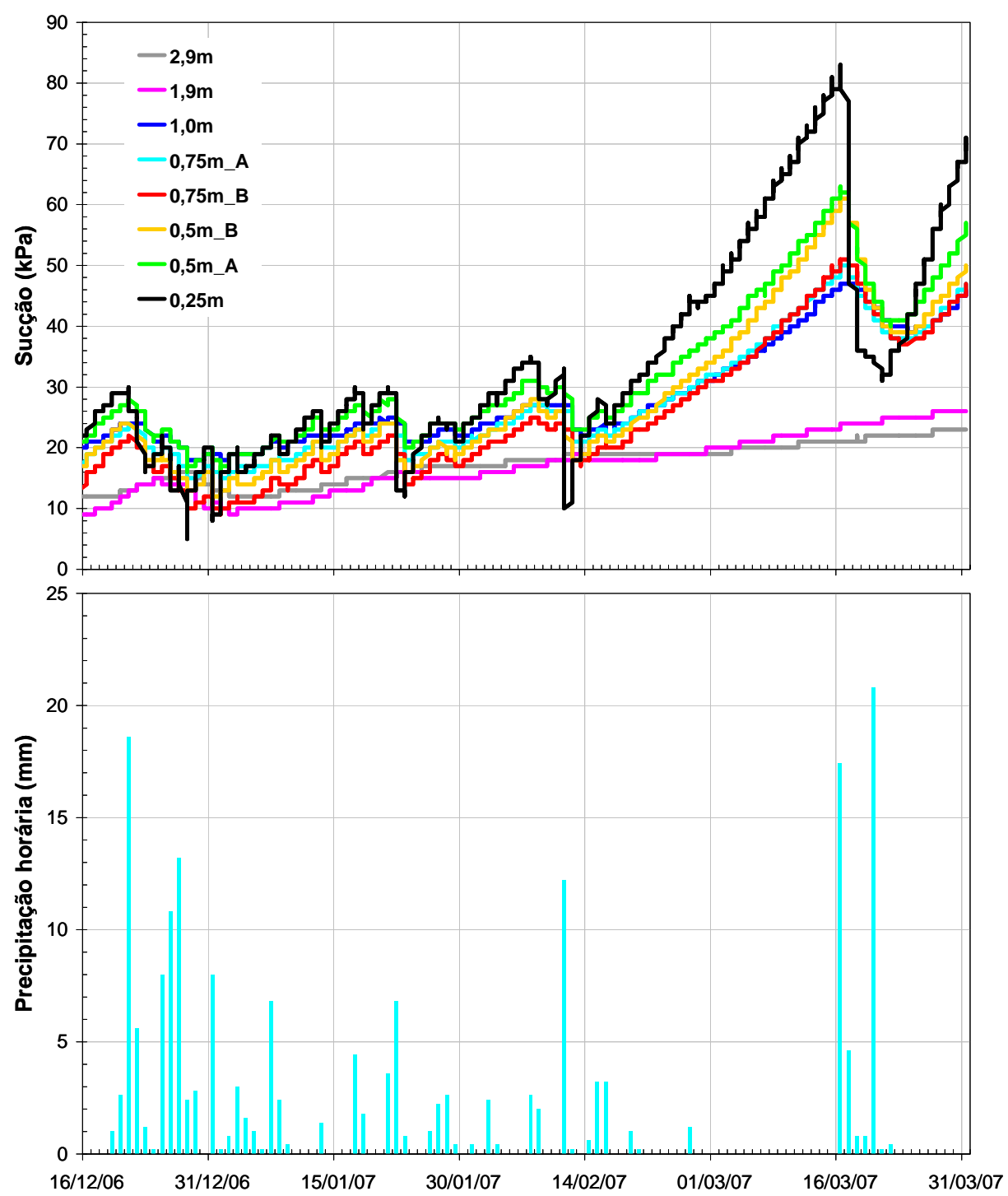

FIGURA 6.41 - REGISTROS DE SUCÇÃO E PRECIPITAÇÃO HORÁRIA DA ÁREA DE MARANDUBA. 


\section{CONCLUSÕES E RECOMENDAÇÕES PARA FUTURAS PESQUISAS}

As conclusões da presente pesquisa são abordadas separadamente em função dos principais resultados obtidos em labotarório e nas condições de campo. As abordagens conclusivas versam sobre os aspectos relacionados à caracterização geotécnica e micromorfológica, ao comportamento hidráulico (curvas de retenção de água e condutividade hidráulica), à medição do teor de umidade com GPR e ao monitoramento das variáveis geotécnicas (sucção matricial e teor de umidade) e climatológica (precipitação) e sobre o comportamento geral dos perfis de sucção e umidade.

\section{- Caracterização geotécnica e micromorfológica}

Em relação aos resultados de caracterização geotécnica, constatou-se que os horizontes de alteração mais profundos (horizontes I-B e I-C) são formados predominantemente por solos siltosos e/ou arenosos, enquanto os horizontes superficiais (I-A) apresentam solos mais argilosos. $\mathrm{Na}$ área de Maranduba, o teor de argila diminui consideravelmente com o aumento da profundidade do perfil de alteração. Na área do Perequê-Mirim esta tendência também ocorre, mas de maneira menos pronunciada. Constatou-se também que os solos representativos das áreas estudadas apresentaram uma significativa variabilidade dos índices físicos ao longo do perfil de alteração, principalmente em relação ao índice de vazios.

A caracterização mineralógica revelou que os materiais formados nos dois perfis de alteração das áreas estudadas apresentam semelhanças significativas do ponto de vista geoquímico e mineralógico, pois são basicamente compostos por quartzo, caolinita e gibbsita, além de certa quantidade variável de oxi-hidróxidos de ferro. O perfil de alteração de Maranduba apresenta mais heterogeneidade na distribuição dos minerais primários (quartzo e magnetita), o qual interfere no grau de ferruginização e na proporção de argila. Os minerais secundários ocorrem desde a base dos perfis de alteração, sendo a gibbsita aparentemente mais abundante que a caolinita. 
Os produtos ferruginosos (hematita e magnetita) ocorrem disseminados ao longo dos perfis de alteração, geralmente nas zonas de maior circulação de água. Esta semelhança na constituição mineralógica dos materiais que compõem os perfis de alteração das áreas estudadas não permitiu estabelecer uma correlação direta entre as feições mineralógicas e as propriedades geotécnicas dos solos residuais estudados.

Em relação aos aspectos microestruturais, constatou-se que a distribuição de macro e microporos é muito variável ao longo dos perfis de alteração, tendendo ser maior nos horizontes de solo superficiais (horizonte I-A) e praticamente nula na rocha sã. A micro e macroporosidade dos solos que compõem os horizontes superficiais são representadas por fissuras (microporos), canais e cavidades (macroporos), algumas de origem biológica. As fissuras correspondem aos poros intra-agregados do fundo matricial, enquanto os canais e cavidades correspondem aos poros interagregados (porosidade estrutural). Observou-se que as fissuras nesse horizonte de solo nem sempre estão interconectadas. Nos horizontes mais profundos dos perfis de alteração (horizontes I-B e I-C) a formação de macroporos parece estar associada com a dissolução dos minerais promovida pela circulação de água nas descontinuidades herdadas da rocha matriz, enquanto a microporosidade está associada com a deposição e formação de volumes constituídos por minerais supérgenos.

\section{- Porosimetria, curvas de retenção de água e condutividade hidráulica}

Os resultados de porosimetria revelaram que, na área de Maranduba, os solos do horizonte superficial (I-A) apresentam quantidades maiores de microporos, enquanto os solos dos horizontes mais profundos (I-B e I-C) apresentam uma quantidade maior de meso e macroporos. Na área do Perequê-Mirim, tanto os solos do horizonte superficial (I-A) quanto os solos do horizonte mais profundo (I-C) apresentam apreciáveis quantidades de microporos e uma baixa quantidade de meso e macroporos. Em termos gerais, a quantidade de meso e macroporos tende a aumentar com o aumento da profundidade, enquanto a quantidade de microporos tende a diminuir. Verificou-se também que a grande maioria dos solos estudados apresenta distribuição bimodal de poros. 
A maior parte das curvas de retenção obtidas com os dados de porosimetria, apresentou tendências de sobreestimativas da capacidade de retenção dos solos analisados. Os resultados obtidos sugerem haver influência do processo de secagem na distribuição dos poros dos solos estudados. Acredita-se que o processo de secagem utilizado na porosimetria possa reduzir a quantidade de macroporos e aumentar a quantidade de microporos e, conseqüentemente, proporcionar um "aumento fictício" na capacidade de retenção de água dos solos. Além disso, deve-se investigar melhor se a condição de saturação total imposta inicialmente, ou seja, de que os poros são totalmente preenchidos com mercúrio, não interfere nos resultados finais.

Em relação às curvas de retenção de água, conclui-se que a grande maioria dos solos estudados apresentou curvas com "patamares”, indicando haver valores distintos de entrada de ar entre macro e microporos, o que caracteriza uma distribuição bimodal de poros. Constatou-se que os solos representativos do horizonte superficial (I-A) das áreas estudadas apresentaram curvas de retenção de água semelhantes e que, em termos gerais, tais solos apresentam maior capacidade de retenção para os níveis de sucções impostos. Os pontos experimentais das curvas de retenção que apresentaram distribuição bimodal de poros foram muito bem ajustados pelo modelo proposto por Durner (dual porosity). Em termos gerais, verificou-se que tanto a distribuição de macro e microporos quanto o teor de argila influenciam sobremaneira a capacidade de retenção de água dos solos residuais tropicais. Acredita-se que as diferenças na capacidade de retenção de água estejam relacionadas com os diferentes graus de intemperismo aos quais os horizontes de solo foram submetidos.

Os resultados de condutividade hidráulica realizados em laboratório revelaram que os solos da área de Maranduba apresentam coeficientes de condutividade hidráulica iguais, enquanto os solos da área do Perequê-Mirim apresentam coeficientes de condutividade hidráulica muito próximos, onde o saprolito (horizonte I-C) mostrou ser ligeiramente mais permeável que o solo superficial (horizonte I-A). Verificou-se existir uma relação direta entre os coeficientes de condutividade hidráulica com a distribuição de meso e macroporos para os solos representativos da área de Maranduba. 
A partir dos ensaios de campo, constatou-se que os solos representativos das áreas estudadas apresentaram valores de condutividade hidráulica saturada da mesma ordem de grandeza. No laboratório, observou-se que a condutividade hidráulica saturada obtida com o infiltrômetro tende a ser ligeiramente menor que aquela obtida com o permeâmetro de carga variável. Acredita-se que essa diferença é devida às condições iniciais de umidade consideradas nos ensaios.

\section{- Medição do teor de umidade com GPR}

O GPR mostrou ser um método promissor para o monitoramento do teor de umidade nas encostas e taludes situados em áreas de risco a escorregamentos. Obteve-se uma boa relação entre a constante dielétrica média e o teor de umidade volumétrica determinado com a técnica gravimétrica. Comparando-se os valores de umidade medidos com a técnica gravimétrica com os valores estimados pelo método GPR, encontrou-se uma precisão de $0,0458 \mathrm{~m}^{3} \cdot \mathrm{m}^{-3}$ para a antena de $100 \mathrm{MHz}$ e uma precisão de $0,0435 \mathrm{~m}^{3} \cdot \mathrm{m}^{-3}$ para a antena de $200 \mathrm{MHz}$. Comparando esses valores com os resultados encontrados na literatura internacional, verifica-se que os resultados obtidos com o método GPR para as condições geológico-geotécnicas brasileiras forneceram valores bastante confiáveis.

Deve-se considerar que as precisões obtidas no presente estudo estão relacionadas tanto com o tipo de técnica utilizada para medir o teor de umidade gravimétrica, quanto com o arranjo empregado para estimar o teor de umidade volumétrica com GPR (no caso medidas CMP). Por exemplo, na técnica gravimétrica tem-se os problemas relacionados com a variação de umidade durante as etapas de acondicionamento e transporte das amostras de solo ao laboratório. No método GPR tem-se as incertezas inerentes aos diferentes tipos de arranjos utilizados, das freqüências das antenas, a profundidade de análise e a quantidade de refletores que estão sendo identificados. Além disso, deve-se ressaltar que a utilização de valores da constante dielétrica obtidos com a velocidade de propagação de ondas diretas no terreno ou com ondas refletidas influencia o grau de precisão das medidas do teor de umidade do solo no campo. 


\section{- Monitoramento da sucção, teor de umidade e precipitação}

Os resultados de calibração dos sensores GMS permitem concluir que os diferentes procedimentos de saturação utilizados praticamente não interferem no seu desempenho para a medição da sucção. O tempo de resposta do sensor GMS mostrou ser da ordem de 6 (seis) vezes maior que o do tensiômetro convencional, para a fase de secagem do solo. Para a fase de umedecimento por irrigação, o sensor GMS mostrou ser mais sensível e, portanto, mais ágil para detectar variações de umidade. Os resultados gerais são encontrados em MENDES et al. (2007) ANEXO.

Em termos gerais, os sensores GMS instalados no horizonte superficial (I-A) registraram valores de sucção mais elevados durante a maior parte do período de monitoramento. Houve tendência de diminuição dos valores e da magnitude de oscilação da sucção com o aumento da profundidade. Os sensores GMS instalados no horizonte de saprolito apresentaram variações sazonais de sucção bem distintas em relação aos sensores instalados no solo de alteração. Os valores de sucção mais baixos foram registrados em períodos que coincidem com épocas consideradas de maior precipitação, enquanto as sucções mais elevadas foram registradas predominantemente em épocas consideradas secas. A partir das análises dos dados de monitoramento, conclui-se que, tanto a intensidade da chuva quanto a precipitação acumulada contribuíram para as variações significativas registradas pelos sensores GMS instalados nas áreas de estudo.

Os dados registrados pelos sensores FDR revelaram que as variações mais significativas de umidade ocorrem no horizonte superficial (I-A). Observou-se que a umidade do solo tende diminuir com o aumento da profundidade e que há diferenças significativas na distribuição de umidade para os sensores instalados na mesma profundidade. Em termos gerais, os sensores instalados no horizonte superficial (I-A) apresentaram teores de umidade mais elevados em relação aos demais sensores instalados nas áreas de estudo. Na área do Perequê-Mirim, constatou-se existir diferenças significativas nos perfis de umidade das porções interna e externa do talude, sendo que a umidade geralmente foi maior no perfil mais próximo ao talude. Acreditase que essa diferença é devido à presença de vegetação na porção interna do talude. 
As análises conjuntas dos dados de precipitação, umidade e sucção de ambas as áreas de estudo, permitem concluir que as leituras registradas pelos sensores FDR e GMS correspondem perfeitamente às variações de precipitação registradas diariamente. Constatou-se que tanto a intensidade de chuva diária quanto a precipitação mensal acumulada contribuíram para o avanço da frente de saturação nos perfis de alteração das áreas estudada, atuando, porém, de maneira mais tênue na área do Perequê-Mirim.

A partir da avaliação conjunta dos dados de monitoramento da sucção, teor de umidade e precipitação, conclui-se que a implantação de um sistema de alerta em áreas de risco a escorregamentos de encostas e taludes, baseado no monitoramento contínuo de variáveis climatológicas (chuva, vento, temperatura, etc.) e geotécnicas (perfis de sucção e umidade), é técnica e economicamente viável Além disso, conclui-se que a instalação dos sensores GMS e FDR numa profundidade de até 3,0 metros é suficiente para o acompanhamento das variações sazonais de sucção e umidade ao longo dos perfis de solos residuais.

\section{- Recomendações para futuras pesquisas}

Recomenda-se que sejam repetidos os ensaios com medição de sucção e realizados ensaios de resistência não saturada com controle de sucção para analisar a variação dos parâmetros $\phi^{\prime}$ e $\phi^{\text {b }}$ dos solos estudados com o aumento da sucção matricial, pois não foi possível obter análises conclusivas sobre a influência da sucção matricial na resistência ao cisalhamento nos solos residuais investigados. Além disso, seria interessante avaliar a influência do grau de intemperismo no comportamento hidro-mecânico dos horizontes de solo (capacidade de retenção de água e resistência ao cisalhamento), a partir de ensaios experimentais específicos.

Seria interessante monitorar as variáveis geotécnicas levando-se em consideração todas as variáveis climatológicas, e não somente a precipitação, para permitir uma análise mais adequada das condições de balanço hidrológico e estudar sua influência no perfil de umidade e sucção. Desta maneira, pode-se prever com maior exatidão os períodos mais críticos para a ocorrência de escorregamentos em áreas de risco. Recomenda-se avaliar em laboratório a calibração dos 
sensores FDR a partir de medidas realizadas com a técnica gravimétrica e com o TDR, visando estabelecer a precisão dos sensores FDR para medições do teor de umidade volumétrica nas condições de campo.

Recomenda-se também realizar um estudo experimental com o GPR visando definir uma relação petrofísica para os solos residuais tropicais, pois a relação de Topp apresentou dispersões consideráveis durante o monitoramento dos perfis de umidade. Além disso, para tal estudo, recomenda-se que os teores de umidade determinados com o GPR sejam comparados com os teores de umidade medidos com sensores FDR ou TDR. 


\section{REFERÊNCIAS BIBLIOGRÁFICAS}

ABNT - Associação Brasileira de Normas Técnicas (1984). Grãos de solo que passam na peneira de 4,8mm - Determinação da massa especifica - NBR-6508. Rio de Janeiro, 8p.

ABNT - Associação Brasileira de Normas Técnicas (1984). Solo - Análise granulométrica NBR-7181. Rio de Janeiro, 13p.

ABNT - Associação Brasileira de Normas Técnicas (1984). Solo - Determinação do limite de liquidez, NBR 6459. Rio de Janeiro, 6p.

ABNT - Associação Brasileira de Normas Técnicas (1984). Solo - Determinação do limite de plasticidade, NBR 7180. Rio de Janeiro, 3p.

ABNT - Associação Brasileira de Normas Técnicas (1984). Solo - Determinação da massa especifica aparente de amostars indeformadas, com emprego da balança hidrostática, NBR 10838. Rio de Janeiro, 6p.

ABNT - Associação Brasileira de Normas Técnicas (1995). Rochas e solos - NBR-6502. Rio de Janeiro.

ABRAMENTO, M. \& CARVALHO, C. S. (1989). Geotechnical parameters for the study of natural slope instabilization at Serra do Mar Brazil. In: International Conference on Soil Mechanics and Foundation Engineering, 12, Rio de Janeiro.

ABRAMENTO, M. \& PINTO, C. S. (1993). Resistência ao cisalhamento de solo coluvionar não saturado das encostas da Serra do Mar. Revista Solos e Rochas, São Paulo, 16(3): 145-158.

AFFENDI, A. \& FAISAL, H. A. (1996). Suction, rainfall and slope stability. In: South East Asian Geotechnical Conference Kuala Lumpur, $12^{\text {th }}$, Proceedings...Malaysia 1: 539-544.

ALUMBAUGH, D., CHANG, P., PAPROCKI, L., BRAINARD, J., GLASS, R.J., RAUTMAN, C.A. (2002). Estimating moisture contents in the vadose zone using cross-borehole ground penetrating radar: A study of accuracy and repeatability. Water Resource Research, 38:1309. 
AMPARO, N.S., MACHADO, S.L., BOTELHO, M.A.B., DOURADO, T.C. (2007). Uso do GPR como uma ferramenta não intrusiva para o levantamento de perfis de umidade de campo. In: Simpósio Brasileiro de Solos não Saturados, 6, NSAT2007, Salvador: EDUFBA, Vol. 1, pp. 229236.

ANDRADE, M.H.N., DE CAMPOS, T.M.P., VARGAS, E.A. (1992). Retroanálise do escorregamento da encosta do Cactáreo. In: COBRAE, 1, Rio de Janeiro: ABMS/ABGE, Vol. I, pp. 161-172.

ANNAN, A. P. \& COSWAY, S. W. (1992). Ground penetrating radar survey design. In: Symposium on the applications of geophysics to engineering and environmental problems, 5, Oakbrook. Proceedings...Oakbrook: SAGEEP, vol. 2, pp. 329-352.

ANNAN, A. P. \& DAVIS, J. L. (1997). Ground penetrating radar - coming of age at last. Mississauga: Sensors \& Software, Inc., 4p. (Internal Report PEMD\#10). Available: http://www.sensoft.on.ca

ANNAN, A. P. (1992). Ground penetrating radar workshop notes. Mississauga: Sensors \& Software, Inc., 130p. (Internal Report). Available: http://www.sensoft.on.ca

ANNAN, A. P., COSWAY, S. W., REDMAN, J. D. (1991). Water table detection with ground penetrating radar. In: International Congress of Society of Exploration Geophysical, 61, Houston. Expanded Abstract...Houston: SEG, pp. 494-496.

ANNAN, A.P. \& DAVIS, J.L. (1976). Impulse radar soundings in permafrost. Radio Science, vol. 11, pp. 383-394.

ANNAN, A.P., DAVIS, J.L., VAUGHAN, C.J. (1984). Radar mapping of buried pipes and cables. Mississauga: Sensors \& Software, Inc., 6p. (Internal Report PEMD\#17). Available: http://www.sensoft.on.ca

AQUINO, W. F. (2000). Métodos geofísicos eletromagnéticos aplicados ao diagnóstico da contaminação do solo e das águas subterrâneas em área de infiltração de resíduos industriais. Dissertação de Mestrado, Instituto de Geociências/USP, São Paulo, 134p. 
AQUINO, W. F., BOTELHO, M. A. B., GANDOLFO, O. C. B. (1998). Emprego de geo-radar na detecção de intrusão salina e na identificação de estruturas geológicas em áreas costeiras. In: Congresso Brasileiro de Águas Subterrâneas, 10, São Paulo. Resumos Expandidos...São Paulo: SBG, Publicação Eletrônica, 6p.

ARBHABHIRAMA, A. \& KRIDAKORN, C. (1968). Steady Downward Flow to a Water Table. Water Resources Research, 4 (6): 1249-1257.

AVELAR, A.S. \& NETO, A.L.C. (1992). Fluxos d'água subsuperficiais associados à origem das formas côncavas do relevo. In: COBRAE, 1, Rio de Janeiro: ABMS/ABGE, Vol. II, pp. 709-719.

BANO, M. (2004). Modelling of GPR waves for lossy media obeying a complex power law of frequency for dielectric permittivity. Geophysical Prospecting, European Association of Geoscientists \& Engineers, (52):11-26.

BENEVELI, R. M. \& DE CAMPOS, T. M. P. (2004). Efeitos da secagem seguida da saturação na resistência de um solo compactado em laboratório. In: Simpósio Brasileiro de Solos Não Saturados, 5º São Carlos: SGS/EESC/USP, Vilar, O. M. (editor), pp. 09-13.

BERES, M. \& HAENI, F. P. (1991). Application of ground penetrating radar methods in hidrogeologic studies. Ground Water, 29(3): 375-386.

BERKTOLD, A., WOLLNY, K.G., ALSTETTER, H. (1998). Subsurface moisture determination with the ground wave of GPR. In: Proceedings of the International Conference on Ground Penetrating Radar, 7, Lawrence, University of Kansas, pp. 675-680.

BEVAN, B.W. (1984). Environmental effects on ground penetrating radar. In: International Congress of Society of Exploration Geophysical, 54, Atlanta. Expanded Abstracts..., Atlanta: SEG, pp. 201-204.

BEVILAQUA, F.Z., MOURA, A.P., SANTOS, G.T., DAVISON DIAS, R. (2004). Comportamento mecânico dos solos residuais não saturados de granito de Florianópolis. In: Simpósio Brasileiro de Solos Não Saturados, 5, São Carlos, Vol.1, pp. 405-409. 
BINLEY, A., WINSHIP, P., MIDDLETON, R., POKAR, M., WEST, J. (2001). High-resolution characterization of vadose zone dynamics using cross-borehole radar. Water Resource Research, 37:2639-2652.

BINLEY, A., WINSHIP, P., WEST, J., POKAR, M., MIDDLETON, R. (2002). Seasonal variation of moisture content in unsaturated sandstone inferred from borehole radar and resistivity profiles. Journal Hidrology, 267:160-172.

BISHOP, A. W. (1959). The principle of effective stress. Tecknisk Ukeblab, 106 (39): 859-863.

BISHOP, A. W., ALPAN, I., BLIGHT, G. E., DONALD, I.B. (1960). Factors controlling the shear strength of partly saturated cohesive soils. In: Conference On Shear Strength of Cohesive Soils, University of Colorado, pp. 503-532.

BITAR, O. Y. et al. (1985). Planejamento e manejo minerário municipal; a experiência do município de Ubatuba, SP. In: Simpósio Regional de Geologia, 5, São Paulo. Anais...São Paulo: SBG/SP, v.1, pp. 99-111.

BLIGHT, G. E. (1967). Effective stress evaluation for unsaturated soils. Journal of the Soil Mechanics \& Foundation Engineering Division, ASCE 93 (SM2): 125-148.

BLIGHT, G. E. (1987). Lowering of the groundwater by deep rooted vegetation. In: European Conference on Soil Mechanics and Foundation Engineering, $9^{\text {th }}$, Proceedings...Dublin, Ireland 1: 285-288.

BLIGHT, G. E. (1988). Construction in tropical soils. Keynote paper, In: International Conference on Geomechanics in Tropical Soils, $2^{\text {nd }}$, Proceedings...Singapore II: 449-467.

BLIGHT, G. E. (1997). Origin and formation of residual soils. In: G. E. Blight (Ed.), Mechanics of Residual Soils, Rotterdam: Balkema, pp.1-15.

BOHIDAR, R. N. \& HERMANCE, J. F. (2002). The GPR refraction method. Geophysics, Society of Exploration Geophysicists, 67(5): 1474-1485.

BOULANGÉ, B. (1984). Les formations bauxitiques latéritiques de Côte d’Ivoire. Les facies, leur transformations, leur distribuitions et L’évolution du modelé. Trav. Et Doc. ORSTOM, Paris, 367p. 
BOUlet, R, CHAUVEL, A., HUMBEL F. X., LUCAS, Y. (1982). Analyse structurale et cartographie en pédologie (I) - Les études de toposéquences et principaux apports à la connaissance des sols. Cah. ORSTOM, ser. pédol., 19(4): 309-321.

BOULET, R. (1978). Toposéquences des sols tropicaux en Haute-Volta: Equilibre et Déséquilibre Pedobioclimatique. Mémoires ORSTOM, n. ${ }^{\circ}$ 85, 267p.

BRAND, E. W. \& PHILLIPSON, H. B. (1985). Sampling and testing of residual soils. Southeast Asian Geotechnical Society, Scorpion Press, Hong Kong.

BRAND, E. W. (1982). Analysis and design in residual soils, engineering and construction in tropical and residual soils, ASCE, Geotechnical Division Special Conference, Honolulu, Hawaii: 89-143.

BRENNER, R. P., GARGA, V. K., BLIGHT, G. E. (1997). Shear strength behaviour and the measurement of shear strength in residual soils. In: G. E. Blight (Ed.), Mechanics of Residual Soils, Rotterdam: Balkema, pp.155-220.

BRESSANI, L.A., HORN, M.R., BICA, A.V.D., GEHLING, W.Y.Y. (1997). Estudo da resistência ao cisalhamento de um solo residual de granito da região metropolitana de Porto Alegre. In: Simpósio Brasileiro de Solos Não Saturados, 3, ÑSAT97, Rio de Janeiro, Vol.1, pp. 199-206.

BRESSANI, L.A., HORN, M.R., BICA, A.V.D., GEHLING, W.Y.Y., KUNST, L.R. (1997). Field suction measurements in a residual soil slope. In: Panamerican Symposium on Landslides, 2, Rio de Janeiro: ABMS, Vol. 1., pp. 363-369.

BREWER, R. (1964). Fabric and mineral analysis of soils. J. Wiley and Sons, New York.

BROOKS, R. H. \& COREY, A. T. (1964). Hydraulic properties of porous media, Hydrology Paper, 3, Colo. State Univ., Fort Collins, pp. 1-27.

BROOKS, R.H. \& COREY, A.T. (1968). Properties of porous media affecting fluid flow. Journal Irrig. Drain. Division American. Society Civil Engineering, 92 (IR2): 61-66. 
BRUAND, A. \& PROST.R. (1987). Effect of water content on the fabric of a soil material: an experimental approach. European Journal of Soil Science, Vol. 38, Issue 3 , pp. 461-472.

BUJAK, M. (1967). Preventive measures against the rock slide at Tresna dam site. In: Congress on Large Dams, $9^{\text {th }}$, Proceedings...Istambul: 1027-1033.

BURDINE, N. T. (1953). Relative permeability calculations from pore size distribution data, Trans. Am. Inst. Min. Metall. Pet. Eng., 198, pp. 71-78.

BURLAND, J. B. (1965) Some aspects of the mechanical behaviour of partly saturated soils. In: Conference on Moisture Equilibria and Moisture Changes in Soil Beneath Covered Areas, Proceedings...Sidney, Australia, pp. 270-278.

CAMAPUM DE CARVALHO, J. (1985). Etude du comportament mécanique d'une marne compactée. Tese de Doutoramento, Institut National des Sciences Appliquées, França, 181p.

CAMPOS, J.L.E., VARGAS JR., E.A., DE CAMPOS, T.M.P. (1992). Avaliação de campo da permeabilidade saturada/não saturada de solos em encostas. In: COBRAE, 1, Rio de Janeiro: ABMS/ABGE, Vol. I, pp. 371-382.

CANCINO CALLE, J. A. (2000). Análise de ruptura de talude em solo não saturado. Dissertação de Mestrado, EESC-USP, São Carlos, 128p. + anexos.

CANIL, K., MACEDO, E.S., GRAMANI, M.F., ALMEIDA FILHO, G.S., YOSHIKAWA, N. K., MIRANDOLA, F.A, VIEIRA, B.C., BAIDA, L.M.A., AUGUSTO FILHO, O, SHINOHARA, E.J. (2004). Mapeamento de risco em assentamentos precários nas zonas sul e parte da oeste no município de São Paulo (SP). In: Simpósio Brasileiro de Cartografia Geotécnica e Geoambiental, 5, São Carlos. Anais...São Paulo: ABGE, pp.193-204.

CARSEL, R. F. \& R. S. PARRISH. (1988). Developing joint probability distributions of soil water retention characteristics. Water Research Resource, (24): 755-769.

CARVALHO, C. S. (1996). Gerenciamento de riscos geotécnicos em encostas urbanas: uma proposta baseada na análise de decisão. (Tese de Doutoramento), Escola Politécnica da Universidade de São Paulo, São Paulo, 192p. 
CARVALHO, J. B. Q. \& SIMMONS, J. V. (1997). Mineralogy and microstructure. In: G. E. Blight (Ed.), Mechanics of Residual Soils, Rotterdam: Balkema, pp. 31-40.

CARVALHO, J. B. Q. (1981). Study of the microstructure of lateritic soils using scanning electron microscope. In: International Seminar on Lateritization Processes, Proceedings...São Paulo I: 563-568.

CARVALHO, J. B. Q. (1985). Effects of deferation and removal of amorphous silica and alumina on selected properties of Brazilian lateritic soils. In: International Seminar on Laterite, Proceedings...Tokyo II: 559-567.

CARVALHO, J. B. Q. (1991). Microstructure of concretionary lateritic soils. In: Pan American Conference of Soil Mechanics and Foundation Engineering, $9^{\text {th }}$, Proceedings...I: 117-128.

CERRI, L.E.S., ZAINE, J.E., SILVA, V.C.R., SILVA, L.C.R., NÉRI, A.C., BARBOSA, T.T.A., PAULA, J.P.L., SCARANCE, M.R.A.P., SILVA, D.M.B. (2004). Mapeamento de risco em áreas de ocupação precária nas zonas norte, leste e oeste do município de São Paulo (SP). In: Simpósio Brasileiro de Cartografia Geotécnica e Geoambiental, 5, São Carlos. Anais...São Carlos: ABGE, pp.115-122.

CHANDLER, R. J., CRILLY, M. S., MONTGOMERY-SMITH, G. (1992). A low-cost method of assessing clay desiccation for low-rise buildings. Proc. of the Institute of Civil Engineering, 92, n.2, pp. 82-89.

CLEMENTINO, R.V \& LACERDA, W.A. (1992). Resistência ao cisalhamento dos solos residuais e coluvionares de granito do escorregamento da rua Licurgo, RJ. In: COBRAE, 1, Rio de Janeiro: ABMS/ABGE, Vol. II, pp. 463-478.

COLLINS, K. (1985). Towards characterization of tropical soil microstructure. In: International Conference on Geomechanics in Tropical Lateritic and Saprolitic Soils, $1^{\text {st }}$, Proceedings...Brasilia 1: 85-96.

COSTA NUNES, A. J. (1969). Landslides in soils of decomposed rock due to intense rainstorms. In: International Conference on Soil Mechanics and Foundation Engineering, $7^{\text {th }}$, Proceedings...Mexico 2: 547-554. 
COWLAND, J. M. \& CARBRAU, A. M. (1988). Three cut slope failures on relict discontinuities in saprolitic soils. In: International Conference on Geomechanics in Tropical Soils, $2^{\text {nd }}$, Proceedings... Singapore 1: 253-258.

DA ROCHA, J.C.S., ANTUNES, F.S., ANDRADE, M.H.N. (1992). Caracterização geológicageotécnica preliminar dos materiais envolvidos nos escorregamentos da vista chinesa. In: COBRAE, 1, Rio de Janeiro: ABMS/ABGE, Vol. II, pp. 491-502.

DANE, J. H. \& G. C. TOPP, (2002). Methods of soil snalysis, Part 4 - Physical methods. Soil Science Society of America, Madison, WI.

DANIELS, D.J., GUNTON, D.J., SCOTT, H.F. (1988). Introduction to subsurface radar. IEE Proceedings, vol. 135, part. F, n.4, Sp. Issue, pp. 277-388.

DANIELS, J.J. (1988). Locating caves, tunnels and mines. Geophysics: The Leading Edge of Exploration, pp. 32-38.

DANNOWSKI, G. \& YARAMANCI, U. (1999). Estimation of water content and porosity using combined radar and geoelectrical measurements. European Journal Environ. Geophys., 4:71-85.

DAVIS, J. L. \& ANNAN, A. P. (1977). Electromagnetic detection of soil moisture: progress report 1. Canadian Journal Remote Sensing, vol.3, n.1, pp. 76-86.

DAVIS, J. L. \& ANNAN, A. P. (1986). High resolution sounding using ground probing radar. Geoscience of Canada, vol.13, n.3, pp. 205-208.

DAVIS, J. L. \& ANNAN, A. P. (1988). Applications of ground penetrating radar to mining, groundwater and geotechnical projects: Selected case histories. In: Worshop on Ground Probing Radar, Ontario: Geological Survey of Canada, paper 90-4, pp. 49-55.

DAVIS, J. L. \& ANNAN, A. P. (1989). Ground penetrating radar for high resolution mapping of soil and rock stratigraphy. Geophysical Prospecting, European Association of Geoscientists \& Engineers, (37): 531-551.

DAVIS, J. L. \& ANNAN, A. P. (2002). Ground penetrating radar to measure soil water content”, In: Dane, J.H. \& Topp, G.C. (ed.) Methods of soil analysis. Part 4. SSSA Book Ser. 5. SSSA, Madison WI. 
DAVIS, J. L., ANNAN, A. P., VAUGHAN, C.J. (1984). Placer exploration using radar and seismic methods. In:International Congress of Society of Exploration Geophysical, 54, Atlanta. Expanded Abstracts..., Atlanta: SEG, pp. 67-72.

DE CAMPOS, T. M. P., CARRILO, C., TIBANA, S., AGUILAR, S. S. (1992). Determinação da curva característica de sucção em laboratório. COBRAE, $1^{a}$, Rio de Janeiro, pp. 835-851.

DE CAMPOS, T.M.P. \& CARRILLO, C.W. (1995). Direct shear testing on an unsaturated soil from Rio de Janeiro. In: International Conference on Unsaturated Soils, 1, Paris, Balkema, Vol.1, pp. 31-38.

DE CAMPOS, T.M.P. (1997). Resistência ao cisalhamento de solos não-saturados. In: Simpósio Brasileiro de Solos Não Saturados, 3, ÑSAT97, Rio de Janeiro, Vol.2, 399-417.

DE CAMPOS, T.M.P., VARGAS JR., E.A., EISENSTEIN, Z. (1992). Considerações sobre processos de instabilização de encostas em solos não saturados na cidade do Rio de Janeiro. In: COBRAE, 1, Rio de Janeiro: ABMS/ABGE, Vol. II, pp. 741-757.

DEBYE, P. (1929). Polar molecules. Dover Public., Mineola, New York.

DECAGON DEVICES (2005). Mini disk infiltrometer. User’s Manual - version 1.4, 16p.

DEERE, D. V. \& PATTON, F. D. (1971). Slope stability in residual soils. In: Pan American Conference on Soil Mechanics and Foundation Engineering, $4^{\text {th }}$, Proceedings...Puerto Rico 1: 87-170.

DEHAINI, J. (2001). Detecção da pluma de contaminação de hidrocarbonetos em subsuperfície pelo método de radar de penetração. Tese de Doutorado, Instituto de Geociências/USP, São Paulo, 100p.

DELVIGNE, J. E. (1998). Atlas of micromorphology of mineral alteration and weathering. The Canadian mineralogist, Ontario: Mineralogical Association of Canada, Special publication, (15):3, 494p.

Departamento de Águas e Energia Elétrica - D.A.E.E. (2004). Sistema de informações para gerenciamento de recursos hídricos do Estado de São Paulo. São Paulo: FCTH, CD-ROM. 
DIX, H. C. (1955). Seismic velocities from surface measurements. Geophysics, 20:68-86.

DOBSON, M.C., ULABY, F.T., HALLIKAINEN, M.T., EL-RAYES, M.A. (1985). Microwave dielectric behaviour of wet soil. Part II. Dielectric mixing models. IEEE Tranp. Geoscience Remote Sensing, 23:35-46.

DU, S. (1996). Determination of water content in the subsurface with the ground wave of ground penetrating radar. Ph.D. Thesis. Ludwig-Maximilians-Universitat, Munich, Germany.

DU, S., BERKTOLD, A., RUMMEL, P. (1994). The wave nature and propagation characteristics of the ground wave in GPR. In: Symposium for Electromagnetic Depth Exploration, Odenwald. Proceedings..., Odenwald, pp. 480-487.

DURNER, W. (1994). Hydraulic conductivity estimation for soils with heterogeneous pore structure. Water Resources Research, 30(2): 211-223.

ELBACHÁ, A.T., DE CAMPOS, L.E.P., BAHIA, R.F.C. (1992). Tentativa de correlação entre precipitação e deslizamentos na cidade de Salvador. In: COBRAE, 1, Rio de Janeiro: ABMS/ABGE, Vol. II, pp. 647-656.

ENDRES, A.L, CLEMENT, W.P., RUDOLPH, D.L. (2000). Ground penetrating radar imaging of an aquifer during a pumping test. Ground Water Journal, 38:566-576.

ESCARIO, V. \& JUCA, J. F. T. (1989). Strength and deformation of partly saturated soils. In: International Conference on Soil Mechanics and Foundation Engineering, $12^{\text {th }}$, Proceedings...Brookfield, MA, vol.3, pp. 43-46.

ESCARIO, V. \& SAEZ, J. (1986). The shear strength of partly saturated soils. Géotechnique, 36 (3): 453-456.

ESCARIO, V. (1988). Formulationes para la definitión de la resistencia a esfuerzo cortante de los suelos parcialmente saturados. Ingenieria Civil n.68, CEDES.

FEIJÓ, R.L., PAES, N.M., D’ORSI, R.N. (2001). Chuvas e movimentos de massa no município do Rio de Janeiro. In: COBRAE, III, Rio de Janeiro, pp. 223-230. 
FENNER, T. J. \& VENDI, M. A. (1992). Ground penetrating radar for hazardous waste site investigations. In: International Conference on Construction on Polluted and Marginal Land, 2, Proceedings..., pp. 107-114.

FERRÉ, P.A., RUDOLPH, D.L. KACHANOSKI, R.G. (1996). Spatial averaging of water content by time domain reflectometry: implications for twin rod probes with and without dielectric coatings. Water Resource Research. 32:271-279.

FERRÉ, P.A., VON GLINSKI, G., FERRÉ, L.A. (2003). Monitoring the maximum depth of drainage in response to pumping using borehole ground penetrating radar. Vadose Zone Journal. 2:511-518.

FERREIRA, C. J. (2004). Diretrizes para a regeneração sócio-ambiental de áreas degradadas por mineração de saibro (caixas de empréstimo), Ubatuba (SP), Relatório Técnico (Processo Fapesp $n^{o}$.03/07182-5).

FERREIRA, S.R.M \& LIMA, A.F. (2005). Influência da variação da frente de umedecimento na análise da estabilidade da encosta do Alto do Reservatório no Recife. In: $C O B R A E$, 4, Salvador: ABMS, Vol. II, pp. 583-589.

FLACCUS, E. (1959). Landslides and their revegetation in the white montains of a New Hampshire. PhD Thesis, Duke University, Durham, North Carolina, USA.

FONSECA, A.P., LACERDA, W.A., FUTAI, M.M., AGUIAR, V.N. (2005). Influência do teor de mica na resistência ao cisalhamento residual em taludes de solos saprolíticos de gnaisse. In: COBRAE, 4, Salvador: ABMS, Vol. I, pp. 205-212.

FREDLUND, D. G. \& MORGENSTERN, N. R. (1977). Stress state variables for unsaturated soils. Journal of the Geotechnical Engineering Division, ASCE, 103 (GT5): 447-466.

FREDLUND, D. G. \& RAHARDJO, H. (1993). Soil mechanics for unsaturated soils. New York: John Wiley \& Sons, INC.

FREDLUND, D. G. \& XING, A. (1994). Equations for the soil water characteristics curve. Canadian Geotechnical Journal, 31(4): 521-532. 
FREDLUND, D. G. (1995). The scope of unsaturated soil mechanics: an overview. Keynote Address, In: International Conference on Unsaturated Soils, $1^{\text {st }}$, Paris, France, vol.3.

FREDLUND, D. G., MONGENSTERN, N. R., WIDGER, R. A. (1978). The shear strength of unsaturated soils. Canadian Geotechnical Journal 15(3): 313-321.

FREDLUND, D. G., VANAPALLI, S. K., XING, A., PUFAHL, D. E. (1995). Predicting the shear strength function for unsaturated soils using the soil-water characteristic curve. In: International Conference on Unsaturated Soil, 1, Proceedings...Paris, Alonso \& Delage (eds.), v.1, pp. 63-69.

FREDLUND, D. G., XING, A., FREDLUND, M. D., BARBOUR, S. L. (1996). The relationship of the unsaturated soil shear strength to the soil-water characteristic curve. Canadian Geotechnical Journal, 33 (3): 440-448.

FREDLUND, D. G., XING, A., HUANG, S. (1994). Predicting the permeability function for unsaturated soils using the soil-water characteristic curve. Canadian Geotechnical Journal, 31: 533-546.

FRIEDMAN, S.P. (1998). A saturation degree-dependent composite spheres model for describing the effective dielectric constant of unsaturated porous media. Water Resource Research. 34:2949-2961.

FROTA, C.A., LIMA, M.C., GUIMARÃES, E.M., CARVALHO, J.C., PEREIRA, J.H.F. (2001). Study of the mineralogical and physical properties of tropical soils in gullies. In: COBRAE, III, Rio de Janeiro, pp. 151-158.

FUNDUNESP-Fundação para o Desenvolvimento da Unesp (2003). Mapeamento de risco associado a áreas de encosta e margens de córregos nas favelas do município de São Paulo. Relatório Final. Unesp/IGCE/DGA, Rio Claro, 78p.

FUTAI, M.M., ALMEIDA, M.S.S., LACERDA, W.A. (2004). Yield, Strength and critical state conditions of a tropical saturated soil. Journal of Geotechnical and Geoenvironmental Engineering, 130 (11): 1169-1179. 
GALAGEDARA, L.W., PARKIN, G.W., REDMAN, J.D. (2003). An analysis of the ground penetrating radar direct ground wave method for soil water content measurement. Hydrological Processes, John Wiley \& Sons, (17):3615-3628.

GALAGEDARA, L.W., PARKIN, G.W., REDMAN, J.D., ENDRES, A.L. (2002). Temporal and spatial variation of soil water content measured by borehole GPR under irrigation and drainage. Proceedings of the Ninth Conference on Ground Penetrating Radar. Proc. SPIE 4758:180-185.

GAN, J.K.M. \& FREDLUND, D.G. (1988). Multistage direct shear testing of unsaturated soils. Geotechnical Testing Journal, 11 (2): 132-138.

GANDOLFO, O.C.B. (2003). Aplicações de GPR no Brasil: potencialidade e limitações a partir de casos estudados. In: Prado, R.L.; Gandolfo, O.C.B.; Souza, L.A.P. (Orgs.). Workshop de Geofísica Aplicada à Engenharia e Meio Ambiente, 3º São Paulo: SBGf, pp. 35-48.

GARAMBOIS, S., SENECHAL, P., PERROUD, H. (2002). On the use of combined geophysical methods to assess water content and water conductivity of near-surface formations. Journal Hidrology, 259:32-48.

GARDNER, W.R. (1958). Some steady state solutions of the unsaturated moisture flow equation with application to evaporation from a water table. Soil Science, 85: 228-232.

GARGA, V. K. \& BLIGHT, G. E. (1997). Permeability. In: G. E. Blight (Ed.), Mechanics of Residual Soils, Rotterdam: Balkema, pp.79-94.

GERSCOVICH, D.M.S. \& GUEDES, M.N. (2004). Avaliação das relações de condutividade hidráulica em solos brasileiros não saturados. In: Simpósio Brasileiro de Solos Não Saturados, 5, São Carlos, Vol.1, pp. 249-254.

GERSCOVICH, D.M.S., SAYÃO, A.S.F.J. (2002). Evaluation of the soil-water characteristic curve equations for soils from Brazil. In: Third International Conference on Unsaturated Soils UNSAT2002, Recife. Unsaturated Soils. Holanda: A.A. Balkema, vol. 1, pp. 295-300.

GERSCOVICH, D.M.S., VARGAS JR., E.A., DE CAMPOS, T.M.P. (2006). On the evaluation of unsaturated flow in a natural slope in Rio de Janeiro, Brazil. Engineering Geology, (88):23-40 
GILSON, E.W., REDMAN, J.D., PILON, J., ANNAN, A.P. (1996). Near surface applications of borehole radar. In: Proceedings of the SAGEEP'96, Keystone, CO. Envoron. Eng. And Geophys. Society, pp. 545-553.

GOBBI, F., BERNARDES, J.A., BICA, A.V.D., BRESSANI, L.A., FLORES, J.A.A., AZAMBUJA, E. (2005). Estudo da resistência ao cisalhamento do solo residual de gnaisse de Porto Alegre. In: COBRAE, 4, Salvador: ABMS, Vol. I, pp. 173-181.

GREAVES, R. J., LESMES, D. P., LEE, J. M., TOKSOZ, M. N. (1996). Velocity variations and water content estimated from multi-offset, ground penetrating radar. Geophysics, Society of Exploration Geophysicists, 61(3): 683-695.

GREENHOUSE, J., GUDJURGIS, P., SLAINE, D. (1995). Applications of surface geophysics to environmental investigations. Reference Notes for an EEGS Short Course, 173p.

GREENWAY, , D.R., ANDERSON, M.G., BRIAN-BOYS, K.L. (1984). Influence of vegetation on slope stability in Hong-Kong. In: International Symposium of Landslides, 4, Toronto, Canadá, Vol.1, pp. 399-409.

GROTE, K., HUBBARD, S. S, RUBIN, Y. (2002). GPR monitoring of volumetric water content in soils applied to highway construction and maintenance. Leading Edge Explor., 21:482-485.

GROTE, K., HUBBARD, S. S, RUBIN, Y. (2003). Field-scale estimation of volumetric water content using GPR ground wave techniques. Water Resouces Research, v.39, n.11, 1321.

GUSMÃO FILHO, J.A., ALHEIROS, M.M., GUSMÃO, A.D. (1997). Estudo das encostas ocupadas do recife. In: $2^{\text {nd }}$ Pan-American Symposium on landslides, $2^{\text {nd }}$ COBRAE, Rio de Janeiro, Vol.2, pp. 919-927.

HACK, R. (2000). Geophysics for slope stability. Surveys in Geophysics, (21): 423-448.

HAMMON, W.S., ZENG, X., CORBEANU, R.M., McMECHAN, G.A. (2003). Estimation of the spatial distribution of fluid permeability from surface and tomographic GPR data and core, with a 2-D example from the Ferron Sandstone. Utah. Geophysics, 67:1505-1515.

HASTED, J.B. (1973). Aqueous dielectrics. Chapman and Hall, London. 
HEAD, K.H. (1986). Manual of Soil Laboratory Testing. vol. 1, 2 e 3, Pentech Press, London, UK.

HERKELRATH, W.N., HAMBURG, S.P., MURPHY, F. (1991). Automatic, real-time monitoring of soil moisture in a remote field area with time domain reflectrometry. Water Resource Research. 27:857-864.

HILF, J.W. (1956). An investigation of pore pressure in cohesive soils. US Bureau of Reclamation, Technical Memorandum. $\mathrm{N}^{0} 654$.

HOWATT, M. D. \& CATER, R. W. (1985). Passive strength of completely weathered granite. In: International Conference on Geomechanics in Tropical, Lateritic and Saprolitic Soils, $1^{\text {st }}$, Proceedings...Brasilia 2: 371-379.

HOWATT, M. D. (1988). The in situ strength of saturated decomposed granite. In: International Conference on Geomechanics in Tropical Soils, $2^{\text {nd }}$, Proceedings... Singapore 1: 311-316.

HUBBARD, S. S., GROTE, K., RUBIN, Y. (2002). Mapping the volumetric soil water content of a California vineyard using high-frequency GPR ground wave data. Leading Edge Exploration, (21):552-559.

HUBBARD, S. S., PETERSON, J.E., MAJER, E.L., ZAWISLANSKI, P.T., WILLIAMS, K.H., ROBERTS, J., WOBBER, F. (1997). Estimation of permeable pathways and water content using tomographic radar data. Leading Edge Exploration, (16):1623-1630.

HUISMAN, J. A. \& BOUTEN, W. (2003). Accuracy and reproducibility of measuring soil water content with the ground wave of ground penetrating radar. Journal Environ. Eng. Geophysics 8: 65-73.

HUISMAN, J. A., HUBBARD, S. S., REDMAN, J. D., ANNAN, A. P. (2003). Measuring soil water content with ground penetrating radar: A review. Vadose Zone Journal, Soil Science Society of America, (2):476-491. 
HUISMAN, J. A., SNEPVANGERS, J. J. J. C., BOUTEN, W., HEUVELINK, G. B. M. (2002). Mapping spatial variation in surface soil water content: comparison of ground penetrating radar and time domain reflectometry. Journal of Hydrology (Amsterdam), Elsevier, (269): 194-207.

HUISMAN, J. A., SPERL, C., BOUTEN, W., VERSTRATEN, J. M. (2001). Soil water content measurements at different scales: accuracy of time domain reflectometry and ground penetrating radar. Journal of Hydrology (Amsterdam), Elsevier, (245): 48-58.

IG/SMA - IPT/SCTDE (1992). Carta geotécnica do município de Ubatuba - SP. São Paulo, 2v. + anexos.

IRFAN, T. Y. \& WOODS, N. W. (1988). The influence of relict discontinuities on slope stability in saprolitic soils. In: International Conference on Geomechanics in Tropical Soils, $2^{\text {nd }}$, Proceedings...Singapure 1:267-276.

JENNINGS, J. E. B. \& BURLAND, J. B. (1962). Limitations to the use of effective stress in partly saturated soils. Géotechnique, 12 (2): 125-144.

JOL, H. M. (1995). Ground penetrating radar antennae frequencies and transmitter powers compared for penetration deph, resolution and reflection continuity. Geophysical Prospecting, 43(5): 693-709.

JONES, S.B. \& FRIEDMAN, S.P. (2000). Particle shape effect on the effective permittivity of anisotropic or isotropic media consisting of aligned or randomly oriented ellipsoidal particles. Water Resource Research. 36:2821-2833.

KIEHL, E. J. (1979). Manual de edafologia: relações solo-planta. São Paulo: Ceres, 262 p.

KIM, J.; JEONG, S.; PARK, S.; SHARMA, J. (2004). Influence of rainfall-induced wetting on the stability of slopes in weathered soils. Engineering Geology, (75):251-262

KLEIN, V. A., LIBARDI, P. L. (2002). Condutividade hidráulica de um Latossolo Roxo, não saturado, sob diferentes sistemas de uso e manejo. Ciência Rural, Santa Maria, vol. 32, n. 6, pp. 945-953. 
KNOLL, M.D. \& CLEMENT, W.P. (1999). Vertical radar profiling to determine dielectric constant, water content and porosity values at well locations. In: Proceedings of the SAGEEP'99, Oakland, CA. Environ. Eng. And Geophys. Society, pp. 821-830.

LACERDA, W.A. \& LOPES, F.R. (1992). Características geotécnicas de um perfil de alteração na crista de uma encosta gnáissica do maciço do Corcovado, RJ. In: COBRAE, 1, Rio de Janeiro: ABMS/ABGE, Vol. II, pp. 433-443.

LACERDA, W.A. \& SILVEIRA, G.C. (1992). Características de resistência ao cisalhamento e de compressibilidade dos solos residuais e coluvionares da encosta do Soberbo, RJ. In: COBRAE, 1, Rio de Janeiro: ABMS/ABGE, Vol. II, pp. 445-461.

LANZ, E. et al. (1994). Integrated studies of swiss waste disposal sites: results from georadar ond other geophysical surveys. In: International Conference on Ground Penetrating Radar, 5, Ontario. Proceedings..., Ontario: GPR’94, vol.3, pp. 1261-1274.

LEDIEU, J., DE RIDDER, P., DE CLERCK, P., DAUTREBANDE, S. (1986). A method of measuring soil moisture by time domain reflectometry. Journal Hidrology. 88:319-328.

LESMES, D.P., HERBSTZUBER, R., WERTZ, D. (1999). Terrain permittivity mapping: GPR measurements of near-surface soil moisture. In: Proceedings SAGEEP'99, Oakland, CA. Environ. Eng. And Geophys. Society, Denver, CO, pp. 575-582.

LI, A.G.; YUE, Z.Q.; THAM, L.G.; LEE, C.F.; LAW, K.T. (2005). Field-monitored variations of soil moisture and matric suction in a saprolite slope. Canadian Geotechnical Journal, (42):13-26.

LIM, T. T., RAHARDJO, H., CHANGE, M. F. (1996). Climatic effects on negative pore-water pressures in a residual soil slope. In: International Conference on Tropical Soils, $4^{\text {th }}$, Proceedings...Kuala Lumpur, Malaysia 1: 568-574.

LINER, C. L. \& LINER, J. L. (1995). Ground penetrating radar: a near face experience from Washington country, Arkansas. The Leading Edge, 14(1): 17-21.

LO, K. W., LEUNG, C. F., HAYATA, K., LEE, S. L. (1988). Stability of excavated slopes in the weathered Jurong. In: International Conference on Geomechanics in Tropical Soils, $2^{\text {nd }}$, Proceedings...Singapore 1: 227-285. 
LOPES, M.B.L., DE CAMPOS, T.M.P., ANTUNES, F.S., VILLAR, L.F.S. (2007). Influência da sucção na resistência ao cisalhamento de um solo residual de filito da região metropolitana de Belo Horizonte (MG). In: VI Simpósio Brasileiro de Solos Não Saturados, NSAT2007, Salvador: EDUFBA, pp. 433-440.

LUMB, P. (1962). The properties of decomposed granite. Géotechnique 12(2): 226-243.

LUMB, P. (1975). Slope failures in Hong Kong. Quarterly Journal of Engineering Geology 8: 31-65.

LUNT, I. A., HUBBARD, S. S., RUBIN, Y. (2004). Soil moisture content estimation using ground penetrating radar reflection data. Journal of Hydrology (Amsterdam), Elsevier, xx:1-16.

LUXMOORE, R. J. (1981). Micro, meso and macroporosity of soil. Soil Science Society American Journal, Madison, v. 45, pp. 671-672.

MACEDO, E.S., CANIL, K., GRAMANI, M.F., ALMEIDA FILHO, G.S., YOSHIKAWA, N. K., MIRANDOLA, F.A., VIEIRA, B.C., BAIDA, L.M.A., AUGUSTO FILHO, O, SHINOHARA, E.J. (2004a). Mapeamento de áreas de risco de escorregamentos e solapamento de margens no município de São Paulo - SP: o exemplo da Favela Serra Pelada, Subprefeitura Butantã. In: Simpósio Brasileiro de Desastres Naturais, 1, Florianópolis. Anais...Florianópolis: GEDN/UFSC, CD-ROM, pp. 59-72.

MACEDO, E.S., OGURA, A.T., CANIL, K., ALMEIDA FILHO, G.S, GRAMANI, M.F., SILVA, F.C., CORSI, A.C., MIRANDOLA, F.A. (2004b). Modelos de fichas descritivas para áreas de risco de escorregamento, inundação e erosão. In: Simpósio Brasileiro de Desastres Naturais, 1, Florianópolis. Anais...Florianópolis: GEDN/UFSC, CD-ROM, pp. 892-907.

MACHADO, S. L. \& VILAR, O. M. (1998). Resistência ao cisalhamento de solos não saturados: ensaios de laboratório e determinação expedita. Solos \& Rochas, 2 (21): 65-78.

MACHADO, S.L. (1995). Estudo da compressão confinada e do colapso de um solo arenoso compactado em edômetro com sucção controlada. Dissertação (Mestrado). Escola de Engenharia de São Carlos, Universidade de São Paulo, EESC-USP, 157p. 
MACHADO, S.L., BOTELHO, M.A.B., AMPARO, N.S., DOURADO, T.C. (2004a). Utilização do radar de penetração do solo, GPR, para medidas de teores de água no solo. In: Simpósio Brasileiro de solos não saturados, 5, São Carlos, Vol. 1.

MACHADO, S.L., CARVALHO, M.F., MATTA, B.M. (2004b). Utilização do permeâmetro Guelph para estudo da condutividade hidráulica de solos residuais de granulito na cidade de Salvador-BA. In: Simpósio Brasileiro de Solos Não Saturados, 5, São Carlos, Vol.1, pp. 255-261.

MACHADO, S.L., DOURADO, T.C., AMPARO, N.S. (2005). The use of the Ground Penetrating Radar, GPR, as a non intrusive method to measuring soil water content. In: EXPERUS-2005, Trento. Advanced Experimental Unsaturated Soil Mechanics, Vol. 1.

MAEKAWA, S. \& FENNER, T. J. (1994). Study of cavity depth estimation behind concrete tunnel lining using GPR. In: International Conference on Ground Penetrating Radar, 5, Proceedings...Ontario: GPR’94, vol.3, pp. 895-906.

MALAGUTTI FILHO, W. et al. (1997). Aplicação integrada de técnicas geofísicas no aterro sanitário de Rio Claro - SP: resultados preliminares. In: Congresso Internacional da Sociedade Brasileira de Geofísica, 5, São Paulo. Resumos Expandidos..., São Paulo: SBGf, vol.1, pp. 422425.

MALONE, A. W. \& SHELTON, J. C. (1982). Landslides in Hong Kong 1978-1980. Enginnering and construction in tropical residual soils, ASCE, Geotechnical Division Special Conference, Honolulu, Hawaii: 424-442.

MARCHIORI-FARIA, D.G., GUEDES, A.C.M., FERREIRA, C.J., ROSSINI-PENTEADO, D., ARMANI, G., SANTORO, J., TOMINAGA, L.K., PRESSINOTTI, M.M.N., BROLLO, M.J., VEDOVELLO, R., MENDES, R.M. (2005). Mapeamento de áreas de risco a escorregamento e inundação - Termo de Cooperação Técnica IG-CEDEC - Relatório Técnico do Município de Ubatuba (SP), 16 p. + anexos.

MARINHO, F. A. M. \& OLIVEIRA, O. M. (2006). The filter paper method revisited. Geotechnical Testing Journal, ASTM, 29 (3): 250-258. 
MARINHO, F. A. M. (1994). Medição de sucção com o método do papel filtro. COBRAMSEF, $10^{\circ}$, Foz do Iguaçu, vol.2, pp. 515-522.

MARINHO, F. A. M. (1995). A técnica do papel filtro para a medição de sucção. Encontro sobre Solos Não Saturados, Porto Alegre, RS, pp. 112-125.

MARINHO, F.A.M. (1997). Medição de sucção em solos. In: Simpósio Brasileiro de Solos Não Saturados, 3, ÑSAT97, Rio de Janeiro, pp. 373-397.

MARTINEZ, G.S.S., FLORES, J.A.A., QUEIROZ DE CARVALHO, J.B. (2004). Propriedades mineralógicas e químicas de solos residuais tropicais e relações com propriedades geotécnicas selecionadas. In: Simpósio Brasileiro de Solos Não Saturados, 5, São Carlos, Vol.1, pp. 459-464.

MATHIAS, E. L. \& RADHAKRISHNA, H. S. (1968). Volume change characteristics of partially saturated soils. Géotechnique, 18 (4): 432-448.

MENDES, R.M., FUNARI, A.H., MARINHO, F.A.M. (2007). Avaliação do sensor de matriz granular (GMS) para medição de sucção. In: Simpósio Brasileiro de Solos Não Saturados, 6, ÑSAT07, Salvador-BA, volume único + CDROM, pp. 122-128.

MOLINARI, D.C. (2005). Infiltração de água e deslizamentos em encostas: o caso da Fazenda Caipuru - Presidente Figueiredo (Amazonas). In: COBRAE, 4, Salvador: ABMS, Vol. I, pp. 431441.

MORGENSTERN, N. R. \& DE MATOS, M. (1975). Stability of slopes in residual soils. In: Pan American Conference on Soil Mechanics and Foundation Engineering, $5^{\text {th }}$, Proceedings...Buenos Aires, Argentina 3: 369-384.

MUALEM, Y. (1976). A new model for predicting the hydraulic conductivity of unsaturated porous media, Water Resource Research, 12, pp. 513-522.

NAKASHIMA, Y., ZHOU, H., SATO, M. (2001). Estimation of groundwater level by GPR in an area with multiple ambiguous reflections. Journal Appl. Geophys., 47:241-249.

NASCIMENTO, C.T., KOIDE, S., PIRES, A.C.B. (1998). Análise geofísica, por meio de GPR, do espalhamento de efluente de fossa séptica no subsolo. In: Congresso Brasileiro de Águas Subterrâneas, 10, São Paulo. Resumos Expandidos..., São Paulo: SBG, Publicação Eletrônica, 9p. 
NUNES, V.M., ALLEMÃO, A.V.F., MIRANDA, J.C., CASTRO JR., E., COELHO NETTO, A.L. (1992). Sistemas radiculares e hidrologia de encostas florestadas: subsídios à análise de estabilidade. In: COBRAE, 1, Rio de Janeiro: ABMS/ABGE, Vol. III, pp. 781-797.

O'LOUGHLIN, C.L. (1974). A study of the tree root strength determination following clear felling. Canadian Journal Forest Resources, 4 (1): 10-13.

OBERG, A. L. \& SALLFORS, G. (1995). A rational approach to the determination of the shear strength parameters of unsaturated soils. In: International Conference on Unsaturated Soils, 1, Proceedings...Paris, Alonso \& Delage (eds.), v.1, pp. 151-158.

OLHOEFT, G. R. (1987). Electrical properties from $10^{-3}$ to $10^{+9} \mathrm{~Hz}$ : physics and chemistry. In: International Conference on Ground Penetrating Radar, 6, Sendai. Proceedings..., Sendai: GPR’96, pp. 1-3.

OLHOEFT, G. R. (1996). Application of ground penetrating radar. In: Proceedings Phys. Chem. Media II, 154:281-298.

OLIVEIRA, A. M. S. \& BRITO, S. N. A. (1998). Caracterização e classificação dos solos. In: Pastore, E.L. \& Fortes, R.M. Geologia de engenharia, São Paulo: ABGE, pp. 197-211.

OWEN, T. E. (1995). Ground penetrating radar. Journal of Applied Geophysics, vol.33, n.1-3, Special Iss., 225p.

PAIXÃO, M.S.G., PRADO, R.L. (2006). Estudo da aplicabilidade do método GPR para estimativa de teor de umidade em solos. Análise comparativa entre resultados obtidos em diferentes períodos pluviométricos. Revista Brasileira de Geofísica, vol. 24, pp. 1-10.

PAIXÃO, M.S.G., PRADO, R.L., DIOGO, L.A. (2004). Estimativas dos teores de umidade utilizando o GPR no modo multi-offset. Um estudo na cidade de São Paulo/SP. In: Simpósio de Geofísica, I, São Paulo. Anais-CDROM. Rio de Janeiro: Sociedade Brasileira de Geofísica.

PARKIN, G., REDMAN, D., VON BERTOLDI, P., ZHANG, Z. (2000). Measurement of soil water content below a wastewater trench using ground penetrating radar. Water Resource Research, 36:2147-2154. 
PETERSON, J.E. (2001). Pre-inversion corretions and analysis of radar tomographic data. Journal Environ. Eng. Geophys., 6:1-18.

PORSANI, J. L. \& RODRIGUES, A. R. (1995). O método GPR aplicado à caracterização de reservatórios: um exemplo na Bacia Potiguar - RN. In: Congresso Internacional da Sociedade Brasileira de Geofísica, 4, Rio de Janeiro. Resumos Expandidos..., Rio de Janeiro: SBGf, vol.2, pp. 843-845.

PORSANI, J. L. (1999). Ground penetrating radar (GPR): proposta metodológica de emprego em estudos geológico-geotécnicos nas regiões de Rio Claro - SP. Tese de Doutorado, Instituto de Geociências e Ciências Exatas/UNESP, Rio Claro, 145p.

PRADEL, D. \& RAAD, G. (1993). Effect of permeability on surficial stability of homogeneous slope. Journal of Geotechnical Engineering, ASCE 119(2): 315-332.

PRANDINI, F.L., GUIDICINI, G., BOTTURA, J.A., PONÇANO, W.L., SANTOS, A.R. (1976). Atuação da cobertura vegetal na estabilidade de encostas: uma resenha crítica. In: Congresso Brasileiro de Florestas Tropicais, 2, Mossoró (RN), pp. 1-22.

RAHARDJO, H; LEE, T.T.; LEONG, E.C. (2005). Response of a residual soil slope to rainfall. Canadian Geotechnical Journal, (42):340-351.

REDMAN, J.D., DAVIS, J.L., GALAGEDARA, L.W., PARKIN, G.W. (2002). Field studies of GPR air launched surface reflectivity measurements of soil water content In: Proceedings of the Ninth Conference on Ground Penetrating Radar, 4758:156-161.

REIS, R.M. \& VILAR, O.M. (2004). Resistência ao cisalhamento de dois solos residuais de gnaisse não saturados. In: Simpósio Brasileiro de Solos Não Saturados, 5, São Carlos, Vol.1, pp. 109-114.

RICHARDS, B. G. (1985). Geotechnical aspects of residual soils in Australia. In: Brand E. W. \& H. B. Phillipson (Eds), Sampling and Testing of Residual Soils, Hong Kong: Scorpion Press, pp. 23-30. 
RICHARDS, L. A. (1965). Physical conditions of water in soil. In: BLACK, C. A. (Ed.). Methods of soil analysis. Madison: American Society for Testing and Materials, pp. 128-152.

ROBILLARD, C. et al. (1994). Shallow bedrock profiling using GPR. In: International Conference on Ground Penetrating Radar, 5, Proceedings..., Ontario: GPR’94, pp. 1167-1179.

RODRIGUES, A. R. \& PORSANI, J. L. (1995). Aplicações do método GPR na geofísica ambiental: localização de área com tanque desenterrado e dutos. In: Congresso Internacional da Sociedade Brasileira de Geofísica, 4, Rio de Janeiro. Resumos Expandidos..., Rio de Janeiro: SBGf, vol.2, pp. 942-944.

RODRIGUES, A. R. \& PORSANI, J. L. (1997). Diferentes litologias, diferentes situações, diferentes respostas. A utilização do método GPR como ferramenta de suporte à geologia. In: Congresso Internacional da Sociedade Brasileira de Geofísica, 5, São Paulo. Resumos Expandidos..., São Paulo: SBGf, vol.1, pp. 540-543.

ROHM, S. A. (1992). Resistência ao cisalhamento de um solo arenoso laterizado não saturado da região de São Carlos-SP. Tese de Doutoramento, EESC-USP, São Carlos.

ROHM, S.A. \& VILAR, O.M. (1995). Shear strength of an unsaturated sandy soil. In: International Conference on Unsaturated Soils, 1, Paris, Balkema, Vol.1, pp. 189-193.

ROTH, K., SCHULIN, R., FLUHLER, H., ATTINGER, W. (1990). Calibration of time domain reflectrometry for water content measurement using a composite dielectric approach. Water Resource Research. 26:2267-2273.

ROWE, P. W. (1974). The importance of soil fabric and its relevance in engineering practice. Rankine Lecture, Géotecnique 24(3): 265-310.

RUCKER, D.F.\& FERRÉ, P.A. (2003). Near-surface water content estimation with borehole ground penetrating radar using critically refracted waves. Vadose Zone Journal, 2:247-252.

SANTOS, C. R. \& VILLAR, O. M. (2004a). Análise paramétrica da estabilidade de taludes em solos não saturados: a influência do tipo de solo. In: Simpósio Brasileiro de Solos Não Saturados, 5, São Carlos: SGS/EESC-USP, v.1, pp. 181-188. 
SANTOS, C. R. \& VILLAR, O. M. (2004b). Análise paramétrica da influência da condutividade hidráulica e da curva de retenção na infiltração e na estabilidade de taludes em solos não saturados. In: Simpósio Brasileiro de Solos Não Saturados, 5, São Carlos: SGS/EESC-USP, v.1, pp. 189-194.

SATO, M. \& VERSTEEG, R. (1998). Ground penetrating radar (GPR'96). Journal of Applied Geophysics, vol.40, n.1-3, Special Iss., 163p.

SAUCK, W.A., ALVES, J.G.V., LUIZ, J.G. (1995). Successful applications of GPR in the lower Amazon Region, Belém, Pará, Barzil. In: Congresso Internacional da Sociedade Brasileira de Geofísica, 4, Rio de Janeiro. Resumos Expandidos..., Rio de Janeiro: SBGf, vol.2, pp. 974-975.

SCAIFE, J. E. \& ANNAN, A. P. (1991). Ground penetrating radar: a powerful high resolution tool for mining engineering and environmental problems. Mississauga: Sensors \& Software, Inc., 24p. (Internal Report PEMD\#59). Available: http://www.sensoft.on.ca

SCAIFE, J. E. (1997). Geophysical techniques in urban areas. Environmental Geology of Urban Areas, Mississauga: Geological Association of Canada, pp. 439-443.

SCHILLING, G.H., LACERDA, W.A., BARROS, W.T. (1992). Instrumentação da encosta do Soberbo. In: COBRAE, 1, Rio de Janeiro: ABMS/ABGE, Vol. I, pp. 307-325.

SHAW, G. (1978). The search for dangerous dams. Smithsouiam, 9 (1): 36-45.

SIGURDSSON, T. (1994). Application of GPR for geological mapping, exploration of industrial mineralization and sulphide deposits. In: International Conference on Ground Penetrating Radar, 5, Ontario. Proceedings..., Ontario: GPR’94, pp. 941-955.

SILVEIRA, C.S., CORRÊA, R.S., JANSEN, R.C., BARBOSA, M.C., NETTO, A.L.C. (2001). Fluxos preferenciais em ambiente florestal: o papel dos sistemas radiculares - Parque Nacional da Tijuca/RJ. In: COBRAE, III, Rio de Janeiro, pp. 171-176.

SKEMPTON, A. W. (1953). The colloidal “Activity” of clays. In: International Conference on Soil Mechanics and Foundation Engineering, $3^{\text {th }}$, Proceeding...Zurich, pp.57-61. 
SMITH, D. G. \& JOL, H. M. (1995). Ground penetrating radar: antenna frequencies and maximum probable depths of penetration in quaternary sediments. Journal of Applied Geophysics, vol.33, pp. 93-100.

SOUSA NETO, J.B., LACERDA, W.A., COUTINHO, R.Q. (2001). Variabilidade nos parâmetros geotécnicos de alguns solos residuais brasileiros. In: COBRAE, III, Rio de Janeiro, pp. 305-315.

SPERL, C. (1999). Determination of spatial and temporal variations of the soil water content in na agro-ecosystem with ground penetrating radar. (in German) Ph.D. Thesis. Technische Universitat Munchen, Munich Germany.

STEWART, R.D. \& UNTERBERGER, R.R. (1976). Seeing throught rock salt with radar. Geophysics, vol.41. n.1, pp. 123-132.

STOFFREGEN, H., ZENKER, T., WESSOLEK, G. (2002). Accuracy of soil water content measurements using ground penetrating radar: comparasion of ground penetrating radar and lysimeter data. Journal Hydrology, 267:201-206.

SUÁREZ, J. (1997). La vegetación em la estabilización de deslizamientos. In: $2^{\text {nd }}$ Pan-American Symposium on landslides, $2^{\text {nd }}$ COBRAE, Rio de Janeiro, Vol.2, pp. 739-746.

TERZAGHI, K. (1936). A Fundamental fallacy of earth pressure computation. Boston Society of Civil Engineers, April.

TILLARD, S. \& DUBOIS, J.C. (1995). Analysis of GPR data: wave propagation velocity determination. Journal Applied Geophysical, 33:77-91.

TOLEDO, M. C. M., OLIVEIRA, S. M. B., MELFI, A. J. (2000). Intemperismo e formação do solo. In: TEIXEIRA, W. et al. (Orgs.), Decifrando a Terra, São Paulo: Oficina de Textos, pp. 140-166.

TOPP, G. C. \& DAVIS, J. L. (1985). Measurement of soil water content using time domain reflectometry (TDR). A field evaluation. Soil Science Society American Journal, vol. 49, pp. 1924. 
TOPP, G. C. (1987). The application of the time domain reflectometry (TDR) to soil water content measurement.

TOPP, G. C., DAVIS, J. L., ANNAN, A. P. (1980). Electromagnetic determination of soil water content: measurements in coaxial transmission line. Water Resource Research, vol. 16, n.3, pp. 574-582.

TSAPARAS, I.; RAHARDJO, H.; TOLL, D. G; LEONG, E.C. (2003). Infiltration characteristics of two instrumented residual soil slopes, Canadian Geotechnical Journal, (40):1012-1032

ULRYCH, T. J., DE LIMA, O. A. L., SAMPAIO, E. E. S. (1994). In search of plumes: a GPR odyssey in Brazil. In: International Congress of Society of Exploration Geophysical, 64, Los Angeles. Expanded Abstract..., Los Angeles: SEG, pp. 569-572.

VAN DAM, R.L., SCHLAGER, W., DEKKERS, M.J., HUISMAN, J.A. (2002). Iron oxides as a cause of GPR reflections. Geophysics. (67): 536-545.

VAN GENUCHTEN, M. Th. (1980). A closed-form equation for predictin the hydraulic conductivity of unsaturated soils. Soil Science Society of America Journal, vol. 44, pp. 892-898.

VAN OVERMEEREN, R. A. (1994). Georadar for hydrogeology. First Break, vol.12, n.8, pp.401-408.

VAN OVERMEEREN, R.A., SARIOWAN, S.V., GEHRELS, J.C. (1997). Ground penetrating radar for determining volumetric soil water content; results of comparative measurements at two sites. Journal Hidrology, 197:316-338.

VANAPALLI, D. G., FREDLUND, D. G., PUFAHL, D. E, CLIFTON, A. W. (1996). Model for the prediction of shear strength with respect to soil suction. Canadian Geotechnical Journal, vol. 23, pp. 379-392.

VANAPALLI, D. G., PUFAHL, D. E., FREDLUND, D. G. (1998). The effects of stress state on the soil-water characteristic behaviour of a compacted sandy-clay till. In: Canadian Geotechnical Conference, $51^{s t}$, Proceedings...Edmonton, pp. 87-94. 
VANAPALLI, S. K. \& FREDLUND, D. G. (2000). Comparison of different procedures to predict unsaturated soil shear strength. Advances in Unsaturated Geotechnics, GEODENVER, Denver, Colorado, pp. 195-209.

VANAPALLI, S.K. \& LOBBEZOO, J.P. (2002). A normalized function for predicting the coefficient of permeability of unsaturated soils. In: UNSAT2002, pp. 839-844.

VARGAS JR., E.A., COSTA FILHO, L.M., CAMPOS, L.E.P., OLIVEIRA, A.R.B. (1986). A study on the relationship between the stability of slopes in residual soils and rain intensity. In: International Symposium on Environmental Geotechnology, vol.1, pp. 491-501.

VARGAS JR., E.A., COSTA FILHO, L.M., DE CAMPOS, T.M.P. (1992). Análise de infiltração em solos de encostas no Rio de Janeiro e sua conseqüência na estabilidade. In: $C O B R A E$, 1, Rio de Janeiro: ABMS/ABGE, Vol. III, pp. 759-770.

VARGAS, M. \& PICHLER, E. (1957). Residual soil and rock slides in Santos, Brazil. In: International Conference of Soil Mechanics \& Foundation Engineering, $4^{\text {th }}$, Proceedings...London II: 394-398.

VARGAS, M. (1974). Engineering properties of residual soils from South-Central Region of Brazil. In: International Congress of the International Association of Engineering Geology, $2^{\text {nd }}$, Proceedings...Sao Paulo 1: 5.1-5.26.

VARGAS, M. (1988). Characterization and classification of tropical soil. In: International Conference on Geomechanics in Tropical Soils, $2^{\text {nd }}$, Proceedings...Singapure, Vol.1, pp. 71-75.

VARGAS, M. (1993). Solos porosos e colapsíveis. São Carlos: Departamento de Geotecnia/EESC-USP, 39p. Apostila.

VARGAS, M. (1999). Revisão histórico-conceitual dos escorregamentos da Serra do Mar. Revista Solos e Rochas, São Paulo, 22(1): 53-83.

VAUGHAN, C.J. (1986). Ground penetrating radar surveys used in archeological investigations. Geophysics, vol.51,n.3, pp. 595-604. 
VAUGHAN, P.R. (1988). Keynote paper: Characterising the mechanical properties of in situ residual soil. In: International Conference on Geomechanics in Tropical Soils, $2^{\text {nd }}$, Proceedings... Singapure 2: 469-487.

VAZ, L.F. (1996). Classificação genética dos solos e dos horizontes de alteração de rocha em regiões tropicais. Revista Solos e Rochas, São Paulo, 19(2), pp. 117-136.

VIEIRA, A.M. \& MARINHO, F.A.M. (2001). Variação sazonal de sucção em um talude de solo residual em São Paulo. In: COBRAE, 3, Rio de Janeiro: ABMS, pp. 287-295.

VILAR, O.M. (2006). A simplified procedure to estimate the shear strength envelope of unsaturated soils. Canadian Geotechnical Journal, 43 (10): 1088-1095.

WEILER, K.W., STEENHUIS, T.S., BOLL, J., KUNG, J.S. (1998). Comparison of ground penetrating radar and time domain reflectometry as soil soil water sensor. Soil Science Society of American Journal, 62:1237-1239.

WHEELER, S. J. \& SIVAKUMAR, V. (1992). Development and applications of a critical state model for unsaturated soil. In: Wroth Memorial Symposium on Predictive Soil Mechanics, Proceedings...Oxford, G.T Houlsby and A. N. Schofield, Eds., ASCE, New York.

WOLLE, C. M. \& CARVALHO, C. S. (1989). Deslizamentos em encostas na Serra do Mar Brasil. Revista Solos e Rochas, São Paulo, 12, (único): 27-36.

WOLLE, C. M. \& HACHICH, W. (1989). Rain-induced land-slides in Southern Brazil. In: International Conference on Soil Mechanics and Foundation Engineering, 12, Rio de Janeiro.

WOLLE, C. M. (1985). Peculiarities of “in situ” behavior of tropical soils: slope stability. Committee on tropical soils. In: International Conference on Geomechanics in Tropical Lateritic and Saprolitic Soils, $1^{\text {st }}$, Proceedings...Brasília.

WOLLE, C. M., GUIDICINI, G., ARAUJO, J. S., PEDROSA, A. (1978). A slide mechanism in the slopes of the Serra do Mar Southern Brazil. In: International Conference of Engineering Geology, 3, Madrid. Proceedings...., 14 pp.

WU, T. (1984). Effect of vegetation on slope stability. Transportation Research Record 965, Transportation Research Board, Washington, DC, 37-46p. 
WYSEURE, G.C.L., MOJID, M.A., MALIK, M.A. (1997). Measurement of volumetric water content by TDR in saline soils. European Journal Soil Science, 48:347-354.

YILMAZ, O. (1987). Seismic data processing. SEG Investigations in Geophysics 2. Society of Exploration Geophysicists, Tulsa, OK.

YONG, R. N., SIU, S. K. H., SCIADAS, N. (1982). Stability analysis of unsaturated soil slopes. Engineering and construction in tropical and residual soils, ASCE Geotechnical Division Special Conference, Honolulu, Hawaii: 483-499.

ZHANG, R. (1997). Determination of soil sorptivity and hydraulic conductivity from the disk infiltrometer. Soil Science Society American Journal, (61): 1024-1030.

ZIEMER, R.R. (1978). An apparatus to mesure the cross-cut shearing strenght of roots. Canadian Journal Forest Resources, 8 (1): 142-144.

ZIEMER, R.R. (1981). Roots and stability of forested slopes. Erosion and sedment transport in Pacific Rim Steeplands. Publication 132. International Association of Hidrological Science, London, 343-361p. 


\section{ANEXO}

MENDES, R.M., FUNARI, A.H., MARINHO, F.A.M. (2007). Avaliação do sensor de matriz granular (GMS) para medição de sucção. In: Simpósio Brasileiro de Solos Não Saturados, 6, ÑSAT07, Salvador-BA, volume único + CDROM, pp. 122-128. 


\title{
Avaliação do sensor de matriz granular (GMS) para medição de sucção
}

\author{
Rodolfo Moreda Mendes \\ Instituto Geológico-SMA, São Paulo, e-mail: rodolfommendes@ig.com.br \\ Fernando A. M. Marinho \\ Escola Politécnica/USP, São Paulo, e-mail: fmarinho@usp.br \\ André Hime Funari \\ Escola Politécnica/USP, São Paulo, e-mail: andfunari@hotmail.com
}

\begin{abstract}
Resumo: O presente trabalho apresenta resultados experimentais obtidos no laboratório de mecânica dos solos da EPUSP envolvendo: a saturação, a instalação, e do tempo de resposta dos sensores de matriz granular (GMS). O objetivo deste estudo é avaliar as vantagens e limitações do GMS para medição da sucção matricial do solo em condições de campo, para fins de engenharia. Nos estudos de laboratório foi utilizado um solo residual compactado proveniente de uma área de estudo situada no município de Ubatuba (SP). Os resultados indicaram que o processo de saturação tem pouca influência no comportamento do sensor. O instrumento apresentou um tempo de resposta muito lento quando comparado com o tensiômetro convencional. No entanto, considera-se que o seu uso pode fornecer dados importantes para estudos de movimentação de água nos solos quando cuidadosamente analisados.
\end{abstract}

\begin{abstract}
The present work presents experimental results from a laboratory investigation carried out at EPUSP involving: the saturation, the installation, and the response time of the granular matrix sensors (GMS). The objective of this study is to evaluate the advantages and limitations of the GMS for measurement of the matrix suction of the soil in the field conditions, for engineering purpose. The soil used for the experimental work was a compacted residual soil from an area located at the city of Ubatuba (SP). The results indicated that the process of saturation has minor effect on the response of the sensor. The instrument presented a slow response time when compared with a conventional tensiometer. However, it is considered that its use can give important information for studies involving water movement in soil.
\end{abstract}

Palavras-chaves: solos residuais; sucção matricial; sensores de matriz granular.

Keywords: residual soils; matrix suction; granular matrix sensor.

\section{INTRODUÇÃO}

A análise de estabilidade de taludes em solos não saturados ganha mais consistência se houver o conhecimento da variação sazonal da sucção nas condições de campo. Esta variável de tensão pode ser determinada direta ou indiretamente no campo a partir de alguns instrumentos já consagrados, tais como o tensiômetro e o sensor de condutividade térmica. No entanto, tais instrumentos apresentam algumas dificuldades e limitações, principalmente quando se pretende realizar medições da sucção matricial do solo no campo, em um número grande de posições.

Um outro instrumento que pode ser utilizado para medir a sucção do solo é o sensor de matriz granular (GMS), inicialmente desenvolvido para a agronomia. Sabe-se que os sensores GMS apresentam algumas vantagens em relação aos demais instrumentos de medição da sucção do solo, tais como seu baixo custo e sua faixa de medição que vai de zero até aproximadamente 200 kPa. Além de não necessitar de manutenção após a instalação. No entanto, suas limitações ainda precisam ser avaliadas para uso na engenharia geotécnica.

O GMS é um instrumento de medição de sucção do tipo resistivo e foi patenteado por Larson (1993) e Hawkins (1985). O sensor foi originalmente desenvolvido para controlar sistemas de irrigação com base na medição da sucção do solo. O GMS é um aperfeiçoamento (significativo) de um dos mais antigos sensores 
desenvolvidos para medição de sucção, o bloco de gesso, utilizado desde a década de 40 .

O GMS permite a medição da condutividade elétrica do solo, que é feita por meio de dois eletrodos envolvidos por uma matriz granular. A condutividade elétrica varia em função do teor de umidade da matriz granular. A partir do equilíbrio entre os valores de sucção matricial do sensor e do solo que o envolve, pode-se obter a sucção do solo por meio de uma curva de calibração.

O sensor GMS possui uma forma cilíndrica envolvida com uma tela de aço sobre uma manta sintética que possibilita o contato com o solo, conforme ilustrado na Figura 1.

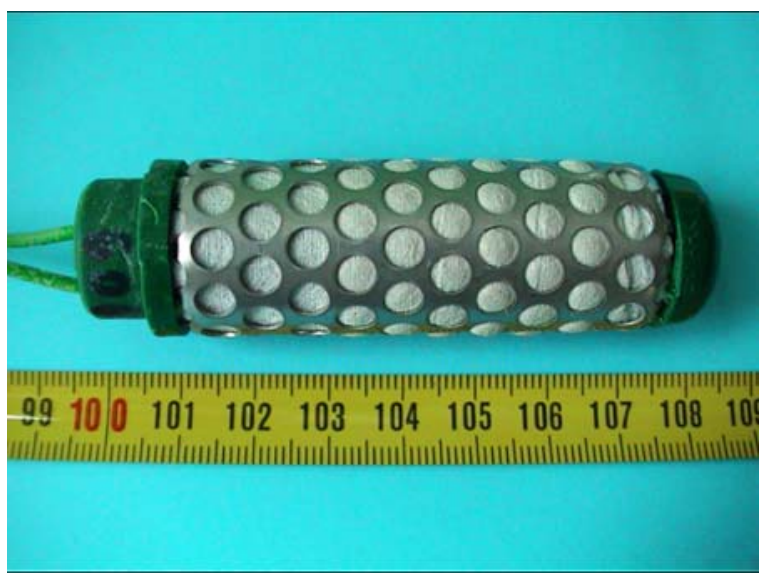

Figura 1. Sensor de matriz granular (GMS).

O sistema comercializado permite leituras automáticas de até 8 sensores. As leituras podem ser armazenadas no sistema de aquisição de dados que acompanha o GMS, e posteriormente transferidas para alguma planilha eletrônica.

$\mathrm{O}$ estudo aqui apresentado enfoca dois aspectos, quais sejam: estudos relacionados com o processo de saturação do sensor e avaliação do tempo de resposta do GMS. O trabalho foi desenvolvido nas instalações do laboratório de mecânica dos solos da Escola Politécnica da USP.

\section{CARACTERÍSTICAS DO SOLO UTILIZADO}

O solo utilizado no presente trabalho foi coletado num perfil de alteração de uma encosta natural da Serra do Mar, situada na praia de Maranduba, no município de Ubatuba, litoral norte do Estado de São Paulo.

O local onde foi coletada a amostra de solo está sendo objeto de estudo, no âmbito de um projeto de pesquisa de doutoramento financiado pela FAPESP. Trata-se de uma área parcialmente degradada por mineração de saibro, onde se encontra exposto um perfil de solo residual ao longo de uma encosta natural remanescente do referido processo de degradação ambiental.

O solo coletado no perfil de alteração foi classificado como uma areia siltosa (SM), segundo o Sistema Unificado de Classificação de Solos (SUCS). A granulometria do solo é composta por $61 \%$ de areia, $35,5 \%$ de silte e $3,5 \%$ de argila, sua massa específica natural é de 2,749 g/cm3, apresentando limite de liquidez de $49 \%$ e índice de plasticidade de $6 \%$.

\section{ENSAIOS EXPERIMENTAIS}

\subsection{Avaliação dos Procedimentos de} Saturação dos Sensores GMS

Foram avaliados seis sensores GMS, a partir de diferentes procedimentos de saturação que envolveu determinados ciclos de submersão em água seguidos por secagem, e uma submersão final de 16 horas e 30 minutos (submersão longa). Dentre os seis sensores avaliados, somente quatro foram submetidos aos cinco ciclos de submersão e secagem, um sensor foi submetido apenas à submersão longa, e um sensor foi submerso em água durante 1 hora e depois saturado aplicando-se vácuo, conforme apresentado na Tabela 1.

Tabela 1. Procedimentos de saturação dos sensores GMS.

\begin{tabular}{cc}
\hline Sensores & Procedimentos \\
\hline GMS-1 & $\begin{array}{r}5 \text { ciclos de submersão e secagem + } \\
\text { submersão longa }\end{array}$ \\
\hline GMS-2 & $\begin{array}{c}\text { 3 ciclos de submersão e secagem + } \\
\text { submersão longa }\end{array}$ \\
\hline GMS-3 & 2 ciclos de submersão e secagem + \\
& submersão longa \\
\hline GMS-4 & submersão longa \\
\hline GMS-5 & Somente submersão longa \\
\hline GMS-6 & Submersão de 1 hora + aplicação \\
& de vácuo
\end{tabular}

Nota: Todas as submersões longas foram de 16 horas e 30 minutos. 
As atividades adotadas para os ciclos de submersão e secagem dos quatro primeiros sensores avaliados, correspondentes aos sensores GMS-1, 2, 3 e 4, são mostrados na Tabela 2.

Tabela 2. Seqüência de atividades adotadas para os ciclos de submersão e secagem.

\begin{tabular}{cc}
\hline Ciclos & Atividades \\
\hline $1^{\circ}$ & Submersão -30 minutos \\
& Secagem -8 horas e 42 minutos \\
\hline $2^{\circ}$ & Submersão -30 minutos \\
& Secagem -14 horas \\
\hline $3^{\circ}$ & Submersão -30 minutos \\
& Secagem -9 horas \\
\hline $4^{\circ}$ & Submersão -30 minutos \\
& Secagem -14 horas \\
\hline & Submersão -30 minutos \\
\end{tabular}

Após terem terminado os procedimentos de saturação de todos os sensores GMS, os mesmos foram cuidadosamente instalados no interior de duas camadas de solo, compactadas dentro de uma caixa plástica de dimensões 41'31'20 cm (comprimento, largura e altura, respectivamente).

O solo utilizado na compactação das camadas foi primeiramente destorroado e peneirado na malha com abertura de 2,0 milímetros (\# 10-ABNT).

$\mathrm{O}$ teor de umidade utilizado na compactação do solo foi de $23 \%$. O volume total envolvido no procedimento de compactação foi dividido em cinco camadas. As camadas receberam a mesma energia de compactação, ou seja, 20 golpes do compactador proctor normal. $\mathrm{Na}$ terceira camada, cada metade recebeu 10 golpes, com a finalidade de manter a mesma proporção de energia despendida por unidade de massa de solo, e se obter um solo de densidade homogênea.

Após o término das duas primeiras camadas de solo, iniciou-se a compactação da primeira metade da terceira camada, sobre a qual instalaram-se os sensores GMS. Após a instalação dos sensores realizou-se a compactação da segunda metade da terceira camada, e posteriormente as 2 camadas restantes.

Os seis sensores GMS foram instalados sobre a primeira metade da terceira camada, estando localizados no meio da caixa plástica. Antes de serem retirados da água (etapa de submersão final de $24 \mathrm{~h}$ ) os sensores foram conectados ao monitor de leituras da Watermark (2006), que registrou o comportamento dos mesmos durante todo o processo de instalação e compactação das camadas sobrejacentes. A disposição dos sensores no interior da caixa plástica é ilustrada na Figura 2.

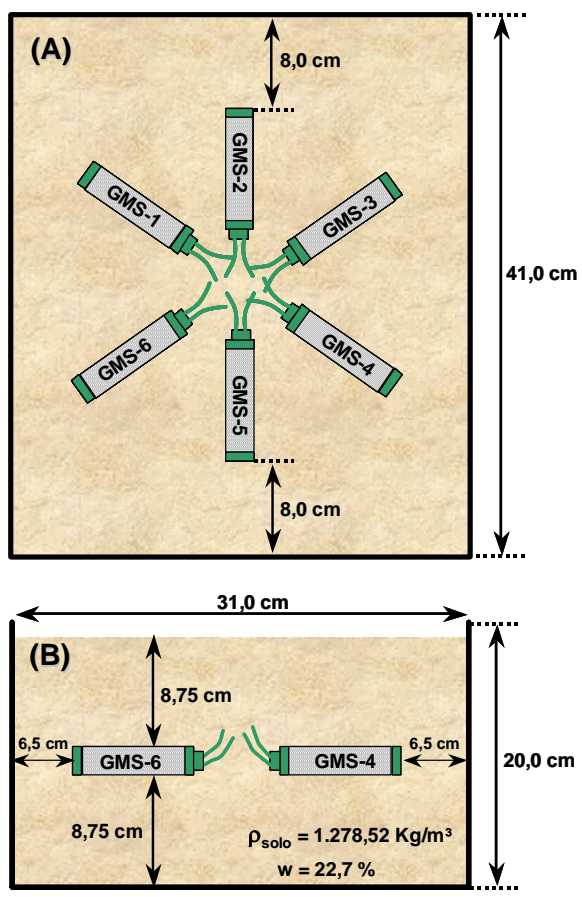

Figura 2. Disposição dos sensores GMS no interior da caixa plástica - (A) vista superior; (B) vista lateral.

\subsection{Avaliação do Tempo de Resposta dos Sensores GMS}

Para se avaliar o tempo de resposta dos sensores GMS, foi necessário estabelecer uma comparação entre o comportamento de tais sensores com algum tipo de instrumento já estudado e calibrado para tal finalidade. Sendo assim, escolheu-se um tensiômetro convencional como instrumento padrão de referência para medir a sucção do solo estudado. Depois de saturado e logo antes de ser instalado, a pedra porosa do tensiômetro foi recoberta com uma pasta feita com o solo amostrado, com o intuito de otimizar o contato entre o tensiômetro e permitir o equilíbrio com o solo ao seu redor.

O tensiômetro foi instalado próximo aos sensores GMS a partir da utilização de uma broca de pequeno diâmetro. O furo foi feito verticalmente com uma profundidade aproximada de 12 centímetros a partir da ponta 
do tensiômetro. $\mathrm{O}$ espaçamento entre o furo e o tensiômetro foi preenchido com a mesma pasta de solo mencionada anteriormente.

\section{RESULTADOS}

\subsection{Resultados dos Procedimentos de Saturação}

A partir das leituras dos sensores GMS feitas pelo datalogger da Watermark (2006), obteve-se uma curva que descreve a variação da sucção dos sensores em função do tempo. Os sensores ficaram instalados no solo durante 11 dias e 14 minutos e apresentaram variações de sucção conforme indicado na Figura 3.

Conforme apresentado na Figura 3, observa-se que logo após a instalação dos sensores na caixa plástica, as leituras de sucção variaram mais rapidamente para as primeiras 24 horas. A sucção dos sensores GMS entrou em equilíbrio com a sucção do solo compactado, sem apresentar variações significativas da sucção, após 150 horas de leitura.

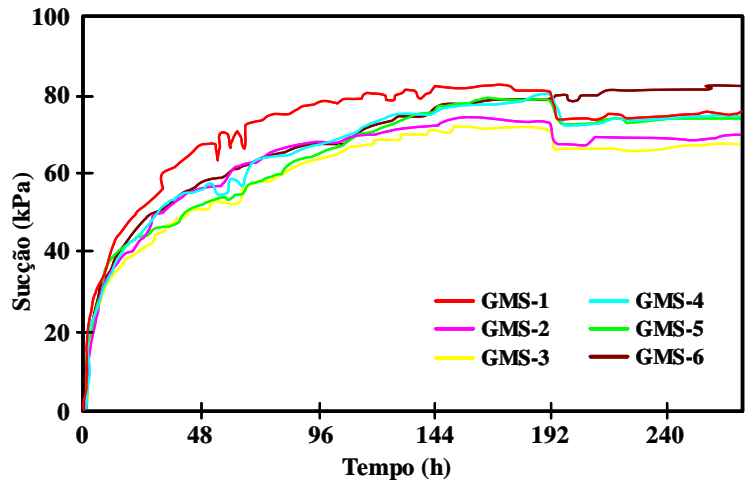

Figura 3. Curva de sucção versus tempo para a fase pré-irrigação até a estabilização dos sensores GMS.

Após os sensores terem atingido o equilíbrio em relação à sucção do solo compactado, as camadas de solo foram irrigadas com 0,5 litro de água, objetivando-se obter o tempo de resposta dos sensores GMS para detectar a variação de umidade do solo, conforme observado na Figura 4.

A partir da análise da Figura 4, verifica-se que os valores de sucção dos sensores GMS diminuíram apreciavelmente para as primeiras 48 horas, e atingiram o equilíbrio com a sucção do solo compactado após aproximadamente 108 horas de leitura.

Os diferentes processos de saturação dos sensores GMS foram analisados sob duas perspectivas: a primeira, visando avaliar a confiabilidade do sensor em realizar as medições, em termos de precisão, e se ele consegue manter um regime permanente de atividade até o equilíbrio; e a segunda, visando avaliar a velocidade de resposta do sensor em comparação com outro tipo de instrumento, que no caso estudado, utilizou-se um tensiômetro.

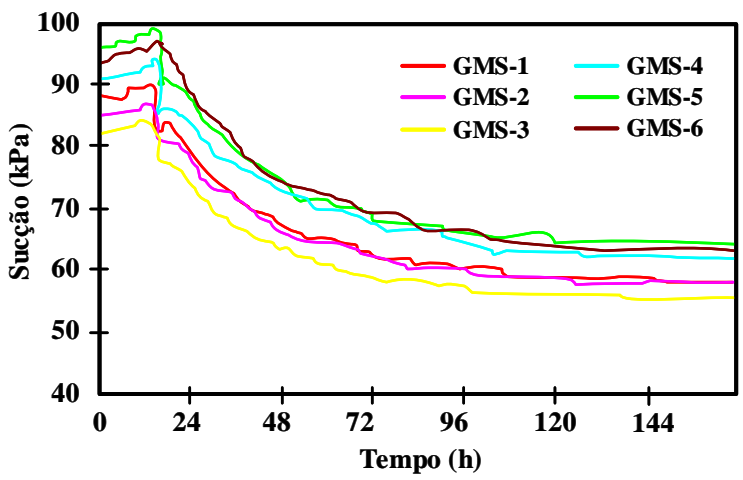

Figura 4. Suç̧ão versus tempo para a fase pósirrigação.

Quanto à capacidade de realizar as medições, verificou-se que todos os sensores GMS demonstraram um resultado satisfatório, demonstrando uma boa precisão.

Ao se fazer uma avaliação comparativa entre as velocidades de resposta dos sensores, observa-se que o sensor GMS-1, que passou pelo processo de saturação consistido de 5 ciclos de submersão/secagem e uma submersão longa, atingiu mais rapidamente o equilíbrio com a sucção do solo do que os outros sensores analisados (aproximadamente 6 dias para a fase de pré-irrigação). Após a irrigação os sensores apresentaram respostas muito semelhantes, levando praticamente o mesmo tempo para atingirem o equilíbrio com o solo compactado.

Na Figura 3 também se observam algumas oscilações rápidas em dois momentos distintos. No primeiro, por volta do segundo dia e meio (60 horas), nota-se uma pequena oscilação nas leituras dos sensores, sendo mais significativa no sensor GMS-1. No segundo momento, em torno do oitavo dia (192 horas), verifica-se uma queda repentina e brusca nas leituras de todos os 
sensores GMS. Não se conseguiu definir a razão destas respostas.

\subsection{Resultados do Tempo de Resposta}

As leituras de sucção do tensiômetro para o solo compactado foram registradas, com o intuito de avaliar o tempo de resposta relativo.

Na Figura 5 estão apresentados os resultados das medições feitas simultaneamente com o GMS e o tensiômetro. Observa-se que a sucção a ser medida neste caso foi bem superior ao do estudo anterior e que o tensiômetro não foi capaz de medir a sucção. O sistema do tensiômetro convencional "cavitou". No entanto, observa-se que a velocidade de resposta no trecho inicial foi significativamente maior no tensiômetro. $\mathrm{Na}$ Figura 5 observa-se que as sucções dos sensores GMS atingiram o equilíbrio após um tempo de aproximadamente 72 horas, para uma sucção do solo compactado de aproximadamente $100 \mathrm{kPa}$. Fazendo-se uma extrapolação dos dados obtidos com o tensiômetro (que não foi capaz de medir a sucção do solo neste caso) teríamos um tempo de equilíbrio de no máximo 12 horas. Assim, verifica-se que, neste caso, o tempo de resposta do GMS é 6 vezes maior que o do tensiômetro.

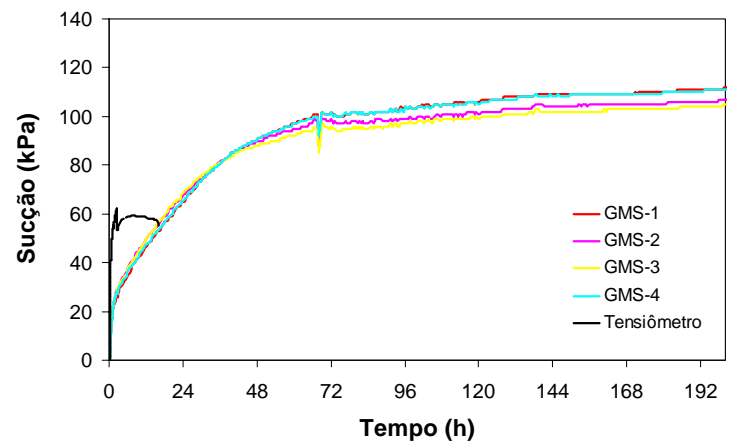

Figura 5. Sucção versus tempo de resposta para o tensiômetro e os sensores GMS.

\section{CONCLUSÕES}

A partir dos resultados obtidos no presente trabalho, pode-se concluir que os processos de saturação utilizados apresentaram resultados similares e satisfatórios, destacando o procedimento adotado para o sensor GMS-1. O sensor GMS-1 aparentemente apresentou um desempenho ligeiramente superior, quando do equilíbrio inicial com o solo compactado. Salienta-se que esta superioridade não se manteve no processo de umedecimento, no qual todos os sensores tiveram resultados equivalentes.

Pode-se concluir que o número de ciclos de submersão e secagem utilizados durante os procedimentos de saturação dos sensores GMS não interfere significativamente na capacidade de medição da sucção do solo nem no tempo de resposta.

Quando comparado com o tensiômetro o GMS possui um tempo de resposta significativamente maior. Assim, conclui-se que sensor GMS não é o aparelho ideal a ser usado quando se necessita de um tempo de resposta relativamente curto. No entanto, o GMS permite acompanhar variações sazonais que possuem grande importância para os problemas relacionados com a movimentação de água nos solos e conseqüentemente em problemas de estabilidade de taludes.

\section{AGRADECIMENTOS}

Os autores gostariam de registrar os seus agradecimentos às seguintes instituições: $\mathrm{CNPq}$ pela concessão da bolsa de iniciação científica e à FAPESP pela concessão do auxílio pesquisa (processo ${ }^{\circ}$ 05/55736-5).

\section{REFERÊNCIAS}

Hawkins, A. J. (1985). Electrical sensor for sensing moisture in soils, United States Patent Patent number 5179347.

Larson, G. F. (1993). Electrical sensor for measuring moisture in landscape and agricultural soils. United States Patent - Patent number 4531087.

Watermark (2006). Soil Moisture Measurement Installation and Operation Manual, Irrometer Company. 